MACKSUEL SOARES DE AZEVEDO

ESTRUTURAS DE AÇO SEM REVESTIMENTO CONTRA FOGO EXTERNAS A EDIFÍCIOS EM INCÊNDIO 
MACKSUEL SOARES DE AZEVEDO

\section{ESTRUTURAS DE AÇO SEM REVESTIMENTO CONTRA FOGO EXTERNAS A EDIFÍCIOS EM INCÊNDIO}

Tese apresentada à Escola Politécnica da Universidade de São Paulo para obtenção do título de Doutor em engenharia

Área de Concentração:

Engenharia de Estruturas

Orientador: Prof. Dr. Valdir Pignatta e Silva. 
Este exemplar foi revisado e alterado em relação à versão original, sob responsabilidade única do autor e com a anuência de seu orientador.

São Paulo, 14 de janeiro de 2010.

Assinatura do autor

Assinatura do orientador

\section{FICHA CATALOGRÁFICA}

Azevedo, Macksuel Soares de

Estruturas de aço externas a edifícios em situação de incêndio / M.S. de Azevedo. -- ed.rev. -- São Paulo, 2010.

$302 \mathrm{p}$.

Tese (Doutorado) - Escola Politécnica da Universidade de São Paulo. Departamento de Engenharia de Estruturas e Geotécnica.

1. Estruturas 2. Estruturas metálicas 3. Incêndio 4. Aço I.Universidade de São Paulo. Escola Politécnica. Departamento de Engenharia de Estruturas e Geotécnica II. t. 


\section{DEDICATÓRIA}

À minha esposa Karla e aos meus pais, Cileida e Edinho, que souberam acreditar e me apoiar. 


\section{AGRADECIMENTOS}

A Deus, pelas bençãos em minha vida. "Confie no Senhor e faça o bem; assim você habitará na terra e desfrutará segurança. Deleite-se no Senhor, e ele atenderá aos desejos do seu coração. Entregue o seu caminho ao Senhor; confie nele, e ele agirá.” (Salmo 37: 3 a 5).

Ao professor Valdir Pignatta e Silva pela amizade, pela paciência e, principalmente, pelos ensinamentos transmitidos.

À minha esposa Karla, por acreditar, por me apoiar e por dividir sua vida comigo. Eu a amo.

Aos meus pais, Cileida e Edinho, por me ensinarem a ser forte, a batalhar pela vida e a acreditar que, apesar das dificuldades, com Deus não há barreiras que não possam ser transpostas.

Aos demais colegas, professores e funcionários da Escola Politécnica da Universidade de São Paulo, pela colaboração.

Ao Instituto Aço Brasil e ao Centro Brasileiro de Construção em Aço, representado por Catia Mac Cord Simões Coelho, pela bolsa de estudo concedida e pelo apoio dado em relação à infraestrutura necessária à elaboração deste trabalho.

A todos aqueles que de alguma maneira ajudaram na realização deste trabalho. 
"O temor do Senhor é o princípio do conhecimento."

(Provérbios 1:7a) 


\section{RESUMO}

Os elementos estruturais de aço externos a edificações em situação de incêndio são expostos à radiação, proveniente das janelas na fachada e das chamas, e à convecção dos gases quentes. A absorção de calor pelo elemento varia de acordo com a sua posição em relação às aberturas. Margaret Law, com apoio de vasta quantidade de dados experimentais sobre incêndio em edifícios, estimou a transferência de calor externa para elementos de aço e o valor máximo da temperatura alcançada por eles. O Eurocode 1, part 1.2 (2002) e o Eurocode 3, part 1.2 (2003) adotaram o método proposto, com pequenas modificações.

A norma brasileira ABNT NBR 14323:1999 - "Dimensionamento de estruturas de aço de edifícios em situação de incêndio - Procedimento" permite empregar o procedimento proposto pelos Eurocodes 1 e 3, porém, sem detalhá-lo.

Neste trabalho, elaborou-se um programa de computador, o ExteelFire, para determinar a máxima temperatura dos elementos estruturais de aço externos a edificações em situação de incêndio, com base no método de Margaret Law. Compararam-se os resultados obtidos via ExteelFire a valores determinados por meio de análise numérica, com auxílio dos programas de computador CFD (Computational Fluid Dynamics) Smartfire e de análise térmica, Super Tempcalc; compararam-se os resultados obtidos via ExteelFire a valores determinados em ensaios de incêndio compartimentado em escala natural (ensaio de Dalmarnock e ensaio da Siderúrgica Mittal Steel Ostrava).

No presente trabalho, também se aplicou o ExteelFire a casos correntes na construção civil, indicando situações em que o revestimento contra fogo pode ser dispensado.

Palavras-chave: Aço, incêndio, estruturas metálicas, elementos externos, Margaret Law. 


\begin{abstract}
Steelworks outside a building in fire situation are exposed to radiation that come from the windows in the façade and from flames, as well as the convection of hot gases. The absorption of the heat for the element depends on its placement in relation to the openings.

Margaret Law, based on many experimental data about fire in buildings, estimated the external heat transfer to steel elements and the maximum temperature value reached by them. The Eurocode 1, part 1.2 (2002) and Eurocode 3, part 1.2 (2003) have adopted the method previously mentioned with small modifications.

The Brazilian standard ABNT NBR 14323:1999 - "Dimensionamento de estruturas de aço de edifícios em situação de incêndio - Procedimento" (Steel structures fire design - Procedure) allows employment proposed by Eurocodes 1 and 3 without detailing it.

A software, ExteelFire, to determine the maximum temperature on external steel structures of buildings in fire, based on Margaret Law's method was elaborated in this work.

Results from ExteelFire and the values determined by numerical analysis, with software CFD (CFD - Computational Fluid Dynamics) Smartfire and Super Tempcalc (thermal analysis) have been compared.

Furthermore, results from ExteelFire and values determined in tests in fire compartment, in natural scale (Dalmarnock experiment and Mittal Steel Ostrava experiment) have also been contrasted.

In this work it was also applied ExteelFire to commonly used situations in civil construction, showing conditions where the thermal protection can be excluded.
\end{abstract}

Keywords: Steel, fire, steel structures, external elements, Margaret Law. 


\section{LISTA DE FIGURAS}

\section{CAPÍTULO 1}

Figura 1.1 - Edificações com estruturas externas de aço: (a) Centre Pompidou, em Paris, França e (b) Hotel Arts Barcelona, Espanha. 4

Figura 1.2 - Edificações brasileiras com estruturas externas de aço: (a) Centro Empresarial do Aço, em São Paulo e (b) Teatro Municipal de Paulínia, em São Paulo. 4

\section{CAPÍTULO 2}

Figura 2.1 - Dimensões utilizadas em cálculos da projeção da chama (LAW, 1978)...............9

Figura 2.2 - Tela inicial do programa de computador Fires.............................................. 10

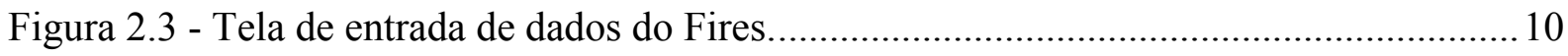

Figura 2.4 - O edifício antes da demolição (WALD, 2009). ................................................ 11

Figura 2.5 - Geometria do compartimento incendiado, carga mecânica e de incêndio (WALD, 2009)...

Figura 2.6 - Distribuição da carga de incêndio em madeira no compartimento (WALD, 2009).

Figura 2.7 - Localização dos termopares para registrar temperaturas dos gases e do aço

(WALD, 2009)

Figura 2.8 - Registro das temperaturas dos gases a $300 \mathrm{~mm}$ abaixo do teto (WALD, 2009).. 14

Figura 2.9 - Localização da placa externa de aço exposta ao calor durante o ensaio (WALD, 2009).

Figura 2.10 - Temperatura do gás e da placa de aço externa durante o ensaio (WALD, 2009). .

Figura 2.11 - Ensaio de incêndio em edifício em Dalmarnock (REIN et al., 2007). 16

Figura 2.12 - Layout do apartamento. Vista do lado noroeste (REIN et al., 2007). 17 
Figura 2.13 - Carga de combustível e sua distribuição no compartimento experimental. Vista (a) do lado NW e (b) do lado NE (REIN et al., 2007). 18

Figura 2.14 - Planta baixa do compartimento experimental mostrando a distribuição da mobília e a localização dos sensores (REIN et al., 2007). 18

Figura 2.15 - Condição inicial de ventilação do compartimento experimental (REIN et al., 2007).

Figura 2.16 - Visualização da fonte de ignição, sofá, estante de livros e itens próximos do compartimento experimental, (a) antes do incêndio e (b) após o incêndio (REIN et al., 2007). 20

Figura 2.17 - Curva temperatura média-tempo dos gases dentro do compartimento (REIN et al., 2007).

Figura 2.18 - Contornos da temperatura do gás (em $\left.{ }^{\circ} \mathrm{C}\right)$ da seção S1-S1, de acordo com figura 2.12. As figuras estão em ordem cronológica em relação ao tempo de ignição: (a) 201s, (b) 251s, (c) 351s, (d) 420s, (e) 661s e (f) 901s (REIN et al., 2007).

Figura 2.19 - Taxa de liberação de calor do incêndio utilizando o princípio da depreciação do oxigênio. Alternativa simplificada utilizando fatores de ventilação para cálculo de HRR é mostrada no "Vent Cases" correspondentes aos diferentes eventos de mudança de ventilação. (REIN et al., 2007).

Figura 2.20 - Imagens da câmera instalada no $3^{\circ}$ piso, mostrando o fogo externo que emana da janela do compartimento experimental. (a) vento norte às $12 \mathrm{~h}: 41 \mathrm{~min}: 36 \mathrm{~s}$ e (b) somente vento às $12 \mathrm{~h}: 41 \mathrm{~min}: 48 \mathrm{~s}$ (REIN et al., 2007).

Figura 2.21 - Contorno da temperatura externa que escoa do compartimento (em ${ }^{\circ} \mathrm{C}$ ). (a) seção S2-S2 às 12:41:36 e (b) S3-S3 às 12:41:36, com valores de eixo conforme figura 2.12 (REIN et al., 2007). 26

\section{CAPÍTULO 3}

Figura 3.1 - Curva temperatura-tempo de um incêndio real (BUCHANAN, 2001)...............28

Figura 3.2 - Curvas de incêndio-padrão (EUROCODE 1, part 1.2, 2002).............................. 30

Figura 3.3 - Curva temperatura-tempo conforme modelo de incêndio natural (EUROCODE 1, part 1.2, 2002) 
Figura 3.4 - Taxa de liberação de calor para incêndios $\mathrm{t}^{2}$ (BUCHANAN, 2001)..................... 35

Figura 3.5 - Cálculo das taxas de liberação de calor para incêndios $\mathrm{t}^{2}$ (BUCHANAN, 2001)....

Figura 3.6 - Mecanismos de transferência de calor (AZEVEDO, 2005). .............................. 37

Figura 3.7 - Transferência de calor unidimensional por condução........................................39

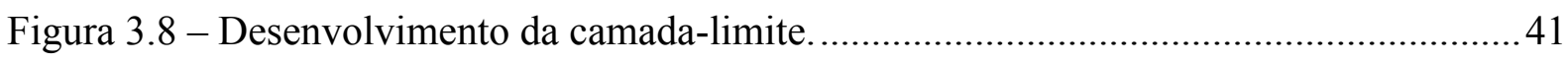

Figura 3.9 - Desenvolvimento da camada-limite de velocidade sobre uma placa plana.........42

Figura 3.10 - Radiação de uma superfície para a outra (BUCHANAN, 2001) .......................47

Figura 3.11 - Superfície emissora e receptora (BUCHANAN, 2001) ..................................47

\section{CAPÍTULO 4}

Figura 4.1 - Danos típicos de incêndio em estruturas de aço. Centro de distribuição de alimentos da Nestlé, em São Bernardo do Campo, em 2001.

Figura 4.2 - Colapso total de um edifício residencial em São Petersburgo - Rússia, 2002 (COSTA, 2007).

Figura 4.3 - Variação dos fatores de redução para a resistência ao escoamento e o módulo de elasticidade do aço com o aumento da temperatura (ABNT NBR 14323:1999). 51

Figura 4.4 - Calor específico do aço em função da temperatura. ............................................52

Figura 4.5 - Condutividade térmica do aço em função da temperatura....................................53

Figura 4.6 - Alongamento do aço em função da temperatura. ...............................................54

Figura 4.7 - Fator de massividade (REAL, 2003) ........................................................5

\section{CAPÍTULO 5}

Figura 5.1 - Indicação das temperaturas utilizadas na equação de equilíbrio (LAW, 1978)....60

Figura 5.2 - Fluxo de calor para perfil de aço envolvido pela chama....................................61

Figura 5.3 - Fluxo de calor para perfil de aço fora da chama. ..............................................65 
Figura 5.4 - Fluxo de calor por unidade de área devido à radiação das chamas acima da janela, com experimentos em escala natural, realizados em Borehamwood, comparado com a fluxo de calor por radiação calculada para a emissividade completa das chamas (LAW, 1978).

Figura 5.5 - Experiência utilizando radiômetro, modelo em escala natural, em Borehamwood (LAW, 1978). 73

Figura 5.6 - Soma da radiação da janela e da chama recebida por um radiômetro a 4,5m ou $6 \mathrm{~m}$ de distância, com experimentos em escala natural em borehamwood (LAW, 1978). .73

Figura 5.7 - Dimensões de um compartimento com uma abertura...... .76

Figura 5.8 - Variação de $\dot{m} / A_{v} h^{1 / 2}$ com as dimensões do compartimento e a ventilação (LAW, 1978). 77

Figura 5.9 - Variação da temperatura de um incêndio com as dimensões do compartimento e a área de ventilação, considerando ventilação natural (LAW, 1978)...... .78

Figura 5.10 - Variação da temperatura com a carga de incêndio, as dimensões do compartimento e a área de ventilação. Ventilação natural (LAW, 1978).

Figura 5.11 - Variação da temperatura com a carga de incêndio, as dimensões do compartimento e a área de ventilação. Ventilação forçada (Laboratórios Underwriters apud LAW, 1978). 80

Figura 5.12 - Variação da temperatura de um incêndio com as dimensões do compartimento e a área de ventilação. .83

Figura 5.13 - Variação da temperatura máxima em compartimento com alta ventilação. 84

Figura 5.14 - Variação da temperatura máxima em compartimento com baixa ventilação. ... 84

Figura 5.15 - Distribuição da temperatura na seção transversal da chama (LAW, 1978)....... 85

Figura 5.16 - Dimensões da chama para ventilação natural (LAW, 1978). …......................... 86

Figura 5.17 - Dimensões da chama para ventilação forçada (LAW, 1978). ............................ 87

Figura 5.18 - Altura das chamas em ensaios em escala natural com ventilação natural (LAW, 1978). 89

Figura 5.19 - Altura da chama com ventilação natural (EUROCODE 1, PART 1-2, 2002)....90 
Figura 5.20 - Altura da chama quando existe marquise ou sacada 90

Figura 5.21 - Altura da chama em ensaios em escala natural com ventilação forçada (Laboratórios Underwriters, apud LAW, 1978).

Figura 5.22 - Deflexão da chama devido à presença de marquise acima da janela, com ventilação forçada (EUROCODE 1, PART 1.2, 2002).

Figura 5.23 - Projeção horizontal do topo da chama para ensaios em escala natural, com ventilação natural, considerando parede acima da janela (LAW, 1978).

Figura 5.24 - Projeção horizontal da chama para ventilação natural (EUROCODE 1, PART $1.2,2002)$ 95

Figura 5.25 - Projeção horizontal da chama quando existe marquise ou sacada com ventilação natural (EUROCODE 1, PART 1.2, 2002).

Figura 5.26 - Projeção horizontal do topo da chama, para ensaios em escala - natural, com ventilação forçada, considerando os dados dos Laboratórios Underwriters (LAW, 1978).

Figura 5.27 - Projeção horizontal da chama para ventilação forçada (EUROCODE 1, PART $1.2,2002)$ .98

Figura 5.28 - Largura da chama para ventilação natural (LAW, 1978). .98

Figura 5.29 - Largura da chama para ventilação forçada (LAW, 1978). .99

Figura 5.30 - Comprimento do eixo da chama para ventilação natural, caso exista parede acima da janela ou $\mathrm{h}_{\mathrm{eq}} \leq 1,25 \mathrm{w}($ EUROCODE 1, PART 1.2, 2002). 100

Figura 5.31 - Comprimento do eixo da chama para ventilação natural, caso não exista parede acima da janela ou $h_{e q}>1,25 w($ EUROCODE 1, PART 1.2, 2002). 100

Figura 5.32 - Comprimento da chama para ventilação forçada. 102

Figura 5.33 - Distribuição da temperatura da chama para ensaios em escala natural com ventilação forçada, considerando dados dos Laboratórios Underwriters (LAW, 1978).

Figura 5.34 - Distribuição da temperatura da chama para ensaios em escala natural com ventilação natural (LAW, 1978). 
Figura 5.35 - Medidas e cálculos das temperaturas dos pilares de aço não revestidos contra fogo, envolvidos pela chama, em ensaios em escala-natural com ventilação natural (LAW, 1978).

Figura 5.36 - Medidas e cálculos das temperaturas dos pilares de aço protegidos, envolvidos pela chama, em ensaios em escala natural com ventilação natural (LAW, 1978). .

Figura 5.37 - Elementos estruturais protegidos (LAW, 1978). 107

Figura 5.38 - Temperaturas medidas e calculadas para pilares de aço envolvidos pela chama, para ensaios em escala-natural, com ventilação forçada (Laboratórios Underwriters, apud LAW, 1978).

Figura 5.39 - Temperaturas medidas e calculadas para vigas de borda envolvidas pela chama, para ensaios em escala natural, com ventilação natural (LAW, 1978). 108

Figura 5.40 - Temperaturas medidas e calculadas para pilares não envolvidos pela chama, ensaios em escala-natural, com ventilação natural (LAW, 1978).

Figura 5.41 - Temperaturas medidas e calculadas para pilares não envolvidos pela chama, para ensaios em escala-natural, com ventilação forçada (Laboratórios Underwriters, apud LAW, 1978).

Figura 5.42 - Temperaturas medidas e calculadas para viga de borda, para ensaios em escalanatural, com ventilação forçada (Laboratórios Underwriters, apud, LAW, 1978)..

Figura 5.43 - Envoltória retangular da superfície receptora.

Figura 5.44 - Superfície receptora em plano paralelo com a superfície irradiante (EUROCODE 1, PART 1.2, 2002).

Figura 5.45 - Superfície receptora perpendicular ao plano da superfície irradiante (EUROCODE 1, PART 1.2, 2002).

Figura 5.46 - Superfície receptora em um plano com ângulo $\theta$ em relação à superfície irradiante (EUROCODE 1, PART 1.2, 2002).

Figura 5.47 - Geometria do compartimento. 


\section{CAPÍTULO 6}

Figura 6.1 - Interface do programa de computador Visual Basic. 119

Figura 6.2 - Tela de splash do ExteelFire 2.0. 120

Figura 6.3 - Tela 1 do ExteelFire 2.0. Dados de entrada sobre o compartimento incendiado.....

Figura 6.4 - Tela 2 do ExteelFire 2.0. Dados relativos ao elemento estrutural e à carga de incêndio. Pilar em frente a uma abertura.

Figura 6.5 - Tela 2 do ExteelFire 2.0. Dados relativos ao elemento estrutural e à carga de incêndio. Pilar entre aberturas.

Figura 6.6 - Tela 2 do ExteelFire 2.0. Dados relativos ao elemento estrutural e à carga de incêndio. Viga paralela à parede.

Figura 6.7 - Tela 3 do ExteelFire 2.0. Cálculos da geometria da chama e sua posição em relação ao elemento estrutural. Pilar em frente a uma abertura. 125

Figura 6.8 - Tela 3 do ExteelFire 2.0. Cálculos da geometria da chama e sua posição em relação ao elemento estrutural. Pilar entre aberturas.

Figura 6.9 - Tela 3 do ExteelFire 2.0. Cálculos da geometria da chama e sua posição em relação ao elemento estrutural. Viga paralela à parede.

Figura 6.10 - Tela 4 do ExteelFire 2.0. Cálculos da temperatura da chama na janela e ao longo do seu eixo e cálculo dos fatores de configuração. Pilar em frente a uma abertura ou vigas paralelas à parede.

Figura 6.11 - Tela 4 do ExteelFire 2.0. Cálculos da temperatura da chama na janela e ao longo do seu eixo e cálculo dos fatores de configuração. Pilar entre aberturas. 128

Figura 6.12 - Tela 5 do ExteelFire 2.0. Cálculos da absortividade da chama, do fluxo de calor por radiação das aberturas e das chamas e o coeficiente de transferência de calor por convecção. Pilar em frente a uma abertura ou viga paralela à parede. 128

Figura 6.13 - Tela 5 do ExteelFire 2.0. Cálculos da absortividade da chama, do fluxo de calor por radiação das aberturas e das chamas e o coeficiente de transferência de calor por convecção. Pilar entre aberturas 
Figura 6.14 - Dados para verificação do fator de ventilação quando existe abertura em mais de uma parede.

Figura 6.15 - Gráfico da variação da taxa de combustão em relação à largura total das aberturas nas paredes diferentes da fachada.

Figura 6.16 - Situações de cálculo para pilares em frente a uma abertura com ventilação natural (a) Fires e ExteelFire 1.0 e (b) ExteelFire 2.0. .

Figura 6.17 - Variação da intensidade de radiação devido (a) à chama (b) ao compartimento para pilares parcialmente envolvidos.

Figura 6.18 - Situações de cálculo para pilares em frente a uma abertura com ventilação forçada (a) Fires e ExteelFire 1.0 e (b) ExteelFire 2.0.

Figura 6.19 - Possíveis situações para cálculo do pilar entre aberturas. Ventilação natural. 134 Figura 6.20 - Ângulo $\theta$ para o fator de configuração na face 3 do pilar. Ventilação natural. ....

Figura 6.21 - Possíveis posições para pilar entre aberturas. Ventilação forçada. 134

Figura 6.22 - Viga de borda (a) ventilação natural (b) ventilação forçada. Fires e ExteelFire 1.0 . 135

Figura 6.23 - Situações admitidas pelo ExteelFire 2.0 para cálculo de vigas (a) ventilação natural (b) ventilação forçada.

\section{CAPÍTULO 7}

Figura 7.1 - Distribuição da temperatura da chama para ensaios em escala natural com ventilação forçada, considerando dados dos Laboratórios Underwriters (LAW, 1978), do AISI (1979) e do Eurocode, Part 1-2 (2002).

Figura 7.2 - Gráfico da variação da altura da chama, segundo Law (1978), o AISI (1979) e o Eurocode, Part 1-2 (2002). Dados de ensaio em escala natural dos Laboratórios Underwriters.

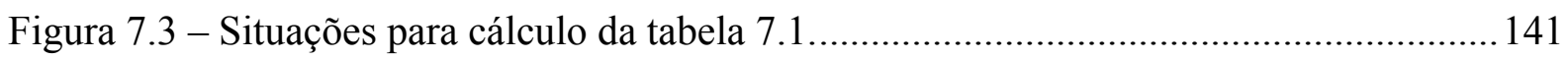

Figura 7.4 - Situações para cálculo da tabela 7.2 ............................................................ 144

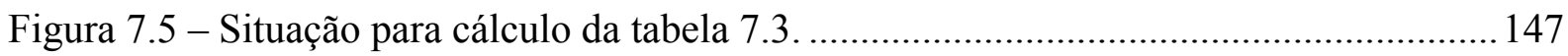




\section{CAPÍTULO 8}

Figura 8.1 - Modelo do compartimento e do elemento estrutural para análise paramétrica.. 149

Figura 8.2 - Variação da Temperatura de um pilar com a distância à janela. 150

Figura 8.3 Variação da temperatura de um pilar com a altura do compartimento. 150

Figura 8.4 - Variação da temperatura de um pilar com a profundidade do compartimento. 151

Figura 8.5 - Variação da temperatura de um pilar com a distância à borda da janela. 151

Figura 8.6 Variação da temperatura de um pilar com a sua largura.

Figura 8.7 - Pilar em frente à abertura e envolvido pela chama. 152

Figura 8.8 - Pilar em frente a abertura e não envolvido pela chama. 152

Figura 8.9 - Variação da temperatura de um pilar com a carga de incêndio de cálculo. 153

Figura 8.10 - Distância vertical $\left(d_{v}\right)$ da viga à borda superior da abertura e distância horizontal da viga $(d)$ à parede da fachada. 153

Figura 8.11 - Variação da temperatura de uma viga com a distância vertical à borda superior da abertura. 154

Figura 8.12 - Variação da temperatura de uma viga com a distância horizontal à parede da fachada. 154

Figura 8.13 - Variação da temperatura de uma viga com a profundidade do compartimento.....

Figura 8.14 - Variação da temperatura de uma viga com a carga de incêndio de cálculo..... 155

Figura 8.15 - Planta baixa do pavimento-tipo de uma escola. 156

Figura 8.16 - Planta baixa do pavimento-tipo de um edifício de escritório. 157

Figura 8.17 - Posicionamento do pilar entre aberturas com distância à parede da fachada... 158

Figura 8.18 - Inclinação da chama externa devido ao vento. 160

Figura 8.19 - Posicionamento do pilar entre aberturas encaixado na parede da fachada....... 160

Figura 8.20 - Situação para cálculo da tabela 8.3. 162

Figura 8.21 - Dimensões dos pilares e distância à chama...... 
Figura 8.22 - Viga paralela e adjacente à parede da fachada. 164

Figura 8.23 - Situações para cálculo da tabela 8.4. 165

Figura 8.24 - Situações para cálculo da tabela 8.5 168

\section{CAPÍTULO 9}

Figura 9.1 - Componentes do SMARTFIRE V4.1 (a) Tela de apresentação (b) Tela do "SMARTFIRE Scenario Designer" (c) Tela do "SMARTFIRE Case Specification Environment" (d) Tela do "SMARTFIRE Interactive Meshing System" (e) Tela do "SMARTFIRE CFD Engine" (f) Tela do "SMARTFIRE Data View Post Processing Visualization System". (FSEG, 2008).

Figura 9.2 - Geometria do compartimento incendiado.

Figura 9.3 - Localização e geometria da fonte do incêndio.

Figura 9.4 - Variação da taxa de liberação de massa do combustível com o tempo.

Figura 9.5 - Isotermas em Kelvin. Corte vertical (plano xy) no centro do compartimento incendiado.

Figura 9.6 - Isotermas em Kelvin. Corte horizontal (plano xz) do compartimento experimental. Localizado $30 \mathrm{~cm}$ abaixo do teto.

Figura 9.7 - Isotermas em Kelvin. Corte vertical (plano yz) localizado na janela do compartimento. 182

Figura 9.8 - Chama externa considerando uma iso-superfície de $538^{\circ} \mathrm{C}$ 183

\section{CAPÍTULO 10}

Figura 10.1 - Geometria do compartimento.

Figura 10.2 - Ensaio 1. Temperaturas (em Kelvin) no interior do compartimento. Corte no meio do vão (plano xy).

Figura 10.3 - Ensaio 1. Temperaturas (em Kelvin) no interior do compartimento. Corte no meio do vão (plano yz). 
Figura 10.4 - Ensaio 1. Temperaturas (em Kelvin) no interior do compartimento. Corte na altura de 1,40 $\mathrm{m}$ do piso (plano $\mathrm{xz}$ ).

Figura 10.5 - Ensaio 1. Temperaturas (em Kelvin) no interior do compartimento. Corte na altura de 2,50 $\mathrm{m}$ do piso (plano $\mathrm{xz}$ ).

Figura 10.6 - Ensaio 2. Temperaturas (em Kelvin) no interior do compartimento. Corte no meio do vão (plano xy).

Figura 10.7 - Ensaio 2. Temperaturas (em Kelvin) no interior do compartimento. Corte no meio do vão (plano yz).

Figura 10.8 - Ensaio 2. Temperaturas (em Kelvin) no interior do compartimento. Corte na altura de 1,40 $\mathrm{m}$ do piso (plano $\mathrm{xz}$ ).

Figura 10.9 - Ensaio 2. Temperaturas (em Kelvin) no interior do compartimento. Corte na altura de 2,50 $\mathrm{m}$ do piso (plano $\mathrm{xz}$ ).

Figura 10.10 - Ensaio 3. Temperaturas (em Kelvin) no interior do compartimento. Corte no meio do vão (plano xy).

Figura 10.11 - Ensaio 3. Temperaturas (em Kelvin) no interior do compartimento. Corte no meio do vão (plano yz).

Figura 10.12 - Ensaio 3. Temperaturas (em Kelvin) no interior do compartimento. Corte na altura de 1,40 $\mathrm{m}$ do piso (plano $\mathrm{xz}$ ).

Figura 10.13 - Ensaio 3. Temperaturas (em Kelvin) no interior do compartimento. Corte na altura de 2,50 $\mathrm{m}$ do piso (plano $\mathrm{xz}$ ).

Figura 10.14 - Ensaio 4. Temperaturas (em Kelvin) no interior do compartimento. Corte no meio do vão (plano xy).

Figura 10.15 - Ensaio 4. Temperaturas (em Kelvin) no interior do compartimento. Corte no meio do vão (plano yz).

Figura 10.16 - Ensaio 4. Temperaturas (em Kelvin) no interior do compartimento. Corte na altura de 1,40 $\mathrm{m}$ do piso (plano $\mathrm{xz}$ ).

Figura 10.17 - Ensaio 4. Temperaturas (em Kelvin) no interior do compartimento. Corte na altura de 2,50 $\mathrm{m}$ do piso (plano $\mathrm{xz}$ ).

Figura 10.18 - Ensaio 5. Temperaturas (em Kelvin) no interior do compartimento. Corte no meio do vão (plano xy). 
Figura 10.19 - Ensaio 5. Temperaturas (em Kelvin) no interior do compartimento. Corte no meio do vão (plano yz).

Figura 10.20 - Ensaio 5. Temperaturas (em Kelvin) no interior do compartimento. Corte na altura de 1,40 $\mathrm{m}$ do piso (plano $\mathrm{xz}$ ).

Figura 10.21 - Ensaio 5. Temperaturas (em Kelvin) no interior do compartimento. Corte na altura de 2,50 $\mathrm{m}$ do piso (plano $\mathrm{xz}$ ).

Figura 10.22 - Ensaio 6. Temperaturas (em Kelvin) no interior do compartimento. Corte no meio do vão (plano xy).

Figura 10.23 - Ensaio 6. Temperaturas (em Kelvin) no interior do compartimento. Corte no meio do vão (plano yz).

Figura 10.24 - Ensaio 6. Temperaturas (em Kelvin) no interior do compartimento. Corte na altura de 1,40 $\mathrm{m}$ do piso (plano $\mathrm{xz}$ ).

Figura 10.25 - Ensaio 6. Temperaturas (em Kelvin) no interior do compartimento. Corte na altura de 2,50 $\mathrm{m}$ do piso (plano $\mathrm{xz}$ ).

Figura 10.26 - Ensaio 1. Temperaturas (em Kelvin) no plano da janela. Corte no plano yz. 202

Figura 10.27 - Ensaio 2. Temperaturas (em Kelvin) no plano da janela. Corte no plano yz. 202

Figura 10.28 - Ensaio 3. Temperaturas (em Kelvin) no plano da janela. Corte no plano yz. 203

Figura 10.29 - Ensaio 4. Temperaturas (em Kelvin) no plano da janela. Corte no plano yz. 204

Figura 10.30 - Ensaio 5. Temperaturas (em Kelvin) no plano da janela. Corte no plano yz. 204

Figura 10.31 - Ensaio 6. Temperaturas (em Kelvin) no plano da janela. Corte no plano yz. 205

Figura 10.32 - Variação da taxa de liberação de massa do combustível com o tempo. ........206

Figura 10.33 - Ensaio 1. Altura máxima da chama durante um intervalo de $200 \mathrm{~s}$ de simulação.

Figura 10.34 - Ensaio 2. Altura máxima da chama durante um intervalo de $200 \mathrm{~s}$ de simulação.

Figura 10.35 - Ensaio 3. Altura máxima da chama durante um intervalo de $200 \mathrm{~s}$ de simulação. 208

Figura 10.36 - Ensaio 4. Altura máxima da chama durante um intervalo de $200 \mathrm{~s}$ de simulação. 
Figura 10.37 - Ensaio 5. Altura máxima da chama durante um intervalo de $200 \mathrm{~s}$ de simulação.

Figura 10.38 - Ensaio 6. Altura máxima da chama durante um intervalo de $200 \mathrm{~s}$ de simulação.

Figura 10.39 - Geometria do compartimento experimental.

Figura 10.40 - Planta baixa das posições do elemento estrutural em relação à abertura.

Figura 10.41 - Dimensões e fatores de massividade dos perfis de aço.

Figura 10.42 - Discretização das malhas dos pilares da figura 10.41. 215

Figura 10.43 - Localização das curvas temperatura-tempo calculadas pelo Smartfire. 216

Figura 10.44 - Curvas temperatura-tempo calculadas pelo Smartfire. Perfis a 0,50m da abertura.

Figura 10.45 Curvas temperatura-tempo calculadas pelo Smartfire. Perfis a 1,00 m da abertura.

Figura 10.46 - Variação da temperatura do aço em função do tempo do pilar (a) da figura 12.3 a $0,50 \mathrm{~m}$ da abertura.

Figura 10.47 - Variação da temperatura do aço em função do tempo utilizando o pilar (b) da figura 10.41 a $0,50 \mathrm{~m}$ da abertura.

Figura 10.48 - Variação da temperatura do aço em função do tempo do pilar (a) da figura 10.41 a $1,00 \mathrm{~m}$ da abertura.

Figura 10.49 - Variação da temperatura do aço em função do tempo do pilar (b) da figura 10.41 a $1,00 \mathrm{~m}$ da abertura.

Figura 10.50 - Temperatura na seção dos pilares (a) e (b) da figura 10.41.

Figura 10.51 - Variação da temperatura do aço em função do tempo do pilar (c) da figura 10.41 a $0,50 \mathrm{~m}$ da abertura.

Figura 10.52 - Variação da temperatura do aço em função do tempo do pilar (d) da figura 10.41 a $0,50 \mathrm{~m}$ da abertura.

Figura 10.53 - Variação da temperatura do aço em função do tempo do pilar (c) da figura 10.41 a $1,00 \mathrm{~m}$ da abertura. 
Figura 10.54 - Variação da temperatura do aço em função do tempo do pilar (d) da figura 10.41 a $1,00 \mathrm{~m}$ da abertura.

Figura 10.55 - Temperatura na seção dos pilares (c) e (d) da figura 10.41. 224

\section{CAPÍTULO 11}

Figura 11.1 - Curva temperatura-tempo de um incêndio-padrão.

Figura 11.2 - Temperatura crítica de pilares de aço com fy = $250 \mathrm{MPa}$ (VELARDE, 2008).....

Figura 11.3 - Temperatura crítica de pilares de aço com fy = $345 \mathrm{MPa}$ (VELARDE, 2008)....

Figura 11.4 - Temperatura crítica de vigas de aço admitindo-se plastificação total da seção transversal, sob laje de concreto.

Figura 11.5 - Geometria do compartimento. 232

Figura 11.6 - Geometria e sistema estrutural do pilar. 233

\section{CAPÍTULO 12}

Figura 12.1 - Layout do compartimento experimental (REIN et al., 2007).........................234

Figura 12.2 - Planta do compartimento ensaiado (REIN et al., 2007) ................................. 235

Figura 12.3 - Curva temperatura média-tempo dos gases dentro do compartimento (REIN et al., 2007). 236

Figura 12.4 - Contornos da temperatura do gás (em ${ }^{\circ} \mathrm{C}$ ) da seção S1-S1, de acordo com figura 12.2. Tempo após a ignição de $901 \mathrm{~s}$ 236

Figura 12.5 - Taxa de liberação de calor do incêndio do incêndio de Dalmarnock (REIN et al., 2007).

Figura 12.6 - Isotermas externas ao compartimento (em $\left.{ }^{\circ} \mathrm{C}\right)$. (a) seção S2-S2 às 12:41:36 e (b) S3-S3 às 12:41:36, com valores de eixo conforme figura 2.12 (REIN et al., 2007).

Figura 12.7 - Modelo do compartimento para o ExteelFire (Dalmanorck). 238 
Figura 12.8 - Distribuição da carga de incêndio em madeira no compartimento (WALD, 2009).

Figura 12.9 - Localização dos termopares para registrar temperaturas dos gases e do aço (WALD, 2009). 240

Figura 12.10 - Localização da placa externa de aço exposta ao calor durante o ensaio (WALD, 2009).

Figura 12.11 - Modelo do compartimento para o ExteelFire (Ostrava). 242

Figura 12.12 - Dimensões e posição da chapa de aço em relação à abertura do compartimento.

\section{CAPÍTULO 13}

Figura 13.1 - Comparação entre os resultados do ExteelFire aos resultados do Smartfire,

Super Tempcalc, de Mittal e de Dalmarnock. 


\section{LISTA DE TABELAS}

\section{CAPÍTULO 2}

Tabela 2.1 - Temperaturas dos gases a $300 \mathrm{~mm}$ abaixo do teto (WALD, 2009)

Tabela 2.2 - Temperaturas externas do aço (WALD, 2009)

Tabela 2.3 - Eventos registrados pelas câmeras e os respectivos tempos em relação à ignição (REIN et al., 2009)

\section{CAPÍTULO 3}

Tabela 3.1 - Taxas de crescimento para incêndios t-quadrado (EWER, 2004 e BUCHANAN, 2001)

Tabela 3.2 - Propriedades térmicas de alguns materiais (DRYSDALE apud BUCHANAN, 2001). 38

\section{CAPÍTULO 4}

Tabela 4.1 - Fator de massividade para alguns elementos estruturais sem revestimento contra fogo (ABNT NBR 14323:1999) 56

Tabela 4.2 - Fator de massividade para alguns elementos estruturais com revestimento contra fogo (ABNT NBR 14323:1999). 57

\section{CAPÍTULO 5}

Tabela 5.1 - Constantes da eq. 5.11 para cilindros não-circulares em escoamento cruzado de um gás (INCROPERA et al., 2008).

Tabela 5.2 - Propriedades dos elementos de vedação (ABNT NBR 14323:2003 e OZONE $\mathrm{V} 2.0,2001)$.

Tabela 5.3 - Geometria do compartimento, inverso do grau de ventilação e fator térmico dos elementos de compartimentação 


\section{CAPÍTULO 7}

Tabela 7.1 - Distância mínima do pilar à parede. Pilar em frente a abertura. Abertura em uma parede.

Tabela 7.2 - Distância mínima do pilar à parede. Pilar em frente a abertura. Aberturas em duas paredes

Tabela 7.3 - Distância mínima do pilar à abertura. Pilar entre aberturas 147

\section{CAPÍTULO 8}

Tabela 8.1 - Distância mínima dos pilares à borda da abertura $\left(\mathrm{d}_{\mathrm{e}}=\mathrm{d}_{\mathrm{d}}\right)$. Pilares posicionados entre aberturas com distância $d$ da parede da fachada. 158

Tabela 8.2 - Distância mínima dos pilares à borda da abertura. Pilares encaixados na parede da fachada.

Tabela 8.3 - Distância mínima do pilar à abertura. Pilar entre aberturas. 162

Tabela 8.4 - Distância mínima da viga ao topo da abertura. 164

Tabela 8.5 - Distância mínima do pilar à parede. Pilar em frente à abertura. Abertura em uma parede. 166

Tabela 8.6 - Distância mínima do pilar à parede. Pilar em frente à abertura. Aberturas em duas paredes. 169

\section{CAPÍTULO 9}

Tabela 9.1 - Propriedades dos materiais do cenário de incêndio (FSEG, 2008 e ABNT NBR 14323:2003)

\section{CAPÍTULO 10}

Tabela 10.1 - Taxa de combustão determinada pelo ExteelFire 
Tabela 10.2 - Altura da chama pelo ExteelFire e Smartfire 210

Tabela 10.3 - Temperatura máxima do pilar utilizando o Smartfire/Super Tempcalc e o ExteelFire

\section{CAPÍTULO 11}

Tabela 11.1 - Esforços resistentes em situação de incêndio 229

\section{CAPÍTULO 12}

Tabela 12.1 - Comparação entre o Eurocode $\left(q_{f i, d}=560 \mathrm{MJ} / \mathrm{m}^{2}\right)$ e o experimento de Dalmarnock (considerando a janela e as portas como ventilação externa) .......238

Tabela 12.2 - Comparação entre o Eurocode $\left(q_{f i, d}=560 \mathrm{MJ} / \mathrm{m}^{2}\right)$ e o experimento de Dalmarnock (considerando apenas a janela como ventilação externa) 239

Tabela 12.3 - Comparação entre o ExteelFire e o experimento da Siderúrgica Mittal Steel Ostrava 


\section{LISTA DE SÍMBOLOS}

$A \quad$ é a área da seção transversal do elemento estrutural de aço $\left(\mathrm{m}^{2}\right)$

$A \quad$ é a área da seção atravessada pelo calor $\left(\mathrm{m}^{2}\right)$

$A_{f} \quad$ é a área de piso do compartimento $\left(\mathrm{m}^{2}\right)$

$A_{m} \quad$ é a área do elemento exposta ao fogo $\left(\mathrm{m}^{2}\right)$

$A_{t} \quad$ é a área total que inclui o piso, o teto e as paredes descontadas as áreas das janelas $\left(\mathrm{m}^{2}\right)$

$A_{v} \quad$ é a área da janela ou a soma das áreas das janelas em todas as paredes $\left(\mathrm{m}^{2}\right)$

$A_{v 1} \quad$ é o somatório das áreas das janelas na parede $1\left(\mathrm{~m}^{2}\right)$

$A_{v 2} \quad$ é o somatório das áreas das janelas na parede $2\left(\mathrm{~m}^{2}\right)$

$a \quad$ é a distância do pilar à abertura (m)

$a_{z} \quad$ é a absortividade da chama

$b \quad$ é a absortividade térmica do enclausuramento (W.s $\mathrm{s}^{0,5} / \mathrm{m}^{2} \mathrm{~K}$ )

C é potencial calorífico da madeira $(\mathrm{MJ} / \mathrm{kg})$

C é uma constante adimensional

$C_{i} \quad$ é o coeficiente de proteção do elemento na face $i$ do elemento estrutural

c é o calor específico do material $\left(\mathrm{J} / \mathrm{kg}^{\circ} \mathrm{C}\right)$

$c_{a} \quad$ é o calor específico do aço $\left(\mathrm{J} / \mathrm{kg}^{\circ} \mathrm{C}\right)$

$c_{z} \quad$ é o calor específico da chama $\left(\mathrm{kJ} / \mathrm{kg}^{\circ} \mathrm{C}\right)$

$W_{2} / W_{1}$ é a razão entre a profundidade e a largura do compartimento

d é o comprimento característico da superfície (m)

d é a distância do elemento estrutural à parede da fachada (m)

$d_{i} \quad$ é a dimensão da seção transversal do elemento na face $i$ do elemento estrutural (m)

$d_{d} \quad$ é a distância do pilar à borda direita da janela (m)

$d_{e} \quad$ é a distância do pilar à borda esquerda da janela $(\mathrm{m})$

$d_{v} \quad$ é a distância vertical da viga em relação ao topo da abertura (m) 
$d_{1} \quad$ Comprimento da face do pilar perpendicular à parede (m)

$d_{1} \quad$ Comprimento da face da viga paralela à parede $(\mathrm{m})$

$d_{2} \quad$ Comprimento da face do pilar paralelo à parede $(\mathrm{m})$

$d_{2} \quad$ Comprimento da face da viga perpendicular à parede $(\mathrm{m})$

$E \quad$ é o módulo de elasticidade do aço a $20^{\circ} \mathrm{C}(\mathrm{MPa})$

$E \quad$ é a energia total liberada (J)

$E_{\theta} \quad$ é o módulo de elasticidade dos aços laminados a uma temperatura $\theta_{a}$

$F_{v} \quad$ é o fator de ventilação $\left(\mathrm{m}^{0,5}\right)$

$F \quad$ é o fator de massividade $\left(\mathrm{m}^{-1}\right)$

$f_{y} \quad$ é a resistência ao escoamento do aço a $20^{\circ} \mathrm{C}(\mathrm{MPa})$

$f_{y, \theta} \quad$ é a resistência ao escoamento dos aços laminados a uma temperatura $\theta_{a}(\mathrm{MPa})$

$g \quad$ é a aceleração da gravidade $\left(\mathrm{m} / \mathrm{s}^{2}\right)$

$H \quad$ é a altura do compartimento incendiado (m)

$H_{i} \quad$ é o potencial calorífico específico de cada componente i do material combustível $(\mathrm{MJ} / \mathrm{kg})$

$h \quad$ é a altura da janela (m)

$h \quad$ é a altura da região da superfície irradiante (m);

$h_{e q} \quad$ é a altura equivalente das aberturas do compartimento (m)

$\dot{h}_{a b s} \quad$ é o fluxo de calor absorvido pelo elemento de aço na unidade de tempo por unidade de área superficial $\left(\mathrm{kW} / \mathrm{m}^{2}\right)$

$\dot{h}_{c} \quad$ é o fluxo de calor por unidade de área devido à convecção $\left(\mathrm{W} / \mathrm{m}^{2}\right)$

$\dot{h}_{c z} \quad$ é o fluxo de calor por unidade de área devido à convecção da chama $\left(\mathrm{kW} / \mathrm{m}^{2}\right)$

$\dot{h}_{k} \quad$ é o fluxo de calor por unidade de área devido à condução $\left(\mathrm{W} / \mathrm{m}^{2}\right)$

$\dot{h}_{\text {perd }}$ é o fluxo de calor por unidade de área perdido por condução distante da área aquecida $\left(\mathrm{kW} / \mathrm{m}^{2}\right)$ 
$\dot{h}_{r o} \quad$ é o fluxo de calor devido à radiação relacionado com o ambiente em torno do elemento $\left(\mathrm{kW} / \mathrm{m}^{2}\right)$

$\dot{h}_{r f}$ é o fluxo de calor por unidade de área devido à radiação das aberturas do compartimento $\left(\mathrm{kW} / \mathrm{m}^{2}\right)$

$\dot{h}_{r z} \quad$ é o fluxo de calor por unidade de área devido à radiação da chama $\left(\mathrm{kW} / \mathrm{m}^{2}\right)$

$\dot{h}_{z} \quad$ é o fluxo de calor por unidade de área devido à radiação da chama $\left(\mathrm{kW} / \mathrm{m}^{2}\right)$

$I_{f} \quad$ é a intensidade de calor por radiação das aberturas $\left(\mathrm{kW} / \mathrm{m}^{2}\right)$

$I_{z} \quad$ é a intensidade de calor por radiação das chamas $\left(\mathrm{kW} / \mathrm{m}^{2}\right)$

$k_{E, \theta}$ é o fator de redução do módulo de elasticidade de todos os tipos de aço

$k_{y, \theta}$ é o fator de redução da resistência ao escoamento dos aços laminados a quente

$L \quad$ é a massa total da carga de incêndio $(\mathrm{kg})$

$L_{c} \quad$ é a profundidade do núcleo $(\mathrm{m})$

$l \quad$ é o comprimento do aço a $20^{\circ} \mathrm{C}(\mathrm{m})$

$M_{a} \quad$ é a massa por unidade de comprimento do elemento de aço $(\mathrm{kg} / \mathrm{m})$

$m \quad$ é uma constante adimensional

$\dot{m} \quad$ é a taxa de liberação de massa do combustível $(\mathrm{kg} / \mathrm{s})$

$N_{u} \quad$ é o número de Nusselt

$n \quad$ é a razão entre a largura e a altura da metade superior da janela, ou seja, $n=2 w / h$

$P \quad$ é o peso molecular $(\mathrm{kg} / \mathrm{K} . \mathrm{mol})$

Pr é o número de Prandl

$\dot{Q} \quad$ é a taxa de liberação de calor (MW)

$\dot{Q}_{c} \quad$ é o fluxo de calor por convecção (kW)

$\dot{Q}_{c z} \quad$ é o fluxo de calor por convecção da chama (kW)

$\dot{Q}_{k} \quad$ é o fluxo de calor por condução (W)

$\dot{Q}_{p} \quad$ é a taxa de liberação de calor máxima (W) 
$\dot{Q}_{r} \quad$ é o fluxo de calor por radiação (W)

$\dot{Q}_{r f} \quad$ é o fluxo de calor por radiação das aberturas $(\mathrm{kW})$

$\dot{Q}_{r z} \quad$ é o fluxo de calor por radiação da chama (kW);

$q_{f i} \quad$ é o valor da carga de incêndio específica $\left(\mathrm{MJ} / \mathrm{m}^{2}\right)$

$q_{f, d} \quad$ é o valor de cálculo da carga de incêndio específica $\left(\mathrm{MJ} / \mathrm{m}^{2}\right)$

$R_{e} \quad$ é o número de Reynolds

$r \quad$ é a distância entre a superfície radiante e a superfície receptora (m)

$r_{o} \quad$ é o raio efetivo da metade superior da janela (m), ou seja, $r_{o}=\left(\frac{A_{v}}{2 \pi}\right)^{1 / 2}(\mathrm{~m})$

$s \quad$ é a distância entre as duas superfícies (m)

$t \quad$ é o tempo (h, min ou s)

$t_{\text {lim }}$ é a duração do incêndio quando controlado pelo material combustível (h)

$u \quad$ é o perímetro do elemento estrutural de aço exposto ao incêndio (m)

$u_{\infty} \quad$ é a velocidade mássica de escoamento do fluido afastado da superfície $(\mathrm{m} / \mathrm{s})$

$u_{m} \quad$ é o perímetro efetivo do material de revestimento contra fogo (m)

$u_{z} \quad$ é a velocidade do gás $(\mathrm{m} / \mathrm{s})$

$V \quad$ é o volume do elemento estrutural de aço $\left(\mathrm{m}^{3}\right)$

$v \quad$ é a velocidade do vento $(\mathrm{m} / \mathrm{s})$

$x \quad$ é o comprimento característico (m)

$x \quad$ é a distância vertical acima do topo da janela (m)

$x \quad$ é a projeção horizontal da chama (m)

$X \quad$ é o comprimento da chama ao longo do seu eixo (m)

$z \quad$ é a altura da chama externa (m)

$W_{a} \quad$ é a largura da marquise ou sacada (m)

$W_{c} \quad$ é a largura do núcleo $(\mathrm{m})$

$W_{l} \quad$ é a largura da parede 1, que contém a maior área de janela (m) 
$W_{2} \quad$ é largura da parede perpendicular a parede 1 do compartimento incendiado (m)

$w \quad$ é a largura da janela (m)

$w \quad$ é a largura da região da superfície irradiante (m)

$w_{1} \quad$ Largura total das aberturas na parede principal (m)

$w_{i} \quad$ Largura total das aberturas nas paredes, exceto a parede principal (m)

$w_{t} \quad$ é o somatório das larguras das janelas (m)

$w_{z} \quad$ é a largura da chama (m)

$\alpha \quad$ é o coeficiente de intensidade do incêndio (MW/s $\left.{ }^{2}\right)$

$\alpha \quad$ é a difusidade térmica $\left(\mathrm{m}^{2} / \mathrm{s}\right)$

$\alpha_{a} \quad$ é o coeficiente de transferência de calor do aço $\left(\mathrm{kW} / \mathrm{m}^{20} \mathrm{C}\right)$

$\alpha_{c} \quad$ é o coeficiente de transferência de calor por convecção $\left(\mathrm{W} / \mathrm{m}^{20} \mathrm{C}\right)$

$\alpha_{z} \quad$ é o coeficiente de transferência de calor por convecção da chama $\left(\mathrm{W} / \mathrm{m}^{20} \mathrm{C}\right)$

$\beta \quad$ é o coeficiente de expansão térmica $\left(\mathrm{K}^{-1}\right)$

$\Delta l \quad$ é a expansão térmica do aço provocada pelo aumento de temperatura (m)

$\varepsilon \quad$ é a emissividade resultante das superfícies radiante e receptora

$\varepsilon_{e} \quad$ é a emissividade da superfície radiante

$\varepsilon_{f} \quad$ é a emissividade na janela

$\varepsilon_{r} \quad$ é a emissividade da superfície receptora

$\varepsilon_{z} \quad$ é a emissividade da chama

$\eta \quad$ é o inverso do fator de ventilação $\left(\mathrm{m}^{-1 / 2}\right)$

$\Theta \quad$ é a temperatura adimensional da chama

$\theta \quad$ é a temperatura $\left({ }^{\circ} \mathrm{C}\right)$

$\theta_{a} \quad$ é a temperatura do aço $\left({ }^{\circ} \mathrm{C}\right)$

$\theta_{e} \quad$ é a temperatura da superfície emissora $\left({ }^{\circ} \mathrm{C}\right)$

$\theta_{g} \quad$ é a temperatura dos gases quentes $\left({ }^{\circ} \mathrm{C}\right)$ 
$\theta_{g(m a ́ x)}$ é a temperatura máxima dos gases dentro do compartimento incendiado $\left({ }^{\circ} \mathrm{C}\right)$

$\theta_{\ell} \quad$ é a temperatura local $\left({ }^{\circ} \mathrm{C}\right)$

$\theta_{l w} \quad$ é a temperatura da chama no ponto oposto ao topo da janela $\left({ }^{\circ} \mathrm{C}\right)$

$\theta_{r} \quad$ é a temperatura da superfície receptora $\left({ }^{\circ} \mathrm{C}\right)$

$\theta_{s} \quad$ é a temperatura da superfície $\left({ }^{\circ} \mathrm{C}\right)$

$\theta_{x} \quad$ é a temperatura no topo da chama $\left({ }^{\circ} \mathrm{C}\right)$

$\theta_{w} \quad$ é a temperatura da chama na janela $\left({ }^{\circ} \mathrm{C}\right)$

$\theta_{z} \quad$ é a temperatura da chama $\left({ }^{\circ} \mathrm{C}\right)$

$\theta_{o} \quad$ é a temperatura ambiente no Brasil $\left({ }^{\circ} \mathrm{C}\right)$

$\theta_{o w} \quad$ é a temperatura da chama no topo da janela $\left({ }^{\circ} \mathrm{C}\right)$

$\theta_{\infty} \quad$ é a temperatura dos gases quentes $\left({ }^{\circ} \mathrm{C}\right)$

$\theta_{1} \quad$ é o ângulo formado entre a normal $\hat{n}_{1}$ ao elemento de superfície $d A_{1}$ e a reta $s$ que liga $d A_{1}$ a $d A_{2} ;$

$\theta_{2} \quad$ é o ângulo formado entre a normal $\hat{n}_{2}$ ao elemento de superfície $d A_{2}$ e a reta $s$ que liga $d A_{1}$ a $d A_{2}$.

$\lambda \quad$ é a condutividade térmica do material $\left(\mathrm{W} / \mathrm{m}^{\circ} \mathrm{C}\right)$

$\lambda_{a} \quad$ é a condutividade térmica do aço $\left(\mathrm{W} / \mathrm{m}^{\circ} \mathrm{C}\right)$

$\lambda_{l} \quad$ é a espessura da chama em relação a face i do elemento estrutural (m)

$\lambda_{z} \quad$ é a condutividade térmica do gás $\left(\mathrm{kW} / \mathrm{m}^{\circ} \mathrm{C}\right)$

$\mu \quad$ é a viscosidade do fluido $(\mathrm{kg} / \mathrm{ms})$

$\mu_{z} \quad$ é a viscosidade do gás $(\mathrm{kg} / \mathrm{ms})$

$\rho \quad$ é a massa específica do material $\left(\mathrm{kg} / \mathrm{m}^{3}\right)$

$\rho_{a} \quad$ é a massa específica do aço $\left(\mathrm{kg} / \mathrm{m}^{3}\right)$

$\rho_{z} \quad$ é a densidade do gás quente $\left(\mathrm{kg} / \mathrm{m}^{3}\right)$

$\sigma \quad$ é a constante de Stefan-Boltzmann $\left(5,67 \times 10^{-8} \mathrm{~W} / \mathrm{m}^{2 o} \mathrm{C}\right)$ 
$\tau \quad$ é o tempo de duração do incêndio (s)

$\tau_{f} \quad$ é o menor valor de duração do incêndio à queima livre (s)

$\phi \quad$ é o fator de configuração

$\phi_{f} \quad$ é o fator de configuração das aberturas

$\phi_{z} \quad$ é o fator de configuração da chama 


\section{SUMÁRIO}

RESUMO i

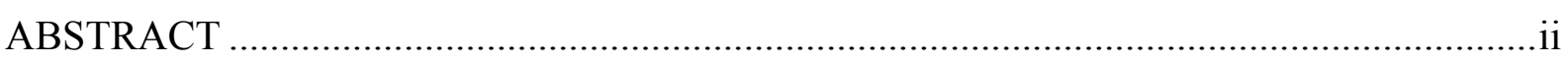

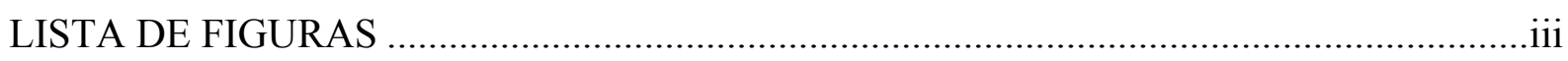

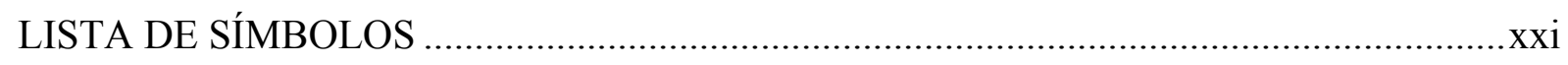

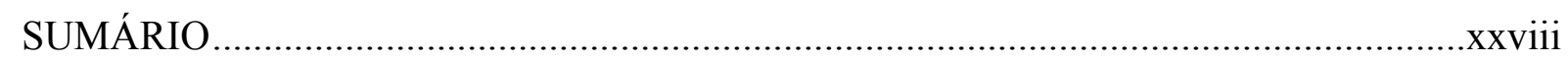

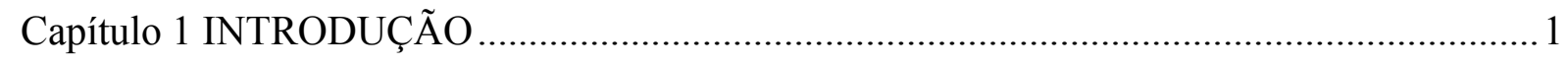

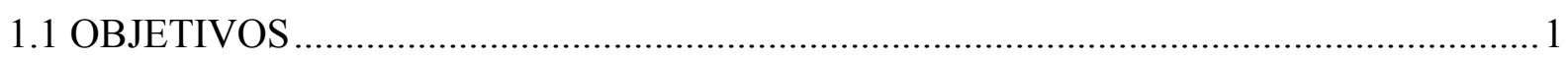

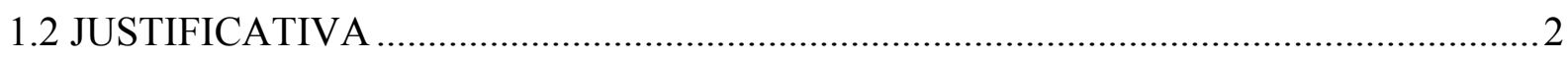

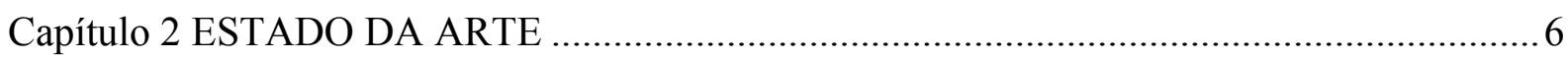

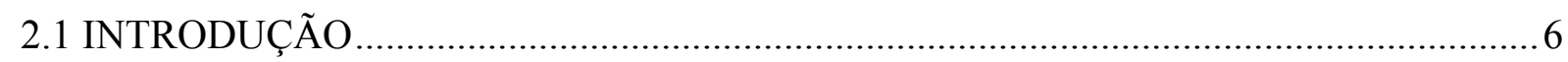

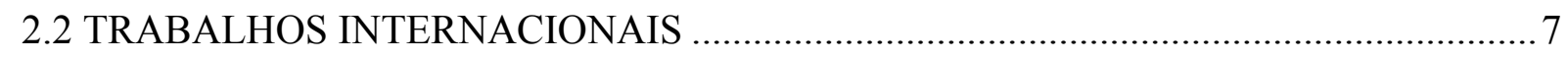

2.2.1 Estudos experimentais para projeção externa da chama ..........................................

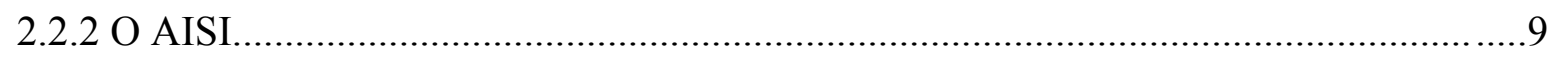

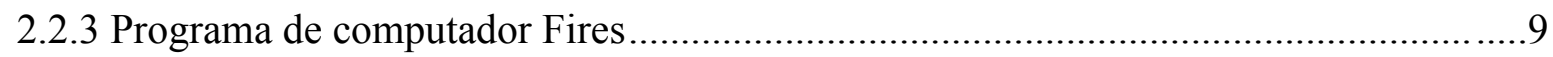

2.2.4 O experimento da Siderúrgica Mittal Steel Ostrava..............................................10

2.2.4.1 Temperatura do aço externo ao compartimento incendiado................................ 15

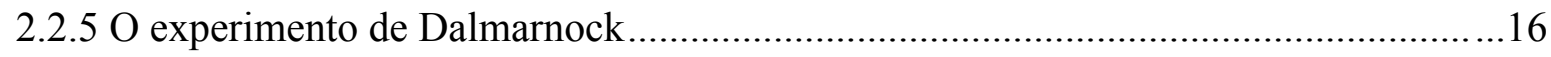

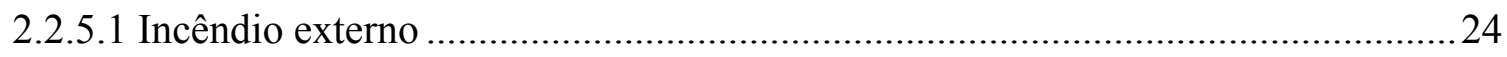

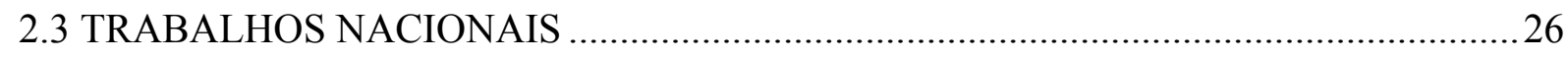

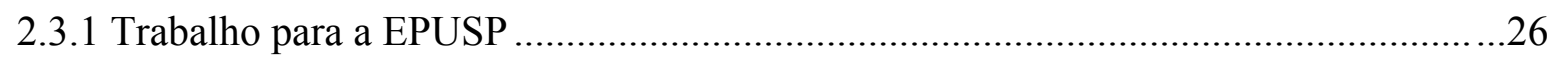

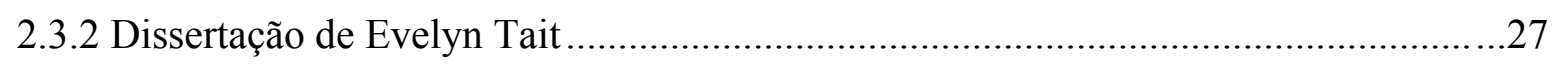

2.3.3 Dissertação de Macksuel Soares de Azevedo.........................................................27

Capítulo 3 CARACTERÍSTICAS DO INCÊNDIO ....................................................... 28

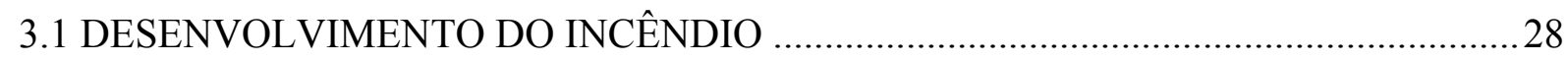


3.2 INCÊNDIO-PADRÃO 29

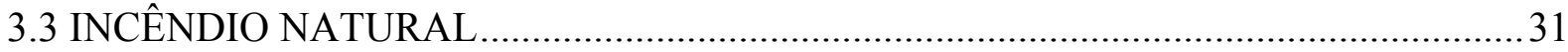

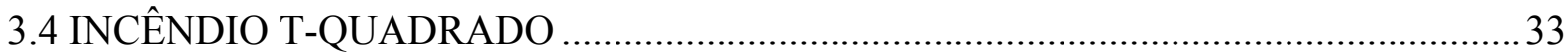

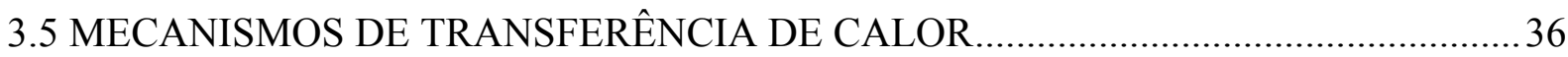

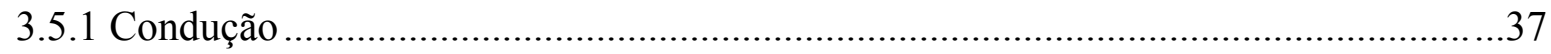

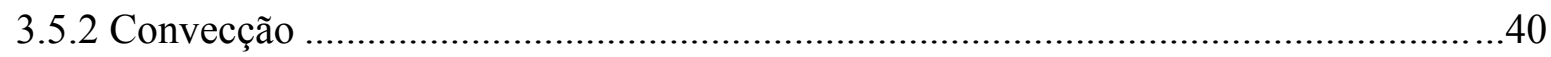

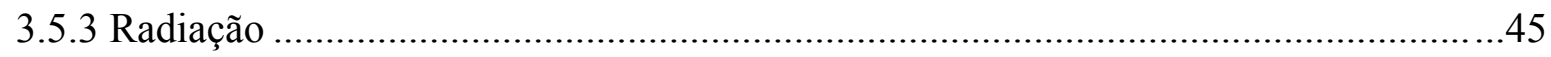

Capítulo 4 ESTRUTURAS DE AÇO EXPOSTAS AO INCÊNDIO ....................................49

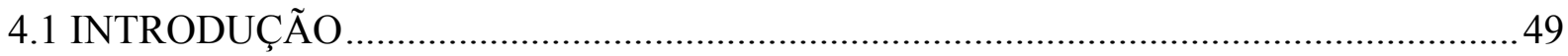

4.2 RESISTÊNCIA AO ESCOAMENTO E MÓDULO DE ELASTICIDADE .....................50

4.3 PROPRIEDADES TÉRMICAS DO AÇO ................................................................... 51

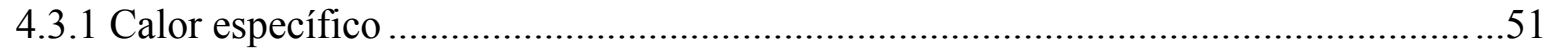

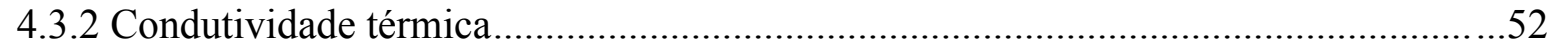

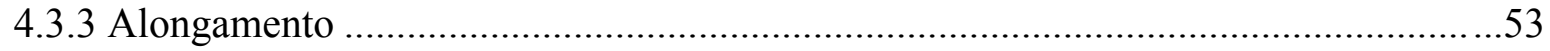

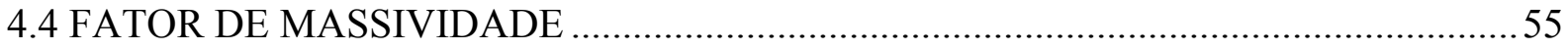

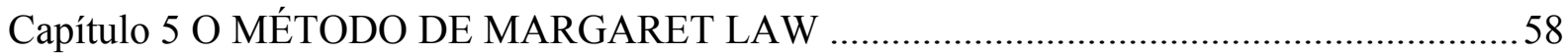

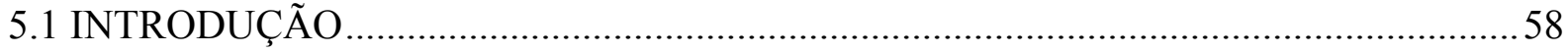

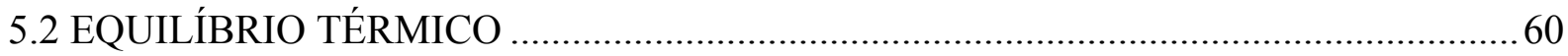

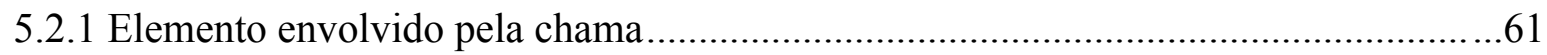

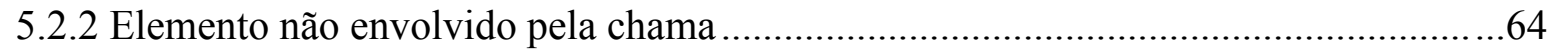

5.2.3 Convecção das chamas e dos gases quentes ..........................................................66

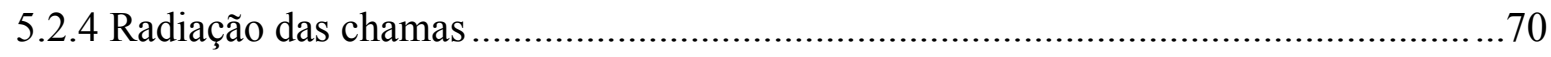

5.3 O INCÊNDIO NO INTERIOR DO COMPARTIMENTO ......................................... 74

5.3.1 Taxa de liberação de massa do combustível......................................................... 75

5.3.2 Temperatura dentro do compartimento ....................................................... 78

5.3.2.1 O metodo de Law e a curva de incêndio natural ................................................. 81 


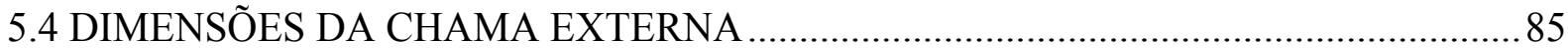

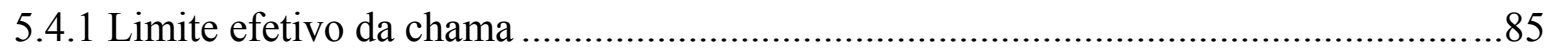

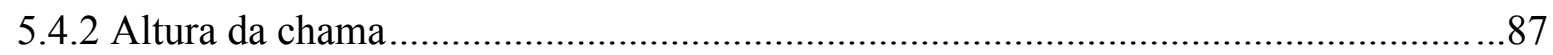

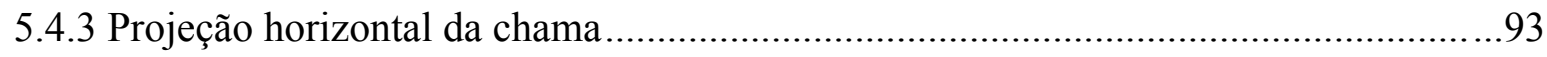

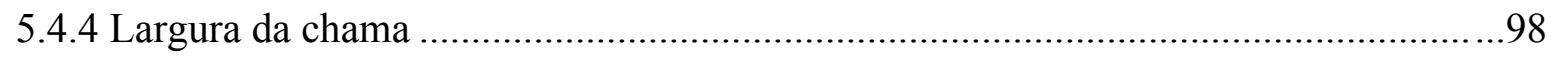

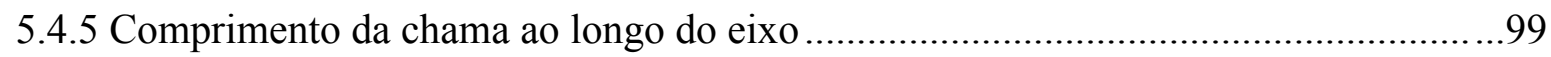

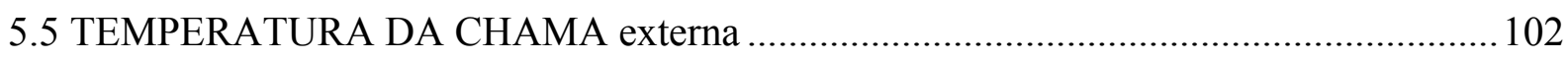

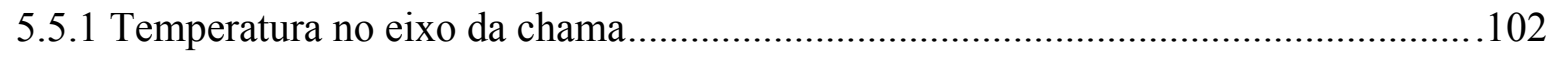

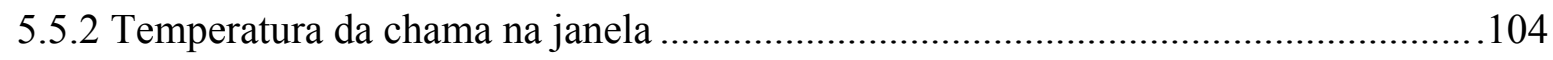

5.6 Análise DA TEMPERATURA DOS ELEMENTOS EXTERNOS ................................105

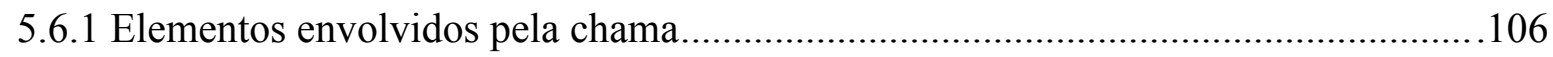

5.6.2 Elementos não envolvidos pela chama ............................................................109

5.6.3 Considerações sobre as temperaturas do aço.......................................................110

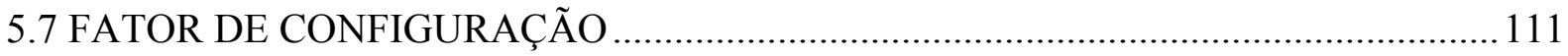

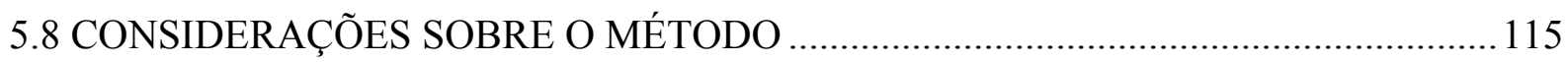

5.8.1 Desenvolvimento do incêndio e da chama para grandes compartimentos ................115

5.8.2 Parâmetros geométricos do compartimento ..........................................................116

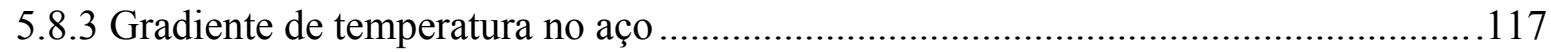

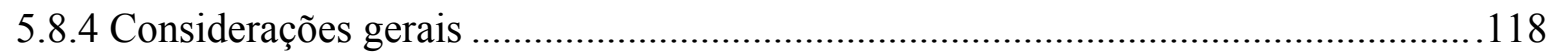

Capítulo 6 PROGRAMA DE COMPUTADOR EXTEELFIRE 2.0.................................... 119

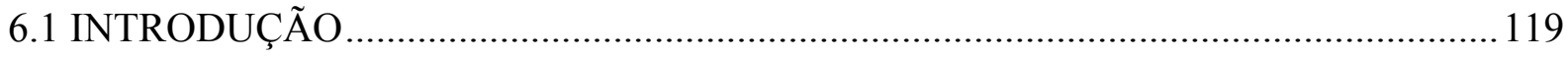

6.2 DESCRIÇÃO DO PROGRAMA DE COMPUTADOR .............................................. 120

6.3 COMPARAÇÃO ENTRE O fires, EXTEELFIRE 1.0 e o exteelfire 2.0 ........................129

6.3.1 Taxa de combustão ...................................................................................... 130

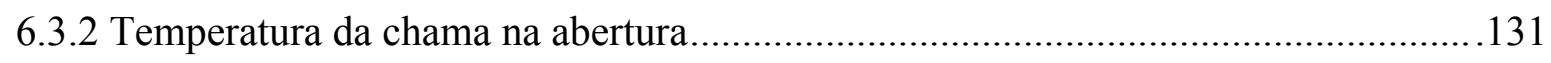

6.3.3 Pilar posicionado em frente a uma abertura .....................................................132 
6.3.4 Pilar posicionado entre aberturas 133

6.3.5 Considerações sobre vigas. 135

6.3.6 Considerações sobre faces isoladas..... 136

Capítulo 7 COMPARAÇÕES ENTRE O EUROCODE E O AISI. 137

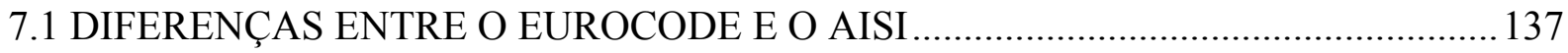

7.1.1 Carga de incêndio específica .137

7.1.2 Dimensões do compartimento 137

7.1.3 Parede acima das aberturas 138

7.1.4 Área total da superfície do compartimento. 138

7.1.5 Temperatura da chama ao longo do seu eixo 138

7.1.6 Altura da chama 139

7.1.7 Vigas 140

7.1.8 Proteção das faces do elemento 141

7.2 COMPARAÇÃO NUMÉRICA 141

Capítulo 8 APLICAÇÕES DO EXTEELFIRE 2.0 149

8.1 VARIAÇÃO DA TEMPERATURA NA ESTRUTURA 149

8.2 ELEMENTOS ESTRUTURAIS SEM REVESTIMENTO CONTRA FOGO 155

8.2.1 Pilares junto à parede cega 156

8.2.2 Vigas junto à parede cega 163

8.2.3 Pilares em frente a janelas 165

Capítulo 9 ANÁLISE TÉRMICA VIA SMARTFIRE

9.1 OBJETIVO DO SMARTFIRE.

9.2 GENERALIDADES SOBRE O SMARTFIRE V4.1

9.3 VALIDAÇÃO

9.4 CENÁRIO DO INCÊNDIO

9.4.1 O compartimento incendiado 
9.4.2 Taxa de liberação de calor

9.4.3 O modelo de combustão dos gases

9.4.4 Limite de oxigenação. 179

9.5 TEMPERATURA DENTRO DO COMPARTIMENTO ............................................... 180

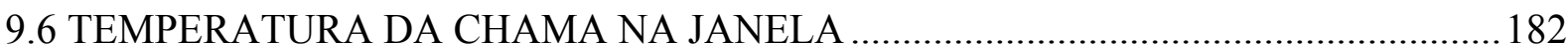

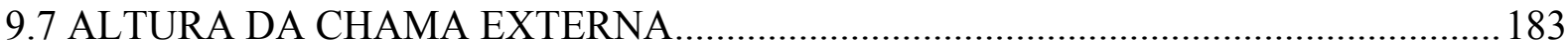

Capítulo 10 COMPARAÇÃO ENTRE OS RESULTADOS DO EXTEELFIRE E DO

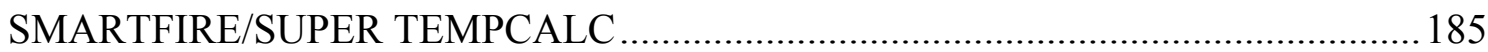

10.1 TEMPERATURA NO INTERIOR DO COMPARTIMENTO ..................................186

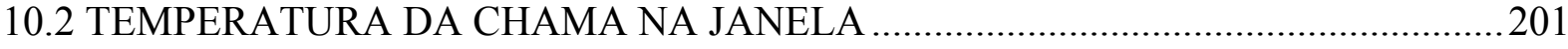

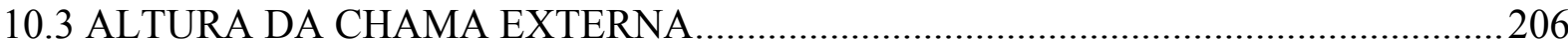

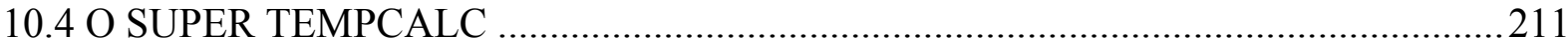

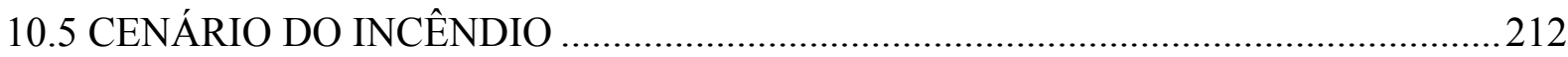

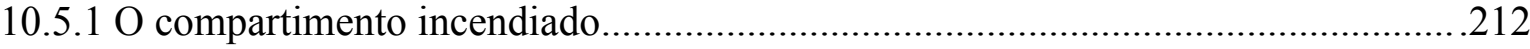

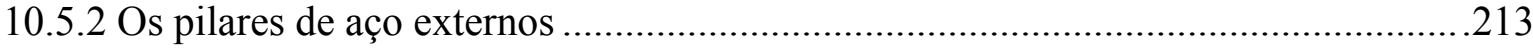

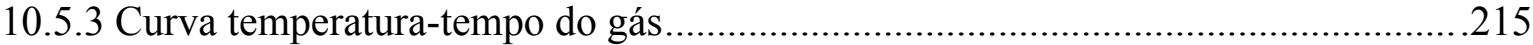

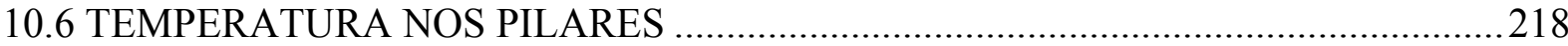

Capítulo 11 SEGURANÇA ESTRUTURAL EM SITUAÇÃO DE INCÊNDIO ...................226

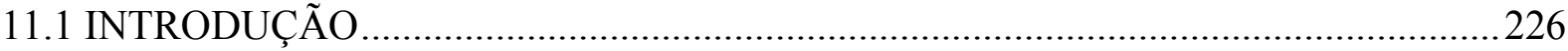

11.2 DETERMINAÇÃO DA TEMPERATURA ATUANTE NO ELEMENTO

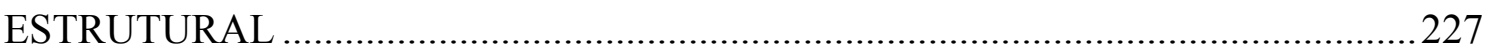

11.3 DETERMINAÇÃO DA TEMPERATURA CRÍTICA DO ELEMENTO ESTRUTURAL 228

11.4 EXEMPLO 232

Capítulo 12 OS EXPERIMENTOS DE DALMARNOCK E DA SIDERÚRGICA MITTAL

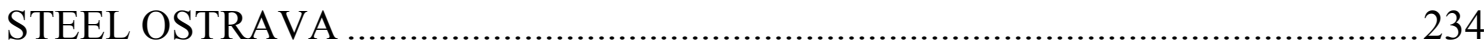

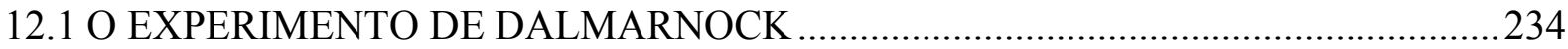


12.2 O EXPERIMENTO DA SIDERÚRGICA MITTAL STEEL OSTRAVA 239

Capítulo 13 CONCLUSÕES E RECOMENDAÇÕES PARA TRABALHOS FUTUROS ..244 13.1 CONCLUSÕES .244

13.2 SUGESTÕES PARA TRABALHOS FUTUROS. 248

REFERÊNCIAS BIBLIOGRÁFICAS 249

ANEXO A 


\subsection{OBJETIVOS}

O objetivos desta Tese são:

- Elaborar um programa de computador para determinar a máxima temperatura dos elementos estruturais de aço externos a edificações em situação de incêndio, com base no método de Margaret Law.

- Comparar os resultados obtidos pelo programa de computador a ser desenvolvido a valores determinados por meio de análise numérica, com auxílio dos programas de computador CFD (Computational Fluid Dynamics) Smartfire e de análise térmica, Super Tempcalc.

- Comparar os resultados obtidos pelo programa de computador a ser desenvolvido a valores determinados em ensaios de incêndio compartimentado em escala natural (ensaio de Dalmarnock e ensaio da Siderúrgica Mittal Steel Ostrava).

- Aplicar o programa de computador a ser desenvolvido a alguns casos correntes na construção civil, indicando situações em que o revestimento contra fogo pode ser dispensado. 


\subsection{JUSTIFICATIVA}

De acordo com Law (1978), na década de 70 os projetos tradicionais de segurança contra incêndio nos edifícios não eram suficientemente flexíveis e nem eram adequados para lidar com o desenvolvimento da arquitetura moderna na construção dos edifícios.

Para os elementos estruturais, as normas de segurança contra incêndio exigiam um desempenho de resistência ao fogo com base em um período especificado de exposição do elemento a uma elevação padronizada de temperatura.

Nesse modelo, além da simplificação, geralmente antieconômica, de substituir o incêndio real por um incêndio padronizado, não havia um método específico para as estruturas de aço externas a edificações. Esses elementos deviam ser projetados com as mesmas exigências de resistência ao fogo e, consequentemente, com os mesmos revestimentos contra fogo que os elementos estruturais de aço internos, mesmo que as condições externas da exposição ao fogo fossem, reconhecidamente, menos severas.

Os elementos estruturais internos em situação de incêndio são cercados pelas chamas e pelas superfícies aquecidas tais como paredes, piso e teto do compartimento. Essas condições de aquecimento são similares àquelas do ensaio-padrão de resistência ao fogo, onde o elemento é introduzido em um forno.

Os elementos estruturais externos a edificações são expostos à radiação, proveniente das janelas na fachada e das chamas, e à convecção dos gases quentes. $\mathrm{O}$ valor da intensidade da radiação recebida varia de acordo com a posição do elemento em relação às janelas. O fluxo de calor também varia de acordo com a posição do elemento e perde calor para a temperatura ambiente. Dependendo das dimensões do elemento estrutural, da sua posição e da severidade do incêndio, os elementos estruturais externos podem ser projetados de forma a não necessitar de revestimento contra fogo.

Uma comissão constituída por Arup R \& D, Constrado (Constructional Steel Research and Development Organisation) e AISI (American Iron and Steel Institute) foi formada com a finalidade de pesquisar e desenvolver um método a ser utilizado em projetos de engenharia de segurança contra incêndio, de forma que identificasse a posição adequada de um elemento estrutural de aço externo a uma edificação, a fim de dispensar o revestimento contra fogo. 
Margaret Law participou dessa comissão e procurou adotar uma abordagem de projeto que analisava a transferência de calor para o elemento estrutural localizado no ambiente externo ao compartimento incendiado. No caso dos elementos estruturais de aço, as condições críticas podem ser definidas em termos de temperatura crítica do elemento de aço isolado e, dada as condições de transferência de calor, o cálculo da temperatura do aço é relativamente direta. $\mathrm{O}$ problema principal ao adotar essa abordagem de projeto é definir a transferência de calor externa. Foi obtida uma grande quantidade de dados sobre incêndio em edifícios, bem como sobre o comportamento da chama, sendo possível estimar a transferência de calor externa para projetos de edifícios. As correlações foram derivadas de modelos em escala reduzida e também de medidas em escala natural.

A atual norma brasileira ABNT NBR 14323:1999 permite determinar os esforços atuantes e resistentes nos elementos estruturais de aço em situação de incêndio e, a partir desses valores, verificar a segurança estrutural nessa condição excepcional de ações. Embora sejam apresentados métodos simplificados, a norma permite o emprego de métodos avançados de análise térmica e estrutural.

Os métodos simplificados são apropriados às estruturas internas a edificações. Apesar de poderem também ser aplicados às estruturas externas, conduzem a resultados antieconômicos, em vista do abrandamento dos efeitos do incêndio nessa situação. Para a determinação da temperatura em elementos estruturais de aço situados no exterior de um edifício, a ABNT NBR 14323:1999 recomenda, sem detalhar, um procedimento proposto pelo Eurocode 1, Part 1.2 (2002) e pelo Eurocode 3, Part 1.2 (2003).

A utilização de elementos estruturais de aço externos às edificações tem se mostrado, do ponto de vista da arquitetura, uma opção moderna, tanto internacionalmente, conforme figura 1.1, quanto no Brasil, conforme figura 1.2. 

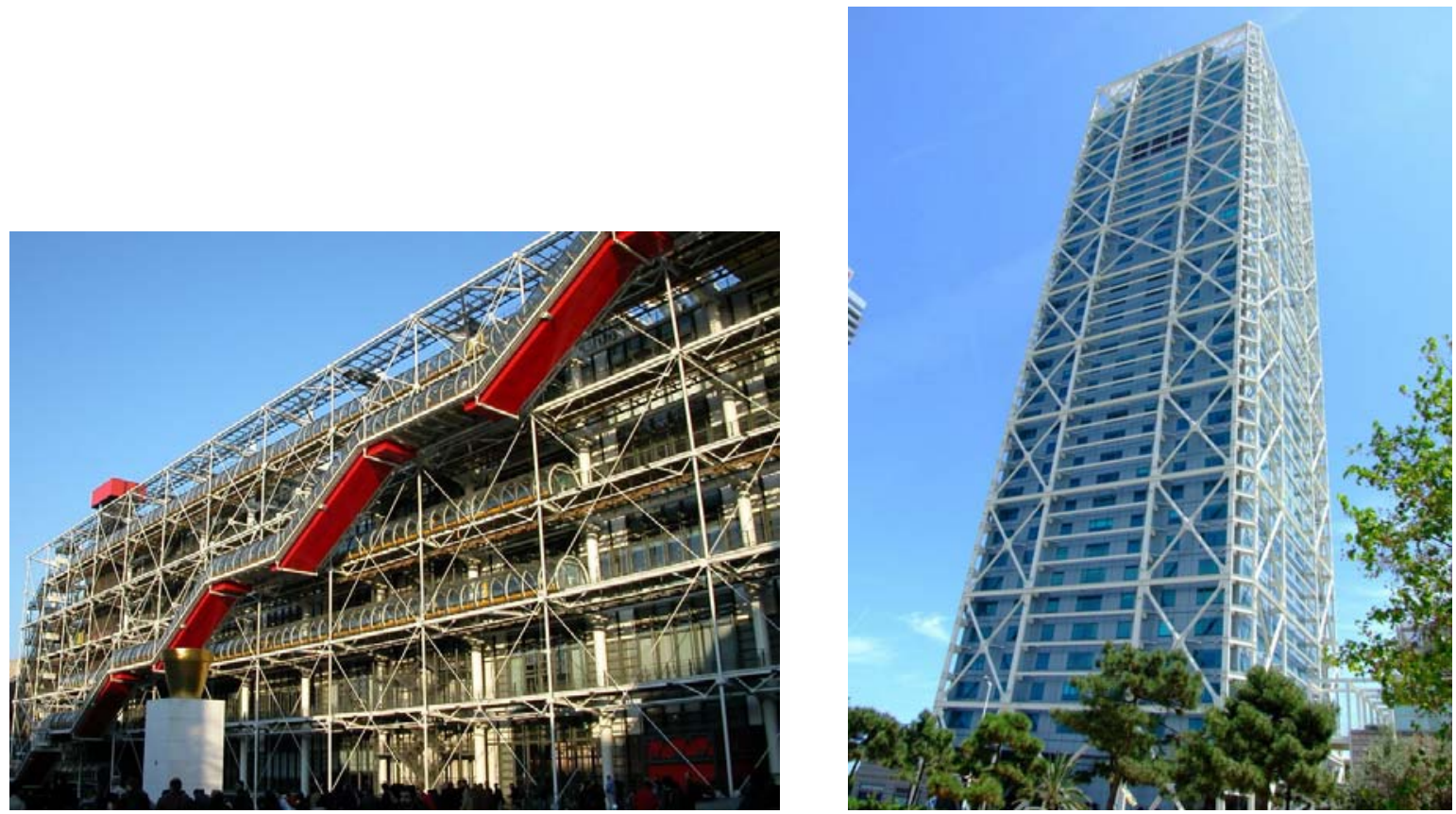

Figura 1.1 - Edificações com estruturas externas de aço: (a) Centre Pompidou, em Paris, França e (b) Hotel Arts Barcelona, Espanha.
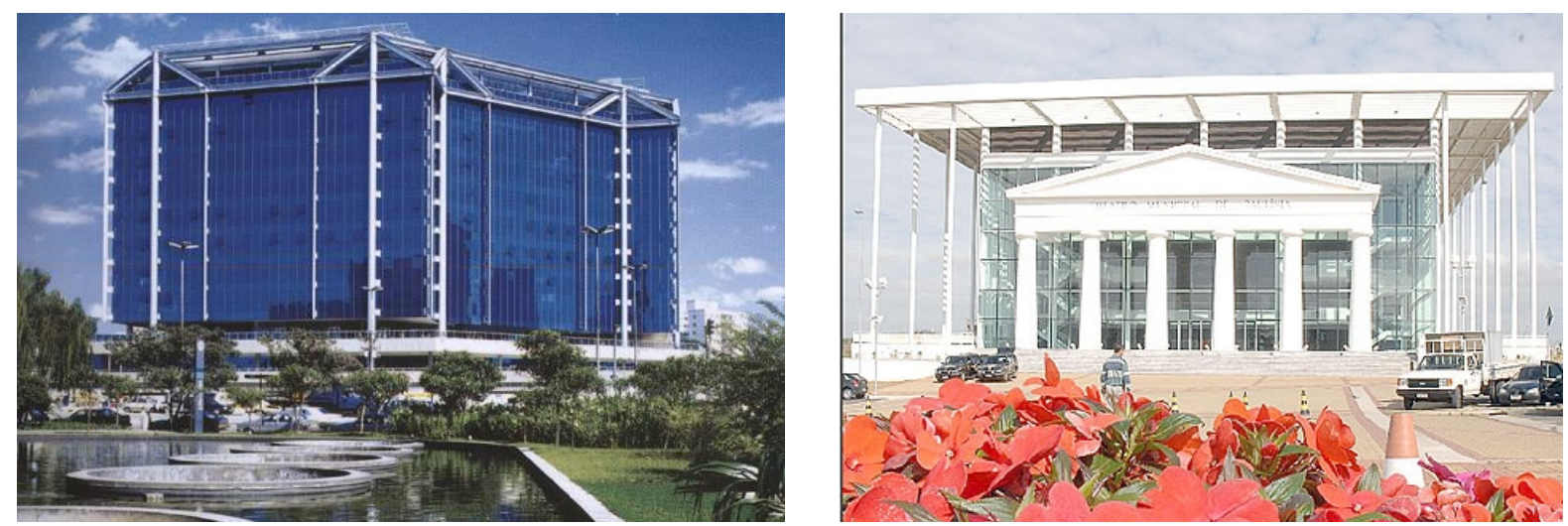

Figura 1.2 - Edificações brasileiras com estruturas externas de aço: (a) Centro Empresarial do Aço, em São Paulo e (b) Teatro Municipal de Paulínia, em São Paulo.

As condições de aquecimento dos elementos estruturais externos são bem mais brandas do que as condições internas ao compartimento incendiado. Os elementos externos são expostos à transferência de calor devido à radiação proveniente das aberturas e das chamas que emergem para fora do compartimento e, quando próximos a essas aberturas, acrescenta-se a transferência de calor devido à convecção dos gases quentes.

O valor da intensidade de calor recebida varia de acordo com a quantidade de material combustível, a ventilação dentro do compartimento e a posição do elemento em relação às aberturas.

Os elementos estruturais podem dispensar o revestimento contra fogo dependendo de seu posicionamento em relação às aberturas. 
Em virtude do método recomendado pelo Eurocode ser bastante trabalhoso, na década de 90 foi elaborado pela ARBED (Acieries Reunies Burbach-Esch-Dudelange) o programa de computador Fires. Esse programa de computador, desenvolvido em ambiente "DOS", calculava algumas situações restritas e apresentava erros de cálculos.

Na presente Tese, modificou-se o ExteelFire 1.0, desenvolvido em Azevedo (2005), a fim de possibilitar a determinação da temperatura do elemento estrutural de aço externo a edificação, abrangendo todas as posições de pilares e vigas, transformando-o no ExteelFire 2.0. A principal dificuldade encontrada foi na implementação matemática dos cálculos dos fatores de configuração (item 5.7). O cálculo desses fatores é bastante trabalhoso, pois se modificam em função da dimensão e posição da chama e da posição relativa entre o elemento estrutural e as aberturas.

O ExteelFire 2.0 é uma importante ferramenta a ser utilizada em projetos e pesquisas. A sua utilização para casos correntes na construção civil pode auxiliar arquitetos e engenheiros a encontrarem um melhor posicionamento do elemento estrutural externo a edificações em relação às suas aberturas, a fim de prescindir de material de revestimento contra fogo, reduzindo o valor da construção.

A aplicação do ExteelFire 2.0 na análise de experimentos com compartimentos incendiados em escala natural, tais como Dalmarnock e Mittal Steel Ostrava, é relevante na aferição dos resultados do método analítico do Eurocode em relação a um incêndio real.

Quando o método apresentado no Eurocode, com base nos estudos de Margaret Law, foi concebido, não havia disponibilidade de programas de computador CFD (Computational Fluid Dynamics). Nesta Tese será empregado o Smartfire, um avançado programa de computador de dinâmica computacional dos fluidos, para comparar aos resultados obtidos via método simplificado do Eurocode. Essa análise trará maior conhecimento dos métodos e poderá aumentar a confiabilidade no método simplificado ou ressaltar suas limitações. 


\subsection{INTRODUÇÃ̃O}

No início da década de 1930, a companhia norte-americana United States Steel Corporation desenvolveu um tipo de aço cujo nome comercial era Cor-Ten. Esse aço, quando exposto ao tempo, sem pintura anticorrosiva, adquire uma camada externa, pátina, que aderente ao elemento de aço, o protegeria da corrosão atmosférica. $\mathrm{O}$ aço Cor-Ten foi desenvolvido originalmente para a indústria ferroviária, mas sua utilização era atrativa para construção de pontes e outras estruturas externas, dispensando pintura.

Entretanto, quando esse aço foi utilizado nas estruturas externas a edifícios, não foram incorporados benefícios, pois as normas existentes exigiam que todos os elementos estruturais, tanto externos, quanto internos a edificação fossem revestidos com material de revestimento contra fogo. "Arup R\&D", então, criou uma comissão juntamente com o CONSTRADO - "Constructional Steel Research and Development Organization" e o AISI "American Iron and Steel Institute" para desenvolver um método que permitisse identificar a posição na qual estruturas externas pudessem ser projetadas, a fim de, também, dispensar o material de revestimento contra fogo. A pesquisadora Margaret Law foi convidada a fazer parte do grupo Arup R\&D, para desenvolver a pesquisa e escrever um artigo sobre estruturas de aço externas a edificações em situação de incêndio. $O$ resultado da pesquisa foi a elaboração de um método analítico para determinação da temperatura de estruturas de aço externas a edificações em situação de incêndio. Atualmente, esse método é recomendado pelo Eurocode. 


\subsection{TRABALHOS INTERNACIONAIS}

\subsubsection{Estudos experimentais para projeção externa da chama}

Em 1960, Yokoi apud Law (1978) realizou o primeiro estudo sobre a projeção das chamas que emergem das janelas. Em suas análises, ele derivou correlações para a distribuição da temperatura e da velocidade do fluxo dos gases quentes, que se elevam durante a combustão do álcool em bandejas retangulares.

Yokoi considerou a metade superior da janela como fonte de calor com formato retangular, e deduziu correlações para as colunas de gases quentes que emergem provenientes de vários tamanhos e formas de janelas de um compartimento em escala reduzida de dimensões $40 \mathrm{~cm} \mathrm{x}$ $40 \mathrm{~cm}$ x $20 \mathrm{~cm}$ de altura, contendo incêndio por álcool. Ele demonstrou o efeito da parede acima da janela e a forma da janela na distribuição, além da trajetória da coluna de gases quentes.

A parede acima da janela absorve o calor da coluna de gases quentes e restringe o ar que entra pela lateral da parede. De acordo com Yokoi apud Law (1978), quanto mais larga a janela, mais próxima da parede ficará a coluna de gases quentes que emerge para fora do compartimento.

Yokoi considerou a forma da janela como sendo $n=w /(1 / 2 h)$, ou seja, a relação entre a largura e a altura da metade superior da janela, e derivou uma série de formatos da coluna de gases quentes para diferentes valores de $n$.

Foi obtida uma boa concordância entre os resultados de ensaios com seu modelo e experimentos, utilizando edifícios em escala natural construídos com estruturas de concreto e combustível em madeira. Para que houvesse boa concordância, foi necessário realizar alguns ajustes para a emissividade das chamas provenientes da madeira e para as propriedades térmicas da parede acima da janela. De acordo com as observações realizadas por Yokoi, quando houver ventilação controlada no compartimento, o gás que emerge continuará a queimar depois que deixar a janela, e isso afeta a correlação.

No período de 1959 a 1964, Webster et al. apud Law (1978) realizaram uma série de ensaios, a maioria utilizando modelos em escala reduzida. Eles utilizaram compartimentos cúbicos 
abertos em um dos lados, contendo carga de incêndio formada por madeira. Foram feitas medições visuais da altura da chama.

Em 1961, Thomas apud Law (1978) correlacionou os resultados de Webster et al. utilizando as mesmas análises dimensionais empregadas por Yokoi. Essa análise era derivada do conhecimento sobre o escoamento dos gases, considerando o fluxo como sendo turbulento. Ao assumir a temperatura do topo da chama como sendo $538^{\circ} \mathrm{C}$, obteve um ajuste razoável entre os dados de Webster et al. e os de Yokoi.

Em 1969, Seigel apud Law (1978) relatou algumas descobertas provenientes dos ensaios realizados nos Laboratórios Underwriters. Um compartimento em escala natural foi utilizado como cenário do incêndio. Nele foram colocadas várias janelas com tamanhos e formas diferentes. A carga de incêndio era formada por madeira.

Um suplemento de ar foi introduzido na maioria dos experimentos, com o objetivo de aumentar a taxa de combustão da madeira. Nessa condição, o compartimento foi considerado bem ventilado, ou seja, condição de queima-livre. Foram registradas visualmente a altura e a projeção da chama, bem como a distribuição da temperatura da coluna de gases quentes que emergiu para fora do compartimento. A correlação de Seigel tratou as chamas como jatos horizontais forçados, sendo a projeção definida pela temperatura de $538^{\circ} \mathrm{C}$ no topo da chama.

Vários ensaios foram realizados em Borehamwood (cidade no Reino Unido), em compartimentos em escala natural com ventilação natural, contendo combustível de madeira. As alturas visuais da chama foram registradas, mas somente como produto da experiência principal, assim esses valores são aproximados.

A maioria dos experimentos em escala natural foram projetados especificamente para estudar a projeção da chama. As informações obtidas foram generalizadas, relacionando as correlações descritas acima. Esse processo tem pelo menos dois aspectos importantes: demonstrar a validade das correlações obtidas pelo uso dos modelos e ilustrar a diferença entre o ambiente ideal do laboratório e as condições naturais. Por exemplo, observou-se na prática que a carga de incêndio pode queimar de forma desigual, ou a projeção da chama que emerge das janelas pode ser assimétrica.

A figura 2.1 ilustra as características principais de interesse para a projeção da chama. 


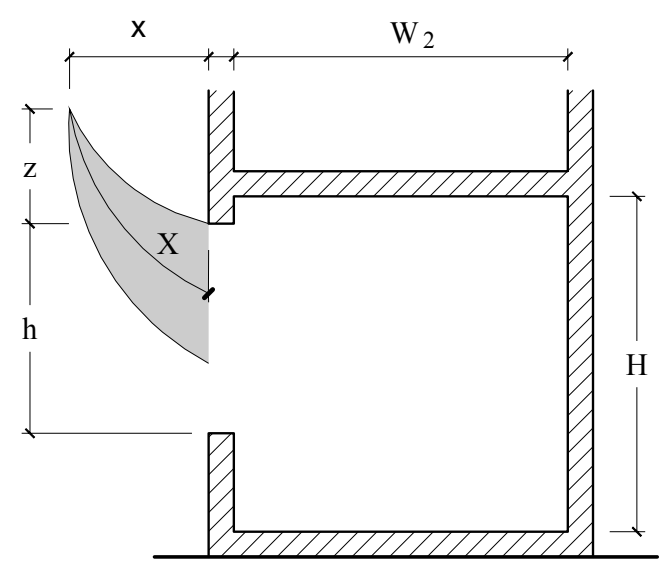

Seção Lateral

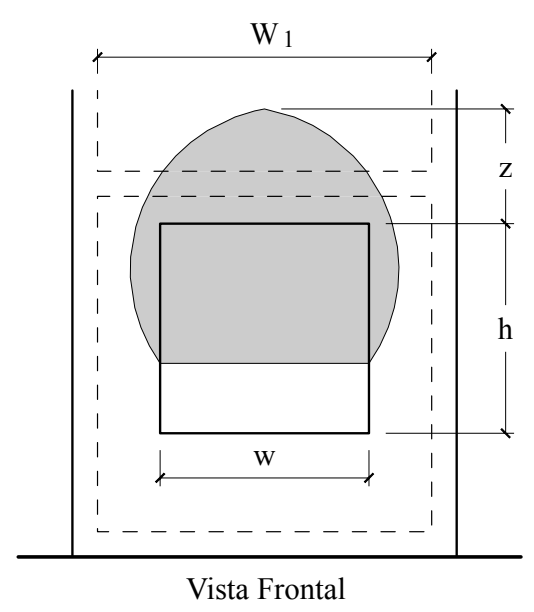

Figura 2.1 - Dimensões utilizadas em cálculos da projeção da chama (LAW, 1978).

\subsubsection{O AISI}

O AISI (American Iron and Steel Institute) publicou em 1979 um texto sobre estruturas externas em situação de incêndio, com base no método de Margaret Law. Nessa publicação são apresentadas tabelas com o intuito de fornecer subsídios para o projeto de estruturas externas de aço sem revestimento contra fogo. Comentários sobre as diferenças entre AISI e Eurocode serão apresentados no capítulo 7 desta Tese.

\subsubsection{Programa de computador Fires}

O programa de computador Fires foi desenvolvido na década de 90 pela ARBED (Acieries Reunies Burbach-Esch-Dudelange), hoje integrante do grupo ArcelorMittal, desenvolvido em ambiente "DOS". Ele calcula a temperatura máxima dos pilares localizados em frente a uma abertura e entre aberturas. O programa calcula também a temperatura máxima de uma viga encostada na parede da fachada e fixada na altura do topo da janela.

A figura 2.2 mostra a tela inicial, e a figura 2.3 mostra a tela de entrada de dados do programa de computador Fires. 


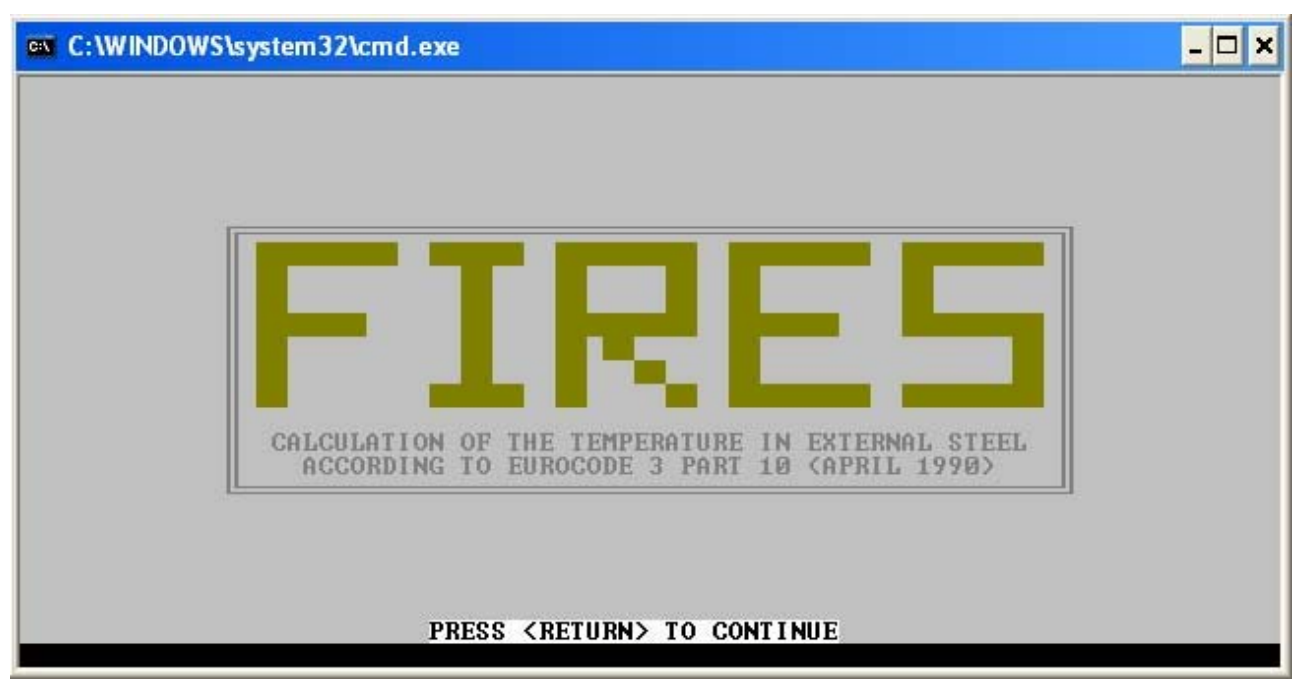

Figura 2.2 - Tela inicial do programa de computador Fires.

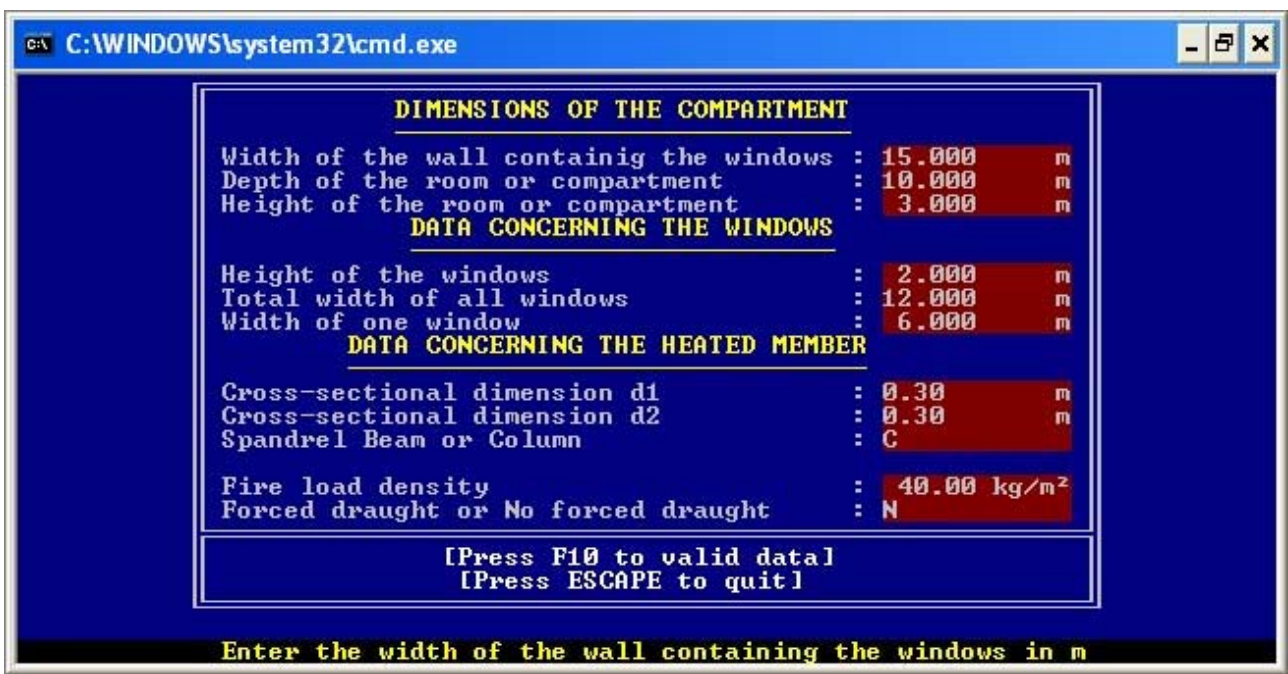

Figura 2.3 - Tela de entrada de dados do Fires.

O Fires é incompleto e apresentava alguns erros de cálculo como será visto no capítulo 6 desta Tese.

\subsubsection{O experimento da Siderúrgica Mittal Steel Ostrava}

O projeto de pesquisa foi desenvolvido pela Czech Technical University em Praga, República

Tcheca. O ensaio do incêndio foi realizado em um edifício da Siderúrgica Mittal Steel Ostrava, no dia 16 de maio de 2006. O programa experimental investigou o comportamento estrutural global de um compartimento de um edifício de aço de três pavimentos que seria 
demolido. $\mathrm{O}$ foco principal da pesquisa foi o desenvolvimento da temperatura de vários elementos estruturais não protegidos e suas conexões, a distribuição das forças horizontais e o comportamento das vigas não restringidas lateralmente durante o incêndio natural. A experiência também permitiu estudar a transferência de calor para os elementos externos.

O edifício era composto por estruturas de aço, com três pavimentos, com lajes mistas e paredes de tijolos cerâmicos. O tamanho interno do compartimento era de 3,80 m x 5,95 m com altura de 2,78 m. Uma abertura de 2,40 m x 1,40 m ventilou o compartimento durante o ensaio do incêndio.

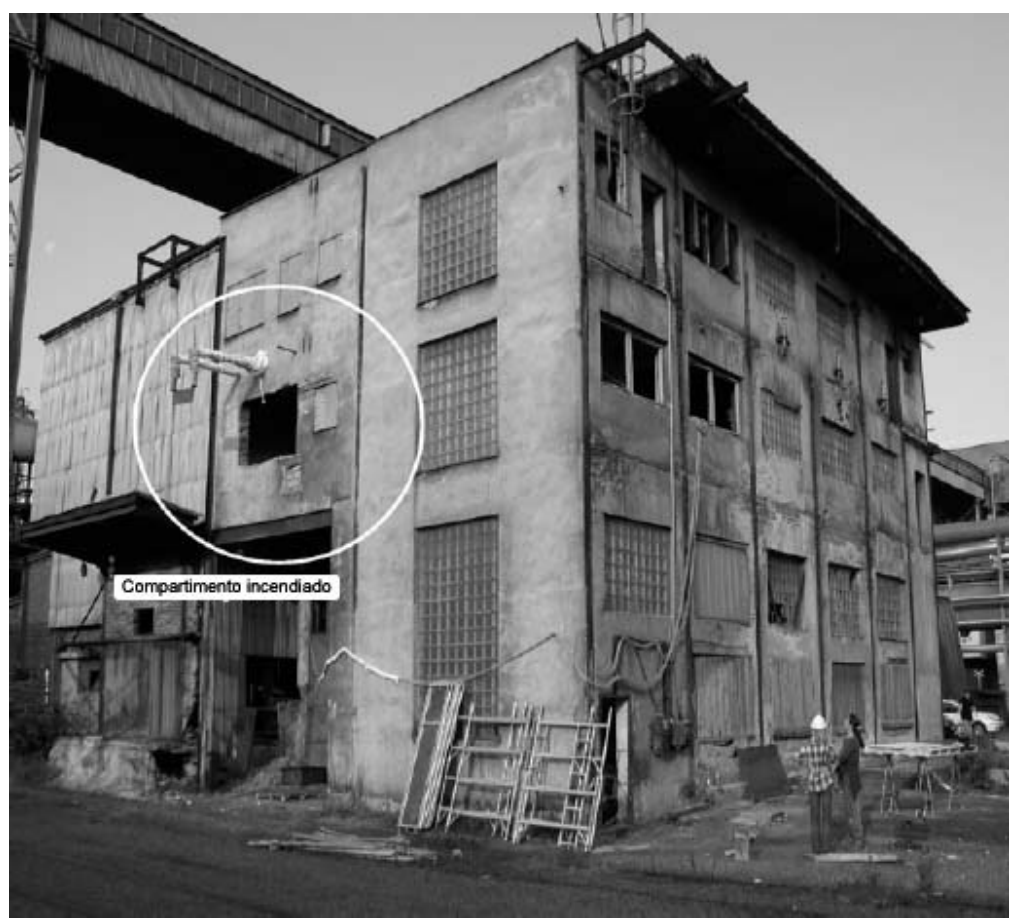

Figura 2.4 - O edifício antes da demolição (WALD, 2009).

As portas e os pilares foram protegidos com placas isolantes térmicas. As cargas foram colocadas no piso acima do compartimento incendiado e eram compostas por 26 tambores de aços e 50 caixas plásticas contendo água e distribuídos uniformemente. As cargas foram colocadas em cima de paletes isolados termicamente do piso por $50 \mathrm{~mm}$ de lã mineral (figura 2.5).

A carga de incêndio era composta por caibros de madeira macia seca à umidade de $13 \%$, com seção transversal de $50 \mathrm{~mm}$ x $50 \mathrm{~mm}$, comprimento de $1 \mathrm{~m}$ e massa específica média de 506 $\mathrm{kgm}^{-3}$. No compartimento, os caibros de madeira foram colocados em oito pilhas, conforme a 
figura 2.6, criando uma carga específica de incêndio de $1039 \mathrm{MJm}^{-2}$. A ignição das oito pilhas foi simultânea.
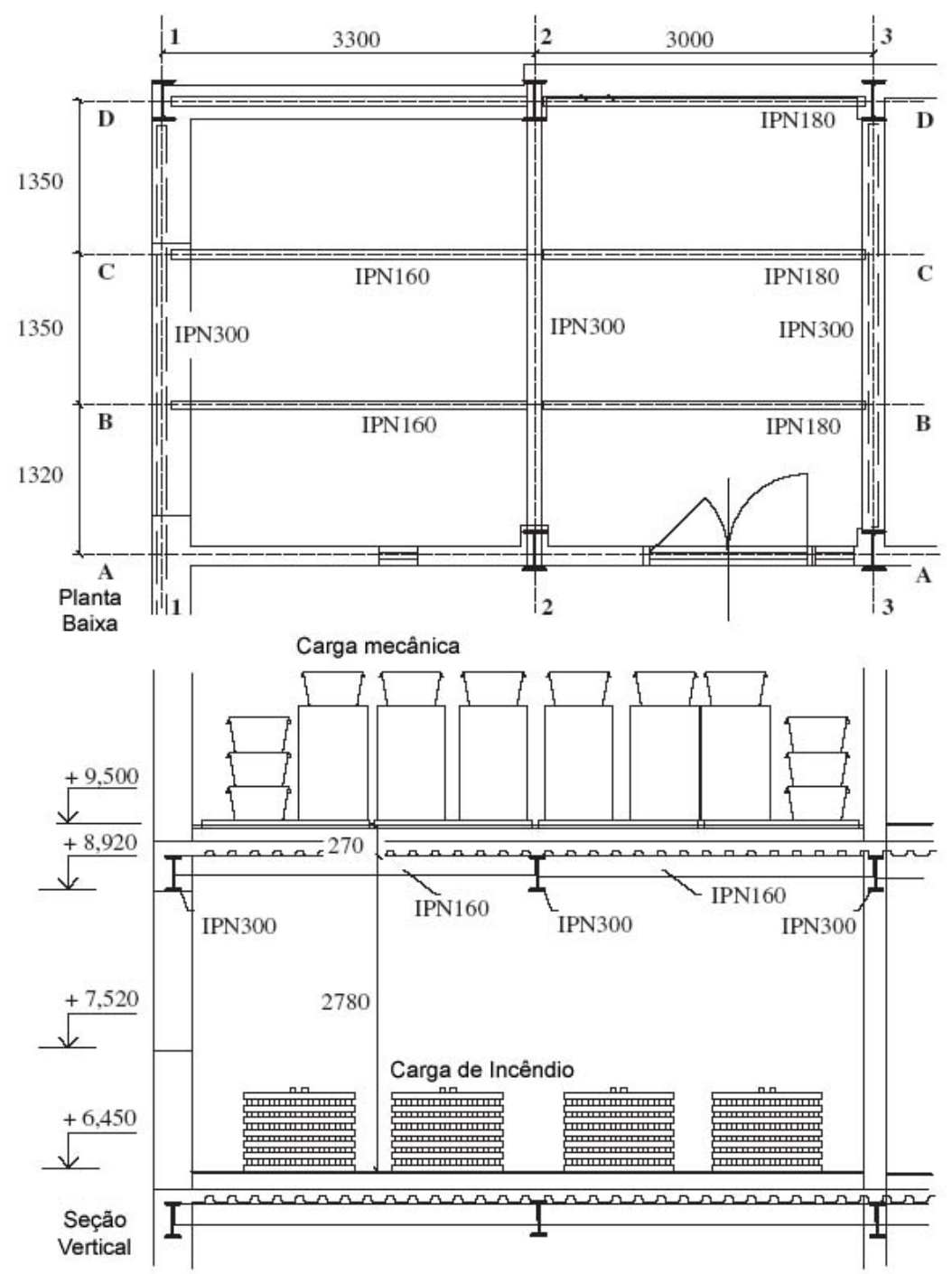

Figura 2.5 - Geometria do compartimento incendiado, carga mecânica e de incêndio (WALD, 2009).


Figura 2.6 - Distribuição da carga de incêndio em madeira no compartimento (WALD, 2009). 
A temperatura do gás dentro do compartimento incendiado foi medida por quatro termopares, localizados $30 \mathrm{~cm}$ abaixo do teto, marcados por TGi, como mostra a figura 2.7. Dois termopares foram colocados na frente do compartimento a $0,50 \mathrm{~m}$ e $1,00 \mathrm{~m}$ da parede. $\mathrm{Na}$ estrutura foram colocados seis termopares e, nas conexões, mais sete, marcados por TCi.

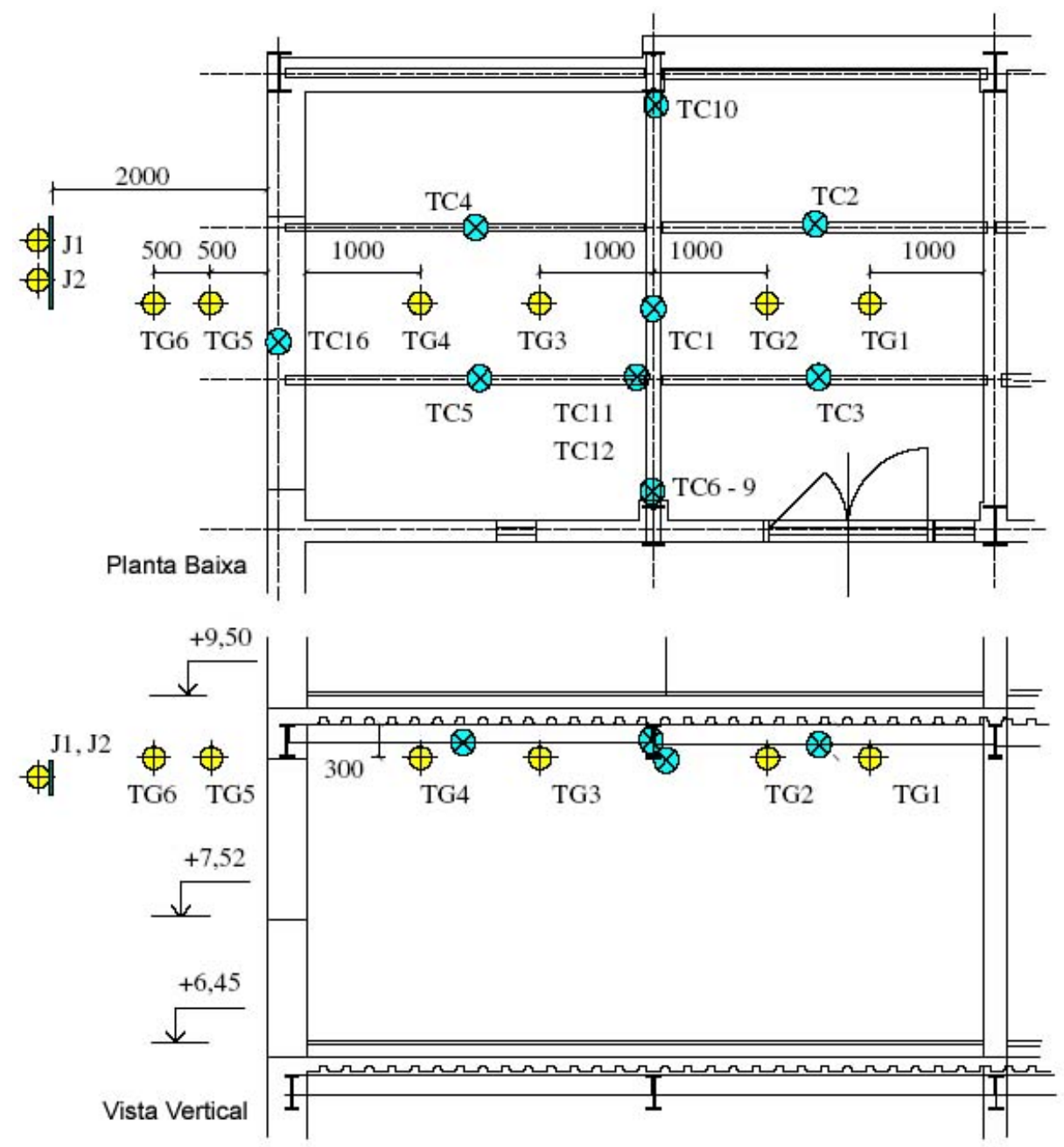

Figura 2.7 - Localização dos termopares para registrar temperaturas dos gases e do aço (WALD, 2009).

O desenvolvimento das temperaturas dos gases é mostrado na tabela 2.1 e na figura 2.8 . No início do incêndio, aproximadamente $30 \mathrm{~min}$, o gás estava mais aquecido na frente do compartimento (termopares TG3 e TG4), se comparado à parte traseira (TG1 e TG2). Após $30 \mathrm{~min}$, as maiores temperaturas foram registradas na parte traseira do compartimento incendiado. As temperaturas máximas foram lidas nos termopares $\mathrm{TG} 1$ e $\mathrm{TG} 2,1050^{\circ} \mathrm{C}$ e $1032^{\circ} \mathrm{C}$, respectivamente. $\mathrm{Na}$ parte dianteira foram registradas temperaturas máxima de $957^{\circ} \mathrm{C}$ e $920^{\circ} \mathrm{C}$ nos termopares TG3 e TG4, respectivamente. 
Tabela 2.1 - Temperaturas dos gases a $300 \mathrm{~mm}$ abaixo do teto (WALD, 2009)

\begin{tabular}{ccccccc}
\hline $\begin{array}{c}\text { Termopares } \\
\text { Tempo }(\min )\end{array}$ & $\begin{array}{c}\text { TG1 } \\
\left({ }^{\circ} \mathrm{C}\right)\end{array}$ & $\begin{array}{c}\text { TG2 } \\
\left({ }^{\circ} \mathrm{C}\right)\end{array}$ & $\begin{array}{c}\text { TG3 } \\
\left({ }^{\circ} \mathrm{C}\right)\end{array}$ & $\begin{array}{c}\text { TG4 } \\
\left({ }^{\circ} \mathrm{C}\right)\end{array}$ & $\begin{array}{c}\text { TG5 } \\
\left({ }^{\circ} \mathrm{C}\right)\end{array}$ & $\begin{array}{c}\text { TG6 } \\
\left({ }^{\circ} \mathrm{C}\right)\end{array}$ \\
\hline 0 & 23 & 23 & 23 & 23 & 23 & 23 \\
15 & 405 & 442 & 508 & 474 & 264 & 64 \\
30 & 498 & 522 & 659 & 648 & 306 & 76 \\
45 & 826 & 848 & 918 & 918 & 556 & 143 \\
52 & 915 & 939 & $957^{\mathrm{a}}$ & $920^{\mathrm{a}}$ & 460 & 168 \\
60 & 981 & 977 & 949 & 903 & 484 & 185 \\
62 & $1050^{\mathrm{a}}$ & $1032^{\mathrm{a}}$ & 944 & 896 & 573 & 260 \\
75 & 904 & 894 & 830 & 794 & 506 & 164 \\
90 & 697 & 688 & 663 & 631 & 303 & 103 \\
120 & 416 & 409 & 423 & 390 & 161 & 56 \\
\hline
\end{tabular}

${ }^{\text {a }}$ Máximo valor registrado

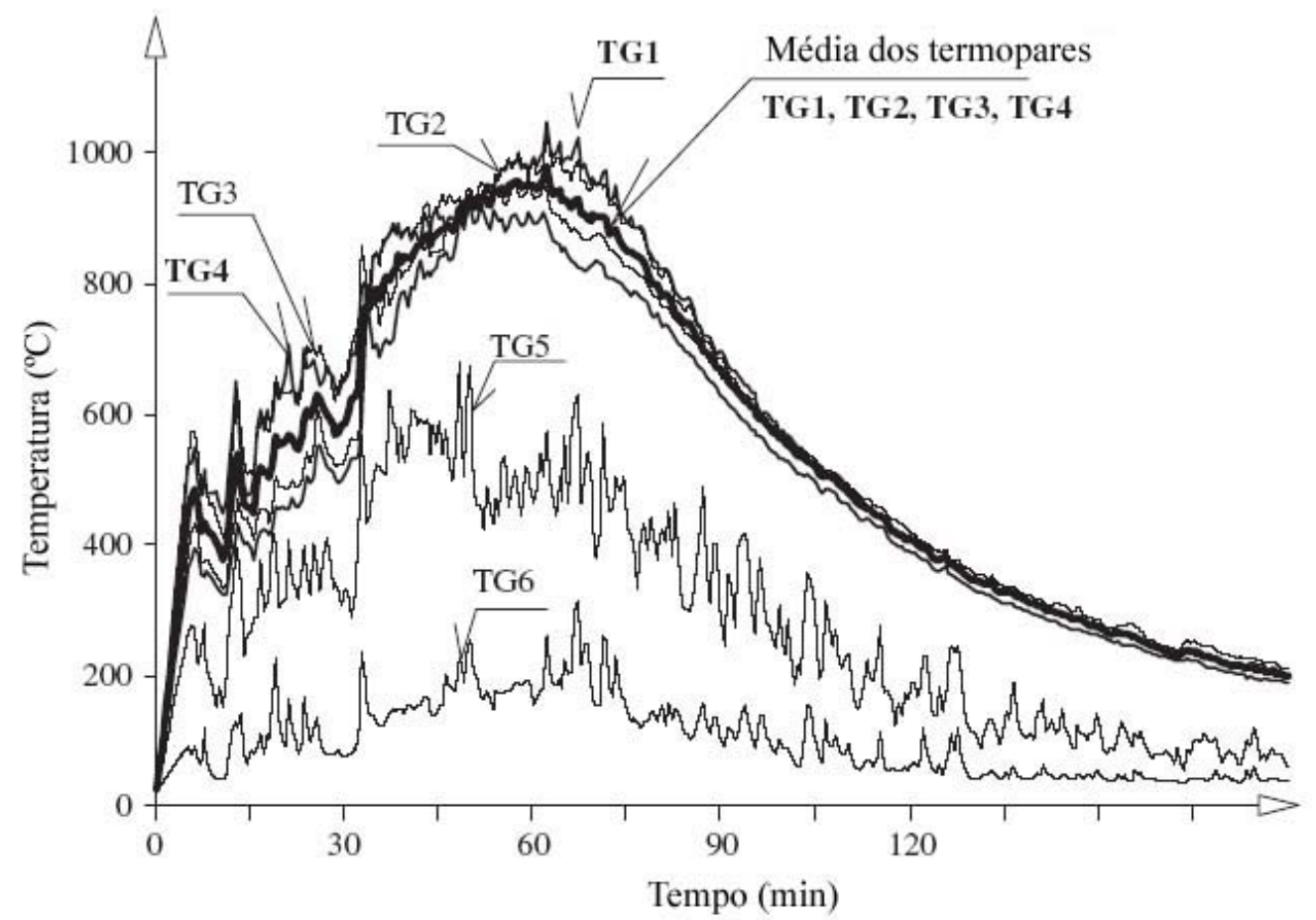

Figura 2.8 - Registro das temperaturas dos gases a $300 \mathrm{~mm}$ abaixo do teto (WALD, 2009). 


\subsubsection{Temperatura do aço externo ao compartimento incendiado}

À frente da abertura do compartimento, foi suspensa, por ganchos, uma placa de aço de 0,95 $\mathrm{m} \times 0,30 \mathrm{~m}$, espessura de $10 \mathrm{~mm}$ a uma distância de 2,00 $\mathrm{m}$ da parede da fachada, conforme a figura 2.9. Dois termopares $\mathrm{J} 1$ e $\mathrm{J} 2$ foram colocados horizontalmente no centro dessa placa a $250 \mathrm{~mm}$ das bordas.

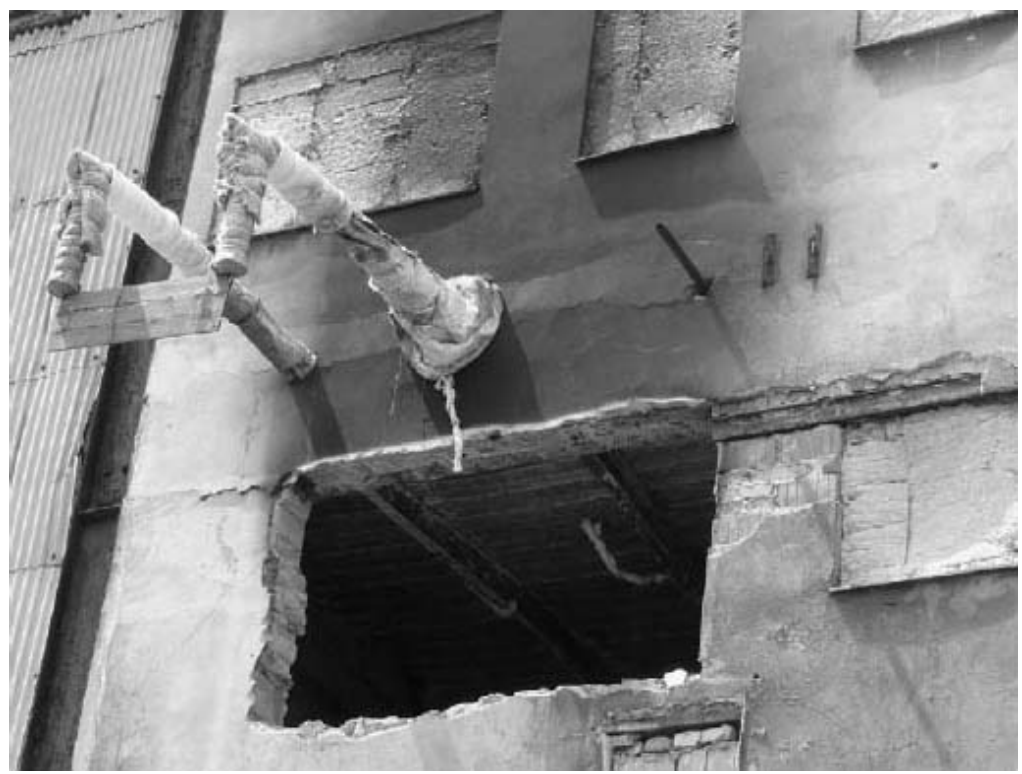

Figura 2.9 - Localização da placa externa de aço exposta ao calor durante o ensaio (WALD, 2009).

Na tabela 2.2, são mostradas as temperaturas registradas pelos termopares da placa de aço externa. As temperaturas mais baixas foram registradas no termopar mais próximo da borda da abertura (J1).

Tabela 2.2 - Temperaturas externas do aço (WALD, 2009)

\begin{tabular}{rcccccccccc}
\hline Tempo & $(\min )$ & 0 & 15 & 30 & 45 & 60 & 64 & 75 & 90 & 120 \\
\hline Termopar J1 & $\left({ }^{\circ} \mathrm{C}\right)$ & 23 & 60 & 106 & 218 & 273 & $279^{\mathrm{a}}$ & 253 & 206 & 116 \\
Termopar J2 & $\left({ }^{\circ} \mathrm{C}\right)$ & 23 & 64 & 117 & 242 & 300 & $306^{\mathrm{a}}$ & 281 & 229 & 131 \\
\hline
\end{tabular}

${ }^{a}$ Máximo valor registrado

Na figura 2.10, são mostradas as temperaturas dentro e fora do compartimento, bem como as temperaturas na placa de aço colocada fora do compartimento. 


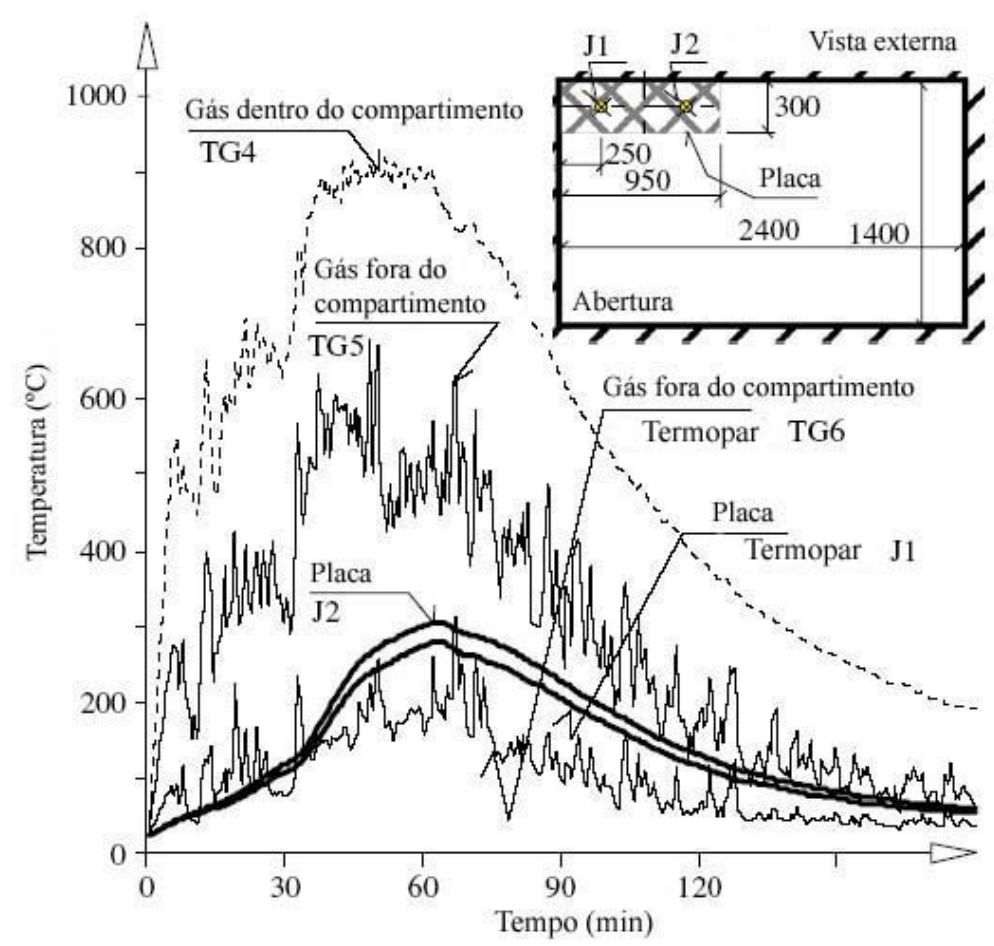

Figura 2.10 - Temperatura do gás e da placa de aço externa durante o ensaio (WALD, 2009).

No capítulo 14 desta Tese, serão apresentadas as comparações entre os resultados deste ensaio e os valores determinados por meio do ExteelFire 2.0.

\subsubsection{O experimento de Dalmarnock}

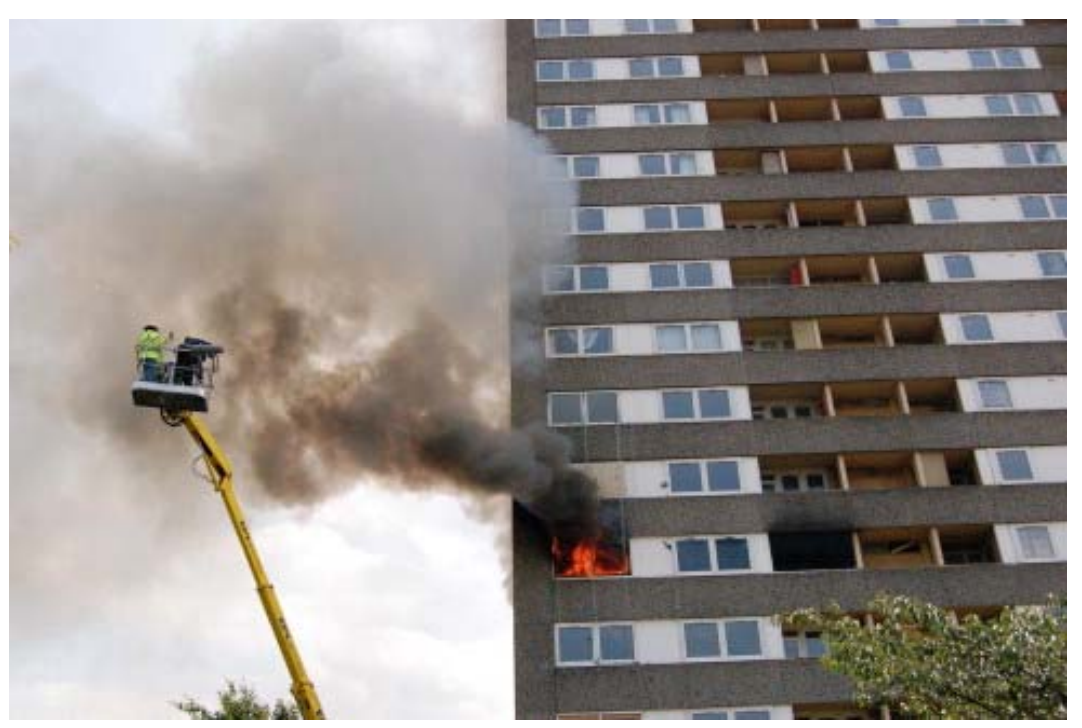

Figura 2.11 - Ensaio de incêndio em edifício em Dalmarnock (REIN et al., 2007). 
O Centro Britânico para Engenharia de Segurança contra Incêndio da Universidade de Edimburgo conduziu uma série de ensaios de incêndio em escala natural, em um edifício a ser demolido na cidade de Dalmarnock, em Glasgow, Inglaterra. A estrutura do edifício residencial era de concreto e possuía 23 pavimentos, sendo seis apartamentos por andar, conforme figuras 2.11 e 2.12. O ensaio foi realizado no dia 25 de julho de 2006.

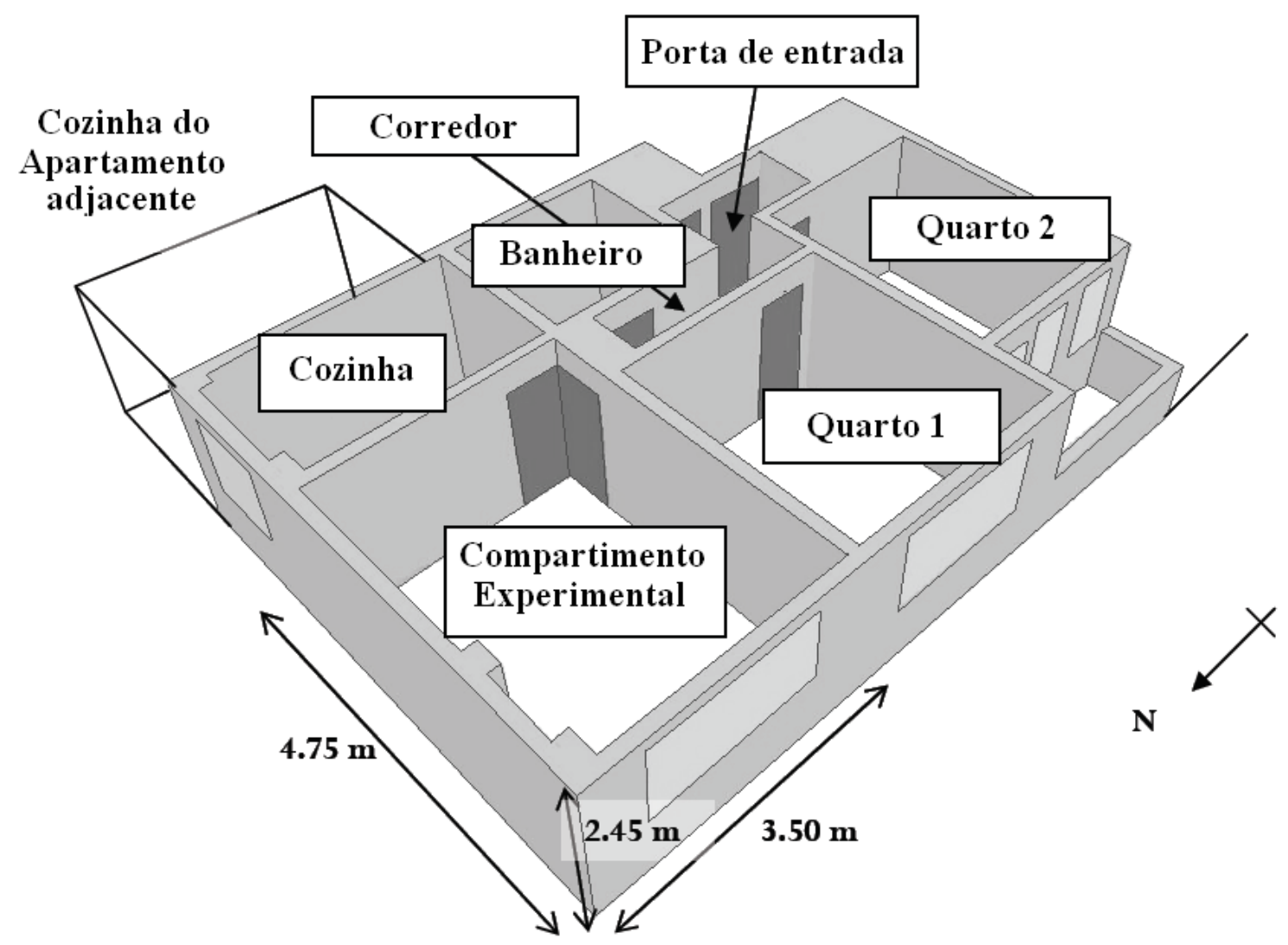

Figura 2.12 - Layout do apartamento. Vista do lado noroeste (REIN et al., 2007).

Toda a mobília e revestimento de dentro do apartamento foram removidos, com exceção da mobília fixa da cozinha e as portas. A parede da cozinha foi removida e substituída por "steel framing". As portas da cozinha e do corredor foram removidas, e a mobília do compartimento experimental, que simulava um escritório, devidamente identificada, foi colocada no local. A disposição da mobília foi feita de forma que o combustível se concentrasse na parte de trás do compartimento, longe da janela, como visto na figura 2.13. 


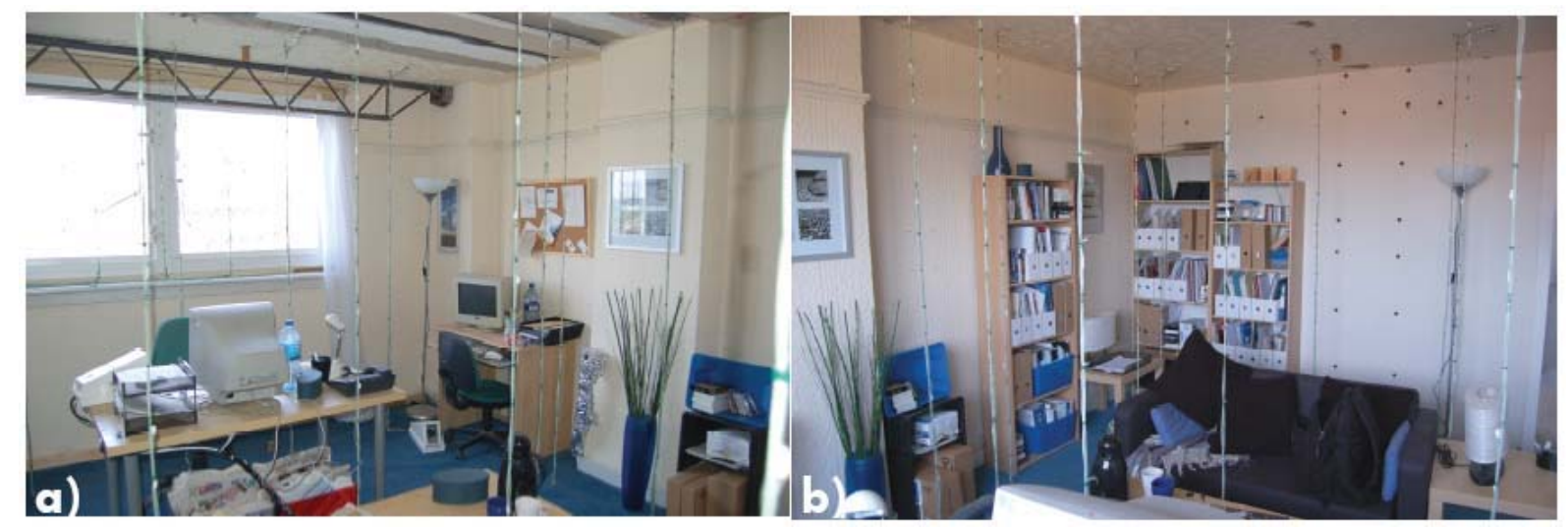

Figura 2.13 - Carga de combustível e sua distribuição no compartimento experimental. Vista (a) do lado NW e (b) do lado NE (REIN et al., 2007).

A figura 2.14 mostra a planta baixa do compartimento experimental, bem como a mobília e a instrumentação utilizada.

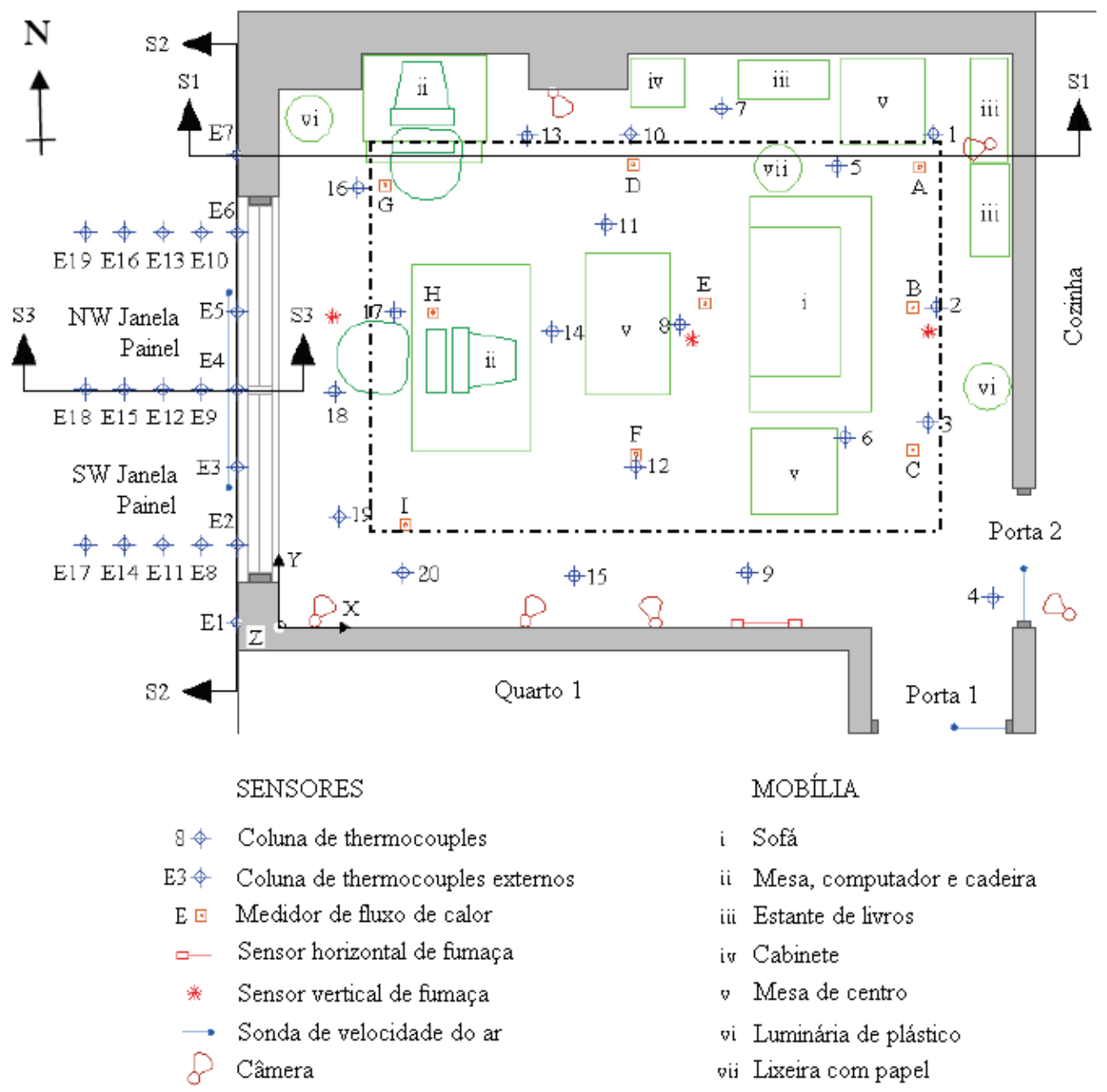

Figura 2.14 - Planta baixa do compartimento experimental mostrando a distribuição da mobília e a localização dos sensores (REIN et al., 2007). 
Os parâmetros de ventilação têm impacto significativo no desenvolvimento e comportamento do incêndio. $\mathrm{Na}$ etapa inicial de crescimento, os incêndios são geralmente bem ventilados e controlados pelo material combustível. Mas, após a etapa de combustão generalizada, o incêndio pode ser controlado pela ventilação. Como condições iniciais de ventilação, adotouse que as janelas do compartimento experimental e do quarto 1 estariam fechadas, enquanto a janela do quarto 2, da cozinha e todas as portas do apartamento estariam abertas. Essa condição inicial é mostrada na figura 2.15 .

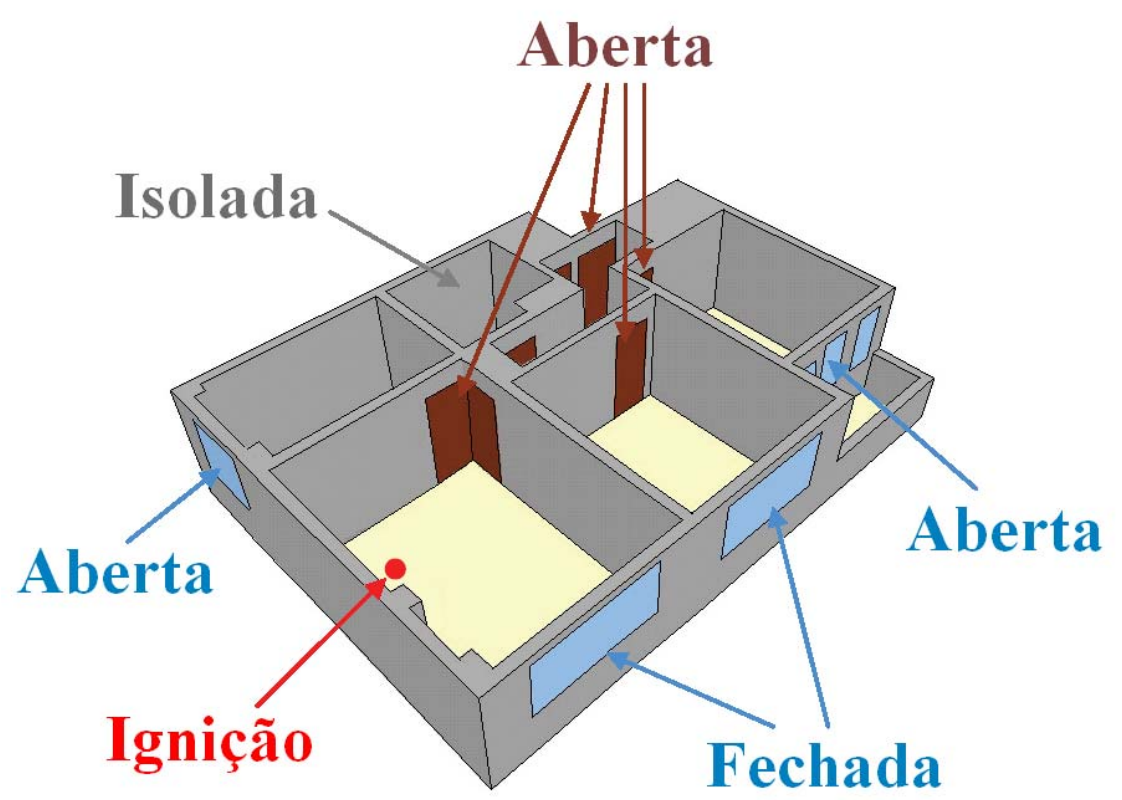

Figura 2.15 - Condição inicial de ventilação do compartimento experimental (REIN et al., 2007).

Os dados das condições ambientais anteriores à ignição foram gravados. Foram colocados $500 \mathrm{ml}$ de heptano na lixeira contendo papel, às $12 \mathrm{~h} 23 \mathrm{~min}$ uma tocha de fogo foi utilizada para iniciar a ignição dos papéis na lixeira, e o incêndio começou a se desenvolver.

Um cobertor colocado em cima do sofá e da lixeira despejou sobre o braço do sofá o fogo proveniente da lixeira quase que imediatamente. Isso inflamou o estofado do sofá de poliuretano, espalhando rapidamente o fogo. Após $4 \mathrm{~min}$ e $30 \mathrm{~s}$ de queima do sofá, foi conduzida a ignição da estante que continha livros, próxima ao sofá e à lixeira de papel, no lado NE do compartimento.

O fogo progrediu consumindo a estante com livros, caracterizando o flashover, que projetou a chama no teto em direção ao corredor. De repente, a visibilidade foi reduzida no corredor principal e, simultaneamente, ocorreu a ignição dos papéis localizados em diversos pontos. Isso foi seguido pela descida da camada de fumaça ao nível do piso. 
Consequentemente, no pós-flashover a visibilidade do compartimento foi drasticamente reduzida, somente câmeras especiais forneceram pouca informação sobre a subsequente progressão na propagação do fogo. Não obstante, análises de dados do sensor de incêndio mostraram que o fogo queimou firmemente nos 8 min seguintes, e uma fumaça escura foi observada ao escoar para fora do compartimento através das frestas da moldura da janela, que não foram completamente vedadas ou isoladas hermeticamente. Sete minutos após o flashover, a janela da cozinha quebrou-se, embora estivesse parcialmente aberta. A janela do compartimento experimental permaneceu intacta.

O painel noroeste da janela do compartimento experimental foi quebrado manualmente aos 13 min e $21 \mathrm{~s}$ de incêndio. Enquanto a maior parte da fumaça escura escoava para fora do compartimento, ocorreu o desenvolvimento da chama externa 4 min 30 s mais tarde. Momentos após o segundo painel da janela ser quebrado, o incêndio queimou livremente por um total de 19 min antes da brigada interferir na extinção do incêndio. O resumo das etapas do desenvolvimento do incêndio em relação ao tempo de ignição podem ser vistos na tabela 2.3 .

Análises posteriores ao incêndio mostraram que a maioria do combustível do compartimento foi queimada. Somente alguns componentes de metal e alguns papéis enegrecidos não foram consumidos, conforme mostra a figura 2.16 .
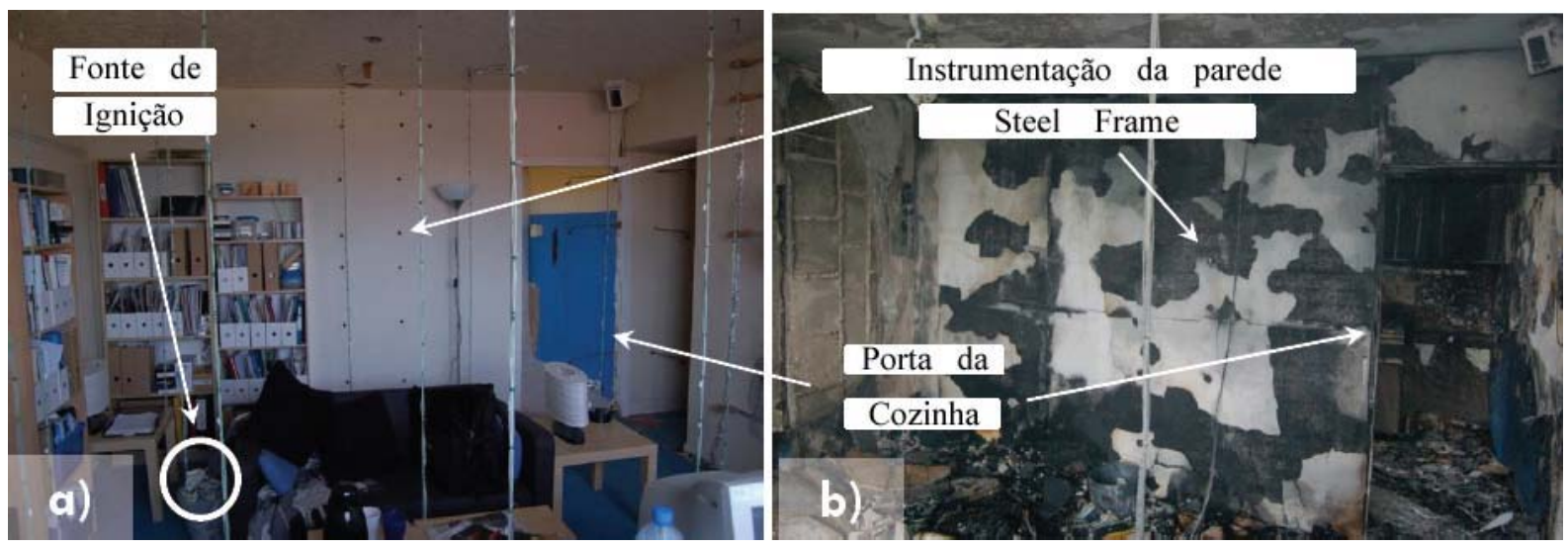

Figura 2.16 - Visualização da fonte de ignição, sofá, estante de livros e itens próximos do compartimento experimental, (a) antes do incêndio e (b) após o incêndio (REIN et al., 2007). 
Tabela 2.3 - Eventos registrados pelas câmeras e os respectivos tempos em relação à ignição (REIN et al., 2009)

\begin{tabular}{|c|c|c|}
\hline \multicolumn{3}{|c|}{ Período de crescimento } \\
\hline Evento registrado & Tempo & Tempo da ignição \\
\hline Ignição & $12 \mathrm{~h} 23 \mathrm{~min} 00 \mathrm{~s}$ & $0 \mathrm{~s}$ \\
\hline Ignição do estofado do sofá & $12 \mathrm{~h} 23 \min 09 \mathrm{~s}$ & $9 \mathrm{~s}$ \\
\hline Fumaça visível no corredor principal & $12 \mathrm{~h} 26 \min 06 \mathrm{~s}$ & $186 \mathrm{~s}$ \\
\hline Ignição da estante de livros & $12 \mathrm{~h} 27 \min 35 \mathrm{~s}$ & $275 s$ \\
\hline \multicolumn{3}{|c|}{ Período de flashover } \\
\hline Evento registrado & Tempo & Tempo da ignição \\
\hline Fogo consome estante de livros & $12 \mathrm{~h} 28 \mathrm{~min} 00 \mathrm{~s}$ & $300 \mathrm{~s}$ \\
\hline $\begin{array}{l}\text { Chama projetada para o teto do corredor, } \\
\text { pouca visibilidade no corredor principal }\end{array}$ & $12 \mathrm{~h} 28 \min 15 \mathrm{~s}$ & $315 \mathrm{~s}$ \\
\hline $\begin{array}{l}\text { Ignição do abajur de papel e dos papéis } \\
\text { na mesa }\end{array}$ & $12 \mathrm{~h} 28 \min 23 \mathrm{~s}$ & $323 \mathrm{~s}$ \\
\hline \multicolumn{3}{|c|}{ Período de pós-flashover } \\
\hline Evento registrado & Tempo & Tempo da ignição \\
\hline Janela da cozinha quebrada & $12 \mathrm{~h} 35 \mathrm{~min} 00 \mathrm{~s}$ & $720 \mathrm{~s}$ \\
\hline $\begin{array}{l}\text { Janela do compartimento quebrada (vidro } \\
\text { NW) }\end{array}$ & $12 \mathrm{~h} 36 \min 21 \mathrm{~s}$ & $801 \mathrm{~s}$ \\
\hline Chama externa & $12 \mathrm{~h} 41 \mathrm{~min} 00 \mathrm{~s}$ & $1080 \mathrm{~s}$ \\
\hline $\begin{array}{l}\text { Janela do compartimento quebrada (vidro } \\
\text { SW) }\end{array}$ & $12 \mathrm{~h} 41 \mathrm{~min} 31 \mathrm{~s}$ & $1111 \mathrm{~s}$ \\
\hline Brigada de incêndio, começo da extinção & $12 \mathrm{~h} 42 \min 00 \mathrm{~s}$ & $1140 \mathrm{~s}$ \\
\hline Maioria combustão lenta, sem chama & $12 \mathrm{~h} 45 \mathrm{~min} 00 \mathrm{~s}$ & $1320 \mathrm{~s}$ \\
\hline
\end{tabular}

A temperatura média cresce nos primeiros $100 \mathrm{~s}$ quando alcança um pequeno período de estado estacionário, enquanto o sofá é queimado durante $100 \mathrm{~s}$. Nesse tempo, é alcançada a etapa 1 da figura 2.17. Esse período representa um incêndio localizado, onde o desvio-padrão da temperatura total do compartimento é relativamente baixo. Enquanto o incêndio começa a se espalhar, as temperaturas médias do compartimento aumentam, conduzindo a um desvio padrão ligeiramente maior, tornando os resultados dos termopares afetados pelo fogo e pela fumaça.

A caracterização do período de flashover fica claramente indicada cerca de $300 \mathrm{~s}$ de incêndio, onde a curva temperatura-tempo se torna muito íngreme. Isso ocorreu após o incêndio se 
propagar para a estante de livro próxima ao sofá. Nesse momento, o desvio-padrão da temperatura do compartimento está no nível mais elevado, diminuindo significativamente com o declive da temperatura média para a condição de estado quase estacionário. Em seguida, há uma ligeira ascensão da temperatura média, havendo uma diminuição do desviopadrão antes do primeiro painel da janela do compartimento quebrar.

Essa mudança nas condições de ventilação conduz a uma segunda etapa significante no comportamento das temperaturas médias, indicando que o incêndio se tornou controlado pela ventilação no período de pós-flashover. Isso é confirmado por um vídeo externo, que mostrou grandes quantidades de fumaça escura emanando da janela do compartimento, quando quebrada.

Após cerca de 900 s, o incêndio alcançou um período quase estacionário, obtendo, nessa etapa, as mais altas temperaturas do ensaio. Após pequena variação da temperatura média, seguiu-se a intervenção da brigada de incêndio.

A figura 2.17 mostra a curva temperatura média-tempo do incêndio, mostrando nas linhas verticais tracejadas as etapas de tempo representando os principais eventos ocorridos.

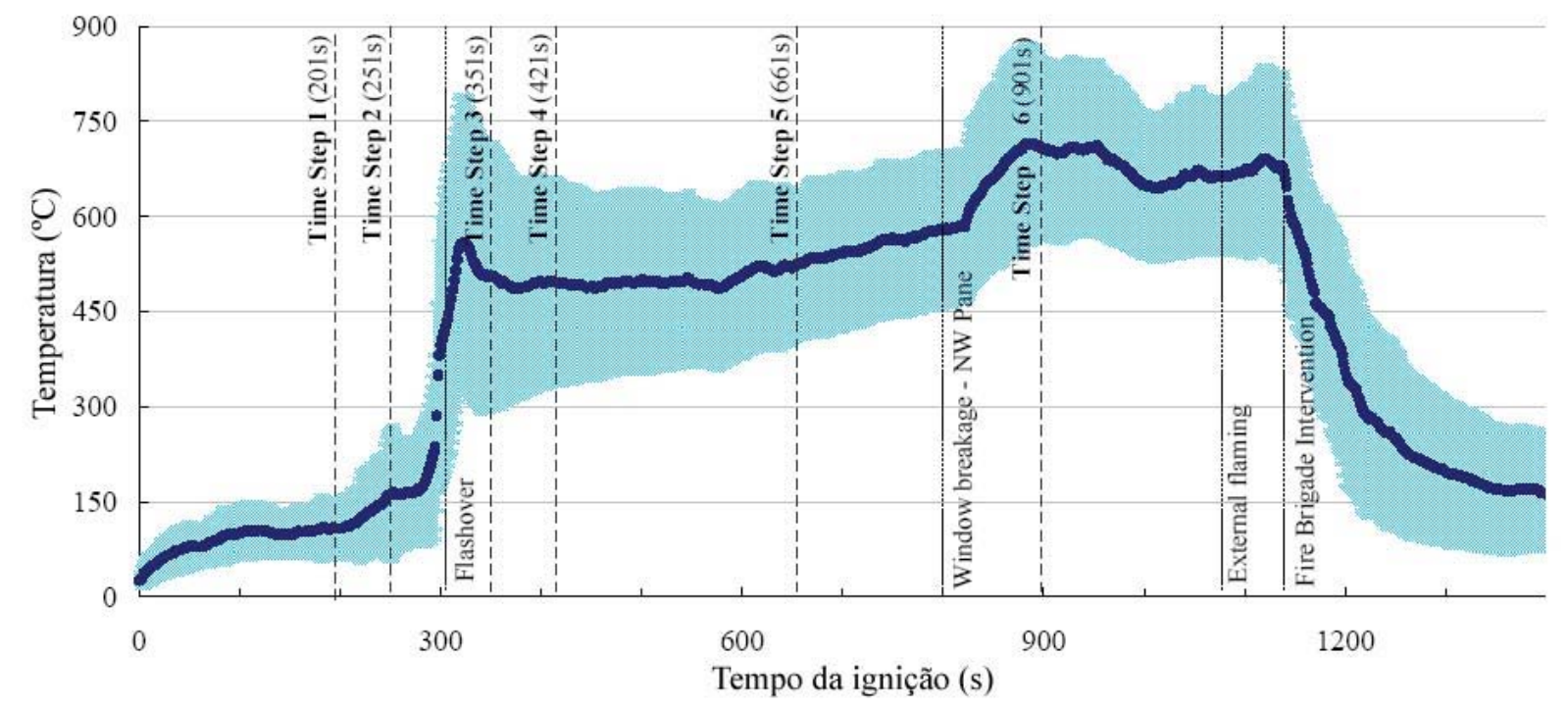

Figura 2.17 - Curva temperatura média-tempo dos gases dentro do compartimento (REIN et al., 2007).

$\mathrm{Na}$ figura 2.18, foram desenhadas isotermas em um plano, com a finalidade de ilustrar a variação da temperatura no compartimento durante o desenvolvimento do incêndio nas principais etapas definidas no tempo. A seção S1-S1 encontra-se discriminada na figura 2.14. 

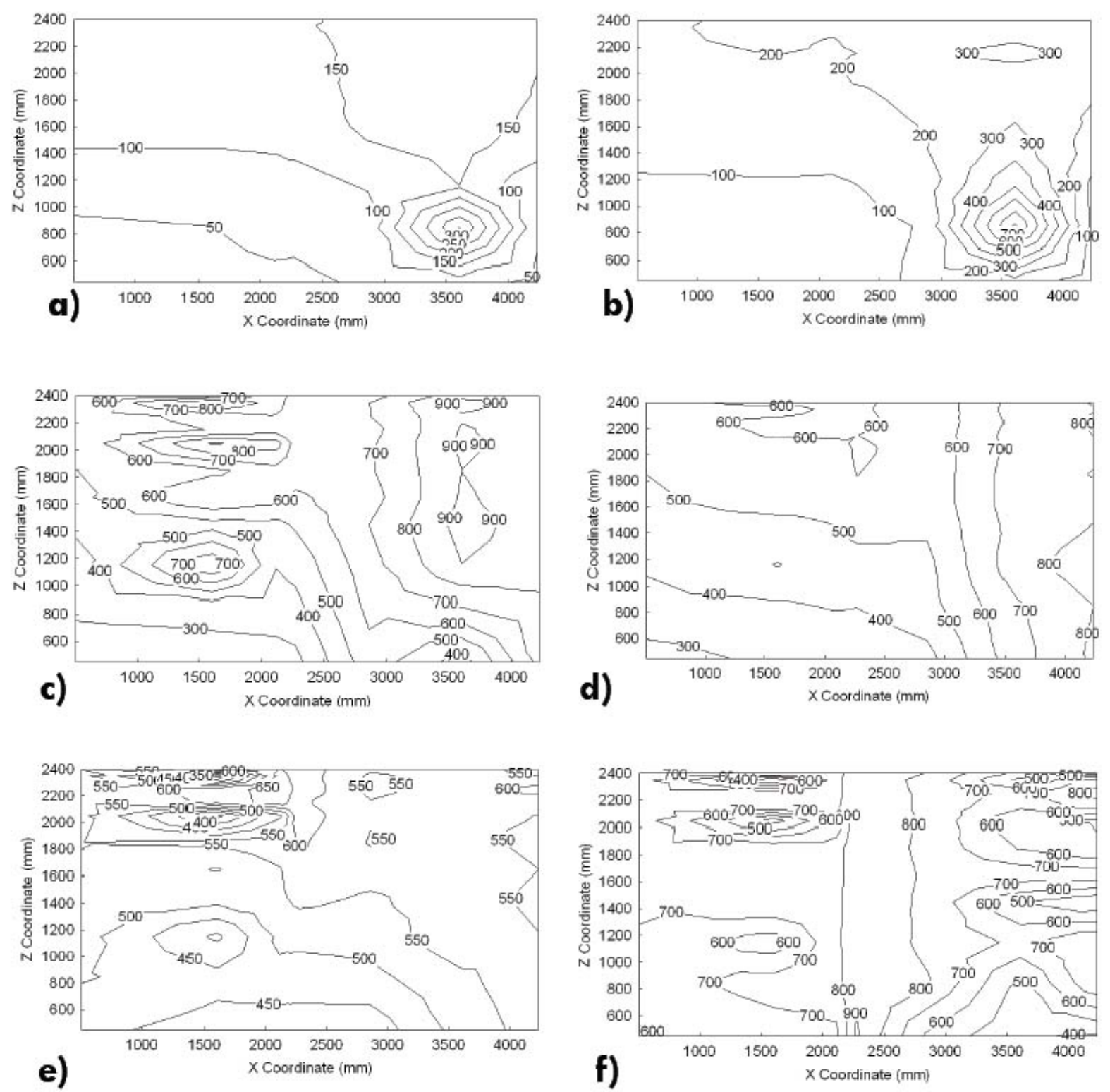

Figura 2.18 - Contornos da temperatura do gás (em ${ }^{\circ} \mathrm{C}$ ) da seção S1-S1, de acordo com figura 2.12. As figuras estão em ordem cronológica em relação ao tempo de ignição: (a) 201s, (b) 251s, (c) 351s, (d) 420s, (e) 661s e (f) 901s (REIN et al., 2007).

A tendência é de que a taxa de liberação de calor corresponda à temperatura média do compartimento. A taxa de liberação de calor cresce de um incêndio de estado quase estacionário a $3 \mathrm{MW}$ para um incêndio em torno de $5 \mathrm{MW}$, no instante em que a primeira janela do compartimento quebra, responsável por um aumento nas temperaturas do compartimento, nas etapas de tempo 5 e 6, conforme a figura 2.19. Embora essa seja uma medida relativamente "grosseira" do HRR, ela fornece uma boa indicação da ordem da magnitude do tamanho do incêndio. 


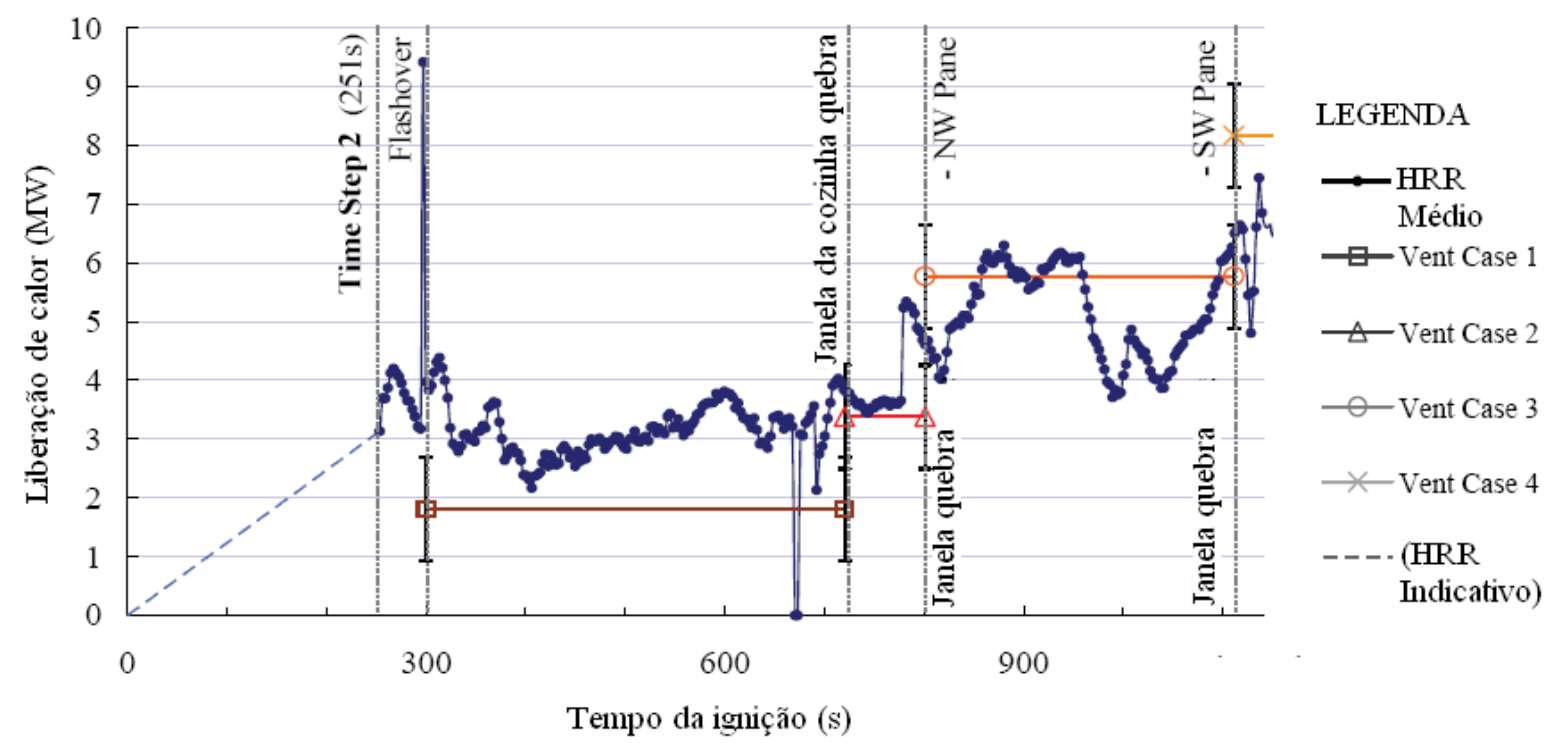

Figura 2.19 - Taxa de liberação de calor do incêndio utilizando o princípio da depreciação do oxigênio. Alternativa simplificada utilizando fatores de ventilação para cálculo de HRR é mostrada no "Vent Cases" correspondentes aos diferentes eventos de mudança de ventilação. (REIN et al., 2007).

\subsubsection{Incêndio externo}

A título de contribuição para caracterização do experimento do incêndio de Dalmarnock, foi realizada uma análise do incêndio externo. No pós-flashover, uma chama externa foi observada, uma vez que a janela do compartimento foi quebrada. Desde que isso ocorreu para os estágios mais atrasados do incêndio (após etapa de tempo 5 da figura 2.17), foram comparados os dados dos termopares externos e os dados coletados sobre o fluxo de calor, a maioria entre as etapas 5 e 6 do incêndio.

Os termopares externos foram dispostos para conseguir desenhar isotermas em três dimensões, da chama externa ao longo do tempo de incêndio.

Apesar da investigação da distribuição da velocidade dos gases na abertura principal da janela, existe uma considerável incerteza na geometria da chama, devido a outras influências nos fluxos, que são difíceis de quantificar. Nessas influências, incluem-se a direção e a intensidade do movimento dos gases após passar pelo edifício, devido ao vento e aos significativos fluxos turbulentos.

Conforme mostra a figura 2.20, foi observada a mudança de direção do vento durante o ensaio. Essa mudança tem efeito sobre a quantidade de gases que emergem para fora de cada 
abertura. Para a finalidade dessa análise, as medidas externas dos termopares foram assumidas como sendo a temperatura do gás.

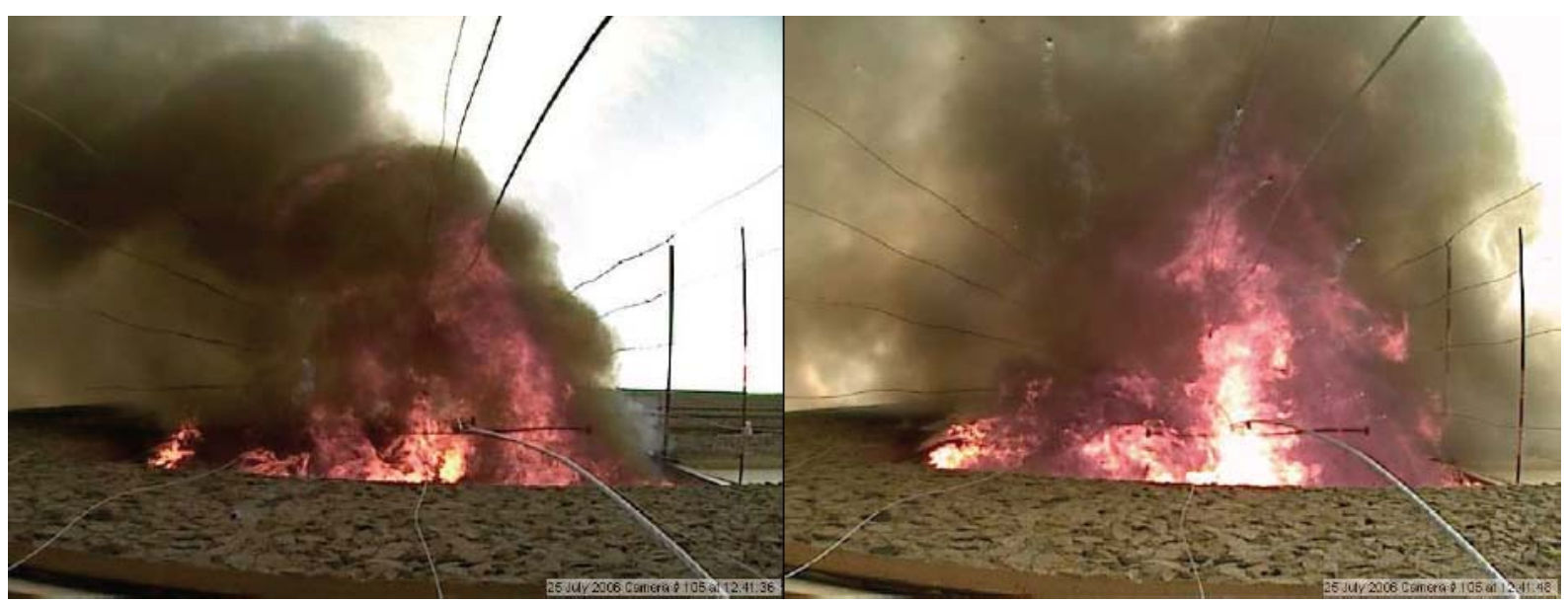

Figura 2.20 - Imagens da câmera instalada no $3^{\circ}$ piso, mostrando o fogo externo que emana da janela do compartimento experimental. (a) vento norte às $12 \mathrm{~h}: 41 \mathrm{~min}: 36 \mathrm{~s} \mathrm{e}$ (b) somente vento às $12 \mathrm{~h}: 41 \mathrm{~min}: 48 \mathrm{~s}$ (REIN et al., 2007).

Antes do painel da janela quebrar, a máxima temperatura externa registrada pelos termopares mais próximos do topo superior do painel NW da janela era de aproximadamente $230^{\circ} \mathrm{C}$. Foi observado que os termopares estavam envolvidos pela fumaça que escoava pela moldura da janela. A média das temperaturas máximas registradas por cada termopar externo durante o período era relativamente baixa, em torno de $60^{\circ} \mathrm{C}$. Com a ruptura do primeiro painel da janela, a maioria dos termopares registrou um aumento significativo na temperatura, particularmente aqueles do painel NW.

A temperatura externa máxima registrada pelo termopar foi de $860^{\circ} \mathrm{C}$, com média de $400^{\circ} \mathrm{C}$, incluindo todos os termopares que medem até meia-altura da janela do $5^{\circ}$ piso.

A variação da temperatura através da chama mostrada na figura 2.20 pode ser vista na figura 2.21. As isotermas da figura 2.21(a) são mostradas segundo a seção S2-S2 da figura 2.14 e abrangem os termopares E1 a E7, paralelos à janela do compartimento. As isotermas da figura 2.21(b) são mostradas segundo a seção S3-S3 da figura 2.14 e abrangem os termopares 4, 9, 12,15 e 18, perpendiculares à janela e localizados na sua linha central.

A figura 2.21 mostra um gradiente grande de temperatura através da chama e pode ser usado para determinar a geometria externa da chama enquanto varia no tempo. A figura 2.21(a) mostra as isotermas visualizadas da janela e pode-se notar na isoterma de $100^{\circ} \mathrm{C}$ que a chama foi afetada pelo vento noroeste. 

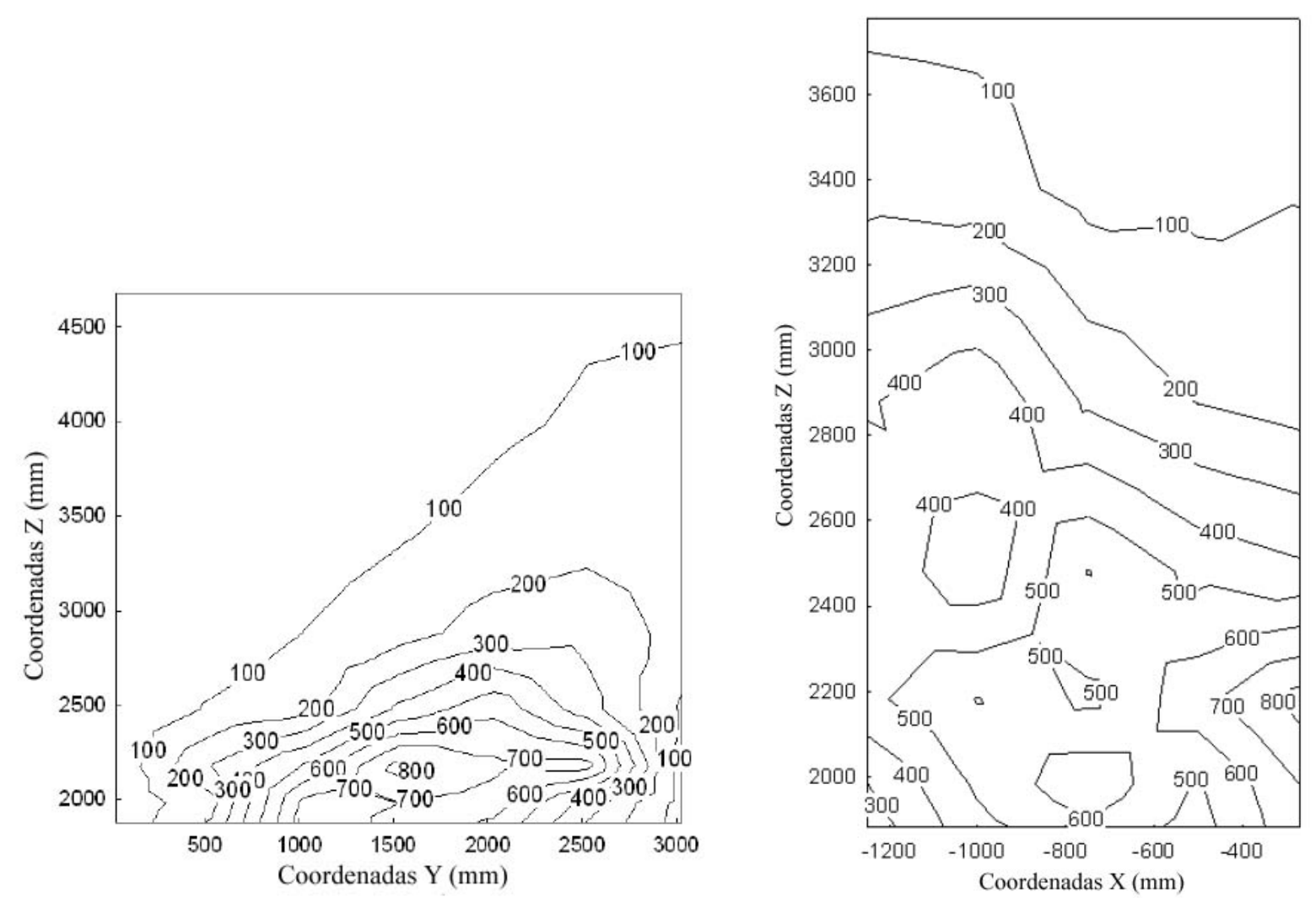

Figura 2.21 - Contorno da temperatura externa que escoa do compartimento $\left(e m{ }^{\circ} \mathrm{C}\right)$. (a) seção S2-S2 às 12:41:36 e (b) S3-S3 às 12:41:36, com valores de eixo conforme figura 2.12 (REIN et al., 2007).

No capítulo 14 desta Tese, serão apresentadas comparações entre os resultados deste ensaio e valores determinados por meio do ExteelFire 2.0.

\subsection{TRABALHOS NACIONAIS}

\subsubsection{Trabalho para a EPUSP}

Em 1999, os engenheiros Alessandro de Souza Campos e Marcelo de Freitas Palmeira realizaram um trabalho para a disciplina PEF 5705 - "Dimensionamento de estruturas em situação de incêndio", da pós-graduação em Engenharia de Estruturas da EPUSP (Escola Politécnica da Universidade de São Paulo). No trabalho "Estruturas de aço externas a edificações em situação de incêndio", os autores compilaram a formulação do Eurocode 1, 
part 1.2 (2002) e do Eurocode 3, part 1.2 (2003) e utilizaram o programa de computador Fires para algumas simulações.

\subsubsection{Dissertação de Evelyn Tait}

Em 2001 foi defendida uma dissertação de mestrado na UFMG (Universidade Federal de Minas Gerais) intitulada "Determinação da temperatura em elementos estruturais externos de aço em situação de incêndio". A autora, Evelyn Tait, apresentou o método desenvolvido por Margaret Law, que determinava a temperatura máxima de elementos de aço externos a edificações, elaborou uma rotina de cálculo e exemplificou algumas situações.

\subsubsection{Dissertação de Macksuel Soares de Azevedo}

No ano de 2005, foi defendida a dissertação de mestrado do autor desta Tese na UFES (Universidade Federal do Espírito Santo) intitulada "Determinação da temperatura em elementos estruturais de aço externos a edificações em situação de incêndio".

Nesse trabalho foi explicada a origem do método proposto por Margaret Law em 1978 e a sua aplicação atual pelos Eurocodes 1, part 1.2 (2002) e Eurocode 2, part 1.2 (2003). Os cálculos matemáticos necessários ao método, que não foram expostos adequadamente pelos Eurocodes 1 e 3, foram detalhados por exemplos, sobre as diversas situações possíveis.

Foi elaborado um programa de computador, o ExteelFire 1.0, que calculava a máxima temperatura dos elementos estruturais de aço para pilares externos, em três posições específicas em relação às aberturas. Em frente à abertura, quando envolvido, ou não, pela chama e entre as aberturas, quando não envolvido pela chama. O programa também calculava a máxima temperatura de uma viga localizada adjacente e, imediatamente superior à abertura, também chamada de viga de borda.

Análises paramétricas foram realizadas utilizando o ExteelFire 1.0 para verificar a máxima temperatura do elemento estrutural em relação à variáveis importantes, tais como: carga de incêndio, geometria do compartimento, posição do elemento estrutural em relação às aberturas e ventilação. 


\subsection{DESENVOLVIMENTO DO INCÊNDIO}

Para que um incêndio ocorra, é necessário haver, simultaneamente, fonte de calor, combustível e comburente (oxigênio). $O$ incêndio se principia quando a combinação entre eles resulte em aquecimento suficiente para gerar a combustão.

O incêndio, no que concerne ao estudo das estruturas, pode ser caracterizado por uma curva que fornece a temperatura dos gases em função da duração do incêndio. A figura 3.1 mostra uma curva temperatura-tempo dos gases quentes de um incêndio dentro de um compartimento.

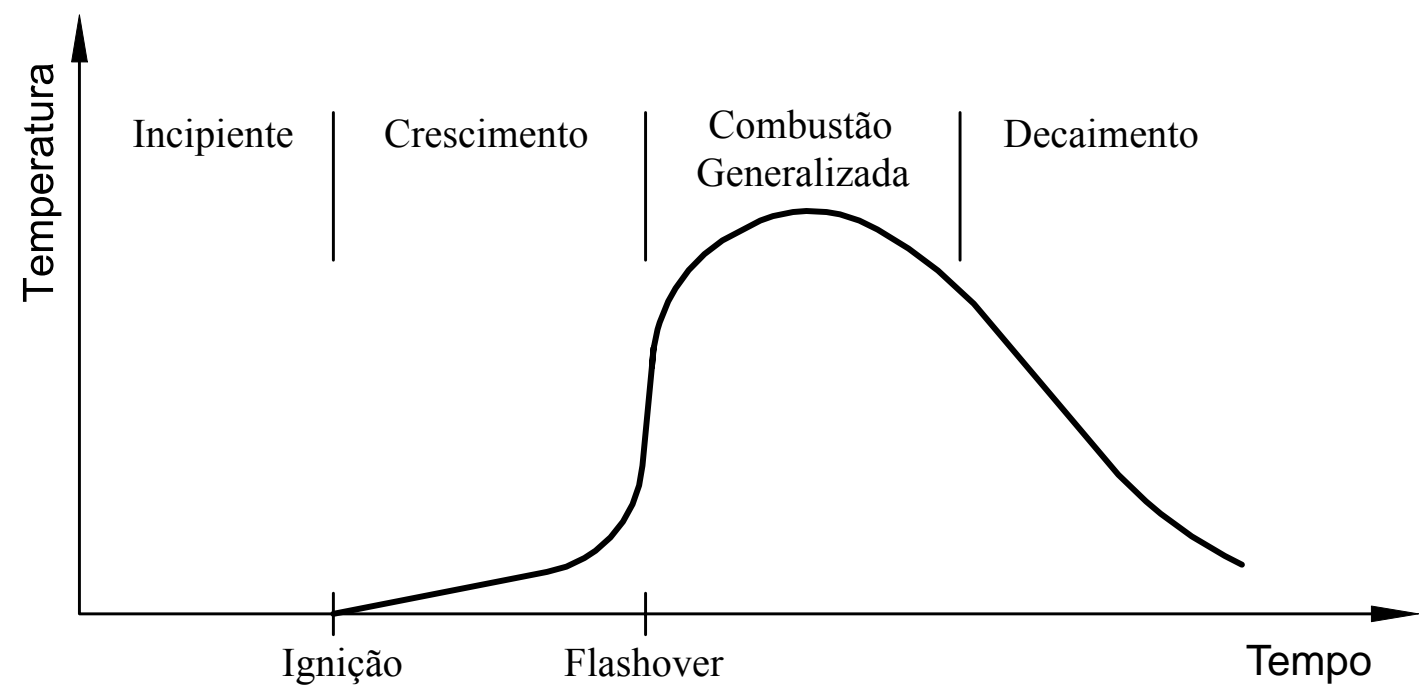

Figura 3.1 - Curva temperatura-tempo de um incêndio real (BUCHANAN, 2001).

No período incipiente, o combustível presente no ambiente começa a ser aquecido, mas cessada a fonte de calor, o fogo não se sustenta.

A ignição caracteriza o início da combustão do material, marcando a transição para o período de crescimento. Estabelece-se uma reação de combustão autossustentável. 
No período de crescimento, as temperaturas permanecem baixas e o incêndio espalha-se lentamente. De início, na superfície do combustível e, em seguida, com o crescimento do incêndio, mais rapidamente, fornecendo um retorno da radiação proveniente das chamas e dos gases quentes para outro material combustível. A taxa de combustão nesse período é geralmente controlada pela natureza da superfície do material combustível.

O flashover corresponde ao instante em que ocorre o aumento brusco da inclinação da curva temperatura-tempo. Ele caracteriza o ponto de transição para o período de combustão generalizada. A partir desse instante, as temperaturas sobem rapidamente.

No período de combustão generalizada, ocorre um rápido desenvolvimento do incêndio, passando de superficial para volumétrico. Nessa fase, as temperaturas no ambiente são elevadas e as taxas de produção de calor muito altas. Toda a superfície exposta está queimando, a taxa de liberação de calor é, geralmente, governada pela ventilação disponível no compartimento.

No período de extinção, ocorre uma diminuição progressiva das temperaturas, geralmente pela falta de combustível, e a taxa de combustão volta a ser controlada pelo material combustível.

\subsection{INCÊNDIO-PADRÃO}

Quando houver necessidade de verificação da segurança contra incêndio da estrutura de uma edificação, deve-se considerar o efeito da ação térmica, empregando-se um modelo de incêndio representado por curvas temperatura-tempo. A caracterização de um incêndio por meio de curvas temperatura-tempo nem sempre é possível, uma vez que existe grande variabilidade dos parâmetros que nela influem. A curva temperatura-tempo utilizada em ensaios de resistência ao fogo é chamada de curva de incêndio-padrão, como ilustrada na figura 3.2.

No modelo do incêndio-padrão, admite-se que a temperatura dos gases do ambiente em chamas respeite as curvas padronizadas para ensaio. 


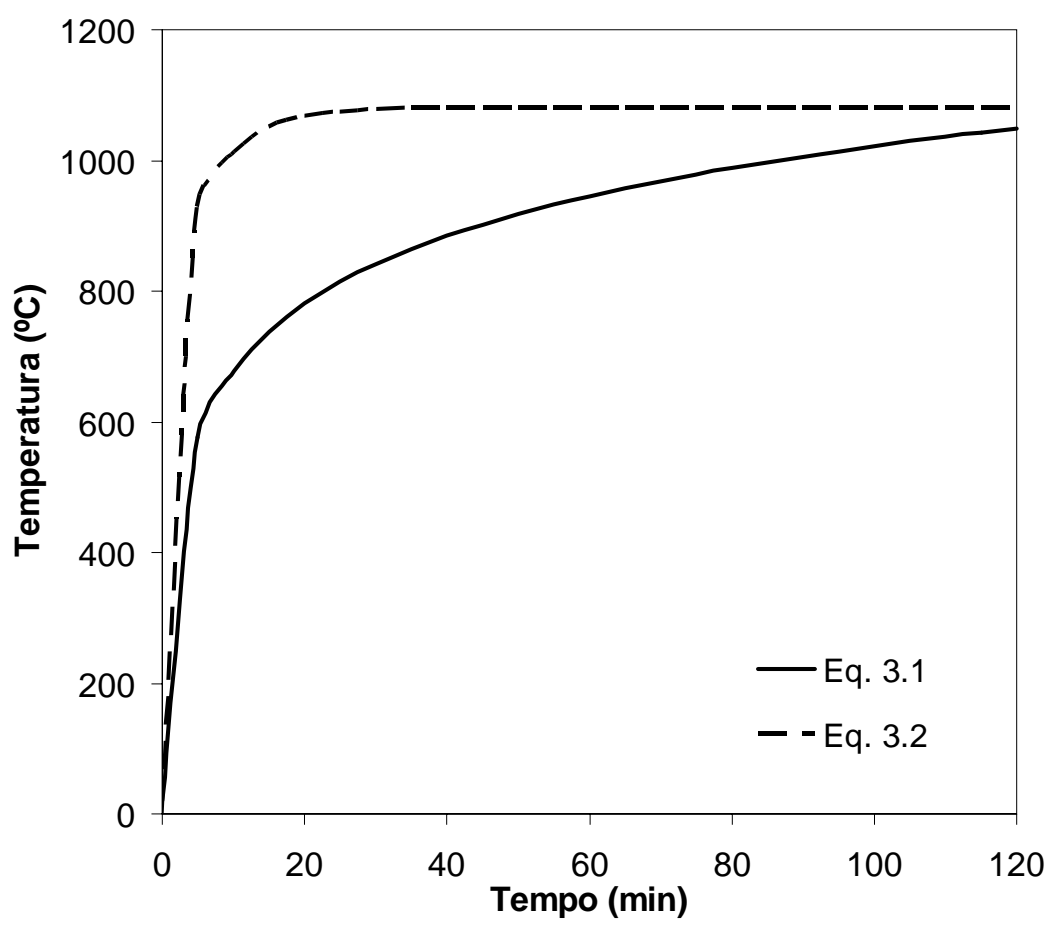

Figura 3.2 - Curvas de incêndio-padrão (EUROCODE 1, part 1.2, 2002).

A principal característica de um incêndio, no que concerne ao estudo das estruturas, é, portanto, a curva que fornece a temperatura dos gases em função do tempo de incêndio. A partir dessa curva (figura 3.1) é possível calcular-se a máxima temperatura atingida pelas peças estruturais e a sua correspondente resistência às altas temperaturas. No entanto, a curvapadrão possui apenas um ramo ascendente, o que admite que a temperatura dos gases seja sempre crescente com o tempo e independente das características do ambiente e da carga de incêndio.

Segundo Eurocode 1, Part 1.2 (2002) a curva do incêndio-padrão dentro de um compartimento é dada pela eq. 3.1 .

$$
\theta_{g}=\theta_{o}+345 \log (8 t+1)
$$

Onde:

$\theta_{g} \quad$ é a temperatura dos gases $\left({ }^{\circ} \mathrm{C}\right)$;

$\theta_{o} \quad$ é a temperatura ambiente $\left({ }^{\circ} \mathrm{C}\right)$;

$t \quad$ é o tempo (min). 
A figura 3.2 mostra uma alternativa para projeto, fornecida pelo Eurocode 1. Para incêndio onde o elemento estrutural está envolvido em chamas provenientes de material combustível à base de hidrocarbonetos, utiliza-se a eq. 3.2.

$$
\theta_{g}=1080\left(1-0,325 e^{-0,167 t}-0,675 e^{-2,5 t}\right)+\theta_{o}
$$

Embora não represente o desenvolvimento de um incêndio real, convencionou-se adotar a curva de incêndio-padrão como modelo para análise experimental de estruturas, de materiais de revestimento contra fogo, de portas corta-fogo, etc.

\subsection{INCÊNDIO NATURAL}

As curvas temperatura-tempo naturais foram construídas a partir de ensaios, ou modelos matemáticos aferidos a ensaios, e de incêndios que simulam a real situação de um compartimento incendiado.

Os resultados dos ensaios realizados demostraram que na curva de incêndio natural a variação de temperatura ocorre em função de alguns parâmetros, tais como: geometria, ventilação, características térmicas dos elementos de vedação e carga de incêndio.

A curva apresenta, como característica principal, um ramo ascendente, que corresponde à fase de aquecimento, e um ramo descendente, que corresponde à fase de resfriamento, conforme figura 3.3. 


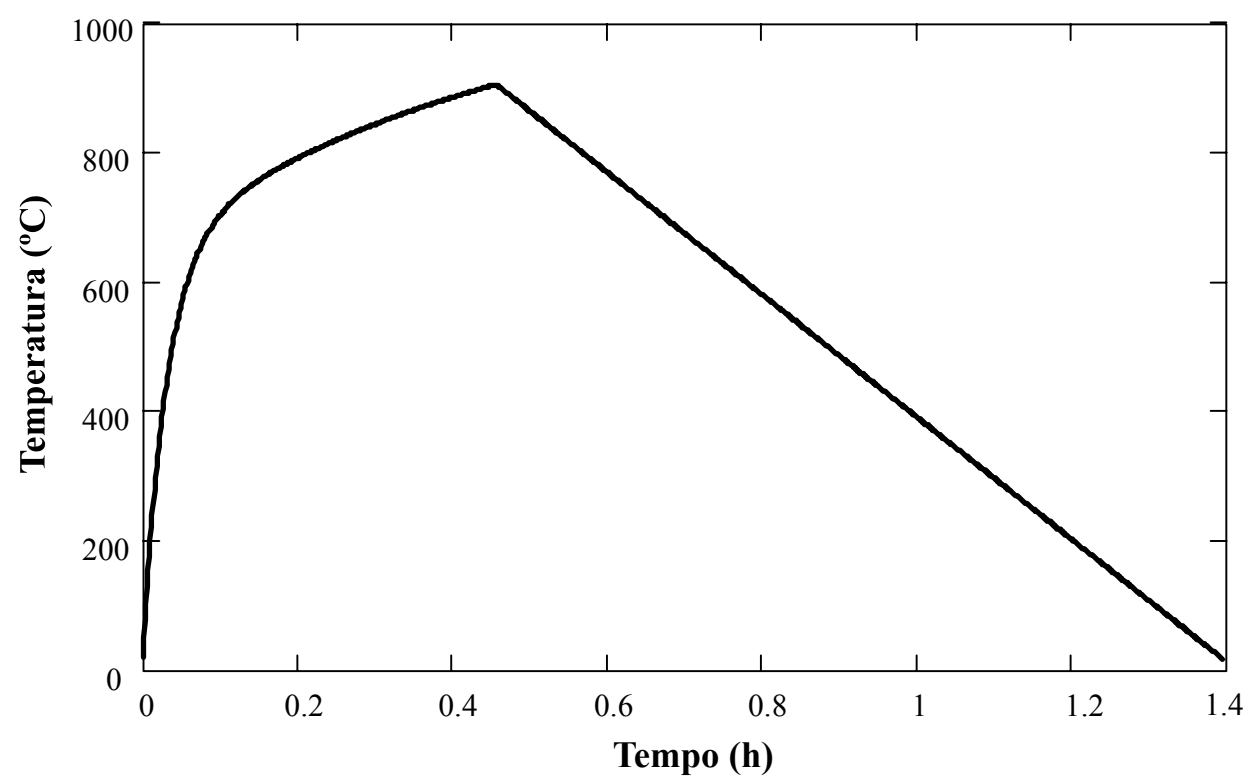

Figura 3.3 - Curva temperatura-tempo conforme modelo de incêndio natural (EUROCODE 1, part 1.2, 2002).

A equação do Eurocode 1, part 1.2 (2002) para o ramo ascendente da curva de incêndio natural é dada pela eq. 3.3.

$$
\theta_{g}=1325\left(1-0,324 e^{-0,2 t^{*}}-0,204 e^{-1,7 t^{*}}-0,472 e^{-19 t^{*}}\right)+\theta_{o}
$$

Onde:

$t^{*} \quad$ é o tempo fictício (h) dado por $t^{*}=t \Gamma$, sendo $\Gamma=\frac{\left(F_{v} / 0,04\right)^{2}}{(b / 1160)^{2}}$

$F_{v} \quad$ é o fator de ventilação $\left(\mathrm{m}^{0,5}\right)$ sendo $F_{v}=\frac{A_{v} h^{1 / 2}}{A_{t}}$

$b \quad$ é a absortividade térmica para o enclausuramento $\left(\mathrm{Ws}^{0,5} / \mathrm{m}^{2} \mathrm{~K}\right)$ sendo $b=\sqrt{\rho c \lambda}$;

$A_{v} \quad$ é a área das aberturas do compartimento $\left(\mathrm{m}^{2}\right)$;

$A_{t} \quad$ é a área total da superfície interna do compartimento $\left(\mathrm{m}^{2}\right)$;

$h_{e q} \quad$ é a altura equivalente das aberturas do compartimento (m);

$\rho \quad$ é a massa específica $\left(\mathrm{kg} / \mathrm{m}^{3}\right)$;

c é o calor específico $(\mathrm{J} / \mathrm{kg} \mathrm{K})$;

$\lambda$ é a condutividade térmica $(\mathrm{W} / \mathrm{m} \mathrm{K})$. 
O ramo descendente da curva de incêndio natural depende do valor do tempo fíctício máximo, $t^{*}{ }_{\max }$, sendo dado pela equação 3.4 .

$$
\begin{aligned}
& \theta_{g}=\theta_{\text {max }}-625\left(t^{*}-t^{*}{ }_{\text {max }} \cdot x\right) \quad \text { se } t^{*}{ }_{\text {max }} \leq 0,5 \\
& \theta_{g}=\theta_{\text {max }}-250\left(3-t^{*}{ }_{\text {max }}\right)\left(t *-t *_{\text {max }} \cdot x\right) \quad \text { se } \quad 0,5<t^{*} \text { max } \leq 2 \\
& \theta_{g}=\theta_{\text {max }}-250\left(t^{*}-t^{*}{ }_{\text {max }} \cdot x\right) \quad \text { se } \quad t^{*}{ }_{\text {max }}>2
\end{aligned}
$$

Onde:

$t^{*}{ }_{\max }=t_{\max } \Gamma$

$t_{\max }=\max \left[\left(0,2 \cdot 10^{-3} \cdot q_{t, d} / F_{V}\right) ; t_{\mathrm{lim}}\right]$;

$q_{t, d}=q_{f, d} \frac{A_{f}}{A_{t}} \quad\left(\mathrm{MJ} / \mathrm{m}^{2}\right) \quad$ sendo $\quad 50 \leq q_{t, d} \leq 1000\left(\mathrm{MJ} / \mathrm{m}^{2}\right)$

$q_{f, d} \quad$ é o valor de cálculo da carga de incêndio específica $\left(\mathrm{MJ} / \mathrm{m}^{2}\right)$;

$A_{f} \quad$ é a área de piso $\left(\mathrm{m}^{2}\right)$;

$t_{\text {lim }} \quad$ é a duração do incêndio quando controlado pelo material combustível (h).

\subsection{INCÊNDIO T-QUADRADO}

No modelo de incêndio conhecido por "incêndio $t^{2}$ " (t-quadrado), o crescimento da taxa de liberação de calor, $\dot{Q}$, emitido pela fonte do incêndio, é assumido como proporcional ao quadrado do tempo, conforme eq. 3.5.

$$
\dot{Q}=\alpha t^{2}
$$

Onde:

$\dot{Q} \quad$ é a taxa de liberação de calor (MW);

$t \quad$ é o tempo (s);

$\alpha \quad$ é o coeficiente de intensidade do incêndio $\left(\mathrm{MW} / \mathrm{s}^{2}\right)$. 
Os valores de $\alpha$ são fornecidos pela tabela 3.1, em função da velocidade de propagação do incêndio (lento, médio, rápido e ultra-rápido), produzindo taxas de liberação de calor conforme a figura 3.4. A escolha da constante $\alpha$ depende do tipo e da geometria do combustível.

Tabela 3.1 - Taxas de crescimento para incêndios t-quadrado (EWER, 2004 e BUCHANAN, 2001)

\begin{tabular}{c|c|c}
\hline $\begin{array}{c}\text { Taxa de } \\
\text { crescimento do } \\
\text { incêndio }\end{array}$ & $\begin{array}{c}\alpha \\
\left(\mathbf{M W} / \mathbf{s}^{\mathbf{2}}\right)\end{array}$ & $\begin{array}{c}\text { Descrição do tipo de incêndio real } \\
\text { Lento }\end{array}$ \\
\hline Médio & 0,0030 & $\begin{array}{c}\text { Produtos de madeira densa } \\
\text { Pranchas horizontais de madeira }\end{array}$ \\
\hline Rápido & 0,0117 & $\begin{array}{c}\text { Mobília de madeira contínua como mesas } \\
\text { Mobília individual com pequena quantidade de } \\
\text { plástico. }\end{array}$ \\
\hline Ultra-rápido & 0,1880 & $\begin{array}{c}\text { Alguma mobília estofada } \\
\text { Empilhamento alto de paletes de madeira } \\
\text { Caixas de papelão em páletes }\end{array}$ \\
\hline
\end{tabular}




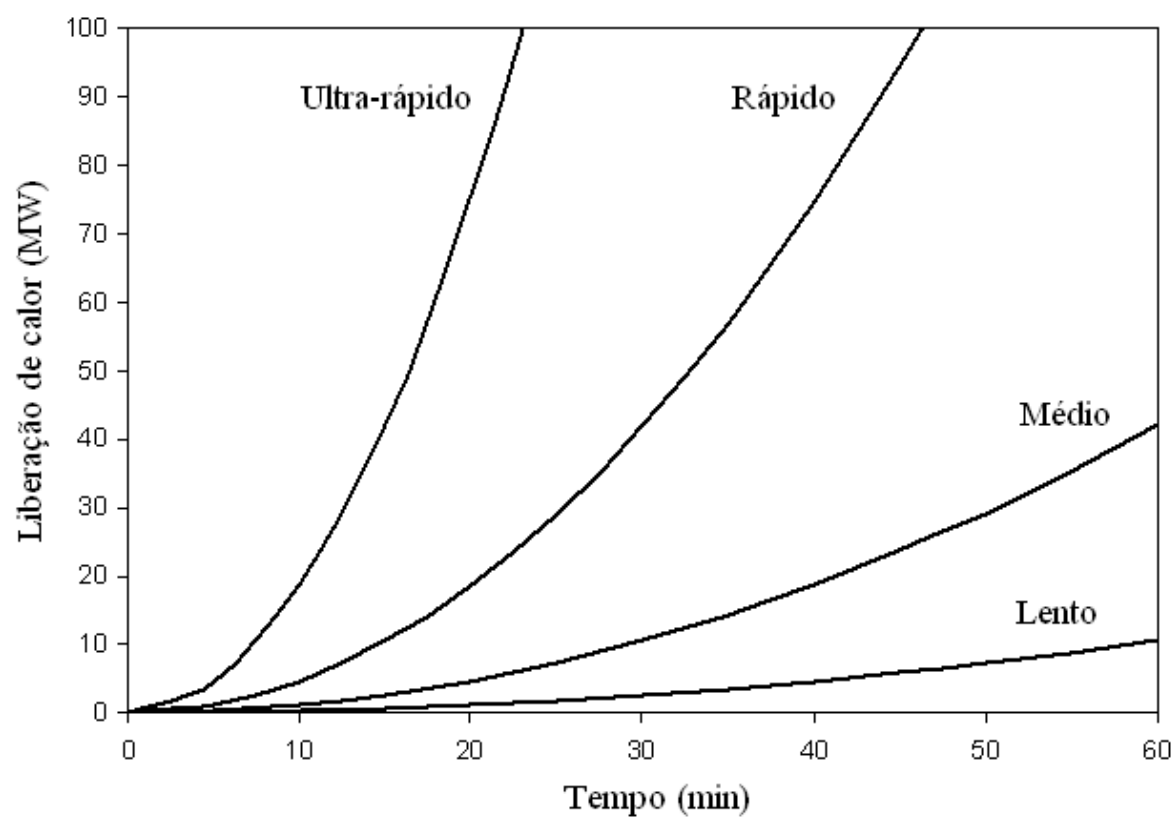

Figura 3.4 - Taxa de liberação de calor para incêndios t² (BUCHANAN, 2001).

A partir de um instante $t_{1}$, o incêndio alcança a taxa de liberação de calor máxima, $\dot{Q}_{p}(\mathrm{MW})$, e se mantém constante, como se vê na figura 3.5.

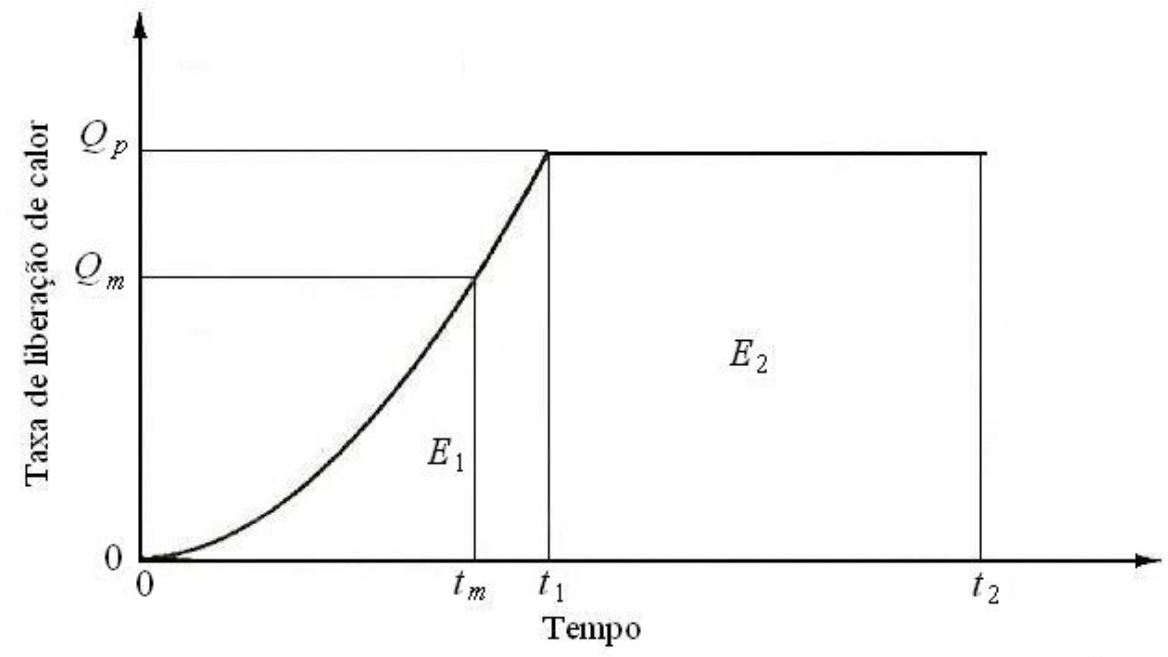

Figura 3.5 - Cálculo das taxas de liberação de calor para incêndios t² (BUCHANAN, 2001).

Da eq. 3.5, encontra-se $t_{1}$, conforme eq. 3.6.

$$
t_{1}=\sqrt{\frac{\dot{Q}_{p}}{\alpha}}
$$


Sabendo-se que a energia total liberada, $E$, é determinada pela eq. 3.7 , a energia $E_{1}$ é encontrada pela eq. 3.8.

$$
\begin{gathered}
E=\int_{0}^{t} \dot{Q} d t \\
E_{1}=\frac{t_{1} \dot{Q}_{p}}{3}
\end{gathered}
$$

Caso a energia total $E(\mathrm{MJ})$ seja maior que $E_{1}$, haverá uma fase estacionária de combustão $E_{2}$ (MJ), com duração $t_{b}$, conforme eqs. 3.9 e 3.10 .

$$
\begin{gathered}
E_{2}=E-E_{1} \\
t_{b}=t_{2}-t_{1}=\frac{E_{2}}{\dot{Q}_{p}}
\end{gathered}
$$

Se o combustível for insuficiente para alcançar a etapa de liberação máxima de calor, ele se extinguirá em um tempo $t_{m}$ determinado, a partir da eq. 3.7, conforme eq. 3.11 .

$$
t_{m}=\left(3 \frac{E}{\alpha}\right)^{1 / 3}
$$

\subsection{MECANISMOS DE TRANSFERÊNCIA DE CALOR}

O conhecimento de transferência de calor é fundamental para entender o desenvolvimento do incêndio. A transferência de calor ocorre por três processos: condução, convecção e radiação, conforme a figura 3.6. Os processos de transferência de calor podem ocorrer separadamente ou juntos, dependendo das circunstâncias. 


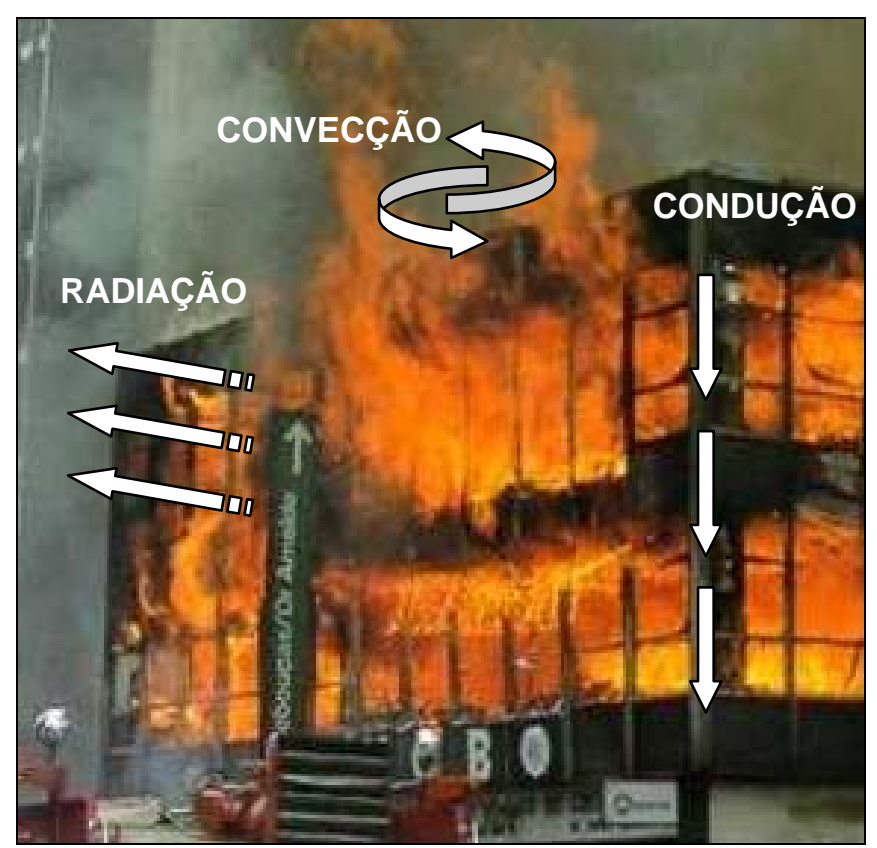

Figura 3.6 - Mecanismos de transferência de calor (AZEVEDO, 2005).

\subsubsection{Condução}

A condução é um importante mecanismo de transferência de calor em materiais sólidos. Um sólido pode ser composto por elétrons livres e átomos ligados em arranjos. Consequentemente, o transporte de energia térmica pode ser devido a dois efeitos, migração dos elétrons livres e ondas vibracionais dos átomos ligados em arranjos.

Em materiais bons condutores de calor, como o aço, essa transferência de calor ocorre principalmente por interações envolvendo elétrons livres. Os materiais que são bons condutores elétricos também são bons condutores de calor. Em materiais maus condutores de calor, o calor é conduzido principalmente por vibrações mecânicas da estrutura molecular.

A condução de calor é um importante fator na ignição das superfícies sólidas, nas barreiras de resistência ao fogo e nos elementos estruturais. Algumas propriedades do material são necessárias para os cálculos da transferência de calor em materiais sólidos, tais como, densidade, calor específico e condutividade térmica. Existem duas propriedades derivadas que frequentemente são necessárias no processo de transferência de calor por condução. São a difusidade térmica, dada por $\alpha=\lambda / \rho c$ e a inércia térmica, $\lambda \rho c$. As propriedades térmicas para alguns materiais podem ser obtidas na tabela 3.2 . 
Tabela 3.2 - Propriedades térmicas de alguns materiais (DRYSDALE apud BUCHANAN, 2001)

\begin{tabular}{|c|c|c|c|c|c|}
\hline Material & $\begin{array}{c}\text { Condutividade } \\
\text { térmica } \\
\lambda \\
(\mathrm{W} / \mathbf{m K})\end{array}$ & $\begin{array}{c}\text { Calor } \\
\text { específico } \\
\text { c } \\
\text { (J/kg.K) }\end{array}$ & $\begin{array}{l}\text { Densidade } \\
\qquad \begin{array}{c}\rho \\
\left(\mathrm{kg} / \mathrm{m}^{3}\right)\end{array}\end{array}$ & $\begin{array}{c}\text { Difusidade } \\
\text { térmica } \\
\alpha \\
\left(\mathbf{m}^{2} / \mathbf{s}\right)\end{array}$ & $\begin{array}{c}\text { Inércia } \\
\text { térmica } \\
\lambda \rho c \\
\left(\mathbf{W}^{2} \mathbf{s} / \mathbf{m}^{4} \mathbf{K}^{2}\right)\end{array}$ \\
\hline Cobre & 387 & 380 & 8940 & $1,14 \times 10^{-4}$ & $1,3 \times 10^{9}$ \\
\hline Aço (leve) & 45,8 & 460 & 7850 & $1,26 \times 10^{-4}$ & $1,6 \times 10^{8}$ \\
\hline Tijolo (comum) & 0,69 & 840 & 1600 & $5,2 \times 10^{-4}$ & $9,3 \times 10^{5}$ \\
\hline Concreto & $0,8-1,4$ & 880 & $1900-2300$ & $5,7 \times 10^{-4}$ & $2,0 \times 10^{6}$ \\
\hline Vidro (placa) & 0,76 & 840 & 2700 & $3,3 \times 10^{-4}$ & $1,7 \times 10^{6}$ \\
\hline Emboço de Gipsita & 0,48 & 840 & 1440 & $4,1 \times 10^{-4}$ & $5,8 \times 10^{5}$ \\
\hline Carvalho $^{a}$ & 0,17 & 2380 & 800 & $8,9 \times 10^{-4}$ & $3,2 \times 10^{5}$ \\
\hline Pinho amarelo ${ }^{a}$ & 0,14 & 2850 & 640 & $8,3 \times 10^{-4}$ & $2,5 \times 10^{5}$ \\
\hline Asbesto & 0,15 & 1050 & 577 & $2,5 \times 10^{-4}$ & $9,1 \times 10^{4}$ \\
\hline $\begin{array}{l}\text { Placa de isolamento de } \\
\text { fibra }\end{array}$ & 0,041 & 2090 & 229 & $8,6 \times 10^{-4}$ & $2,0 \times 10^{4}$ \\
\hline Espuma de poliuretano $^{b}$ & 0,034 & 1400 & 20 & $1,2 \times 10^{-4}$ & $9,5 \times 10^{2}$ \\
\hline $\mathrm{Ar}$ & 0,026 & 1040 & 1,1 & $2,2 \times 10^{-4}$ & -- \\
\hline
\end{tabular}

${ }^{a}$ Propriedades medidas perpendicular à direção da fibra.

Quando os materiais com baixa inércia térmica são expostos ao aquecimento, as temperaturas da superfície aumentam rapidamente e prontamente se inflamam. Para uma dada carga de incêndio, os compartimentos vedados por paredes constituídas por materiais de inércia térmica baixa experimentarão uma temperatura mais elevada do que os compartimentos com materiais de inércia térmica alta.

Na condução unidimensional em regime estacionário, a transferência de calor por condução é diretamente proporcional ao gradiente de temperatura entre dois pontos, como ilustrado na 
figura 3.7, com constante de proporcionalidade conhecida como condutividade térmica, $\lambda$. A transferência de calor ocorre exclusivamente na direção do gradiente. O sistema caracterizado como regime estacionário é aquele em que a temperatura de um ponto independe do tempo e é função tão somente da posição.

O fluxo de calor por condução unidimensional em regime estacionário pode ser quantificado pela eq. 3.12, conhecida como Lei de Fourier.

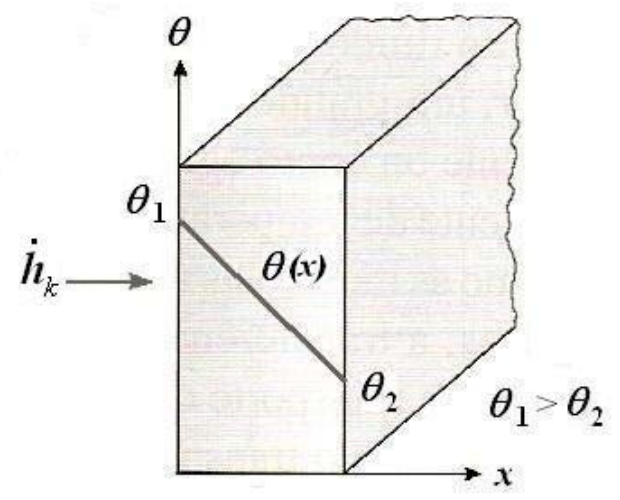

Figura 3.7 - Transferência de calor unidimensional por condução.

$$
\dot{h}_{k}=-\lambda \frac{d \theta}{d x}
$$

Onde:

$\dot{h}_{k} \quad$ é o fluxo de calor por unidade de área devido à condução $\left(\mathrm{W} / \mathrm{m}^{2}\right)$;

$\lambda \quad$ é a condutividade térmica do material $\left(\mathrm{W} / \mathrm{m}^{\circ} \mathrm{C}\right)$;

$\theta \quad$ é a temperatura $\left({ }^{\circ} \mathrm{C}\right)$;

$x \quad$ é a distância na direção do fluxo de calor (m).

Muitos problemas relacionados à transferência de calor são dependentes do tempo. Quando a temperatura em vários pontos do sistema varia com o tempo, o fluxo de calor é considerado não estacionário ou transiente. Uma vez que a variação da temperatura indica uma variação da energia interna, conclui-se que o armazenamento de energia faz parte do fluxo de calor transiente. A transferência de calor condutivo unidimensional em um material sem liberação de calor interno é governada pela eq. 3.13. 


$$
\frac{d^{2} \theta}{d x^{2}}=\frac{1}{\alpha} \frac{d \theta}{d t}
$$

Onde:

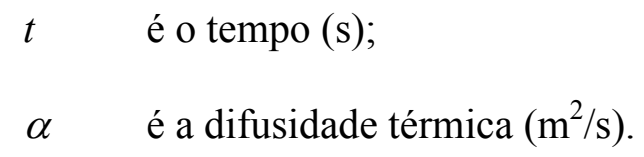

Verifica-se na eq. 3.13 que os materiais com baixa difusidade térmica conduzem mais calor que os materiais com alta difusidade térmica, quando expostos à temperatura superficial em regime transiente.

\subsubsection{Convecção}

Convecção é a transferência de calor por movimentação dos fluidos, gases ou líquidos. A transferência de calor por convecção é um importante fator na propagação da chama, no transporte ascendente da fumaça e na permanência dos gases quentes no teto ou para fora das aberturas do compartimento incendiado.

O processo de convecção transporta uma grande quantidade de energia química liberada durante o incêndio para o ambiente circunvizinho, por meio da movimentação dos gases quentes. A movimentação pode ser induzida pelo próprio incêndio, ou seja, os gases quentes ascendem e o ar frio imediatamente os substitui. A circulação dos gases também pode ser induzida por uma fonte externa ao incêndio, tal como o vento. Com base nessa definição, a transferência de calor por convecção é subdividida em convecção natural e forçada. A convecção natural e a forçada podem ocorrer simultaneamente, resultando em um modelo misturado de transferência de calor por convecção.

Considere o escoamento de um fluido sobre a superfície aquecida da figura 3.8. De acordo com Incropera et al. (2008), a interação entre um fluido e a superfície desenvolve uma região no fluido por meio da qual a sua velocidade varia entre zero, no contato com a superfície $(y=$ 0 ), e um valor finito $u_{\infty}$, associado ao escoamento do fluido. Essa região é chamada de camada-limite de velocidade. 


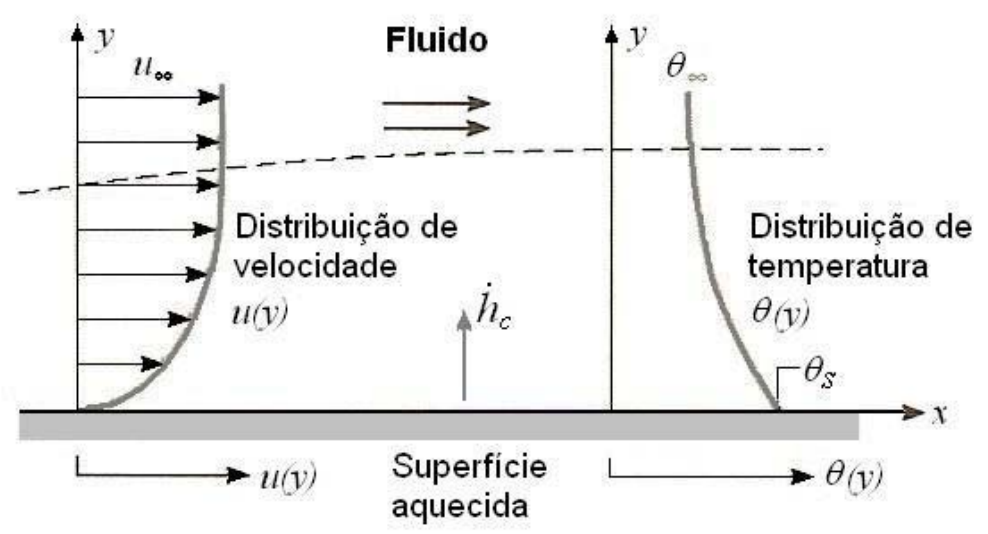

Figura 3.8 - Desenvolvimento da camada-limite.

Se as temperaturas na superfície e no fluido forem diferentes, existirá uma região no fluido através da qual a temperatura variará de $\theta_{s}$, em $y=0$, até $\theta_{\infty}$, associada à região do escoamento afastada da superfície. Essa região, conhecida como camada-limite térmica, pode ser menor, maior ou ter o mesmo tamanho daquela através da qual a velocidade varia.

O processo de transferência de calor por convecção pode ser expresso por meio da lei de Newton, do resfriamento, conforme a eq. 3.14.

$$
\dot{h}_{c}=\alpha_{c}\left(\theta_{s}-\theta_{\infty}\right)
$$

Onde:

$\dot{h}_{c} \quad$ é o fluxo de calor por convecção $\left(\mathrm{W} / \mathrm{m}^{2}\right)$;

$\alpha_{c} \quad$ é o coeficiente de transferência de calor por convecção $\left(\mathrm{W} / \mathrm{m}^{20} \mathrm{C}\right)$;

$\theta_{\infty} \quad$ é a temperatura dos gases quentes $\left({ }^{\circ} \mathrm{C}\right)$;

$\theta_{s} \quad$ é a temperatura da superfície $\left({ }^{\circ} \mathrm{C}\right)$.

$\mathrm{Na}$ figura 3.9, é ilustrado o desenvolvimento de uma camada-limite sobre uma placa plana. $\mathrm{Na}$ maioria das situações coexistem as condições de escoamento laminar e turbulento, com a seção laminar precedendo à turbulenta. Para cada condição, o movimento de fluido é caracterizado por componentes da velocidade nas direções $x$ e $y$. O movimento do fluido se afastando da superfície se faz necessário pela desaceleração do fluido próximo à parede, na medida em que a camada-limite cresce na direção $x$. 


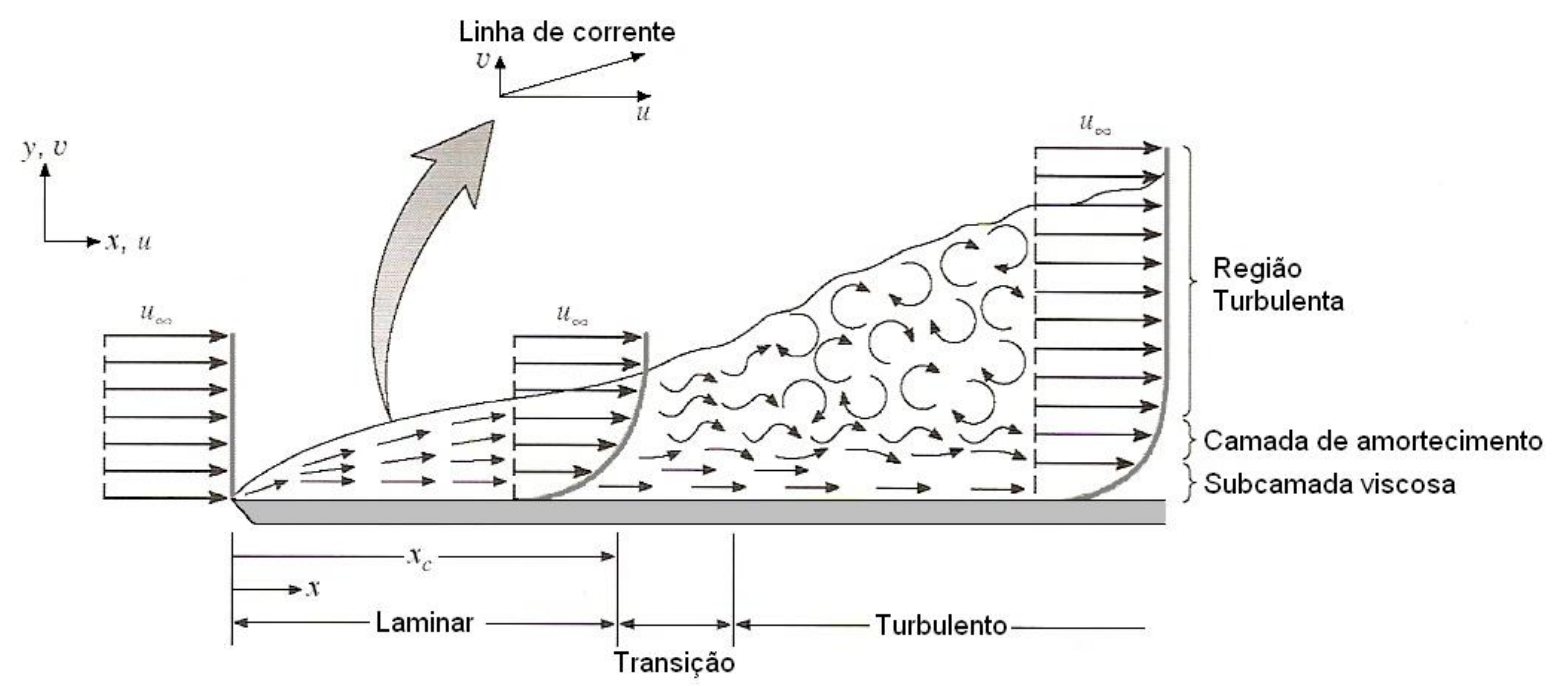

Figura 3.9 - Desenvolvimento da camada-limite de velocidade sobre uma placa plana.

Na camada-limite laminar, o movimento do fluido é altamente ordenado, sendo possível identificar linhas de corrente, ao longo das quais as partículas do fluido se movimentam. A espessura da camada-limite aumenta, e o gradiente de velocidade em $y=0$ diminui no sentido do escoamento (aumento de $x$ ). O comportamento altamente ordenado continua até que uma zona de transição é atingida, ao longo da qual ocorre uma conversão das condições laminares para as turbulentas. As condições na zona de transição se modificam com o tempo. $\mathrm{O}$ escoamento, algumas vezes, demonstra comportamento laminar e, outras vezes, característica de escoamento turbulento.

De acordo com Incropera et al. (2008), quando o escoamento na camada-limite é completamente turbulento, de maneira geral, ele é altamente irregular, sendo caracterizado pelo movimento tridimensional aleatório de, relativamente, grandes parcelas do fluido. A mistura no interior da camada-limite direciona o fluido com alta velocidade na direção da superfície do sólido e transfere o fluido com movimento mais lento para dentro da corrente livre. A maior parte da mistura é promovida por vórtices na direção do escoamento, que são gerados intermitentemente próximos à placa plana, onde eles crescem e decaem rapidamente.

Variações da velocidade e da pressão ocorrem em qualquer ponto no interior da camadalimite turbulenta, como resultado das interações que levam às condições de escoamento caótico. Três regiões distintas na camada-limite turbulenta podem ser delineadas em função da distância da superfície: a subcamada viscosa, na qual o transporte é denominado pela difusão e o perfil de velocidades é aproximadamente linear; a camada de amortecimento, na 
qual a difusão e a mistura turbulenta são comparáveis; e uma zona turbulenta, na qual o transporte é denominado pela mistura turbulenta.

A transição do escoamento laminar para o turbulento deve-se aos mecanismos de gatilho, tais como a interação de estruturas transientes do escoamento, que se desenvolvem naturalmente no interior do fluido, ou pequenos distúrbios que existem no interior de muitas camadaslimites típicas. Esses distúrbios podem originar-se em flutuações na corrente livre, ou podem ser induzidos pela rugosidade superficial ou, ainda, por minúsculas vibrações na superfície.

O início da turbulência depende da amplificação ou atenuação dos mecanismos de gatilho na direção do escoamento do fluido, o que, por sua vez, depende de um agrupamento adimensional de parâmetros chamado de número de Reynolds, dado pela eq. 3.15.

$$
\operatorname{Re}_{x}=\frac{\rho u_{\infty} x}{\mu}
$$

Onde:

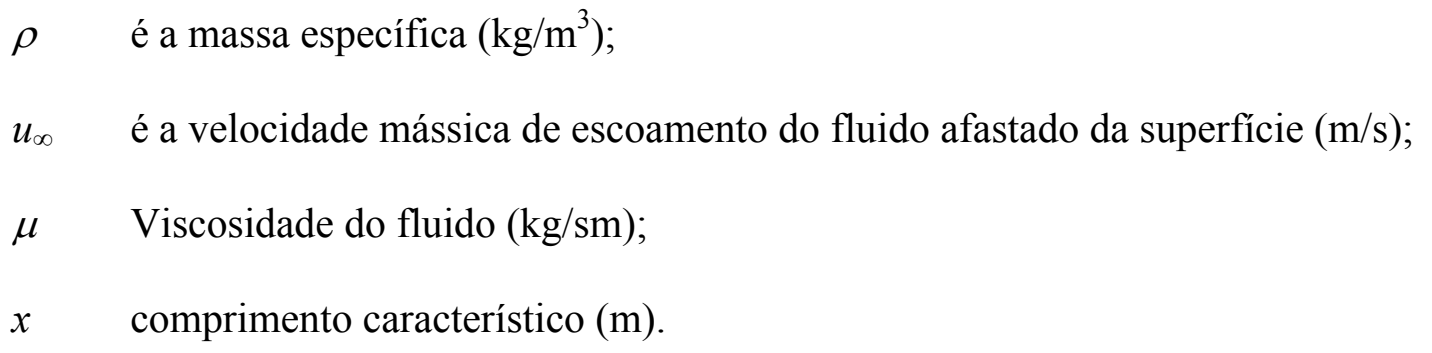

O número de Reynolds representa a razão entre as forças de inércia e as viscosas. Se o número de Reynolds for pequeno, as forças de inércia serão insignificantes em relação às forças viscosas. Os distúrbios são, então, dissipados, e o escoamento permanece laminar. Entretanto, para um número de Reynolds grande, as forças de inércia podem ser suficientes para amplificar os mecanismos de gatilho, dessa forma a transição para a turbulência ocorre.

Outro número importante no processo de transferência de calor por convecção é o número de Nusselt. De acordo com Incropera et al. (2008), ele fornece uma medida da transferência de calor por convecção que ocorre na superfície. Para uma geometria específica, como, uma placa plana de comprimento $L$, o número de Nusselt é representado pela eq. 3.16. 


$$
N u=f\left(x^{*}, \operatorname{Re}_{L}, \operatorname{Pr}\right)
$$

Onde:

$x^{*} \equiv \frac{x}{L}$ é o comprimento em relação ao comprimento da placa $L$;

$\mathrm{Re}_{L} \quad$ é o número de Reynolds conforme eq. 3.15;

Pr é o número de Prandl.

Para efeito de comparação, o número de Nusselt representa para a camada-limite térmica o que o coeficiente de atrito representa para a camada-limite de velocidade. A eq. 3.16 indica que, para uma dada geometria, o número de Nusselt deve ser uma função universal de $x^{*}, \operatorname{Re}_{L}$ e Pr.

O número de Prandl (Pr) é o parâmetro que relaciona as espessuras relativas das camadaslimite hidrodinâmica e térmica. Camada-limite hidrodinâmica é a região do escoamento onde atuam as forças viscosas, e camada-limite térmica é a região onde os gradientes de temperatura estão presentes no escoamento.

$$
\operatorname{Pr}=\frac{c_{p} \mu}{\lambda}
$$

Onde:

$c_{p} \quad$ é o calor específico $\left(\mathrm{J} / \mathrm{kg}^{\circ} \mathrm{C}\right)$

$\mu \quad$ é a viscosidade $(\mathrm{kg} / \mathrm{s} . \mathrm{m})$;

$\lambda \quad$ é a condutividade térmica $\left(\mathrm{W} / \mathrm{m}^{\circ} \mathrm{C}\right)$.

Se a função for conhecida, ela pode ser usada para calcular o valor de $N u$ para diferentes fluidos e para diferentes valores de $V$ e $L$. Onde $V$ é a velocidade a montante da superfície e $L$ é o comprimento característico da superfície. A partir do conhecimento de $N u$, o coeficiente convectivo local $\alpha_{c}$ pode ser determinado, e o fluxo térmico local pode, então, ser calculado pela eq. 3.14. 
Como o coeficiente de transferência de calor médio é obtido por uma integração ao longo da superfície do corpo, ele deve ser independente da variável espacial $x^{*}$. Assim, a dependência funcional do número de Nusselt médio é dada pela eq. 3.18.

$$
\bar{N} u=\frac{\alpha_{c} L}{\lambda}
$$

Onde:

$\lambda \quad$ é a condutividade térmica do material $\mathrm{em} \mathrm{W} / \mathrm{m}^{\circ} \mathrm{C}$.

\subsubsection{Radiação}

Segundo Buchanan (2001), a radiação é a transferência de energia por meio de ondas eletromagnéticas que podem viajar pelo vácuo, ou através de sólido transparente ou líquido. A radiação é muito importante nos incêndios, porque é o principal mecanismo de transferência de calor das chamas para a superfície dos combustíveis, da fumaça quente para os objetos do edifício e do edifício incendiado para o edifício adjacente.

O fluxo de calor por radiação em um ponto na superfície receptora é dado pela eq. 3.19.

$$
\dot{h}_{r}=\phi \varepsilon_{e} \sigma \theta_{e}^{4}
$$

Onde:

$\phi \quad$ é o fator de configuração (adimensional);

$\varepsilon_{e} \quad$ é a emissividade da superfície emissora (adimensional);

$\sigma \quad$ é a constante de Stefan-Boltzmann $\left(5,67 \times 10^{-8} \mathrm{~W} / \mathrm{m}^{2} \mathrm{~K}^{4}\right)$.

$\theta_{e} \quad$ é a temperatura absoluta da superfície emissora $(\mathrm{K})$.

O fluxo de calor resultante da superfície emissora para a superfície receptora é dado pela eq. 3.20 . 


$$
\dot{h}_{r}=\phi \varepsilon \sigma\left(\theta_{e}^{4}-\theta_{r}^{4}\right)
$$

Onde:

$\theta_{r} \quad$ é a temperatura absoluta da superfície receptora $(\mathrm{K})$;

$\varepsilon \quad$ é a emissividade resultante das duas superfícies dada pela eq. 3.21.

$$
\varepsilon=\frac{1}{1 / \varepsilon_{e}+1 / \varepsilon_{r}-1}
$$

Onde:

$\varepsilon_{r} \quad$ é a emissividade na superfície receptora.

A emissividade $\varepsilon$ indica a eficiência da superfície emissora como um radiador, com um valor que varia de zero a 1,0. O radiador que possui emissividade igual a 1,0 é chamado de "corpo negro".

No incêndio, a maioria das superfícies quentes, partículas de fumaça ou chamas luminosas, tem a emissividade entre 0,7 e 1,0. A emissividade pode mudar durante o incêndio. $\mathrm{O}$ aço galvanizado, por exemplo, tem emissividade muito baixa até a temperatura alcançar aproximadamente $400^{\circ} \mathrm{C}$, quando o zinco derrete e o aço desencapado fica exposto ao fogo.

O fator de configuração $\phi$ é a medida de quanto o emissor da radiação é visto pela superfície receptora. Em situação geral, como mostrado na figura 3.10, o fator de configuração para a radiação incidente no ponto 2 , com distância $r$ da superfície radiante e área $A_{l}$ é dado pela eq. 3.22 .

$$
\phi=\int^{A_{1}} \frac{\cos \beta_{1} \cos \beta_{2}}{\pi r^{2}} d A_{1}
$$




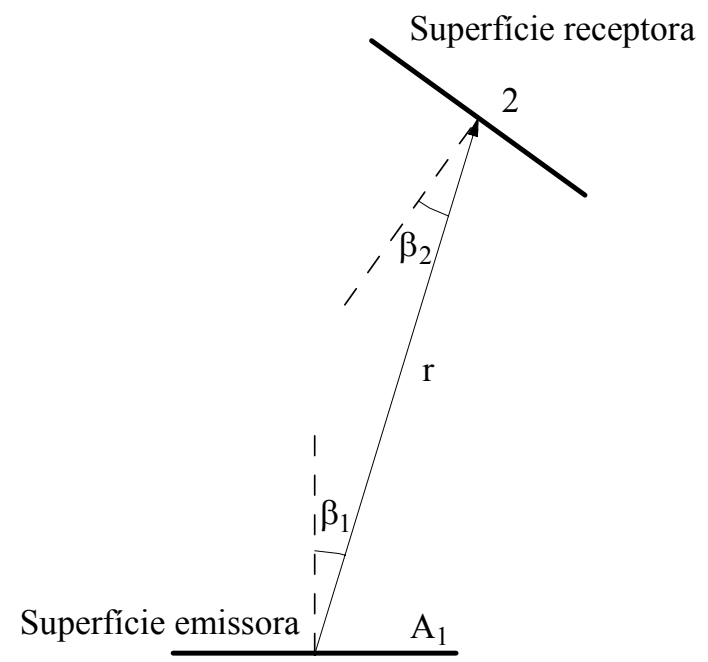

Figura 3.10 - Radiação de uma superfície para a outra (BUCHANAN, 2001).

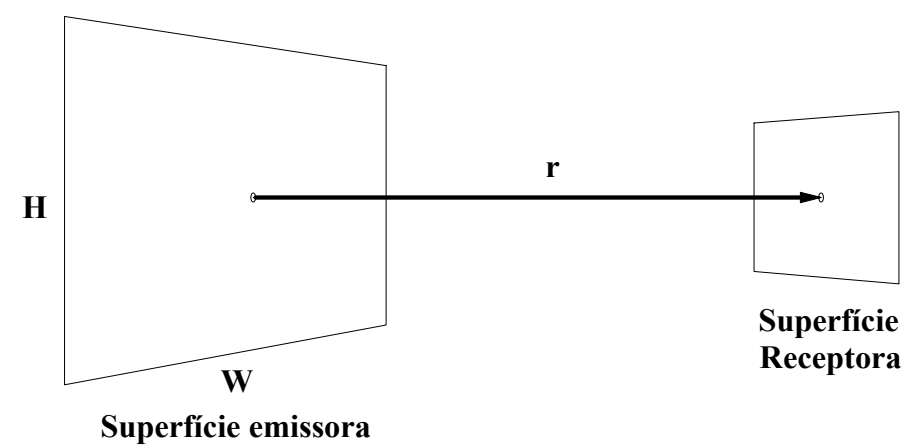

Figura 3.11 - Superfície emissora e receptora (BUCHANAN, 2001).

Para o caso particular de duas faces paralelas, o fator de configuração $\phi$ em um ponto da superfície receptora, a uma distância $r$ do centro da superfície retangular que emite a radiação é:

$$
\phi=\frac{1}{90}\left[\frac{a}{\sqrt{1+a^{2}}} \tan ^{-1}\left(\frac{b}{\sqrt{1+a^{2}}}\right)+\frac{b}{\sqrt{1+b^{2}}} \tan ^{-1}\left(\frac{a}{\sqrt{1+b^{2}}}\right)\right]
$$

Onde:

$a=H / 2 r$

$b=W / 2 r$

$H$ é a altura do retângulo da superfície radiante;

$W \quad$ é a largura do retângulo da superfície radiante. 
Se a distância $r$ for grande em relação ao tamanho da superfície emissora, o fator de configuração é aproximadamente dado pela eq. 3.24.

$$
\phi=\frac{A_{1}}{\pi r^{2}}
$$

Onde:

$A_{1} \quad$ é a área da superfície emissora $\left(A_{1}=H . W\right)$ conforme figura 3.11 . 
Capítulo 4 ESTRUTURAS DE AÇO EXPOSTAS AO INCÊNDIO

\subsection{INTRODUÇÃO}

Quando uma estrutura é exposta ao incêndio, a resistência e o módulo de elasticidade são reduzidos, o que pode conduzir a deformações exageradas e até mesmo ao colapso, dependendo das cargas aplicadas, como ilustrado nas figuras 4.1 e 4.2.

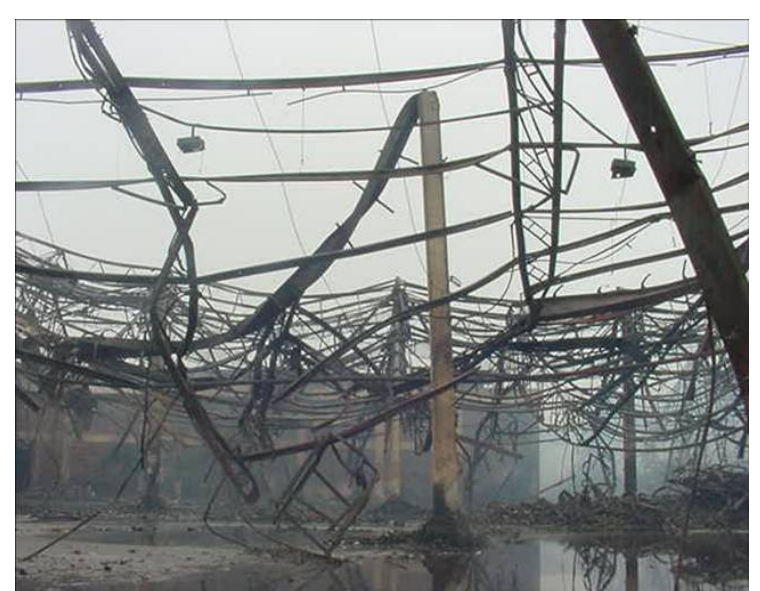

Figura 4.1 - Danos típicos de incêndio em estruturas de aço. Centro de distribuição de alimentos da Nestlé, em São Bernardo do Campo, em 2001.

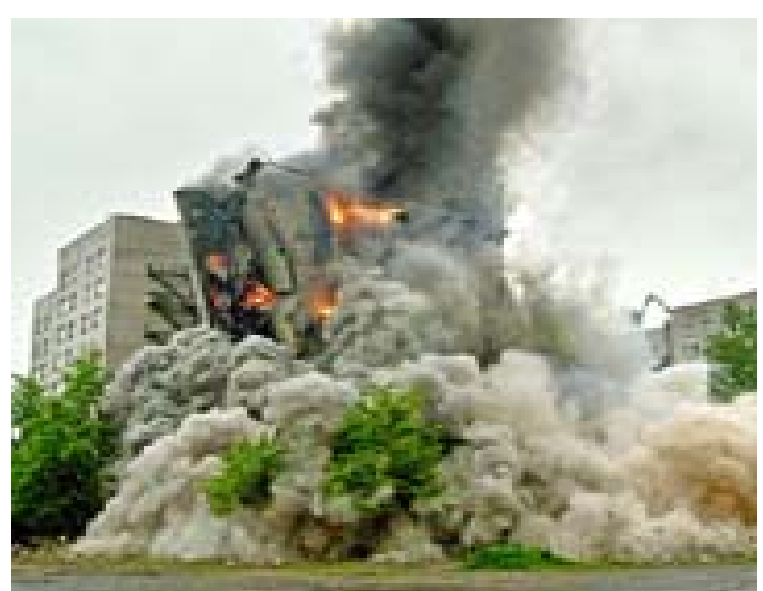

Figura 4.2 - Colapso total de um edifício residencial em São Petersburgo - Rússia, 2002 (COSTA, 2007).

Quando exposto às altas temperaturas, o aço, assim como os demais materiais estruturais, apresenta variações em suas propriedades mecânicas e térmicas. Para o cálculo das temperaturas em estruturas expostas ao incêndio, é necessário conhecer essas propriedades.

O aumento das temperaturas do aço depende da severidade do incêndio, das dimensões do perfil, da área exposta ao incêndio e das medidas de proteção aplicadas.

A massa específica do aço é $7850 \mathrm{~kg} / \mathrm{m}^{3}$ e se mantém constante com o aumento da temperatura. 


\subsection{RESISTÊNCIA AO ESCOAMENTO E MÓDULO DE ELASTICIDADE}

De acordo com a ABNT NBR 14323:1999, para taxas de aquecimento entre $2^{\circ} \mathrm{C} / \mathrm{min}$ e $50^{\circ} \mathrm{C} / \mathrm{min}$, os fatores de redução relativos aos valores a $20^{\circ} \mathrm{C}$, para a resistência ao escoamento dos aços laminados a quente $\left(k_{y, \theta}\right)$, e o módulo de elasticidade de todos os tipos de aço $\left(k_{E, \theta}\right)$, em temperatura elevada, são os apresentados na figura 4.3.

Resistência ao escoamento dos aços laminados a quente:

$$
k_{y, \theta}=\frac{f_{y, \theta}}{f_{y}}
$$

Módulo de elasticidade de todos os tipos de aço:

$$
k_{E, \theta}=\frac{E_{\theta}}{E}
$$

Onde:

$f_{y, \theta} \quad$ é a resistência ao escoamento dos aços laminados a uma temperatura $\theta_{a}$;

$f_{y} \quad$ é a resistência ao escoamento do aço a $20^{\circ} \mathrm{C}$;

$E_{\theta} \quad$ é o módulo de elasticidade de todos os tipos de aço a uma temperatura $\theta_{a}$;

E é o módulo de elasticidade de todos os aços a $20^{\circ} \mathrm{C}$. 


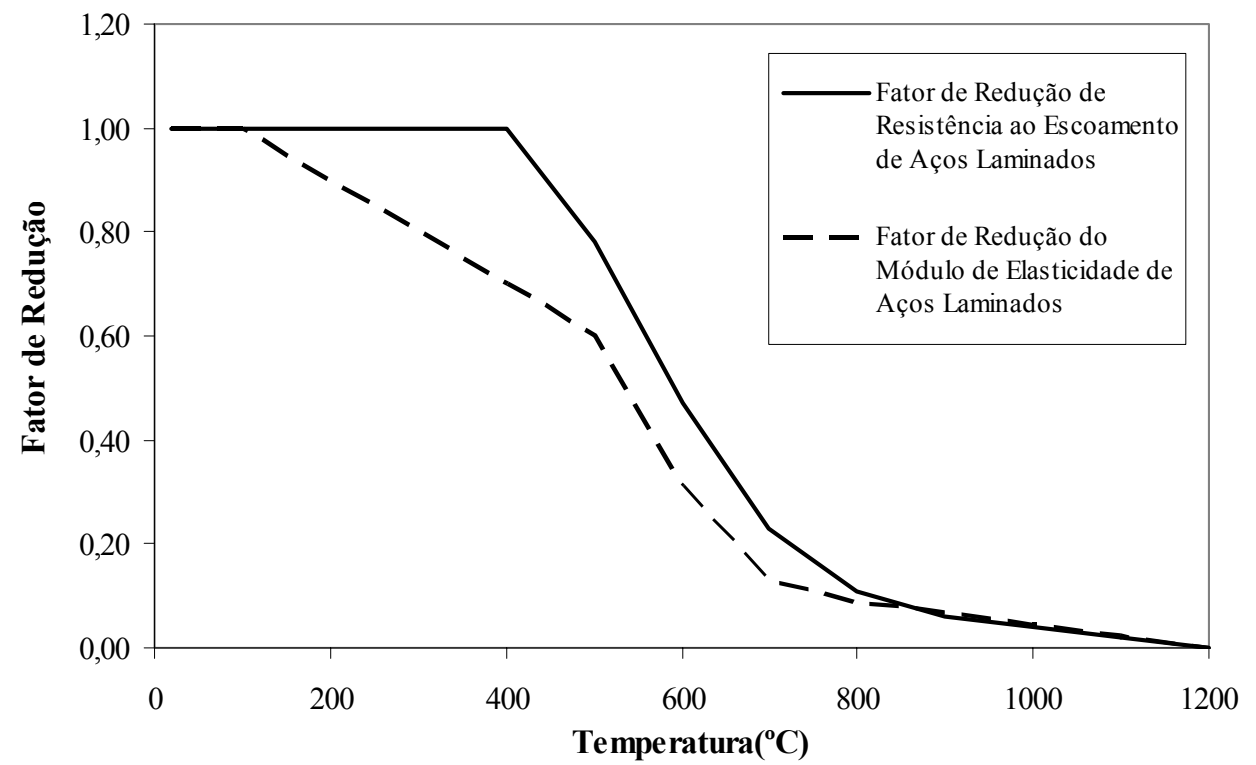

Figura 4.3 - Variação dos fatores de redução para a resistência ao escoamento e o módulo de elasticidade do aço com o aumento da temperatura (ABNT NBR 14323:1999).

\subsection{PROPRIEDADES TÉRMICAS DO AÇO}

As características térmicas do aço são variáveis com a temperatura. Nos itens a seguir, são apresentados os valores dessas características em função da temperatura, conforme ABNT NBR 143423:1999.

\subsubsection{Calor específico}

Considera-se como calor específico a quantidade de calor necessária para elevar de $1^{\circ} \mathrm{C}$ a unidade de massa de dado material. O calor específico do aço, $c_{a}$, aumenta mediante o acréscimo de temperatura. A variação do calor específico do aço com o aumento da temperatura pode ser determinada de acordo com a eq. 4.3 , em $\mathrm{J} / \mathrm{kg}^{\circ} \mathrm{C}$. 
Para $20^{\circ} \mathrm{C} \leq \theta_{a}<600^{\circ} \mathrm{C}: \quad c_{a}=425+7,73 \times 10^{-1} \theta_{a}-1,69 \times 10^{-3} \theta_{a}^{2}+2,22 \times 10^{-6} \theta_{a}^{3}$

Para $600^{\circ} \mathrm{C} \leq \theta_{a}<735^{\circ} \mathrm{C}: \quad c_{a}=666+\frac{13002}{738-\theta_{a}}$

Para $735^{\circ} \leq \theta_{a}<900^{\circ} \mathrm{C}: \quad c_{a}=545+\frac{17820}{\theta_{a}-731}$

Para $900^{\circ} \mathrm{C} \leq \theta_{a} \leq 1200^{\circ} \mathrm{C}: \quad c_{a}=650$

Onde:

$\theta_{a} \quad$ é a temperatura do aço.

O calor específico do aço varia com a temperatura de acordo com a figura 4.4, onde o resultado do calor específico de pico obtido a $735^{\circ} \mathrm{C}$ é proveniente das alterações na microestrutura do aço. Para a utilização de métodos simplificados de cálculo, o calor específico do aço pode ser considerado como sendo $600 \mathrm{~J} / \mathrm{kg}^{\circ} \mathrm{C}$.

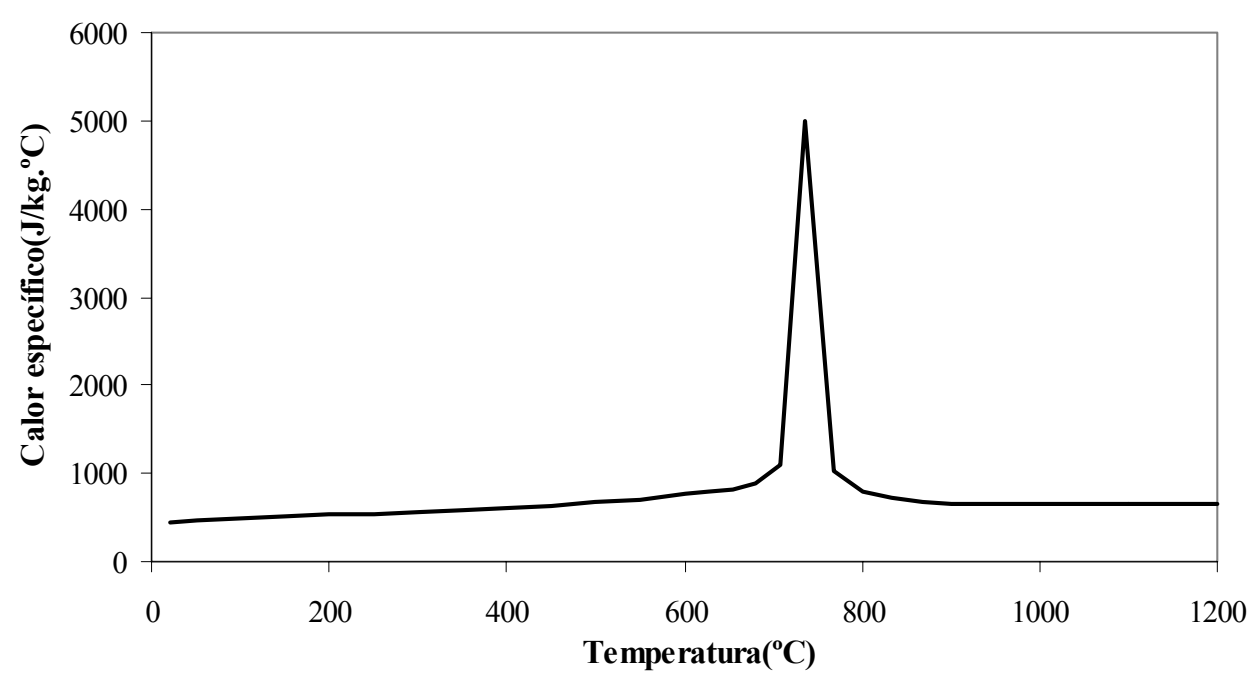

Figura 4.4 - Calor específico do aço em função da temperatura.

\subsubsection{Condutividade térmica}

A condutividade térmica está relacionada à capacidade térmica do material de conduzir calor. Conforme eq. 4.4, a condutividade térmica do aço $\lambda_{a}$ varia de acordo com a temperatura e é expressa em $\mathrm{W} / \mathrm{m}^{\circ} \mathrm{C}$. 
Para $20^{\circ} \mathrm{C} \leq \theta_{a}<800^{\circ} \mathrm{C}$ :

$$
\lambda_{a}=54-3,33 \times 10^{-2} \times \theta_{a}
$$

Para $800^{\circ} \mathrm{C} \leq \theta_{a} \leq 1200^{\circ} \mathrm{C}$ :

$$
\lambda_{a}=27,3
$$

A variação da condutividade térmica do aço com a temperatura pode ser vista pela figura 4.5.

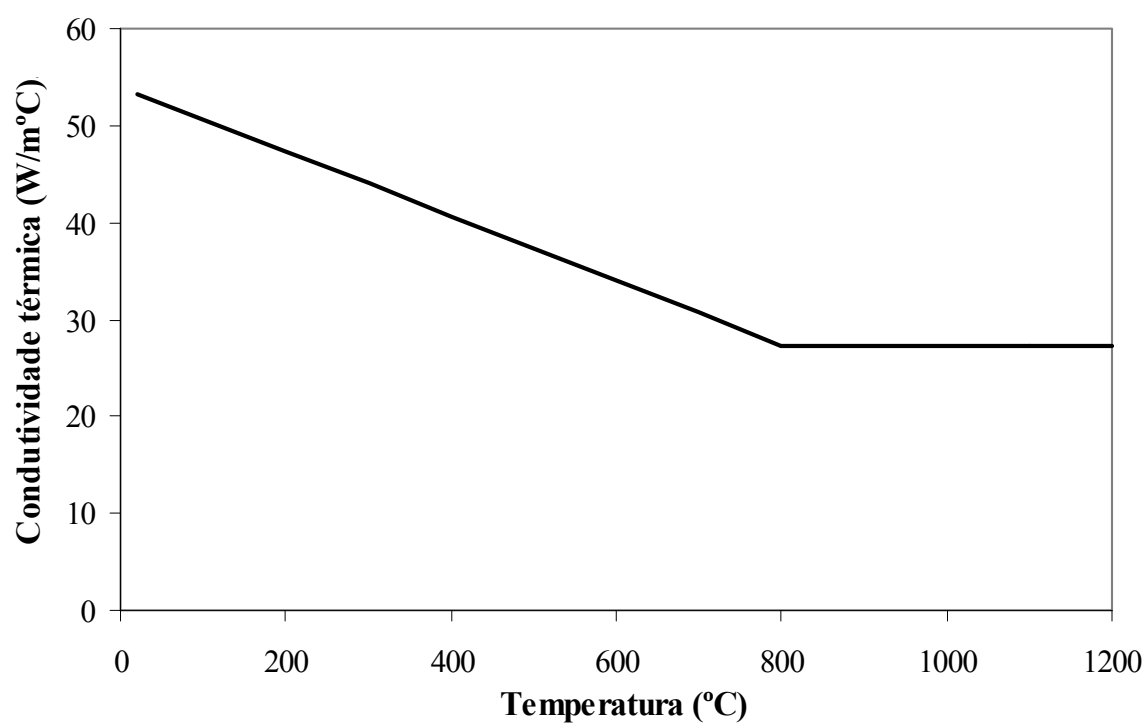

Figura 4.5 - Condutividade térmica do aço em função da temperatura.

Em método simplificado de cálculo, o valor da condutividade térmica pode ser considerado independente da temperatura do aço e igual a $\lambda_{a}=45 \mathrm{~W} / \mathrm{m}^{\circ} \mathrm{C}$.

\subsubsection{Alongamento}

Como resultado da elevada expansão térmica que os aços apresentam, os elementos estruturais de aço podem sofrer dilatações significativas durante o incêndio. Essas deformações introduzem, no início do incêndio, esforços consideráveis nos componentes de conexões entre os perfis, podendo ocasionar perda de estabilidade da estrutura.

O alongamento do aço varia com a temperatura, de acordo com a eq. 4.5. 
Para $20^{\circ} \mathrm{C} \leq \theta_{a}<750^{\circ} \mathrm{C}: \quad \frac{\Delta l}{l}=1,2 \times 10^{-5} \theta_{a}+0,4 \times 10^{-8} \theta_{a}^{2}-2,416 \times 10^{-4}$

Para $750^{\circ} \mathrm{C} \leq \theta_{a} \leq 860^{\circ} \mathrm{C}$ :

$$
\frac{\Delta l}{l}=1,1 \times 10^{-2}
$$

Para $860^{\circ} \mathrm{C}<\theta_{a} \leq 1200^{\circ} \mathrm{C}$ :

$$
\frac{\Delta l}{l}=2 \times 10^{-5} \theta_{a}-6,2 \times 10^{-3}
$$

Onde:

$\theta_{a} \quad$ é a temperatura do aço $\left({ }^{\circ} \mathrm{C}\right)$;

$\Delta l \quad$ é a expansão térmica do aço, provocada pelo aumento de temperatura (m);

$l \quad$ é o comprimento a $20^{\circ} \mathrm{C}(\mathrm{m})$.

A variação do alongamento do aço em função da temperatura é verificada na figura 4.6.

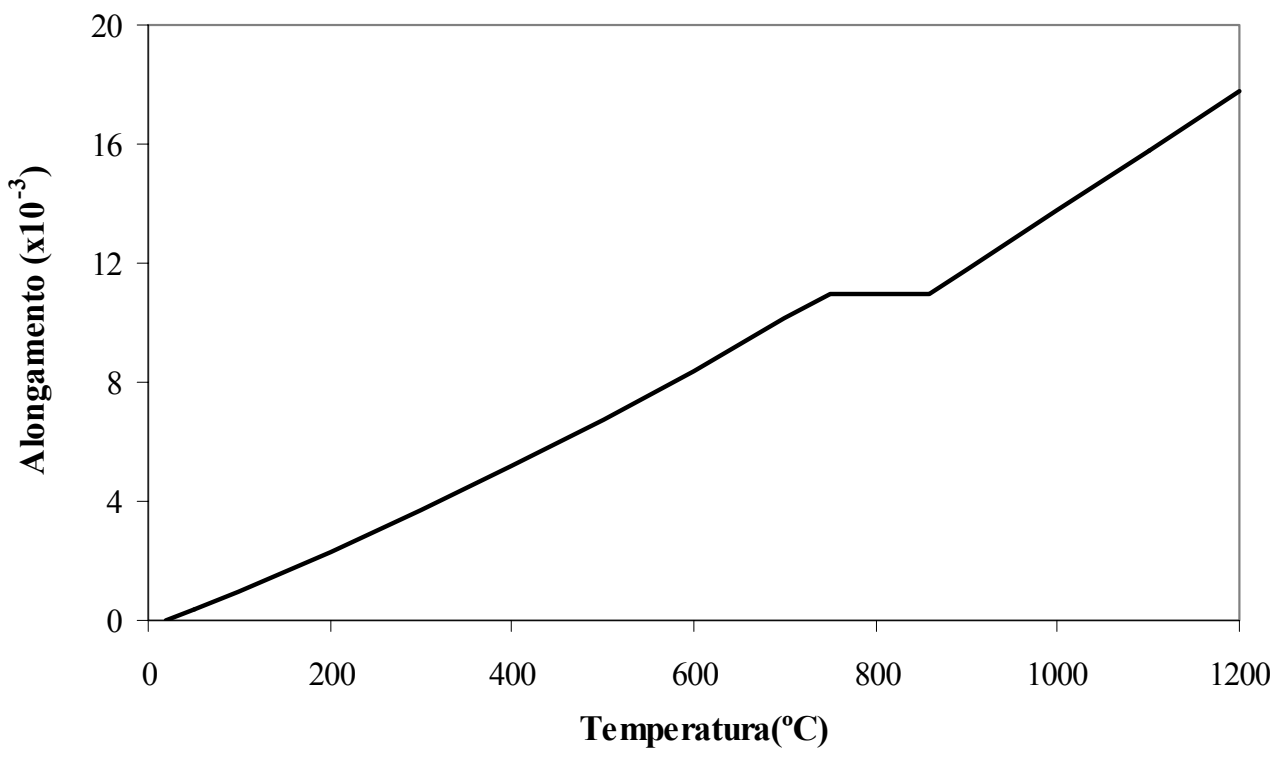

Figura 4.6 - Alongamento do aço em função da temperatura.

Para modelos simplificados de cálculo, o valor do alongamento do aço em função da temperatura pode ser considerado como demonstrado na eq. 4.6.

$$
\frac{\Delta \ell}{\ell}=14 \times 10^{-6}\left(\theta_{a}-20\right)
$$




\subsection{FATOR DE MASSIVIDADE}

O fator de massividade expressa a razão entre a área exposta ao fogo e o volume aquecido do elemento estrutural. Trata-se de uma característica geométrica importante, pois o fluxo de calor é diretamente proporcional à área exposta ao incêndio, e a absorção de calor é proporcional ao volume do elemento de aço.

Para elementos prismáticos, o fator de massividade resulta na relação entre o perímetro exposto ao fogo $(u)$ e a área da seção transversal do elemento $(A)$, como mostra a eq. 4.7.

$$
\frac{A_{m}}{V}=\frac{u \cdot l}{A \cdot l}=\frac{u}{A}
$$

Onde:

$A_{m} \quad$ é a área do elemento exposta ao fogo $\left(\mathrm{m}^{2}\right)$;

$V \quad$ é o volume do elemento estrutural de aço $\left(\mathrm{m}^{3}\right)$;

$u \quad$ é o perímetro da seção transversal (m);

$l \quad$ é o comprimento do elemento a $20^{\circ} \mathrm{C}(\mathrm{m})$;

$A \quad$ é a área da seção transversal do elemento estrutural de aço $\left(\mathrm{m}^{2}\right)$.

As tabelas 4.1 e 4.2 fornecem a determinação dos fatores de massividade das seções mais utilizadas na construção civil, de acordo com a ABNT NBR 14323:1999. 
Tabela 4.1 - Fator de massividade para alguns elementos estruturais sem revestimento contra fogo (ABNT NBR 14323:1999)

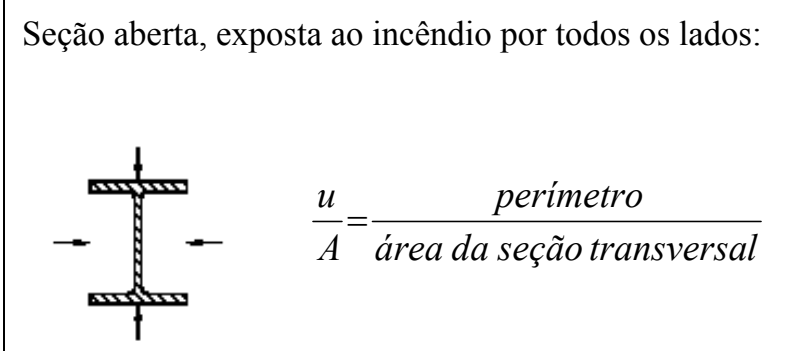

Seção aberta, exposta ao incêndio por três lados:

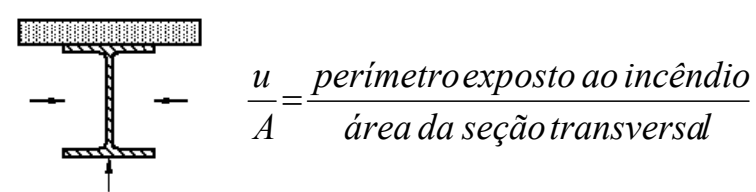

Mesa de seção I, exposta ao incêndio por três lados:

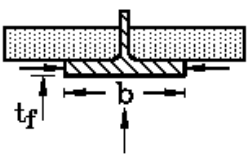

$$
\frac{u}{A}=\frac{b+2 t_{f}}{b t_{f}}
$$

Seção tubular, de forma circular, exposta ao incêndio por todos os lados:

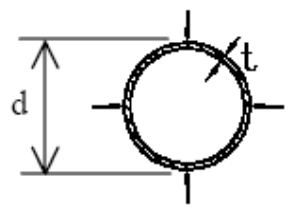

$$
\frac{u}{A}=\frac{d}{t(d-t)}
$$

Seção tubular, de forma retangular (ou seção caixão soldada de espessura uniforme), exposta ao incêndio por todos os lados:

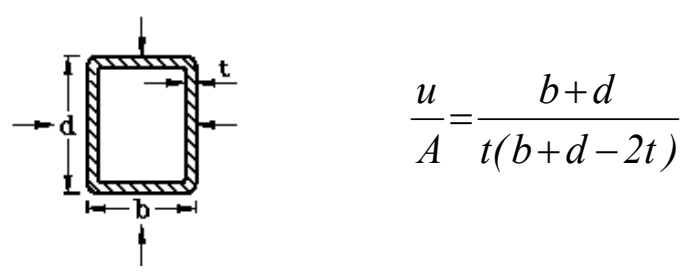

Seção caixão soldada, exposta ao incêndio por todos os lados:

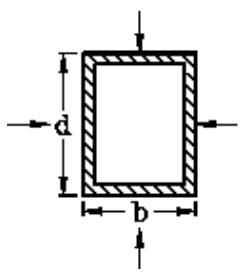

$$
\frac{u}{A}=\frac{2(b+d)}{\text { área da seção transversal }}
$$

Seção I com reforço em caixão, exposta ao incêndio

Cantoneira exposta ao incêndio por todos os lados: por todos os lados:

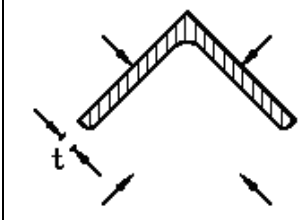

$$
\frac{u}{A}=\frac{2+\sqrt{2}}{2 t}
$$

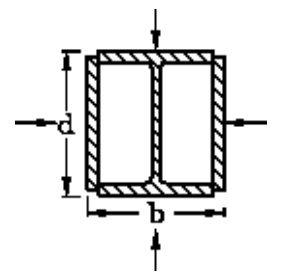

$$
\frac{u}{A}=\frac{2(b+d)}{\text { área da seção transversal }}
$$

Chapa exposta ao incêndio por três lados:

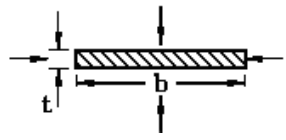

$$
\frac{u}{A}=\frac{2(b+t)}{b t}
$$

$$
\frac{u}{A}=\frac{b+2 t}{b t}
$$


Tabela 4.2 - Fator de massividade para alguns elementos estruturais com revestimento contra fogo (ABNT NBR 14323:1999).

\begin{tabular}{l|l|}
$\begin{array}{l}\text { Seção com revestimento tipo contorno, de espessura } \\
\text { uniforme, exposta ao incêndio por todos os lados: }\end{array}$ & $\begin{array}{l}\text { Seção com revestimento tipo caixa, de espessura } \\
\text { uniforme, exposta ao incêndio por todos os lados: }\end{array}$ \\
\hline$\frac{u}{A}=\frac{\text { perímetro da seção da peça de aço }}{\text { área da seção da peça de aço }}$ & Seção com com com revestimento tipo contorno, de espessura \\
uniforme, exposta ao incêndio por três lados: & uniforme, exposta ao incêndio por três lados. \\
\hline &
\end{tabular}

O valor do fator de massividade é tanto menor quanto mais robusto for o elemento estrutural. Um elemento com baixo fator de massividade aquece mais lentamente do que outro com um elevado valor desse fator, conforme ilustrado na figura 4.7.

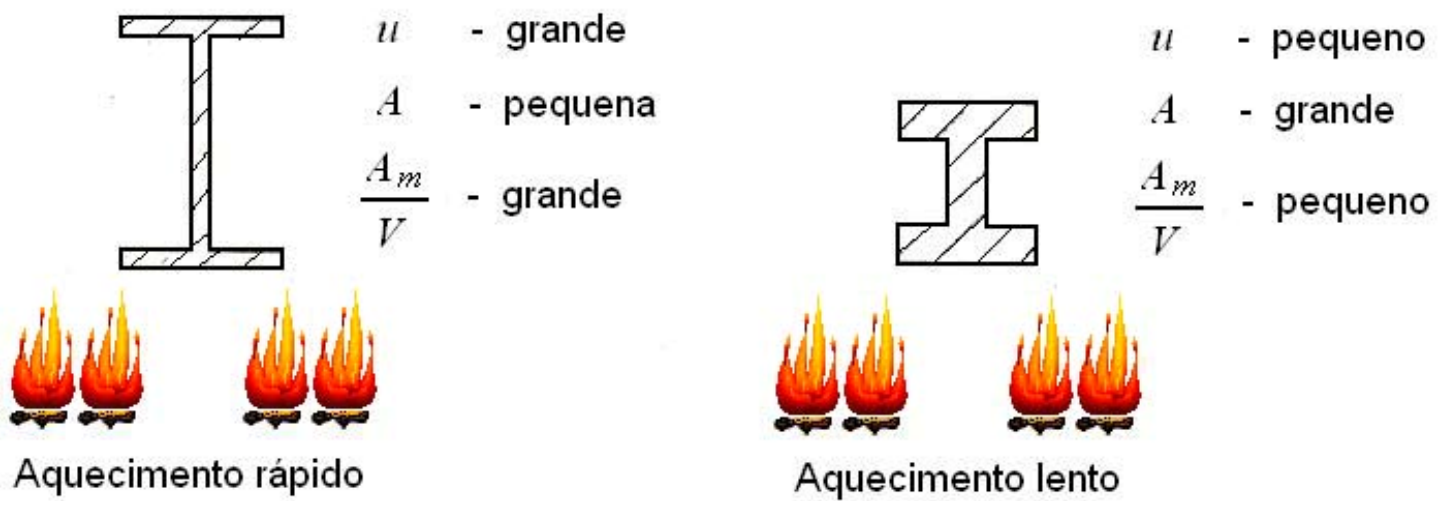

Figura 4.7 - Fator de massividade (REAL, 2003). 


\section{Capítulo 5}

\section{O MÉTODO DE MARGARET LAW}

\subsection{INTRODUÇÃO}

As temperaturas nas vizinhanças dos elementos estruturais externos a edificações são inferiores àquelas no interior do compartimento incendiado. O Eurocode 1, part 1-2 (2002) apresenta um método que permite determinar essas temperaturas e o Eurocode 3, part 1-2 (2003) complementa o método, indicando um procedimento analítico para determinação da temperatura em elementos de aço.

De acordo com Arup (2006), esse método foi desenvolvido por Margaret Law que, em 1972, tornou-se pesquisadora no departamento de engenharia civil do Ministério de Tecnologia da Inglaterra. Nessa época, duas situações contribuíram para o desenvolvimento do método.

À época, houve uma competição para a criação de um novo centro de artes em Paris, chamado Centre Beauborg, hoje denominado Centre Pompidou. Os vencedores foram os arquitetos Richard Rogers e Renzo Piano, juntamente com Arup. A estrutura era de aço, externa ao edifício, e a proposta era a de que não houvesse revestimento contra fogo, então pediram ajuda a Margaret Law.

Ao mesmo tempo, a siderúrgica British Steel, por meio do Constrado (Constructional Steel Research and Development Organisation), contratou Arup para desenvolver um artigo sobre estruturas de aço sem revestimento contra fogo em edifícios. Law foi convidada por Arup a fazer parte da equipe de Turlogh O'Brien, responsável pelo grupo de pesquisa e desenvolvimento do Constrado.

Os elementos estruturais tinham uma exigência de desempenho com base em um período especificado de exposição ao incêndio-padrão de resistência ao fogo. Os elementos estruturais de aço externos a edificações deveriam ser projetados conforme incêndio-padrão, ou seja, com as mesmas exigências de resistência ao fogo, e consequentemente, com os mesmos 
revestimentos contra fogo que os elementos estruturais de aço internos, mesmo que as condições externas da exposição ao fogo fossem menos severas.

As condições de aquecimento dos elementos estruturais internos a um compartimento incendiado são semelhantes às condições apresentadas no incêndio-padrão de resistência ao fogo, onde um elemento é introduzido em um forno. Ou seja, esses elementos estão em um ambiente cercado pelas chamas e pelas superfícies aquecidas tais como parede, teto e piso do compartimento incendiado.

As condições de aquecimento dos elementos estruturais externos a edificações são diferentes dos internos. Os elementos externos são expostos à transferência de calor devido à radiação, proveniente do compartimento incendiado por meio das aberturas e das chamas que emergem por essas aberturas e devido à convecção dos gases quentes. O valor da intensidade de calor recebida varia de acordo com a quantidade de material combustível, a ventilação dentro do compartimento e a posição do elemento em relação às aberturas.

De acordo com Law (1978), nos primeiros ensaios, as experiências eram realizadas simulando uma exposição externa por inserção de uma janela, em ensaio padronizado, na parede de um forno. Isso não foi considerado satisfatório, porque não importava qual o tempo de duração do ensaio, a exposição à chama era menos severa do que a proveniente de um incêndio real.

Ensaios, com base científica, realizados com elementos externos expostos às chamas e à radiação proveniente de incêndio reais confirmaram que as exigências poderiam ser mais brandas do que os requeridos pelas normas para elementos estruturais internos a edificações.

As condições críticas para os elementos estruturais de aço podem ser definidas em termos de temperatura crítica do aço. Dada as condições de transferência de calor, o cálculo da temperatura do aço é, relativamente, direta. Ao adotar essa abordagem de projeto, o problema principal é definir a transferência de calor externa.

Foi possível estimar a transferência de calor externa para projetos de edifícios utilizando uma grande quantidade de informações sobre incêndios em edifícios e sobre o comportamento da chama. As correlações obtidas no método foram derivadas de modelos em escala reduzida e também de medições em modelos de escala natural.

As bases para um procedimento específico de projeto para o uso do aço estrutural no exterior de edificações em situação de incêndio foram formadas a partir do trabalho de Margaret Law. 
Neste capítulo, serão apresentados os principais conceitos envolvidos no método de Margaret Law e inseridos alguns comentários de como ela obteve a formulação proposta. Em Azevedo (2005), essa formulação é amplamente analisada.

\subsection{EQUILÍBRIO TÉRMICO}

A figura 5.1 indica as temperaturas utilizadas na equação de equilíbrio térmico (eq. 5.6 e 5.8), onde $\theta_{z}$ se refere à temperatura da chama externa, $\theta_{a}$ à temperatura do aço, $\theta_{g}$ à temperatura dos gases dentro do compartimento incendiado e $\theta_{o}$ à temperatura do ar no ambiente externo à edificação em graus Celsius. As temperaturas indicadas possuem valores absolutos, ou seja, $\theta_{z}$ $=\Delta \theta_{z}+\theta_{o}, \theta_{a}=\Delta \theta_{a}+\theta_{o}$ e $\theta_{g}=\Delta \theta_{g}+\theta_{o}$.

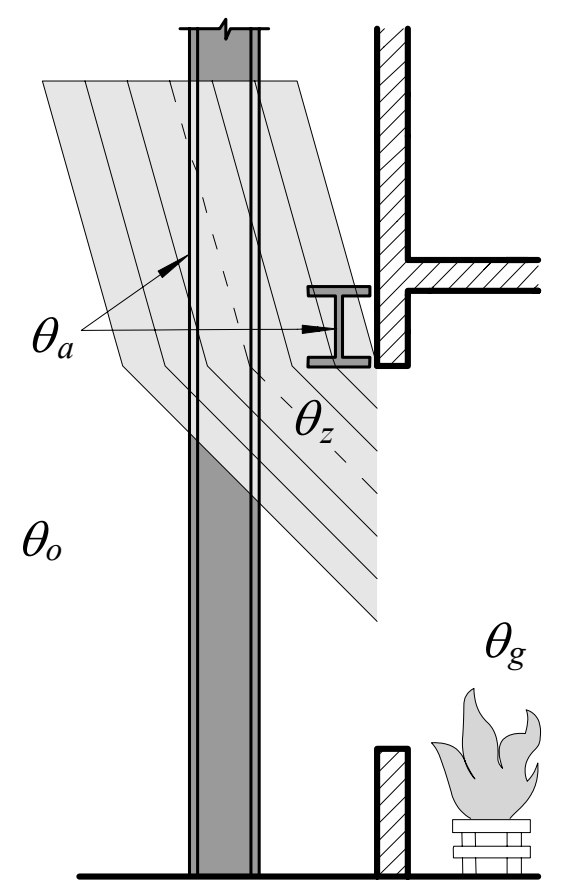

Figura 5.1 - Indicação das temperaturas utilizadas na equação de equilíbrio (LAW, 1978).

Para a elaboração da equação de equilíbrio térmico, é necessário saber como se comportam as transferências de calor para a superfície do aço. Quando o elemento estrutural externo à edificação está envolvido ou não pela chama, deve-se considerar as transferências de calor intervenientes no sistema, conforme eq. 5.1. 


$$
\dot{h}_{c z}+\dot{h}_{r z}+\dot{h}_{r f}+\dot{h}_{r o}=\dot{h}_{a b s}+\dot{h}_{p e r d}
$$

\subsubsection{Elemento envolvido pela chama}

A temperatura de um elemento de aço externo à edificação, quando envolvido pela chama, pode ser determinada a partir do equilíbrio térmico representado pela eq. 5.1 e pela figura 5.2.

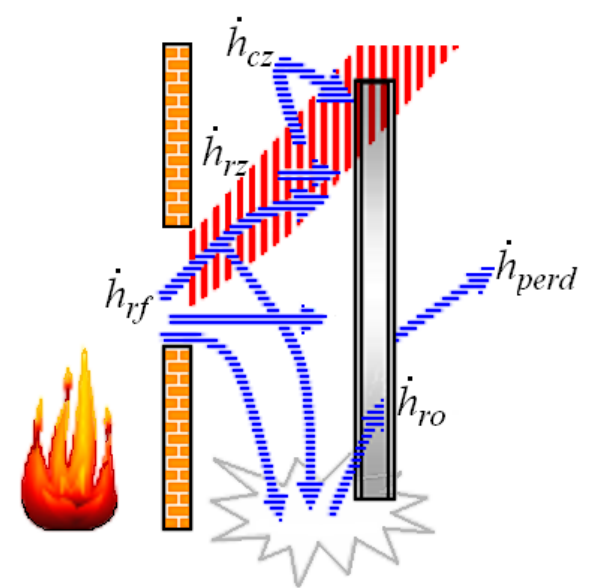

Figura 5.2 - Fluxo de calor para perfil de aço envolvido pela chama.

Em que:

$\dot{h}_{c z}=\alpha_{z}\left[\left(\theta_{z}+273,15\right)-\left(\theta_{a}+273,15\right)\right]$ é o fluxo de calor por unidade de área devido à convecção na chama $\left(\mathrm{kW} / \mathrm{m}^{2}\right)$, em que $\alpha_{z}$ é o coeficiente de transferência de calor por convecção da chama $\left(\mathrm{kW} / \mathrm{m}^{2 \mathrm{o}} \mathrm{C}\right), \theta_{z}$ é a temperatura da chama externa $\left({ }^{\circ} \mathrm{C}\right)$ e $\theta_{a}$ é a temperatura do aço $\left({ }^{\circ} \mathrm{C}\right)$.

$\dot{h}_{r z}=\phi_{z} \varepsilon_{z} \varepsilon_{a} \sigma\left[\left(\theta_{z}+273,15\right)^{4}-\left(\theta_{a}+273,15\right)^{4}\right\rfloor$ é o fluxo de calor por unidade de área devido à radiação da chama $\left(\mathrm{kW} / \mathrm{m}^{2}\right)$, em que $\varepsilon_{z}$ é a emissividade da chama, $\varepsilon_{a}$ é a emissividade do aço, $\phi_{z}$ é o fator de configuração da chama e $\sigma$ é a constante de Stefan-Boltzmann e vale $56,7 \times 10^{-12} \mathrm{~kW} / \mathrm{m}^{2 \mathrm{o}} \mathrm{C}^{4}$. 
$\dot{h}_{r f}=\phi_{f} \varepsilon_{f} \varepsilon_{a}\left(1-\varepsilon_{z}\right) \sigma\left[\left(\theta_{g}+273,15\right)^{4}-\left(\theta_{a}+273,15\right)^{4}\right\rfloor$ é o fluxo de calor por unidade de área devido à radiação das aberturas do compartimento $\left(\mathrm{kW} / \mathrm{m}^{2}\right)$, em que $\phi_{f}$ é o fator de configuração das janelas em relação à superfície do aço, $\varepsilon_{f}$ é a emissividade da abertura do compartimento e $\theta_{g}$ é a temperatura dos gases dentro do compartimento incendiado $\left({ }^{\circ} \mathrm{C}\right)$. Trata-se da parcela $\left(1-\varepsilon_{z}\right)$ do fluxo realmente transmitida ao aço; outra parte $\left(\varepsilon_{z}\right)$ é absorvida pela chama e transferida ao elemento através da radiação da chama $\left(\dot{h}_{r z}\right)$.

$\dot{h}_{r o}=\left(1-\phi_{f}\right) \varepsilon_{a}\left(1-\varepsilon_{z}\right) \sigma\left[\left(\theta_{o}+273,15\right)^{4}-\left(\theta_{a}+273,15\right)^{4}\right]$ é o fluxo de calor devido à radiação do ambiente em torno do elemento $\left(\mathrm{kW} / \mathrm{m}^{2}\right)$, em que $\theta_{o}$ é a temperatura do ar no ambiente externo à edificação e a emissividade $\varepsilon_{0}$ do ambiente é unitária. $O$ aquecimento desse “ambiente" é decorrente das parcelas $\left(1-\phi_{f}\right)$, radiação das aberturas, e $\left(1-\varepsilon_{z}\right)$, radiação das chamas, que não foram transferidas diretamente ao elemento por meio de $\dot{h}_{r z}$ e $\dot{h}_{r f}$.

$\dot{h}_{a b s}=\frac{M_{a} c_{a}}{u_{a}} \frac{d\left(\theta_{a}+273,15\right)}{d t}$ é o calor absorvido pelo elemento de aço na unidade de tempo por unidade de área superficial. Onde: $M_{a}$ é a massa por unidade de comprimento $(\mathrm{kg} / \mathrm{m}) ; c_{a}$ é o calor específico do aço $\left(\mathrm{kJ} / \mathrm{kg}^{\circ} \mathrm{C}\right) ; u_{a}$ é o perímetro da seção transversal do elemento de aço (m).

A massa por unidade de comprimento, $M_{a}$, dividida pelo perímetro, $u_{a}$, fornece a massa por unidade de área superficial. Substituindo $M_{a}$ por $m_{a} / L$ e considerando a massa do aço como sendo o produto da massa específica pelo volume, $m_{a}=\rho_{a} V$, obteremos $\left(\rho_{a} c_{a} V / A_{\text {lateral }}\right) d \theta_{a} / d t$. A divisão da área superficial pelo volume aquecido, $A_{\text {lateral }} / V$, nos fornece o fator de massividade, $F$, do elemento estrutural. O fluxo de calor por unidade de área absorvido passa a ser escrito como $\dot{h}_{a b s}=\frac{\rho_{a} c_{a}}{F} \frac{d\left(\theta_{a}+273,15\right)}{d t}$.

$\dot{h}_{\text {perd }}$ representa a intensidade de calor perdido por condução distante da área aquecida, que será desprezada, a favor da segurança. 
Substituindo-se os termos da eq. 5.1, tem-se a eq. 5.2.

$$
\begin{gathered}
\alpha_{z}\left[\left(\theta_{z}+273,15\right)-\left(\theta_{a}+273,15\right)\right]+\phi_{z} \varepsilon_{z} \varepsilon_{a} \sigma\left[\left(\theta_{z}+273,15\right)^{4}-\left(\theta_{a}+273,15\right)^{4}\right]+ \\
+\phi_{f} \varepsilon_{f} \varepsilon_{a}\left(1-\varepsilon_{z}\right) \sigma\left[\left(\theta_{g}+273,15\right)^{4}-\left(\theta_{a}+273,15\right)^{4}\right]+ \\
\quad \\
+\left(1-\phi_{f}\right) \varepsilon_{a}\left(1-\varepsilon_{z}\right) \sigma\left[\left(\theta_{o}+273,15\right)^{4}-\left(\theta_{a}+273,15\right)^{4}\right]=\frac{\rho_{a} c_{a}}{F} \frac{d\left(\theta_{a}+273,15\right)}{d t}
\end{gathered}
$$

Admitindo-se $\varepsilon_{a}=1, \varepsilon_{f}=1$ e $\phi_{z}=1$ (devido ao aço estar imerso nas chamas) e considerando o termo $\sigma\left(\theta_{o}+273,15\right)^{4}$, um valor muito pequeno em relação a $\sigma\left(\theta_{a}+273,15\right)^{4}$, resulta a eq. 5.3, que, simplificada, torna-se a eq. 5.4.

$$
\begin{gathered}
\alpha_{z}\left[\left(\theta_{z}+273,15\right)-\left(\theta_{a}+273,15\right)\right]+\varepsilon_{z} \sigma\left[\left(\theta_{z}+273,15\right)^{4}-\left(\theta_{a}+273,15\right)^{4}\right]+ \\
+\phi_{f} \varepsilon_{f}\left(1-\varepsilon_{z}\right) \sigma\left[\left(\theta_{g}+273,15\right)^{4}-\left(\theta_{a}+273,15\right)^{4}\right]+ \\
+\left(1-\phi_{f}\right) \varepsilon_{a}\left(1-\varepsilon_{z}\right) \sigma\left[-\left(\theta_{a}+273,15\right)^{4}\right]=\frac{\rho_{a} c_{a}}{F} \frac{d\left(\theta_{a}+273,15\right)}{d t} \\
\begin{array}{r}
\alpha_{z}\left[\left(\theta_{z}+273,15\right)-\left(\theta_{a}+273,15\right)\right]+\varepsilon_{z} \sigma\left(\theta_{z}+273,15\right)^{4}+\phi_{f} \varepsilon_{f}\left(1-\varepsilon_{z}\right) \sigma\left(\theta_{g}+273,15\right)^{4}- \\
-\sigma\left(\theta_{a}+273,15\right)^{4}=\frac{\rho_{a} c_{a}}{F} \frac{d\left(\theta_{a}+273,15\right)}{d t}
\end{array}
\end{gathered}
$$

Ao considerar a condição de estado estacionário, obtém-se $\theta_{g}$ constante e igual ao seu valor máximo representado pela eq. 5.37 (item 5.3.2 desta Tese). Nessa condição, o lado direito da eq. 5.4 é igual a zero visto que $d \theta_{a} / d t=0$, ou seja, a temperatura do elemento estrutural não varia com o tempo. Na prática, as condições de estado estacionário podem não ser atingidas, mas, se tais condições forem assumidas, será calculada a temperatura máxima do aço a favor da segurança. 


$$
\begin{array}{r}
\alpha_{z}\left[\left(\theta_{z}+273,15\right)-\left(\theta_{a}+273,15\right)\right]+\varepsilon_{z} \sigma\left(\theta_{z}+273,15\right)^{4}+\phi_{f}\left(1-\varepsilon_{z}\right) \sigma\left(\theta_{g}+273,15\right)^{4}- \\
-\sigma\left(\theta_{a}+273,15\right)^{4}=0
\end{array}
$$

Considerando que a emissividade da chama $\left(\varepsilon_{z}\right)$ possui o mesmo valor que a absortividade da chama $\left(a_{z}\right)$ e reordenando a eq. 5.5, tem-se, finalmente, a eq. 5.6, que é a expressão recomendada pelo Eurocode 3, Part 1-2 (2003).

$$
\begin{aligned}
\sigma\left(\theta_{a}+273,15\right)^{4}+\alpha_{z}\left(\theta_{a}+273,15\right)=\varepsilon_{z} \sigma\left(\theta_{z}\right. & +273,15)^{4}+ \\
& +\phi_{f}\left(1-a_{z}\right) \sigma\left(\theta_{g}+273,15\right)^{4}+\alpha_{z}\left(\theta_{z}+273,15\right)
\end{aligned}
$$

Sendo:

$\alpha_{z} \quad$ o coeficiente de convecção da chama, determinado conforme eq. 5.19 (item 5.2.3 desta Tese);

$\varepsilon_{z} \quad$ a emissividade da chama, determinada conforme eq. 5.24 (item 5.2.4 desta Tese);

$\theta_{g} \quad$ a temperatura dos gases dentro do compartimento, determinada pela eq. 5.37 (item 5.3.2 desta Tese);

$\theta_{z} \quad$ a temperatura da chama, determinada conforme eq. 5.75 (item 5.5.1 desta Tese);

$\phi_{f} \quad$ o fator de configuração, determinado conforme item 5.7 desta Tese.

\subsubsection{Elemento não envolvido pela chama}

Quando a superfície do aço estiver fora do fluxo convectivo da chama e dos gases quentes, ou seja, quando o elemento estrutural não estiver envolvido pela chama, o equilíbrio térmico é determinado pela mesma eq. 5.1, com as seguintes modificações (figura 5.3): 


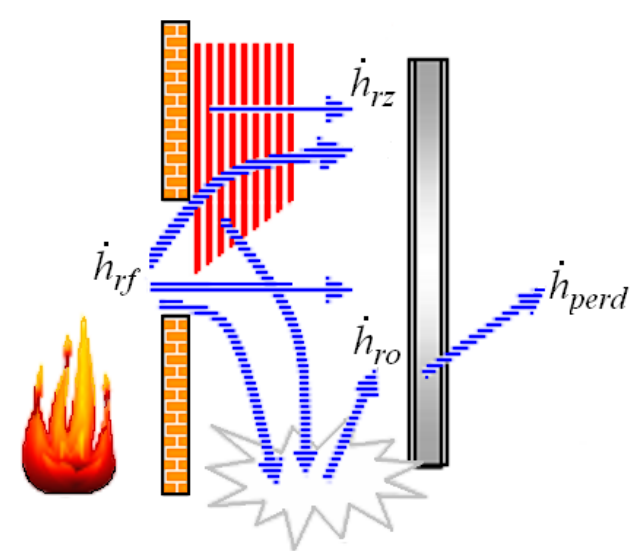

Figura 5.3 - Fluxo de calor para perfil de aço fora da chama.

Sendo:

$\dot{h}_{c z}=0$, pois o elemento de aço está fora da chama;

$\dot{h}_{\text {perd }}=\alpha_{a}\left[\left(\theta_{a}+273,15\right)-\left(\theta_{o}+273,15\right)\right]$ representa o fluxo de calor perdido pelo aço por convecção e segundo Law (1978), pode ser tomado como sendo $\alpha_{z}\left[\left(\theta_{a}+273,15\right)-\left(\theta_{o}+273,15\right)\right]$;

Admitindo-se $\varepsilon_{a}=1, \varepsilon_{f}=1$ e considerando o termo $\sigma\left(\theta_{o}+273,15\right)^{4}$, um valor muito pequeno em relação a $\sigma\left(\theta_{a}+273,15\right)^{4}$, tem-se a eq. 5.7, que, rearranjada, resulta na eq. 5.8, que é a expressão recomendada pelo Eurocode 3, Part 1-2 (2003).

$$
\begin{gathered}
\varepsilon_{z} \phi_{z} \sigma\left(\theta_{z}+273,15\right)^{4}+\phi_{f} \sigma\left(\theta_{g}+273,15\right)^{4}-\sigma\left(\theta_{a}+273,15\right)^{4}- \\
-\alpha_{z}\left[\left(\theta_{a}+273,15\right)-\left(\theta_{o}+273,15\right)\right]=0 \\
\sigma\left(\theta_{a}+273,15\right)+\alpha_{z}\left(\theta_{a}+273,15\right)=\varepsilon_{z} \phi_{z} \sigma\left(\theta_{z}+273,15\right)^{4}+\phi_{f} \sigma\left(\theta_{g}+273,15\right)^{4}+293 \alpha_{z}
\end{gathered}
$$




\subsubsection{Convecção das chamas e dos gases quentes}

Antes dos cálculos serem realizados, é necessário calcular a velocidade da chama com a finalidade de determinar $\alpha_{z}$ para a transferência de calor por convecção. $\mathrm{O}$ coeficiente de transferência de calor por convecção, $\alpha_{z}$, depende do fluxo de massa do gás por unidade de área, $u_{z} \rho_{z}$, dos gases quentes e do tamanho e da orientação da superfície receptora; pode ser obtido das relações entre o número de Nusselt, $N_{u}$, mostrado na eq. 5.9 e o número de Reynolds, $R_{e}$, mostrado na eq. 5.10. O item 3.4.2 desta Tese, comenta sobre a relação existente entre o número de Nusselt e o número de Reynolds.

$$
\begin{gathered}
N u=\frac{\alpha_{z} d}{\lambda_{z}} \\
\operatorname{Re}=\frac{u_{z} \rho_{z} d}{\mu_{z}}
\end{gathered}
$$

Onde:

$$
\begin{aligned}
& u_{z} \quad \text { é a velocidade do gás }(\mathrm{m} / \mathrm{s}) ; \\
& d \quad \text { é o comprimento característico da superfície }(\mathrm{m}) ; \\
& \lambda_{z} \quad \text { é a condutividade térmica do gás }\left(\mathrm{kW} / \mathrm{m}^{\circ} \mathrm{C}\right) ; \\
& \rho_{z} \quad \text { é densidade do gás }\left(\mathrm{kg} / \mathrm{m}^{3}\right) ; \\
& \mu_{z} \quad \text { é a viscosidade do gás }(\mathrm{kg} / \mathrm{ms}) .
\end{aligned}
$$

As propriedades térmicas do gás são definidas à temperatura da camada-limite, ou seja, no meio da temperatura entre o gás quente e a superfície. Incropera et al. (2008) mostrou na tabela 5.1 as correlações entre os números de Nusselt e Reynolds para um prisma reto com escoamento cruzado, ou seja, perpendicular à superfície.

De acordo com Incropera et al. (2008), a eq. 5.11 é amplamente utilizada para $\operatorname{Pr} \geq 0,7$. O número de Prandtl, Pr, é o parâmetro que relaciona as espessuras relativas das camadas limites hidrodinâmica e térmica, conforme item 3.5.2 desta Tese. 


$$
\bar{N} u_{d} \equiv \frac{\alpha_{z} d}{\lambda_{z}}=C \operatorname{Re}_{d}^{m} \operatorname{Pr}^{1 / 3}
$$

Onde:

$\alpha_{z} \quad$ é o coeficiente de transferência de calor por convecção da chama $\left(\mathrm{kW} / \mathrm{m}^{2{ }^{\circ}} \mathrm{C}\right)$;

C é uma constante adimensional;

$m \quad$ é uma constante adimensional.

Tabela 5.1 - Constantes da eq. 5.11 para cilindros não-circulares em escoamento cruzado de um gás (INCROPERA et al., 2008).

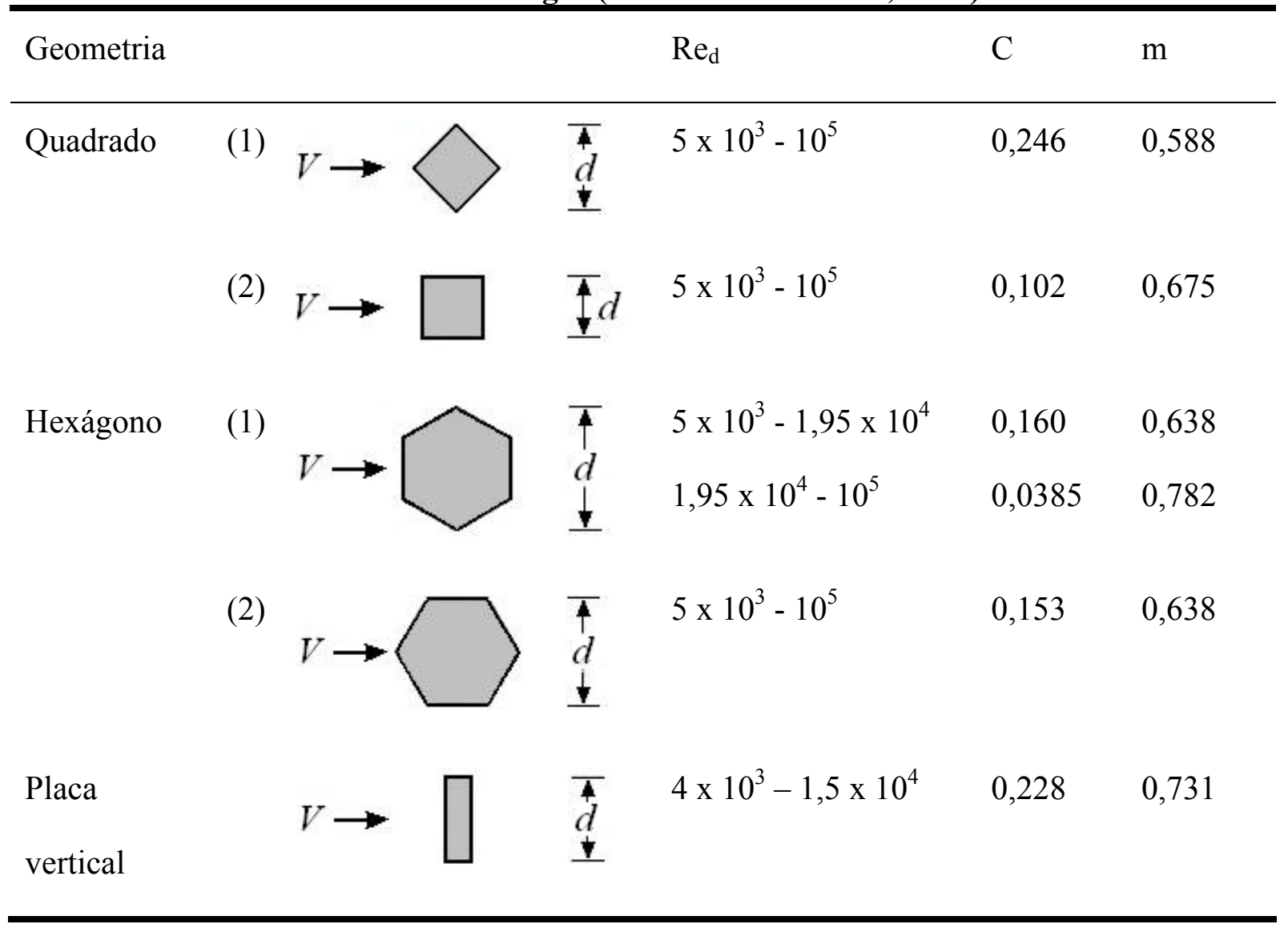

Law (1978) comenta que um fluxo de calor incidente a $45^{\circ}$ sobre um tronco de prisma de seção transversal quadrada possui a constante " $C$ " da eq. 5.11 como sendo 0,24 e $\operatorname{Pr}=1,0$, adequados tanto a pilares como a vigas, obtendo a eq. 5.12. 
Ao se observar a primeira linha da tabela 5.1 (INCROPERA, 2008) verifica-se sua compatibilidade com a relação proposta por Law.

$$
N u=0,24 \mathrm{Re}^{0,6}
$$

Para ventilação natural, uma das hipóteses do método é admitir que a transferência de calor por convecção somente ocorre nas estruturas imersas nas chamas. Foi considerado para essa situação que o fluxo de massa por unidade de área é aproximadamente o mesmo que o da abertura. O fluxo de massa que sai pela abertura do compartimento depende dos processos pelo qual o ar é movimentado no incêndio.

Ao analisar experimentos em escala natural, Law considerou o fluxo de massa por unidade de área determinado pela eq. 5.13, desde que o plano neutro (fronteira entre os fluxos de gás quente saindo do compartimento e ar frio entrando) sobre o qual as chamas e os gases quentes deixam o compartimento seja aproximadamente $2 h / 3$ abaixo do topo da janela.

$$
u_{z} \rho_{z} \cong 9,6 \frac{\dot{m}}{A_{v}}
$$

Onde:

$\dot{m} \quad$ é a taxa de liberação de massa do combustível $(\mathrm{kg} / \mathrm{s})$

$A_{v} \quad$ é a área da janela $\left(\mathrm{m}^{2}\right)$.

O número de Reynolds é obtido aplicando-se a eq. 5.13 na eq. 5.10 obtendo-se a eq. 5.14 .

$$
R_{e}=\frac{9,6 \dot{m} d}{A_{v} \mu_{z}}
$$

Ao se combinar as eq. 5.12 e 5.14, tem-se a eq. 5.15 .

$$
\alpha_{z}=0,93 \lambda_{z}\left[\frac{\dot{m}}{\mu_{z} A_{v}}\right]^{0,6}\left[\frac{1}{d}\right]^{0,4}
$$


Sendo o valor do coeficiente de transferência de calor por convecção, $\alpha_{z}$, pouco sensível à temperatura, foi adotado um valor representativo a uma temperatura de $732^{\circ} \mathrm{C}$. Dessa forma a eq. 5.15 tornar-se a eq. 5.16 .

$$
\alpha_{z}=0,026\left[\frac{\dot{m}}{A_{v}}\right]^{0,6}\left[\frac{1}{d}\right]^{0,4}
$$

Para a situação do incêndio em condição de queima-livre, a eq. 5.16 superestima o valor de $\alpha_{z}$ e o seu uso conduz a uma solução ligeiramente conservadora.

Para incêndio com ventilação forçada, o fluxo de massa do gás quente incluirá o ar provido e emergirá pela área inteira da janela. Por meio de análises experimentais, Law (1978) estabeleceu que o coeficiente de transferência de calor da chama será dado pela eq. 5.17 ou pela eq. 5.18.

$$
\alpha_{z}=0,24 \lambda_{z}\left[\frac{\dot{m}}{\mu_{z} A_{v}}+\frac{u_{z} \rho_{z}}{\mu_{z}}\right]^{0,6}\left[\frac{1}{d}\right]^{0,4}
$$

ou

$$
\alpha_{z}=0,0065\left[\frac{\dot{m}}{A_{v}}+1,3 u_{z}\right]^{0,6}\left[\frac{1}{d}\right]^{0,4}
$$

O Eurocode 1, Part 1-2 (2002), estabelece para o valor de $\alpha_{z}$ a eq. 5.19.

$$
\alpha_{z}=0,0098\left[\frac{\dot{m}}{A_{v}}+\frac{u_{z}}{1,6}\right]^{0,6}\left[\frac{1}{d}\right]^{0,4}
$$

Quando a estrutura de aço estiver distante da chama, ela perderá calor por convecção natural, conforme as eq. 5.20 e 5.21 .

- Para pilares:

$$
\alpha_{a}=0,0014\left(\frac{\theta_{a}-\theta_{o}}{d}\right)^{0,25}
$$

- Para vigas, a constante da eq. 5.20 tem valor 0,0012 .

Quando $d$ exceder 0,30m:

$$
\alpha_{a}=0,002\left(\theta_{a}-\theta_{o}\right)^{0,25}
$$

Onde $\alpha_{a}$ é o coeficiente de transferência de calor do aço $\left(\mathrm{kW} / \mathrm{m}^{2 \mathrm{o}} \mathrm{C}\right)$. 


\subsubsection{Radiação das chamas}

Law (1978) considerou que a emissividade da chama, $\varepsilon_{z}$, depende da espessura da chama, $\lambda$, e pode ser considerada conforme a eq. 5.22.

$$
\varepsilon=1-e^{-b \lambda}
$$

Segundo Beyreis et al. apud Law (1978), o valor de $b$, na eq. 5.22, para chamas provenientes da combustão da madeira dentro de um compartimento, pode ser adotado igual a $0,518 \mathrm{~m}^{-1}$. Esse valor é mais elevado do que o proposto por Seigel para chamas fora do compartimento ou por Heselden, que sugere um valor aproximado de $0,30 \mathrm{~m}^{-1}$.

Helseden apud Law (1978) realizou medições diretas do fluxo de calor das chamas que emergem das aberturas. O experimento foi realizado em escala natural, em Borehamwood (cidade do sudoeste do condado de Hertfordshire, ao norte de Londres), onde um medidor de fluxo de calor foi colocado na parede a uma altura de $0,55 \mathrm{~m}$ acima do topo da janela. Ele considerou o valor medido do fluxo de calor por unidade de área devido à radiação, $\dot{h}_{z}$, e negligenciou a transferência por convecção, que era pequena.

$$
\dot{h}_{z} \cong \varepsilon_{z} \sigma\left(\theta_{z}+273,15\right)^{4}
$$

Os valores de $\dot{h}_{z}$ a $0,55 \mathrm{~m}$ acima do topo da janela foram calculados e apresentados na figura 5.4 em função de $\sigma\left(\theta_{z}+273,15\right)^{4}$.

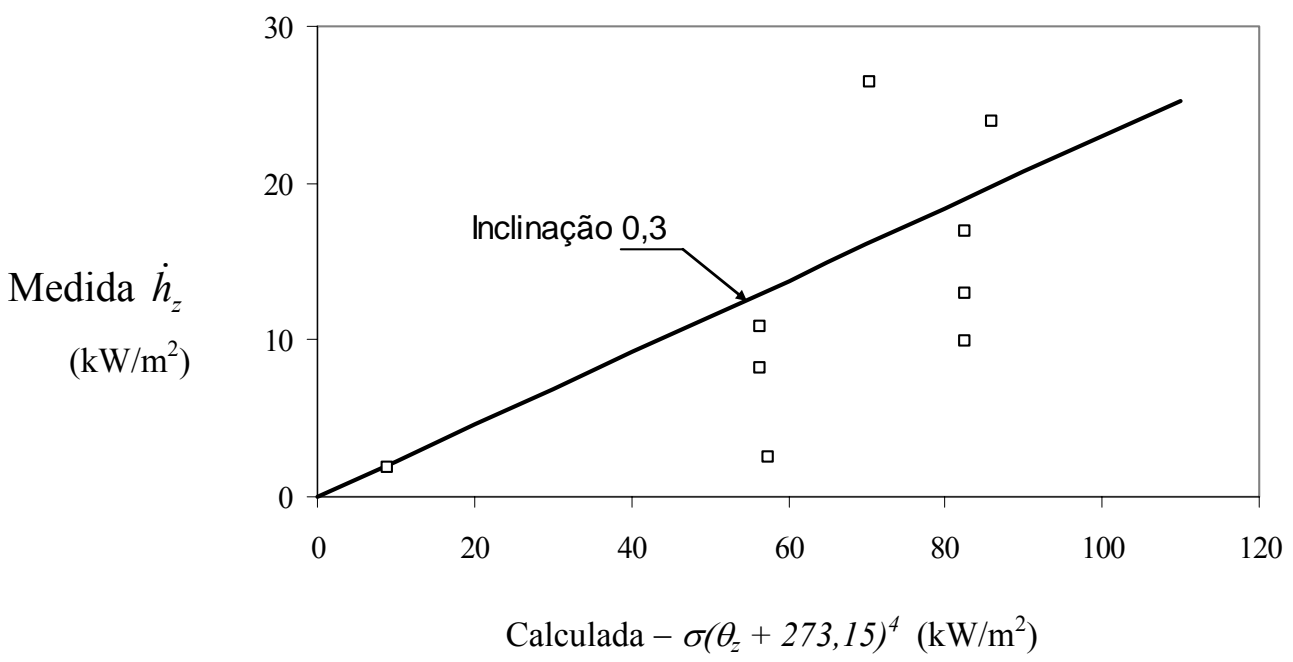

Figura 5.4 - Fluxo de calor por unidade de área devido à radiação das chamas acima da janela, com experimentos em escala natural, realizados em Borehamwood, comparado com a fluxo de calor por radiação calculada para a emissividade completa das chamas (LAW, 1978). 
$\mathrm{Na}$ figura 5.4, o coeficiente angular da reta indica a emissividade da chama, $\varepsilon_{z}$. O valor de 0,3 foi adotado por Seigel em função dos dados obtidos por meio de experimentos, em escala natural, em Borehamwood. Para generalizar o resultado, $\lambda=2 h / 3$ é substituído na eq. 5.22 e dá um valor para $b$ de, aproximadamente, $0,30 \mathrm{~m}^{-1}$, valor sugerido por Heselden. Utilizando o valor sugerido por Beyreis et al., resulta-se em $\varepsilon_{z}=0,47$, que é considerado elevado. Consequentemente, dentro das suposições feitas, é recomendado para as chamas que emergem das janelas, que a emissividade da chama seja determinada conforme a eq. 5.24.

$$
\varepsilon_{z}=1-e^{-0,30 \lambda}
$$

O cálculo detalhado da emissividade aplicado ao método de Margaret Law pode ser encontrado em Azevedo (2005).

Se a superfície estiver envolvida pela chama, a temperatura média radiante pode ser a temperatura local da chama ou a temperatura média entre as diversas temperaturas da chama, de acordo com as circunstâncias.

Para a ventilação forçada, uma face do pilar pode "enxergar" a espessura da chama, que varia com a temperatura local, $\theta_{\ell}$, até o valor da temperatura na superfície plana da janela, $\theta_{w}$. Uma outra face pode "enxergar" uma espessura da chama que varia de $\theta_{\ell}$ até o valor da temperatura no topo da chama, $\theta_{x}$. Utilizando uma suposição conservadora, o valor de $\theta_{z}$ pode ser tomado como o valor local ou o valor mais distante, o que for maior.

Quando uma superfície do elemento estrutural não é envolvida pela chama, ela pode "enxergar" a frente da chama, que varia a temperatura de $\theta_{w}$ na base para $\theta_{x}$ no topo.

A uma distância grande, a temperatura média radiante, $\theta_{z}$, pode ser calculada conforme eq. 5.25 , ou seja, é a média entre a quarta potência da temperatura, em kelvin, da chama na janela e a quarta potência da temperatura no topo da chama.

$$
\left(\theta_{z}+273,15\right)^{4}=\frac{\left(\theta_{w}+273,15\right)^{4}+\left(\theta_{x}+273,15\right)^{4}}{2}
$$

Próximo à frente da chama, a temperatura média radiante para o ponto na superfície que recebe a taxa máxima de calor é dada pela eq. 5.26. A temperatura média radiante da chama é aproximadamente a temperatura média na janela. 


$$
\left(\theta_{z}+273,15\right)^{4} \cong\left(\theta_{w}+273,15\right)^{4}
$$

Para incêndios com ventilação forçada, de acordo com Law (1978), a eq. 5.26 é uma razoável aproximação para a maioria das situações de interesse prático.

Para incêndios com ventilação natural, a radiação é recebida principalmente pela parte da chama que fica acima da janela, a porção abaixo é menor, menos significativa. A temperatura média radiante, $\theta_{z}$, para uma grande distância da frente da chama a um ponto na superfície do elemento estrutural é dada pela eq. 5.27.

$$
\left(\theta_{z}+273,15\right)^{4} \cong \frac{\left(\theta_{o w}+273,15\right)^{4}+\left(\theta_{x}+273,15\right)^{4}}{2}
$$

Onde:

$\theta_{o w} \quad$ é a temperatura da chama no topo da janela $\left({ }^{\circ} \mathrm{C}\right)$;

$\theta_{x} \quad$ é a temperatura no topo da chama $\left({ }^{\circ} \mathrm{C}\right)$.

Próximo à frente da chama, a temperatura devido à radiação em um ponto da superfície do elemento recebe a taxa máxima de calor e a temperatura da chama pode ser dada conforme a eq. 5.28 .

$$
\left(\theta_{z}+273,15\right)^{4} \cong\left(\theta_{o w}+273,15\right)^{4}
$$

De acordo com Law (1978), a eq. 5.28 é uma aproximação razoável para a maioria das situações de interesse prático para incêndios com ventilação natural.

Os valores medidos da radiação da chama e da janela foram realizados por meio de radiômetro, em modelo de incêndio em escala natural, conforme figura 5.5. 

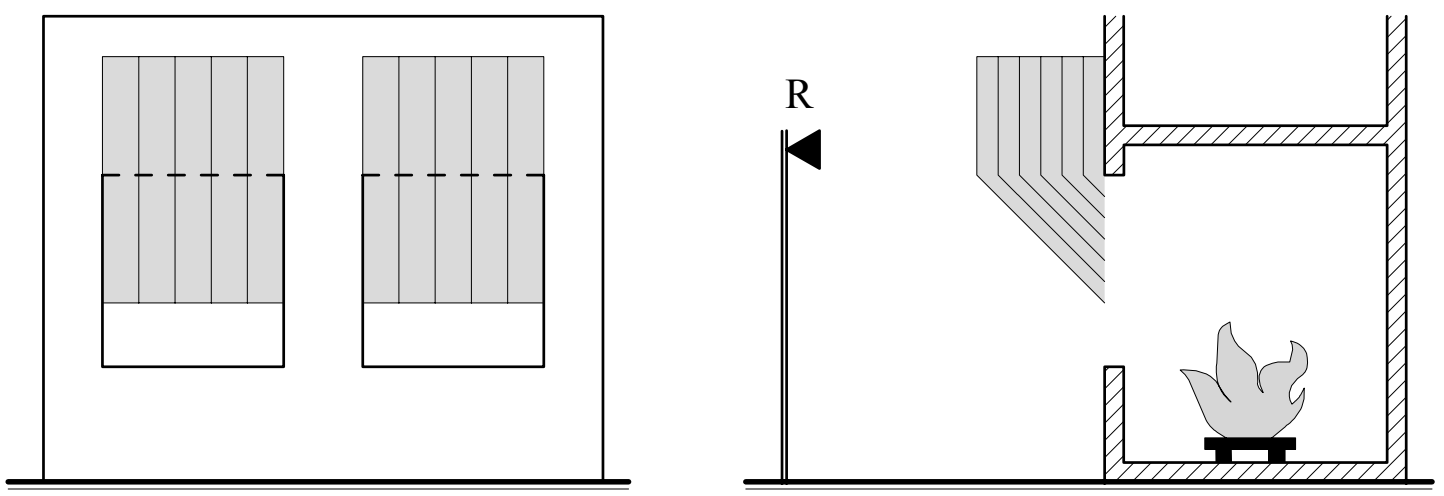

$\mathrm{R}=$ Radiômetro

Figura 5.5 - Experiência utilizando radiômetro, modelo em escala natural, em Borehamwood (LAW, 1978).

Na figura 5.6, são comparados os valores medidos do fluxo de calor por radiação proveniente das janela e da chama que emerge, com ventilação natural, aos valores calculados pelo método descrito. Os valores que estiverem acima da curva estão a favor da segurança. A comparação mostra que os cálculos tendem a superestimar a intensidade da radiação recebida, mas de forma aceitável.

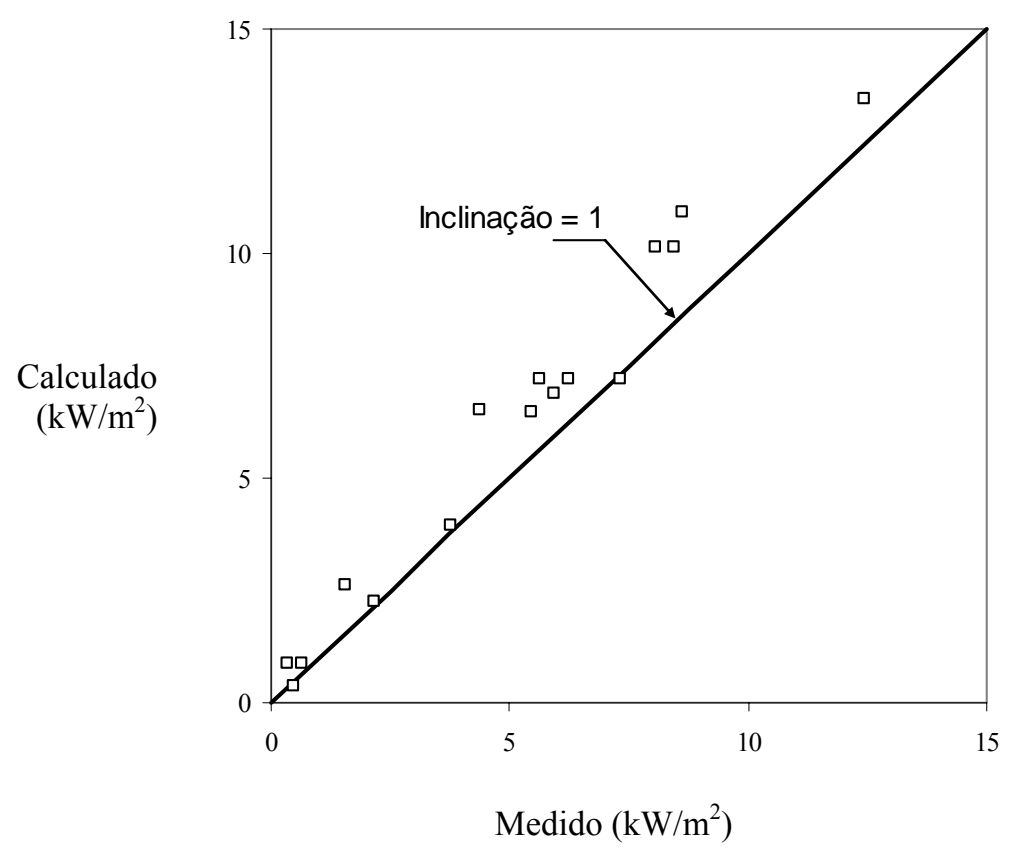

Figura 5.6 - Soma da radiação da janela e da chama recebida por um radiômetro a 4,5m ou $6 \mathrm{~m}$ de distância, com experimentos em escala natural em borehamwood (LAW, 1978). 


\subsection{O INCÊNDIO NO INTERIOR DO COMPARTIMENTO}

O incêndio dentro do compartimento compreende, de forma simplificada, três fases: aquecimento, combustão generalizada e resfriamento. Os maiores danos estruturais ocorrem durante o período de combustão generalizada e essa fase foi estudada por um número considerável de pesquisadores. A análise do desenvolvimento completo do incêndio é complexa e os modelos desenvolvidos possuem simplificações, destacando-se que a distribuição da temperatura é considerada uniforme em todo o compartimento incendiado e o material combustível queima de maneira uniforme. Contudo, parâmetros importantes foram definidos e um substancial banco de dados passou a existir tornando possível mostrar como esses parâmetros interagem.

O pesquisador pioneiro nessa área foi Ingberg (1928) apud Law (1978) que relacionou a carga de incêndio específica (carga de incêndio por unidade de área de piso) e a severidade do incêndio, o que formou a base para o requerimento de tempo de resistência ao fogo para elementos estruturais. A importância da ventilação em termos de área e altura das aberturas na parede, geralmente janelas, foi quantificada por Fujita apud Law (1978).

Mais tarde, por meio de trabalhos de pesquisa realizados por Helseden (1972) apud Law (1978), com o apoio do Conseil International du Batiment (CIB), foi modificada a relação de Fujita a partir de parâmetros como tamanho e forma do compartimento incendiado. Foi utilizada uma carga de incêndio em madeira para representar mais facilmente o combustível, sendo os dados avaliados em função da mobília do compartimento.

A maioria dos experimentos foi realizada com ar estacionário ou condições brandas de ventilação, onde o escoamento de ar foi estabelecido pelo comportamento e desenvolvimento do incêndio e as dimensões do compartimento. Essa condição de vento é chamada de ventilação natural. Em alguns experimentos, foi incluído um suprimento extra de ar. Essa condição de vento é chamada de ventilação forçada. 


\subsubsection{Taxa de liberação de massa do combustível}

$\mathrm{Na}$ exposição da chama externa, as características mais importantes no desenvolvimento do incêndio no período de combustão generalizada são: a taxa de liberação de massa do combustível, que afeta o tamanho da chama que emerge para o exterior do compartimento e a duração do incêndio, e a temperatura do incêndio dentro do compartimento, que afeta a radiação proveniente da abertura.

Para a ventilação natural, segundo Heselden (1968) apud Law (1978), testes realizados sobre a carga de incêndio mostraram que a redução de massa na unidade de tempo é aproximadamente constante no período de combustão generalizada, quando a carga de incêndio cai de $80 \%$ para $30 \%$ de seu valor inicial. Essa taxa é definida como taxa de liberação de massa, $\dot{m}$, em $\mathrm{kg} / \mathrm{s}$, sendo definida pela eq. 5.29.

$$
\dot{m}=\frac{L}{\tau}
$$

Onde:

$L \quad$ é a massa total da carga de incêndio $(\mathrm{kg})$;

$\tau \quad$ é o tempo de duração do incêndio (s).

Em compartimentos com ampla ventilação, ou seja, em condição de queima-livre, o valor de $\tau$ passa a ser $\tau_{f}$, sendo determinado pelas características da carga de incêndio. A presença de materiais combustíveis, geometricamente esbeltos e com grande área superficial, reduz o tempo de duração do incêndio. Portanto, para qualquer tipo de material combustível, a taxa de liberação de massa do combustível, $\dot{m}$, é diretamente proporcional à carga de incêndio, $L$, conforme eq. 5.30 .

$$
\dot{m}=\frac{L}{\tau_{f}}
$$

Onde $\tau_{f}$ é o menor valor de duração do incêndio à queima-livre em segundos.

No Eurocode 1, Part 1-2 (2002), o termo utilizado $\tau_{f}$ tem o mesmo significado que o termo $t_{\text {lim. }}$. Ele estabelece valores limites para o tempo de duração do incêndio de acordo com a taxa de crescimento. Para incêndio onde a taxa de crescimento é lenta $t_{\text {lim }}=25$ minutos, para taxa 
de crescimento média $t_{l i m}=20$ minutos e para taxa de crescimento rápida $t_{l i m}=15$ minutos. Para a maioria da mobília encontrada nos edifícios, o valor de $t_{\text {lim }}$ pode ser adotado igual a 20 minutos.

$\mathrm{Na}$ condição de incêndio controlado pela ventilação, ou seja, quando as aberturas são pequenas em relação ao tamanho do compartimento e não fornecem ventilação suficiente para sustentar a taxa de liberação de massa, conforme eq. 5.30 (combustão controlada pelo combustível) é necessário estabelecer novos limites para essa taxa. Consideram-se parâmetros importantes para a análise do incêndio sob ventilação controlada: a área $\left(A_{v}\right)$ e a altura $(h)$ das janelas; a área total $\left(A_{t}\right)$ das superfícies fechadas do compartimento, excluíndo as janelas, para as quais o calor é perdido; e a razão entre a profundidade, $W_{2}$, e a largura, $W_{l}$, do compartimento, conforme a figura 5.7.

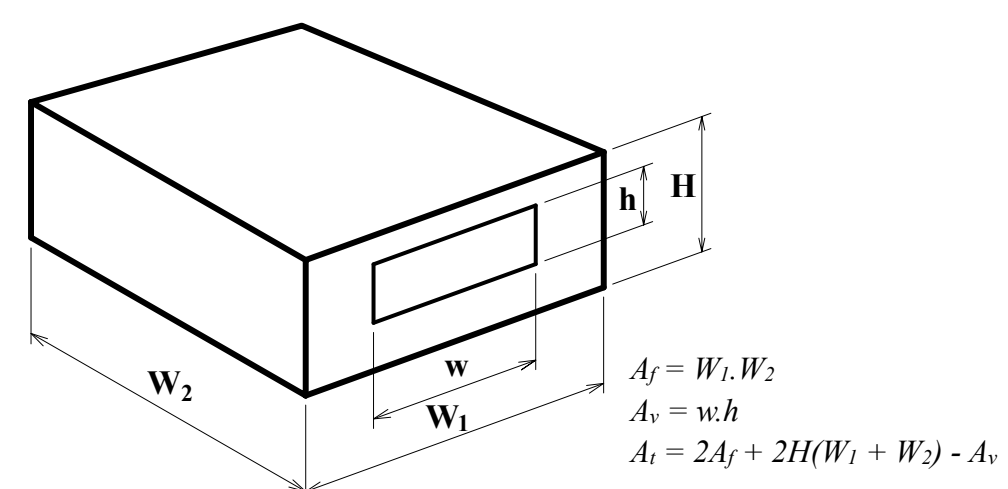

Figura 5.7 - Dimensões de um compartimento com uma abertura.

Thomas (1974) apud Law (1978) fornece uma correlação por intermédio de dados obtidos no CIB (Conseil International du Batiment), utilizando um compartimento com $50 \mathrm{~cm}, 100 \mathrm{~cm} \mathrm{e}$ altura de $150 \mathrm{~cm}$. Para as dimensões utilizadas no compartimento, Thomas modificou a eq. 5.31, estabelecida por Fujita, para a eq. 5.32.

$$
\dot{m}=0,0885 A_{v} h^{1 / 2}
$$

Os valores da taxa de liberação de massa, $\dot{m}$, medidos em situação de escala natural e ventilação controlada, como mostrado na figura 5.8, concordam de forma razoável com os dados do CIB. A linha traçada por Thomas é a melhor através dos pontos e pode ser representada pela eq. 5.32 .

$$
\dot{m}=\frac{0,18\left(1-e^{-0,036 \eta}\right)}{\left(W_{2} / W_{1}\right)^{1 / 2}} A_{v} h^{1 / 2}
$$


Sendo $\eta$ o inverso do grau de ventilação e calculado conforme a eq. 5.33.

$$
\eta=\frac{A_{t}}{A_{v} h^{1 / 2}}
$$

Para uma dada carga de incêndio e geometria do compartimento, a taxa de liberação de massa, $\dot{m}$, pode ser calculada por ambas as eq. 5.30 e 5.32. A eq. 5.30 é utilizada quando existe ventilação suficiente para ocorrer a combustão dependente do material combustível. Quando a combustão é limitada pela ventilação, utiliza-se a eq. 5.32.

Na prática, se a eq. 5.30 apresentar um valor menor do que a eq. 5.32, significa que há uma condição de queima-livre do combustível, caso contrário, será uma condição de ventilação controlada.

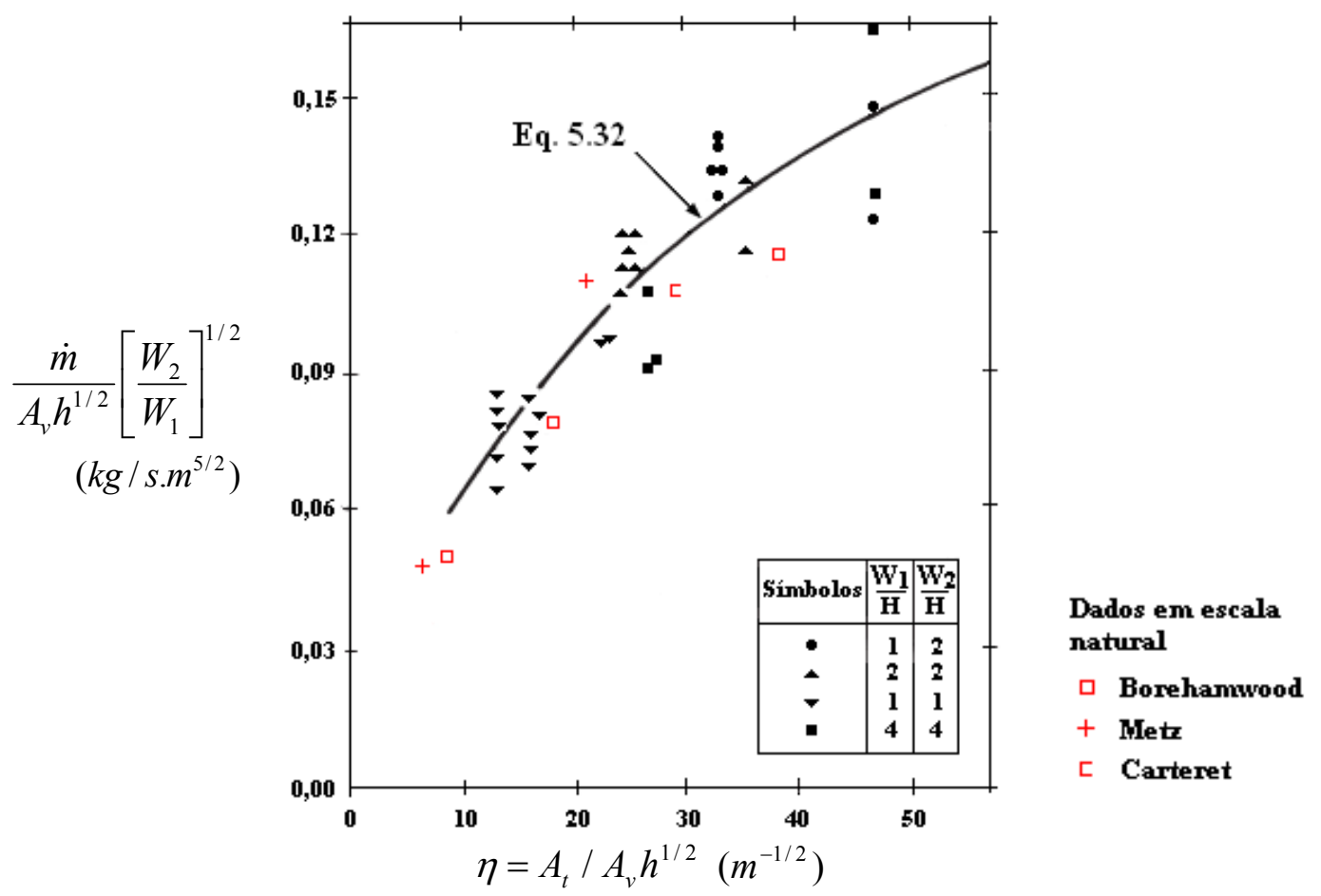

Figura 5.8 - Variação de $\dot{m} / A_{v} h^{1 / 2}$ com as dimensões do compartimento e a ventilação (LAW, 1978).

Para ventilação forçada, segundo Law (1978), não existe muita informação avaliada sobre os seus efeitos na taxa de liberação de massa. Observações feitas durante ensaios nos Laboratórios Underwriters, no entanto, indicam que o efeito máximo pode ser dado como condição de queima-livre, conforme eq. 5.30. 


\subsubsection{Temperatura dentro do compartimento}

A temperatura dentro do compartimento incendiado atinge um valor máximo que depende da carga de incêndio, das dimensões do compartimento e da ventilação. Thomas apud Law (1978) obteve a temperatura máxima de um incêndio após o flashover, no período de combustão generalizada, por meio de medidas realizadas no $\mathrm{CIB}$, em função de $\eta$, como mostrado na eq. 5.34 e na figura 5.9.

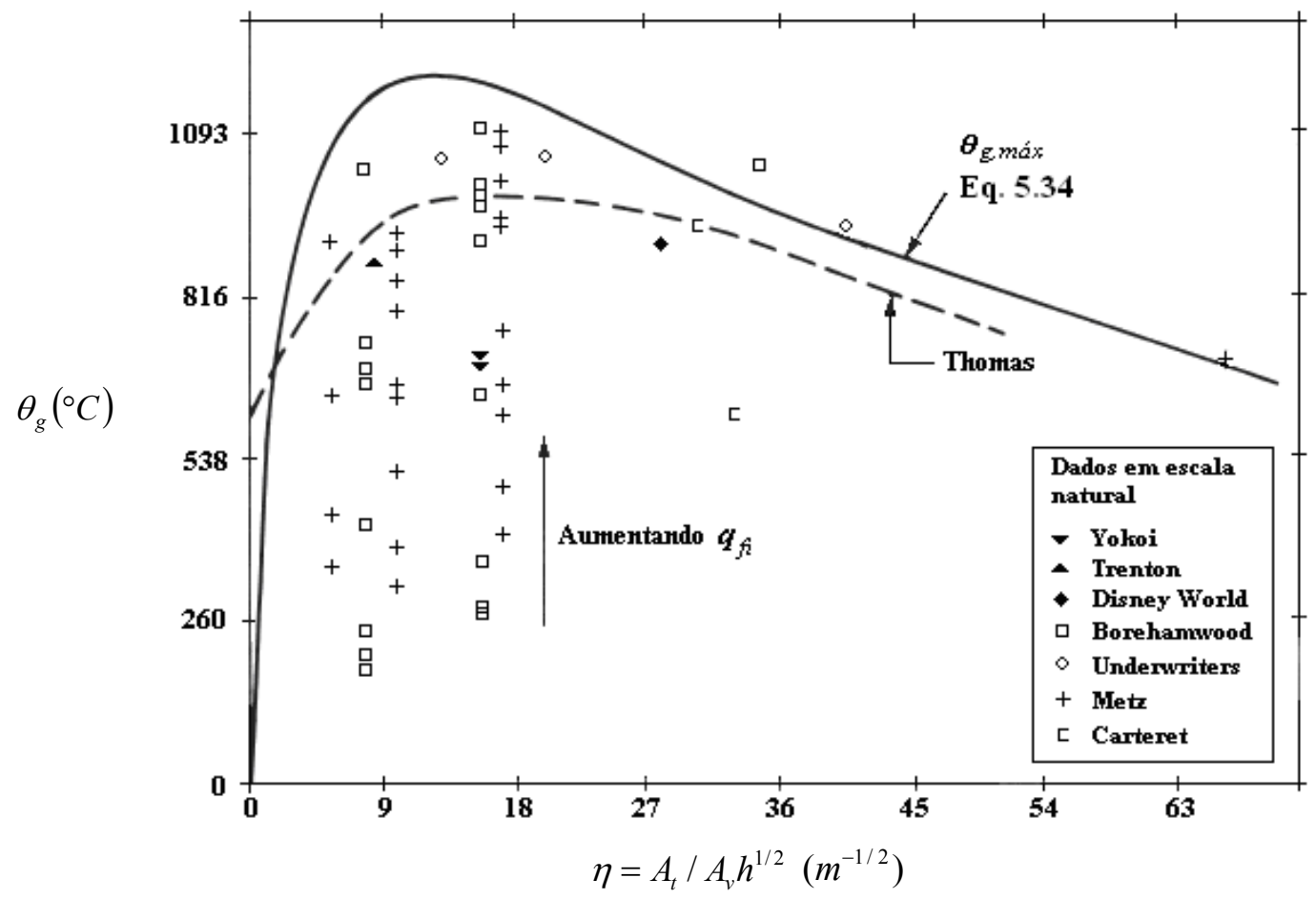

Figura 5.9 - Variação da temperatura de um incêndio com as dimensões do compartimento e a área de ventilação, considerando ventilação natural (LAW, 1978).

Uma informação importante sobre a figura 5.9 é que a temperatura dentro do compartimento se eleva a um valor máximo, para $\eta$ compreendido entre 9 e $18 \mathrm{~m}^{-1 / 2}$. A partir desse trecho, a curva declina. $\mathrm{O}$ valor de $\theta_{g \text {,máx }}$ também depende da carga de incêndio, conforme figura 5.9, onde os resultados obtidos por meio de ensaios em escala natural com baixa carga específica de incêndio ficam abaixo da curva de Thomas.

Admite-se que exista um limite superior ou um máximo valor de $\theta_{g}$ para um dado valor de $\eta$. Então foi proposta a eq. 5.34. 


$$
\theta_{g, \text { máx }}=6000 \frac{\left(1-e^{-0,1 \eta}\right)}{\eta^{1 / 2}}+\theta_{o}
$$

Onde:

$\theta_{o} \quad$ corresponde a temperatura ambiente, no Brasil se utiliza o valor de $20^{\circ} \mathrm{C}$;

$\eta \quad$ é o inverso do grau de ventilação, conforme eq. 5.33 .

Para cargas de incêndio com valores baixos, $\theta_{g, \text { máx }}$ não é alcançado. Conclui-se que a elevação da temperatura do elemento não é simplesmente devido à carga de incêndio específica, mas à carga de incêndio em relação à ventilação e às dimensões do compartimento.

Análises iniciais, tanto dos dados do CIB, quanto dos dados de ensaios em escala natural, mostraram que a eq. 5.35 é um parâmetro importante, que relaciona a carga total de incêndio com a área de ventilação e a área da superfície aquecida. Ele foi usado para modificar a eq. 5.34, no caso do valor máximo, como apresentado na eq. 5.36 e na figura 5.10.

$$
\begin{gathered}
\psi=\frac{L}{\left(A_{v} A_{t}\right)^{1 / 2}} \\
\frac{\theta_{g}-\theta_{o}}{\theta_{g, \text { max }}-\theta_{o}}=1-e^{-0,05 \psi}
\end{gathered}
$$

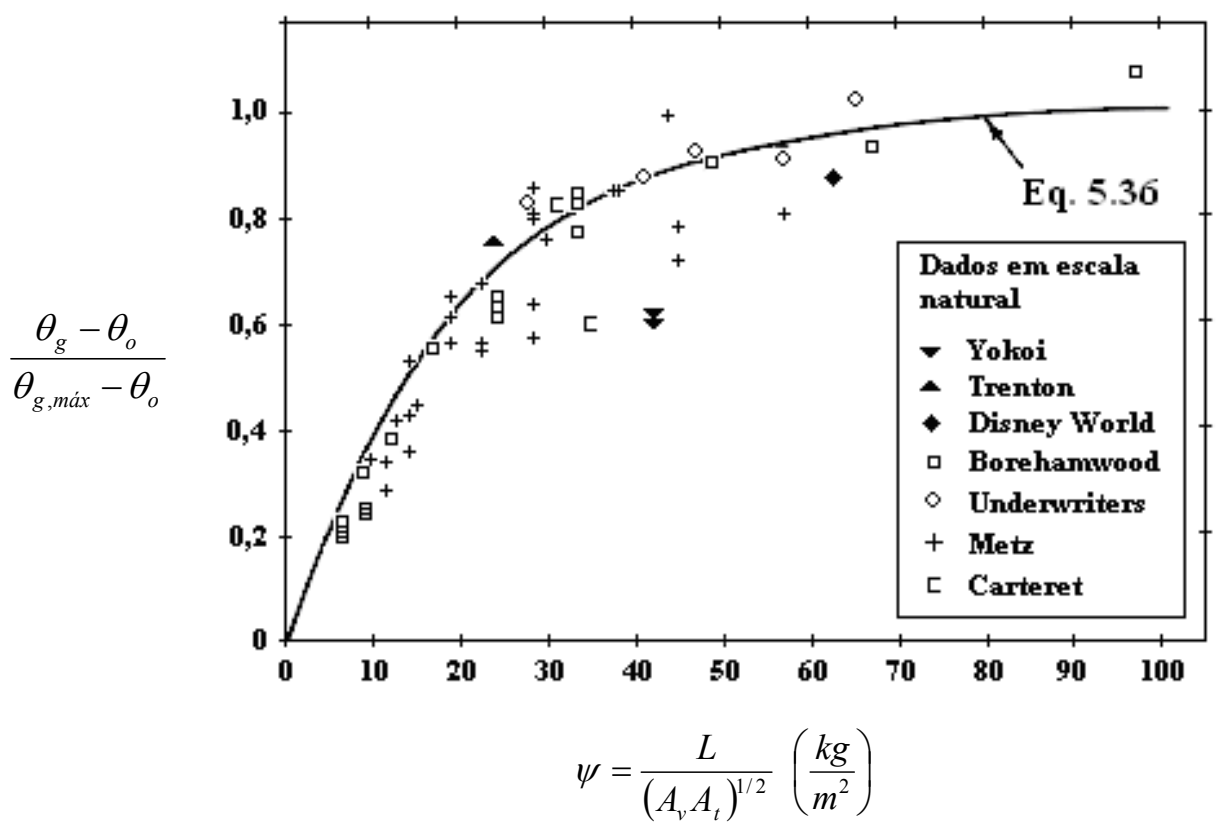

Figura 5.10 - Variação da temperatura com a carga de incêndio, as dimensões do compartimento e a área de ventilação. Ventilação natural (LAW, 1978). 
Ao se combinar as eq. 5.34 e 5.36, tem-se a eq. 5.37 .

$$
\theta_{g}=6000 \frac{\left(1-e^{-0,1 \eta}\right)}{\eta^{1 / 2}}\left(1-e^{-0,05 \psi}\right)+\theta_{o}
$$

Não existe muita informação sobre os efeitos da ventilação forçada na taxa de liberação de massa, mas observações feitas durante os ensaios nos Laboratórios Underwriters indicam, no entanto, que o efeito máximo pode ser obtido como se fosse condição de queima-livre, conforme a eq. 5.30. Os dados obtidos nos ensaios mostraram uma variação pouco significativa da temperatura em relação a $\eta$ ou com o suplemento extra de ar, mas $\theta_{g}$ pode ser relacionado com $\psi$, como mostra a figura 5.11. A curva obedece a eq. 5.38.

$$
\theta_{g}=1200\left(1-e^{-0,04 \psi}\right)+\theta_{o}
$$

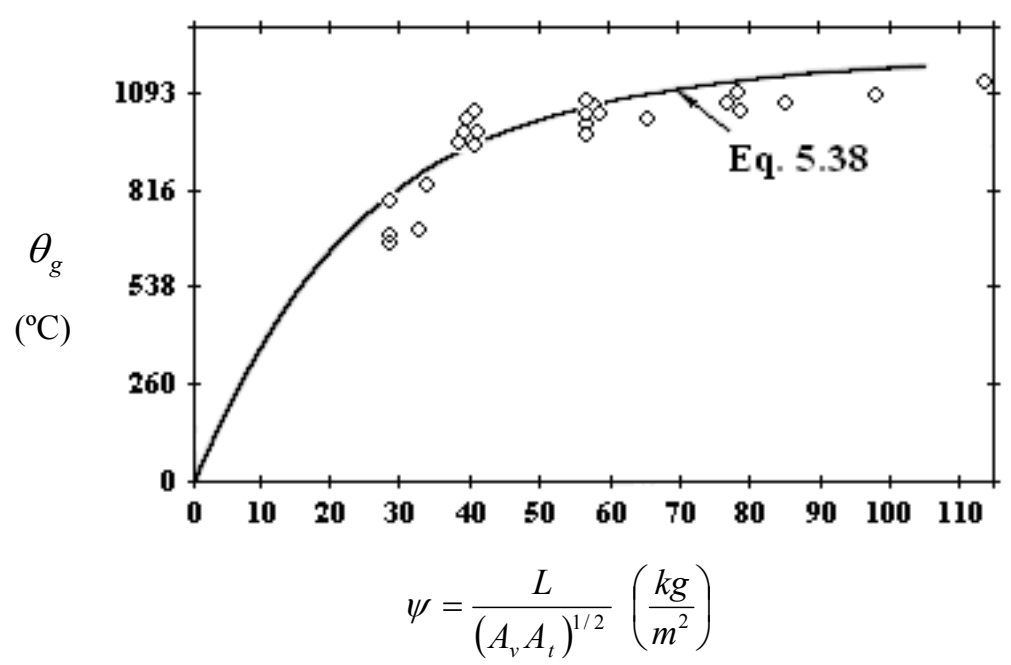

Figura 5.11 - Variação da temperatura com a carga de incêndio, as dimensões do compartimento e a área de ventilação. Ventilação forçada (Laboratórios Underwriters apud LAW, 1978).

Como pode ser observado na figura 5.11 o valor de $\theta_{g}$ decresce com a entrada de suplemento extra de ar. Nesse caso, a eq. 5.38 pode estar superestimando a temperatura do incêndio quando existe um vento forte. 


\subsubsection{O metodo de Law e a curva de incêndio natural}

Thomas apud Law (1978) obteve uma relação da temperatura máxima que um incêndio pode alcançar após o flashover, no período de combustão generalizada, em função do inverso do fator de ventilação, $\eta$, como mostrado na eq. 5.34. O termo $\eta$ é representado pela eq. 5.33.

As curvas temperatura-tempo naturais (item 3.3 desta Tese), recomendadas pelo Eurocode 1, part 1-2 (2002) dependem da ventilação, carga de incêndio e dos materiais de vedação do compartimento. A fim de comparar os resultados via Eurocode 1 e Thomas, utilizaram-se as características dos materiais apresentadas na tabela 5.2.

Tabela 5.2 - Propriedades dos elementos de vedação (ABNT NBR 14323:2003 e OZONE V2.0, 2001)

\begin{tabular}{c|c|c|c|c}
\hline Elemento & Característica & $\begin{array}{c}\text { Densidade } \\
\rho\end{array}$ & $\begin{array}{c}\text { Calor específico } \\
\mathrm{c} \\
\left(\mathrm{kg} / \mathrm{m}^{3}\right)\end{array}$ & $\begin{array}{c}\text { Condutividade } \\
(\mathrm{J} / \mathrm{kg} . \mathrm{K})\end{array}$ \\
\hline Piso & Concreto & 2400 & 1000 & $(\mathrm{~W} / \mathrm{m} . \mathrm{K})$ \\
\hline Teto & Concreto & 2400 & 1000 & 1,60 \\
Paredes* & Tijolo & 1600 & 840 & 1,60 \\
\hline
\end{tabular}

* Para a alvenaria foram adotados os parâmetros recomendados pelo código computacional OZONE V2.0 (2001).

A tabela 5.3 mostra a geometria do compartimento utilizado para a elaboração das figuras 5.12 a 5.14. Nessa tabela são apresentados os valores referentes ao inverso do grau de ventilação e ao fator térmico dos elementos de compartimentação. 
Tabela 5.3 - Geometria do compartimento, inverso do grau de ventilação e fator térmico dos elementos de compartimentação

\begin{tabular}{|c|c|c|c|c|c|c|c|c|c|}
\hline & \multicolumn{9}{|c|}{ Simulações } \\
\hline & 1 & 2 & 3 & 4 & 5 & 6 & 7 & 8 & 9 \\
\hline $\begin{array}{r}\text { Largura do } \\
\text { compartimento }(\mathrm{m})\end{array}$ & 4,00 & 4,00 & 4,00 & 8,00 & 8,00 & 10,00 & 10,00 & 10,00 & 10,00 \\
\hline $\begin{array}{l}\text { Profundidade do } \\
\text { compartimento (m) }\end{array}$ & 3,00 & 3,00 & 3,00 & 8,00 & 8,00 & 10,00 & 10,00 & 10,00 & 10,00 \\
\hline $\begin{array}{r}\text { Altura do } \\
\text { compartimento }(\mathrm{m})\end{array}$ & 2,80 & 2,80 & 2,80 & 3,00 & 3,00 & 3,00 & 3,00 & 3,00 & 3,00 \\
\hline $\begin{array}{r}\text { Altura das janelas } \\
(\mathrm{m})\end{array}$ & 2,00 & 1,50 & 1,50 & 1,50 & 1,50 & 1,50 & 1,50 & 1,50 & 1,50 \\
\hline $\begin{array}{r}\text { Largura das janelas } \\
\text { (m) }\end{array}$ & 7,00 & 6,00 & 3,00 & 6,00 & 4,00 & 4,50 & 3,80 & 3,10 & 2,65 \\
\hline$\eta\left(\mathrm{m}^{-1 / 2}\right)$ & 2,485 & 4,917 & 10,651 & 19,505 & 29,666 & 37,891 & 45,022 & 55,373 & 64,914 \\
\hline$\sqrt{\rho c \lambda}\left(\mathrm{J} / \mathrm{m}^{2} \mathrm{~s}^{1 / 2 \mathrm{o}} \mathrm{C}\right)$ & 1453 & 1408 & 1375 & 1559 & 1551 & 1602 & 1600 & 1598 & 1596 \\
\hline
\end{tabular}

A eq. 5.34, proposta por Thomas, não considera a carga de incêndio. Para fins de comparação, adotaram-se os valores de carga de incêndio, indicados na tabela 5.4, para determinação da temperatura máxima do incêndio natural. Admitiu-se que o valor de cálculo da carga de incêndio coincide com o valor característico. Os resultados são apresentados na figura 5.12.

Tabela 5.4 - Cargas de incêndio específicas (ABNT NBR 14432:2000)

\begin{tabular}{l|c}
\hline \multicolumn{1}{c|}{ Tipo de ocupação } & $\begin{array}{c}\text { Cargas de incêndio específicas } \\
\mathrm{q}_{\mathrm{fi}} \\
\left(\mathrm{MJ} / \mathrm{m}^{2}\right)\end{array}$ \\
\hline Residencial & 300 \\
Escritório & 700 \\
Padaria & 1000 \\
Biblioteca & 2000 \\
Indústria de espumas & 3000 \\
Indústria de tintas e solventes & 4000 \\
\hline
\end{tabular}




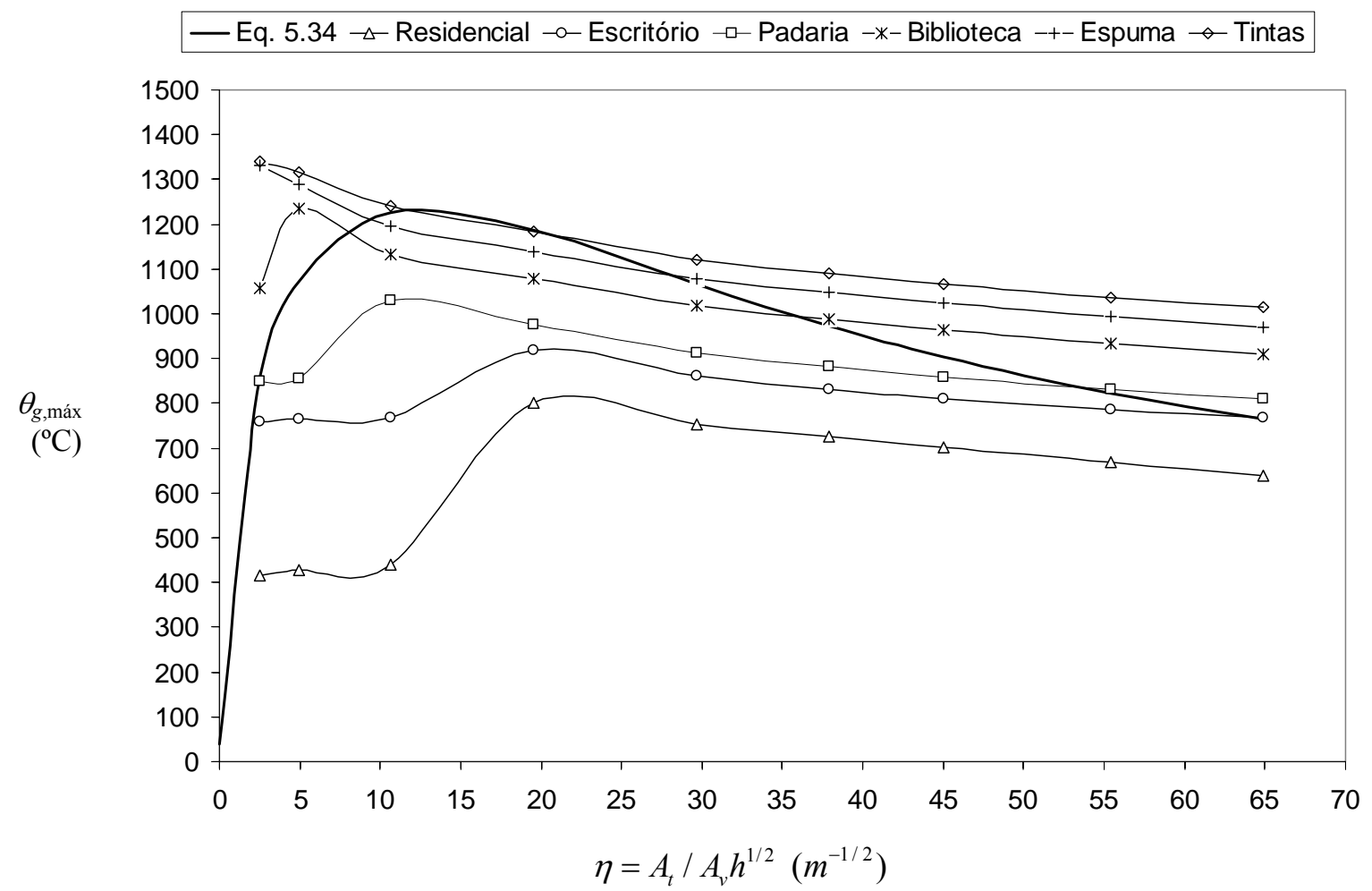

Figura 5.12 - Variação da temperatura de um incêndio com as dimensões do compartimento e a área de ventilação.

Para cargas de incêndio específicas inferiores a $1000 \mathrm{MJ} / \mathrm{m}^{2}$, verifica-se na figura 5.12 que as temperaturas da curva de incêndio natural ficam abaixo da curva proposta por Thomas para os valores de $\eta$ mais significativos (entre $5 \mathrm{~m}^{-1 / 2}$ e $55 \mathrm{~m}^{-1 / 2}$ ). Para cargas de incêndio específicas maiores, a curva de Thomas pode levar a valores contra a segurança.

Ao analisar os resultados experimentais, em escala natural, da figura 5.9, Law concluiu que a temperatura dos gases dentro do compartimento não depende somente da ventilação, mas também da carga de incêndio. A proposta de Thomas foi melhorada ao introduzir o fator $\psi$, dado pela eq. 5.35, resultando na eq. 5.37, adotada pelo Eurocode 1, Part 1-2, Annex B (2002).

As figuras 5.13 e 5.14 mostram os valores das temperaturas máximas, respectivamente para alta ventilação $\left(\eta=10,651 \mathrm{~m}^{-1 / 2}\right)$ e baixa ventilação $\left(\eta=55,373 \mathrm{~m}^{-1 / 2}\right)$, conforme a expressão proposta por Law, comparando-os aos extraídos da curva de incêndio natural do Eurocode 1, Part 1-2 (2002). 


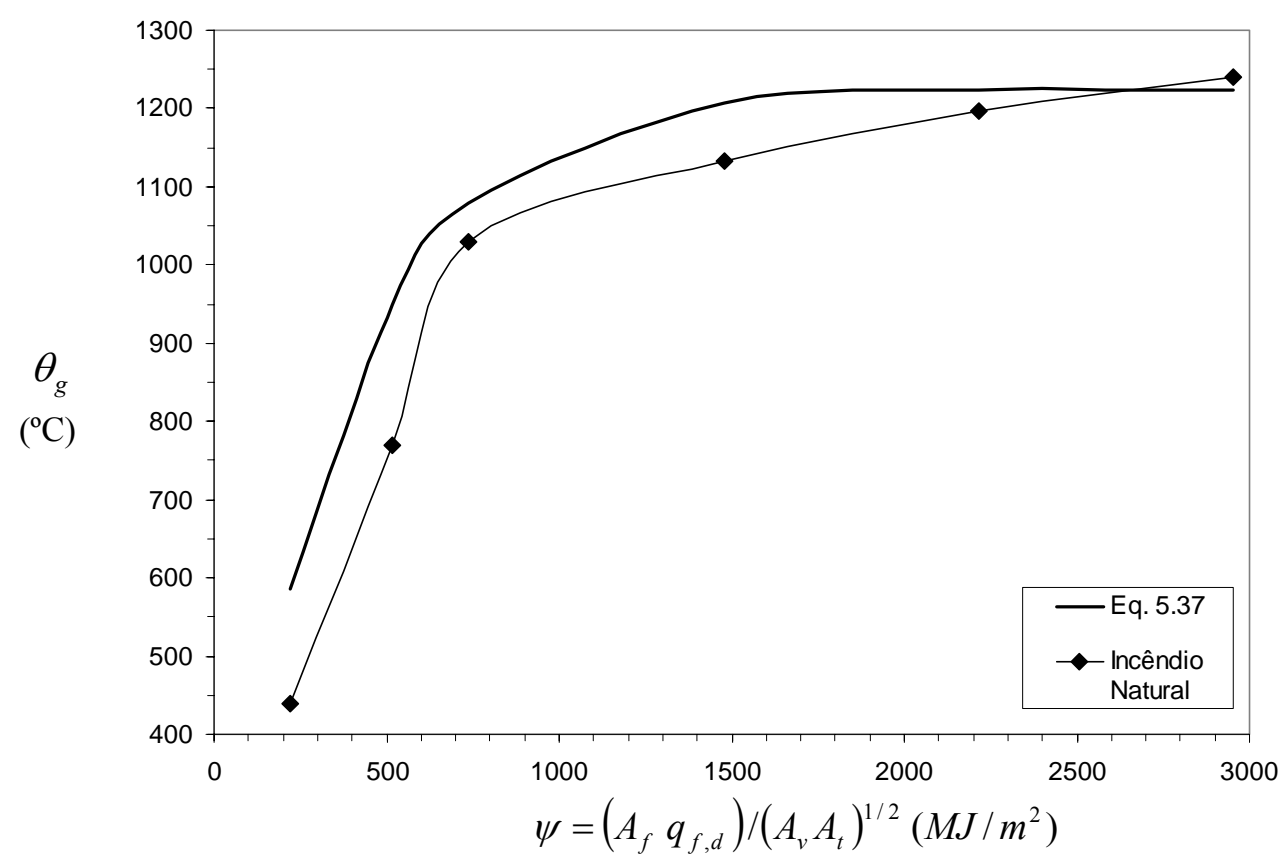

Figura 5.13 - Variação da temperatura máxima em compartimento com alta ventilação.

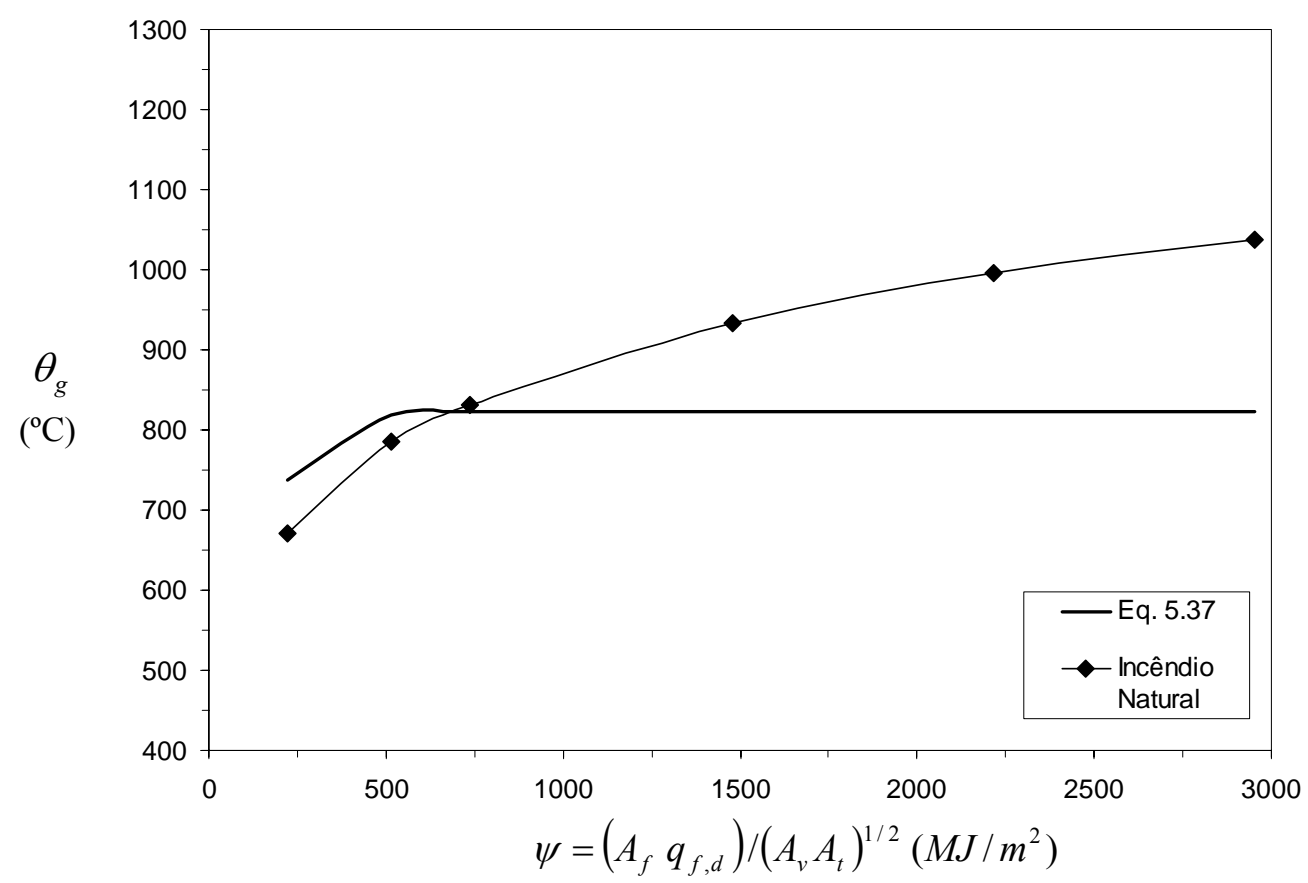

Figura 5.14 - Variação da temperatura máxima em compartimento com baixa ventilação.

Analisando-se as figuras 5.13 e 5.14, percebe-se que a proposta de Law está melhor calibrada para compartimentos bem ventilados, se comparada aos resultados obtidos por meio do modelo de incêndio natural do Eurocode 1, Part 1-2 (2002). 
Para compartimentos pouco ventilados, a temperatura dentro do compartimento, proposta por Law, se estabiliza. Sendo o incêndio controlado pela ventilação, em um determinado momento, o aumento da carga de incêndio não mais influenciará no aumento da temperatura. No incêndio natural, a temperatura máxima dos gases continua aumentando ao incrementar a carga específica de incêndio.

\subsection{DIMENSÕES DA CHAMA EXTERNA}

\subsubsection{Limite efetivo da chama}

Para conseguir estimar a transferência de calor para as estruturas de aço, é necessário definir um contorno geométrico para a chama que emerge para fora do compartimento incendiado. Na seção transversal, a distribuição da temperatura pode ser ilustrada conforme a figura 5.15. Foi definida uma aproximação para o contorno do limite da chama de $538^{\circ} \mathrm{C}$. Esse valor é consistente com a definição do topo da chama. Contudo, desde que o efeito da transferência de calor por radiação possa ser integrado, pode-se estabelecer uma temperatura uniforme equivalente e propor uma função equivalente.

Sendo a transferência de calor por radiação sensível ao valor da temperatura, foi prudente adotar a temperatura axial máxima para a função equivalente na definição da espessura efetiva.

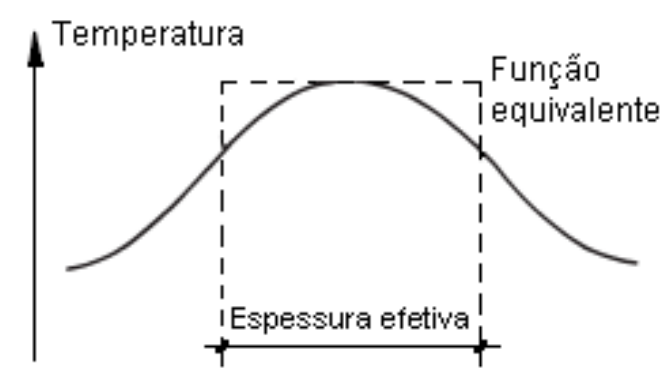

Figura 5.15 - Distribuição da temperatura na seção transversal da chama (LAW, 1978). 
Na ventilação natural, a chama emerge acima de um plano neutro que fica localizado em dois terços superiores da altura da janela. Abaixo desse plano, o ar frio entra no compartimento incendiado. Desde que a variação das dimensões da chama seja pequena com a distância da janela, é razoável assumir que a função equivalente permanece a mesma em toda a trajetória, ou seja, $w$ x $2 h / 3$. Isso é ilustrado na figura 5.16. De acordo com Law (1978), essa suposição é considerada consistente com os valores estimados da emissividade.

$\mathrm{O}$ vento pode inclinar a chama lateralmente e considerou-se um valor médio durante todo o incêndio. A inclinação não poderia exceder a $45^{\circ}$, como mostrado na figura 5.16 (c). Essa suposição parece razoável por causa da velocidade do vento externo ser da mesma ordem de grandeza da velocidade com que os gases quentes saem do compartimento.

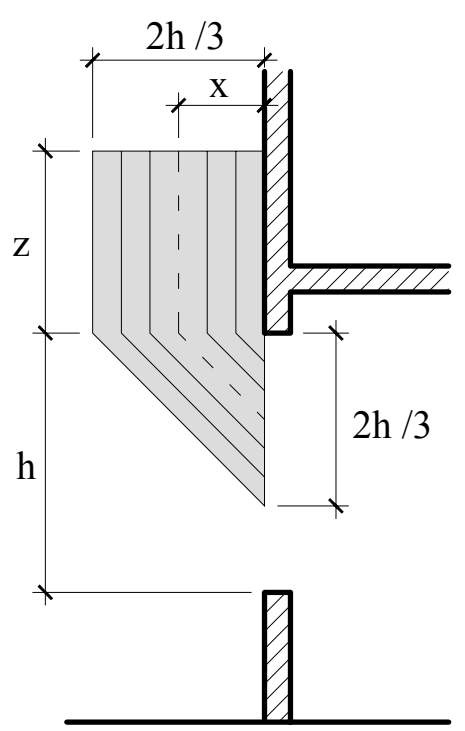

(a) Seção transversal vertical

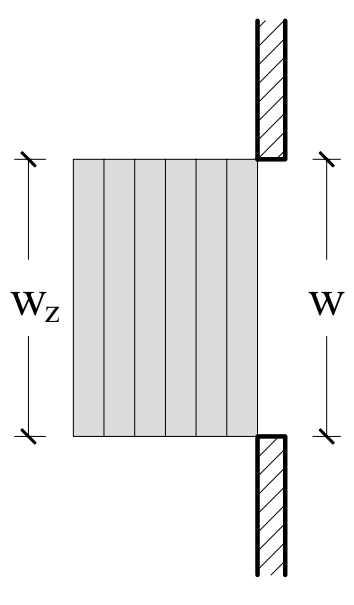

(b) Seção transversal horizontal sem vento.

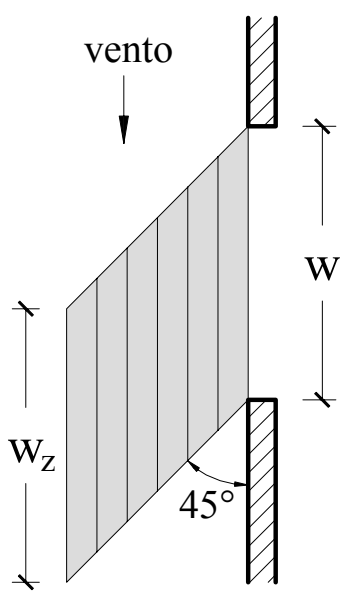

(c) Seção transversal horizontal com vento.

Figura 5.16 - Dimensões da chama para ventilação natural (LAW, 1978).

Para ventilação forçada, a chama emerge por toda a abertura. A largura aumenta com a distância, sendo razoável admitir que a dimensão vertical também aumente. Entretanto, o aumento vertical superior é contido pelo valor de $z$. Foi proposto que o tamanho da chama $h \mathrm{x}$ $w$ aumente até $h \times(w+0,4 x)$ no topo da chama, conforme figura 5.17. 


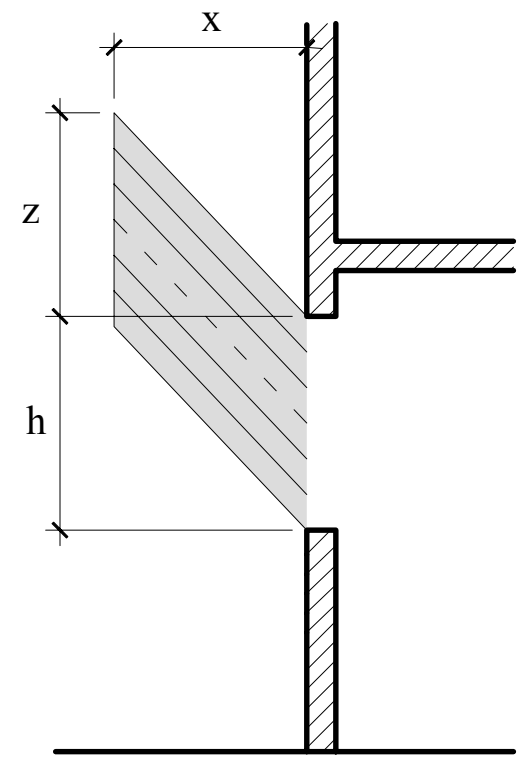

(a) Seção transversal vertical

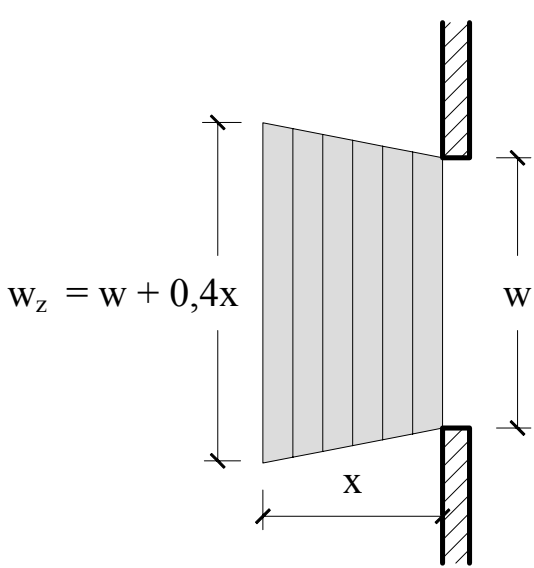

(b) Seção transversal horizontal ção forçada (LAW, 1978).

\subsubsection{Altura da chama}

De acordo com Yokoi apud Law (1978), para a ventilação natural, foi feita a correlação $y / r_{o}$, onde $y$ é a altura acima do topo da janela e $r_{o}$ é o raio efetivo da metade superior da janela. Sendo $\Theta$ um termo adimensional envolvendo a elevação da temperatura e a taxa de fornecimento de calor, obteve-se um conjunto de curvas para diferentes valores de $n$, que é a razão entre a largura e a altura da metade superior da janela.

Thomas apud Law (1978) demonstrou que essas curvas podem ser relacionadas a $n^{1 / 3} y$ com $\Theta$. Thomas e Law analisaram os dados de Yokoi, Webster et al. e Seigel sugeriram a eq. 5.39.

$$
\frac{n^{1 / 3}(z+h)}{r_{o}}=\frac{2}{\Theta}
$$

Onde:

$(z+h)$ é a altura do topo da chama acima da base da janela de altura $\mathrm{h}(\mathrm{m})$, assumindo-se a temperatura do topo igual a $538^{\circ} \mathrm{C}$;

$n \quad$ é a razão entre a largura e a altura da metade superior da janela, ou seja, $n=2 w / h$;

$r_{o} \quad$ é o raio efetivo da metade superior da janela $(\mathrm{m})$, ou seja, $r_{o}=\left(\frac{A_{v}}{2 \pi}\right)^{1 / 2}$; 
$\Theta \quad$ é a temperatura adimensional da chama, conforme eq. 5.40.

$$
\Theta=\theta_{z}\left[\frac{r_{o}^{5} c_{z}{ }^{2} \rho_{z}{ }^{2} g}{\dot{m}^{2} C^{2} \theta_{o}}\right]^{1 / 3}
$$

Onde:

$\theta_{z} \quad$ é a temperatura da chama $\left({ }^{\circ} \mathrm{C}\right)$;

$c_{z} \quad$ é o calor específico da chama $\left(\mathrm{J} / \mathrm{kg}^{\circ} \mathrm{C}\right)$;

$\rho_{z} \quad$ é a densidade do gás quente $\left(\mathrm{kg} / \mathrm{m}^{3}\right)$;

$g \quad$ é a aceleração da gravidade $\left(\mathrm{m} / \mathrm{s}^{2}\right)$;

$\dot{m} \quad$ é a taxa de liberação de massa do combustível $(\mathrm{kg} / \mathrm{s})$;

C é potencial calorífico da madeira $(\mathrm{J} / \mathrm{kg})$;

$\theta_{o} \quad$ é a temperatura ambiente $\left({ }^{\circ} \mathrm{C}\right)$.

Reordenando a eq. 5.39, obtém-se a eq. 5.41.

$$
\frac{z+h}{h}=2 \pi^{1 / 3}\left[\frac{\dot{m}}{A_{v} \rho_{z}(g h)^{1 / 2}}\right]^{2 / 3}\left[\frac{C^{2} \theta_{o}}{c_{z}{ }^{2}\left(\theta_{z}-\theta_{o}\right)^{3}}\right]^{1 / 3}
$$

Onde foram assumidos: a temperatura no topo da chama $\theta_{z}=538^{\circ} \mathrm{C}$, o potencial calorífico da madeira $C=16 \mathrm{MJ} / \mathrm{kg}$, e o calor específico da chama $c_{z}=1,02 \mathrm{~kJ} / \mathrm{kg}^{\circ} \mathrm{C}$.

Reescrevendo a eq. 5.41, obtém-se a eq. 5.42.

$$
\frac{z+h}{h}=23,5\left[\frac{\dot{m}}{A_{v} \rho_{z}(g h)^{1 / 2}}\right]^{2 / 3}
$$

De acordo com Law (1978), dados resultantes de incêndios em escala natural indicaram que a eq. 5.42 superestimava os valores da altura da chama. Propôs, então, a eq. 5.43, na qual introduziu " $n$ ", em que é a razão entre a largura e a altura da metade superior da janela, ou seja, $n=2 w / h$. 


$$
\frac{z+h}{h}=8,9\left[\frac{\dot{m}}{A_{v} \rho_{z}(g h)^{1 / 2}}\right]^{0,51} n^{0,12}
$$

Entretanto, após novos estudos, concluiu-se que a influência de $n$ era pequena e voltou-se ao formato da eq. 5.42, com ajustes, resultando na eq. 5.44.

$$
\frac{z+h}{h}=16\left[\frac{\dot{m}}{A_{v} \rho_{z}(g h)^{1 / 2}}\right]^{2 / 3}
$$

Foram agrupados dados obtidos em vários experimentos em escala natural que permitiram construir os gráficos apresentados na figura 5.18.

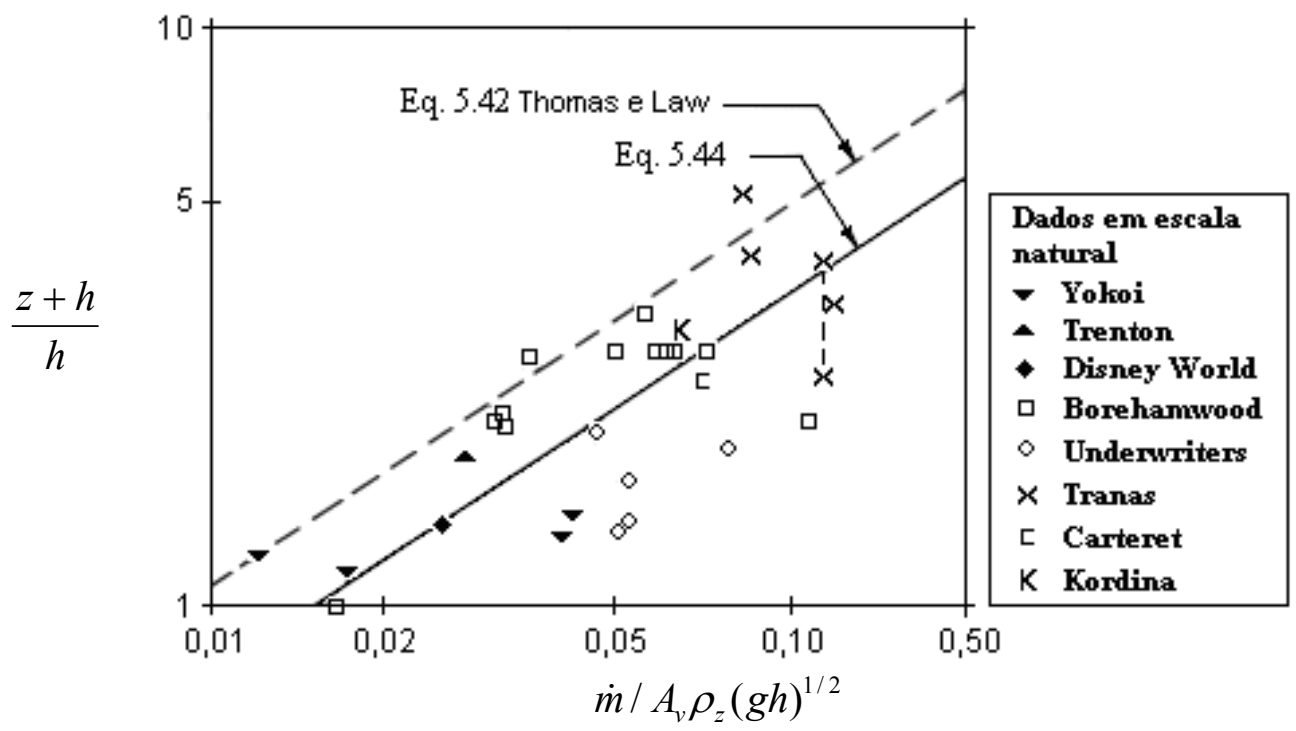

Figura 5.18 - Altura das chamas em ensaios em escala natural com ventilação natural (LAW, 1978).

A eq. 5.44 pode ser reescrita na forma da eq. 5.45 .

$$
z+h=12,8\left[\frac{\dot{m}}{w}\right]^{2 / 3}
$$

A figura 5.19 ilustra a altura da chama para ventilação natural. 


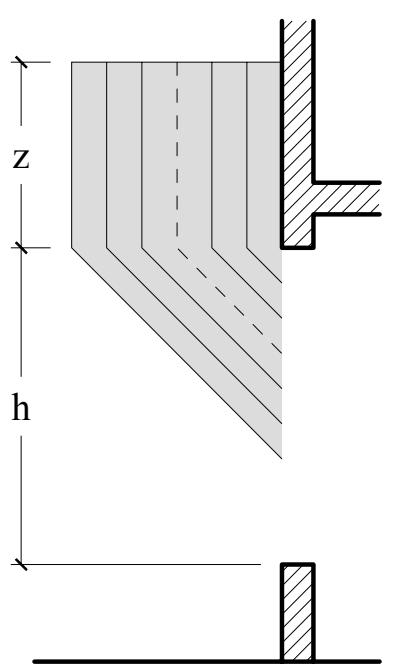

Figura 5.19 - Altura da chama com ventilação natural (EUROCODE 1, PART 1-2, 2002).

De acordo com o Eurocode 1, Part 1-2 (2002), caso haja marquise ou sacada acima da janela, com projeção horizontal, $W_{a}$, com parede acima da janela e altura da janela $h \leq 1,25 w$, a altura da chama será reduzida de $W_{a}(1+\sqrt{2})$, conforme se observada na eq. 5.46 e na figura 5.20.

$$
\begin{aligned}
& z_{1}=12,8\left[\frac{\dot{m}}{w}\right]^{2 / 3}-h \\
& z=z_{1}-W_{a}(1+\sqrt{2})
\end{aligned}
$$
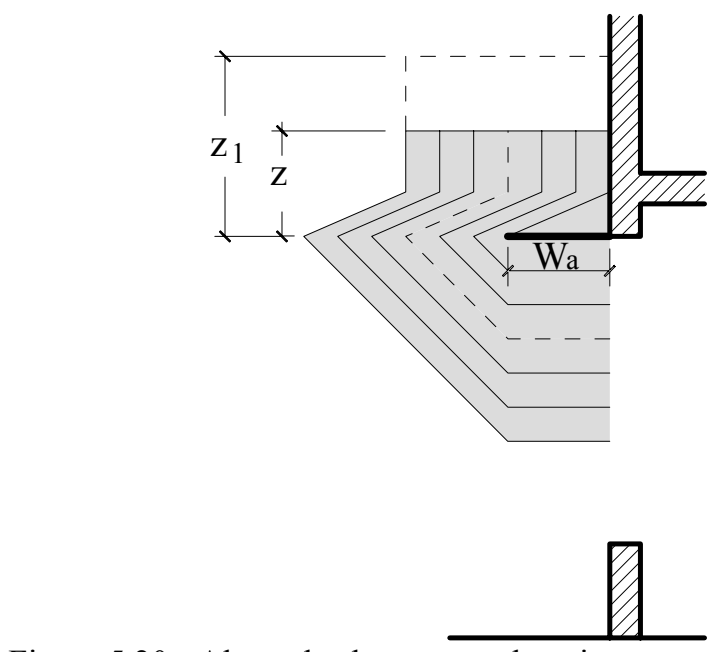

Figura 5.20 - Altura da chama quando existe marquise ou sacada.

Caso haja marquise ou sacada acima da janela, sem parede acima da janela e $h>1,25 w$, a altura da chama será subtraída de $W_{a}$, conforme eq. 5.47. 


$$
z=z_{1}-W_{a}
$$

Para a situação de ventilação forçada, a correlação de Seigel apud Law (1978) tem por hipótese que o efeito principal de uma corrente de ar forçada aumenta a taxa de combustão de um incêndio com ventilação controlada. $O$ efeito do incêndio em queima-livre era insignificante quando se utilizava a variação da ventilação forçada. Contudo, para uma determinada taxa de liberação de massa, o vento pode afetar o tamanho e a direção da chama. Por isso, análises de regressão de dados, semelhantes à ventilação natural, mas incluindo o número de Froude $\left(v^{2} / g h\right)$, foram realizadas, obtendo-se a eq. 5.48.

$$
\frac{z+h}{h}=6,99\left[\frac{\dot{m}}{A_{v} \rho_{z}(g h)^{1 / 2}}\right]^{0,784} n^{0,434}\left[\frac{v^{2}}{g h}\right]^{-0,216}
$$

Onde:

$z \quad$ é a altura da chama externa (m);

$h \quad$ é a altura da janela (m);

$\dot{m} \quad$ é a taxa de liberação de massa do combustível $(\mathrm{kg} / \mathrm{s})$;

$A_{v} \quad$ é a área da janela ou a soma das áreas das janelas em todas as paredes $\left(\mathrm{m}^{2}\right)$;

$\rho_{z} \quad$ é a densidade do gás quente $\left(\mathrm{kg} / \mathrm{m}^{3}\right)$;

$g \quad$ é a aceleração da gravidade $\left(\mathrm{m} / \mathrm{s}^{2}\right)$;

$v \quad$ é a velocidade do vento $(\mathrm{m} / \mathrm{s})$;

$n \quad$ é a razão entre a largura e a altura da metade superior da janela, ou seja, $n=2 w / h$.

Seigel modificou a eq. 5.48 para a eq. 5.49 .

$$
v^{0,432}(z+h)=11,3\left[\frac{\dot{m}}{A_{v}^{1 / 2}}\right]^{0,784}
$$


Os dados para a altura da chama, em situação de ventilação forçada, são mostrados na figura 5.21 e indicam a correlação proposta por Seigel, com o termo $\dot{m} / A_{v}^{1 / 2}$ elevado à potência unitária, visando simplificar a eq. 5.49 para a eq. 5.50 .

$$
v^{0,43}(z+h)=16,9\left[\frac{\dot{m}}{A_{v}^{1 / 2}}\right]
$$

Reordenando a eq. 5.50, resulta-se na eq. 5.51.

$$
z=16,9\left(\frac{1}{v}\right)^{0,43}\left[\frac{\dot{m}}{A_{v}^{1 / 2}}\right]-h
$$

Na figura 5.21, os valores da velocidade do vento, $v$, variam de $0,51 \mathrm{~m} / \mathrm{s}$ até $1,86 \mathrm{~m} / \mathrm{s}$.

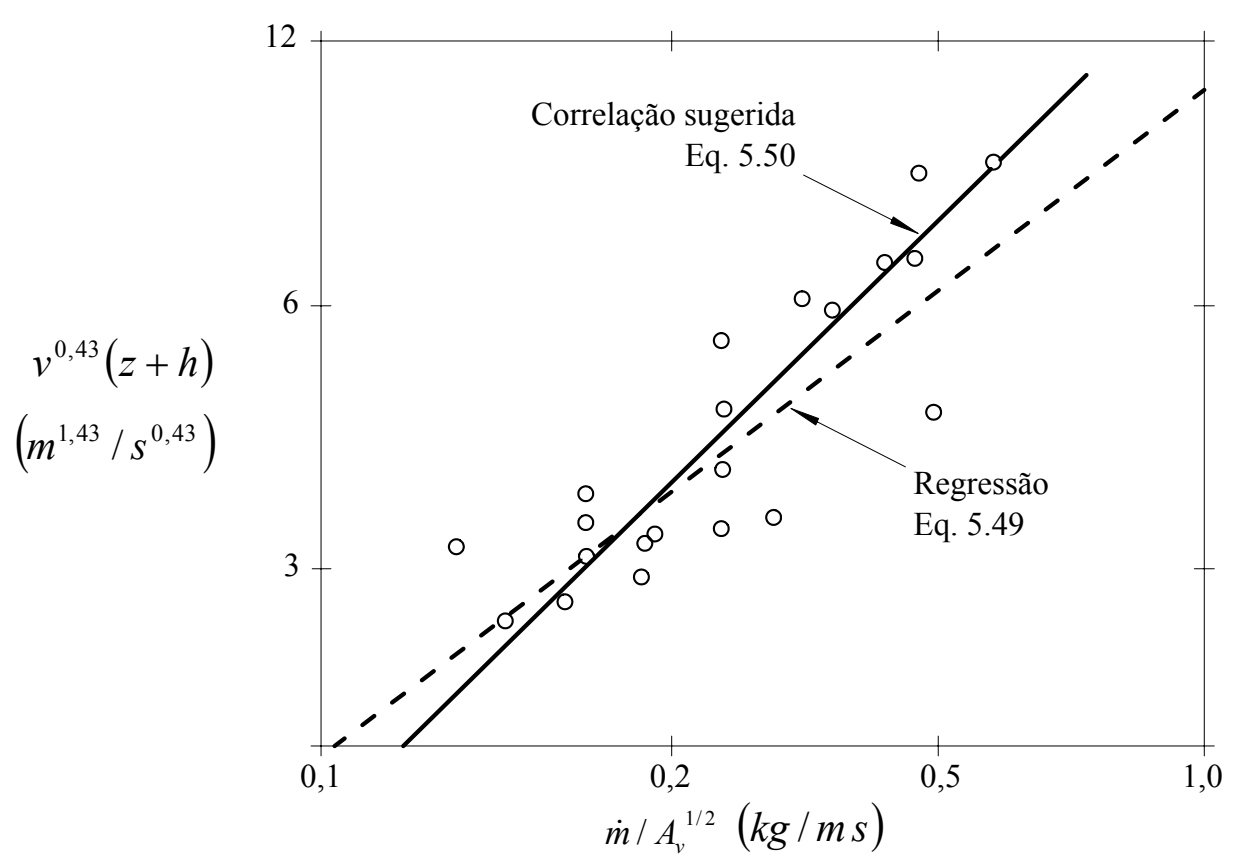

Figura 5.21 - Altura da chama em ensaios em escala natural com ventilação forçada (Laboratórios Underwriters, apud LAW, 1978).

Caso exista marquise ou sacada acima da janela, conforme figura 5.22, a trajetória da chama, mesmo depois da inclinação se tornar horizontal pela marquise ou sacada, continua sendo igual à anterior, considerando a altura da chama inalterada. 


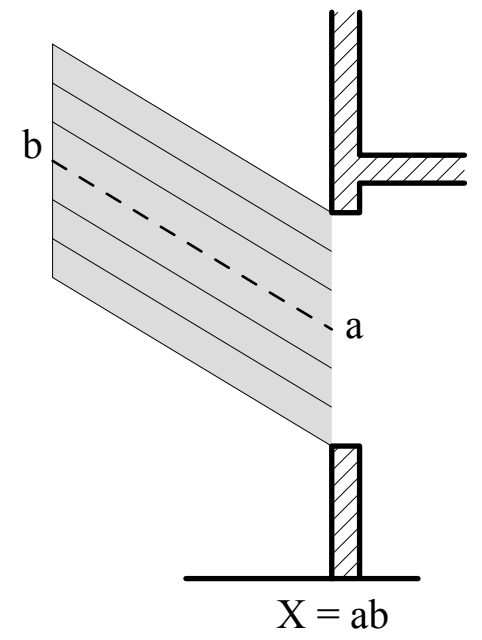

Corte da seção vertical

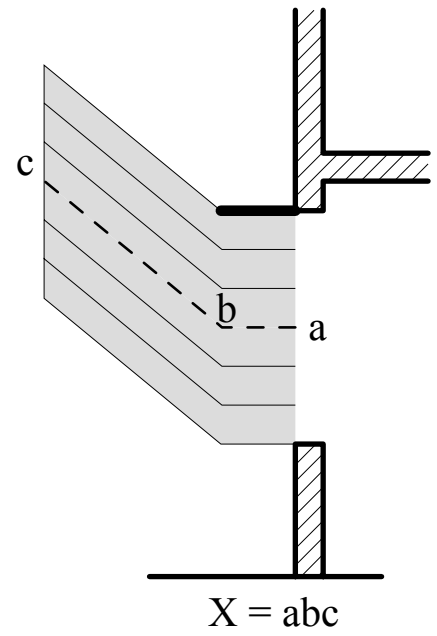

Corte da seção vertical

Figura 5.22 - Deflexão da chama devido à presença de marquise acima da janela, com ventilação forçada (EUROCODE 1, PART 1.2, 2002).

\subsubsection{Projeção horizontal da chama}

Law (1978) fez uma análise de regressão linear do topo da chama, considerando a temperatura igual a $538^{\circ} \mathrm{C}$, até a janela para estabelecer a projeção horizontal da chama conforme eq. 5.52 .

$$
\frac{x}{h}=\frac{0,454}{n^{0,53}}
$$

Onde: $x$ é a projeção horizontal da chama (m) e $n$ é igual a $2 w / h$.

Os resultados de ensaios para a projeção horizontal da chama são mostrados na figura 5.23. 


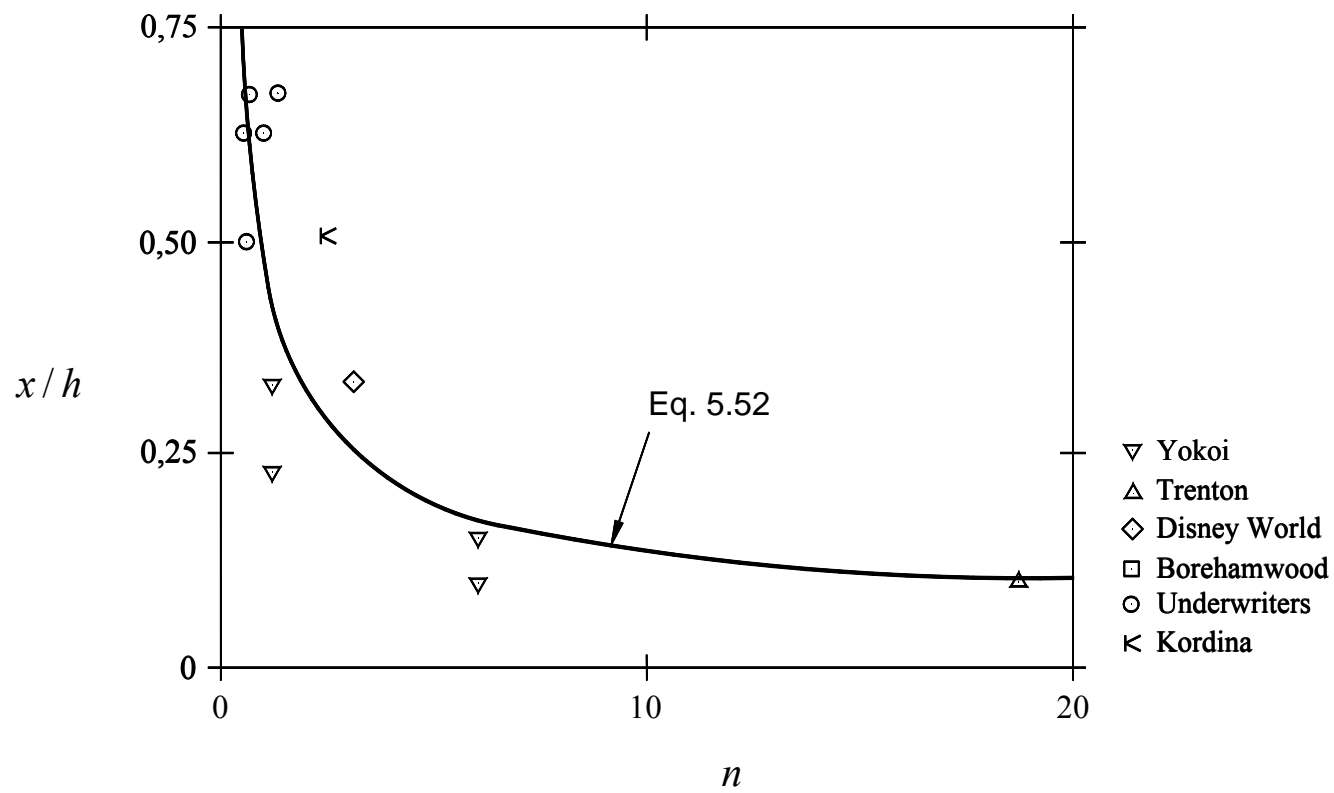

Figura 5.23 - Projeção horizontal do topo da chama para ensaios em escala natural, com ventilação natural, considerando parede acima da janela (LAW, 1978).

A eq. 5.52 indica que a projeção do topo da chama decresce com $n$, como demonstrado por Yokoi, sendo menor do que a metade da altura da janela para valores de $n$ que excedem a unidade, o que inclui a maioria dos casos. A eq. 5.52 é a correta recomendação para situações onde possa existir parede acima da janela. Yokoi demonstrou que sem a parede acima da janela, o valor de $x$ pode ser independente de $n$. Na ausência de outros dados, a relação $x / h$ pode ser representada pela eq. 5.53 .

$$
\frac{x}{h}=0,60\left[\frac{z}{h}\right]^{1 / 3}
$$

O Eurocode 1, Part 1-2 (2002) estabelece que, para ventilação natural, a projeção horizontal da chama é calculada como indicado a seguir:

- Para compartimentos com parede acima da janela:

Para $\mathrm{h} \leq 1,25 \mathrm{w}$ :

$$
x=\frac{h}{3}
$$

Para $h>1,25 w$ e distância a outra janela $>4 w:$ 


$$
x=0,3 h\left(\frac{h}{w}\right)^{0,54}
$$

Demais casos:

$$
x=0,454\left(\frac{h}{2 w}\right)^{0,54}
$$

- Para compartimentos sem parede acima da janela:

$$
x=0,6 h\left(\frac{z}{h}\right)^{1 / 3}
$$

A figura 5.24 mostra a projeção horizontal da chama, $x$, considerando ventilação natural.

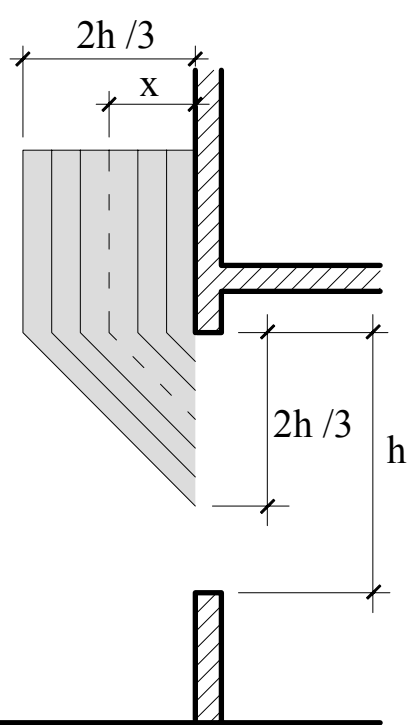

(a) Seção transversal vertical com parede acima da janela ou $\mathrm{h} \leq 1,25 \mathrm{w}$.

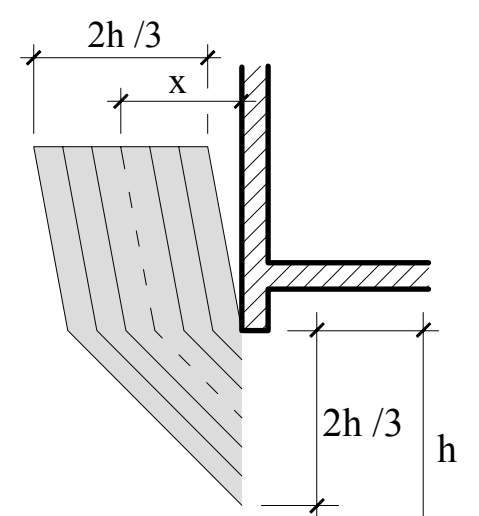

(b) Seção transversal vertical sem parede acima da janela ou $\mathrm{h}>1,25 \mathrm{w}$.

Figura 5.24 - Projeção horizontal da chama para ventilação natural (EUROCODE 1, PART 1.2, 2002).

$\mathrm{Na}$ ventilação natural, a chama emerge acima de um plano neutro, que fica localizado a dois terços abaixo da parte superior da janela. Abaixo desse plano, o ar frio proveniente do ambiente externo penetra no compartimento incendiado. A figura 5.24 mostra a profundidade da chama, que tem o valor de $2 h / 3$. 
Se houver marquise ou sacada acima da janela, a projeção horizontal da chama, $x$, é acrescida da largura da marquise ou sacada, $W_{a}$, conforme figura 5.25.

- Com parede acima da janela:

Para $\mathrm{h} \leq 1,25 \mathrm{w}$ :

$$
x=\frac{h}{3}+W_{a}
$$

Para $h>1,25 w$ e distância a outra janela $>4 w$ :

$$
x=0,3 h\left(\frac{h}{w}\right)^{0,54}+W_{a}
$$

Demais casos:

$$
x=0,454\left(\frac{h}{2 w}\right)^{0,54}+W_{a}
$$

- Sem parede acima da janela:

$$
x=0,6 h\left(\frac{z}{h}\right)^{1 / 3}+W_{a}
$$

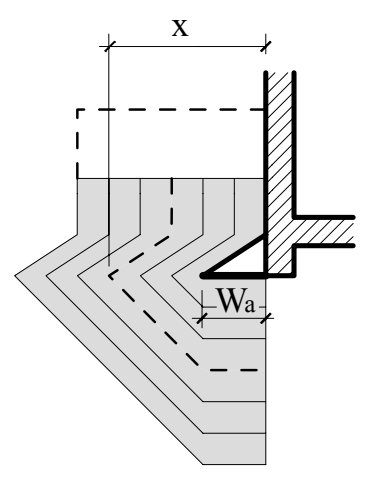

Figura 5.25 - Projeção horizontal da chama quando existe marquise ou sacada com ventilação natural (EUROCODE 1, PART 1.2, 2002).

Na ventilação forçada, de acordo com Law (1978), uma análise similar para a altura da chama feita por Seigel, também foi feita para a projeção horizontal, obtendo-se a eq. 5.62. 


$$
\frac{x}{h}=6,85\left[\frac{\dot{m}}{A_{v} \rho_{z}(g h)^{1 / 2}}\right]^{0,760} n^{0,444}\left[\frac{v^{2}}{g h}\right]^{0,216}
$$

Da eq. 5.62, Law deduziu a eq. 5.63.

$$
x \cong\left[\frac{v^{2}}{g h}\right]^{0,216}(z+h)
$$

Os dados relativos à projeção horizontal da chama, $x$, são apresentados na figura $5.27 \mathrm{e}$ mostram a correlação da eq. 5.64, derivada da eq. 5.63.

$$
x=0,61\left[\frac{v^{2}}{h}\right]^{0,22}(z+h)
$$

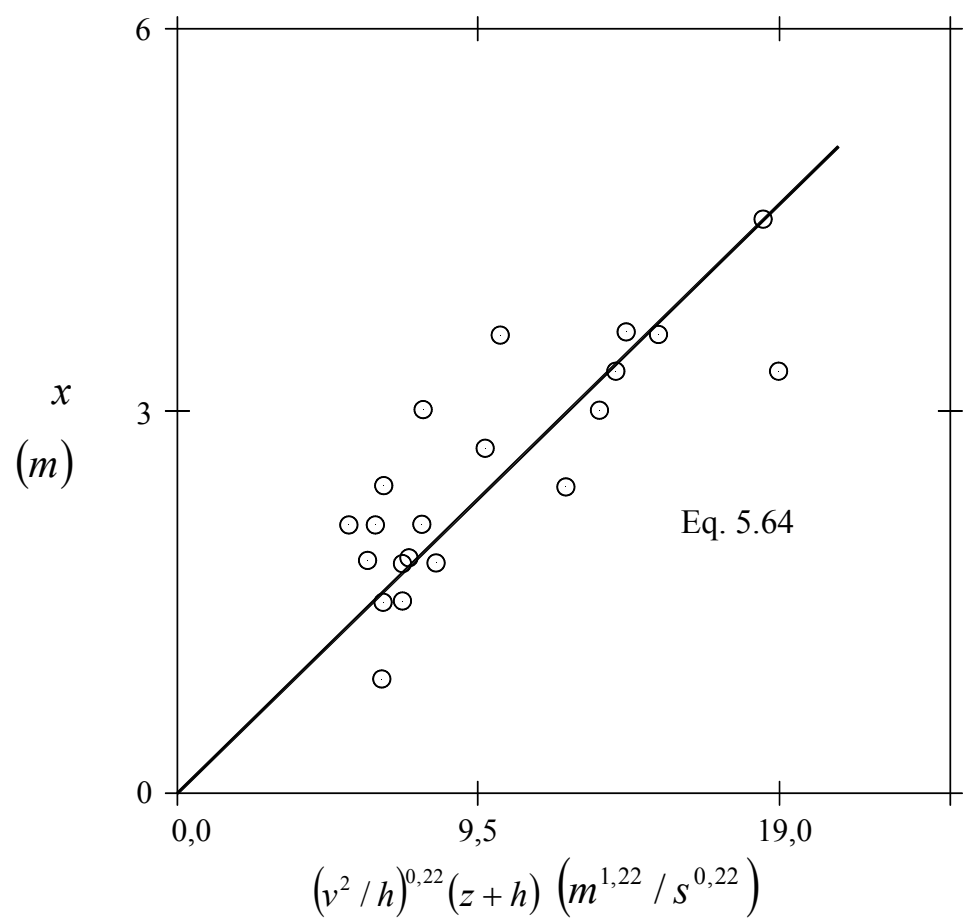

Figura 5.26 - Projeção horizontal do topo da chama, para ensaios em escala - natural, com ventilação forçada, considerando os dados dos Laboratórios Underwriters (LAW, 1978).

A figura 5.27 mostra a projeção horizontal da chama para ventilação forçada. 


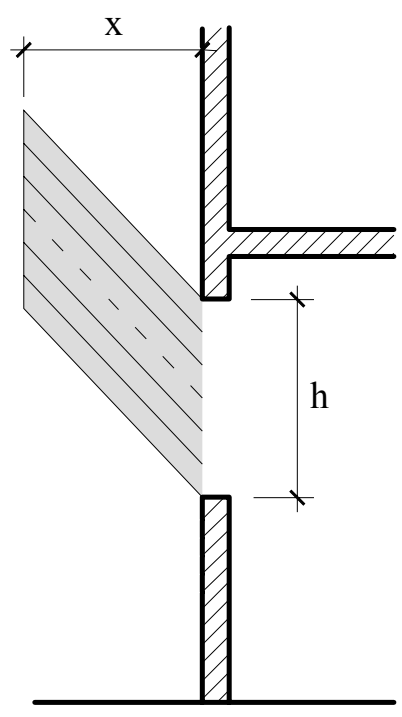

(a) Seção transversal vertical

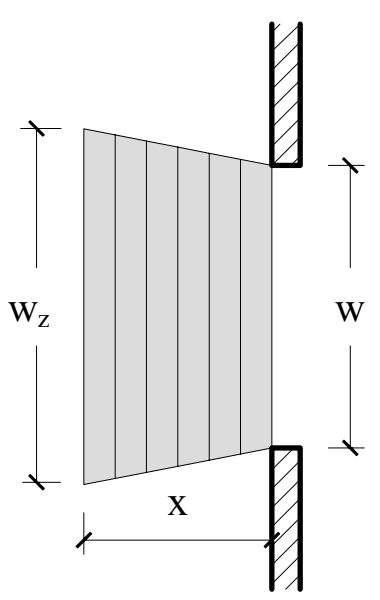

(b) Seção transversal horizontal

Figura 5.27 - Projeção horizontal da chama para ventilação forçada (EUROCODE 1, PART 1.2, 2002).

\subsubsection{Largura da chama}

Nos ensaios realizados com ventilação natural, foi observado que a largura máxima da chama que emerge das janelas não apresenta valores maiores que a largura da janela. Portanto, considera-se que a largura da chama seja a largura da janela, como ilustrado na figura 5.28.

$$
w_{\mathrm{z}}=w
$$

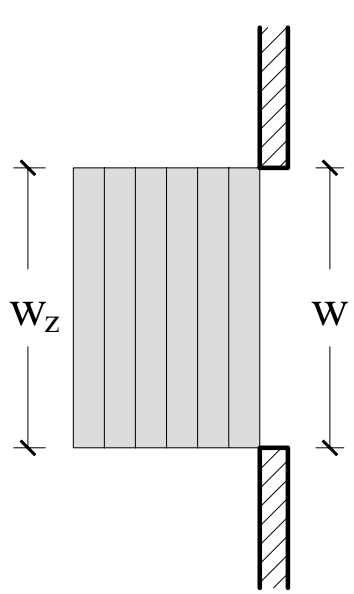

(a) Seção transversal horizontal sem vento

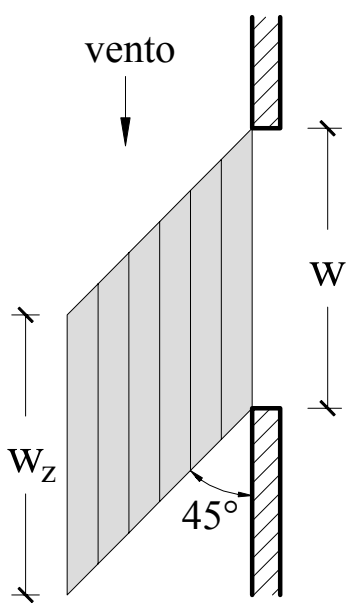

(b) Seção transversal horizontal com vento

Figura 5.28 - Largura da chama para ventilação natural (LAW, 1978). 
Para ventilação forçada, de acordo com Law (1978), a largura máxima da chama que emerge, $w_{z}$, geralmente excede a largura da janela. $\mathrm{O}$ ângulo possui valor médio de $11^{\circ}$, como ilustrado na figura 5.29. Esse valor é dado pela eq. 5.66.

$$
\begin{aligned}
& \frac{w_{z}-w}{2 x}=0,194 \\
& w_{z} \cong w+0,4 x
\end{aligned}
$$

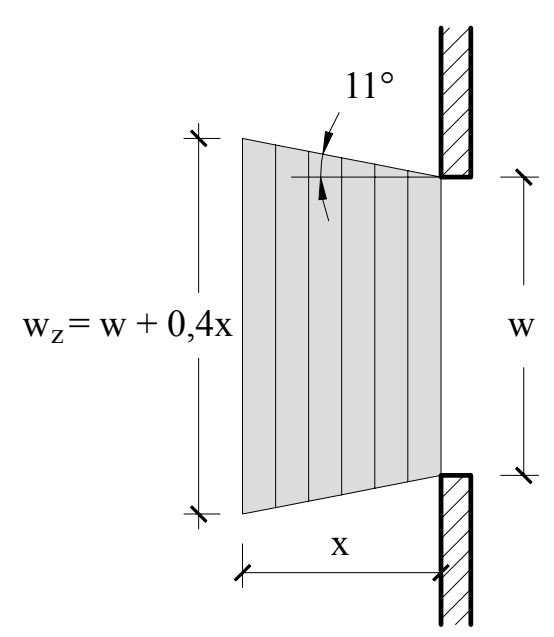

Figura 5.29 - Largura da chama para ventilação forçada (LAW, 1978).

\subsubsection{Comprimento da chama ao longo do eixo}

De acordo com o Eurocode 1, Part 1-2 (2002), o comprimento da chama ao longo do eixo, em ventilação natural, pode ser calculado conforme as eq. 5.67 e 5.68 .

- Caso exista parede acima da janela ou se $h_{e q} \leq 1,25 w$, utiliza-se a eq. 5.67. 


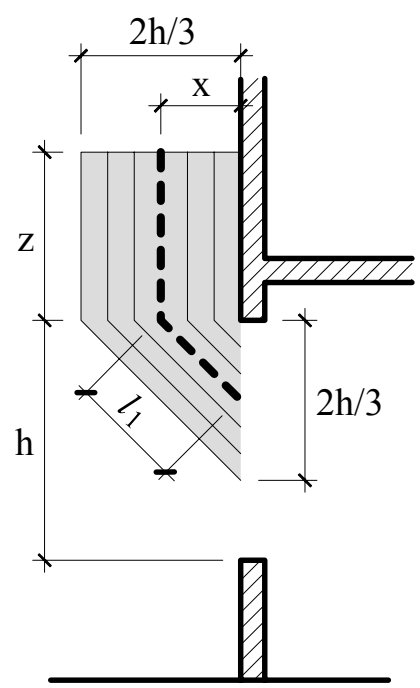

Figura 5.30 - Comprimento do eixo da chama para ventilação natural, caso exista parede acima da janela ou $\mathrm{h}_{\mathrm{eq}} \leq 1,25 \mathrm{w}($ EUROCODE 1, PART 1.2, 2002).

$$
\begin{gathered}
l_{1}=\sqrt{x^{2}+\left(\frac{h}{3}\right)^{2}} \cong \frac{h}{2} \\
X=z+l_{1} \\
X=z+\frac{h}{2}
\end{gathered}
$$

- Caso não exista parede acima da janela ou se $h_{e q}>1,25 w$, utiliza-se a eq. 5.68 .

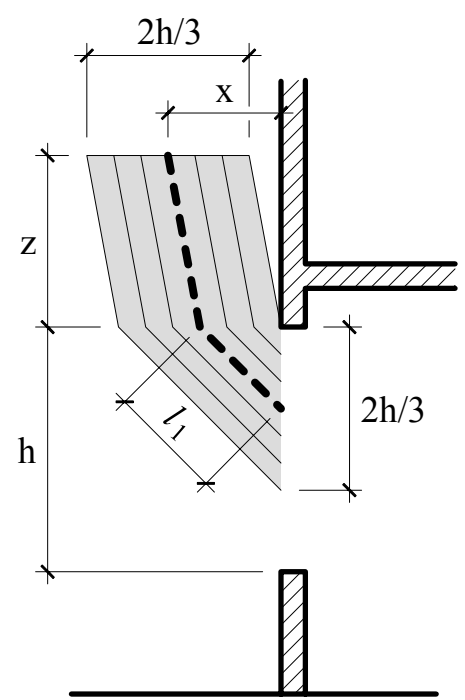

Figura 5.31 - Comprimento do eixo da chama para ventilação natural, caso não exista parede acima da janela ou $h_{e q}>1,25 w$ (EUROCODE 1, PART 1.2, 2002). 


$$
\begin{gathered}
l_{1}=\sqrt{x^{2}+\left(\frac{h}{3}\right)^{2}} \cong \frac{h}{2} \\
X=\sqrt{z^{2}+\left(x-\frac{h}{3}\right)^{2}}+l_{1} \\
X=\sqrt{z^{2}+\left(x-\frac{h}{3}\right)^{2}}+\frac{h}{2}
\end{gathered}
$$

Para a ventilação forçada, Seigel apud Law (1978) tratou a chama como um jato que emerge sobre toda a janela e propôs a eq. 5.69.

$$
l \propto \frac{\dot{m}}{A_{v}^{1 / 2}\left(\theta_{z}-\theta_{o}\right)}
$$

Onde $l$ é a distância da linha de centro em que ocorre a elevação da temperatura da chama, $\theta_{z}$.

A partir dos dados obtidos pelos Laboratórios Underwriters, Seigel estabeleceu um limite para o topo da chama, onde $l=X$, na eq. 5.70 para incêndios com queima "normal". Queima normal foi definida como ventilação suficiente para que a madeira utilizada como carga de incêndio se queime à taxa máxima, ou seja, como se fosse queima-livre.

$$
X=0,0104 \frac{L}{A_{v}^{1 / 2}}-0,3901
$$

Para essa carga de incêndio em madeira, o valor de $t_{\text {lim }}$ obtido foi de 1560 segundos, podendo a eq. 5.70 ser reescrita conforme a eq. 5.71 .

$$
X=16,2864 \frac{\dot{m}}{A_{v}^{1 / 2}}-0,3901
$$

Sendo $\dot{m}=\frac{L}{t_{\lim }}=\frac{L}{1560}$

A correlação de Seigel foi baseada na suposição de que o efeito principal de uma corrente de ar forçada é aumentar a taxa de combustão de um incêndio com ventilação controlada. $O$ efeito do incêndio em queima-livre foi insignificante para o raio de ação da ventilação forçada. 
De acordo com o Eurocode 1, Part 1-2 (2002), o comprimento da chama para ventilação forçada pode ser calculado a partir de considerações geométricas, como apresentado na figura 5.32 e escrito na eq. 5.72 .

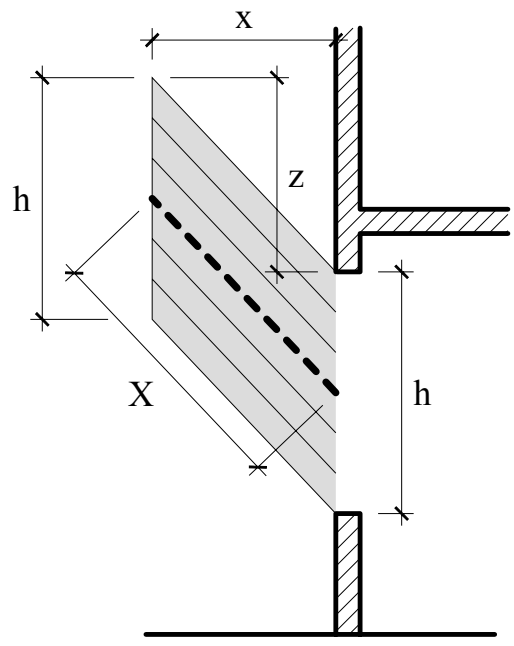

Figura 5.32 - Comprimento da chama para ventilação forçada.

$$
X=\left(z^{2}+x^{2}\right)^{1 / 2}
$$

\subsection{TEMPERATURA DA CHAMA EXTERNA}

\subsubsection{Temperatura no eixo da chama}

Para ventilação forçada, segundo Seigel, foram analisados os dados referentes à distribuição da temperatura das chamas que emergem pela janela, e obteve-se a eq. 5.73.

$$
\begin{array}{lll}
\text { Para } & \frac{l A_{v}^{1 / 2}}{\dot{m}}<6,39: & \frac{\theta_{z}-\theta_{o}}{\theta_{w}-\theta_{o}}=1,0 \\
\text { Para } & \frac{l A_{v}^{1 / 2}}{\dot{m}}>6,39: & \frac{\theta_{z}-\theta_{o}}{\theta_{w}-\theta_{o}}=4,068\left[\frac{l A_{v}^{1 / 2}}{\dot{m}}\right]^{-3 / 4}
\end{array}
$$

Onde: 
$\theta_{z} \quad$ é a temperatura medida no eixo da chama $\left({ }^{\circ} \mathrm{C}\right)$;

$\theta_{o} \quad$ é a temperatura do ar no ambiente externo $\left({ }^{\circ} \mathrm{C}\right)$;

$\theta_{w} \quad$ é a temperatura medida na janela $\left({ }^{\circ} \mathrm{C}\right)$;

$l \quad$ é a distância ao longo do eixo da chama até a janela (m).

A eq. 5.73 acompanha o incêndio-padrão da distribuição da temperatura encontrada para jatos, conforme mostrado na figura 5.33. Ao combinar as eq. 5.71 e 5.73, obtém-se $\left(\theta_{z}-\theta_{o}\right) /\left(\theta_{w}-\theta_{o}\right) \cong 0,5$, que é o valor correto para o topo da chama.

Uma correlação similar à eq. 5.73, para dados em ventilação forçada, é dada pela eq. 5.74. Essa correlação é mais vantajosa do ponto de vista analítico por evitar uma descontinuidade na curva, conforme mostra a figura 5.33 .

$$
\frac{\theta_{z}-\theta_{o}}{\theta_{w}-\theta_{o}}=1-0,027 \frac{l A_{v}^{1 / 2}}{\dot{m}}
$$

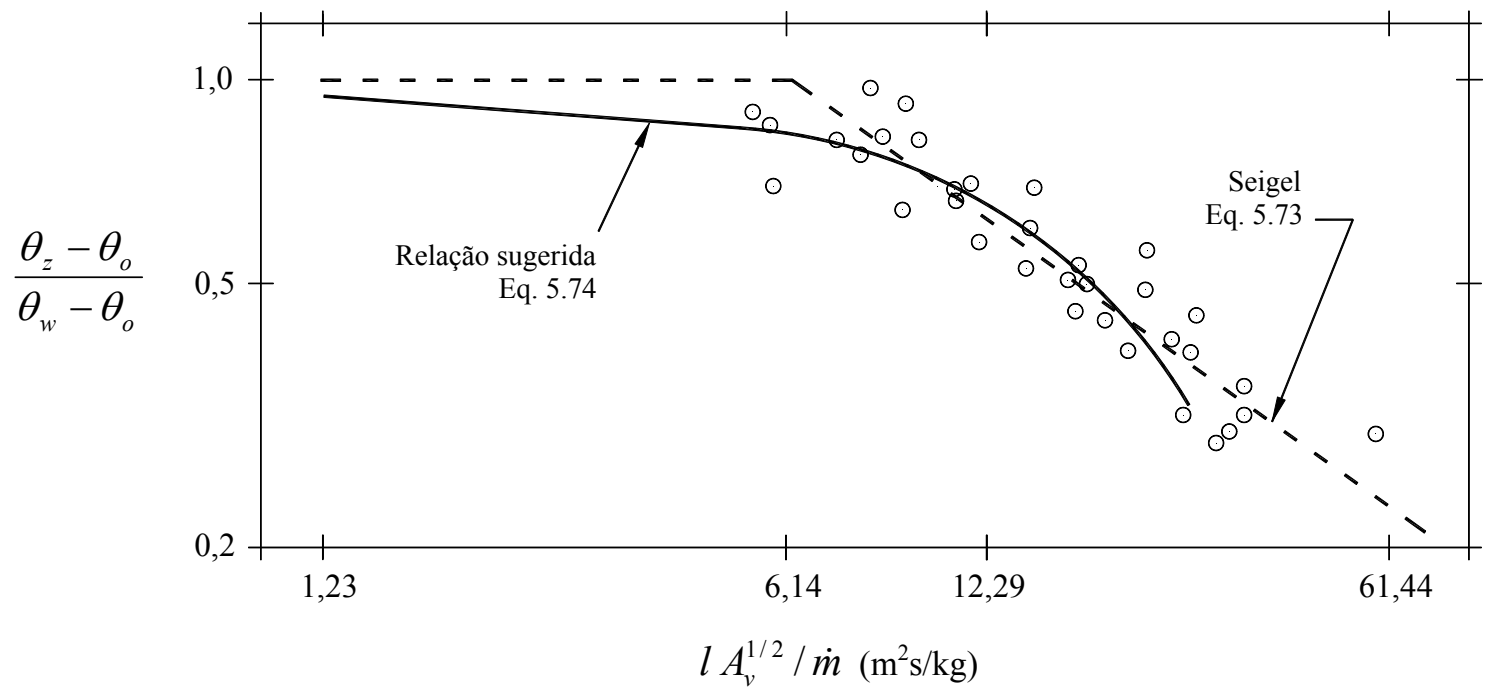

Figura 5.33 - Distribuição da temperatura da chama para ensaios em escala natural com ventilação forçada, considerando dados dos Laboratórios Underwriters (LAW, 1978).

Na condição de ventilação natural, foi adotada uma aproximação similar à ventilação forçada para correlacionar os dados da temperatura. Esses dados são melhores correlacionados em função do termo $l w / \dot{m}$, conforme a eq. 5.75 e a figura 5.34 . 


$$
\frac{\theta_{z}-\theta_{o}}{\theta_{w}-\theta_{o}}=1-0,027 \frac{l w}{\dot{m}}
$$

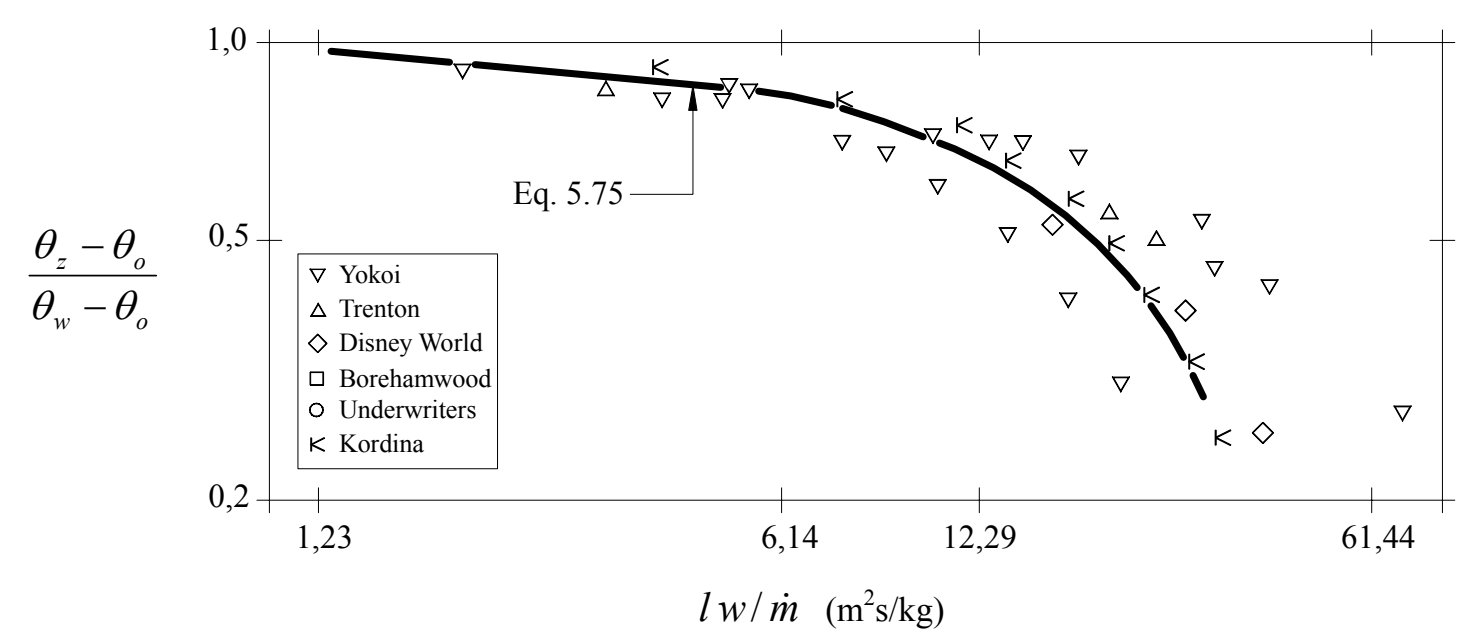

Figura 5.34 - Distribuição da temperatura da chama para ensaios em escala natural com ventilação natural (LAW, 1978).

As figuras 5.33 e 5.34 mostram que a temperatura da chama decresce diretamente proporcional ao aumento da distância ao longo do eixo da chama.

\subsubsection{Temperatura da chama na janela}

De acordo com Law (1978), ao considerar a temperatura no topo da chama como sendo $538^{\circ} \mathrm{C}$ e substituindo e $l=X$ nas eq. 5.74 e 5.75, o valor da temperatura da chama na janela, $\theta_{w}$, pode ser determinado.

Para ventilação natural, de acordo com Law (1978), a temperatura da chama na janela é dada pela eq. 5.76 .

$$
\theta_{w}=\frac{520}{\left[1-0,027\left(X \frac{w_{t}}{\dot{m}}\right)\right]}+\theta_{o}
$$


Para ventilação forçada, Law (1978) considerou os resultados da figura 5.33 e adotou a temperatura do topo da chama igual a $538^{\circ} \mathrm{C}$ para sugerir a eq. 5.77 , que determina a temperatura da chama na janela.

$$
\theta_{w}=\frac{520}{\left[1-0,027\left(X \frac{A_{v}^{1 / 2}}{\dot{m}}\right)\right]}+\theta_{o}
$$

O cálculo das temperaturas ao longo do eixo da chama até alcançar a janela independe do cálculo da temperatura dentro do compartimento incendiado. No cálculo da temperatura da chama na janela, admitiu-se um valor limite para a temperatura no topo da chama como sendo $538^{\circ} \mathrm{C}$ e, por meio de derivações estabelecidas nas equações 5.74 e 5.75 , chegou-se à temperatura na janela, conforme as equações 5.76 e 5.77 .

Nos incêndios com ventilação natural, pode-se chegar a valores de temperatura da chama na janela, $\theta_{w}$, maiores do que a temperatura do incêndio dentro do compartimento, $\theta_{g}$. Esse resultado não é esperado, desde que uma quantidade de gás não queimado possa ser emitido para fora do compartimento. Para incêndios com ventilação forçada, o valor de $\theta_{w}$ geralmente é menor do que $\theta_{g}$.

\subsection{ANÁLISE DA TEMPERATURA DOS ELEMENTOS EXTERNOS}

Nas seções anteriores foram feitas correlações para a determinação das temperaturas interna e externa a um compartimento incendiado, tendo como base experimentos realizados em escala natural. Para estabelecer correlações e modelos de transferência de calor para os elementos de aço externos, foi necessário estabelecer uma geometria para a chama que emerge para fora do compartimento, que foram comparadas às medidas feitas em ensaios em escala natural.

Nas figuras 5.35, 5.36, 5.38, 5.39, 5.40, 5.41 e 5.42, os pontos localizados acima da linha com declividade unitária representam situações a favor da segurança. 


\subsubsection{Elementos envolvidos pela chama}

Foram realizadas comparações entre os valores calculados e medidos para pilares envolvidos pela chama em incêndios com ventilação natural, conforme mostram as figuras 3.35 e 3.36. Para condição de pilares não revestidos contra fogo, conforme a figura 3.35, as temperaturas calculadas tendem a exceder os valores medidos, com exceção de um registro dos Laboratórios Underwriters que ficou abaixo e distante da linha com declividade unitária.

A figura 5.36 mostra os resultados para pilares com proteção antitérmica nas mesas. As superfícies protegidas estão localizadas na direção do fogo e são ilustradas na figura 3.37(a). No método, foi assumido que não existe transferência de calor para a face protegida. Essa consideração não é realística para os efeitos da tempertura atingida na face protegida, pois a transferência de calor não é nula.

De acordo com a figura 5.36, essa falta de precisão nos cálculos para os efeitos da temperatura atingida da face protegida foi considerada segura, exceto para as leituras dos Laboratórios Underwriters.

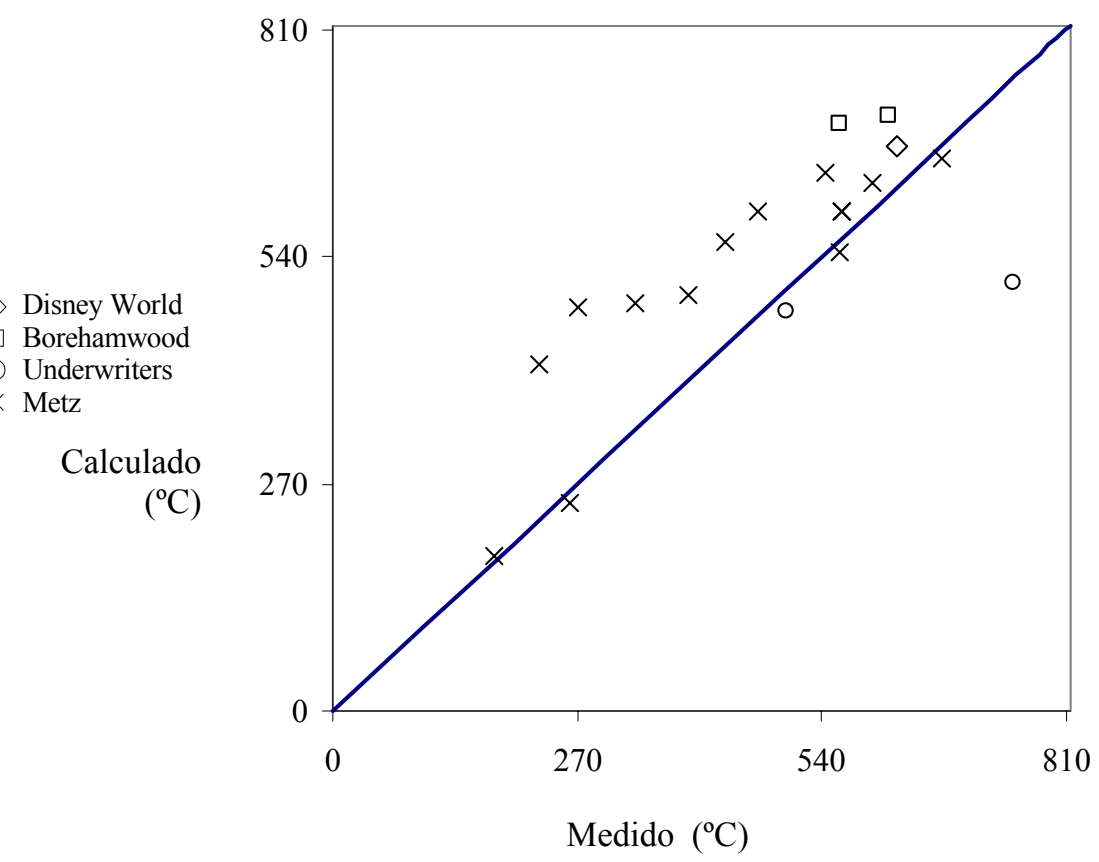

Figura 5.35 - Medidas e cálculos das temperaturas dos pilares de aço não revestidos contra fogo, envolvidos pela chama, em ensaios em escala-natural com ventilação natural (LAW, 1978). 


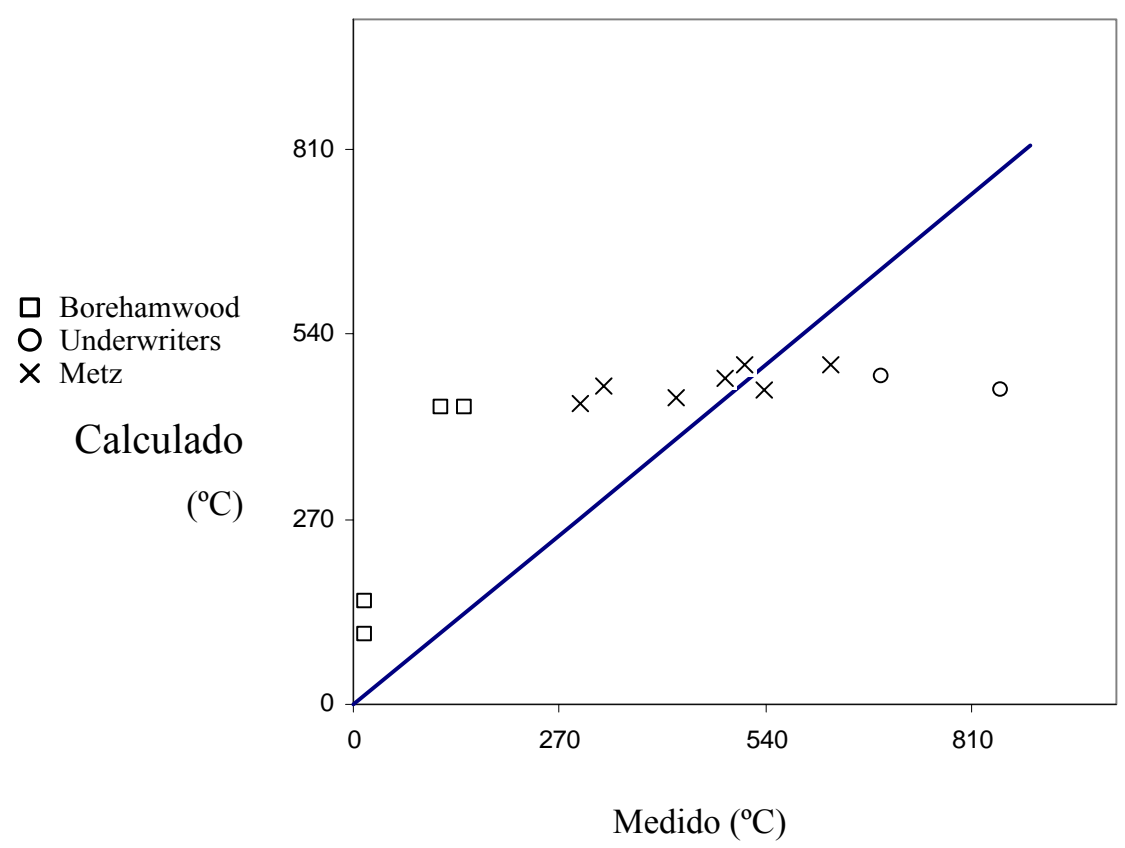

Figura 5.36 - Medidas e cálculos das temperaturas dos pilares de aço protegidos, envolvidos pela chama, em ensaios em escala natural com ventilação natural (LAW, 1978).

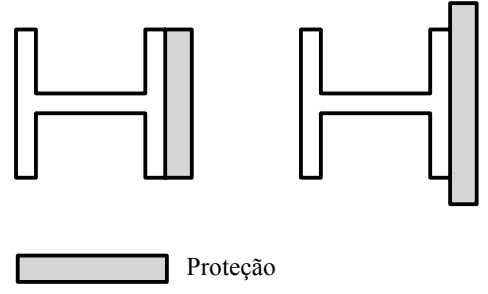

(a) Pilares protegidos

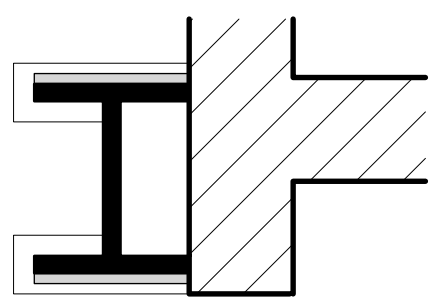

(b) Viga de borda protegida

Figura 5.37 - Elementos estruturais protegidos (LAW, 1978).

Na figura 5.38 são mostradas comparações entre as temperaturas calculadas e as medidas dos pilares sem revestimento contra fogo, em incêndios, em escala natural, com ventilação forçada. As temperaturas calculadas são, em geral, mais baixas que os valores medidos. Isso é contra a segurança e o significado desses resultados não foi esclarecido por Law (1978). 


\section{Resultados dos ensaios \\ - Valores estimados}

Calculado

$\left({ }^{\circ} \mathrm{C}\right)$

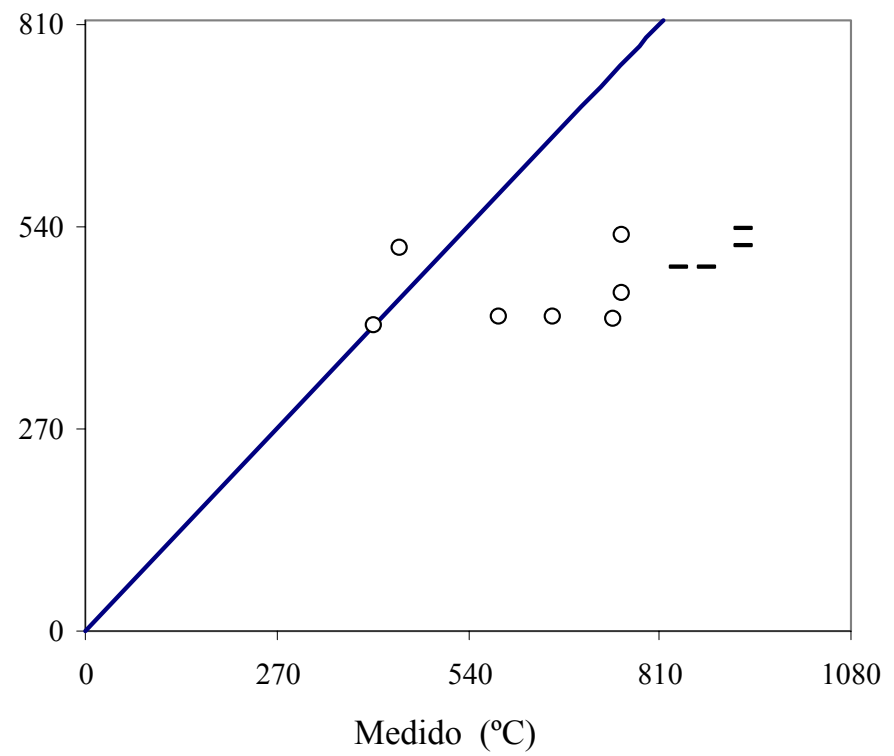

Figura 5.38 - Temperaturas medidas e calculadas para pilares de aço envolvidos pela chama, para ensaios em escala-natural, com ventilação forçada (Laboratórios Underwriters, apud LAW, 1978).

A figura 3.39 mostra comparações entre as temperaturas calculadas e as medidas em vigas de borda nos ensaios em escala natural, realizados em Borehamwood e Trenton. Em Treton, as mesas da viga foram protegidas com revestimento contra fogo, conforme mostrado na figura 5.37(b). Para esse caso, nos cálculos, foi assumido que não havia transferência de calor para as mesas. De acordo com Law (1978), o resultado mostrou-se satisfatório.

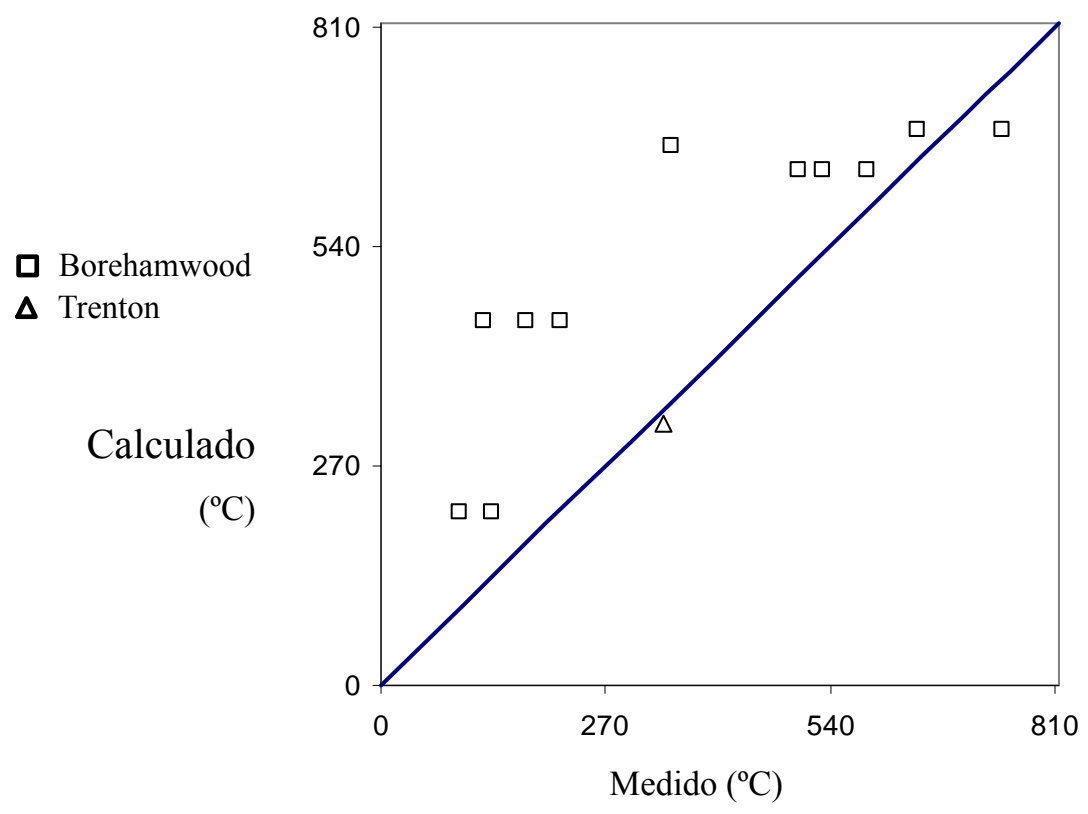

Figura 5.39 - Temperaturas medidas e calculadas para vigas de borda envolvidas pela chama, para ensaios em escala natural, com ventilação natural (LAW, 1978). 


\subsubsection{Elementos não envolvidos pela chama}

Os resultados obtidos na comparação entre os valores calculados pelo método e os medidos em ensaios, em escala natural, para pilares não envolvidos pela chama, são apresentados na figura 5.40, para incêndios com ventilação natural, e na figura 5.41, para ventilação forçada. De acordo com Law (1978), existe uma razoável concordância, embora os valores medidos nos ensaios dos Laboratórios Underwriters tenham sido maiores que os valores calculados pelo método. Esses resultados, contrários à segurança, não foram esclarecidos.

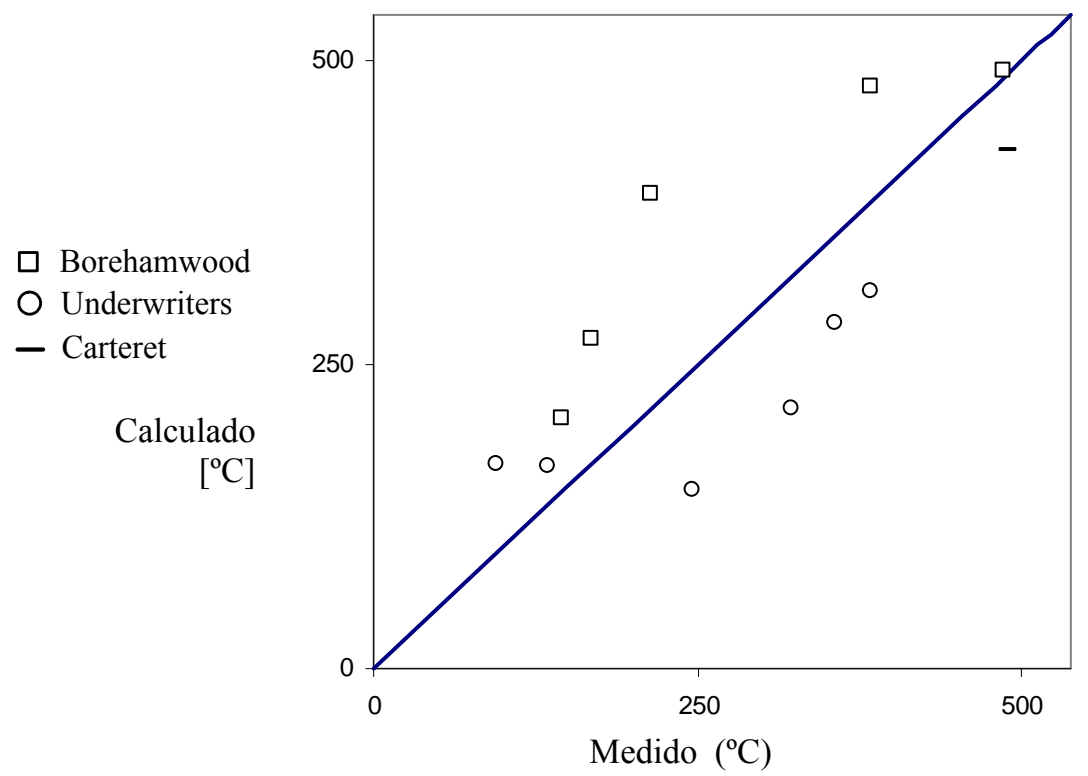

Figura 5.40 - Temperaturas medidas e calculadas para pilares não envolvidos pela chama, ensaios em escalanatural, com ventilação natural (LAW, 1978).

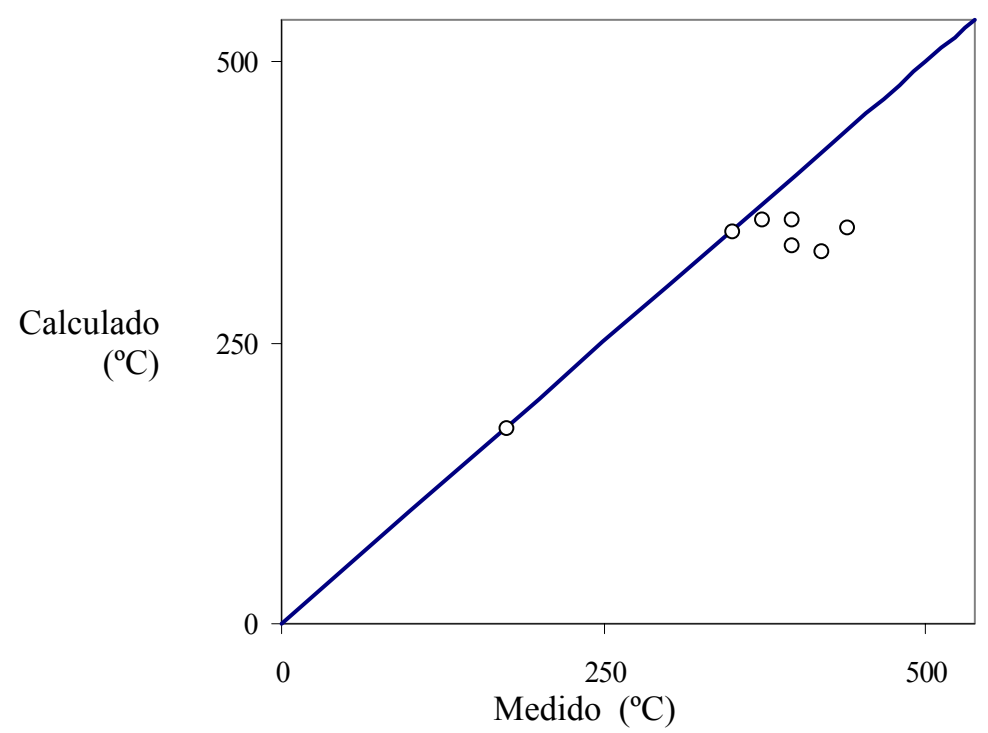

Figura 5.41 - Temperaturas medidas e calculadas para pilares não envolvidos pela chama, para ensaios em escala-natural, com ventilação forçada (Laboratórios Underwriters, apud LAW, 1978). 
A figura 5.42 mostra uma comparação entre os resultados obtidos por meio de cálculos e por ensaios dos Laboratórios Underwriters, para uma viga de borda não envolvida pela chama, em incêndio com ventilação forçada. Foram colocadas marquises para proteger a parte inferior da mesa da viga, nas duas situações em que foram realizados os ensaios. Segundo Law (1978), existe um acordo razoável para ambos os resultados, emboram alguns valores medidos tenham resultados maiores que os calculados.

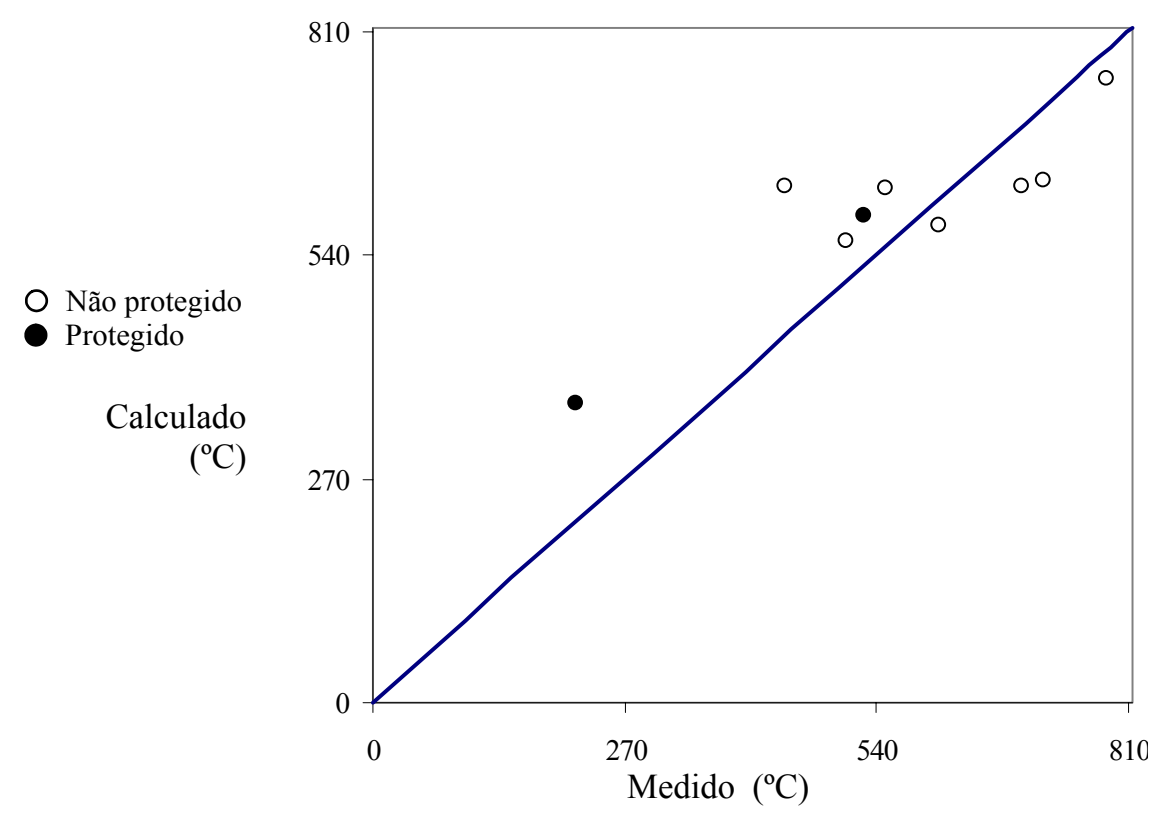

Figura 5.42 - Temperaturas medidas e calculadas para viga de borda, para ensaios em escala-natural, com ventilação forçada (Laboratórios Underwriters, apud, LAW, 1978).

\subsubsection{Considerações sobre as temperaturas do aço}

Embora haja boa concordância entre os valores calculados e os medidos das temperaturas do aço, existem resultados que necessitam de considerações adicionais. De acordo com as figuras 5.35 e 5.36, algumas temperaturas calculadas para os pilares de Metz e para os pilares de Borehamwood são bastante altas. Nesses ensaios, as cargas de incêndio eram baixas. Em razão disso, é possível que a duração da chama externa tenha sido menor do que a duração do incêndio. Algumas das temperaturas calculadas para os pilares nos ensaios dos Laboratórios Underwriters são mostradas nas figuras de 5.35 a 5.38. De acordo com Law (1978), as razões para as discrepâncias entre os valores calculados pelo método e os medidos em ensaios não estão claras. 
Na figura 5.38, as temperaturas calculadas para pilares envolvidos pela chama para ventilação forçada certamente não são menores do que os valores medidos. De acordo com Law (1978), os valores calculados não foram grandes o suficiente para compensar os erros nas medições dos laboratórios Underwriters. A satisfatória concordância dos resultados obtidos por meio do cálculo com os conseguidos nos Laboratórios Underwriters sugerem que o método é aceitável. Nas aferições apresentadas, as temperaturas do aço atingiram cerca de $538^{\circ} \mathrm{C}$. Em ensaios padronizados, geralmente adotam-se, por simplicidade, valores fixos de temperaturas críticas, por exemplo, a ASTM E-119 (2007) assume $538^{\circ} \mathrm{C}$ para pilares e $593^{\circ} \mathrm{C}$ para vigas, e a LPS 1107 adota $550{ }^{\circ} \mathrm{C}$ (LPS, 1987).

\subsection{FATOR DE CONFIGURAÇÃO}

O fator de configuração para transferência de radiação proveniente de uma superfície emissora para uma superfície receptora, de acordo com o Eurocode 1, Part 1-2 (2002), é definido como a fração da energia radiativa que deixa a superfície emissora e chega na superfície receptora. Seu valor depende do tamanho da superfície irradiante, da distância entre a superfície irradiante e a superfície receptora além da orientação relativa entre elas.

Para o cálculo de temperaturas em elementos externos, pode ser assumido que as superfícies irradiantes tenham formas retangulares. Esse procedimento é necessário para simplificar os cálculos dos fatores de configuração. Incluem-se como superfícies irradiantes de calor as janelas e outras aberturas nas paredes externas do compartimento incendiado e também as superfícies retangulares equivalentes das chamas.

No cálculo do fator de configuração, deve ser desenhada uma envoltória retangular em torno da seção transversal do elemento que recebe calor por radiação, como indicado na figura 5.43. $\mathrm{O}$ valor do fator de configuração, $\phi$, deve ser determinado para o ponto médio, $P$, de cada face desse retângulo. 


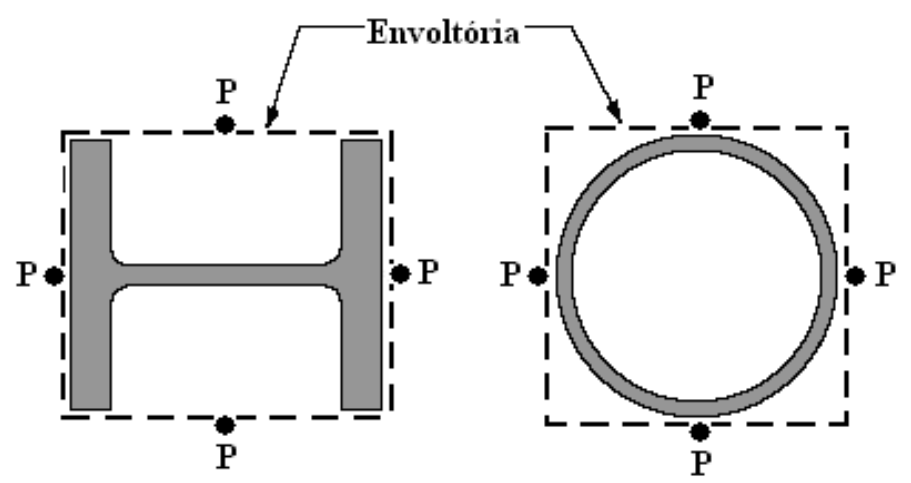

Figura 5.43 - Envoltória retangular da superfície receptora.

O fator de configuração para cada superfície receptora deve ser determinado como sendo a soma das contribuições de cada uma das zonas na superfície irradiante, geralmente quatro, que é visível do ponto $P$ na superfície receptora, como indicado nas figuras 5.44 e 5.45. Essas zonas devem ser definidas em relação a um ponto $X$, onde uma linha horizontal perpendicular à superfície receptora se encontra com o plano que contém a superfície irradiante. Nenhuma contribuição deve ser feita por zonas que não são visíveis do ponto $P$, tal como ilustrada pela figura 5.45 .

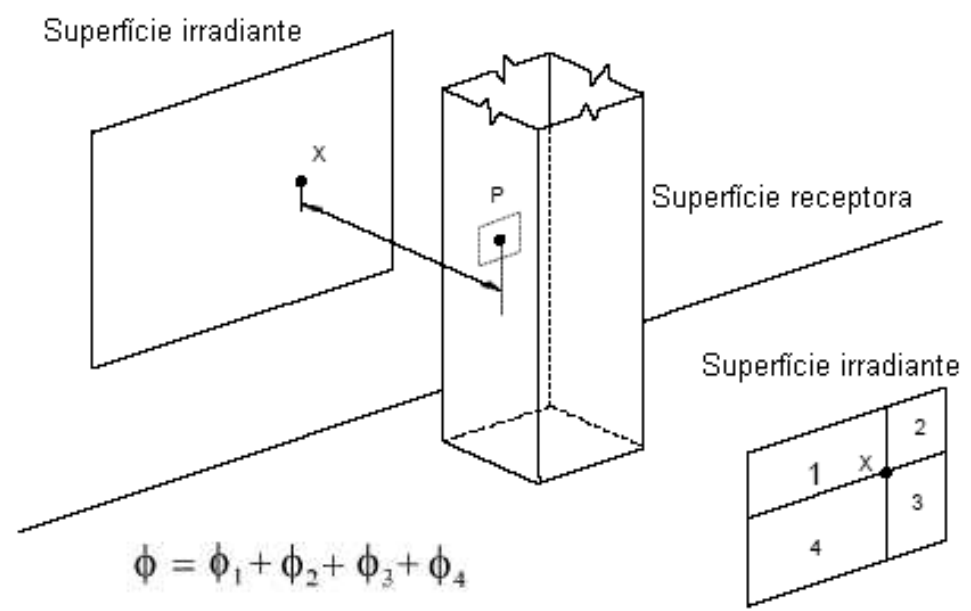

Figura 5.44 - Superfície receptora em plano paralelo com a superfície irradiante (EUROCODE 1, PART 1.2, 2002). 


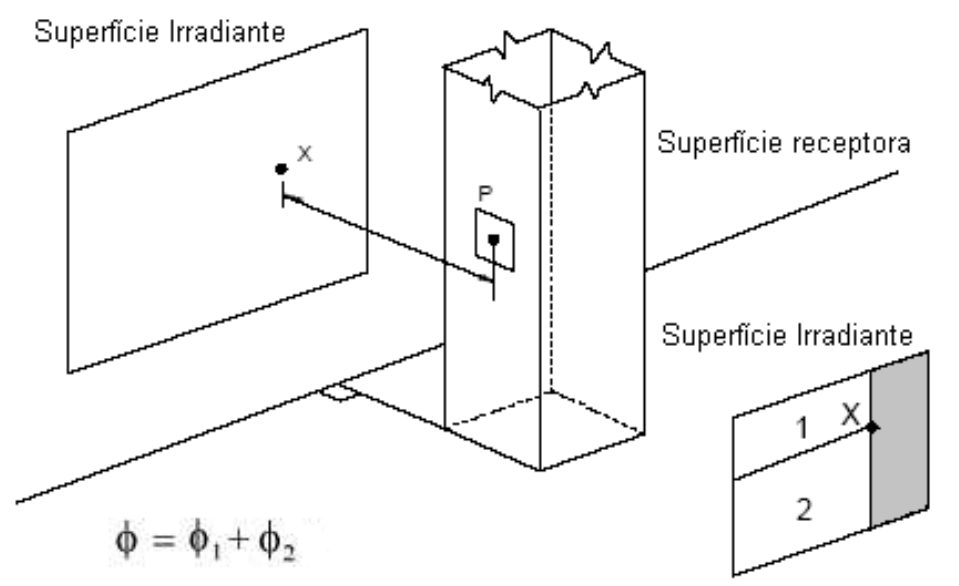

Figura 5.45 - Superfície receptora perpendicular ao plano da superfície irradiante (EUROCODE 1, PART 1.2, 2002).

Se o ponto $X$ se encontrar ao lado de fora da superfície irradiante, o fator de configuração pode ser determinado por adição da contribuição de dois retângulos que se estendem do ponto $X$ para o lado mais distante da superfície irradiante. Então, subtrai-se a contribuição dos dois retângulos que se estendem de $X$ até o lado mais próximo da superfície irradiante.

A contribuição de cada zona pode ser determinada como ilustrado na figura 5.46 e descrito a seguir:

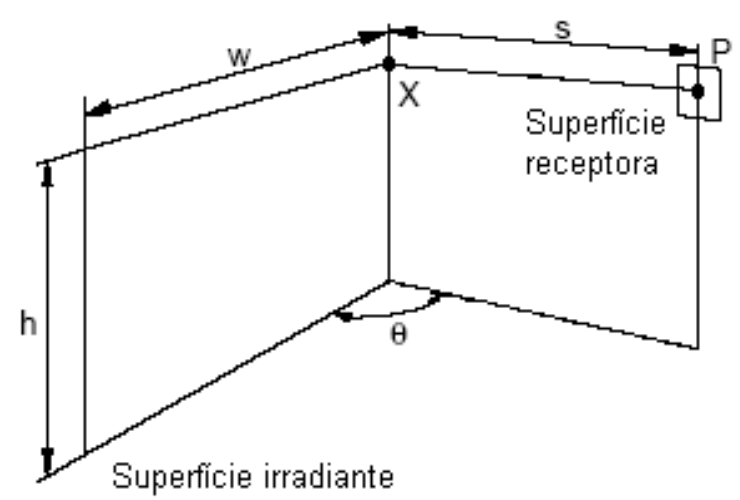

Figura 5.46 - Superfície receptora em um plano com ângulo $\theta$ em relação à superfície irradiante (EUROCODE 1, PART 1.2, 2002).

Quando a superfície receptora é paralela à superfície irradiante, utiliza-se a eq. 5.78.

$$
\phi=\frac{1}{2 \pi}\left\{\frac{a}{\left(1+a^{2}\right)^{0.5}} \tan ^{-1}\left[\frac{b}{\left(1+a^{2}\right)^{0.5}}\right]+\frac{b}{\left(1+b^{2}\right)^{0.5}} \tan ^{-1}\left[\frac{a}{\left(1+b^{2}\right)^{0.5}}\right]\right\}
$$


Onde:

$a=h / s$

$\mathrm{b}=\mathrm{w} / \mathrm{s}$

$s \quad$ é a distância entre o ponto $P$ e o ponto $X(\mathrm{~m})$;

$h \quad$ é a altura da região da superfície irradiante (m);

w é a largura da região da superfície irradiante (m).

Quando a superfície receptora é perpendicular a superfície irradiante, utiliza-se a eq. 5.79.

$$
\phi=\frac{1}{2 \pi}\left\{\tan ^{-1}(a)-\frac{1}{\left(1+b^{2}\right)^{0.5}} \tan ^{-1}\left[\frac{a}{\left(1+b^{2}\right)^{0.5}}\right]\right\}
$$

Quando a superfície receptora está em um plano que forma um ângulo $\theta$ com a superfície irradiante, utiliza-se a eq. 5.80 .

$$
\begin{aligned}
\phi=\frac{1}{2 \pi}\left\langle\tan ^{-1}(a)-\frac{1-b \cos \theta}{\left(1+b^{2}-2 b \cos \theta\right)^{0.5}} \tan ^{-1}\left[\frac{a}{\left(1+b^{2}-2 b \cos \theta\right)^{0.5}}\right]+\right. \\
\left.+\frac{a \cos \theta}{\left(a^{2}+\operatorname{sen}^{2} \theta\right)^{0.5}}\left\{\tan ^{-1}\left[\frac{b-\cos \theta}{\left(a^{2}+\operatorname{sen}^{2} \theta\right)^{0.5}}\right]+\tan ^{-1}\left[\frac{\cos \theta}{\left(a^{2}+\operatorname{sen}^{2} \theta\right)^{0.5}}\right]\right\}\right)
\end{aligned}
$$

O fator de configuração global, $\phi$, para o elemento que sofre transferência de calor por radiação, pode ser determinado pela média ponderada dos fatores de configuração para cada face do elemento em relação aos respectivos tamanhos da face, e é dado pela eq. 5.81 .

$$
\phi=\frac{\left(C_{1} \phi_{1}+C_{2} \phi_{2}\right) d_{1}+\left(C_{3} \phi_{3}+C_{4} \phi_{4}\right) d_{2}}{\left(C_{1}+C_{2}\right) d_{1}+\left(C_{3}+C_{4}\right) d_{2}}
$$

Onde:

$\phi_{i} \quad$ é o fator de configuração do elemento na face $i$;

$d_{i} \quad$ é a dimensão da seção transversal do elemento na face $i(\mathrm{~m})$; 
$C_{i} \quad$ é o coeficiente de proteção do elemento na face $i$.

Para face protegida $C_{i}=0$;

Para face desprotegida $C_{i}=1$.

Os cálculos detalhados dos fatores de configuração aplicado ao método de Margaret Law, pode ser encontrado em Azevedo (2005).

\subsection{CONSIDERAÇÕES SOBRE O MÉTODO}

\subsubsection{Desenvolvimento do incêndio e da chama para grandes compartimentos}

De acordo com Law (1978), as correlações para o desenvolvimento do incêndio e da chama mostram uma satisfatória concordância entre os valores cálculados e os medidos em experimentos realizados em escala natural. Esses experimentos foram realizados em compartimentos do tamanho de salas. O maior experimento foi realizado em Treton, onde o compartimento tinha $17,10 \mathrm{~m}$ de largura por $7,30 \mathrm{~m}$ de profundidade.

Nos cálculos, supõe-se que todo o compartimento é envolvido simultaneamente pelo incêndio, contudo, para grandes compartimentos o incêndio é progressivo. Isso pode superestimar a temperatura do incêndio e o tamanho da chama.

O incêndio progressivo poderia demandar um longo tempo para seu completo desenvolvimento, mas a suposição da simultaneidade no seu desenvolvimento foi assumido por ter sido considerado as condições de transferência de calor em estado estacionário. Isso é razoável, uma vez que permite que as correlações possam ser utilizadas para grandes compartimentos e que os erros para grandes tamanhos tendem a ser a favor da segurança.

A duração efetiva do incêndio em condição de queima-livre depende do tipo, espessura e espaçamento entre as cargas de incêndio. As cargas de incêndio experimentais são usualmente constituídas de madeira, que é uma forma fácil de reproduzir o combustível. Nos experimentos foram considerados os estudos realizados sobre os efeitos do material combustível de madeira na taxa de combustão. 
Pouca informação foi avaliada sobre a mobília, mas pode-se assumir que os incêndios que envolvem a maioria das mobílias de residências, escritórios, escolas e hospitais apresentam resultados similares com os ensaios realizados com combustível em madeira com queimalivre de 20 min. Materiais de revestimentos combustíveis utilizados em tetos e paredes podem tornar o tempo de combustão mais curto, como demonstrado em ensaios realizados em Borehamwood.

\subsubsection{Parâmetros geométricos do compartimento}

No cálculo da taxa de combustão para incêndios controlados pela ventilação, com ventilação natural, usando a eq. 5.32, $\left(W_{2} / W_{1}\right)$, representa-se a razão entre a profundidade do compartimento e a largura da parede que contém as aberturas. Se existirem janelas em mais de uma parede, $\left(W_{2} / W_{1}\right)$ será reduzido conforme eq. 5.82. Como regra geral, a parede que possui a maior área de abertura é a parede com largura $W_{1}$.

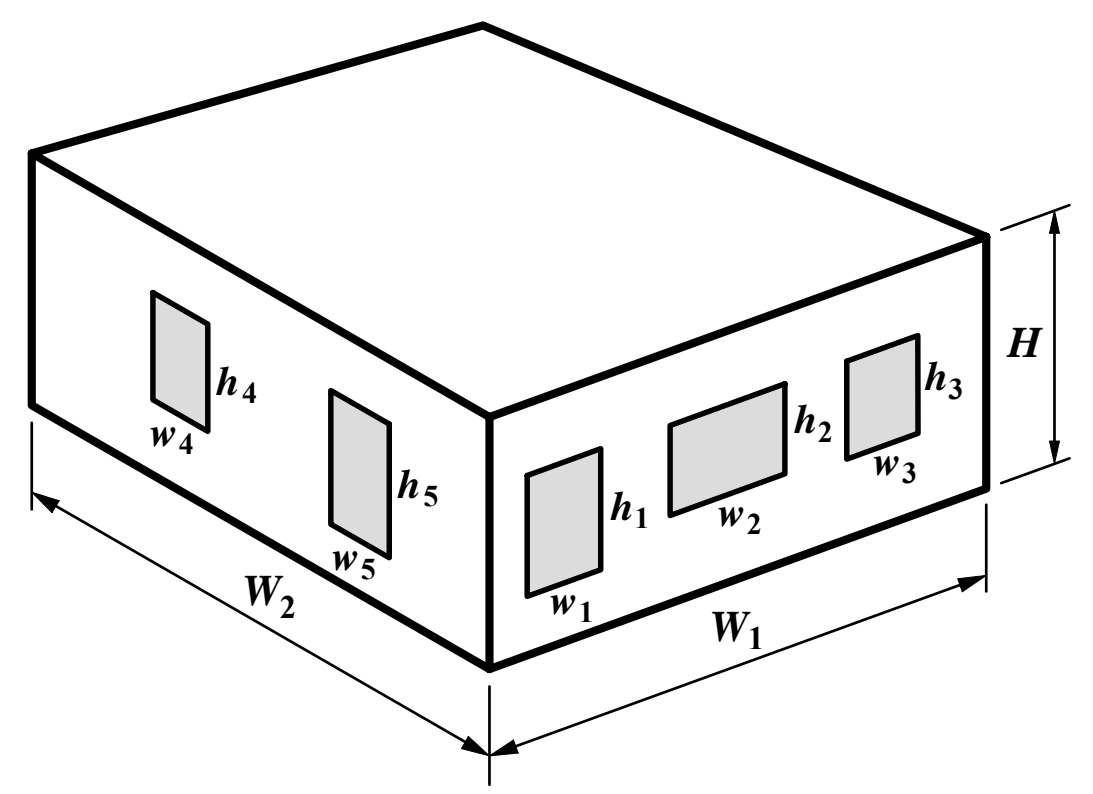

Figura 5.47 - Geometria do compartimento.

$$
\left(\frac{W_{2}}{W_{1}}\right)_{\text {efetivo }}=\frac{\left(A_{v}\right)}{A_{v}}\left(\frac{W_{2}}{W_{1}}\right)
$$


Onde:

$\left(A_{v}\right)_{1}$ é área das aberturas da parede com largura $W_{1}$;

$A_{v} \quad$ é a área total das aberturas em todas as paredes.

Onde existe mais de uma abertura, o valor de $A_{v}$, utilizado nas eq.5.15, 5.32 e 5.37 para ventilação natural, será a soma das áreas individuais, conforme a eq. 5.83.

$$
A_{v}=A_{1}+A_{2}+A_{3}+\ldots+A_{n}
$$

Para a ventilação forçada, o valor de $A_{v}$ usado nas eq. 5.38, 5.50 e 5.74 é a soma das áreas individuais das aberturas por onde as chamas emergem.

O valor de $w$ usado nas eq. 5.45 e 5.75 para incêndios com ventilação natural é a soma das larguras individuais, conforme a eq. 5.84 .

$$
w=w_{1}+w_{2}+w_{3}+\ldots+w_{n}
$$

Quando as aberturas possuem diferentes alturas, o valor de $h$ usado nas eq. 5.32, 5.37 e no cálculo de $n=2 w / h$ para incêndios com ventilação natural será conforme a eq. 5.85.

$$
h=\frac{A_{1} h_{1}+A_{2} h_{2}+\ldots+A_{n} h_{n}}{A_{1}+A_{2}+\ldots+A_{n}}
$$

Existe uma exceção no cálculo de $n$ quando as aberturas forem muito espaçadas. De acordo com Yokoi apud Law (1978), quando o espaço entre as aberturas exceder a duas larguras da abertura, as chamas das aberturas podem ser assumidas como separadas e $n$ pode ser calculado como se fosse uma abertura individual.

\subsubsection{Gradiente de temperatura no aço}

De acordo com Law (1978), as medições das temperaturas dos pilares mostram, em geral, que o máximo valor é alcançado no nível do topo da abertura, tendo uma difereça entre o nível do topo e o nível da parte inferior da abertura em torno de $205^{\circ} \mathrm{C}$. 
A maneira como a temperatura diminui acima da abertura irá variar de acordo a altura da chama. Pode haver um gradiente de temperatura através da seção tais que a mesa interna que enfrenta o fogo poderia ser $205^{\circ} \mathrm{C}$ maior do que a mesa externa, principalmente quando a mesa interna está revestida.

Os cálculos descritos não são sensíveis para estimar o tamanho dos gradientes de temperatura em um elemento de aço externo a um compartimento incendiado.

\subsubsection{Considerações gerais}

A exposição ao incêndio dos elementos estruturais externos não deve ser simulada pelo modelo do incêndio-padrão, mas calculada caso a caso. A transferência de calor para esses elementos depende da trajetória e da temperatura da chama, da temperatura do compartimento incendiado, da posição do elemento e do resfriamento do elemento com o ambiente ao redor. O método de cálculo teve por base estudos que compreendem modelos e ensaios de incêndio em escala natural. O cálculo da temperatura do aço é satisfatório e concorda com os valores medidos nos referidos ensaios.

A chama externa e o comportamento do incêndio interno podem ser calculados, dada a quantidade e o tipo de carga de incêndio, as dimensões do compartimento incendiado e as dimensões das aberturas.

Apesar desta Tese não enfatizar o cálculo da temperatura do aço devido à ventilação forçada, é relevante ressaltar que, devido à formulação proposta por Law (1978), em alguns casos, as dimensões das chamas externas serão excessivas (figura 6.7), provavelmente, acima da realidade. No entanto, observa-se que os valores de temperatura no aço são aceitáveis, pois, para a estrutura imersa em chamas, as dimensões das chamas afetam tão somente o valor da emissividade, que é limitada superiormente em 1. 
Capítulo 6 PROGRAMA DE COMPUTADOR EXTEELFIRE 2.0

\subsection{INTRODUÇÃO}

O programa de computador ExteelFire 2.0 foi implementado na linguagem de programação Microsoft Visual Basic ${ }^{\circledR}$. Esse sistema de programação é usado para escrever programas de computador para ambiente Windows, sendo considerado uma ferramenta para desenvolvimento rápido de aplicativos, ou RAD (Rapid Application Development). A figura 6.1 apresenta a interface do programa de computador Visual Basic.

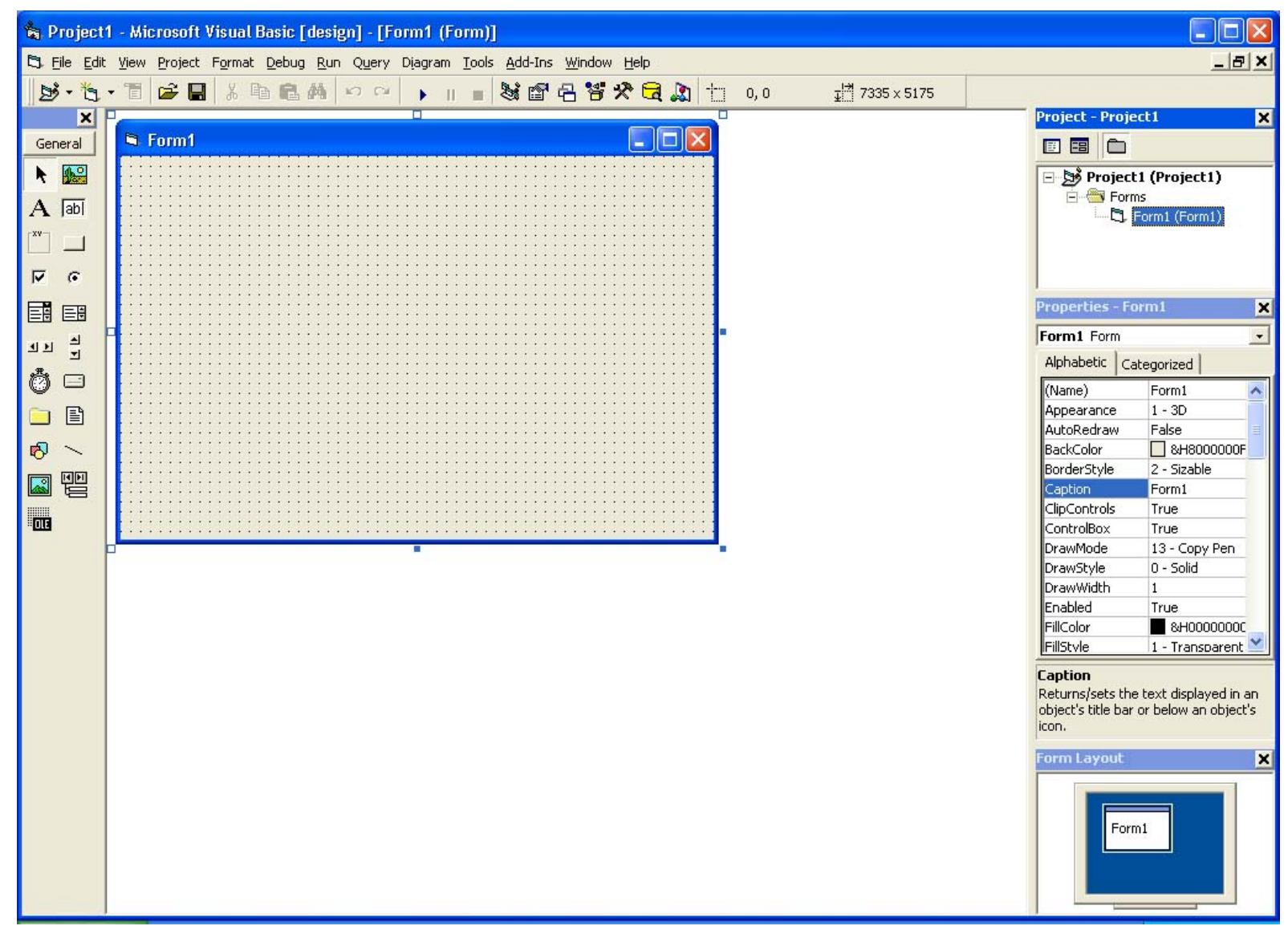

Figura 6.1 - Interface do programa de computador Visual Basic. 
Um programa de computador é um conjunto de instruções que um computador deve seguir para desempenhar uma tarefa específica. Uma linguagem de programação como o Visual Basic é usada para traduzir instruções compreensíveis para os seres humanos, nos passos que o computador pode reconhecer e seguir.

\subsection{DESCRIÇÃO DO PROGRAMA DE COMPUTADOR}

A maioria dos aplicativos para Windows exibe uma janela inicial com informações sobre o produto quando ele é carregado. Essa janela é chamada de tela de splash. A figura 6.2 mostra a tela de splash do ExteelFire 2.0.

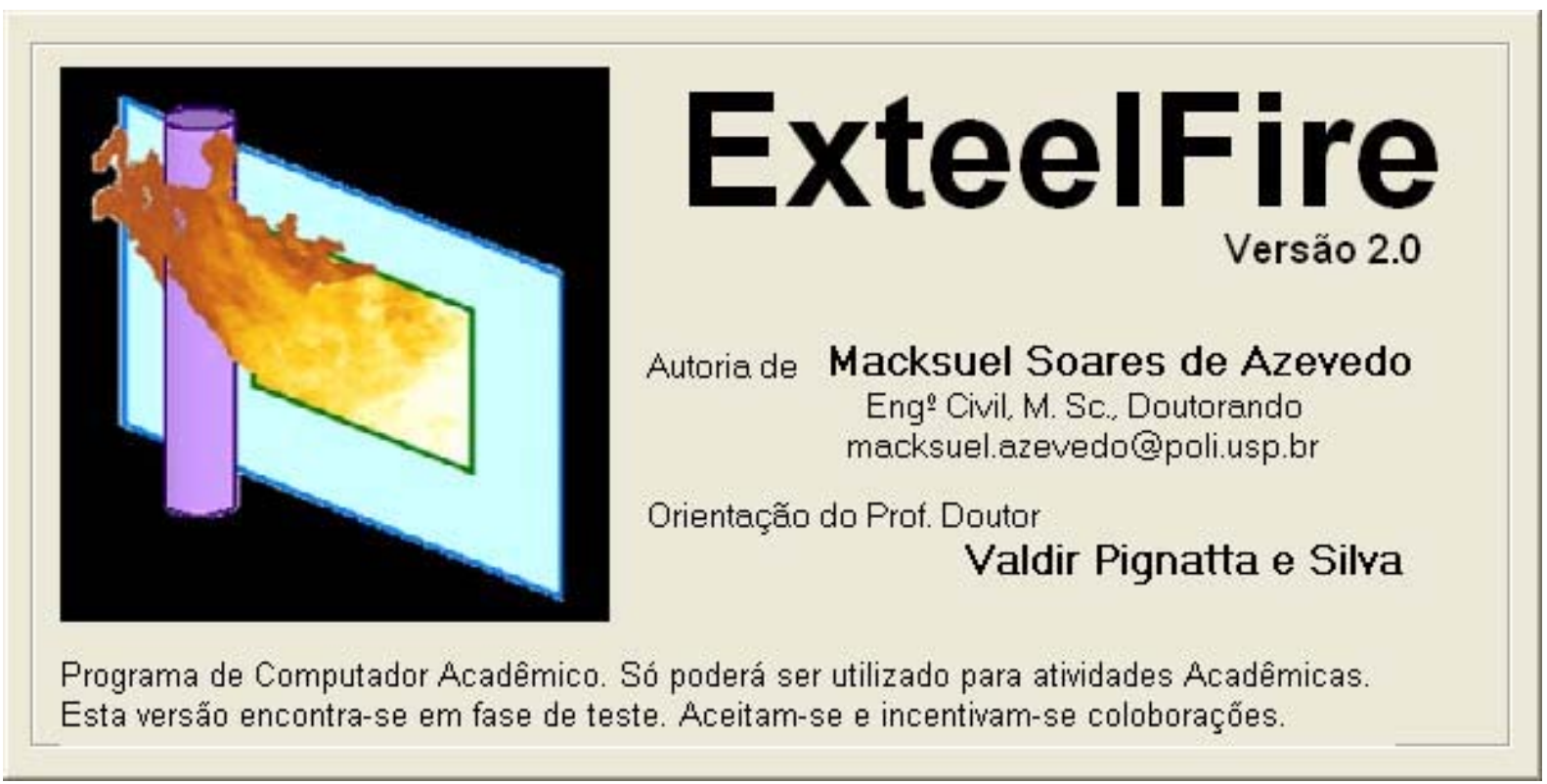

Figura 6.2 - Tela de splash do ExteelFire 2.0.

O programa ExteelFire 2.0 foi desenvolvido para determinar a máxima temperatura de elementos estruturais de aço externos à edificação em situação de incêndio, tanto para pilares quanto para vigas. A formulação teve como base o método de Margaret Law e obedece aos procedimentos descritos pelo Eurocode 1, Part 1-2 (2002) e pelo Eurocode 3, Part 1-2 (2003). 
A figura 6.3 apresenta a primeira tela do programa ExteelFire 2.0. A tela refere-se à entrada de dados sobre o compartimento incendiado. $\mathrm{Na}$ primeira parte, escolhe-se o tipo de compartimento que pode ser: compartimento com uma janela, compartimento com mais de uma janela ou compartimento com janelas em mais de uma parede. Pode-se, ainda, especificar se o compartimento possui ou não núcleo em seu interior.

$\mathrm{Na}$ segunda parte da tela, digitam-se os dados relativos às dimensões do compartimento, tais como: largura, profundidade e altura, caso haja núcleo, os dados relativos à largura e profundidade do núcleo. Na terceira parte da tela, digitam-se os dados relativos às janelas do compartimento, tais como: altura e largura. As áreas de piso, de janelas e área total do compartimento são calculadas e indicadas nessa tela.

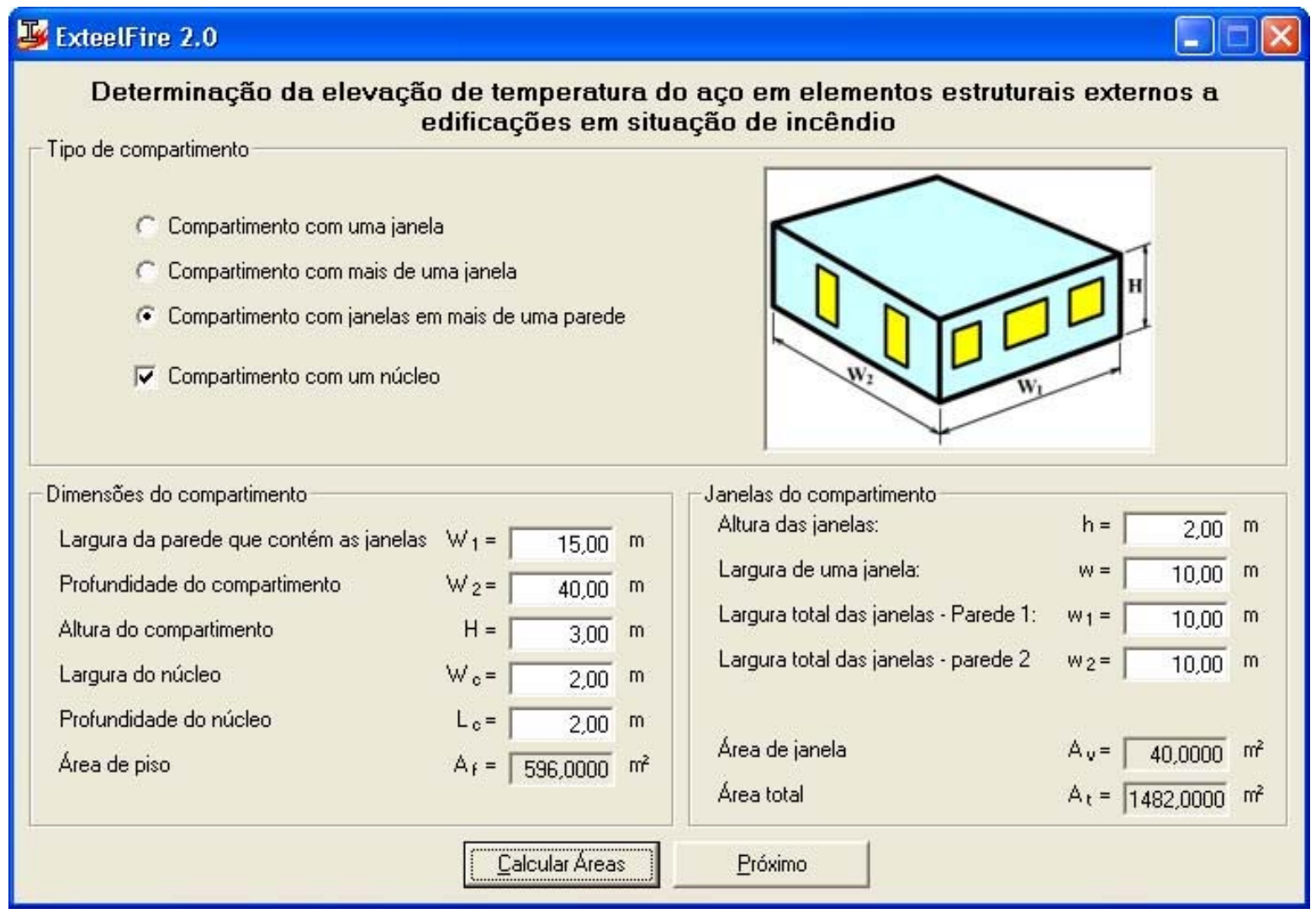

Figura 6.3 - Tela 1 do ExteelFire 2.0. Dados de entrada sobre o compartimento incendiado.

A segunda tela é mostrada na figura 6.4 e refere-se aos dados de entrada do elemento estrutural. $\mathrm{O}$ elemento estrutural pode ser um pilar ou viga. $\mathrm{O}$ seu posicionamento deve ser indicado em relação às janelas e ao compartimento.

Esse posicionamento pode ser: pilar em frente a uma janela, conforme figura 6.4; pilar entre janelas, conforme figura 6.5; ou viga paralela à parede, conforme figura 6.6. Pode-se, ainda, 
indicar a existência de marquise ou sacada acima da janela e a existência de parede acima da janela, fatores que interferem na geometria da chama. Caso haja marquise ou sacada acima da janela é necessário informar a largura da mesma.

O ExteelFire 2.0 permite estabelecer de forma individual qual face do elemento estrutural está protegida, ou seja, impedida de receber fluxo de calor.

Indica-se o valor de cálculo da carga de incêndio específica e a carga total de incêndio é calculada e indicada na tela (figura 6.4).

O valor de cálculo da carga de incêndio é o valor característico da carga de incêndio específica do compartimento em chamas afetado por coeficientes de ponderação, que considerem o desempenho da proteção ativa e as consequências do incêndio, conforme eq. 6.1 .

$$
q_{f i, d}=q_{f i, k} \gamma_{s} \gamma_{n}
$$

Onde:

$q_{f i, d} \quad$ é o valor de cálculo da carga de incêndio por área de piso $\left(\mathrm{MJ} / \mathrm{m}^{2}\right)$;

$q_{f i, k} \quad$ é o valor característico da carga de incêndio por unidade de área de piso $\left(\mathrm{MJ} / \mathrm{m}^{2}\right)$;

$\gamma_{s}$ é o coeficiente de ponderação relacionado ao risco (perigo e consequências) do incêndio (adimensional);

$\gamma_{n}$ é o coeficiente de ponderação relacionado aos dispositivos de proteção, que permite reduzir a severidade do incêndio (adimensional).

O valor característico da carga de incêndio específica pode ser encontrado na ABNT NBR 14323:1999, no entanto, não há qualquer menção aos fatores de ponderação a serem adotados. Costa e Silva (2005) apresentaram uma sugestão sobre os coeficientes de ponderação a serem empregados. 
Para a análise de um pilar selecionado, em frente a uma abertura, conforme figura 6.4, é necessário especificar os dados relativos ao pilar, tais como: distância até a parede, dimensões da seção do pilar e distância do pilar à borda esquerda da abertura.

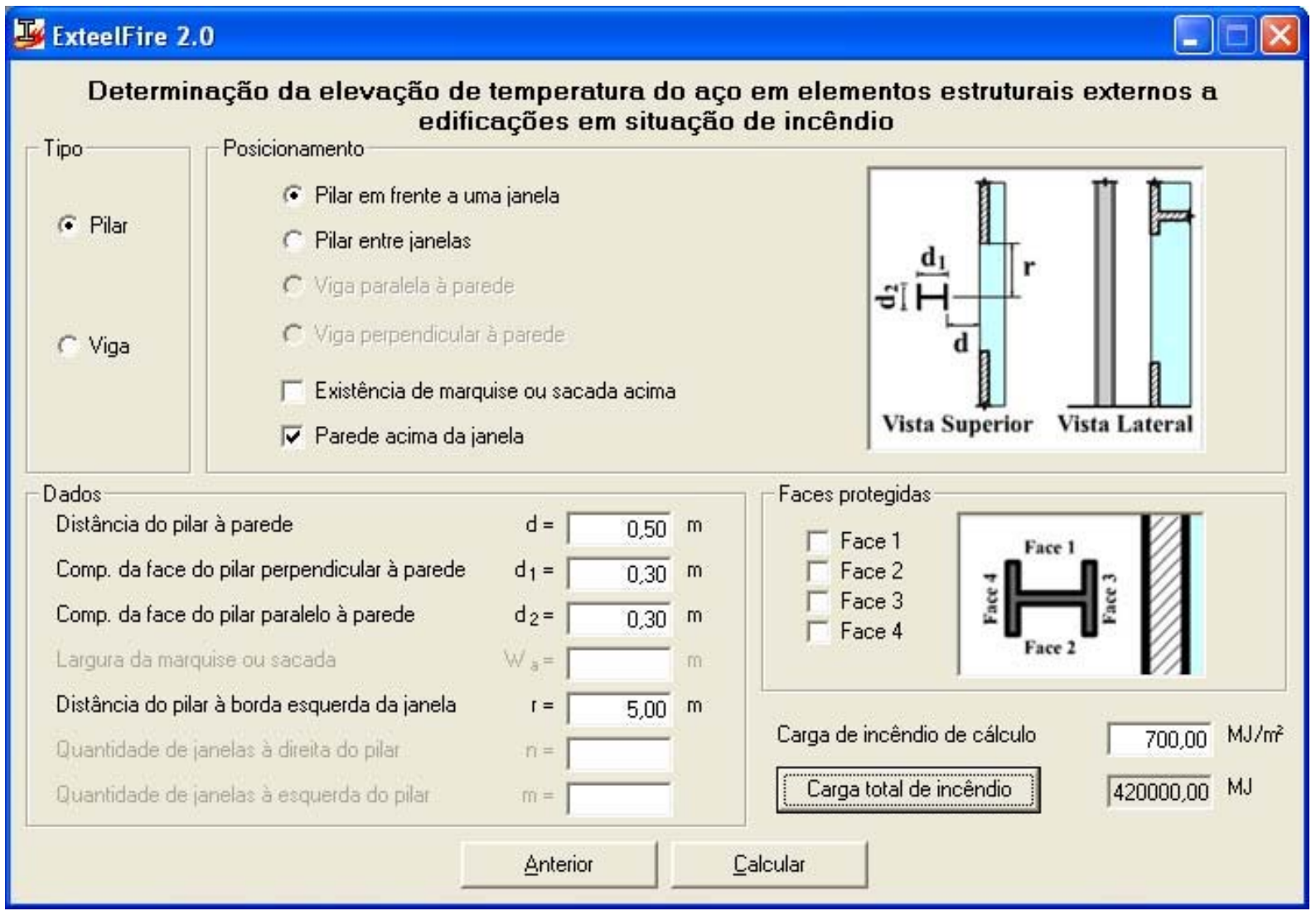

Figura 6.4 - Tela 2 do ExteelFire 2.0. Dados relativos ao elemento estrutural e à carga de incêndio. Pilar em frente a uma abertura.

A figura 6.5 mostra a segunda tela do ExteelFire 2.0 para situação de pilar posicionado entre as aberturas. Deve-se indicar a distância do pilar às bordas esquerda e direita da janela e a quantidade de janelas à esquerda e à direita do pilar.

A figura 6.6 mostra a segunda tela para situação de viga paralela à parede da fachada. Indicam-se a distância da viga à parede, as dimensões da sua seção transversal e a distância vertical em relação ao topo da abertura. 


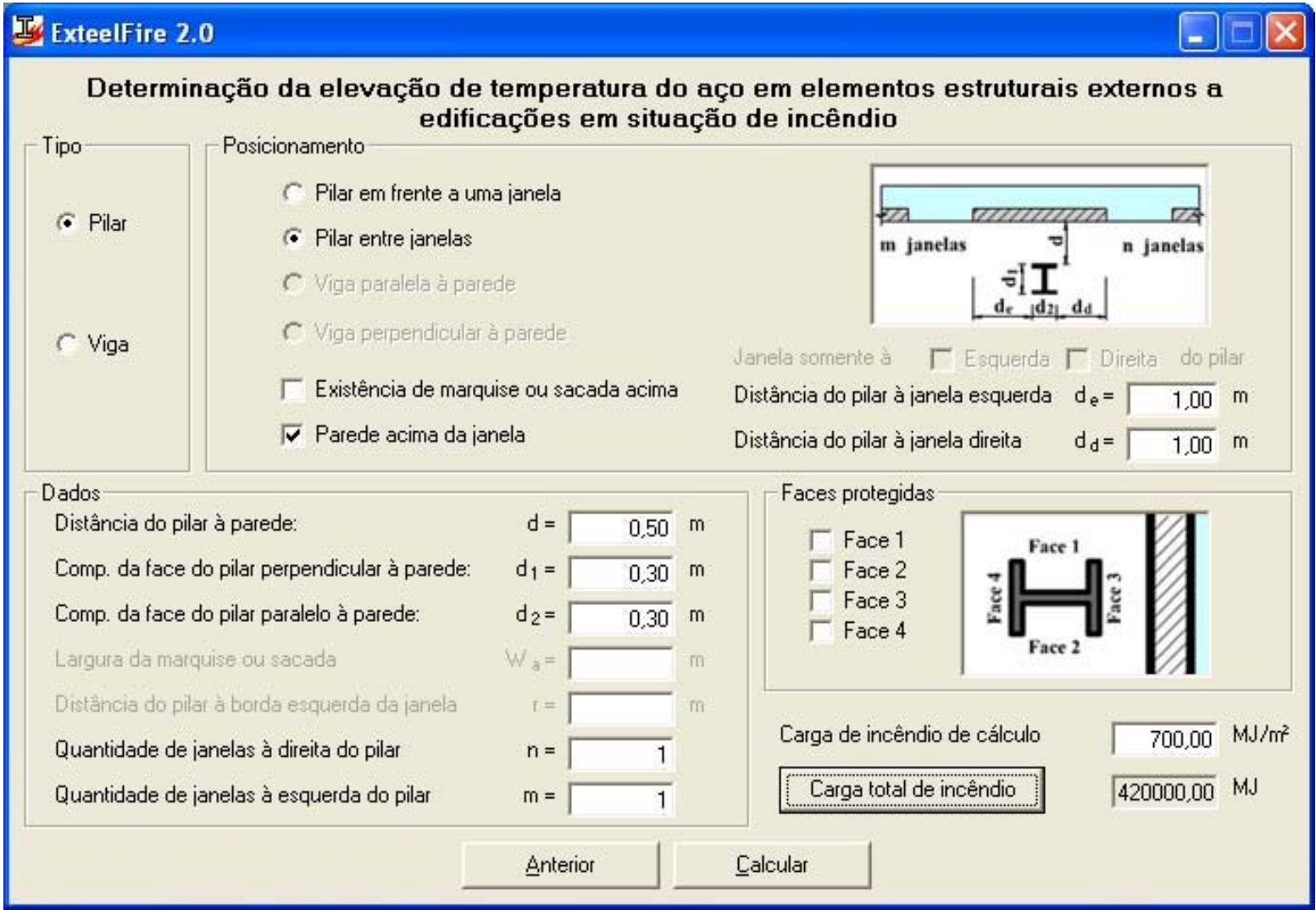

Figura 6.5 - Tela 2 do ExteelFire 2.0. Dados relativos ao elemento estrutural e à carga de incêndio. Pilar entre aberturas.

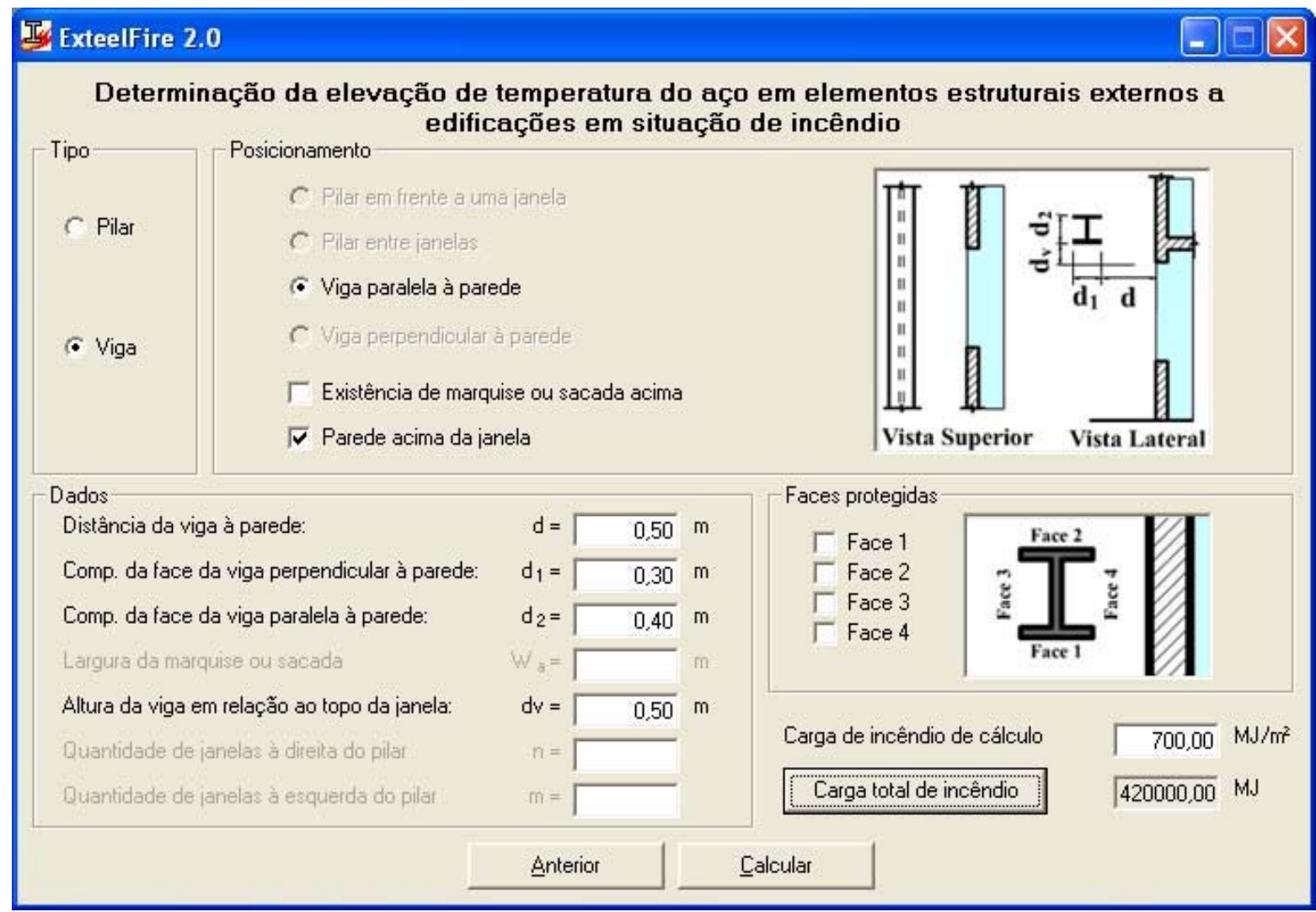

Figura 6.6 - Tela 2 do ExteelFire 2.0. Dados relativos ao elemento estrutural e à carga de incêndio. Viga paralela à parede. 
As figuras 6.7, 6.8 e 6.9 mostram a terceira tela do ExteelFire 2.0 para pilar posicionado em frente a uma janela, pilar entre janelas e viga paralela à parede, respectivamente. A partir dos dados anteriormente fornecidos, o programa calcula e indica a taxa de combustão, a temperatura máxima dos gases dentro do compartimento e a geometria da chama, ou seja, altura, projeção horizontal, largura e comprimento ao logo do seu eixo. A posição do elemento estrutural em relação à chama é identificada.

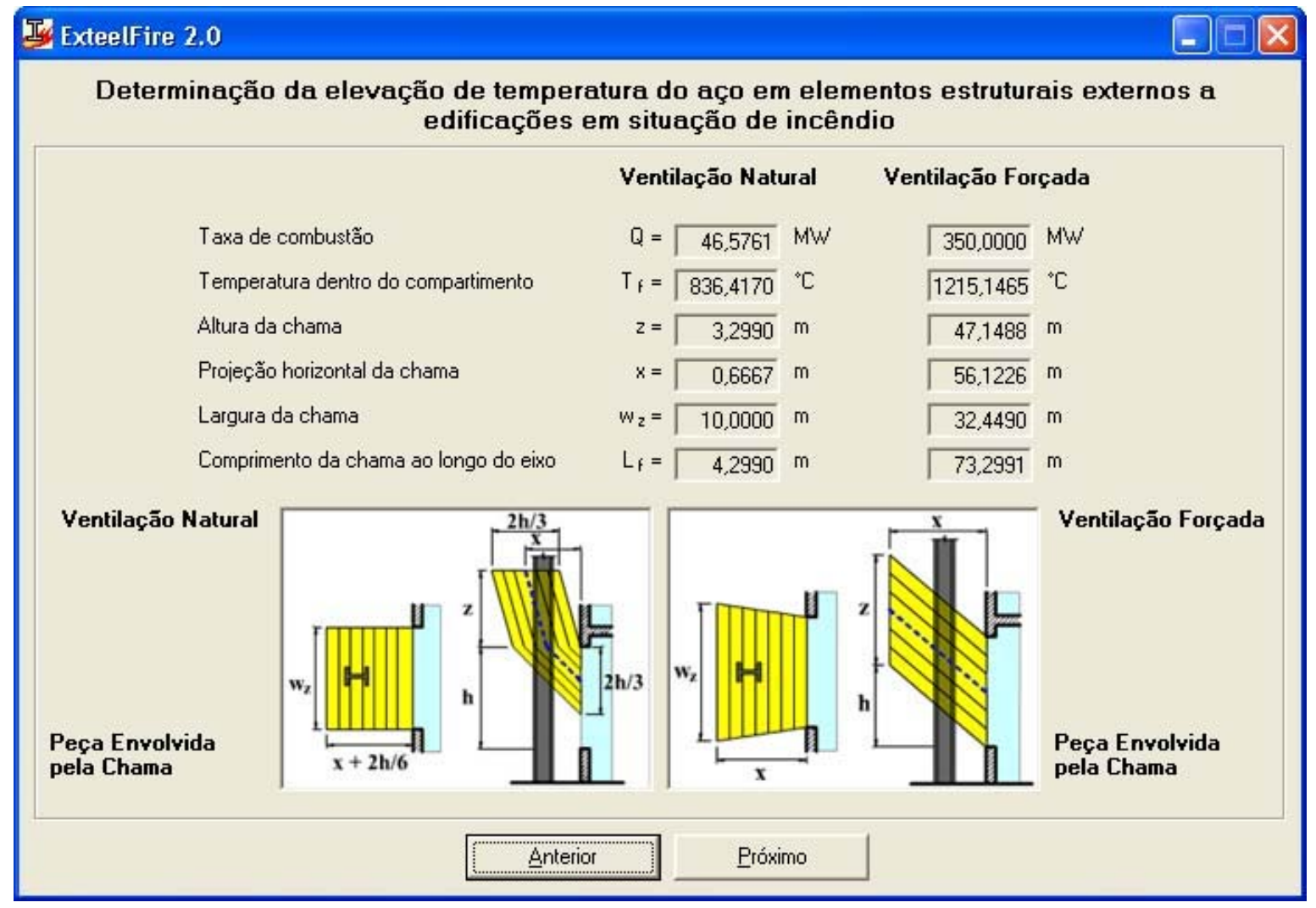

Figura 6.7 - Tela 3 do ExteelFire 2.0. Cálculos da geometria da chama e sua posição em relação ao elemento estrutural. Pilar em frente a uma abertura. 


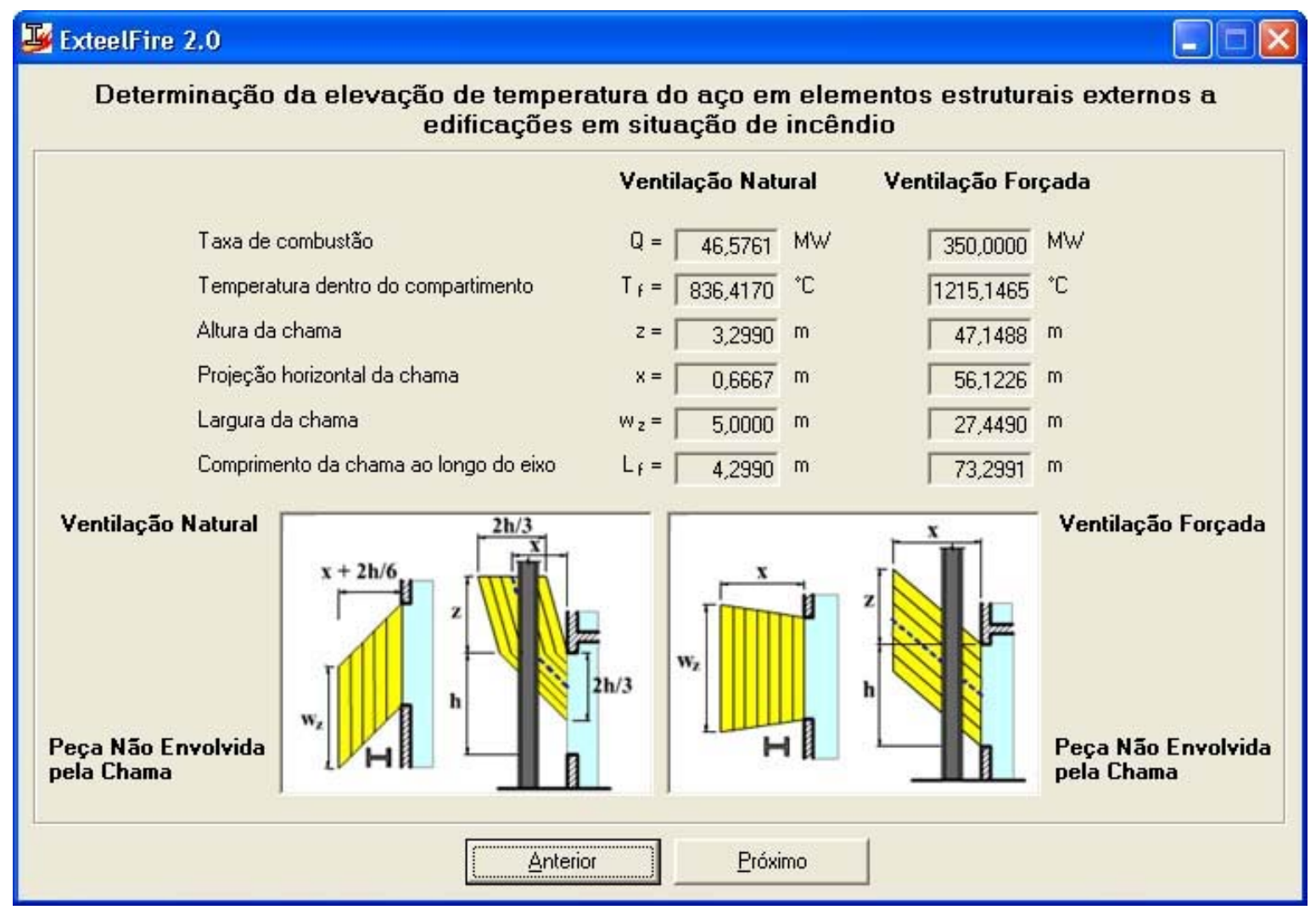

Figura 6.8 - Tela 3 do ExteelFire 2.0. Cálculos da geometria da chama e sua posição em relação ao elemento estrutural. Pilar entre aberturas.

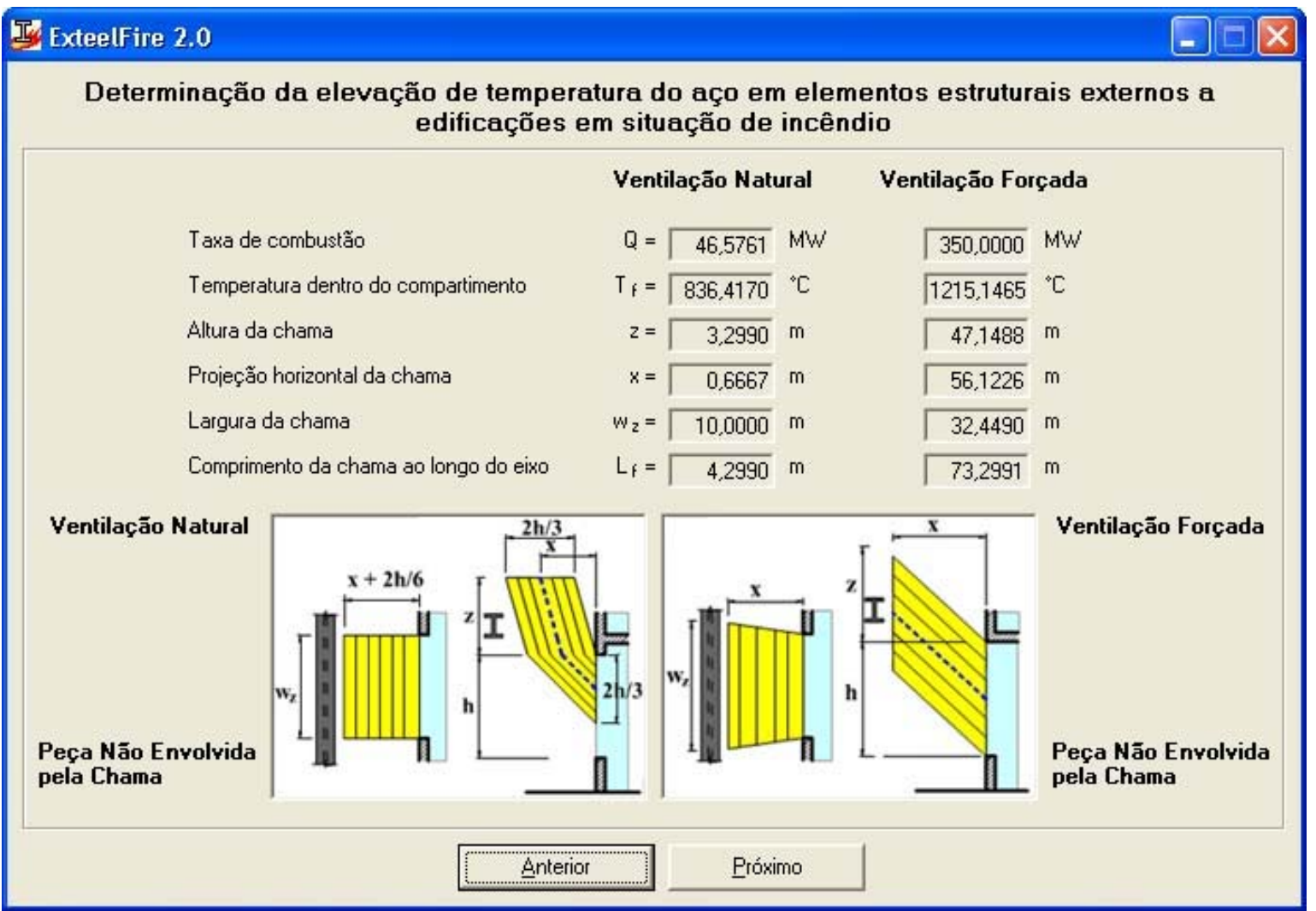

Figura 6.9 - Tela 3 do ExteelFire 2.0. Cálculos da geometria da chama e sua posição em relação ao elemento estrutural. Viga paralela à parede. 
As figuras 6.10 e 6.11 mostram a quarta tela com os resultados dos cálculos das temperaturas da chama na janela e no seu eixo próximo ao elemento, também os fatores de configuração da janela e da chama como superfície irradiante.

\begin{tabular}{|c|c|c|c|c|c|c|c|}
\hline Ify Exteelfire 2.0 & & & & & & - & $x$ \\
\hline Determinação da elevação & $\begin{array}{l}\text { de temperatura } \\
\text { dificações em sit }\end{array}$ & $\begin{array}{l}\text { lo aço } \\
\text { lação }\end{array}$ & $\begin{array}{l}\text { em elem } \\
\text { e incên }\end{array}$ & $\begin{array}{l}\text { nentos } \\
\text { dio }\end{array}$ & truturais exte & ernos a & \\
\hline & & & tilação $\mathrm{N}$ & atural & Ventilação Fo & orçada & \\
\hline Temperatura da chama na janela & & $T_{w}=$ & 942,1822 & ${ }^{\circ} \mathrm{C}$ & 775,1701 & ${ }^{\circ} \mathrm{C}$ & \\
\hline Temperatura da chama ao longo do se & eu eixo & $T_{2}=$ & 848,6297 & ${ }^{\circ} \mathrm{C}$ & 772,4464 & ${ }^{\circ} \mathrm{C}$ & \\
\hline Fator de configuração: & & & & & & & \\
\hline Janela como superfície irradiante - $\mathrm{C}$ & Componente da face 1 & $\phi \vdash, 1=$ & 0,1918 & & 0,1918 & & \\
\hline & Componente da face 2 & $\phi 1,2=$ & 0,1918 & & 0,1918 & & \\
\hline & Componente da face 3 & $\phi \uparrow, 3=$ & 0,4843 & & 0,4843 & & \\
\hline & Componente da face 4 & $\phi f, 4=$ & 0,0000 & & 0,0000 & & \\
\hline & Componente geral & $\phi \uparrow=$ & 0,2170 & & 0,2170 & & \\
\hline Chama como superfície irradiante - $\mathrm{C}$ & Componente da face 1 & $\phi_{z, 1}=$ & 0,0000 & & 0,0000 & & \\
\hline & Componente da face 2 & $\phi_{2,2}=$ & 0,0000 & & 0,0000 & & \\
\hline & Componente da face 3 & $\phi_{2,3}=$ & 0,0000 & & 0,0000 & & \\
\hline & Componente da face 4 & $\phi_{2,4}=$ & 0,0000 & & 0,0000 & & \\
\hline & Componente geral & $\phi_{z}=$ & 0,0000 & & 0,0000 & & \\
\hline & Anterior & & óximo & & & & \\
\hline
\end{tabular}

Figura 6.10 - Tela 4 do ExteelFire 2.0. Cálculos da temperatura da chama na janela e ao longo do seu eixo e cálculo dos fatores de configuração. Pilar em frente a uma abertura ou vigas paralelas à parede.

No quinto formulário, mostrado nas figuras 6.12 e 6.13 , são fornecidos os resultados dos cálculos da absortividade da chama, do fluxo de calor por radiação das aberturas e das chamas, do coeficiente de transferência de calor por convecção e, finalmente, os valores da temperatura máxima do aço, em ${ }^{\circ} \mathrm{C}$, para ventilação natural e forçada. Podem-se salvar todos os dados de entrada e os resultados obtidos em um arquivo de documento de texto. 


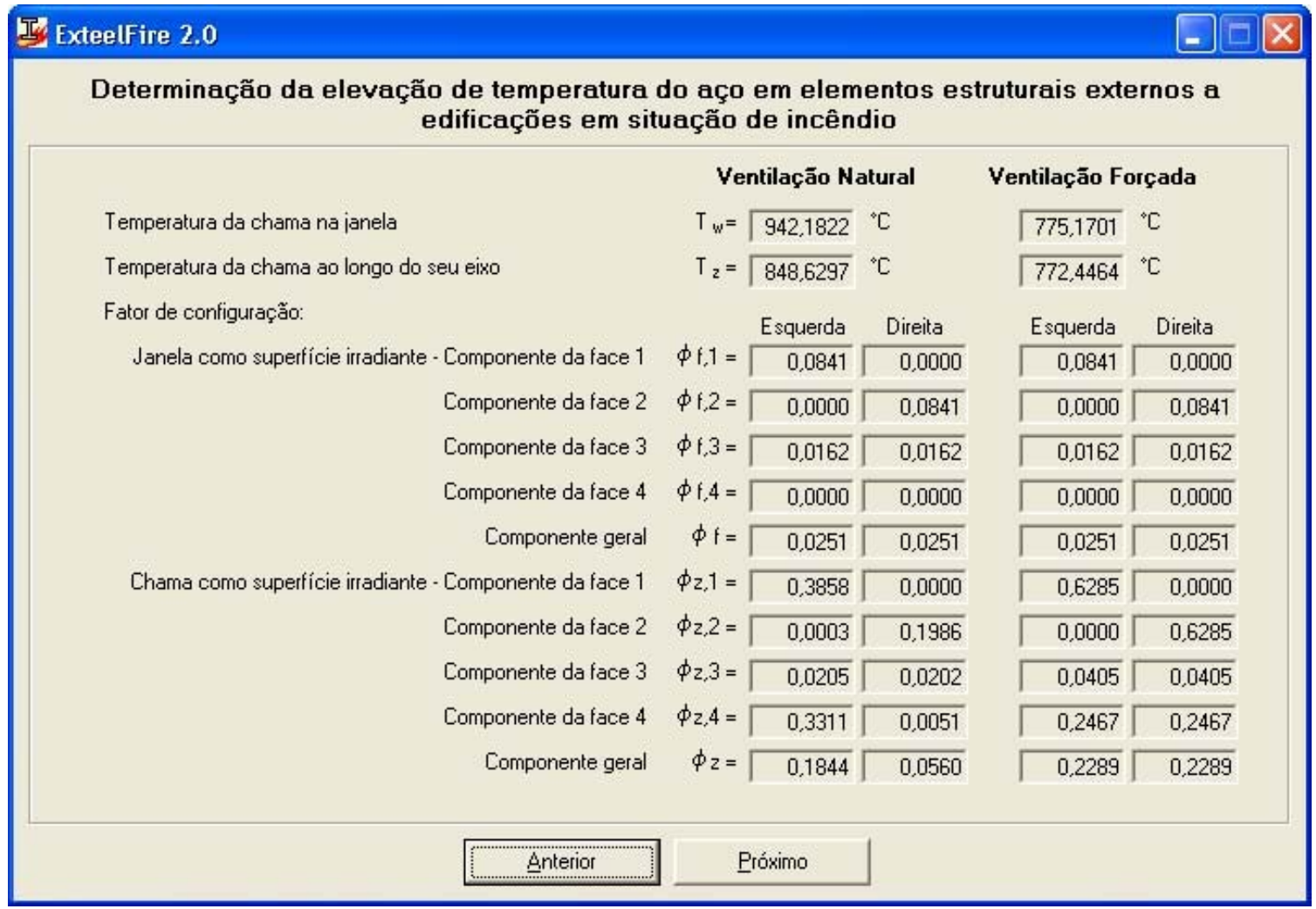

Figura 6.11 - Tela 4 do ExteelFire 2.0. Cálculos da temperatura da chama na janela e ao longo do seu eixo e cálculo dos fatores de configuração. Pilar entre aberturas.

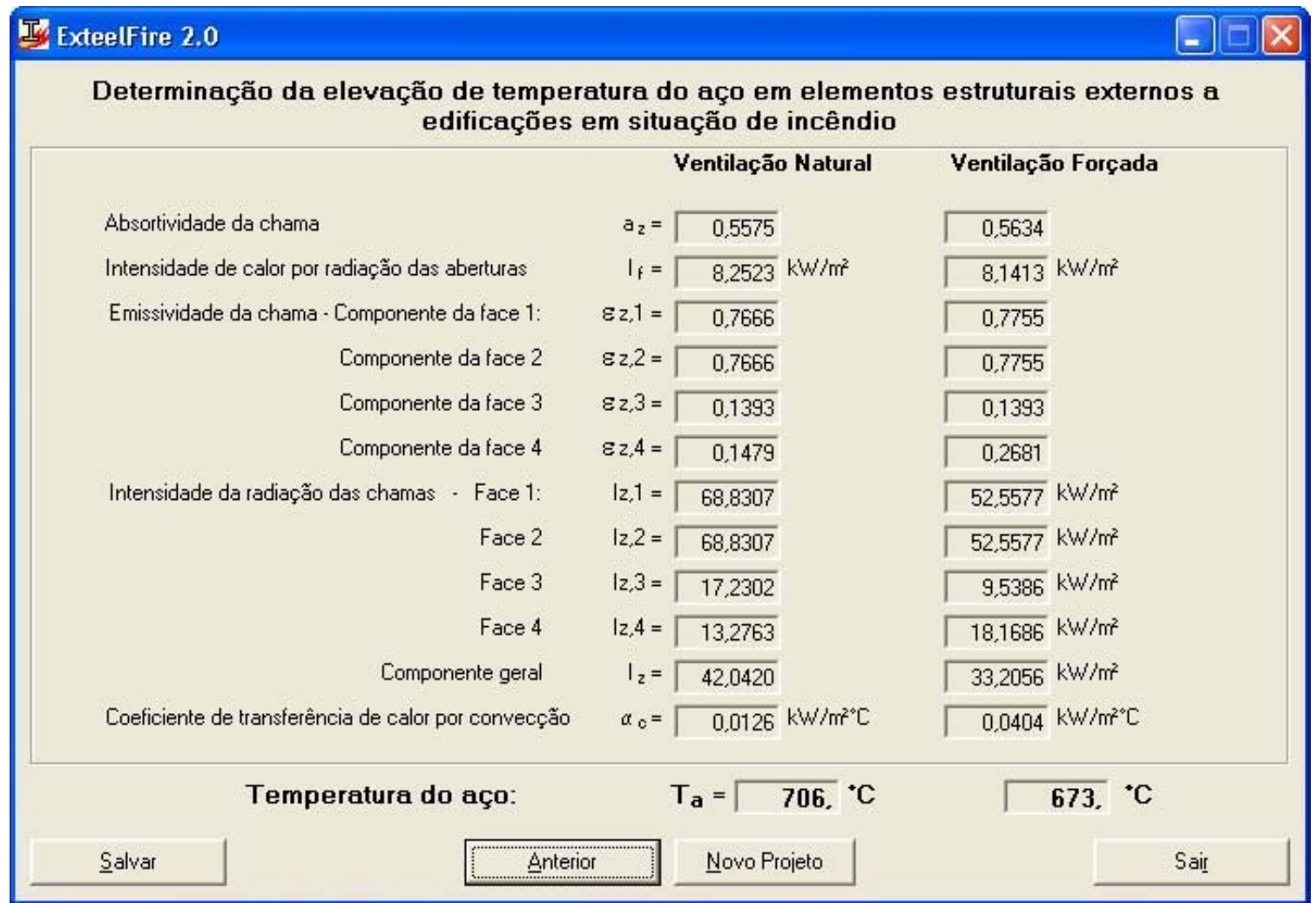

Figura 6.12 - Tela 5 do ExteelFire 2.0. Cálculos da absortividade da chama, do fluxo de calor por radiação das aberturas e das chamas e o coeficiente de transferência de calor por convecção. Pilar em frente a uma abertura ou viga paralela à parede. 


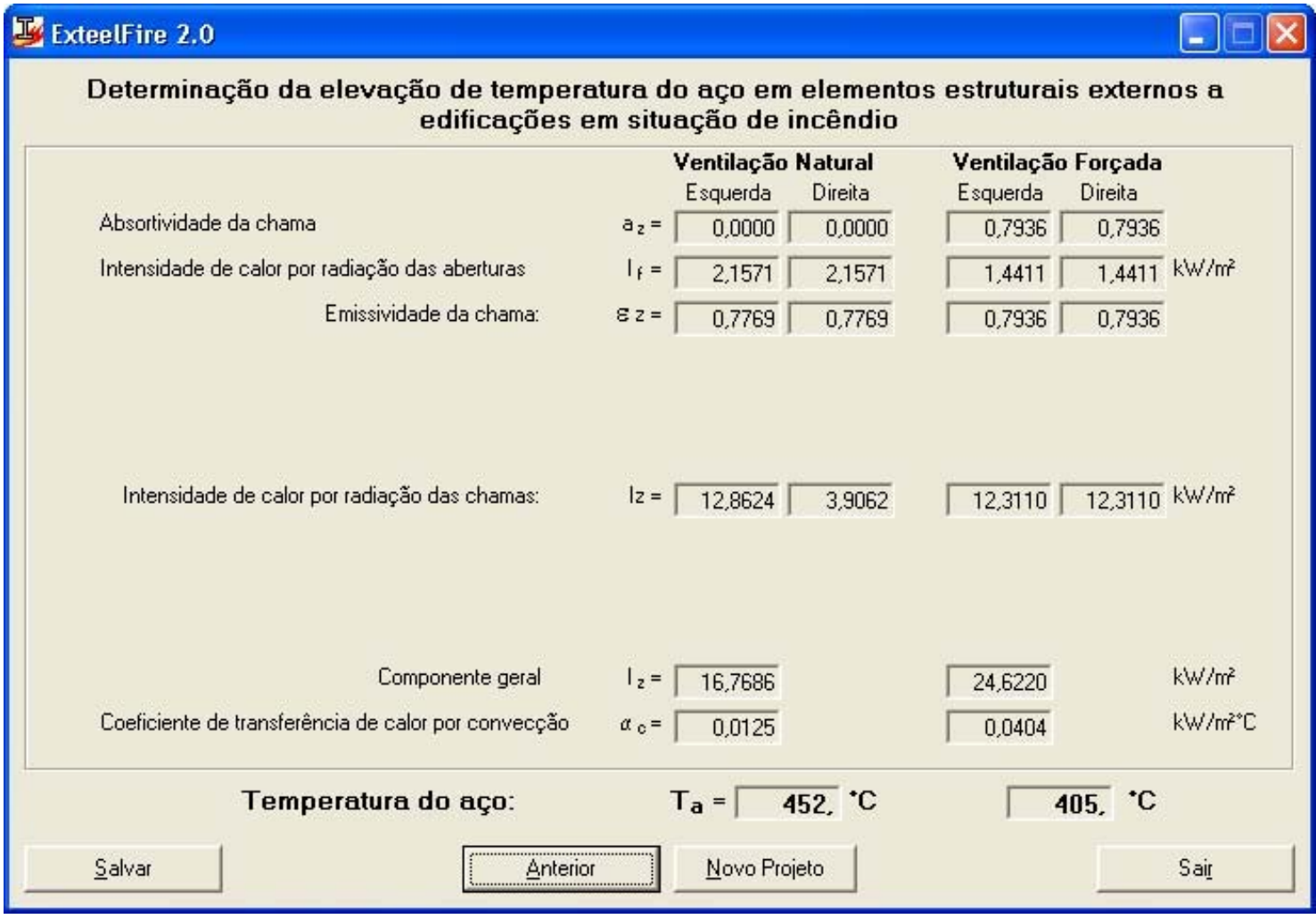

Figura 6.13 - Tela 5 do ExteelFire 2.0. Cálculos da absortividade da chama, do fluxo de calor por radiação das aberturas e das chamas e o coeficiente de transferência de calor por convecção. Pilar entre aberturas.

\subsection{COMPARAÇÃO ENTRE O FIRES, EXTEELFIRE 1.0 E O EXTEELFIRE 2.0}

O ExteelFire 1.0 foi modificado para tornar possível determinar a máxima temperatura do elemento estrutural de aço externo à edificação, abrangendo todas as posições de pilares e vigas, transformando-se no ExteelFire 2.0. A principal dificuldade encontrada foi na implementação matemática dos cálculos dos fatores de configuração. O cálculo desses fatores é trabalhoso e se altera em função da dimensão da chama, de sua posição e da posição relativa entre o elemento estrutural e as aberturas.

Antes do programa de computador ExteelFire, os pesquisadores utilizavam o programa de computador Fires para calcular a temperatura máxima do elemento estrutural de aço externo à edificações. Esse programa de computador foi desenvolvido para ambiente DOS. 
Tanto o ExteelFire 1.0 quanto o Fires apresentam limitações que foram solucionadas no ExteelFire 2.0.

\subsubsection{Taxa de combustão}

Nos cálculos da taxa de combustão, para ventilação natural, quando há incêndio controlado pela ventilação, conforme eq. 5.32, a razão entre a profundidade e a largura da parede que contém as aberturas é expressa por $W_{2} / W_{l}$. Se, contudo, existirem aberturas em mais de uma parede, segundo o Eurocode 1, Part 1-2 (2002), esse valor será reduzido por um fator que é a razão entre as áreas de aberturas na parede principal e a área total de aberturas do compartimento, conforme eq. 5.82. O Fires apenas considera aberturas na parede principal, não considerando a possibilidade de existir aberturas em outras paredes.

O ExteelFire utiliza a taxa de combustão $(\dot{Q})$ em MW e o capítulo 5 desta Tese utiliza o termo taxa de liberação de massa $(\dot{m}) \mathrm{em} \mathrm{kg} / \mathrm{s}$. As equações são as mesmas, considerando que a madeira libera 17,5 MJ por quilograma.

A figura 6.14 mostra um compartimento de escritório, com carga de incêndio específica de $700 \mathrm{MJ} / \mathrm{m}^{2}$, onde existe variação das aberturas totais do compartimento em relação a abertura da parede principal. A figura 6.15 mostra um gráfico sobre a variação da taxa de combustão na condição de queima controlada pela ventilação, utilizando os programas de computador Fires, ExteelFire 1.0 e o ExteelFire 2.0, de acordo com as dimensões da figura 6.14.

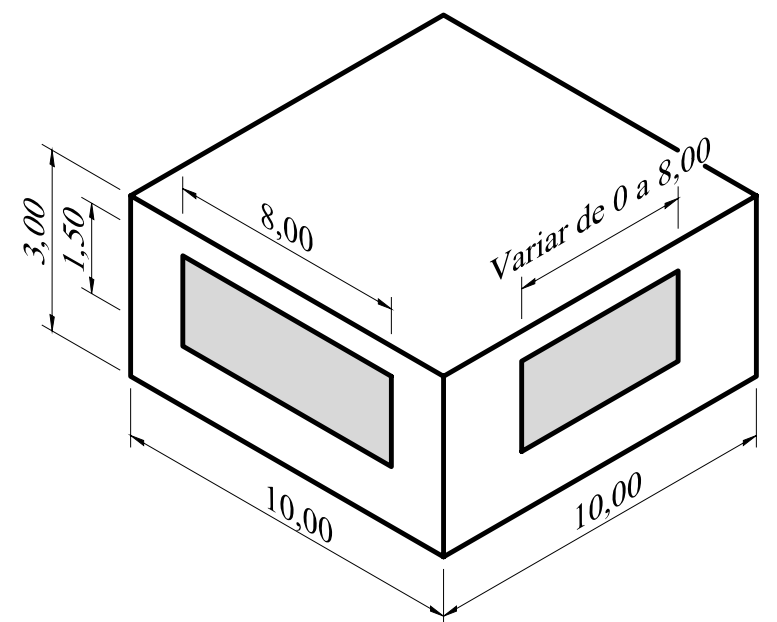

Figura 6.14 - Dados para verificação do fator de ventilação quando existe abertura em mais de uma parede. 


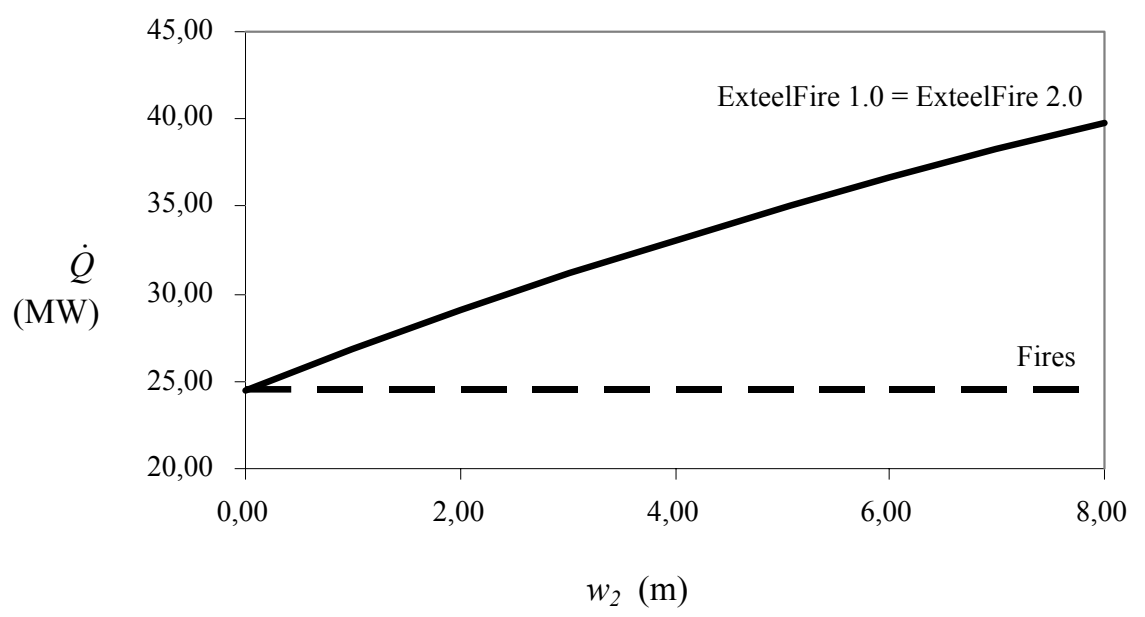

Figura 6.15 - Gráfico da variação da taxa de combustão em relação à largura total das aberturas nas paredes diferentes da fachada.

No gráfico da figura 6.15, observa-se que, mantendo a dimensão da abertura na parede da fachada e variando o tamanho da abertura nas demais paredes, o Fires considera constante a taxa de combustão, como se não existisse a abertura na outra parede. O ExteelFire 2.0 leva em consideração as aberturas existentes em outras paredes, como fica demonstrado com o aumento da taxa de combustão.

\subsubsection{Temperatura da chama na abertura}

Para ventilação natural, o Eurocode 1, Part 1-2 (2002) estabelece o valor da temperatura da chama na abertura, conforme a eq. 5.76. Essa equação deve obedecer à inequação $X \frac{w_{t}}{\dot{m}}<1$. O Fires não considera essa inequação.

Utilizando o exemplo da figura 6.14 com abertura apenas em uma parede, podemos verificar os valores da temperatura na abertura. O Fires calculou $\theta_{w}=1064^{\circ} \mathrm{C}$, o ExteelFire 1.0 e o ExteelFire 2.0, seguindo o Eurocode 1, calculou $\theta_{w}=1006^{\circ} \mathrm{C}$. 
Para ventilação forçada, o Fires não considera o limite da inequação $X \frac{A_{v}^{1 / 2}}{\dot{m}}<1$, estabelecido no Eurocode 1, Part 1-2 (2002), (eq. 5.77 desta Tese). Ocorrendo o mesmo erro relatado para ventilação natural.

\subsubsection{Pilar posicionado em frente a uma abertura}

Para ventilação natural, a Figura 6.16 mostra as situações possíveis de cálculo para o pilar posicionado em frente a uma abertura. O Fires e o ExteelFire 1.0 consideram apenas os pilares quando estão totalmente envolvidos pela chama ou quando não estão envolvidos pela chama, conforme Figura 6.16(a).

O Fires e o ExteelFire 1.0 não consideram a situação 3 da figura 6.16(b), na qual o pilar está parcialmente envolvido pela chama. Nessa situação, ele calcula como se estive totalmente envolvido pela chama, ocasionando um aumento no valor da intensidade de calor por radiação das chamas. Ocorre também uma diminuição da intensidade de calor por radiação, proveniente do compartimento incendiado, devido ao aumento no valor da absortividade da chama.

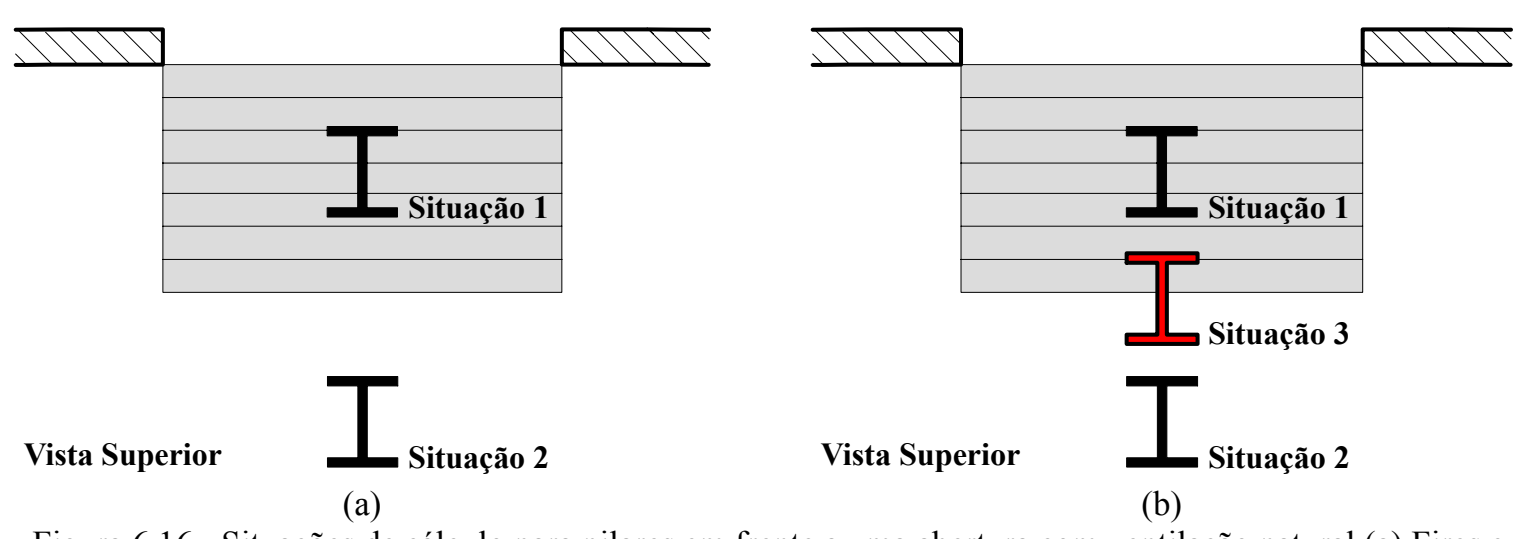

Figura 6.16 - Situações de cálculo para pilares em frente a uma abertura com ventilação natural (a) Fires e ExteelFire 1.0 e (b) ExteelFire 2.0.

Utilizando o compartimento da figura $6.14 \mathrm{com}$ abertura em apenas uma parede e altura da abertura igual a $2 \mathrm{~m}$ para a situação 3 da figura 6.16(b), obtêm-se os resultados apresentados na figura 6.17 . 


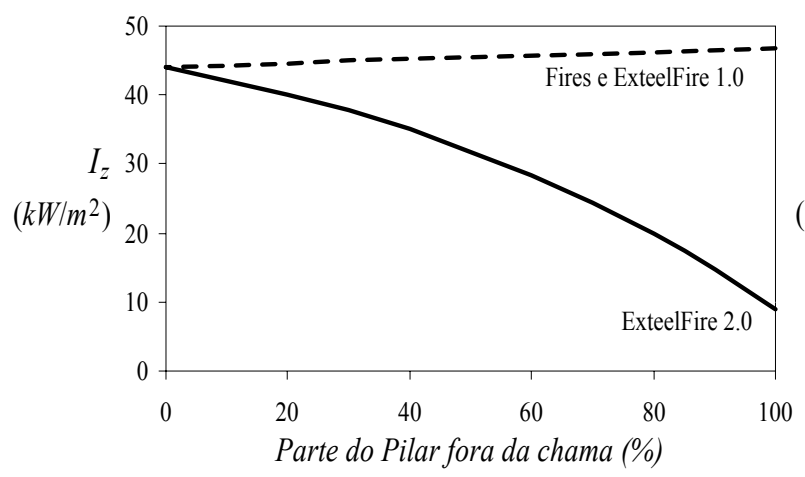

(a)

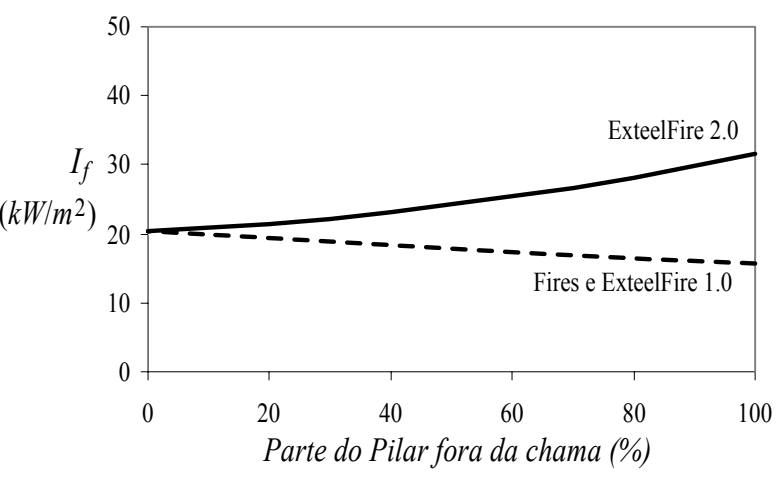

(b)

Figura 6.17 - Variação da intensidade de radiação devido (a) à chama (b) ao compartimento para pilares parcialmente envolvidos.

$\mathrm{Na}$ ventilação forçada, ocorre o mesmo erro encontrado para a ventilação natural quando o pilar está posicionado na situação 3 da figura 6.18 .
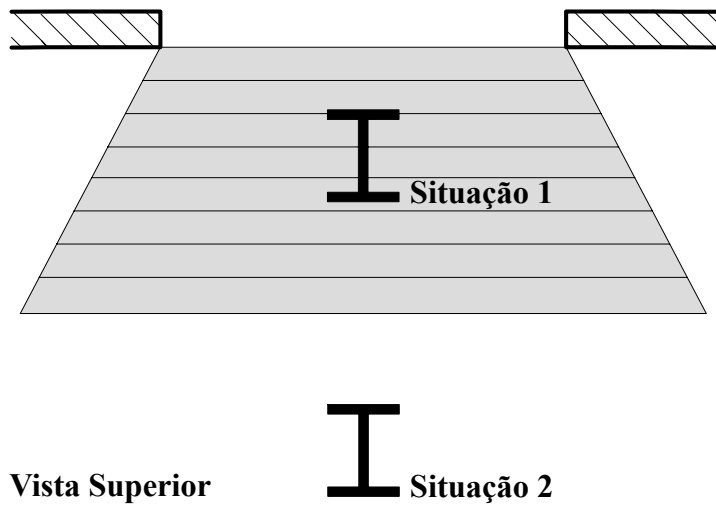

(a)

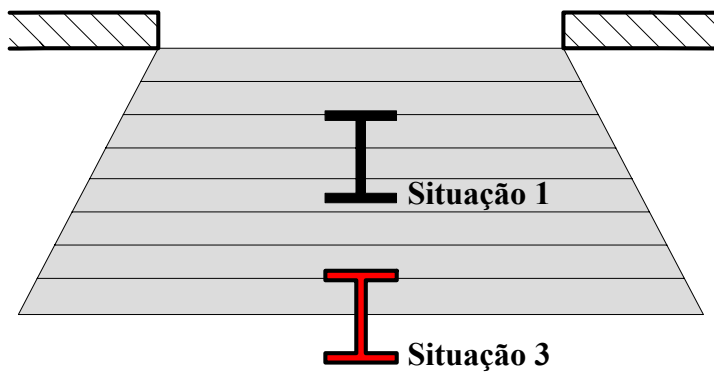

Vista Superior

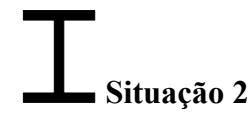

(b)

Figura 6.18 - Situações de cálculo para pilares em frente a uma abertura com ventilação forçada (a) Fires e ExteelFire 1.0 e (b) ExteelFire 2.0.

\subsubsection{Pilar posicionado entre aberturas}

$\mathrm{Na}$ ventilação natural, os fatores de configuração e a espessura da chama para o pilar situado entre aberturas são calculados levando-se em consideração cada situação apresentada na figura 6.19. O Fires considera apenas o pilar posicionado na situação 1 e, o ExteelFire 1.0, nas situações 1 e 2, ocasionando erros de cálculo para as demais situações. O ExteelFire 2.0 contempla todas as situações demonstradas na figura 6.19 . 


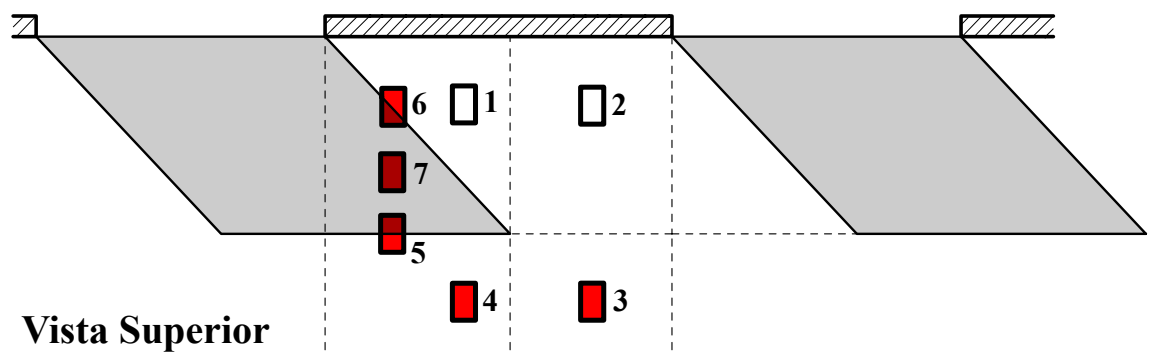

Figura 6.19 - Possíveis situações para cálculo do pilar entre aberturas. Ventilação natural.

O Fires inverteu o cálculo para o fator de configuração na situação 1 . Na chama esquerda do pilar, o valor de $\theta_{\text {esq }}$ para a face 3 é $3 \pi / 4$, o Fires considera $\pi / 4$, conforme ilustrado figura 6.20. Na chama direita do pilar, o valor de $\theta_{\text {dir }}$ para a face 3 é $\pi / 4$, o Fires considera $3 \pi / 4$.

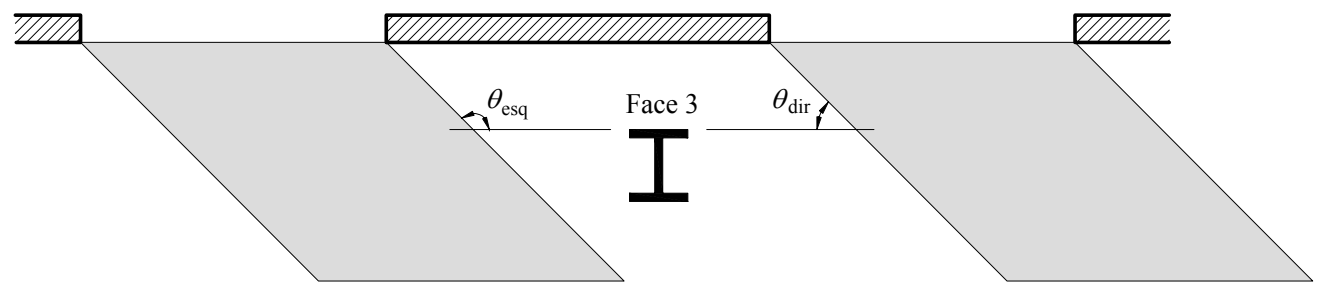

Figura 6.20 - Ângulo $\theta$ para o fator de configuração na face 3 do pilar. Ventilação natural.

$\mathrm{Na}$ ventilação forçada, o pilar situado entre as aberturas apresenta várias situações para o cálculo do fator de configuração e da espessura da chama, conforme mostrado na figura 6.21. O Fires e o ExteelFire 1.0 consideram em seus cálculos apenas o pilar posicionado conforme a situação 1, gerando erro nas demais. O ExteelFire 2.0 considera o pilar posicionado em todas as situações mostradas na figura 6.21.
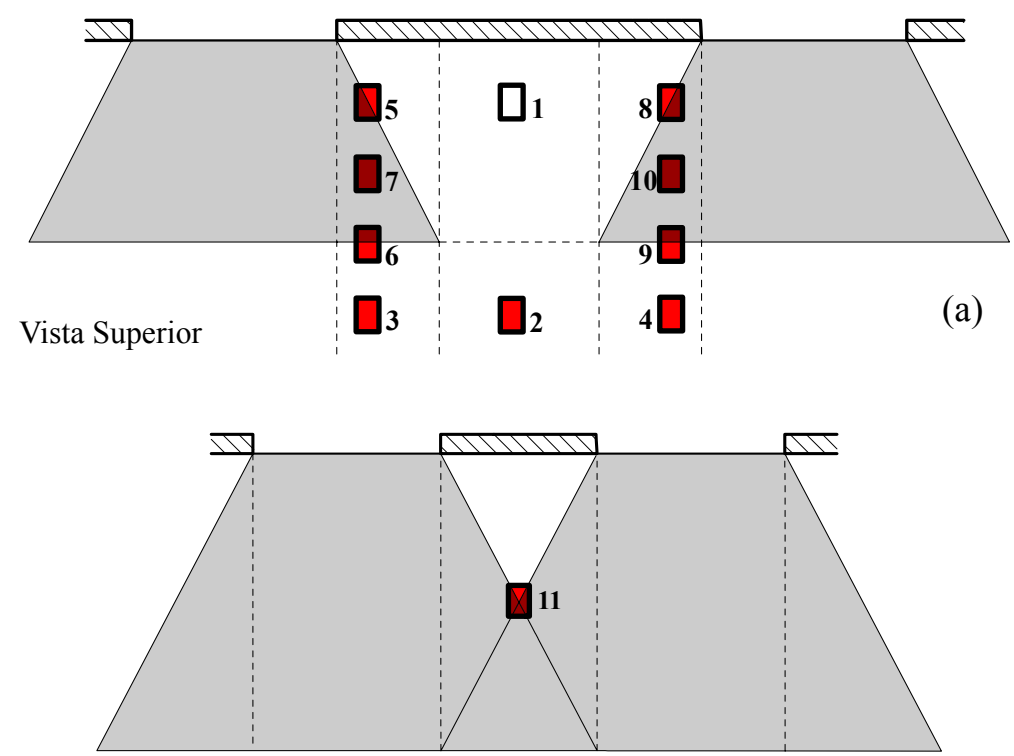

Vista Superior

$\square^{12}$

Figura 6.21 - Possíveis posições para pilar entre aberturas. Ventilação forçada. 


\subsubsection{Considerações sobre vigas}

O Fires e o ExteelFire 1.0 calculam a temperatura máxima apenas para vigas de borda, conforme ilustrado na figura 6.22.

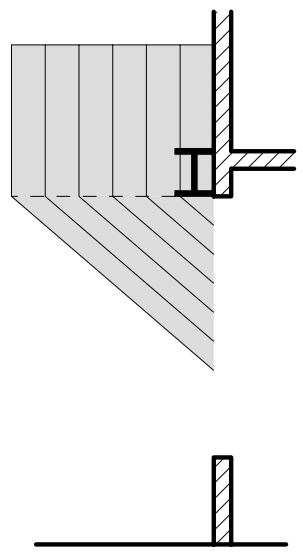

(a)

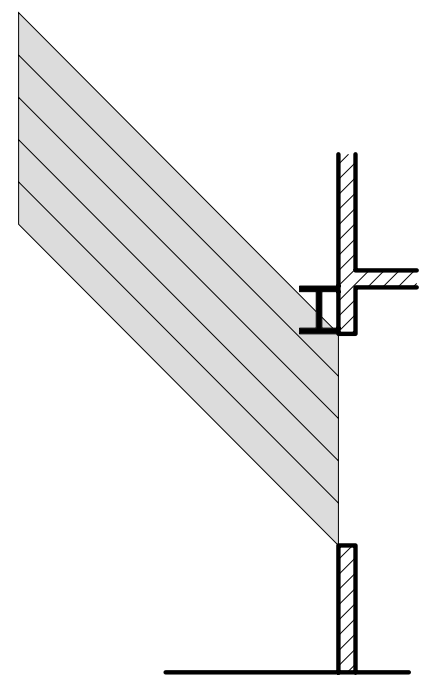

(b)

Figura 6.22 - Viga de borda (a) ventilação natural (b) ventilação forçada. Fires e ExteelFire 1.0.

O ExteelFire 2.0 calcula os fatores de configuração e a espessura da chama para as situações mostradas na figura 6.23. Essas situações compreendem vigas totalmente, parcialmente e não envolvidas pela chama.

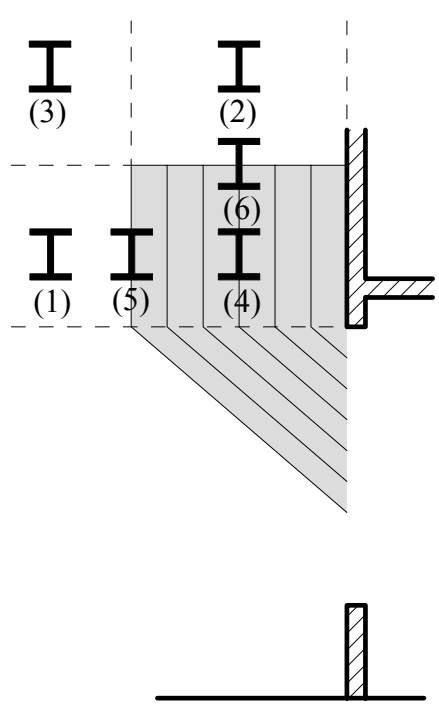

(a)
I(1) $\frac{1}{(9)}$
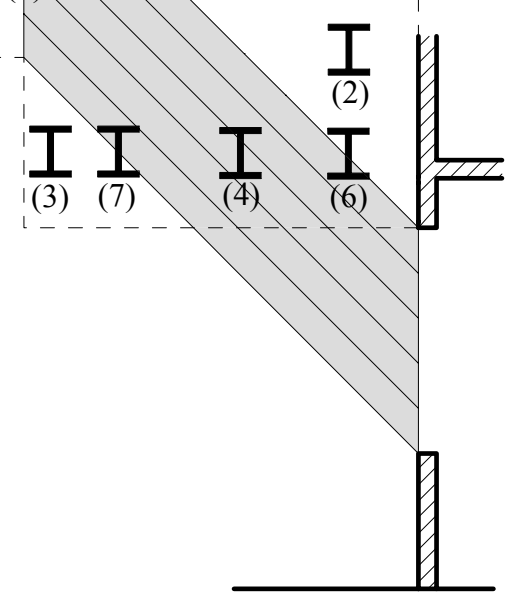

(b)

Figura 6.23 - Situações admitidas pelo ExteelFire 2.0 para cálculo de vigas (a) ventilação natural (b) ventilação forçada. 


\subsubsection{Considerações sobre faces isoladas}

O Fires não considera em seus cálculos o isolamento da face dos pilares. O ExteelFire1.0 e o ExteelFire 2.0 consideram o isolamento individualizado em cada face do pilar.

Quanto às vigas, o Fires considera a viga como sendo totalmente sem proteção das faces ou isolada apenas em suas mesas. Da mesma forma que os pilares, o ExteelFire 1.0 e o ExteelFire 2.0 consideram o isolamento individualizado da face das vigas. 


\section{Capítulo 7}

\section{COMPARAÇÕES ENTRE O EUROCODE E O AISI}

\subsection{DIFERENÇAS ENTRE O EUROCODE E O AISI}

O presente capítulo apresenta uma comparação entre as normas Eurocode (EUROCODE 1, PART 1.2, 2002, e EUROCODE 3, PART 1.2, 2003) e o AISI (1979) no que se refere às estruturas de aço externas a edificações em situação de incêndio. Ambos adotam o método de Margaret Law, porém, possuem algumas diferenças em seus cálculos.

\subsubsection{Carga de incêndio específica}

O Eurocode 1, part 1.2 (2002) considera que o método é válido somente para cargas de incêndio específicas, $q_{f i, d}$, com valores maiores que $200 \mathrm{MJ} / \mathrm{m}^{2}$. O AISI (1979) não estabelece limitação para a mesma.

\subsubsection{Dimensões do compartimento}

O Eurocode 1, part 1.2 (2002) estabelece que as dimensões do compartimento incendiado não podem exceder $70 \mathrm{~m}$ de profundidade, $18 \mathrm{~m}$ de largura e $5 \mathrm{~m}$ de altura. O AISI (1979) não estabelece limites de dimensões do compartimento em seu texto. Entretanto, os exemplos das tabelas apresentam: paredes com aberturas de comprimento de até $73 \mathrm{~m}$, paredes sem aberturas de comprimento de até $18 \mathrm{~m}$ e altura do compartimento de até $5 \mathrm{~m}$. 


\subsubsection{Parede acima das aberturas}

O Eurocode 1, part 1-2 (2002) considera em seus cálculos a existência de paredes acima da abertura, mas não estabelece tamanho mínimo para ser definida como tal. O AISI (1979) considera parede acima quando ela é maior ou igual a 2/3 da altura da chama.

\subsection{4 Área total da superfície do compartimento}

O Eurocode 1, part 1-2 (2002) considera como área total do enclausuramento as paredes, o piso, o teto, incluindo as aberturas existentes. O AISI (1979) não considera as aberturas existentes no cálculo da área total. Essa área total da superfície aquecida do compartimento é considerada no cálculo da taxa de combustão quando controlada pela ventilação e no cálculo da temperatura dentro do compartimento incendiado.

\subsubsection{Temperatura da chama ao longo do seu eixo}

Law (1978) considera a variação da temperatura da chama ao longo do seu eixo para ventilação forçada, conforme a eq. 5.74. O AISI (1979) modificou a eq. 5.74 para a eq. 7.1, com o objetivo de ajustar melhor os pontos dos experimentos em escala natural, realizados pelos Laboratórios Underwriters, conforme a figura 7.1. O Eurocode 1, part 1-2 (2002) adotou a eq. 7.1 .

$$
\frac{\theta_{z}-\theta_{o}}{\theta_{w}-\theta_{o}}=1-0,019 \frac{l \cdot A_{v}^{1 / 2}}{\dot{m}}
$$

Onde:

$\theta_{z} \quad$ é a temperatura medida no eixo da chama $\left({ }^{\circ} \mathrm{C}\right)$;

$\theta_{o} \quad$ é a temperatura do ar no ambiente externo $\left({ }^{\circ} \mathrm{C}\right)$;

$\theta_{w} \quad$ é a temperatura medida na janela $\left({ }^{\circ} \mathrm{C}\right)$;

$l$ é a distância ao longo do eixo da chama até a janela (m); 
$A_{v} \quad$ é a área das aberturas (m);

$\dot{m} \quad$ é a taxa de liberação de massa $(\mathrm{kg} / \mathrm{s})$.

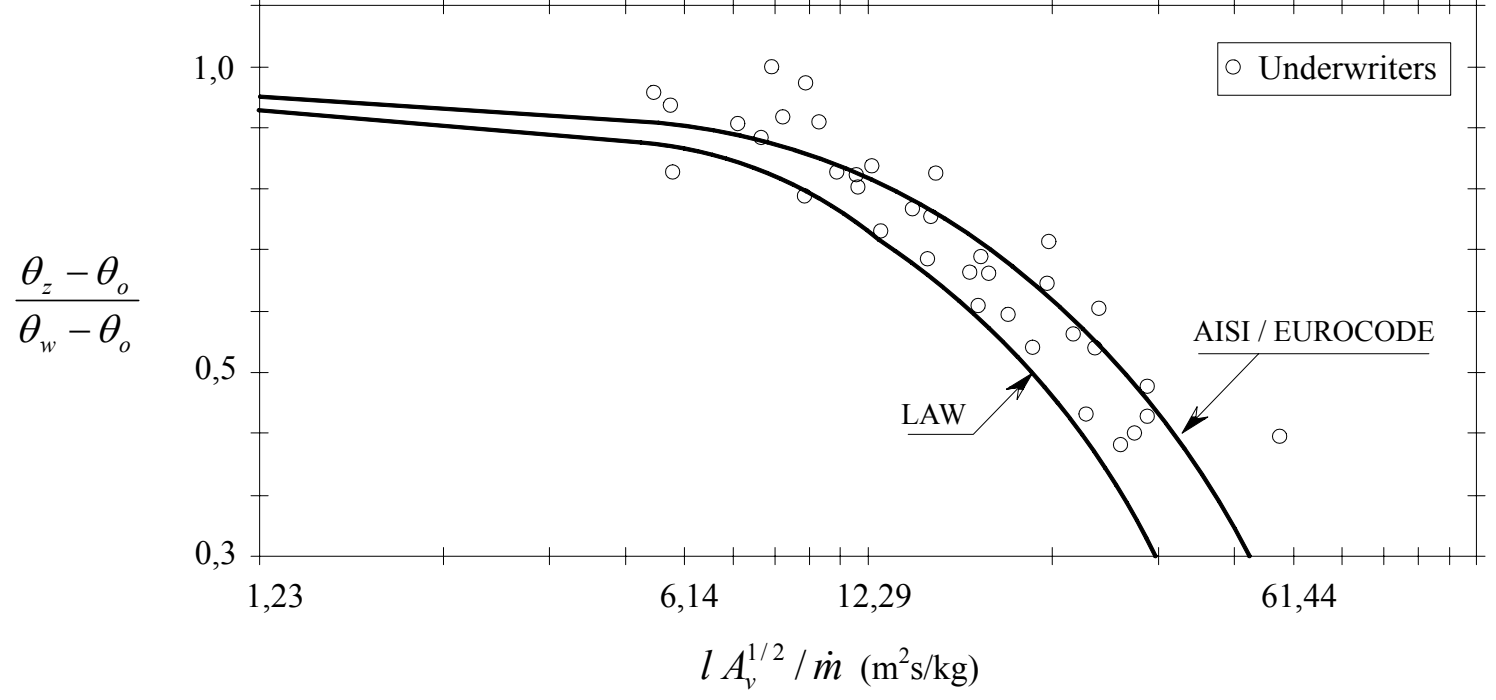

Figura 7.1 - Distribuição da temperatura da chama para ensaios em escala natural com ventilação forçada, considerando dados dos Laboratórios Underwriters (LAW, 1978), do AISI (1979) e do Eurocode, Part 1-2 (2002).

A figura 7.1 ilustra a variação da temperatura ao longo do eixo da chama, segundo Law (1978), o AISI (1979) e o Eurocode 1, part 1-2 (2002). Verifica-se na figura 7.1 que a variação da temperatura da chama em relação à temperatura da abertura, $\left(\theta_{z}-\theta_{o}\right) /\left(\theta_{w}-\theta_{o}\right)$, pelo AISI/EUROCODE é maior. Isso proporciona valores maiores da temperatura da chama.

\subsubsection{Altura da chama}

De acordo com Law (1978), a altura da chama para ventilação forçada é calculada conforme a eq. 5.51. O AISI (1979) e posteriormente o Eurocode 1, part 1-2 (2002), com base nos dados de ensaio em escala natural dos Laboratórios Underwriters, fizeram ajustes na eq. 5.51, transformando-as na eq. 7.2 e 7.3 , respectivamente.

$$
z=22,4\left(\frac{1}{v}\right)^{0,43}\left[\frac{\dot{m}}{A_{w}{ }^{1 / 2}}\right]-h
$$




$$
z=23,9\left(\frac{1}{v}\right)^{0,43}\left[\frac{\dot{m}}{A_{w}{ }^{1 / 2}}\right]-h
$$

Onde:

$\dot{m} \quad$ é a taxa de liberação de massa $(\mathrm{kg} / \mathrm{s})$;

$v \quad$ é a velocidade do vento $(\mathrm{m} / \mathrm{s})$;

$h \quad$ é a altura da abertura (m).

A figura 7.2 mostra a variação de $(\mathrm{z}+\mathrm{h})$ utilizando as equações 5.51, 7.2 e 7.3 propostas por Law, AISI e o Eurocode respectivamente.

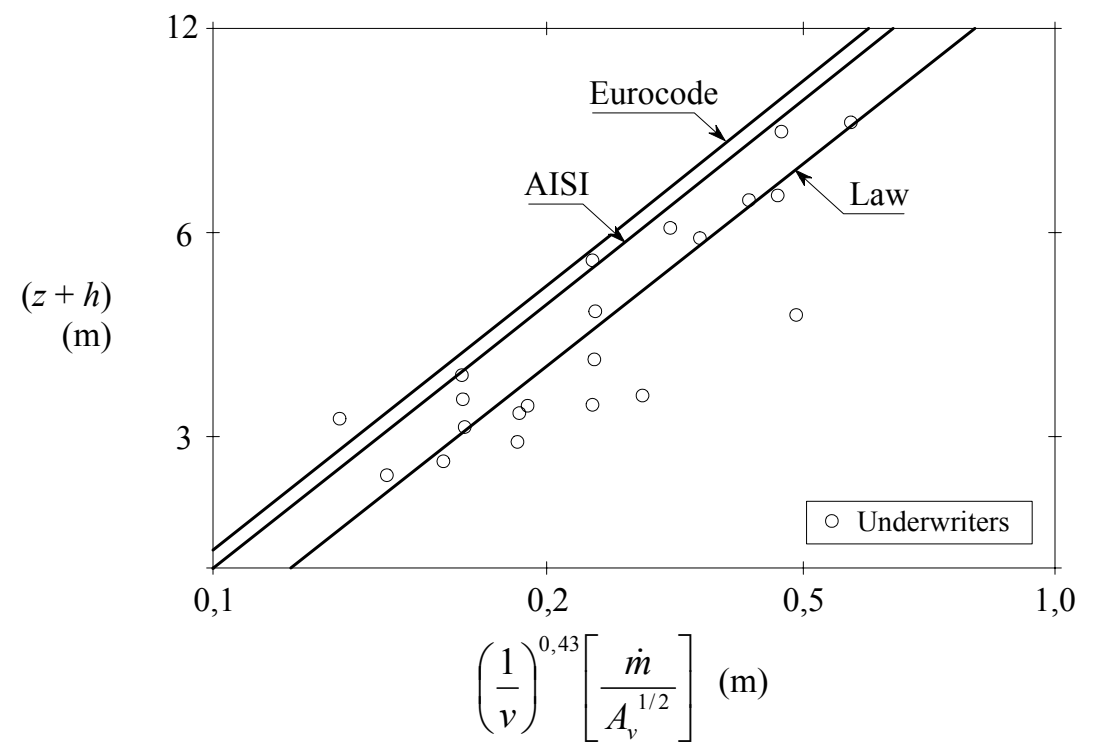

Figura 7.2 - Gráfico da variação da altura da chama, segundo Law (1978), o AISI (1979) e o Eurocode, Part 1-2 (2002). Dados de ensaio em escala natural dos Laboratórios Underwriters.

\subsubsection{Vigas}

O AISI (1979) considera apenas a viga de borda, ou seja, aquela viga que se encontra localizada junto à parede da fachada e na altura do topo da abertura, conforme a figura 6.22. O Eurocode 1, Part 1.2 (2002) permite qualquer posição para a viga, desde que esteja acima do topo da abertura, conforme a figura 6.23. As vigas podem ser paralelas ou perpendiculares à parede. 


\subsubsection{Proteção das faces do elemento}

O Eurocode 1, Part 1.2 (2002) leva em consideração a proteção total das faces individualizadas, considerando $C=0$ para face isolada e $C=1$ para face sem revestimento no cálculo da intensidade de calor por radiação, conforme fluxograma de cálculo da temperatura do elemento externo no anexo A. O AISI (1979) não leva em consideração a proteção das faces.

\subsection{COMPARAÇÃO NUMÉRICA}

As tabelas 7.1, 7.2 e 7.3 têm como base as tabelas do AISI (1979) e foram calculadas pelo ExteelFire 2.0, utilizando o método proposto pelos Eurocode 1, Part 1.2 (2002) e Eurocode 3, Part 1.2 (2003). Os valores são conservadores e podem ser utilizados como parâmetros para projetos em que a temperatura crítica do elemento de aço seja maior que $538^{\circ} \mathrm{C}$ (AISI, 1979). O valor de cálculo da carga de incêndio específica adotado para a construção das tabelas foi $875 \mathrm{MJ} / \mathrm{m}^{2}$, o que corresponde a $50 \mathrm{~kg} / \mathrm{m}^{2}$ de madeira equivalente, valor adotado pelo AISI.

A figura 7.3 mostra as possíveis situações para a distância mínima, $d_{m i n}$, do pilar à parede, quando posicionado em frente a uma abertura. O compartimento possui abertura apenas na parede da fachada.

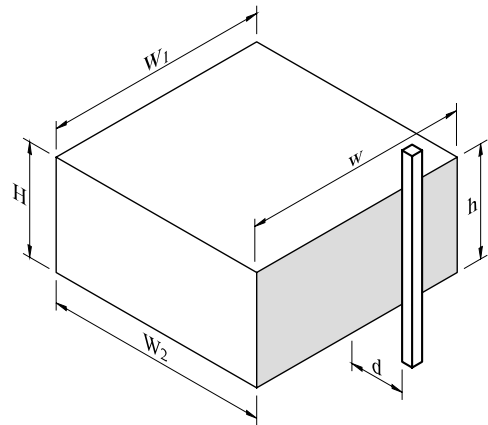

Situação 1

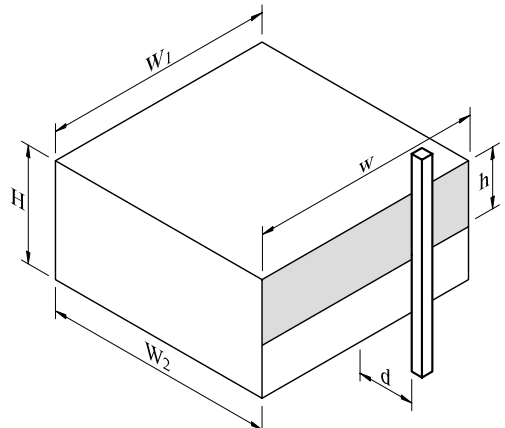

Situação 2

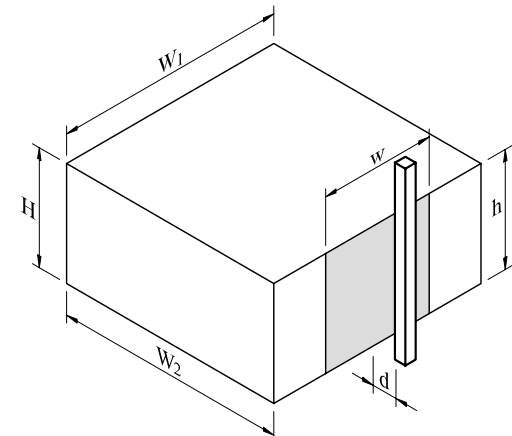

Situação 3

Figura 7.3 - Situações para cálculo da tabela 7.1 . 
Tabela 7.1 - Distância mínima do pilar à parede. Pilar em frente a abertura. Abertura em uma parede

\begin{tabular}{|c|c|c|c|c|c|c|c|c|}
\hline $\begin{array}{c}A_{w} \\
{[\%]}\end{array}$ & $\begin{array}{l}\text { Sit } \\
\text { [ ] }\end{array}$ & $\begin{array}{c}\mathrm{h} \\
{[\mathrm{m}]}\end{array}$ & $\begin{array}{c}\mathrm{W}_{2} \\
{[\mathrm{~m}]}\end{array}$ & $\begin{array}{l}\mathrm{W}_{1} \\
{[\mathrm{~m}]}\end{array}$ & $\begin{array}{c}\mathrm{w} \\
{[\mathrm{m}]}\end{array}$ & $\begin{array}{l}\text { AISI } \\
d_{\min } \\
{[\mathrm{m}]} \\
\end{array}$ & $\begin{array}{c}\text { Com parede } \\
\text { EUROCODE } \\
\mathrm{d}_{\min } \\
{[\mathrm{m}]}\end{array}$ & $\begin{array}{c}\text { Sem parede } \\
\text { EUROCODE } \\
\mathrm{d}_{\min } \\
{[\mathrm{m}]}\end{array}$ \\
\hline \multirow{3}{*}{100} & \multirow{3}{*}{1} & \multirow{3}{*}{2,75} & 4,50 & $\begin{array}{c}4,50 \\
9,00 \\
18,00 \\
36,00 \\
72,00 \\
\end{array}$ & $\begin{array}{c}4,50 \\
9,00 \\
18,00 \\
36,00 \\
72,00 \\
\end{array}$ & $\begin{array}{l}2,13 \\
2,13 \\
2,13 \\
2,13 \\
2,13 \\
\end{array}$ & $\begin{array}{l}1,80 \\
1,80 \\
1,90 \\
1,90 \\
1,90 \\
\end{array}$ & $\begin{array}{l}1,80 \\
1,80 \\
2,10 \\
2,30 \\
2,30 \\
\end{array}$ \\
\hline & & & 9,00 & $\begin{array}{c}4,50 \\
9,00 \\
18,00 \\
36,00 \\
72,00\end{array}$ & $\begin{array}{c}4,50 \\
9,00 \\
18,00 \\
36,00 \\
72,00\end{array}$ & $\begin{array}{l}2,13 \\
2,13 \\
2,44 \\
2,74 \\
2,74 \\
\end{array}$ & $\begin{array}{l}1,90 \\
2,10 \\
2,50 \\
2,60 \\
2,50 \\
\end{array}$ & $\begin{array}{l}1,90 \\
2,20 \\
2,60 \\
2,70 \\
2,80 \\
\end{array}$ \\
\hline & & & 18,00 & $\begin{array}{c}4,50 \\
9,00 \\
18,00 \\
36,00 \\
72,00\end{array}$ & $\begin{array}{c}4,50 \\
9,00 \\
18,00 \\
36,00 \\
72,00\end{array}$ & $\begin{array}{l}2,44 \\
3,66 \\
4,57 \\
5,18 \\
5,18\end{array}$ & $\begin{array}{l}2,40 \\
3,50 \\
4,40 \\
4,90 \\
4,90\end{array}$ & $\begin{array}{l}2,40 \\
3,50 \\
4,50 \\
5,00 \\
5,10\end{array}$ \\
\hline \multirow{6}{*}{50} & 2 & 1,38 & 4,50 & $\begin{array}{c}4,50 \\
9,00 \\
18,00 \\
36,00 \\
72,00 \\
\end{array}$ & $\begin{array}{c}4,50 \\
9,00 \\
18,00 \\
36,00 \\
72,00 \\
\end{array}$ & $\begin{array}{l}1,52 \\
2,13 \\
2,13 \\
2,13 \\
2,44 \\
\end{array}$ & $\begin{array}{l}1,30 \\
1,70 \\
1,80 \\
1,80 \\
1,90 \\
\end{array}$ & $\begin{array}{l}1,30 \\
1,70 \\
1,90 \\
2,00 \\
2,00 \\
\end{array}$ \\
\hline & 3 & 2,75 & 4,50 & $\begin{array}{c}4,50 \\
9,00 \\
18,00 \\
36,00 \\
72,00\end{array}$ & $\begin{array}{c}2,25 \\
4,50 \\
9,00 \\
18,00 \\
36,00 \\
\end{array}$ & $\begin{array}{l}2,13 \\
2,13 \\
2,74 \\
3,05 \\
3,35 \\
\end{array}$ & $\begin{array}{l}1,90 \\
1,90 \\
2,20 \\
2,60 \\
2,80 \\
\end{array}$ & $\begin{array}{l}2,30 \\
2,80 \\
2,70 \\
2,80 \\
3,00\end{array}$ \\
\hline & 2 & 1,38 & 9,00 & $\begin{array}{c}4,50 \\
9,00 \\
18,00 \\
36,00 \\
72,00\end{array}$ & $\begin{array}{c}4,50 \\
9,00 \\
18,00 \\
36,00 \\
72,00\end{array}$ & $\begin{array}{l}1,83 \\
2,44 \\
2,74 \\
3,05 \\
3,05\end{array}$ & $\begin{array}{l}1,40 \\
2,10 \\
2,40 \\
2,60 \\
2,50\end{array}$ & $\begin{array}{l}1,50 \\
2,10 \\
2,50 \\
2,70 \\
2,60\end{array}$ \\
\hline & 3 & 2,75 & 9,00 & $\begin{array}{c}4,50 \\
9,00 \\
18,00 \\
36,00 \\
72,00 \\
\end{array}$ & $\begin{array}{c}2,25 \\
4,50 \\
9,00 \\
18,00 \\
36,00 \\
\end{array}$ & $\begin{array}{l}2,13 \\
2,74 \\
3,96 \\
4,88 \\
5,49 \\
\end{array}$ & $\begin{array}{l}1,90 \\
2,40 \\
3,50 \\
4,30 \\
4,50 \\
\end{array}$ & $\begin{array}{l}2,50 \\
2,60 \\
3,50 \\
4,40 \\
4,70 \\
\end{array}$ \\
\hline & 2 & 1,38 & 18,00 & $\begin{array}{c}4,50 \\
9,00 \\
18,00 \\
36,00 \\
72,00 \\
\end{array}$ & $\begin{array}{c}4,50 \\
9,00 \\
18,00 \\
36,00 \\
72,00\end{array}$ & $\begin{array}{l}1,83 \\
2,44 \\
2,74 \\
3,05 \\
3,05\end{array}$ & $\begin{array}{l}1,00 \\
1,20 \\
1,60 \\
1,80 \\
1,70\end{array}$ & $\begin{array}{l}1,40 \\
1,50 \\
1,70 \\
1,90 \\
1,80 \\
\end{array}$ \\
\hline & 3 & 2,75 & 18,00 & $\begin{array}{c}4,50 \\
9,00 \\
18,00 \\
36,00 \\
72,00 \\
\end{array}$ & $\begin{array}{c}2,25 \\
4,50 \\
9,00 \\
18,00 \\
36,00\end{array}$ & $\begin{array}{l}2,13 \\
2,44 \\
3,66 \\
4,57 \\
5,49\end{array}$ & $\begin{array}{l}1,80 \\
2,00 \\
3,20 \\
3,90 \\
4,40\end{array}$ & $\begin{array}{l}2,50 \\
2,70 \\
3,30 \\
4,20 \\
4,50 \\
\end{array}$ \\
\hline
\end{tabular}




\begin{tabular}{|c|c|c|c|c|c|c|c|c|}
\hline $\begin{array}{l}\mathrm{A}_{\mathrm{w}} \\
{[\%]}\end{array}$ & $\begin{array}{l}\text { Sit } \\
\text { [ ] }\end{array}$ & $\begin{array}{c}\mathrm{h} \\
{[\mathrm{m}]}\end{array}$ & $\begin{array}{c}\mathrm{W}_{2} \\
{[\mathrm{~m}]}\end{array}$ & $\begin{array}{c}\mathrm{W}_{1} \\
{[\mathrm{~m}]}\end{array}$ & $\begin{array}{c}\mathrm{w} \\
{[\mathrm{m}]}\end{array}$ & $\begin{array}{c}\text { AISI } \\
\mathrm{d} \\
{[\mathrm{m}]}\end{array}$ & $\begin{array}{c}\text { Com parede } \\
\text { acima } \\
\text { EUROCODE } \\
\mathrm{d}_{\min } \\
{[\mathrm{m}]}\end{array}$ & $\begin{array}{c}\text { Sem parede } \\
\text { Acima } \\
\text { EUROCODE } \\
\mathrm{d}_{\min } \\
{[\mathrm{m}]}\end{array}$ \\
\hline \multirow{30}{*}{25} & \multirow{5}{*}{2} & \multirow{5}{*}{0,69} & \multirow{5}{*}{4,50} & 4,50 & 4,50 & 1,22 & 0,50 & 0,80 \\
\hline & & & & 9,00 & 9,00 & 1,22 & 0,50 & 0,90 \\
\hline & & & & 18,00 & 18,00 & 1,22 & 0,60 & 0,90 \\
\hline & & & & 36,00 & 36,00 & 1,22 & 0,60 & 1,00 \\
\hline & & & & 72,00 & 72,00 & 1,22 & 0,70 & 1,00 \\
\hline & \multirow{5}{*}{3} & \multirow{5}{*}{2,75} & \multirow{5}{*}{4,50} & 4,50 & 1,13 & 2,13 & 1,90 & 2,50 \\
\hline & & & & 9,00 & 2,25 & 2,13 & 1,90 & 2,90 \\
\hline & & & & 18,00 & 4,50 & 2,74 & 2,10 & 3,20 \\
\hline & & & & 36,00 & 9,00 & 3,96 & 3,10 & 3,30 \\
\hline & & & & 72,00 & 18,00 & 4,88 & 4,00 & 4,00 \\
\hline & \multirow{5}{*}{2} & \multirow{5}{*}{0,69} & \multirow{5}{*}{9,00} & 4,50 & 4,50 & 0,91 & 0,40 & 0,70 \\
\hline & & & & 9,00 & 9,00 & 0,91 & 0,50 & 0,80 \\
\hline & & & & 18,00 & 18,00 & 0,91 & 0,50 & 0,90 \\
\hline & & & & 36,00 & 36,00 & 0,91 & 0,50 & 1,00 \\
\hline & & & & 72,00 & 72,00 & 0,91 & 0,50 & 1,00 \\
\hline & \multirow{5}{*}{3} & \multirow{5}{*}{2,75} & \multirow{5}{*}{9,00} & 4,50 & 1,13 & 2,13 & 1,50 & 2,20 \\
\hline & & & & 9,00 & 2,25 & 2,13 & 1,90 & 2,90 \\
\hline & & & & 18,00 & 4,50 & 2,44 & 1,90 & 3,20 \\
\hline & & & & 36,00 & 9,00 & 3,35 & 2,70 & 3,40 \\
\hline & & & & 72,00 & 18,00 & 4,27 & 3,10 & 3,70 \\
\hline & \multirow{5}{*}{2} & \multirow{5}{*}{0,69} & \multirow{5}{*}{18,00} & 4,50 & 4,50 & 0,91 & 0,30 & 0,60 \\
\hline & & & & 9,00 & 9,00 & 0,91 & 0,50 & 0,80 \\
\hline & & & & 18,00 & 18,00 & 0,91 & 0,50 & 0,90 \\
\hline & & & & 36,00 & 36,00 & 0,91 & 0,50 & 0,90 \\
\hline & & & & 72,00 & 72,00 & 0,91 & 0,50 & 1,00 \\
\hline & \multirow{5}{*}{3} & \multirow{5}{*}{2,75} & \multirow{5}{*}{18,00} & 4,50 & 1,13 & 2,13 & 0,60 & 1,00 \\
\hline & & & & 9,00 & 2,25 & 2,13 & 1,70 & 2,70 \\
\hline & & & & 18,00 & 4,50 & 2,13 & 1,90 & 3,10 \\
\hline & & & & 36,00 & 9,00 & 2,13 & 1,90 & 3,40 \\
\hline & & & & 72,00 & 18,00 & 2,13 & 1,90 & 3,60 \\
\hline
\end{tabular}

conclusão

A tabela 7.1 possui duas comparações de distâncias mínimas do pilar à parede, uma quando o compartimento possui abertura acima e outra quando não. Quando o compartimento possui parede acima da janela, a chama se eleva próxima à parede (figura 5.24 (a)) e quando não possui parede acima da janela, a projeção horizontal da chama é maior (figura 5.24 (b)). O AISI (1979) não especifica se há ou não parede acima.

Verifica-se na tabela 7.1 que os valores calculados para a distância mínima do pilar à parede, de acordo com o Eurocode, quando o compartimento possui parede acima da janela, são menores do que os valores propostos pelo AISI. Quando o compartimento não possui parede 
acima da janela, as distâncias do pilar à parede são proximas do AISI e, em algumas situações, maiores.

A figura 7.4 mostra as possíveis situações para a distância mínima, $d_{m i n}$, do pilar à parede quando posicionado em frente a uma abertura. O compartimento possui aberturas em duas paredes.

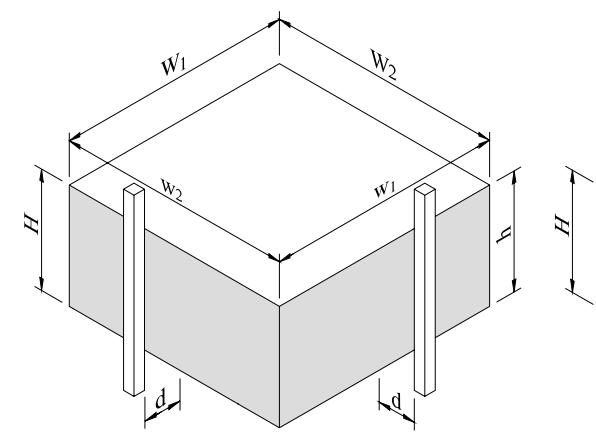

Situação 1

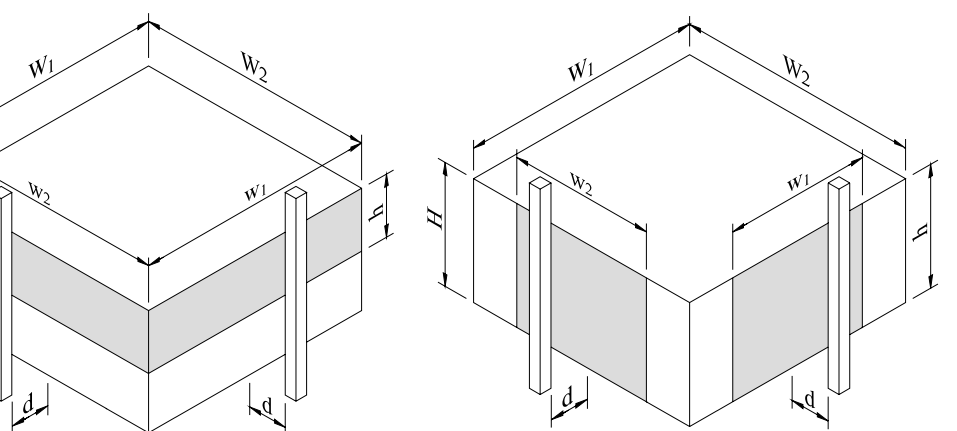

Situação 2
Situação 3

Figura 7.4 - Situações para cálculo da tabela 7.2.

A tabela 7.2 estabelece a distância mínima do pilar à parede, $d_{\min }$, quando situado em frente a uma abertura e houver aberturas em duas paredes do compartimento.

Na tabela 7.2 verifica-se que, quando o compartimento possui parede acima da janela, os valores da distância do pilar à parede são maiores para o AISI (1979) do que os valores calculados segundo o Eurocode 1, part 1-2 (2002) e o Eurocode 3, part 1-2 (2003).

Quando o compartimento não possui parede acima da janela, os valores de distância mínima do pilar à parede, pelo Eurocode, são mais próximos dos valores do AISI, chegando a ultrapassá-los em algumas situações. 
Tabela 7.2 - Distância mínima do pilar à parede. Pilar em frente a abertura. Aberturas em duas paredes

\begin{tabular}{|c|c|c|c|c|c|c|c|c|c|}
\hline & & & & & & & & $\begin{array}{c}\mathrm{C} / \text { parede } \\
\text { acima }\end{array}$ & $\begin{array}{c}\text { S/ parede } \\
\text { Acima }\end{array}$ \\
\hline $\begin{array}{l}\text { Aw } \\
{[\%]}\end{array}$ & $\begin{array}{l}\text { Sit } \\
{[]}\end{array}$ & $\begin{array}{c}\mathrm{h} \\
{[\mathrm{m}]}\end{array}$ & $\begin{array}{l}\mathrm{W}_{2} \\
{[\mathrm{~m}]}\end{array}$ & $\begin{array}{c}\mathrm{w}_{2} \\
{[\mathrm{~m}]}\end{array}$ & $\begin{array}{l}\mathrm{W}_{1} \\
{[\mathrm{~m}]}\end{array}$ & $\begin{array}{c}\mathrm{w}_{1} \\
{[\mathrm{~m}]}\end{array}$ & $\begin{array}{c}\text { AISI } \\
\mathrm{d} \\
{[\mathrm{m}]}\end{array}$ & $\begin{array}{c}\text { Eurocode } \\
\mathrm{d}_{\min } \\
{[\mathrm{m}]}\end{array}$ & $\begin{array}{c}\text { Eurocode } \\
\mathrm{d}_{\min } \\
{[\mathrm{m}]}\end{array}$ \\
\hline \multirow{4}{*}{100} & \multirow{4}{*}{1} & \multirow{4}{*}{2,80} & 9,00 & 9,00 & $\begin{array}{c}9,00 \\
18,00 \\
36,00 \\
72,00\end{array}$ & $\begin{array}{c}9,00 \\
18,00 \\
36,00 \\
72,00\end{array}$ & $\begin{array}{l}2,13 \\
2,13 \\
2,13 \\
2,13\end{array}$ & $\begin{array}{l}1,90 \\
1,90 \\
1,90 \\
1,90\end{array}$ & $\begin{array}{l}2,10 \\
2,10 \\
2,50 \\
2,70\end{array}$ \\
\hline & & & 18,00 & 18,00 & $\begin{array}{c}9,00 \\
18,00 \\
36,00 \\
72,00\end{array}$ & $\begin{array}{c}9,00 \\
18,00 \\
36,00 \\
72,00\end{array}$ & $\begin{array}{l}2,13 \\
2,13 \\
3,66 \\
4,57\end{array}$ & $\begin{array}{l}1,90 \\
2,20 \\
3,50 \\
4,20\end{array}$ & $\begin{array}{l}2,10 \\
2,30 \\
3,70 \\
4,40\end{array}$ \\
\hline & & & 36,00 & 36,00 & $\begin{array}{c}9,00 \\
18,00 \\
36,00 \\
72,00 \\
\end{array}$ & $\begin{array}{c}9,00 \\
18,00 \\
36,00 \\
72,00 \\
\end{array}$ & $\begin{array}{l}2,13 \\
3,66 \\
4,88 \\
5,79 \\
\end{array}$ & $\begin{array}{l}1,90 \\
3,50 \\
4,80 \\
5,40 \\
\end{array}$ & $\begin{array}{l}2,50 \\
3,70 \\
4,90 \\
5,60 \\
\end{array}$ \\
\hline & & & 72,00 & 72,00 & $\begin{array}{c}9,00 \\
18,00 \\
36,00 \\
72,00\end{array}$ & $\begin{array}{c}9,00 \\
18,00 \\
36,00 \\
72,00\end{array}$ & $\begin{array}{l}2,13 \\
4,57 \\
5,79 \\
5,79\end{array}$ & $\begin{array}{l}1,90 \\
4,20 \\
5,40 \\
5,20\end{array}$ & $\begin{array}{l}2,70 \\
4,40 \\
5,60 \\
5,40\end{array}$ \\
\hline \multirow{6}{*}{50} & 2 & 1,40 & 9,00 & 9,00 & $\begin{array}{c}9,00 \\
18,00 \\
36,00 \\
72,00\end{array}$ & $\begin{array}{c}9,00 \\
18,00 \\
36,00 \\
72,00\end{array}$ & $\begin{array}{l}2,13 \\
2,74 \\
2,74 \\
3,05\end{array}$ & $\begin{array}{l}1,70 \\
2,30 \\
2,50 \\
2,50\end{array}$ & $\begin{array}{l}1,70 \\
2,30 \\
2,60 \\
2,60\end{array}$ \\
\hline & 3 & 2,80 & 9,00 & 4,50 & $\begin{array}{c}9,00 \\
18,00 \\
36,00 \\
72,00\end{array}$ & $\begin{array}{c}4,50 \\
9,00 \\
18,00 \\
36,00\end{array}$ & $\begin{array}{l}2,13 \\
3,05 \\
4,27 \\
5,18\end{array}$ & $\begin{array}{l}1,90 \\
2,80 \\
3,90 \\
4,30\end{array}$ & $\begin{array}{l}2,40 \\
2,90 \\
4,00 \\
4,40\end{array}$ \\
\hline & 2 & 1,40 & 18,00 & 18,00 & $\begin{array}{c}9,00 \\
18,00 \\
36,00 \\
72,00\end{array}$ & $\begin{array}{c}9,00 \\
18,00 \\
36,00 \\
72,00\end{array}$ & $\begin{array}{l}2,74 \\
2,74 \\
2,74 \\
2,74\end{array}$ & $\begin{array}{l}2,30 \\
2,50 \\
2,60 \\
2,30\end{array}$ & $\begin{array}{l}2,30 \\
2,60 \\
2,60 \\
2,30\end{array}$ \\
\hline & 3 & 2,80 & 18,00 & 9,00 & $\begin{array}{c}9,00 \\
18,00 \\
36,00 \\
72,00\end{array}$ & $\begin{array}{c}4,50 \\
9,00 \\
18,00 \\
36,00\end{array}$ & $\begin{array}{l}3,05 \\
3,66 \\
5,18 \\
5,79\end{array}$ & $\begin{array}{l}2,80 \\
3,50 \\
4,50 \\
4,80\end{array}$ & $\begin{array}{l}2,90 \\
3,50 \\
4,60 \\
4,90\end{array}$ \\
\hline & 2 & 1,40 & 36,00 & 36,00 & $\begin{array}{c}9,00 \\
18,00 \\
36,00 \\
72,00\end{array}$ & $\begin{array}{c}9,00 \\
18,00 \\
36,00 \\
72,00\end{array}$ & $\begin{array}{l}2,74 \\
2,74 \\
2,13 \\
1,52\end{array}$ & $\begin{array}{l}2,50 \\
2,50 \\
2,00 \\
1,40\end{array}$ & $\begin{array}{l}2,60 \\
2,50 \\
2,00 \\
1,70\end{array}$ \\
\hline & 3 & 2,80 & 36,00 & 18,00 & $\begin{array}{c}9,00 \\
18,00 \\
36,00 \\
72,00\end{array}$ & $\begin{array}{c}4,50 \\
9,00 \\
18,00 \\
36,00\end{array}$ & $\begin{array}{l}4,27 \\
5,18 \\
4,88 \\
4,57\end{array}$ & $\begin{array}{l}3,90 \\
4,50 \\
4,30 \\
3,70\end{array}$ & $\begin{array}{l}4,00 \\
4,60 \\
4,40 \\
3,80\end{array}$ \\
\hline
\end{tabular}




\begin{tabular}{|c|c|c|c|c|c|c|c|c|c|}
\hline & & & & & & & & $\begin{array}{c}\mathrm{C} / \text { parede } \\
\text { acima }\end{array}$ & $\begin{array}{c}\mathrm{S} / \text { parede } \\
\text { Acima }\end{array}$ \\
\hline $\begin{array}{l}\text { Aw } \\
{[\%]}\end{array}$ & $\begin{array}{l}\text { Sit } \\
{[]}\end{array}$ & $\begin{array}{c}\mathrm{h} \\
{[\mathrm{m}]}\end{array}$ & $\begin{array}{l}\mathrm{W}_{2} \\
{[\mathrm{~m}]}\end{array}$ & $\begin{array}{c}\mathrm{w}_{2} \\
{[\mathrm{~m}]}\end{array}$ & $\begin{array}{l}\mathrm{W}_{1} \\
{[\mathrm{~m}]}\end{array}$ & $\begin{array}{c}\mathrm{w}_{1} \\
{[\mathrm{~m}]}\end{array}$ & $\begin{array}{c}\text { AISI } \\
\mathrm{d} \\
{[\mathrm{m}]}\end{array}$ & $\begin{array}{c}\text { Eurocode } \\
\mathrm{d}_{\min } \\
{[\mathrm{m}]}\end{array}$ & $\begin{array}{c}\text { Eurocode } \\
\mathrm{d}_{\min } \\
{[\mathrm{m}]}\end{array}$ \\
\hline \multirow{2}{*}{50} & 2 & 1,40 & 72,00 & 72,00 & $\begin{array}{c}9,00 \\
18,00 \\
36,00 \\
72,00 \\
\end{array}$ & $\begin{array}{c}9,00 \\
18,00 \\
36,00 \\
72,00\end{array}$ & $\begin{array}{l}3,05 \\
2,74 \\
1,52 \\
1,22 \\
\end{array}$ & $\begin{array}{l}2,50 \\
2,30 \\
1,40 \\
1,00 \\
\end{array}$ & $\begin{array}{l}2,60 \\
2,30 \\
1,70 \\
1,80 \\
\end{array}$ \\
\hline & 3 & 2,80 & 72,00 & 36,00 & $\begin{array}{c}9,00 \\
18,00 \\
36,00 \\
72,00 \\
\end{array}$ & $\begin{array}{c}4,50 \\
9,00 \\
18,00 \\
36,00 \\
\end{array}$ & $\begin{array}{l}5,18 \\
5,79 \\
4,57 \\
2,74 \\
\end{array}$ & $\begin{array}{l}4,30 \\
4,80 \\
3,60 \\
2,00 \\
\end{array}$ & $\begin{array}{l}4,40 \\
4,90 \\
3,70 \\
3,40 \\
\end{array}$ \\
\hline \multirow{8}{*}{25} & 2,00 & 1,40 & 9,00 & 4,50 & $\begin{array}{c}9,00 \\
18,00 \\
36,00 \\
72,00 \\
\end{array}$ & $\begin{array}{c}4,50 \\
9,00 \\
18,00 \\
36,00\end{array}$ & $\begin{array}{l}1,52 \\
1,22 \\
0,91 \\
0,91\end{array}$ & $\begin{array}{l}0,80 \\
0,60 \\
0,50 \\
0,50 \\
\end{array}$ & $\begin{array}{l}0,80 \\
0,80 \\
0,80 \\
0,80 \\
\end{array}$ \\
\hline & 3,00 & 2,80 & 9,00 & 2,25 & $\begin{array}{c}9,00 \\
18,00 \\
36,00 \\
72,00 \\
\end{array}$ & $\begin{array}{c}2,25 \\
4,50 \\
9,00 \\
18,00 \\
\end{array}$ & $\begin{array}{l}2,13 \\
2,74 \\
3,96 \\
4,57 \\
\end{array}$ & $\begin{array}{l}1,90 \\
2,20 \\
3,10 \\
3,40 \\
\end{array}$ & $\begin{array}{l}2,80 \\
3,10 \\
3,10 \\
3,40 \\
\end{array}$ \\
\hline & 2,00 & 1,40 & 18,00 & 9,00 & $\begin{array}{c}9,00 \\
18,00 \\
36,00 \\
72,00\end{array}$ & $\begin{array}{c}4,50 \\
9,00 \\
18,00 \\
36,00\end{array}$ & $\begin{array}{l}1,22 \\
0,91 \\
0,91 \\
0,91\end{array}$ & $\begin{array}{l}0,60 \\
0,50 \\
0,50 \\
0,50\end{array}$ & $\begin{array}{l}0,80 \\
0,90 \\
0,90 \\
0,90\end{array}$ \\
\hline & 3,00 & 2,80 & 18,00 & 4,50 & $\begin{array}{c}9,00 \\
18,00 \\
36,00 \\
72,00 \\
\end{array}$ & $\begin{array}{c}2,25 \\
4,50 \\
9,00 \\
18,00 \\
\end{array}$ & $\begin{array}{l}2,74 \\
2,74 \\
3,05 \\
3,05 \\
\end{array}$ & $\begin{array}{r}2,20 \\
2,00 \\
2,30 \\
1,90 \\
\end{array}$ & $\begin{array}{l}3,10 \\
3,10 \\
3,40 \\
3,60 \\
\end{array}$ \\
\hline & 2,00 & 1,40 & 36,00 & 18,00 & $\begin{array}{c}9,00 \\
18,00 \\
36,00 \\
72,00 \\
\end{array}$ & $\begin{array}{c}4,50 \\
9,00 \\
18,00 \\
36,00 \\
\end{array}$ & $\begin{array}{l}0,91 \\
0,91 \\
0,91 \\
0,91 \\
\end{array}$ & $\begin{array}{l}0,50 \\
0,50 \\
0,50 \\
0,50 \\
\end{array}$ & $\begin{array}{l}0,80 \\
0,90 \\
0,90 \\
0,90 \\
\end{array}$ \\
\hline & 3,00 & 2,80 & 36,00 & 9,00 & $\begin{array}{c}9,00 \\
18,00 \\
36,00 \\
72,00 \\
\end{array}$ & $\begin{array}{c}2,25 \\
4,50 \\
9,00 \\
18,00 \\
\end{array}$ & $\begin{array}{l}3,96 \\
3,05 \\
2,13 \\
2,13 \\
\end{array}$ & $\begin{array}{l}3,10 \\
2,30 \\
1,90 \\
1,90 \\
\end{array}$ & $\begin{array}{l}3,40 \\
3,40 \\
3,40 \\
3,30\end{array}$ \\
\hline & 2,00 & 1,40 & 72,00 & 36,00 & $\begin{array}{c}9,00 \\
18,00 \\
36,00 \\
72,00 \\
\end{array}$ & $\begin{array}{c}4,50 \\
9,00 \\
18,00 \\
36,00 \\
\end{array}$ & $\begin{array}{l}0,91 \\
0,91 \\
0,91 \\
0,91 \\
\end{array}$ & $\begin{array}{l}0,50 \\
0,50 \\
0,50 \\
0,50 \\
\end{array}$ & $\begin{array}{l}0,80 \\
0,90 \\
0,90 \\
0,90 \\
\end{array}$ \\
\hline & 3,00 & 2,80 & 72,00 & 18,00 & $\begin{array}{c}9,00 \\
18,00 \\
36,00 \\
72,00\end{array}$ & $\begin{array}{c}2,25 \\
4,50 \\
9,00 \\
18,00\end{array}$ & $\begin{array}{l}4,57 \\
3,05 \\
2,13 \\
2,13\end{array}$ & $\begin{array}{l}3,40 \\
1,90 \\
1,90 \\
1,80\end{array}$ & $\begin{array}{l}3,60 \\
3,60 \\
3,30 \\
3,50\end{array}$ \\
\hline
\end{tabular}


A figura 7.5 mostra a situação de um pilar situado entre aberturas. A distância mínima do pilar à abertura deverá ser o menor valor entre $a$ e $c$, onde $a$ é a distância do pilar à abertura, e $c$ é o comprimento perpendicular da seção do pilar em relação à parede.

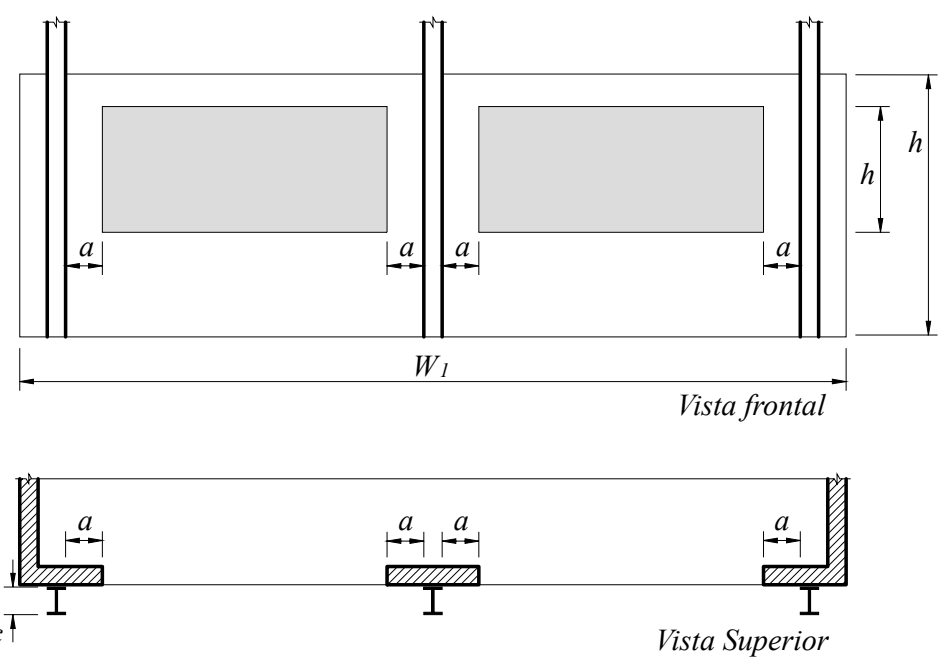

Figura 7.5 - Situação para cálculo da tabela 7.3.

A tabela 7.3 mostra a distância mínima do pilar até a abertura, quando posicionado entre aberturas. Foram consideradas existências de aberturas em uma ou duas paredes, e a profundidade do compartimento variou para diversas situações.

Tabela 7.3 - Distância mínima do pilar à abertura. Pilar entre aberturas

\begin{tabular}{|c|c|c|c|c|}
\hline $\begin{array}{c}\mathrm{H} \\
{[\mathrm{m}]}\end{array}$ & $\begin{array}{l}\mathrm{W}_{1} \\
{[\mathrm{~m}]}\end{array}$ & $\begin{array}{c}\mathrm{h} \\
{[\mathrm{m}]}\end{array}$ & $\begin{array}{l}\text { AISI } \\
a_{\min } \\
{[\mathrm{m}]}\end{array}$ & $\begin{array}{c}\text { Eurocode } \\
\mathrm{a}_{\min } \\
{[\mathrm{m}]}\end{array}$ \\
\hline \multirow{4}{*}{2,75} & 9,00 & $\begin{array}{l}0,90 \\
1,20 \\
1,50 \\
1,80 \\
2,80\end{array}$ & $\begin{array}{l}1,52 \\
0,91 \\
0,91 \\
0,76 \\
0,61\end{array}$ & $\begin{array}{l}0,60 \\
0,70 \\
0,70 \\
0,80 \\
0,70\end{array}$ \\
\hline & 18,00 & $\begin{array}{l}0,90 \\
1,20 \\
1,50 \\
1,80 \\
2,80\end{array}$ & $\begin{array}{l}2,59 \\
1,22 \\
1,22 \\
1,07 \\
0,76\end{array}$ & $\begin{array}{l}0,70 \\
0,90 \\
1,00 \\
1,10 \\
0,90\end{array}$ \\
\hline & 36,00 & $\begin{array}{l}0,90 \\
1,20 \\
1,50 \\
1,80 \\
2,80\end{array}$ & $\begin{array}{l}2,59 \\
1,37 \\
1,22 \\
1,07 \\
0,91\end{array}$ & $\begin{array}{l}0,80 \\
1,00 \\
1,10 \\
1,20 \\
1,10\end{array}$ \\
\hline & 72,00 & $\begin{array}{l}0,90 \\
1,20 \\
1,50 \\
1,80 \\
2,80\end{array}$ & $\begin{array}{l}2,59 \\
1,37 \\
1,22 \\
1,07 \\
0,91\end{array}$ & $\begin{array}{l}0,80 \\
0,90 \\
1,00 \\
1,10 \\
1,10\end{array}$ \\
\hline
\end{tabular}


Na tabela 7.3, verifica-se que os valores de distância mínima do pilar à abertura do compartimento são menores quando calculados pelo Eurocode 1, part 1-2 (2002) e Eurocode 3, part 1-2 (2003). Quando a altura da janela possui 0,90m, o AISI (1979) estabelece valores bem maiores do que os do Eurocode. Foram realizados vários cálculos, variando os demais fatores intervenientes no processo, e não se encontrou valores próximos aos estabelecidos pelo AISI. 
Capítulo 8 APLICAÇÕES DO EXTEELFIRE 2.0

\subsection{VARIAÇÃO DA TEMPERATURA NA ESTRUTURA}

A título de exemplo de aplicação do ExteelFire, apresenta-se a variação da temperatura de um pilar com alguns parâmetros intervenientes no processo para o modelo de compartimento apresentado na figura 8.1. Admitem-se as seguintes dimensões-padrão: $W_{1}=8 \mathrm{~m}, W_{2}=10 \mathrm{~m}$, $H=4 \mathrm{~m}, h=2 \mathrm{~m}, w=6 \mathrm{~m}, d=1 \mathrm{~m}, d_{l}=d_{2}=0,30 \mathrm{~m} \mathrm{e} q_{f, d}=700 \mathrm{MJ} / \mathrm{m}^{2}$.

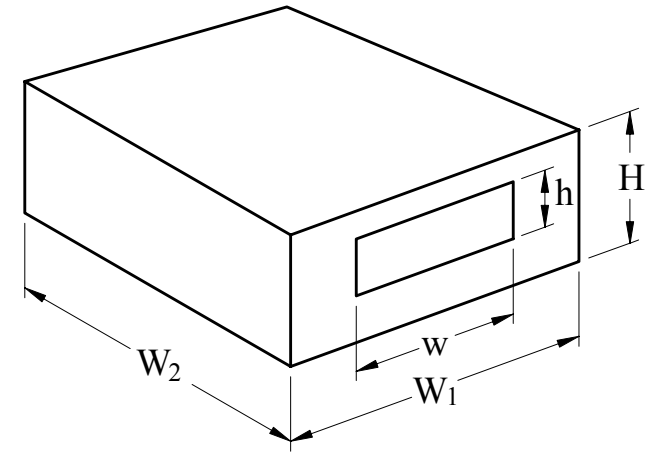

Perspectiva

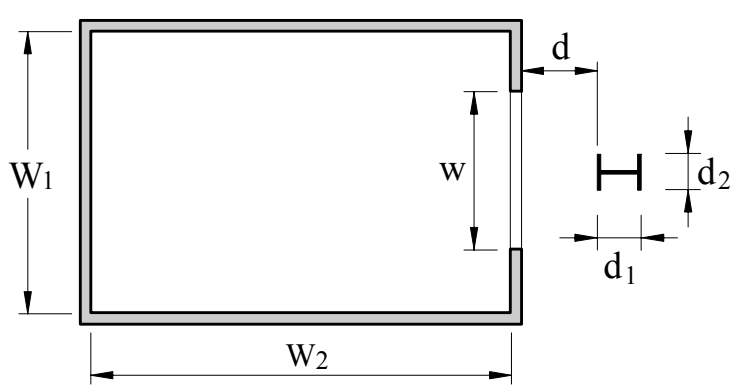

Planta baixa

Figura 8.1 - Modelo do compartimento e do elemento estrutural para análise paramétrica.

Na figura 8.2, observa-se a queda de temperatura em um pilar, à medida que se afasta da janela. A queda brusca apresentada no gráfico significa a fase em que o pilar deixa de estar envolvido pelas chamas. Na figura 8.3, vê-se a variação da temperatura do pilar com a altura do compartimento. Com o aumento da altura do compartimento, aumenta-se a superfície total aquecida dentro do compartimento. A carga de incêndio total permanece inalterada, pois leva em consideração apenas a área de piso, ocasionando uma distribuição da mesma quantidade de calor em um volume maior do compartimento. Consequentemente, diminui-se a temperatura no interior do compartimento e a intensidade de calor que o pilar recebe. 


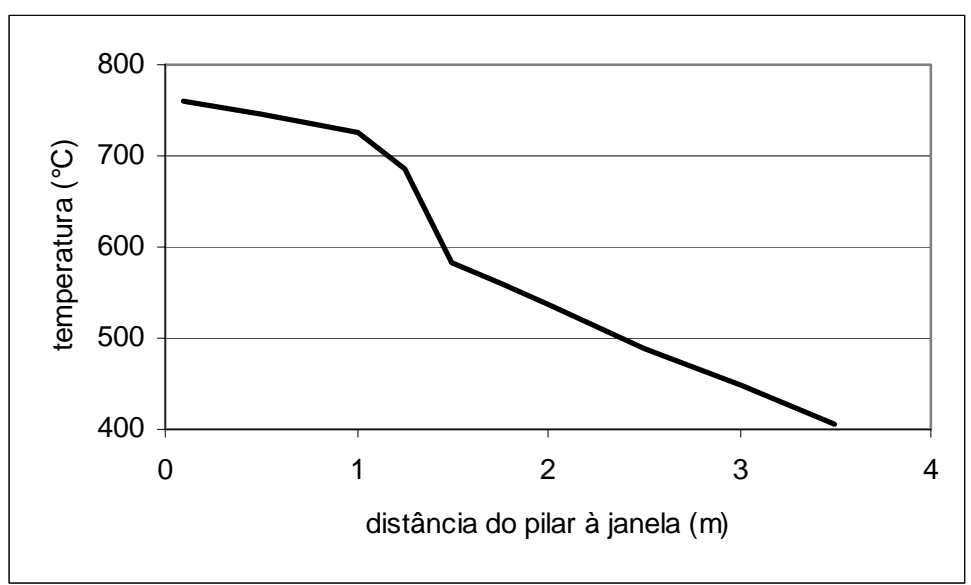

Figura 8.2 - Variação da Temperatura de um pilar com a distância à janela.

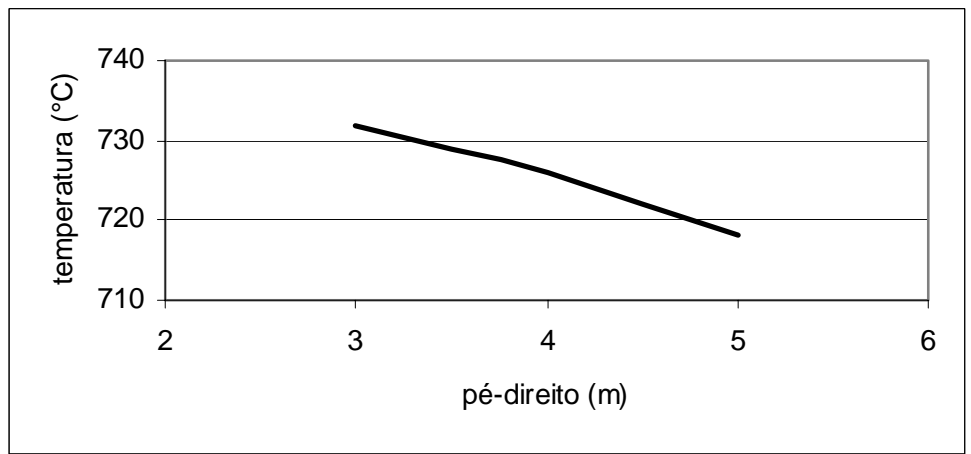

Figura 8.3 Variação da temperatura de um pilar com a altura do compartimento.

$\mathrm{Na}$ figura 8.4, apresenta-se a variação da temperatura do pilar com o aumento da profundidade do compartimento. De início, ocorre o aumento da temperatura do pilar, o que era esperado em vista do aumento da carga de incêndio total. A profundidade e, portanto, a carga total de incêndio, vai aumentando até que a ventilação deixa de ser suficiente para a combustão. A combustão depende da carga de incêndio, mas também da ventilação. A partir daí, o aumento da carga de incêndio torna-se irrelevante e a ventilação vai relativamente diminuindo e, por consequência, a temperatura dentro do compartimento incendiado.

Na figura 8.5, observa-se a variação da temperatura do pilar em relação à sua distância a uma das bordas da janela. Como é óbvio, a temperatura máxima ocorre quando o pilar é centrado na janela, diminuindo simetricamente à medida que o pilar se aproxima das bordas. 


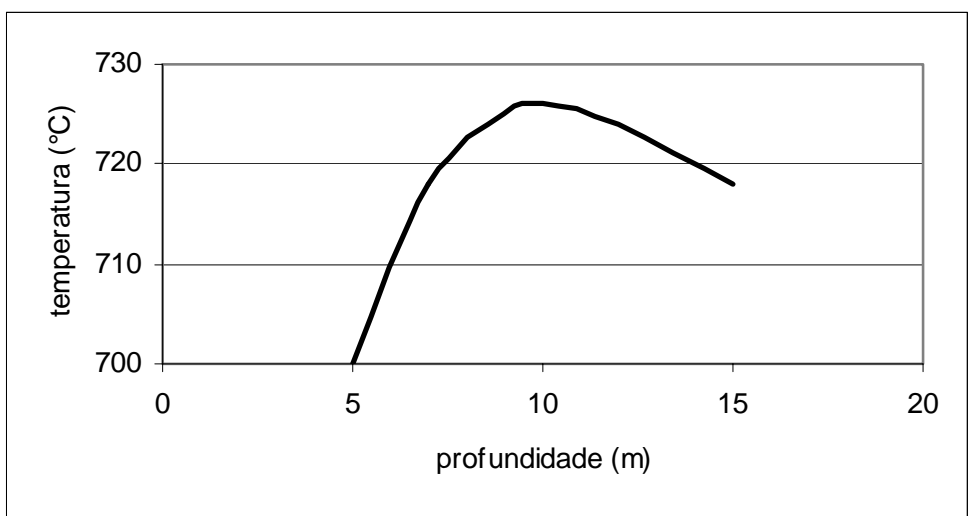

Figura 8.4 - Variação da temperatura de um pilar com a profundidade do compartimento.

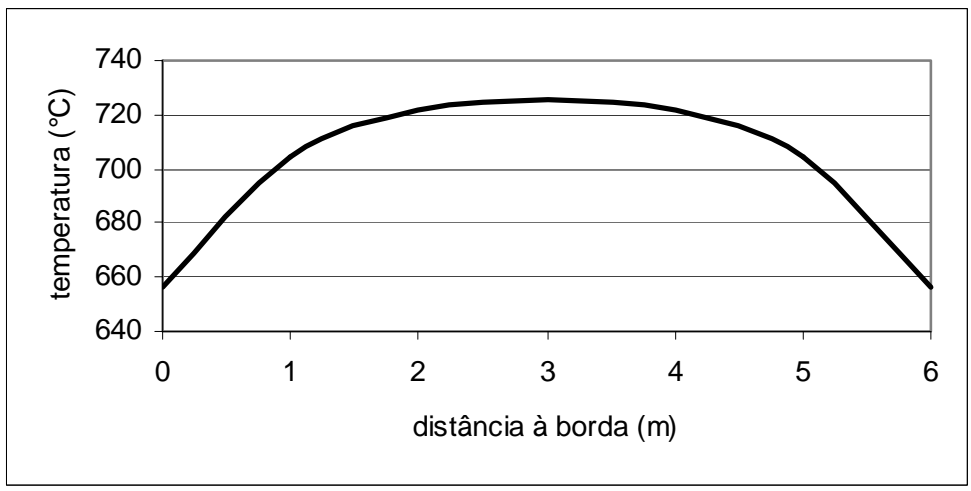

Figura 8.5 - Variação da temperatura de um pilar com a distância à borda da janela.

A figura 8.6 mostra a variação da temperatura do pilar em relação à variação das dimensões da seção transversal dos mesmos. Considerou-se que a largura é igual a altura. Foram consideradas duas situações, uma em que o pilar está distante $0,50 \mathrm{~m}$ da abertura e envolvido pela chama, e outra em que o pilar está distante $1,50 \mathrm{~m}$ da abertura e não envolvido pela chama.

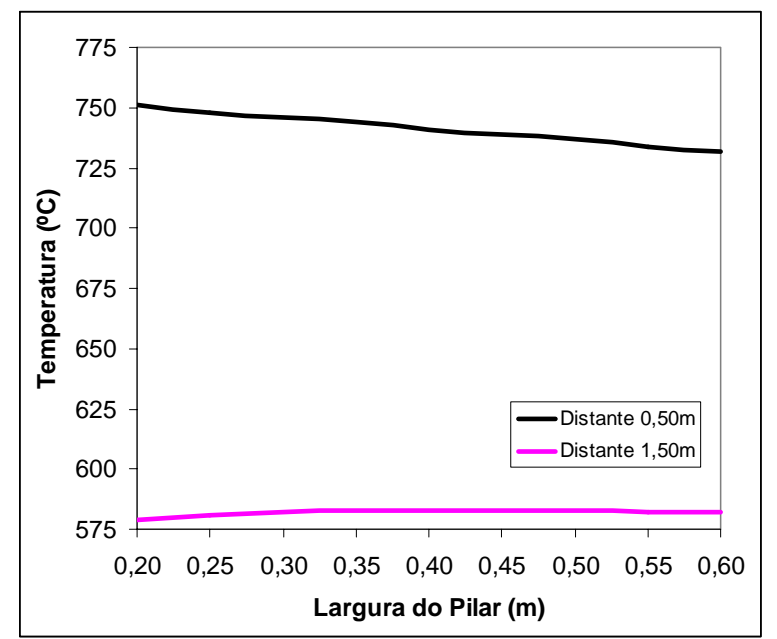

Figura 8.6 Variação da temperatura de um pilar com a sua largura. 
Na figura 8.6, quando o pilar está envolvido pela chama (figura 8.7), observa-se a redução na temperatura do pilar ao aumentar a seção transversal. A redução ocorre devido ao menor coeficiente de convecção das chamas (eq. 5.16) e menor fator de emissividade das chamas (eq. 5.24), conforme definidos pelo método simplificado aqui empregado.

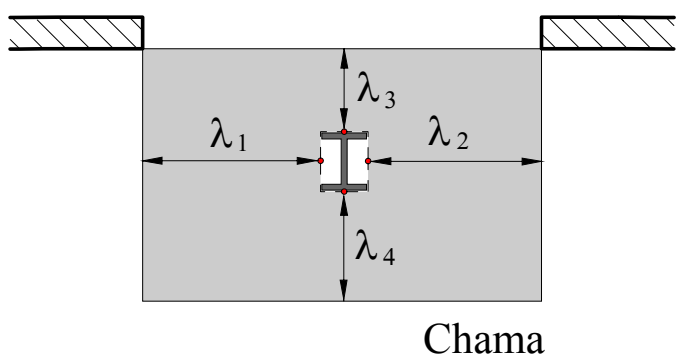

(a)

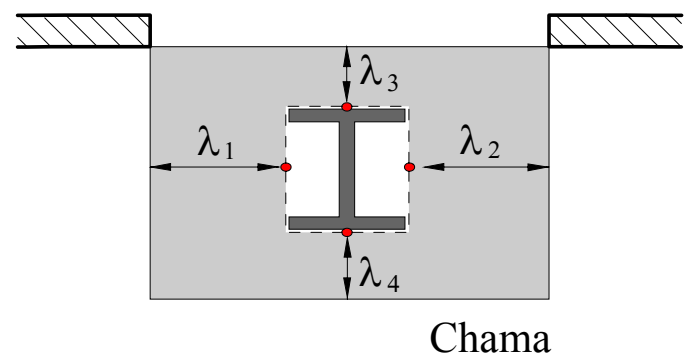

(b)

Figura 8.7 - Pilar em frente à abertura e envolvido pela chama.

No entanto, se a distância do pilar à abertura for de 1,50 m, o pilar não estará envolvido pela chama e a variação da temperatura no pilar com as dimensões de seu contorno não será significativa, como pode-se observar na figura 8.6. Convém lembrar que a temperatura da superfície receptora da radiação proveniente da fonte de calor (chama e abertura do compartimento) é calculada para pontos localizados no meio das faces do pilar e não para toda a superfície. Na figura 8.8, esses pontos são 1, 2 e 3. Se, por um lado, o coeficiente de convecção das chamas é reduzido e os pontos 1 e 2 da figura 8.8 se afastam das chamas reduzindo a temperatura, por outro, o aumento da largura do pilar leva as superfícies do perfil paralelas à alma a terem uma menor "visada" das chamas e, portanto, a uma temperatura menor. Os resultados finais mostram a pequena variação na temperatura.

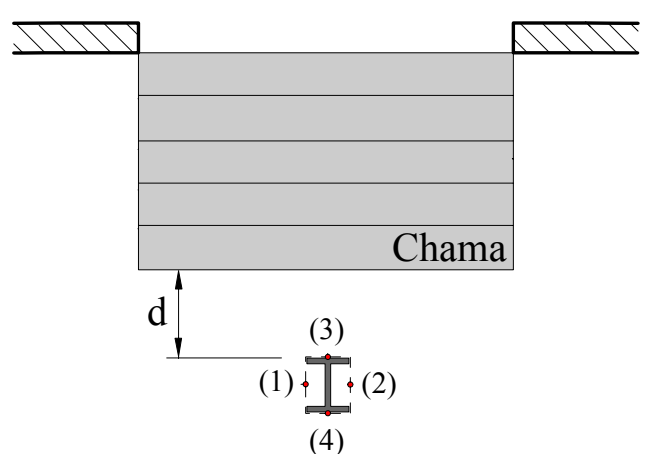

(a)

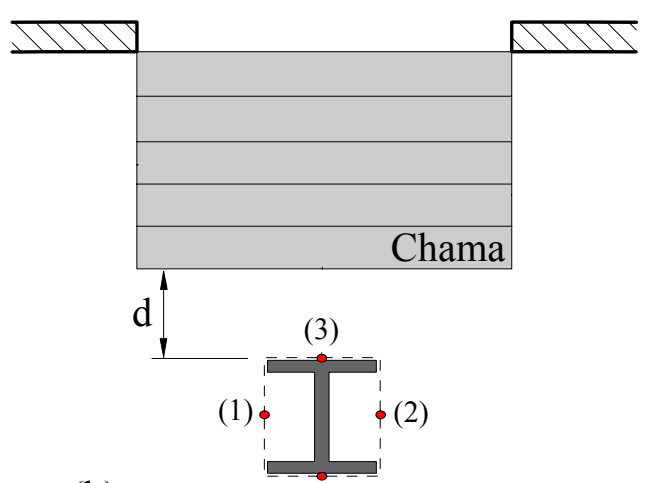

(b)
(4)

Figura 8.8 - Pilar em frente a abertura e não envolvido pela chama. 
Na figura 8.9, nota-se o aumento da temperatura do pilar com o valor de cálculo da carga de incêndio específica até um determinado valor, a partir do qual a temperatura se estabiliza, pois o incêndio passa a ser controlado pela ventilação.

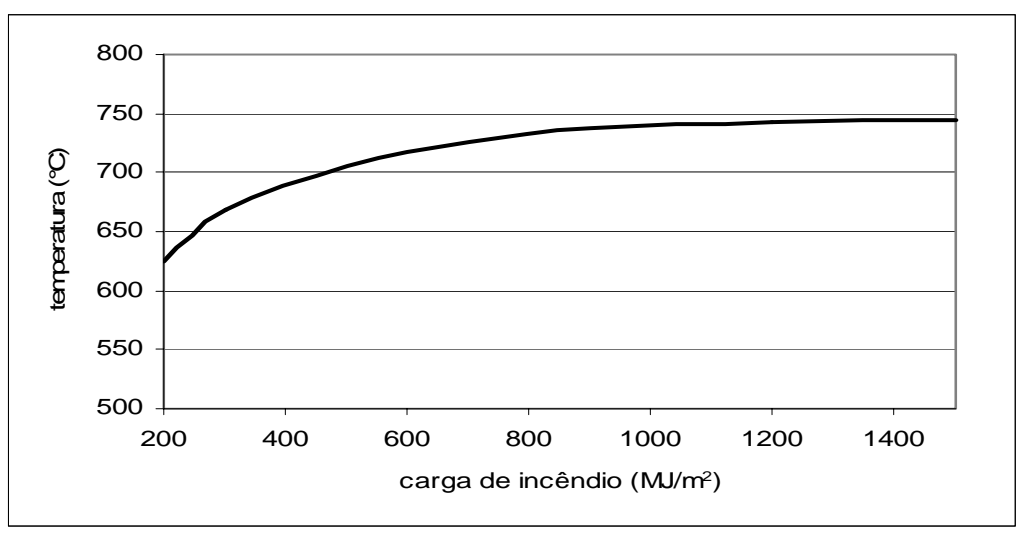

Figura 8.9 - Variação da temperatura de um pilar com a carga de incêndio de cálculo.

Foi realizada, também, uma análise da variação da temperatura de uma viga externa à edificação. A figura 8.10 mostra a distância vertical da viga à borda superior da abertura e também a distância horizontal da viga à parede da fachada.

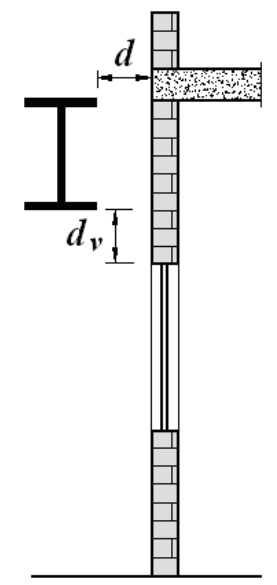

Figura 8.10 - Distância vertical $\left(d_{v}\right)$ da viga à borda superior da abertura e distância horizontal da viga $(d)$ à parede da fachada.

Na figura 8.11, observa-se que a temperatura da viga diminui à medida que aumenta a distância vertical da borda superior da abertura. $\mathrm{Na}$ figura 8.12, observa-se que a temperatura da viga aumenta para, em seguida, diminuir com a distância horizontal à parede da fachada. Isso ocorre porque quando a viga está em contato com a parede (viga de borda), considera-se que a face em contato com a parede está protegida e não recebe fluxo de calor. Após a viga se 
afastar da parede, a face próxima da parede volta a receber o fluxo de calor, aumentando a sua temperatura. Até que, então, ocorre o distanciamento da superfície receptora de calor (a viga) da fonte de calor (o compartimento incendiado e a chama que emerge para fora), ocasionando a diminuição da temperatura.

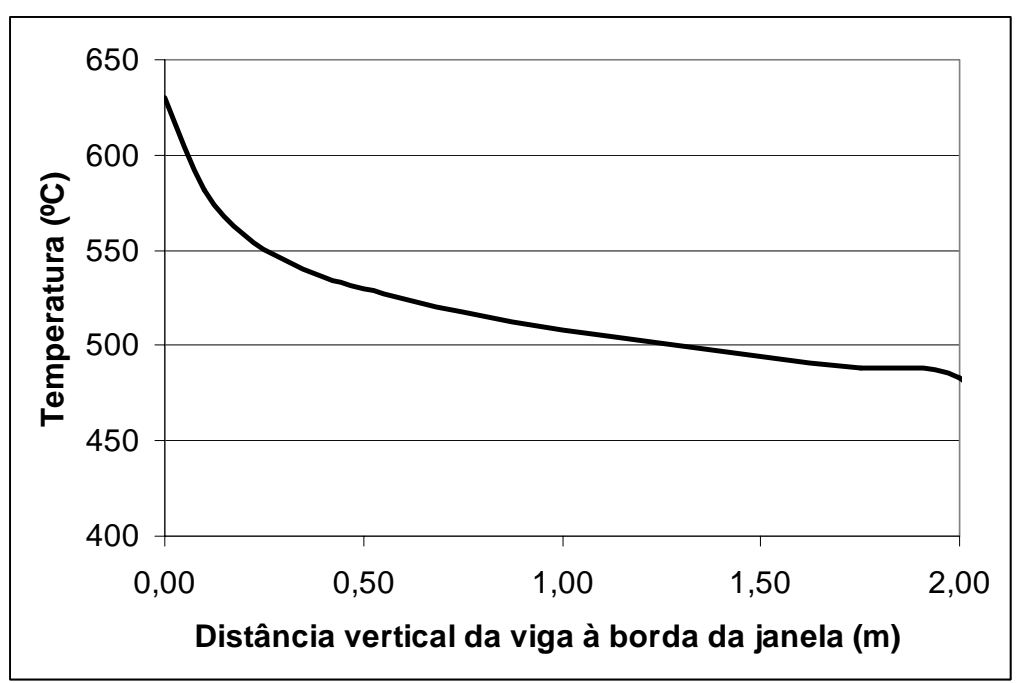

Figura 8.11 - Variação da temperatura de uma viga com a distância vertical à borda superior da abertura.

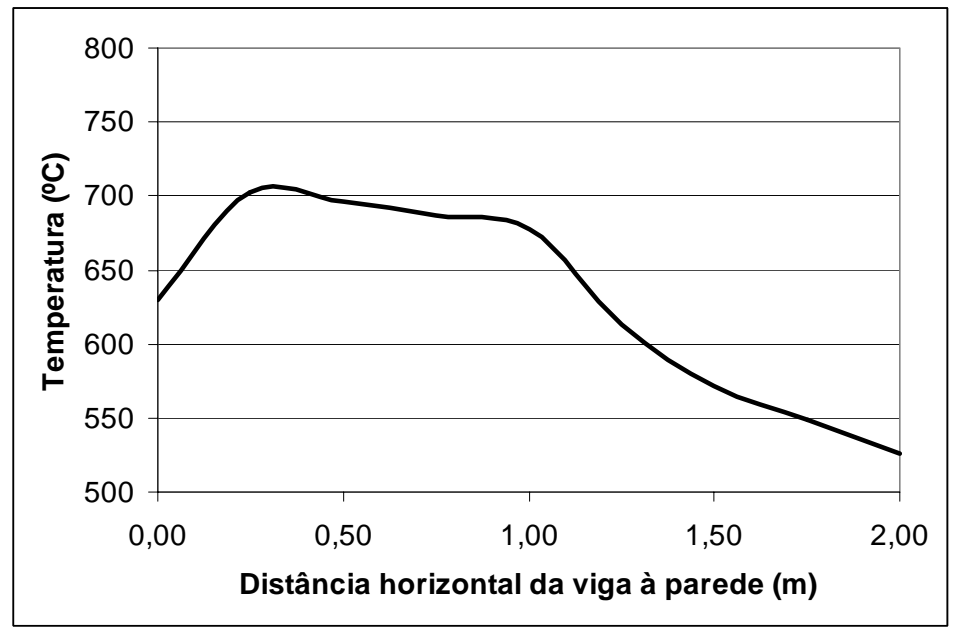

Figura 8.12 - Variação da temperatura de uma viga com a distância horizontal à parede da fachada.

$\mathrm{Na}$ figura 8.13, observa-se que a temperatura da viga aumenta com o aumento da profundidade do compartimento até um ponto onde começa a diminuir. Isso ocorre pelos mesmos motivos expostos para o pilar da figura 8.4.

Na figura 8.14, observa-se que a temperatura de uma viga aumenta com o aumento da carga de incêndio até que começa a ocorrer uma estabilização. Essa estabilização ocorre quando o incêndio passa a ser controlado pela ventilação. 


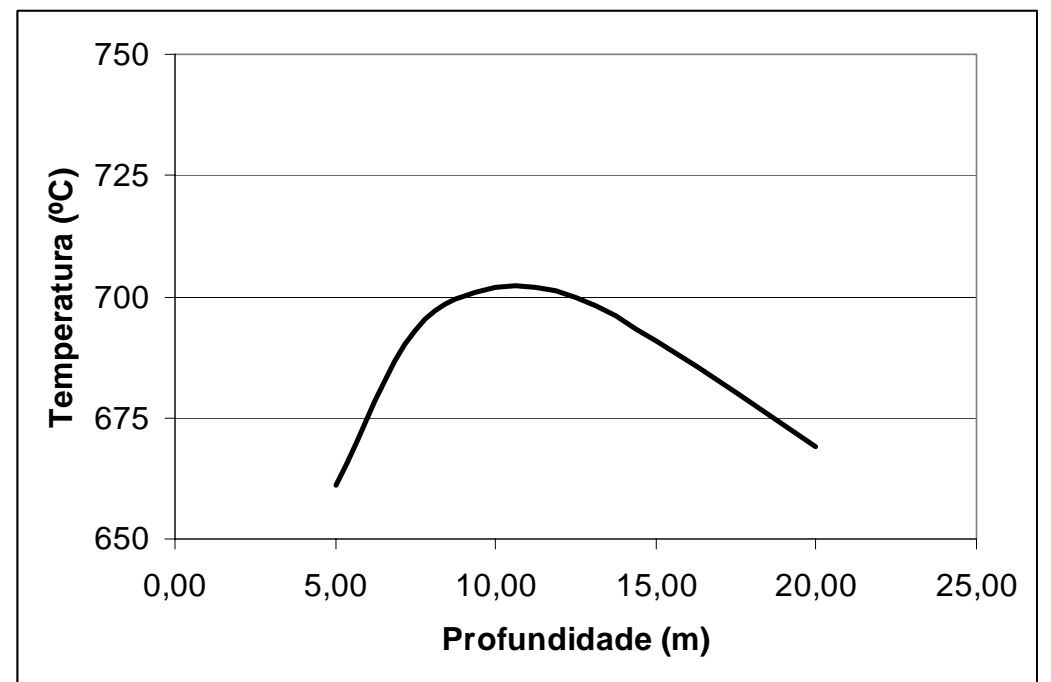

Figura 8.13 - Variação da temperatura de uma viga com a profundidade do compartimento.

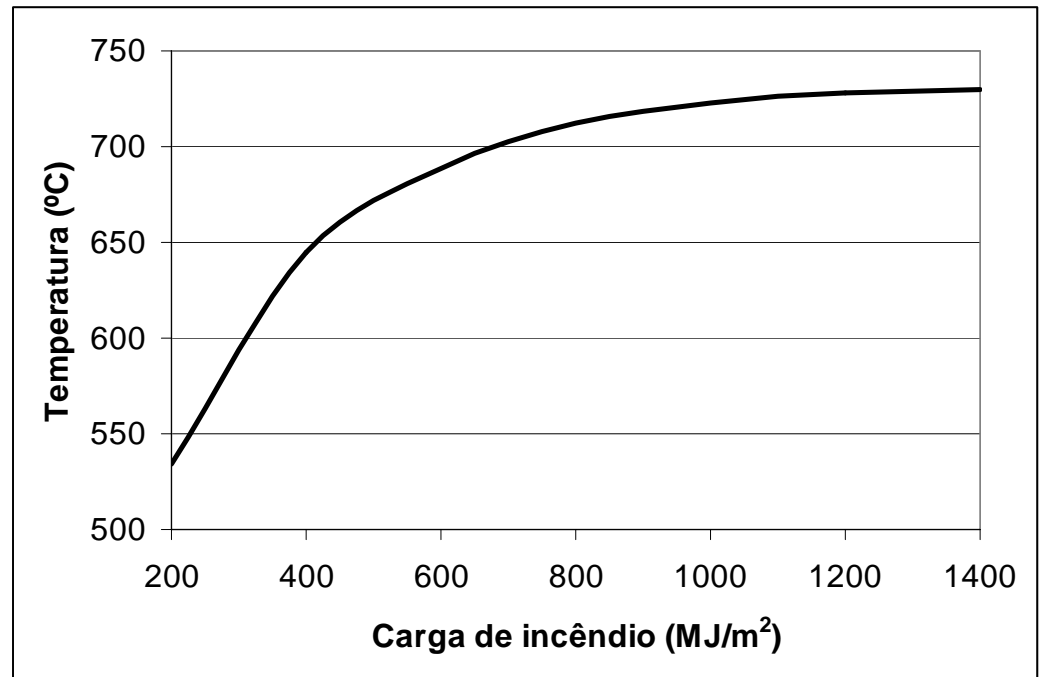

Figura 8.14 - Variação da temperatura de uma viga com a carga de incêndio de cálculo.

\subsection{ELEMENTOS ESTRUTURAIS SEM REVESTIMENTO CONTRA FOGO}

Os elementos estruturais podem dispensar o revestimento contra fogo dependendo do posicionamento em relação às aberturas e das características do compartimento em chamas. 
Com esse objetivo, foram desenvolvidas tabelas com base em algumas situações práticas para edificações que utilizam estruturas externas.

A posição da estrutura externa foi determinada pelo programa de computador ExteelFire 2.0, que tem por base o método descrito na norma europeia Eurocode 1, part 1-2 (2002) e pelo Eurocode 3, part 1-2 (2003).

\subsubsection{Pilares junto à parede cega}

Dois tipos de edificações foram considerados na elaboração das tabelas 8.1, 8.2 e 8.3. Uma escola conforme figura 8.15, e um edifício de escritórios, conforme figura 8.16. No edifício de escritórios, foi considerado um núcleo com carga de incêndio muito baixa, onde estariam localizados escadas e elevadores. Admitiu-se que há compartimentação vertical.

As cargas de incêndio específicas de cálculo foram consideradas $300 \mathrm{MJ} / \mathrm{m}^{2}$ para a escola e $700 \mathrm{MJ} / \mathrm{m}^{2}$ para o pavimento-tipo de escritórios.

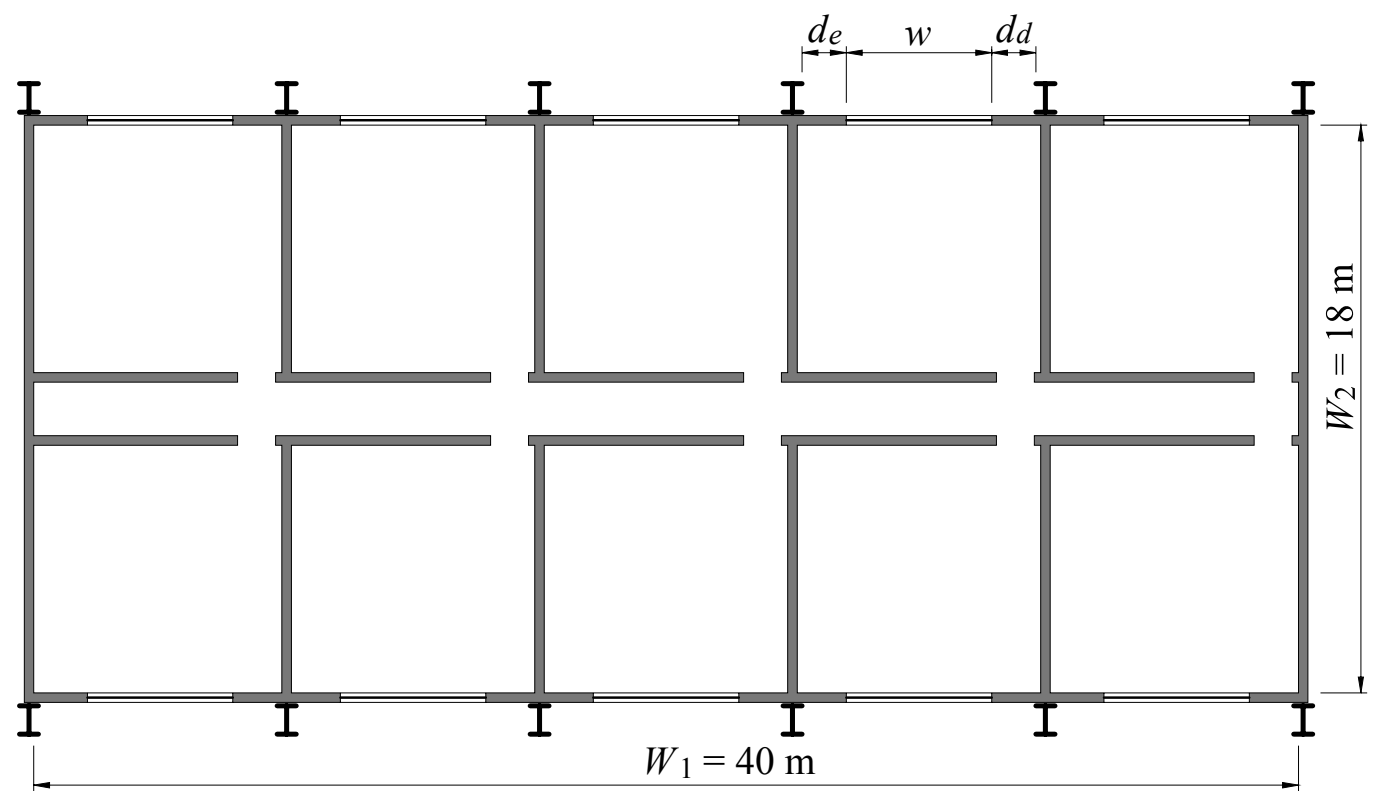

Figura 8.15 - Planta baixa do pavimento-tipo de uma escola. 


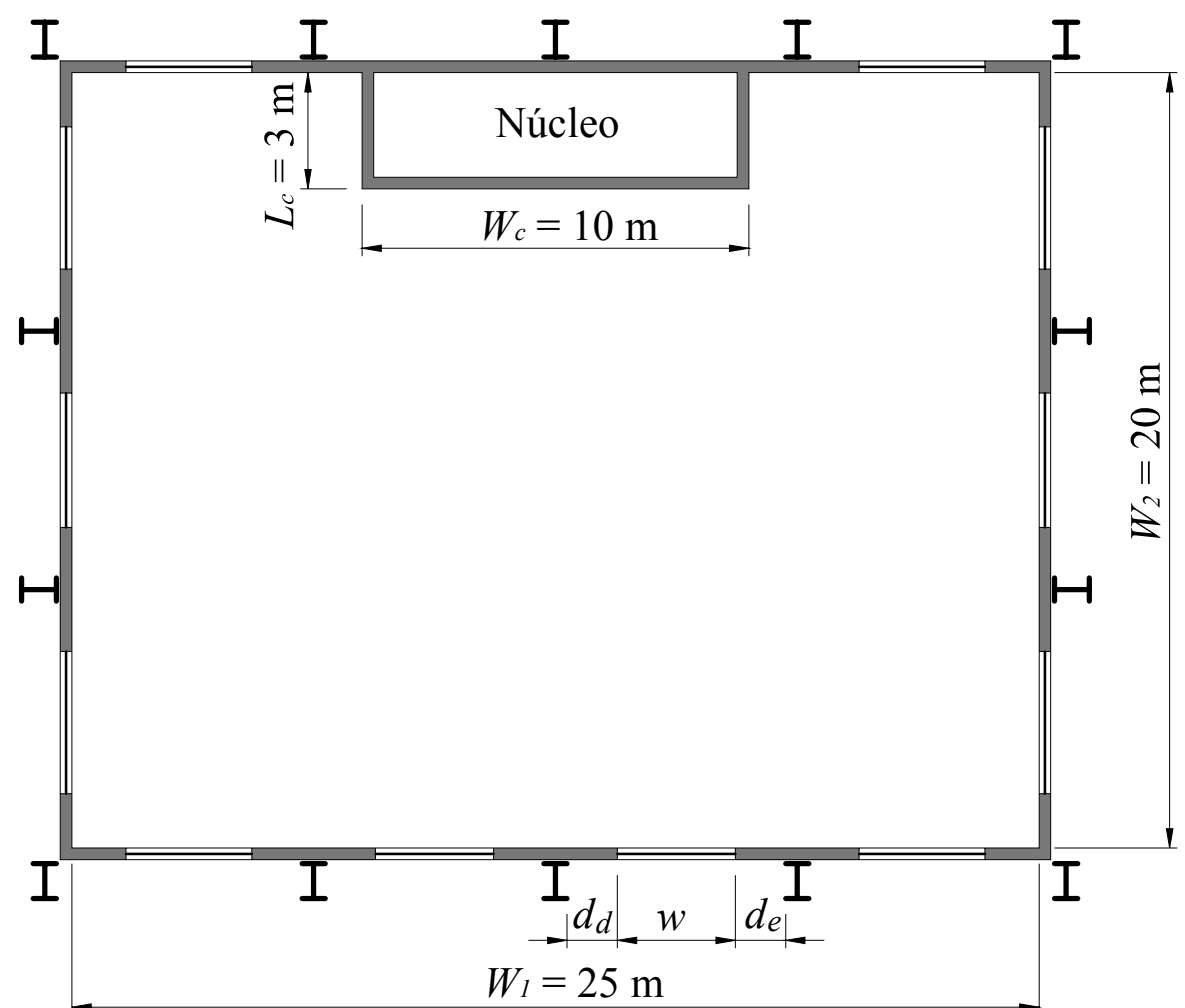

Figura 8.16 - Planta baixa do pavimento-tipo de um edifício de escritório.

Para o correto posicionamento dos elementos estruturais, deve-se comparar a temperatura calculada à temperatura crítica do elemento, em conformidade com a ABNT NBR 14323: 1999. Se a temperatura do elemento de aço for menor que a temperatura crítica, não será necessária a utilização de revestimento contra fogo. É importante observar que, aqui, não é utilizado o TRRF (tempo requerido de resistência ao fogo), somente as temperaturas são consideradas. Por outro lado, o valor de cálculo da carga de incêndio depende das dimensões da edificação, dos meios de proteção contra incêndio, etc. (ver item 6.2).

O Decreto Estadual n 46.076/01 do Estado de São Paulo, na Instrução Técnica N 08/2004, recomenda que a temperatura crítica do aço seja adotada ou como um valor máximo de $550^{\circ} \mathrm{C}$ para aços convencionais, ou calculada para cada elemento estrutural de acordo com a norma ABNT NBR 14323:1999. O posicionamento dos elementos estruturais nas tabelas 8.1, 8.2 e 8.3 foram determinados considerando que a temperatura crítica do elemento estrutural de aço seja $550^{\circ} \mathrm{C}$.

A figura 8.17 mostra a planta baixa de um pilar posicionado entre as aberturas a uma distância $d$ da parede de fachada. 


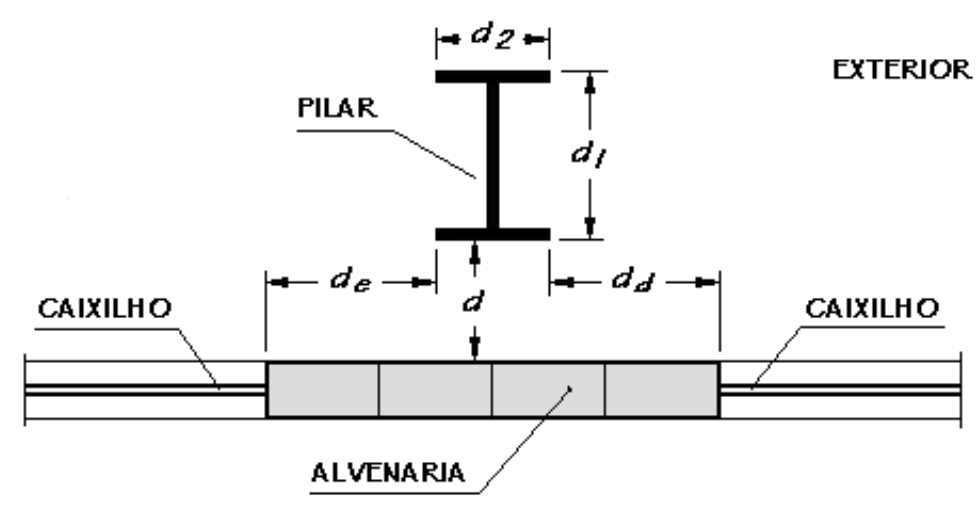

INTERIOR

Figura 8.17 - Posicionamento do pilar entre aberturas com distância à parede da fachada.

A tabela 8.1 mostra a menor distância entre a face de um pilar (d) que se inscreve em um retângulo de dimensões $d_{1} \mathrm{x} d_{2}$ e a parede da fachada, e a distância do pilar às bordas das aberturas, $d_{e}=d_{d}$, para a qual pode ser dispensado o revestimento contra fogo de acordo com a geometria apresentada nas figuras 8.15 e 8.16 .

Tabela 8.1 - Distância mínima dos pilares à borda da abertura $\left(d_{e}=d_{d}\right)$. Pilares posicionados entre aberturas com distância $d$ da parede da fachada

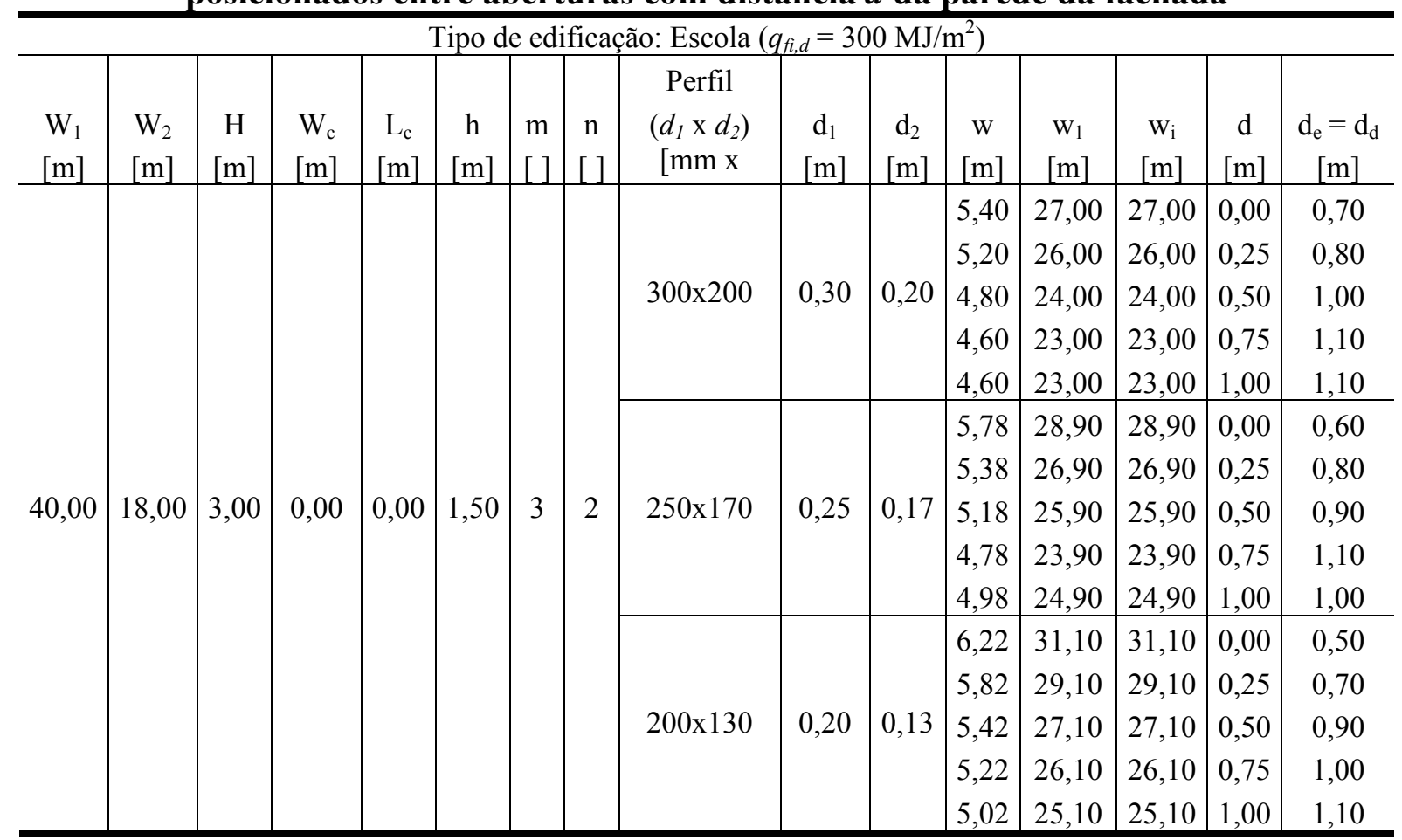

continua 
continuação

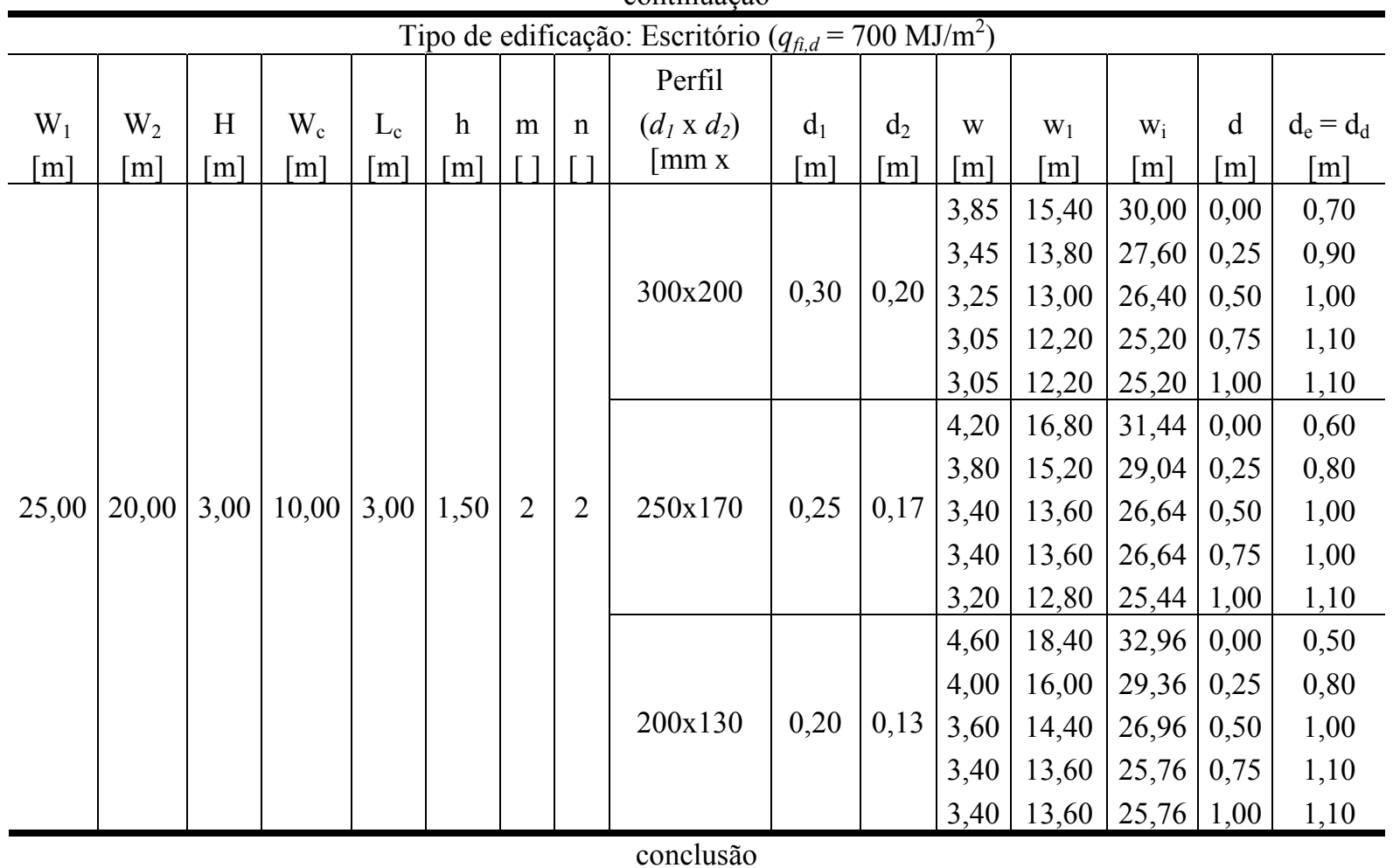

Onde:

$W_{1} \quad$ Largura do compartimento (m);

$W_{2} \quad$ Profundidade do compartimento (m);

$H \quad$ Altura do compartimento (m);

$W_{c} \quad$ Largura do núcleo $(\mathrm{m}) ;$

$L_{c} \quad$ profundidade do núcleo $(\mathrm{m})$;

$h \quad$ Altura da abertura (m);

m Quantidade de janelas à esquerda do pilar;

n Quantidade de janelas à direita do pilar;

$d_{1} \quad$ Comprimento da face do pilar perpendicular à parede $(\mathrm{m})$;

$d_{2} \quad$ Comprimento da face do pilar paralelo à parede (m);

$w \quad$ Largura de uma janela (m);

$w_{1} \quad$ Largura total das aberturas na parede principal (m);

$w_{i} \quad$ Largura total das demais aberturas (m); 
d Distância do pilar à parede $(\mathrm{m})$;

$d_{e} \quad$ Distância do pilar a abertura esquerda (m);

$d_{d} \quad$ Distância do pilar a abertura direita $(\mathrm{m})$

Na tabela 8.1 verifica-se que quanto mais o pilar está afastado da parede, maior é a distância $d_{e}=d_{d}$ necessária para que ele não atinja a temperatura crítica de $550^{\circ} \mathrm{C}$. Isso ocorre pois, para o pilar entre aberturas, considera-se que a chama inclina-se lateralmente de $45^{\circ}$, como mostrado na figura 8.18, causando uma aproximação da chama ao elemento, consequentemente, ocorre um aumento da sua temperatura.

m aberturas

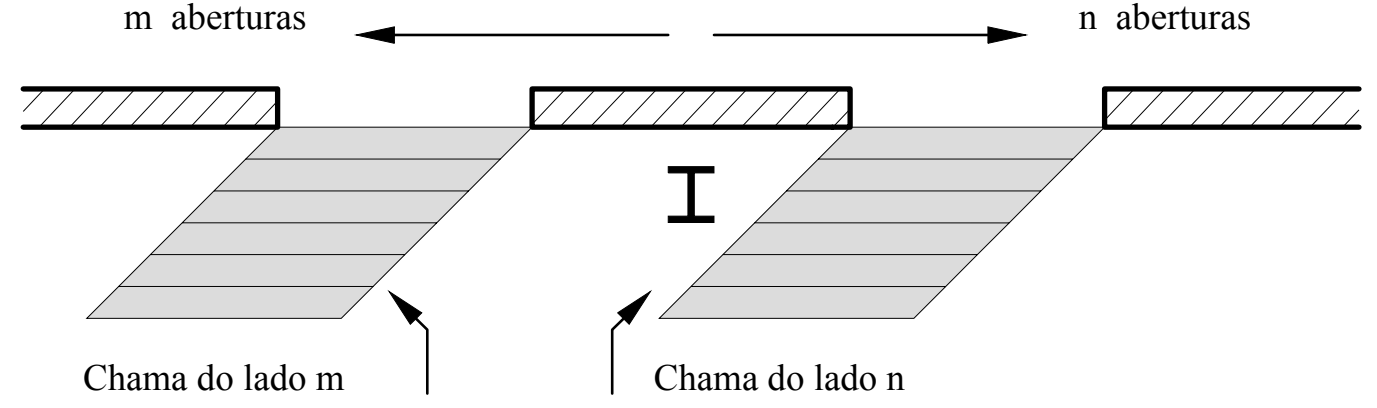

Figura 8.18 - Inclinação da chama externa devido ao vento.

A figura 8.19 mostra o pilar encaixado na parede da fachada da edificação. Nessa situação, admitiu-se que não ocorre transferência de calor da mesa com revestimento às demais partes do perfil. A tabela 8.2 mostra a distância do pilar à abertura, $d_{e}=d_{d}$, a fim de não se atingir a temperatura crítica de $550^{\circ} \mathrm{C}$.

EXTERIOR

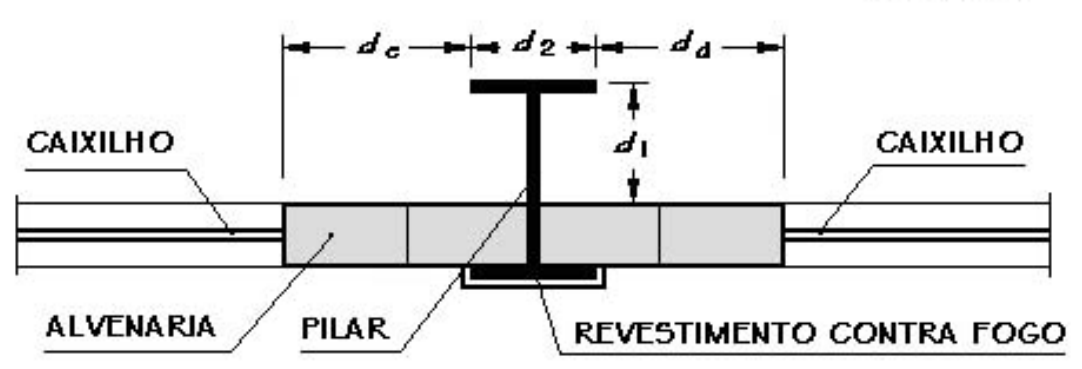

INTERIOR

Figura 8.19 - Posicionamento do pilar entre aberturas encaixado na parede da fachada. 
Tabela 8.2 - Distância mínima dos pilares à borda da abertura. Pilares encaixados na parede da fachada

\begin{tabular}{|c|c|c|c|c|c|c|c|c|c|c|c|c|c|c|}
\hline \multicolumn{15}{|c|}{ Tipo de edificação: Escola $\left(q_{f, d}=300 \mathrm{MJ} / \mathrm{m}^{2}\right)$} \\
\hline $\begin{array}{c}\mathrm{W}_{1} \\
{[\mathrm{~m}]}\end{array}$ & $\begin{array}{l}\mathrm{W}_{2} \\
{[\mathrm{~m}]}\end{array}$ & $\begin{array}{c}\mathrm{H} \\
{[\mathrm{m}]}\end{array}$ & $\begin{array}{l}\mathrm{W}_{\mathrm{c}} \\
{[\mathrm{m}]}\end{array}$ & $\begin{array}{c}\mathrm{L}_{\mathrm{c}} \\
{[\mathrm{m}]}\end{array}$ & $\begin{array}{c}\mathrm{h} \\
{[\mathrm{m}]}\end{array}$ & $\begin{array}{l}\mathrm{m} \\
{[]}\end{array}$ & $\begin{array}{c}\mathrm{n} \\
{[]}\end{array}$ & $\begin{array}{c}\text { Perfil } \\
\left(d_{1} \times d_{2}\right) \\
{[\mathrm{mm} \times}\end{array}$ & $\begin{array}{c}\mathrm{W} \\
{[\mathrm{m}]}\end{array}$ & $\begin{array}{l}\mathrm{w}_{1} \\
{[\mathrm{~m}]}\end{array}$ & $\begin{array}{c}\mathrm{w}_{\mathrm{i}} \\
{[\mathrm{m}]}\end{array}$ & $\begin{array}{c}\mathrm{d}_{1} \\
{[\mathrm{~m}]}\end{array}$ & $\begin{array}{c}\mathrm{d}_{2} \\
{[\mathrm{~m}]}\end{array}$ & $\begin{array}{c}\mathrm{d}_{\mathrm{e}}=\mathrm{d}_{\mathrm{d}} \\
{[\mathrm{m}]}\end{array}$ \\
\hline \multirow{3}{*}{40,00} & \multirow{3}{*}{18,00} & \multirow{3}{*}{3,00} & \multirow{3}{*}{0,00} & \multirow{3}{*}{0,00} & \multirow{3}{*}{1,50} & \multirow{3}{*}{3} & \multirow{3}{*}{2} & $300 \times 200$ & 5,80 & 29,00 & 29,00 & 0,15 & 0,20 & 0,50 \\
\hline & & & & & & & & $250 \times 170$ & 6,18 & 30,90 & 30,90 & 0,10 & 0,17 & 0,40 \\
\hline & & & & & & & & $200 \times 130$ & 6,62 & 33,10 & 33,10 & 0,05 & 0,13 & 0,30 \\
\hline \multicolumn{15}{|c|}{ Tipo de edificação: Escritório $\left(q_{f, d}=700 \mathrm{MJ} / \mathrm{m}^{2}\right)$} \\
\hline $\begin{array}{l}\mathrm{W}_{1} \\
{[\mathrm{~m}]}\end{array}$ & $\begin{array}{c}\mathrm{W}_{2} \\
{[\mathrm{~m}]}\end{array}$ & $\begin{array}{c}\mathrm{H} \\
{[\mathrm{m}]}\end{array}$ & $\begin{array}{c}\mathrm{W}_{\mathrm{c}} \\
{[\mathrm{m}]}\end{array}$ & $\begin{array}{c}\mathrm{L}_{\mathrm{c}} \\
{[\mathrm{m}]}\end{array}$ & $\begin{array}{c}\mathrm{h} \\
{[\mathrm{m}]}\end{array}$ & $\begin{array}{l}\mathrm{m} \\
{[]}\end{array}$ & $\begin{array}{c}\mathrm{n} \\
{[]}\end{array}$ & $\begin{array}{c}\text { Perfil } \\
\left(d_{1} \times d_{2}\right) \\
{[\mathrm{mm} \times}\end{array}$ & $\begin{array}{c}\mathrm{w} \\
{[\mathrm{m}]}\end{array}$ & $\begin{array}{c}\mathrm{w}_{1} \\
{[\mathrm{~m}]}\end{array}$ & $\begin{array}{c}\mathrm{w}_{\mathrm{i}} \\
{[\mathrm{m}]}\end{array}$ & $\begin{array}{c}\mathrm{d}_{1} \\
{[\mathrm{~m}]}\end{array}$ & $\begin{array}{c}\mathrm{d}_{2} \\
{[\mathrm{~m}]}\end{array}$ & $\begin{array}{c}\mathrm{d}_{\mathrm{e}}=\mathrm{d}_{\mathrm{d}} \\
{[\mathrm{m}]}\end{array}$ \\
\hline \multirow{3}{*}{25,00} & \multirow{3}{*}{20,00} & \multirow{3}{*}{3,00} & \multirow{3}{*}{10,00} & \multirow{3}{*}{3,00} & \multirow{3}{*}{1,50} & \multirow{3}{*}{2} & \multirow{3}{*}{2} & $300 \times 200$ & 4,25 & 17,00 & 32,40 & 0,15 & 0,20 & 0,50 \\
\hline & & & & & & & & $250 \times 170$ & 4,60 & 18,40 & 33,84 & 0,10 & 0,17 & 0,40 \\
\hline & & & & & & & & $200 \times 130$ & 4,80 & 19,20 & 34,16 & 0,05 & 0,13 & 0,40 \\
\hline
\end{tabular}

A tabela 8.2 mostra uma pequena variação na distância segura do pilar à abertura devido ao tamanho do perfil. Quanto maior o perfil, mais próxima da fonte de calor (chamas) estará a superfície a ser aquecida, e a temperatura será maior.

A favor da segurança, é possível determinar-se, por meio da tabela 8.3, a mínima distância “ $a$ " (figura 8.20) de forma a dispensar o revestimento contra fogo em pilares encostados na parede da fachada $(d=0)$. Para a construção dessa tabela, foram consideradas as seguintes hipóteses: $d=0$, profundidade do compartimento igual ao valor que conduz à máxima temperatura no compartimento (conforme visto na figura 8.4, há um valor crítico) e largura das janelas iguais aos valores que conduzem à máxima temperatura no pilar (foi realizado um estudo específico para esse fim). Para a construção da tabela, utilizou-se um perfil de dimensões $600 \mathrm{~mm}$ x $100 \mathrm{~mm}$. Perfis com largura inferior a $100 \mathrm{~mm}$ ou superior a $600 \mathrm{~mm}$ podem conduzir a uma temperatura crítica superior à $550^{\circ} \mathrm{C}$ para a distância “ $a$ ", indicada na tabela 8.3. 


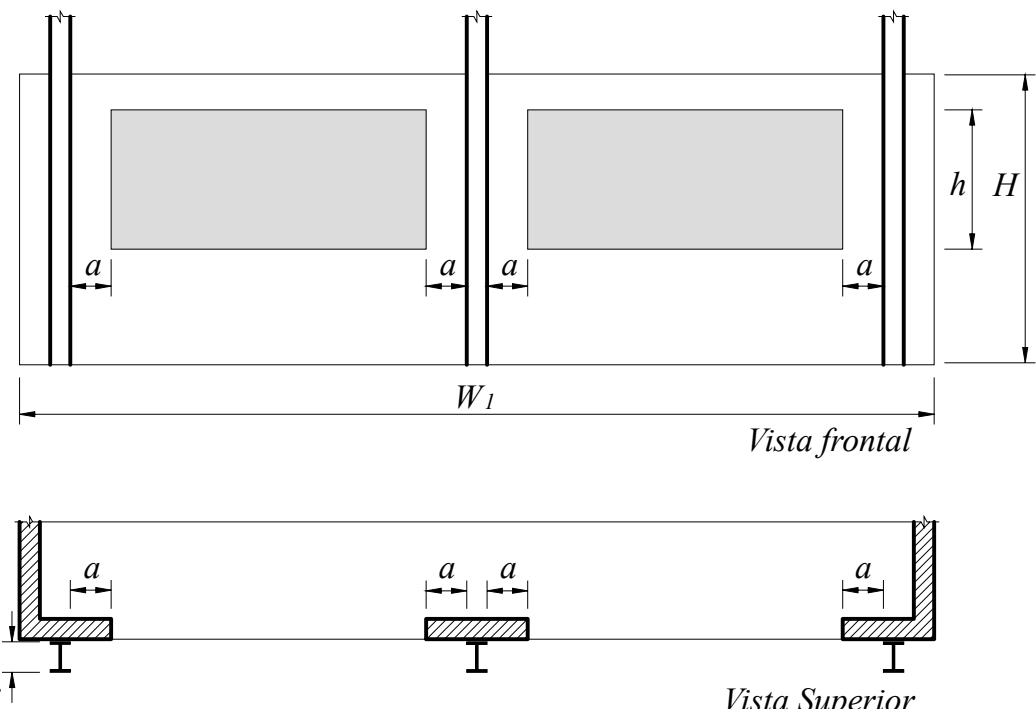

Figura 8.20 - Situação para cálculo da tabela 8.3.

Tabela 8.3 - Distância mínima do pilar à abertura. Pilar entre aberturas

\begin{tabular}{|c|c|c|c|c|}
\hline \multirow[b]{2}{*}{$\begin{array}{c}\mathrm{H} \\
{[\mathrm{m}]}\end{array}$} & \multirow[b]{2}{*}{$\begin{array}{l}\mathrm{W}_{1} \\
{[\mathrm{~m}]}\end{array}$} & \multirow[b]{2}{*}{$\begin{array}{c}\mathrm{h} \\
{[\mathrm{m}]}\end{array}$} & $q_{f, d}=300 \mathrm{MJ} / \mathrm{m}^{2}$ & $q_{f i, d}=700 \mathrm{MJ} / \mathrm{m}^{2}$ \\
\hline & & & $\begin{array}{l}\mathrm{a}_{\min } \\
{[\mathrm{m}]}\end{array}$ & $\begin{array}{l}\mathrm{a}_{\min } \\
{[\mathrm{m}]}\end{array}$ \\
\hline \multirow{20}{*}{2,75} & \multirow{5}{*}{9,00} & 0,90 & 0,60 & 0,60 \\
\hline & & 1,20 & 0,60 & 0,70 \\
\hline & & 1,50 & 0,60 & 0,70 \\
\hline & & 1,80 & 0,60 & 0,80 \\
\hline & & 2,80 & 0,60 & 0,70 \\
\hline & \multirow{5}{*}{18,00} & 0,90 & 0,60 & 0,70 \\
\hline & & 1,20 & 0,60 & 0,90 \\
\hline & & 1,50 & 0,80 & 1,00 \\
\hline & & 1,80 & 0,90 & 1,10 \\
\hline & & 2,80 & 0,90 & 1,10 \\
\hline & \multirow{5}{*}{36,00} & 0,90 & 0,70 & 0,80 \\
\hline & & 1,20 & 0,80 & 1,00 \\
\hline & & 1,50 & 0,80 & 1,20 \\
\hline & & 1,80 & 1,00 & 1,10 \\
\hline & & 2,80 & 0,80 & 1,10 \\
\hline & \multirow{5}{*}{72,00} & 0,90 & 0,70 & 0,80 \\
\hline & & 1,20 & 0,80 & 1,00 \\
\hline & & 1,50 & 0,80 & 1,10 \\
\hline & & 1,80 & 0,80 & 1,10 \\
\hline & & 2,80 & 0,80 & 1,00 \\
\hline
\end{tabular}

Na situação da figura 8.20, quanto maior o perfil, maior será a temperatura atingida por ele, porque estará mais próximo da chama para uma mesma distância “ $a$ ", como pode ser visto na figura 8.21 . 

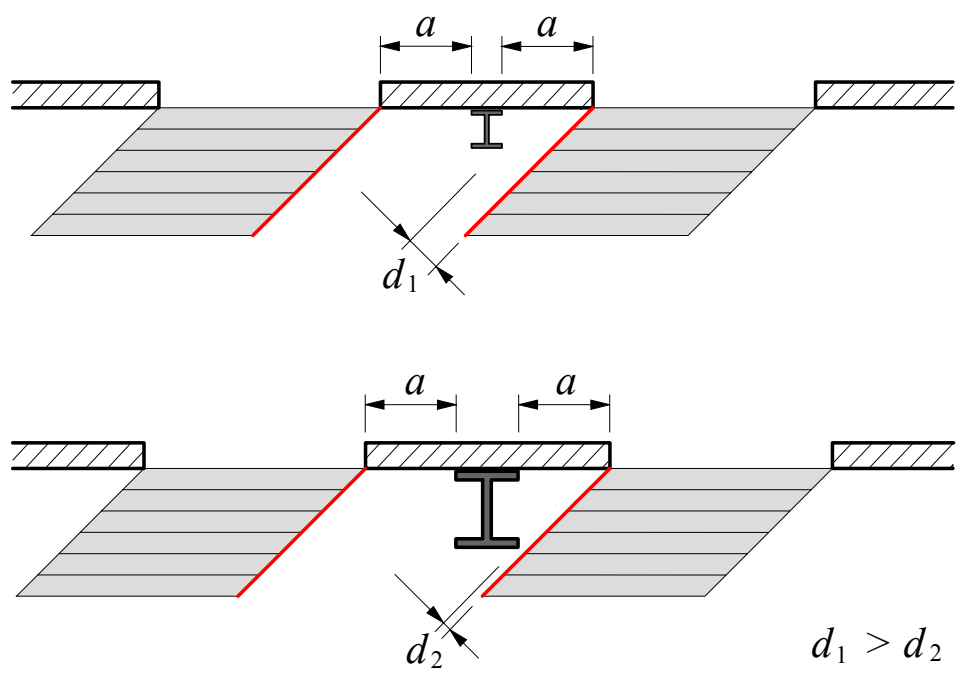

Figura 8.21 - Dimensões dos pilares e distância à chama.

\subsubsection{Vigas junto à parede cega}

Adotando-se o mesmo leiaute apresentado nas figuras 8.15 e 8.16 e a mesma consideração de temperatura crítica do item 8.2.1, estudaram-se duas situações de vigas na fachada, conforme indicado na figura 8.22. Na situação 1, a mesa superior da viga está protegida pela laje de concreto, o que não ocorre na situação 2. Nesse caso, considerou-se que não houve transferência de calor da mesa superior para o perfil bem como na face em contato com a parede. Na situação 2, apenas a face em contato com a parede foi considerada protegida. 


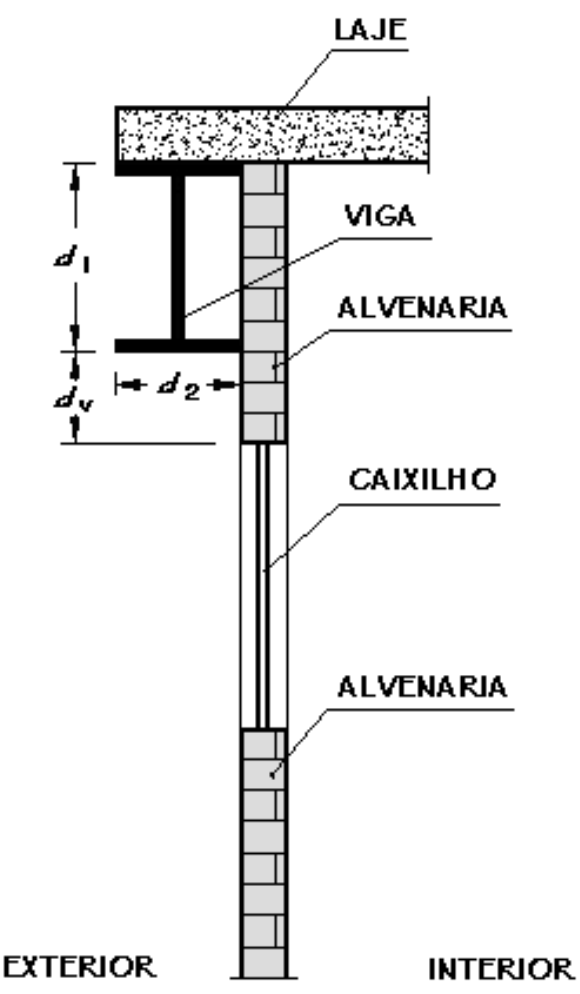

Situação 1

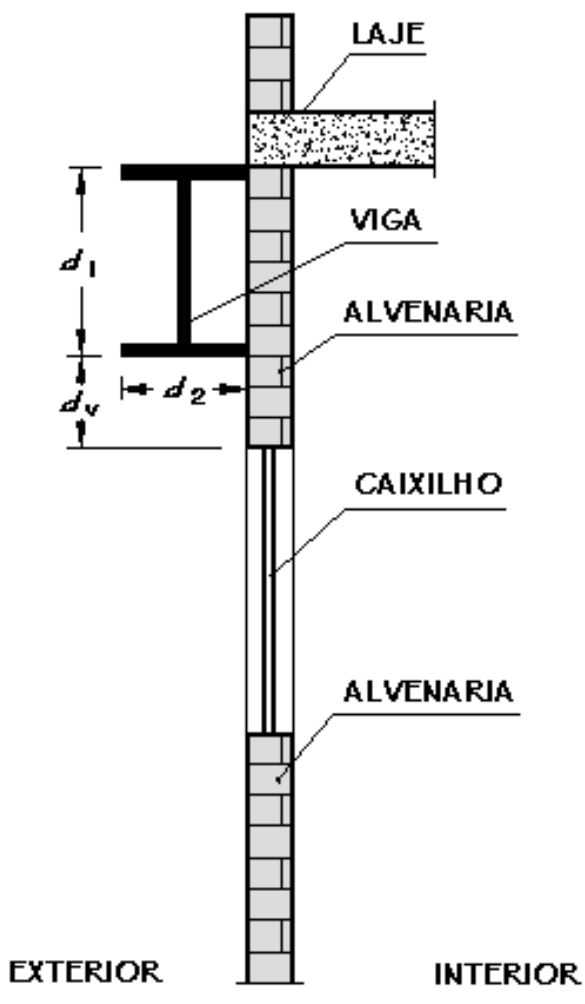

Situação 2

Figura 8.22 - Viga paralela e adjacente à parede da fachada.

Onde $d_{v}$ é a altura da viga em relação ao topo da abertura em metros.

Na tabela 8.4, apresentam-se as mínimas distâncias $d_{v}$ necessárias para não se atingir a temperatura crítica.

Tabela 8.4 - Distância mínima da viga ao topo da abertura

\begin{tabular}{|c|c|c|c|c|c|c|c|c|c|c|c|c|c|}
\hline \multicolumn{14}{|c|}{ Tipo de edificação: Escola $\left(q_{f, d}=300 \mathrm{MJ} / \mathrm{m}^{2}\right)$} \\
\hline & & & & & & & & & Perfil & & & Sit 1 & Sit 2 \\
\hline $\begin{array}{l}\mathrm{W}_{1} \\
{[\mathrm{~m}]}\end{array}$ & $\begin{array}{l}\mathrm{W}_{2} \\
{[\mathrm{~m}]}\end{array}$ & $\begin{array}{c}\mathrm{H} \\
{[\mathrm{m}]}\end{array}$ & $\begin{array}{l}\mathrm{W}_{\mathrm{c}} \\
{[\mathrm{m}]}\end{array}$ & $\begin{array}{c}\mathrm{L}_{\mathrm{c}} \\
{[\mathrm{m}]}\end{array}$ & $\begin{array}{c}\mathrm{h} \\
{[\mathrm{m}]}\end{array}$ & $\begin{array}{c}\mathrm{w} \\
{[\mathrm{m}]}\end{array}$ & $\begin{array}{c}\mathrm{w}_{1} \\
{[\mathrm{~m}]}\end{array}$ & $\begin{array}{l}\mathrm{w}_{\mathrm{i}} \\
{[\mathrm{m}]}\end{array}$ & $\begin{array}{c}(a \times b) \\
{[\mathrm{mm} \times \mathrm{mm}]}\end{array}$ & $\begin{array}{c}\mathrm{d}_{1} \\
{[\mathrm{~m}]}\end{array}$ & $\begin{array}{c}\mathrm{d}_{2} \\
{[\mathrm{~m}]}\end{array}$ & $\begin{array}{c}\mathrm{d}_{\mathrm{v}} \\
{[\mathrm{m}]}\end{array}$ & $\begin{array}{c}\mathrm{d}_{\mathrm{v}} \\
{[\mathrm{m}]}\end{array}$ \\
\hline 40,00 & 18,00 & 3,00 & 0,00 & 0,00 & 1,50 & 40,00 & 40,00 & 40,00 & $\begin{array}{l}400 \times 200 \\
350 \times 175 \\
300 \times 150\end{array}$ & $\begin{array}{l}0,20 \\
0,17 \\
0,15\end{array}$ & $\begin{array}{l}0,40 \\
0,35 \\
0,30\end{array}$ & $\begin{array}{l}0,10 \\
0,10 \\
0,10\end{array}$ & $\begin{array}{l}0,10 \\
0,10 \\
0,10\end{array}$ \\
\hline \multicolumn{14}{|c|}{ Tipo de edificação: Escritório $\left(q_{f, d}=700 \mathrm{MJ} / \mathrm{m}^{2}\right)$} \\
\hline $\begin{array}{l}\mathrm{W}_{1} \\
{[\mathrm{~m}]}\end{array}$ & $\begin{array}{l}\mathrm{W}_{2} \\
{[\mathrm{~m}]}\end{array}$ & $\begin{array}{c}\mathrm{H} \\
{[\mathrm{m}]}\end{array}$ & $\begin{array}{l}\mathrm{W}_{\mathrm{c}} \\
{[\mathrm{m}]}\end{array}$ & $\begin{array}{c}\mathrm{L}_{\mathrm{c}} \\
{[\mathrm{m}]}\end{array}$ & $\begin{array}{c}\mathrm{h} \\
{[\mathrm{m}]}\end{array}$ & $\begin{array}{l}\mathrm{w} \\
{[\mathrm{m}]}\end{array}$ & $\begin{array}{l}\mathrm{w}_{1} \\
{[\mathrm{~m}]}\end{array}$ & $\begin{array}{c}\mathrm{W}_{\mathrm{i}} \\
{[\mathrm{m}]}\end{array}$ & $\begin{array}{c}\text { Perfil } \\
(a \times b) \\
{[\mathrm{mm} \times \mathrm{mm}]}\end{array}$ & $\begin{array}{l}\mathrm{d}_{1} \\
{[\mathrm{~m}]}\end{array}$ & $\begin{array}{c}\mathrm{d}_{2} \\
{[\mathrm{~m}]}\end{array}$ & $\begin{array}{c}\text { Sit } 1 \\
\mathrm{~d}_{\mathrm{v}} \\
{[\mathrm{m}]}\end{array}$ & $\begin{array}{c}\text { Sit } 2 \\
d_{\mathrm{v}} \\
{[\mathrm{m}]}\end{array}$ \\
\hline 25,00 & 20,00 & 3,00 & 10,00 & 3,00 & 1,50 & 25,00 & 25,00 & 40,00 & $\begin{array}{l}400 \times 200 \\
350 \times 175 \\
300 \times 150\end{array}$ & $\begin{array}{l}0,20 \\
0,17 \\
0,15\end{array}$ & $\begin{array}{l}0,40 \\
0,35 \\
0,30\end{array}$ & $\begin{array}{l}0,20 \\
0,20 \\
0,20\end{array}$ & $\begin{array}{l}0,30 \\
0,30 \\
0,30\end{array}$ \\
\hline
\end{tabular}




\subsubsection{Pilares em frente a janelas}

Os valores apresentados nas tabelas 8.5 e 8.6 podem ser utilizados como parâmetros para projetos em que a temperatura crítica do elemento de aço seja maior que $550{ }^{\circ} \mathrm{C}$. Os valores de cálculo das cargas de incêndio específicas foram adotados como sendo $300 \mathrm{MJ} / \mathrm{m}^{2}$ e 700 $\mathrm{MJ} / \mathrm{m}^{2}$. Nos cálculos foi considerada a existência ou não de paredes acima das aberturas.

A figura 8.23 mostra as possíveis situações para a distância mínima, $d_{\min }$, do pilar à parede quando posicionado em frente a uma abertura. O compartimento possui abertura apenas na parede da fachada. A situação 1 refere-se a $100 \%$ de ventilação na parede da fachada. A situação 2 e 3 referem-se ou a $50 \%$ ou a $25 \%$ de ventilação na parede de fachada. Na situação 2, a largura da janela é fixa e igual à largura do compartimento. Na situação 3 , a altura da janela é fixa e igual à altura do compartimento.

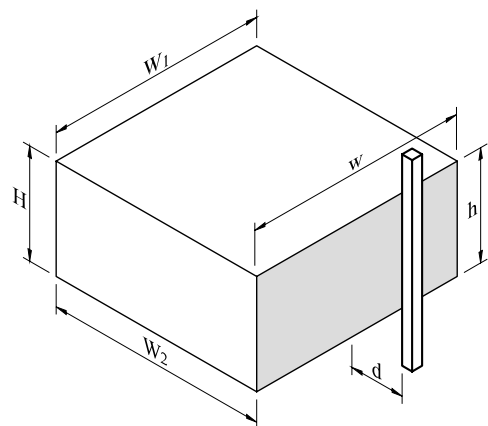

Situação 1

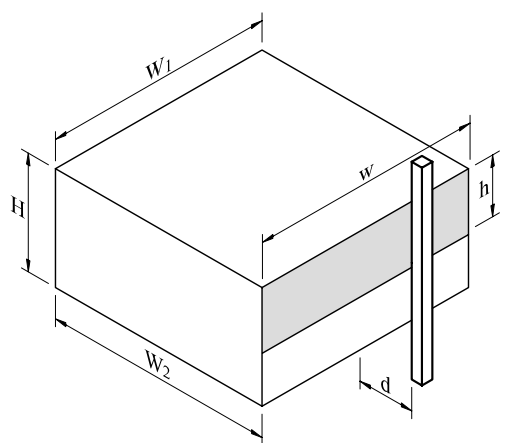

Situação 2

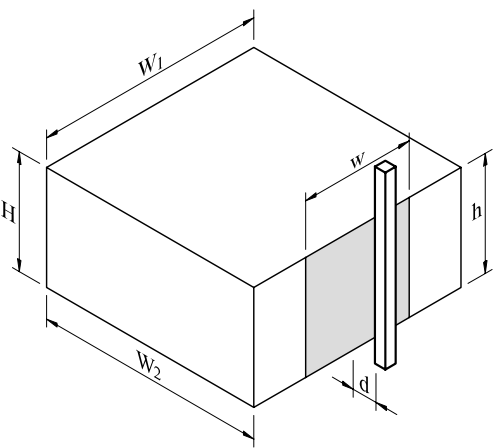

Situação 3

Figura 8.23 - Situações para cálculo da tabela 8.4. 
Tabela 8.5 - Distância mínima do pilar à parede. Pilar em frente à abertura. Abertura em uma parede

\begin{tabular}{|c|c|c|c|c|c|c|c|c|c|}
\hline \multirow[b]{2}{*}{$\begin{array}{l}A_{w} \\
{[\%]}\end{array}$} & \multirow[b]{2}{*}{$\begin{array}{l}\text { Sit } \\
{[]}\end{array}$} & \multirow[b]{2}{*}{$\begin{array}{c}\mathrm{h} \\
{[\mathrm{m}]}\end{array}$} & \multirow[b]{2}{*}{$\begin{array}{l}\mathrm{W}_{2} \\
{[\mathrm{~m}]}\end{array}$} & \multirow[b]{2}{*}{$\begin{array}{l}\mathrm{W}_{1} \\
{[\mathrm{~m}]}\end{array}$} & \multirow[b]{2}{*}{$\begin{array}{c}\mathrm{w} \\
{[\mathrm{m}]}\end{array}$} & \multicolumn{2}{|c|}{$q_{\mathrm{fid}}=300 \mathrm{MJ} / \mathrm{m}^{2}$} & \multicolumn{2}{|c|}{$q_{f i d}=700 \mathrm{MJ} / \mathrm{m}^{2}$} \\
\hline & & & & & & $\begin{array}{c}\mathrm{C} / \text { parede } \\
\mathrm{d}_{\min } \\
{[\mathrm{m}]}\end{array}$ & $\begin{array}{c}\mathrm{S} / \text { parede } \\
\mathrm{d}_{\min } \\
{[\mathrm{m}]}\end{array}$ & $\begin{array}{c}\mathrm{C} / \text { parede } \\
\mathrm{d}_{\min } \\
{[\mathrm{m}]}\end{array}$ & $\begin{array}{c}\mathrm{S} / \text { parede } \\
\mathrm{d}_{\min } \\
{[\mathrm{m}]}\end{array}$ \\
\hline \multirow{15}{*}{100} & \multirow{15}{*}{1} & \multirow{15}{*}{2,75} & \multirow{5}{*}{4,50} & 4,50 & 4,50 & $0,00^{a}$ & $0,00^{a}$ & $0,00^{a}$ & $0,00^{a}$ \\
\hline & & & & 9,00 & 9,00 & $0,00^{a}$ & $0,00^{a}$ & 1,60 & 1,60 \\
\hline & & & & 18,00 & 18,00 & $0,00^{a}$ & $0,00^{a}$ & 1,80 & 2,00 \\
\hline & & & & 36,00 & 36,00 & $0,00^{a}$ & $0,00^{a}$ & 1,90 & 2,10 \\
\hline & & & & 72,00 & 72,00 & $0,00^{a}$ & $0,00^{a}$ & 1,90 & 2,10 \\
\hline & & & \multirow{5}{*}{9,00} & 4,50 & 4,50 & $0,00^{a}$ & $0,00^{a}$ & 1,90 & 1,90 \\
\hline & & & & 9,00 & 9,00 & $0,00^{a}$ & $0,00^{a}$ & 1,90 & 2,10 \\
\hline & & & & 18,00 & 18,00 & 1,80 & 1,80 & 1,90 & 2,30 \\
\hline & & & & 36,00 & 36,00 & 1,80 & 1,90 & 1,90 & 2,60 \\
\hline & & & & 72,00 & 72,00 & 1,90 & 1,90 & 1,90 & 2,70 \\
\hline & & & \multirow{5}{*}{18,00} & 4,50 & 4,50 & 1,70 & 2,00 & 2,10 & 2,10 \\
\hline & & & & 9,00 & 9,00 & 1,90 & 2,30 & 2,70 & 2,80 \\
\hline & & & & 18,00 & 18,00 & 1,90 & 2,50 & 3,80 & 3,90 \\
\hline & & & & 36,00 & 36,00 & 1,90 & 2,50 & 4,10 & 4,20 \\
\hline & & & & 72,00 & 72,00 & 1,90 & 2,50 & 4,10 & 4,20 \\
\hline \multirow{30}{*}{50} & \multirow{5}{*}{2} & \multirow{5}{*}{1,38} & \multirow{5}{*}{4,50} & 4,50 & 4,50 & $0,00^{a}$ & 1,00 & 1,00 & 1,30 \\
\hline & & & & 9,00 & 9,00 & 0,90 & 1,10 & 1,10 & 1,40 \\
\hline & & & & 18,00 & 18,00 & 0,90 & 1,10 & 1,30 & 1,50 \\
\hline & & & & 36,00 & 36,00 & 0,90 & 1,10 & 1,30 & 1,50 \\
\hline & & & & 72,00 & 72,00 & 1,00 & 1,20 & 1,30 & 1,50 \\
\hline & \multirow{5}{*}{3} & \multirow{5}{*}{2,75} & \multirow{5}{*}{4,50} & 4,50 & 2,25 & $0,00^{a}$ & $0,00^{a}$ & 1,70 & 2,20 \\
\hline & & & & 9,00 & 4,50 & $0,00^{a}$ & $0,00^{a}$ & 1,90 & 2,60 \\
\hline & & & & 18,00 & 9,00 & 1,60 & 1,70 & 1,90 & 2,70 \\
\hline & & & & 36,00 & 18,00 & 1,80 & 1,80 & 1,90 & 2,70 \\
\hline & & & & 72,00 & 36,00 & 1,80 & 1,90 & 1,90 & 2,70 \\
\hline & & & & 4,50 & 4,50 & 0,90 & 1,30 & 1,20 & 1,40 \\
\hline & & & & 9,00 & 9,00 & 1,00 & 1,40 & 1,70 & 1,80 \\
\hline & 2 & 1,38 & 9,00 & 18,00 & 18,00 & 1,00 & 1,40 & 2,00 & 2,10 \\
\hline & & & & 36,00 & 36,00 & 1,00 & 1,40 & 2,10 & 2,20 \\
\hline & & & & 72,00 & 72,00 & 1,00 & 1,40 & 2,10 & 2,10 \\
\hline & & & & 4,50 & 2,25 & 1,20 & 2,10 & 1,90 & 2,40 \\
\hline & & & & 9,00 & 4,50 & 1,80 & 2,50 & 2,00 & 2,60 \\
\hline & 3 & 2,75 & 9,00 & 18,00 & 9,00 & 1,90 & 2,50 & 3,00 & 3,00 \\
\hline & & & & 36,00 & 18,00 & 1,90 & 2,50 & 3,60 & 3,60 \\
\hline & & & & 72,00 & 36,00 & 1,90 & 2,50 & 3,80 & 3,90 \\
\hline & & & & 4,50 & 4,50 & 0,90 & 1,30 & 1,00 & 1,40 \\
\hline & & & & 9,00 & 9,00 & 1,00 & 1,50 & 1,00 & 1,50 \\
\hline & 2 & 1,38 & 18,00 & 18,00 & 18,00 & 1,00 & 1,60 & 1,40 & 1,60 \\
\hline & & & & 36,00 & 36,00 & 1,00 & 1,70 & 1,50 & 1,70 \\
\hline & & & & 72,00 & 72,00 & 1,00 & 1,70 & 1,40 & 1,80 \\
\hline & & & & 4,50 & 2,25 & 1,60 & 2,30 & 1,80 & 2,40 \\
\hline & & & & 9,00 & 4,50 & 1,90 & 2,70 & 1,90 & 2,70 \\
\hline & 3 & 2,75 & 18,00 & 18,00 & 9,00 & 1,90 & 2,90 & 2,90 & 2,90 \\
\hline & & & & 36,00 & 18,00 & 2,00 & 3,00 & 3,60 & 3,70 \\
\hline & & & & 72,00 & 36,00 & 2,30 & 3,00 & 3,70 & 3,80 \\
\hline
\end{tabular}


continuação

\begin{tabular}{|c|c|c|c|c|c|c|c|c|c|}
\hline \multirow[b]{2}{*}{$\begin{array}{c}\mathrm{A}_{\mathrm{w}} \\
{[\%]}\end{array}$} & \multirow[b]{2}{*}{$\begin{array}{l}\text { Sit } \\
\text { [ ] }\end{array}$} & \multirow[b]{2}{*}{$\begin{array}{c}\mathrm{h} \\
{[\mathrm{m}]}\end{array}$} & \multirow[b]{2}{*}{$\begin{array}{c}\mathrm{W}_{2} \\
{[\mathrm{~m}]}\end{array}$} & \multirow[b]{2}{*}{$\begin{array}{c}\mathrm{W}_{1} \\
{[\mathrm{~m}]}\end{array}$} & \multirow[b]{2}{*}{$\begin{array}{c}\mathrm{w} \\
{[\mathrm{m}]}\end{array}$} & \multicolumn{2}{|c|}{$q_{\text {fid }}=300 \mathrm{MJ} / \mathrm{m}^{2}$} & \multicolumn{2}{|c|}{$q_{\text {fid }}=700 \mathrm{MJ} / \mathrm{m}^{2}$} \\
\hline & & & & & & $\begin{array}{c}\mathrm{C} / \text { parede } \\
\mathrm{d}_{\min } \\
{[\mathrm{m}]} \\
\end{array}$ & $\begin{array}{c}\mathrm{S} / \text { parede } \\
\mathrm{d}_{\min } \\
{[\mathrm{m}]}\end{array}$ & $\begin{array}{c}\mathrm{C} / \text { parede } \\
\mathrm{d}_{\min } \\
{[\mathrm{m}]} \\
\end{array}$ & $\begin{array}{c}\mathrm{S} / \text { parede } \\
\mathrm{d}_{\min } \\
{[\mathrm{m}]}\end{array}$ \\
\hline \multirow{30}{*}{25} & & & & 4,50 & 4,50 & 0,50 & 0,70 & 0,50 & 0,80 \\
\hline & & & & 9,00 & 9,00 & 0,50 & 0,80 & 0,50 & 0,90 \\
\hline & 2 & 0,69 & 4,50 & 18,00 & 18,00 & 0,50 & 0,80 & 0,50 & 0,90 \\
\hline & & & & 36,00 & 36,00 & 0,50 & 0,80 & 0,50 & 1,00 \\
\hline & & & & 72,00 & 72,00 & 0,50 & 0,80 & 0,50 & 1,00 \\
\hline & & & & 4,50 & 1,13 & 1,00 & 1,90 & 1,40 & 2,00 \\
\hline & & & & 9,00 & 2,25 & 1,30 & 2,20 & 1,90 & 2,90 \\
\hline & 3 & 2,75 & 4,50 & 18,00 & 4,50 & 1,80 & 2,50 & 1,90 & 3,00 \\
\hline & & & & 36,00 & 9,00 & 1,90 & 2,50 & 2,60 & 3,10 \\
\hline & & & & 72,00 & 18,00 & 1,90 & 2,50 & 3,30 & 3,40 \\
\hline & & & & 4,50 & 4,50 & 0,50 & 0,70 & 0,50 & 0,70 \\
\hline & & & & 9,00 & 9,00 & 0,50 & 0,80 & 0,50 & 0,80 \\
\hline & 2 & 0,69 & 9,00 & 18,00 & 18,00 & 0,50 & 0,90 & 0,50 & 0,90 \\
\hline & & & & 36,00 & 36,00 & 0,50 & 0,90 & 0,50 & 1,00 \\
\hline & & & & 72,00 & 72,00 & 0,50 & 0,90 & 0,50 & 1,00 \\
\hline & & & & 4,50 & 1,13 & 1,00 & 1,60 & 1,20 & 1,70 \\
\hline & & & & 9,00 & 2,25 & 1,60 & 2,80 & 1,80 & 2,90 \\
\hline & 3 & 2,75 & 9,00 & 18,00 & 4,50 & 1,90 & 3,10 & 1,90 & 3,20 \\
\hline & & & & 36,00 & 9,00 & 1,90 & 3,10 & 2,30 & 3,40 \\
\hline & & & & 72,00 & 18,00 & 1,90 & 3,10 & 2,60 & 3,60 \\
\hline & & & & 4,50 & 4,50 & 0,50 & 0,50 & 0,50 & 0,50 \\
\hline & & & & 9,00 & 9,00 & 0,50 & 0,80 & 0,50 & 0,80 \\
\hline & 2 & 0,69 & 18,00 & 18,00 & 18,00 & 0,50 & 0,90 & 0,50 & 0,90 \\
\hline & & & & 36,00 & 36,00 & 0,50 & 0,90 & 0,50 & 0,90 \\
\hline & & & & 72,00 & 72,00 & 0,50 & 1,00 & 0,50 & 1,00 \\
\hline & & & & 4,50 & 1,13 & 1,00 & 2,00 & 1,00 & 2,00 \\
\hline & & & & 9,00 & 2,25 & 1,40 & 2,70 & 1,60 & 2,70 \\
\hline & 3 & 2,75 & 18,00 & 18,00 & 4,50 & 1,80 & 3,10 & 1,90 & 3,10 \\
\hline & & & & 36,00 & 9,00 & 1,90 & 3,40 & 1,90 & 3,40 \\
\hline & & & & 72,00 & 18,00 & 1,90 & 3,50 & 1,90 & 3,60 \\
\hline
\end{tabular}

${ }^{a}$ A temperatura dentro do compartimento foi baixa e a altura da chama $(z)$ igual a zero, consequentemente o elemento estrutural não atingiu a temperatura crítica de $550{ }^{\circ} \mathrm{C}$.

$\mathrm{Na}$ tabela 8.5, onde a distância mínima do pilar foi igual a zero, verificou-se que a temperatura dentro do compartimento foi baixa devido ao valor também baixo do termo $\psi=A_{f} q_{f i, d} / \sqrt{A_{v} A_{t}}$ da equação da eq. 5.37, que determina a temperatura dentro do compartimento. 
Outro fator que contribuiu para que o elemento não atingisse a temperatura crítica de $550{ }^{\circ} \mathrm{C}$ foi a relação existente entre a taxa de liberação de massa e a largura da abertura $(\dot{m} / w)$, da eq. 5.45 , que determina a altura da chama. O termo $(\dot{m} / w)$ obteve valores baixos, conduzindo a altura da chama igual a zero.

A figura 8.24 mostra as possíveis situações para a distância mínima, $d_{m i n}$, do pilar à parede quando posicionado em frente a uma abertura. $\mathrm{O}$ compartimento possui aberturas em mais de uma parede. A situação 1 corresponde a 100\% de ventilação nas duas paredes onde se encontram os pilares e as situações 2 e 3 correspondem a $50 \%$ ou a $25 \%$ de ventilação nas respectivas paredes. Na situação 2, é fixada a largura da abertura como sendo a largura do compartimento e, na situação 3, é fixada a altura da abertura como sendo a altura do compartimento.

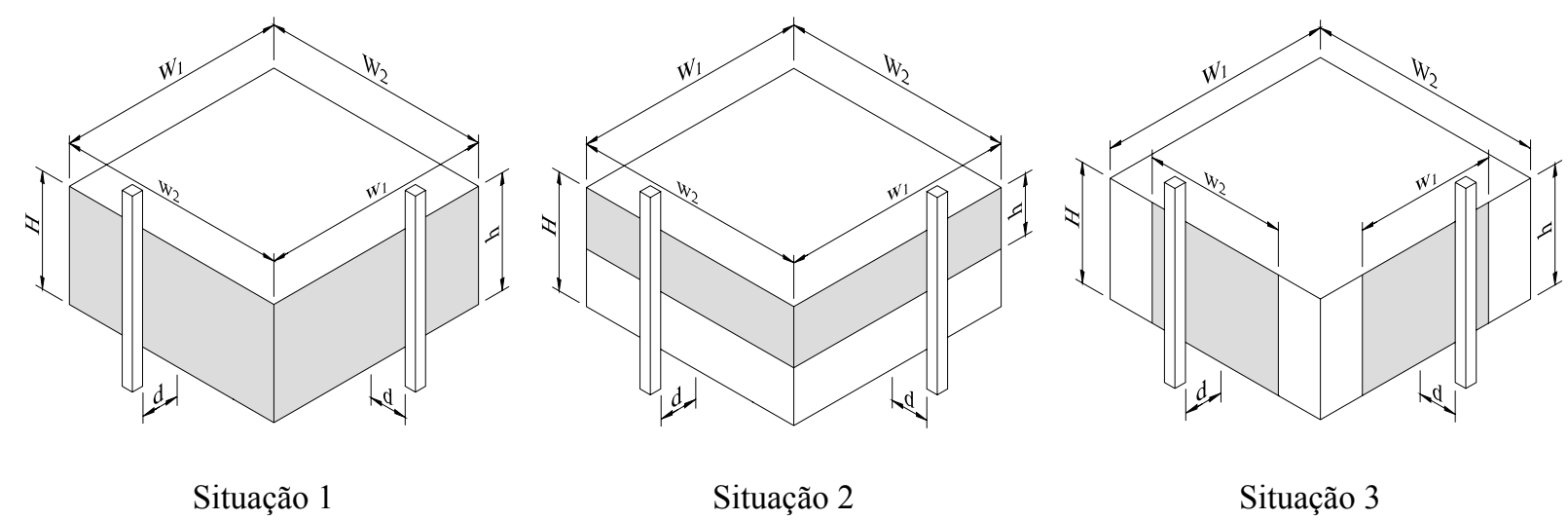

Figura 8.24 - Situações para cálculo da tabela 8.5. 
Tabela 8.6 - Distância mínima do pilar à parede. Pilar em frente à abertura. Aberturas em duas paredes

\begin{tabular}{|c|c|c|c|c|c|c|c|c|c|c|}
\hline \multirow[b]{2}{*}{$\begin{array}{l}\mathrm{Aw} \\
{[\%]}\end{array}$} & \multirow[b]{2}{*}{$\begin{array}{l}\text { Sit } \\
{[]}\end{array}$} & \multirow[b]{2}{*}{$\begin{array}{c}\mathrm{h} \\
{[\mathrm{m}]}\end{array}$} & \multirow[b]{2}{*}{$\begin{array}{c}\mathrm{W}_{2} \\
{[\mathrm{~m}]}\end{array}$} & \multirow[b]{2}{*}{$\begin{array}{c}\mathrm{w}_{2} \\
{[\mathrm{~m}]}\end{array}$} & \multirow[b]{2}{*}{$\begin{array}{l}\mathrm{W}_{1} \\
{[\mathrm{~m}]}\end{array}$} & \multirow[b]{2}{*}{$\begin{array}{c}\mathrm{w}_{1} \\
{[\mathrm{~m}]}\end{array}$} & \multicolumn{2}{|c|}{$q_{\mathrm{fid} d}=300 \mathrm{MJ} / \mathrm{m}^{2}$} & \multicolumn{2}{|c|}{$q_{\mathrm{fid}}=700 \mathrm{MJ} / \mathrm{m}^{2}$} \\
\hline & & & & & & & $\begin{array}{c}\mathrm{C} / \text { parede } \\
\mathrm{d}_{\min } \\
{[\mathrm{m}]}\end{array}$ & $\begin{array}{c}\mathrm{S} / \text { parede } \\
\mathrm{d}_{\min } \\
{[\mathrm{m}]}\end{array}$ & $\begin{array}{c}\mathrm{C} / \text { parede } \\
\mathrm{d}_{\min } \\
{[\mathrm{m}]}\end{array}$ & $\begin{array}{c}\mathrm{S} / \text { parede } \\
\mathrm{d}_{\min } \\
{[\mathrm{m}]}\end{array}$ \\
\hline \multirow{16}{*}{100} & \multirow{16}{*}{1} & \multirow{16}{*}{2,75} & \multirow{4}{*}{9,00} & \multirow{4}{*}{9,00} & 9,00 & 9,00 & $0,00^{a}$ & $0,00^{a}$ & $0,00^{a}$ & $0,00^{a}$ \\
\hline & & & & & 18,00 & 18,00 & $0,00^{a}$ & $0,00^{a}$ & 1,90 & 2,10 \\
\hline & & & & & 36,00 & 36,00 & $0,00^{a}$ & $0,00^{a}$ & 1,90 & 2,50 \\
\hline & & & & & 72,00 & 72,00 & 1,80 & 1,80 & 1,90 & 2,60 \\
\hline & & & \multirow{4}{*}{18,00} & \multirow{4}{*}{18,00} & 9,00 & 9,00 & $0,00^{a}$ & $0,00^{a}$ & 1,90 & 2,10 \\
\hline & & & & & 18,00 & 18,00 & 1,90 & 1,90 & 1,90 & 2,20 \\
\hline & & & & & 36,00 & 36,00 & 1,90 & 2,20 & 2,70 & 2,90 \\
\hline & & & & & 72,00 & 72,00 & 1,90 & 2,40 & 3,40 & 3,50 \\
\hline & & & \multirow{4}{*}{36,00} & \multirow{4}{*}{36,00} & 9,00 & 9,00 & $0,00^{a}$ & $0,00^{a}$ & 1,80 & 1,80 \\
\hline & & & & & 18,00 & 18,00 & 1,90 & 2,20 & 2,70 & 2,90 \\
\hline & & & & & 36,00 & 36,00 & 1,90 & 2,50 & 4,10 & 4,20 \\
\hline & & & & & 72,00 & 72,00 & 2,20 & 2,80 & 4,60 & 4,80 \\
\hline & & & \multirow{4}{*}{72,00} & & 9,00 & 9,00 & $0,00^{a}$ & $0,00^{a}$ & 1,90 & 1,90 \\
\hline & & & & 7200 & 18,00 & 18,00 & 1,90 & 2,40 & 3,40 & 3,50 \\
\hline & & & & 12,00 & 36,00 & 36,00 & 2,20 & 2,70 & 4,60 & 4,70 \\
\hline & & & & & 72,00 & 72,00 & 2,80 & 3,00 & 4,60 & 4,70 \\
\hline & & & & & 9,00 & 9,00 & 0,90 & 1,10 & 1,20 & 1,40 \\
\hline & 2 & 140 & 900 & 900 & 18,00 & 18,00 & 1,00 & 1,30 & 1,80 & 1,80 \\
\hline & 2 & 1,40 & 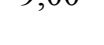 & 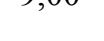 & 36,00 & 36,00 & 1,00 & 1,30 & 2,00 & 2,10 \\
\hline & & & & & 72,00 & 72,00 & 1,00 & 1,50 & 2,10 & 2,10 \\
\hline & & & & & 9,00 & 4,50 & $0,00^{a}$ & $0,00^{a}$ & 1,90 & 2,40 \\
\hline & 3 & & & & 18,00 & 9,00 & 1,80 & 2,20 & 2,20 & 2,70 \\
\hline & 3 & 2,80 & 9,00 & 4,50 & 36,00 & 18,00 & 1,90 & 2,40 & 3,10 & 3,20 \\
\hline & & & & & 72,00 & 36,00 & 1,90 & 2,50 & 3,60 & 3,70 \\
\hline & & & & & 9,00 & 9,00 & 0,90 & 1,30 & 1,60 & 1,70 \\
\hline & 2 & 140 & 1800 & 1800 & 18,00 & 18,00 & 1,00 & 1,40 & 2,10 & 2,10 \\
\hline & 2 & 1,0 & $10, \infty$ & $10, \infty$ & 36,00 & 36,00 & 1,00 & 1,50 & 2,20 & 2,20 \\
\hline & & & & & 72,00 & 72,00 & 1,00 & 1,60 & 1,80 & 1,90 \\
\hline & & & & & 9,00 & 4,50 & 1,80 & 2,20 & 2,20 & 2,70 \\
\hline & 3 & 280 & 1800 & 900 & 18,00 & 9,00 & 1,90 & 2,50 & 3,00 & 3,10 \\
\hline & 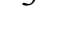 & 2,00 & 10,00 & 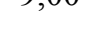 & 36,00 & 18,00 & 1,90 & 2,80 & 3,90 & 4,00 \\
\hline & & & & & 72,00 & 36,00 & 2,30 & 2,90 & 4,10 & 4,20 \\
\hline 50 & & & & & 9,00 & 9,00 & 1,00 & 1,30 & 2,00 & 2,10 \\
\hline & 2 & 140 & 3600 & 3600 & 18,00 & 18,00 & 1,00 & 1,50 & 2,10 & 2,20 \\
\hline & 2 & 1,0 & 3,00 & 0,00 & 36,00 & 36,00 & 1,00 & 1,70 & 1,70 & 1,70 \\
\hline & & & & & 72,00 & 72,00 & 1,00 & 1,70 & 1,10 & 1,70 \\
\hline & & & & & 9,00 & 4,50 & 1,90 & 2,40 & 3,10 & 3,20 \\
\hline & 3 & 280 & 3600 & 1800 & 18,00 & 9,00 & 1,90 & 2,80 & 3,90 & 4,00 \\
\hline & 3 & 2,00 & 50,00 & 10,00 & 36,00 & 18,00 & 2,20 & 3,00 & 3,80 & 3,80 \\
\hline & & & & & 72,00 & 36,00 & 2,00 & 3,20 & 3,10 & 3,30 \\
\hline & & & & & 9,00 & 9,00 & 1,00 & 1,40 & 2,10 & 2,10 \\
\hline & 2 & 140 & 7200 & 7200 & 18,00 & 18,00 & 1,00 & 1,50 & 2,00 & 2,00 \\
\hline & 2 & 1,40 & 2,00 & 2,00 & 36,00 & 36,00 & 1,00 & 1,70 & 1,10 & 1,70 \\
\hline & & & & & 72,00 & 72,00 & 1,00 & 1,80 & 1,00 & 1,80 \\
\hline & & & & & 9,00 & 4,50 & 1,90 & 2,50 & 3,60 & 3,70 \\
\hline & 3 & 280 & 7200 & 3600 & 18,00 & 9,00 & 2,30 & 2,90 & 4,10 & 4,20 \\
\hline & 3 & 2,80 & 12,00 & 30,00 & 36,00 & 18,00 & 2,00 & 3,10 & 3,10 & 3,20 \\
\hline & & & & & 72,00 & 36,00 & 1,90 & 3,40 & 1,90 & 3,40 \\
\hline
\end{tabular}


continuação

\begin{tabular}{|c|c|c|c|c|c|c|c|c|c|c|}
\hline \multirow[b]{2}{*}{$\begin{array}{l}\text { Aw } \\
{[\%]}\end{array}$} & \multirow[b]{2}{*}{$\begin{array}{l}\text { Sit } \\
{[]}\end{array}$} & \multirow[b]{2}{*}{$\begin{array}{c}\mathrm{h} \\
{[\mathrm{m}]}\end{array}$} & \multirow[b]{2}{*}{$\begin{array}{l}\mathrm{W}_{2} \\
{[\mathrm{~m}]}\end{array}$} & \multirow[b]{2}{*}{$\begin{array}{c}\mathrm{W}_{2} \\
{[\mathrm{~m}]}\end{array}$} & \multirow[b]{2}{*}{$\begin{array}{l}\mathrm{W}_{1} \\
{[\mathrm{~m}]}\end{array}$} & \multirow[b]{2}{*}{$\begin{array}{c}\mathrm{W}_{1} \\
{[\mathrm{~m}]}\end{array}$} & \multicolumn{2}{|c|}{$q_{\mathrm{fid}}=300 \mathrm{MJ} / \mathrm{m}^{2}$} & \multicolumn{2}{|c|}{$q_{\mathrm{fid}}=700 \mathrm{MJ} / \mathrm{m}^{2}$} \\
\hline & & & & & & & $\begin{array}{c}\mathrm{C} / \text { parede } \\
\mathrm{d}_{\min } \\
{[\mathrm{m}]}\end{array}$ & $\begin{array}{c}\mathrm{S} / \text { parede } \\
\mathrm{d}_{\min } \\
{[\mathrm{m}]}\end{array}$ & $\begin{array}{c}\mathrm{C} / \text { parede } \\
\mathrm{d}_{\min } \\
{[\mathrm{m}]}\end{array}$ & $\begin{array}{c}\mathrm{S} / \text { parede } \\
\mathrm{d}_{\min } \\
{[\mathrm{m}]}\end{array}$ \\
\hline \multirow{32}{*}{25} & \multirow{4}{*}{2} & \multirow{4}{*}{1,40} & \multirow{4}{*}{9,00} & \multirow{4}{*}{4,50} & 9,00 & 4,50 & 0,50 & 0,80 & 0,60 & 0,80 \\
\hline & & & & & 18,00 & 9,00 & 0,50 & 0,80 & 0,50 & 0,90 \\
\hline & & & & & 36,00 & 18,00 & 0,50 & 0,90 & 0,50 & 1,00 \\
\hline & & & & & 72,00 & 36,00 & 0,50 & 0,90 & 0,50 & 1,00 \\
\hline & \multirow{4}{*}{3} & \multirow{4}{*}{2,80} & \multirow{4}{*}{9,00} & \multirow{4}{*}{2,25} & 9,00 & 2,25 & 1,50 & 2,30 & 1,90 & 2,80 \\
\hline & & & & & 18,00 & 4,50 & 1,90 & 2,70 & 1,90 & 3,10 \\
\hline & & & & & 36,00 & 9,00 & 1,90 & 2,90 & 2,60 & 3,40 \\
\hline & & & & & 72,00 & 18,00 & 1,90 & 3,00 & 2,90 & 3,60 \\
\hline & \multirow{4}{*}{2} & \multirow{4}{*}{1,40} & \multirow{4}{*}{18,00} & \multirow{4}{*}{9,00} & 9,00 & 4,50 & 0,50 & 0,80 & 0,50 & 0,80 \\
\hline & & & & & 18,00 & 9,00 & 0,50 & 0,90 & 0,50 & 0,90 \\
\hline & & & & & 36,00 & 18,00 & 0,50 & 0,90 & 0,50 & 0,90 \\
\hline & & & & & 72,00 & 36,00 & 0,50 & 1,00 & 0,50 & 1,00 \\
\hline & \multirow{4}{*}{3} & \multirow{4}{*}{2,80} & \multirow{4}{*}{18,00} & \multirow{4}{*}{4,50} & 9,00 & 2,25 & 1,90 & 2,70 & 1,90 & 3,10 \\
\hline & & & & & 18,00 & 4,50 & 1,90 & 3,00 & 1,90 & 3,10 \\
\hline & & & & & 36,00 & 9,00 & 1,90 & 3,20 & 1,90 & 3,40 \\
\hline & & & & & 72,00 & 18,00 & 1,90 & 3,40 & 1,90 & 3,60 \\
\hline & \multirow{4}{*}{2} & & & & 9,00 & 4,50 & 0,50 & 0,80 & 0,50 & 0,80 \\
\hline & & 140 & 2600 & 1800 & 18,00 & 9,00 & 0,50 & 0,90 & 0,50 & 0,90 \\
\hline & & 1,40 & 30,00 & 10,00 & 36,00 & 18,00 & 0,50 & 0,90 & 0,50 & 0,90 \\
\hline & & & & & 72,00 & 36,00 & 0,50 & 1,00 & 0,50 & 1,00 \\
\hline & & & & & 9,00 & 2,25 & 1,90 & 2,90 & 2,60 & 3,40 \\
\hline & 300 & 280 & 3600 & 0 & 18,00 & 4,50 & 1,90 & 3,10 & 1,90 & 3,10 \\
\hline & & & & & 36,00 & 9,00 & 1,90 & 3,40 & 1,90 & 3,40 \\
\hline & & & & & 72,00 & 18,00 & 1,90 & 3,60 & 1,90 & 3,60 \\
\hline & & & & & 9,00 & 4,50 & 0,50 & 0,80 & 0,50 & 0,80 \\
\hline & 0 & 140 & 7200 & 2600 & 18,00 & 9,00 & 0,50 & 0,90 & 0,50 & 0,90 \\
\hline & 2 & 1,40 & 12,00 & 30,00 & 36,00 & 18,00 & 0,50 & 0,90 & 0,50 & 0,90 \\
\hline & & & & & 72,00 & 36,00 & 0,50 & 0,90 & 0,50 & 0,90 \\
\hline & & & & & 9,00 & 2,25 & 1,90 & 3,00 & 2,90 & 3,60 \\
\hline & 3 & 280 & 7200 & 1800 & 18,00 & 4,50 & 1,90 & 3,10 & 1,90 & 3,10 \\
\hline & 3 & 2,80 & 12,00 & & 36,00 & 9,00 & 1,90 & 3,30 & 1,90 & 3,30 \\
\hline & & & & & 72,00 & 18,00 & 1,90 & 3,50 & 1,90 & 3,50 \\
\hline
\end{tabular}

${ }^{a}$ A temperatura dentro do compartimento foi baixa e a altura da chama $(z)$ igual a zero consequentemente o elemento estrutural não atingiu a temperatura crítica de $550{ }^{\circ} \mathrm{C}$. 
Capítulo 9

\section{ANÁLISE TÉRMICA VIA SMARTFIRE}

O programa de computador SMARTFIRE é composto por um conjunto de ferramentas interligadas que permite ao usuário avaliar a ação de um incêndio.

A relevância da aplicação de modelos de incêndio tem se tornado fundamental na engenharia de segurança contra incêndio. Os modelos de incêndio permitem análises numéricas mais rápidas e de menor custo que as experimentais, permitindo a aplicação de novos conceitos nos projetos de edifícios.

O SMARTFIRE é um avançado código computacional de dinâmica dos fluidos (CFD Computational Fluid Dynamics) para a simulação de incêndio, desenvolvido pelo grupo de engenharia de segurança contra incêndio (FSEG - Fire Safety Engineering Group), da Universidade de Greenwich, na Inglaterra.

\subsection{OBJETIVO DO SMARTFIRE}

O objetivo do Smartfire é tornar as técnicas de modelos de campo para incêndio acessível às pessoas que não são especialistas em dinâmica computacional dos fluidos. O Smartfire é uma ferramenta útil para pesquisadores e consultores em engenharia de segurança contra incêndio. Para conseguir esse objetivo, ele teve como base uma arquitetura aberta, um excelente ambiente para especificação de caso, um sistema automático de geração de malhas e um programa interativo CFD. 
Ao incorporar conhecimentos específicos sobre CFD e geração de malhas, o Smartfire remove a obscuridão associada ao CFD. Tarefas críticas tais como seleção de soluções, relaxamento de parâmetros, critério de convergência, etapas de tempo, geração de malhas e condições específicas de contorno são realizadas por ferramentas especializadas e automáticas que fazem parte do Smartfire. O usuário pode cancelar as decisões tomadas pelo Smartfire e obter o controle final do processo. Dessa forma, o profissional de segurança contra incêndio só necessita especificar o cenário do incêndio em termos da geometria conhecida e características do incêndio, utilizando referências familiares, então o Smartfire utilizará conhecimentos especializados para configurar a simulação.

\subsection{GENERALIDADES SOBRE O SMARTFIRE V4.1}

O desenvolvimento e a integração do Smartfire utilizam em sua estrutura uma arquitetura aberta, que permite uma comunicação flexível e confiável entre todos os módulos constituintes do software. Conforme figura 9.1, os módulos constituintes do SMARTFIRE V4.1 são: o "SMARTFIRE Scenario Designer", o "SMARTFIRE Case Specification Environment", o "SMARTFIRE Interactive Meshing System", o "SMARTFIRE CFD Engine” e o "SMARTFIRE Data View Post Processing Visualization System".

- O "SMARTFIRE Scenario Designer", figura 9.1 (b), fornece suporte em CAD 2D, que desenha ou insere a planta baixa para o projeto do cenário do incêndio, com formato de arquivo DXF. As ferramentas possuem CAD interativo que permite a construção de edifício de múltiplos andares por meio da adição da planta baixa de cada pavimento. 


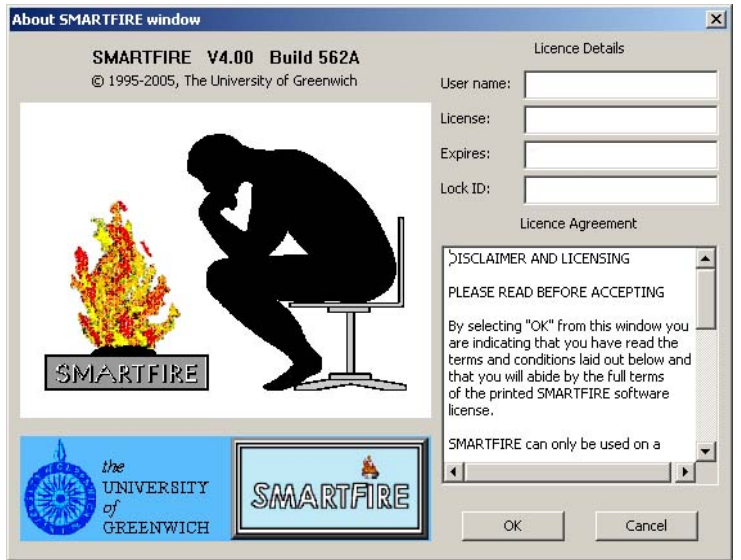

(a)

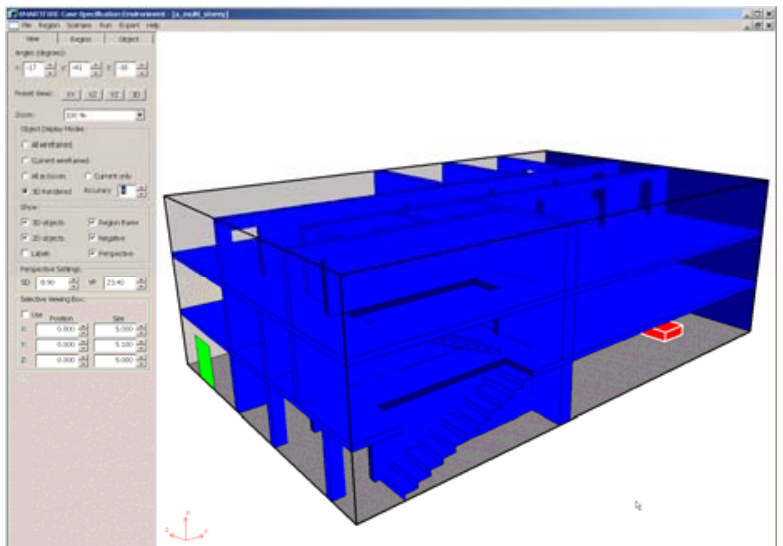

(c)

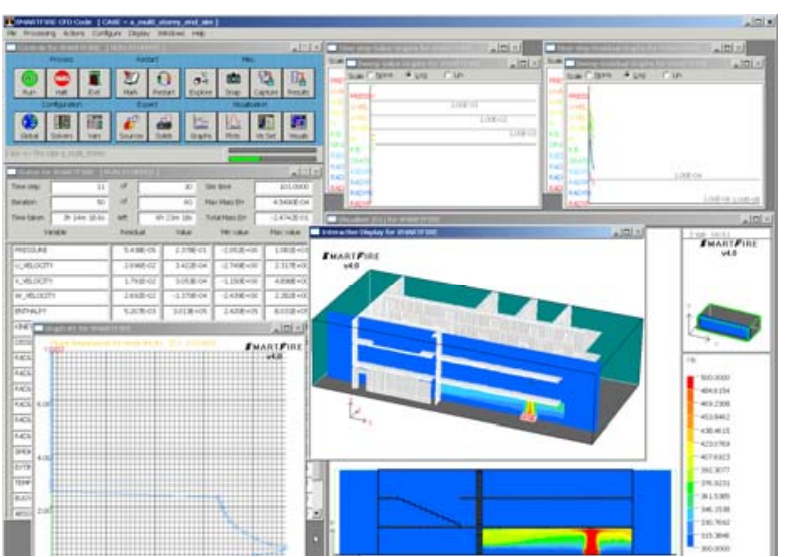

(e)

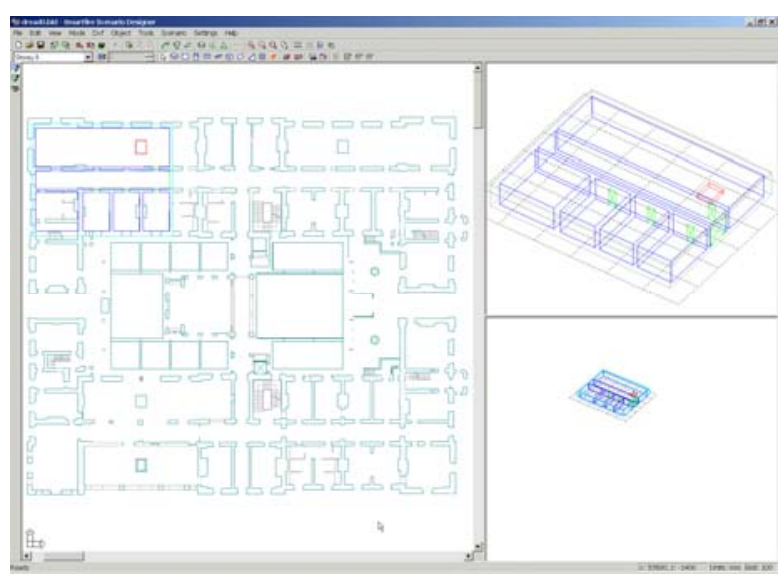

(b)

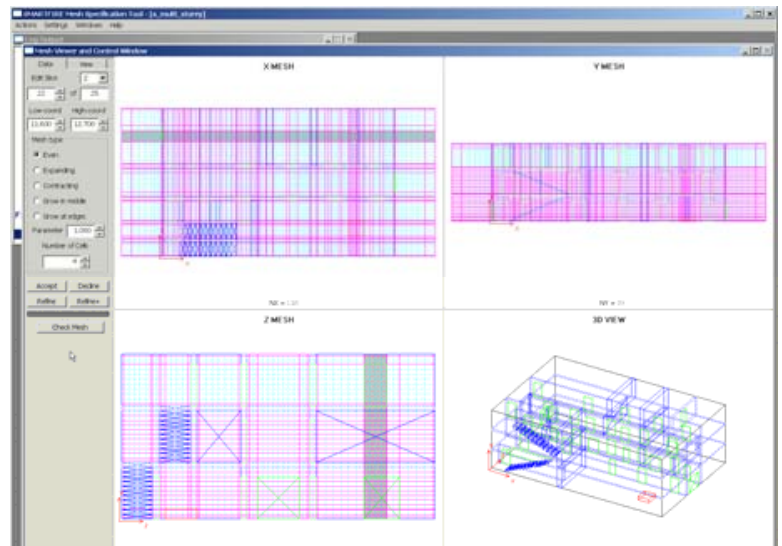

(d)

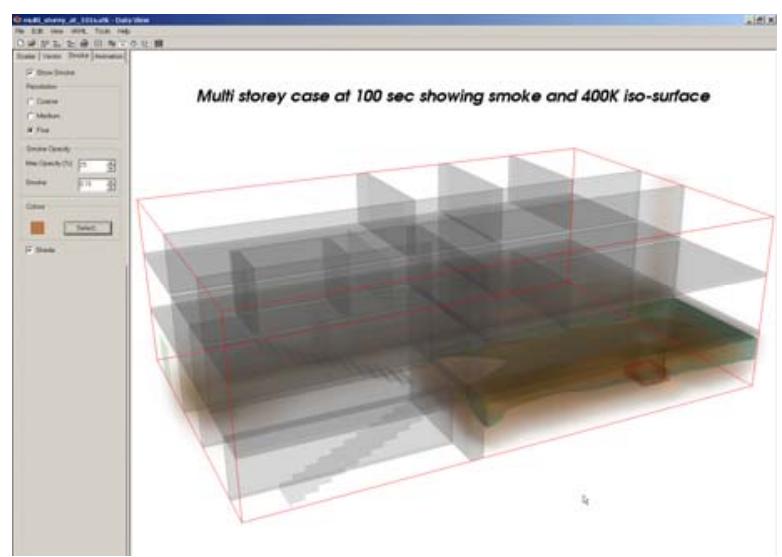

(f)

Figura 9.1 - Componentes do SMARTFIRE V4.1 (a) Tela de apresentação (b) Tela do "SMARTFIRE Scenario Designer" (c) Tela do "SMARTFIRE Case Specification Environment" (d) Tela do "SMARTFIRE Interactive Meshing System" (e) Tela do "SMARTFIRE CFD Engine" (f) Tela do "SMARTFIRE Data View Post Processing Visualization System”. (FSEG, 2008).

- O "SMARTFIRE Case Specification Environment", figura 9.1 (c), é uma dedicada interface gráfica utilizada para especificar o problema. Por meio dela, o usuário cria a geometria, ou seja, a posição das paredes, o tamanho dos compartimentos internos, os obstáculos, a 
localização das aberturas, as entradas e saídas, especifica os materiais da parede, as cargas de incêndio, os monitores e alguns outros objetos requeridos para o cenário. Ela ainda permite controlar todos os modelos físicos (por exemplo, radiação, combustão e fumaça) e a natureza das simulações (por exemplo, uso do material, simulação de duração do tempo, tempo de parada e condições ambientais). Esse componente incorpora um sistema automático e manual para geração de malhas que será posteriormente utilizado para iniciar o "SMARTFIRE CFD Engine". Todos os termos utilizados são projetados para ser o mais familiar possível (por exemplo, tijolo, isolante, etc) e a conversão numérica das propriedades dos materiais são condições de contorno específicas e de desempenho interno. Os incêndios são especificados como uma fonte de calor volumétrica ou utilizando o modelo de combustão dos gases, com uma taxa de liberação de calor do combustível. Fontes múltiplas de incêndio e incêndios com multiestágios podem ser modelados.

- O "SMARTFIRE Interactive Meshing System”, figura 9.1 (d), gera a malha de células para o “SMARTFIRE CFD Engine”. Ele utiliza regras específicas para produzir a quantidade inicial adequada de malhas a partir dos dados geométricos e de cenários definidos pelo usuário. $\mathrm{O}$ usuário pode optar por cancelar e especificar a quantidade de células, ou executar um refinamento interativo da malha, usando testes qualitativos da malha de células. Uma vez que a malha é gerada pode-se iniciar o "SMARTFIRE CFD Engine".

- O "SMARTFIRE CFD Engine", figura 9.1 (e), foi desenvolvido em linguagem de programação $\mathrm{C}++$, utiliza métodos numéricos desenvolvidos em linguagem orientada ao objeto. Ele faz uso de malhas não estruturadas em três dimensões, permitindo geometrias complexas e irregulares.

As características físicas adicionais incluídas no modelo CFD para incêndio incluem vários modelos de radiação térmica, previsão de transferência de calor através das paredes, modelos de combustão simples dos gases e da fumaça, previsão de ventiladores e exaustores, fluxos de ventilação forçada e natural, bem como modificações importantes das equações do fluxo turbulento. O código CFD possui monitoramento interativo de soluções visuais e gráficas, também possui interfaces para ajustes específicos. 
- O "SMARTFIRE Data View Post Processing Visualization System", figura 9.1 (f), fornece uma relação simples, porém eficaz para a visualização do pós-processamento dos dados gerados pelo "SMARTFIRE CFD Engine”. São suportadas as iso-superfícies, os cortes planos escalares, os vetores velocidades, a visualização volumétrica da fumaça e a exposição semitransparente da geometria. A ferramenta fornece facilidades na criação de animações para as sequências de resultados dos dados dos arquivos.

\subsection{VALIDAÇÃO}

De acordo com o FSEG (2008), diversos exercícios de validação foram empreendidos com o Smartfire. Uma extensa análise de documentos de validação para o CFD foi desenvolvida. Foi utilizada física básica do CFD e a funcionalidade de modelagem de incêndio. A base desse trabalho foi estendida para englobar uma metodologia geral, para validação dos modelos de incêndio suportados pelo "UK Home Office". Além disso, a capacidade de geração de malhas foi testada de maneira sistemática e por usuários da área. A validação do programa foi empreendida ainda, com a sua aplicação, para ajudar no projeto e no desenvolvimento de um número crescente de experiências em escala natural de incêndio.

\subsection{CENÁRIO DO INCÊNDIO}

\subsubsection{O compartimento incendiado}

Para fins de comparação entre resultados, utilizando o método simplificado e uma análise via CFD, empregou-se o programa Smartfire. O compartimento estudado tem as seguintes dimensões: 4,00 $\mathrm{m}$ de largura, 3,00 $\mathrm{m}$ de profundidade e 2,80 $\mathrm{m}$ de altura, conforme figura 9.2. Há uma janela com $3,00 \mathrm{~m}$ de largura e 1,50 m de altura. É superposto por outro pavimento. 


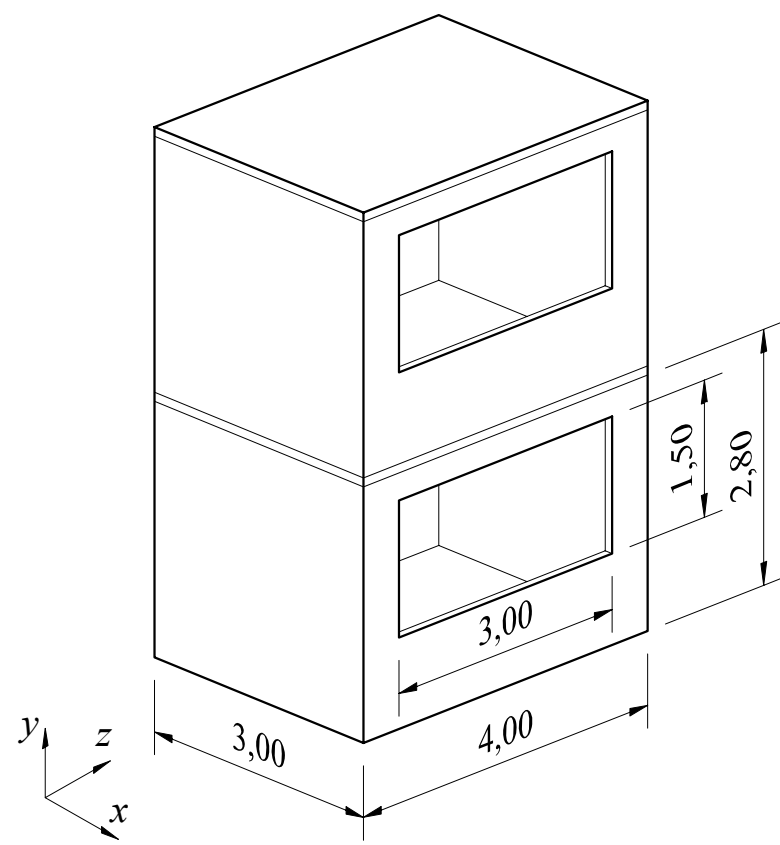

Figura 9.2 - Geometria do compartimento incendiado.

As paredes do compartimento são compostas de tijolos cerâmicos, o piso e o teto são de concreto armado. As propriedades físicas e térmicas necessárias à modelagem são descritas na tabela 9.1, conforme dados fornecidos pelo "Fire Safety Engineering Group", da Universidade de Greenwich, Londres. A temperatura inicial do ar foi considerada $20^{\circ} \mathrm{C}$.

Tabela 9.1 - Propriedades dos materiais do cenário de incêndio (FSEG, 2008 e ABNT NBR 14323:2003)

\begin{tabular}{c|c|c|c|c|c|c|c}
\hline Descrição & Nome & $\begin{array}{c}\lambda \\
{[\mathbf{W} / \mathbf{m K}]}\end{array}$ & $\begin{array}{c}\mathbf{c} \\
{[\mathbf{J} \mathbf{~ k g} / \mathbf{K}]}\end{array}$ & $\begin{array}{c}\rho \\
{\left[\mathbf{k g} / \mathbf{m}^{3}\right]}\end{array}$ & $\begin{array}{c}\mu \\
{[\mathbf{P a} . \mathbf{s}]}\end{array}$ & $\begin{array}{c}\beta \\
{\left[\mathbf{K}^{-\mathbf{1}}\right]}\end{array}$ & $\begin{array}{c}\mathbf{P} \\
{[\mathbf{k g} / \mathbf{K m o l}]}\end{array}$ \\
\hline Aberturas & Ar & 0,02622 & 1045,780 & 1,17736 & 0,00002 & 0,00329 & 29,35 \\
Paredes & Tijolo & 0,69000 & 840,000 & 1600,00000 & $10 \times 10^{9}$ & -- & -- \\
Piso/teto & Concreto & 1,60000 & 1000,000 & 2400,00000 & $10 \times 10^{9}$ & -- & -- \\
\hline
\end{tabular}

Onde:

$\lambda \quad$ é a condutividade térmica $(\mathrm{W} / \mathrm{mK})$;

C é o calor específico $(\mathrm{J} \mathrm{kg} / \mathrm{K})$; 
$\rho \quad$ é a densidade $\left(\mathrm{kg} / \mathrm{m}^{3}\right)$;

$\mu \quad$ é a viscosidade laminar (Pa.s);

$\beta \quad$ é o coeficiente de expansão térmica $\left(\mathrm{K}^{-1}\right)$;

$P \quad$ é o peso molecular (kg/K.mol).

A fonte do incêndio foi localizada no piso, no centro do compartimento, buscando uma distribuição próxima da uniforme. Para o material combustível, adotou-se a madeira de pinho seco. A geometria da fonte do incêndio possui 3,00 $\mathrm{m}$ de largura, 2,00 $\mathrm{m}$ de profundidade e $0,80 \mathrm{~m}$ de altura, conforme a figura 9.3 .

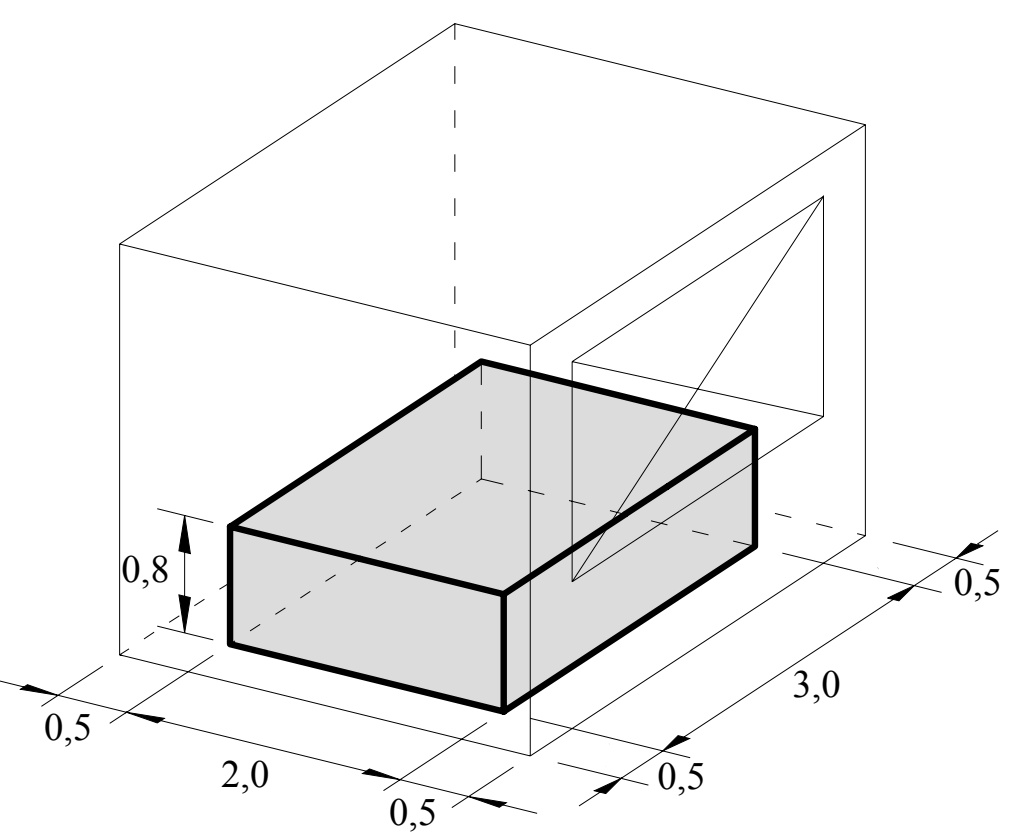

Figura 9.3 - Localização e geometria da fonte do incêndio.

\subsubsection{Taxa de liberação de calor}

Como parâmetro de entrada no Smartfire, adotou-se uma taxa liberação de calor igual a 6,384MW, valor esse calculado pelo ExteelFire para a geometria apresentada na figura 9.2, e carga de incêndio específica de cálculo igual a $700 \mathrm{MJ} / \mathrm{m}^{2}$.

Associou-se a fonte de incêndio (figura 10.2) à curva de "incêndio $t^{2}$ ", conforme item 3.4 desta Tese. De acordo com Buchanan (2001), esse modelo de incêndio é amplamente 
utilizado em análises computacionais. Para adaptar a taxa de liberação de calor (MW) do ExteelFire para o modelo de combustão dos gases do Smartfire, foi necessário converter para taxa de liberação de massa do combustível (kg/s), conforme item 9.4.3.

\subsubsection{O modelo de combustão dos gases}

No modelo de combustão dos gases do Smartfire é utilizada a grandeza $\dot{m}$, que é a taxa de liberação de massa do combustível conforme eq. 9.1.

$$
\dot{m}=\frac{\dot{Q}}{H}
$$

Onde:

$\dot{m} \quad$ é a taxa de liberação de massa do combustível $(\mathrm{kg} / \mathrm{s})$;

$\dot{Q} \quad$ é a taxa de liberação de calor $(\mathrm{J} / \mathrm{s})$;

$H \quad$ é o potencial calorífico específico $(\mathrm{J} / \mathrm{kg})$.

De acordo com Ewer (2008), o FSEG (Fire Safety Engineering Group), da Universidade de Greenwich, emprega a equação de combustão da madeira em pinho seco, com potencial calorífico de 12,46 MJ/kg ao invés de 17,5 MJ/kg, valor normatizado pelo Eurocode 1, Part12 (2002). Em vista de o método de Margaret Law reunir uma série de informações de diferentes ensaios, o que dificulta a identificação do tipo de madeira empregado, foi adotado para a eq. 10.2, a recomendação do FSEG para fins de simulação do Smartfire.

Considerando $\dot{Q}_{\text {máx }}$ igual a $6,384 \mathrm{MW}$, obtém-se a taxa de liberação de massa máxima do combustível $\dot{m}$ igual a $0,5124 \mathrm{~kg} / \mathrm{s}$, com base na eq. 9.1. A figura 9.4 mostra a curva de taxa de liberação de massa adotada. 


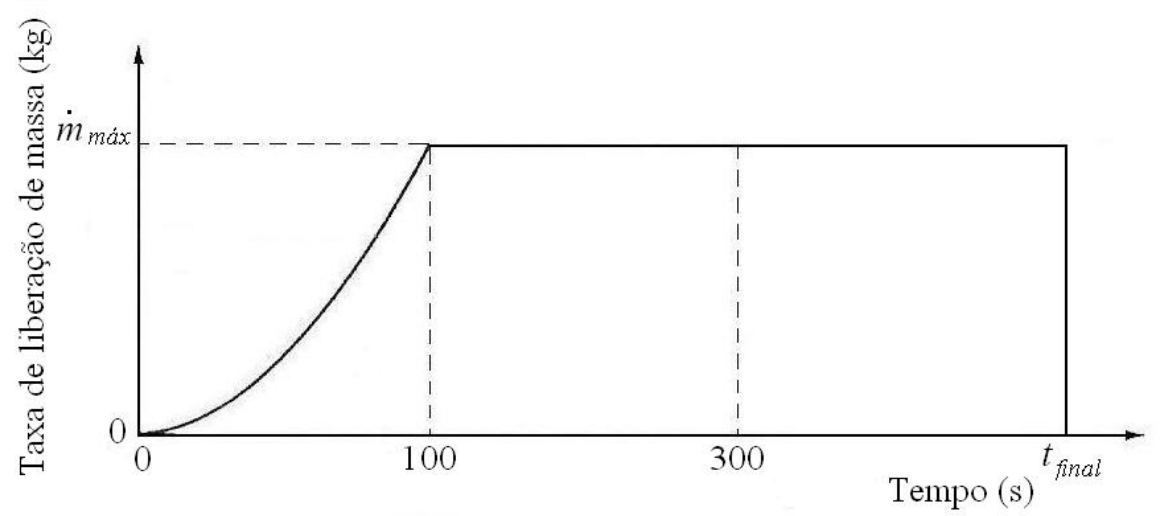

Figura 9.4 - Variação da taxa de liberação de massa do combustível com o tempo.

A taxa de liberação de massa do incêndio está associada à reação química da espécie de combustível (pinho seco) e ao oxigênio presente no ar. De acordo com Drysdale (2002), embora o incêndio seja uma manifestação de reação química, o modelo de combustão pode depender também do estado físico e da distribuição do combustível no ambiente.

Ewer (2008) considerou que as reações moleculares, para combustível em madeira leve, como o pinho, ocorrem conforme a eq. 9.2. Essa equação é uma simplificação do complexo processo de combustão de um incêndio real e está inserida no Smartfire, juntamente com a taxa de liberação de massa da figura 9.4.

$$
1,00 \text { combustivel }+1,05 \mathrm{O}_{2} \Rightarrow 0,85 \mathrm{H}_{2} \mathrm{O}+\mathrm{CO}_{2}+\text { calor }
$$

A eq. 9.2 expressa a combinação de 1 molécula de combustível em madeira de pinho seco com 1,05 moléculas de oxigênio, liberando 0,85 moléculas de água, mais 1 molécula de gás carbônico e produzindo calor.

\subsubsection{Limite de oxigenação}

No modelo, foi introduzido um limite de oxigenação para ocorrer a combustão, isto é, o combustível queimará somente se houver oxigênio suficiente. O limite de oxigenação é altamente dependente da natureza do combustível, da temperatura e, quando o combustível for sólido, da disposição e da rugosidade. 
No modelo, foi considerado que o limite de oxigenação da combustão é dependente da temperatura. Foram fixados valores limites para a razão entre a massa de oxigênio e a massa de gases presentes no ambiente, a fim de sustentar a combustão. Os limites adotados foram fornecidos por Ewer (2008) e apresentam: $23 \%$ para temperaturas abaixo de $400{ }^{\circ} \mathrm{C}, 14 \%$ para temperaturas acima de $600{ }^{\circ} \mathrm{C}$ e, entre essas temperaturas, interpolou-se linearmente.

Isso significa que, para temperaturas mais baixas, são necessários $23 \%$ de oxigênio para sustentar a combustão e, para temperaturas mais altas, o nível de oxigênio para sustentar a combustão pode ser menor, $14 \%$ em massa. Esse tipo de consideração faz com que as temperaturas dentro do compartimento não atinjam valores muito altos, o que seria fora da realidade.

\subsection{TEMPERATURA DENTRO DO COMPARTIMENTO}

A figura 9.5 mostra as isotermas, em Kelvin, em um corte vertical localizado no centro do compartimento incendiado, segundo o plano xy. A maior temperatura encontrada dentro do compartimento foi de $997^{\circ} \mathrm{C}$, próxima ao material combustível.

As temperaturas dentro do compartimento variaram entre $373{ }^{\circ} \mathrm{C}$ e $837{ }^{\circ} \mathrm{C}$, desconsiderando as temperaturas em torno da fonte de calor e as temperaturas próximas ao ar que entra na parte inferior da janela.

As isotermas de um corte horizontal, segundo o plano xz, localizado $30 \mathrm{~cm}$ abaixo do teto do compartimento são mostradas na figura 9.6. Verifica-se que a maior temperatura registrada foi de $837{ }^{\circ} \mathrm{C}$ e encontra-se nas laterais do compartimento. As temperaturas dentro do compartimento tiveram uma variação de $576^{\circ} \mathrm{C}$ a $837^{\circ} \mathrm{C}$. 


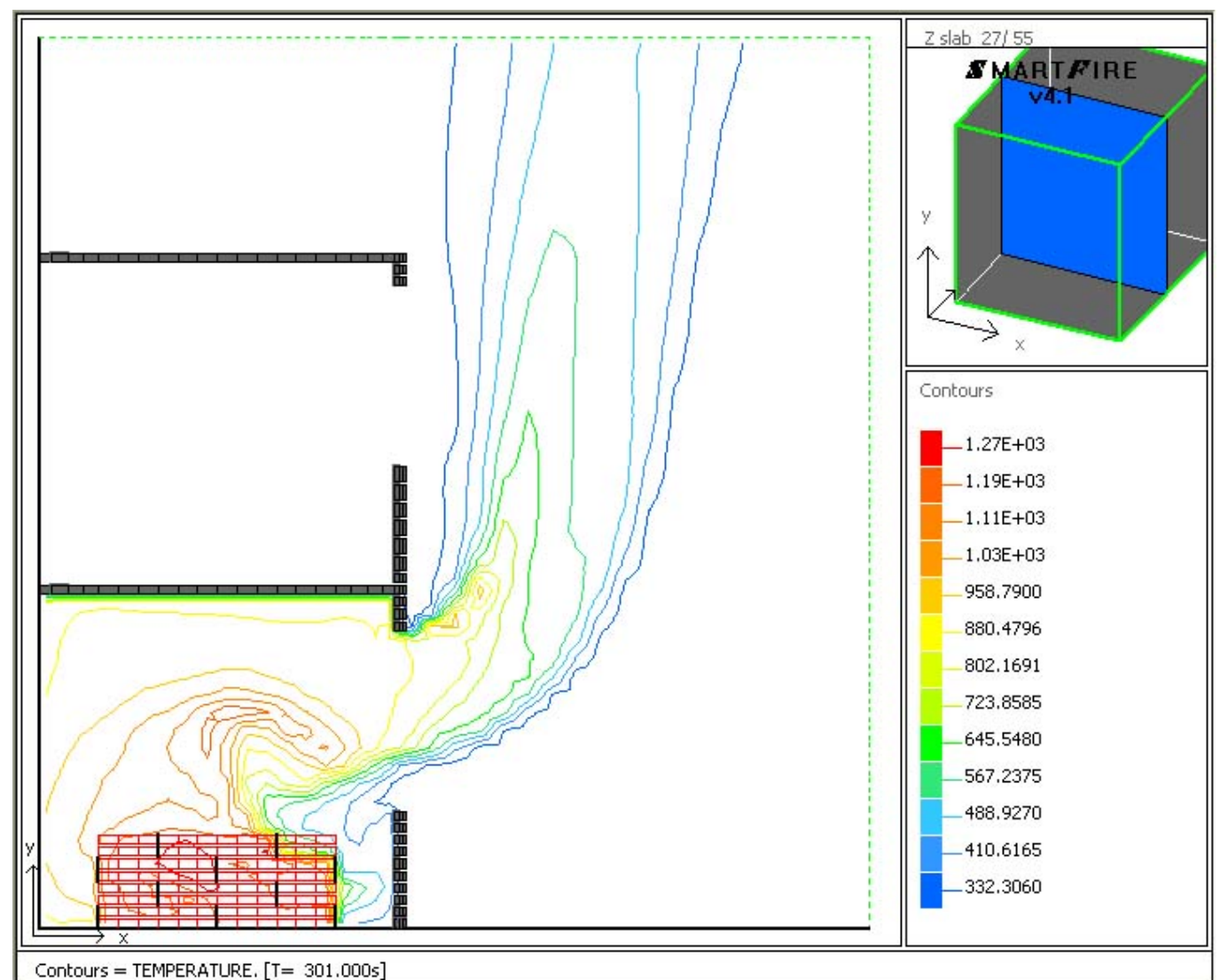

Figura 9.5 - Isotermas em Kelvin. Corte vertical (plano xy) no centro do compartimento incendiado.

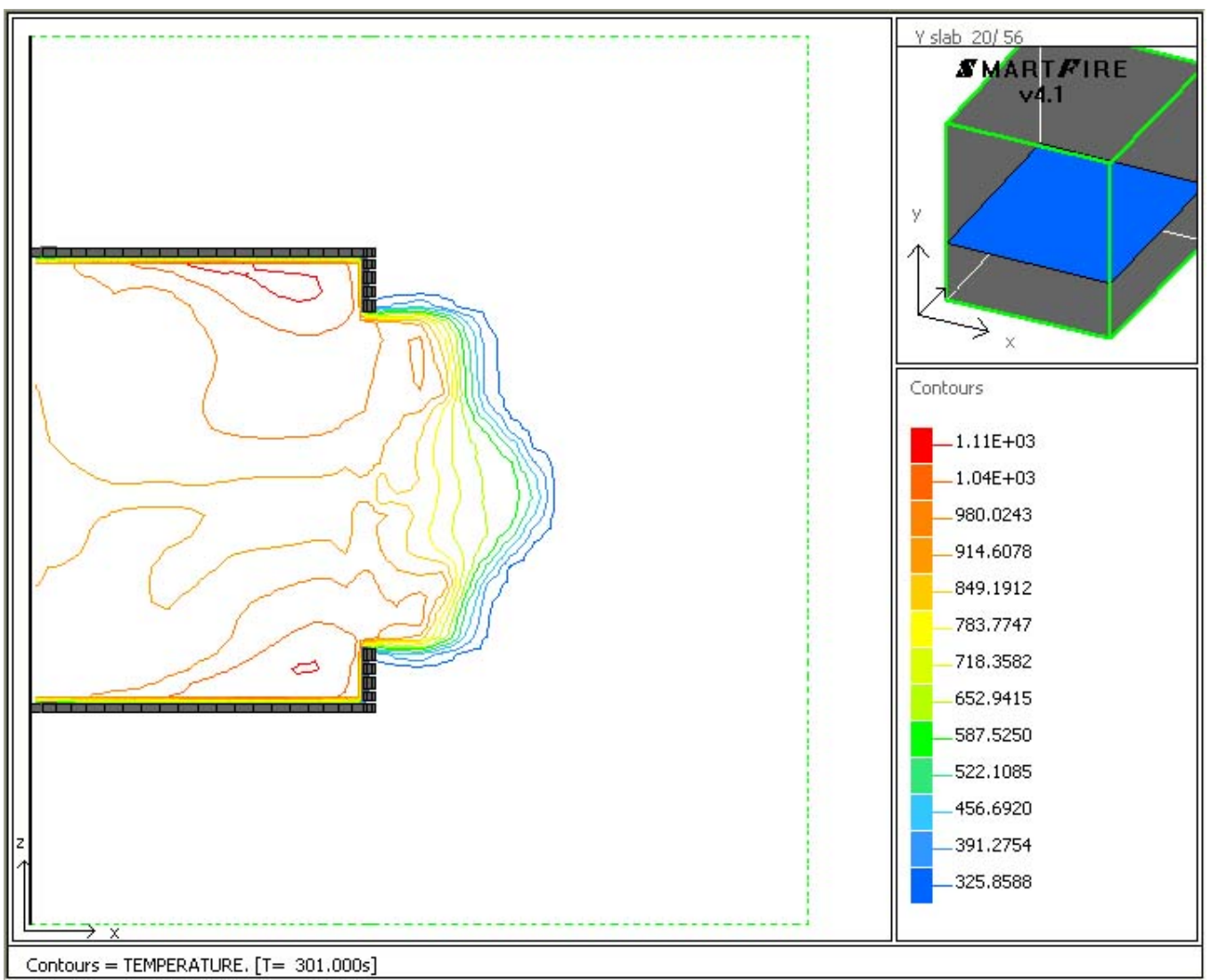

Figura 9.6 - Isotermas em Kelvin. Corte horizontal (plano xz) do compartimento experimental. Localizado $30 \mathrm{~cm}$ abaixo do teto. 


\subsection{TEMPERATURA DA CHAMA NA JANELA}

A figura 9.7 mostra um corte vertical, segundo o plano yz, que passa pela abertura do compartimento. Como se vê, as maiores temperaturas estão na parte superior da janela, por onde a chama sai do compartimento. Na parte inferior estão as menores temperaturas, por onde o ar externo entra no compartimento.

A temperatura máxima foi de $807^{\circ} \mathrm{C}$. Considerando apenas a parte superior da janela, as temperaturas variam entre $560^{\circ} \mathrm{C}$ e $807^{\circ} \mathrm{C}$.

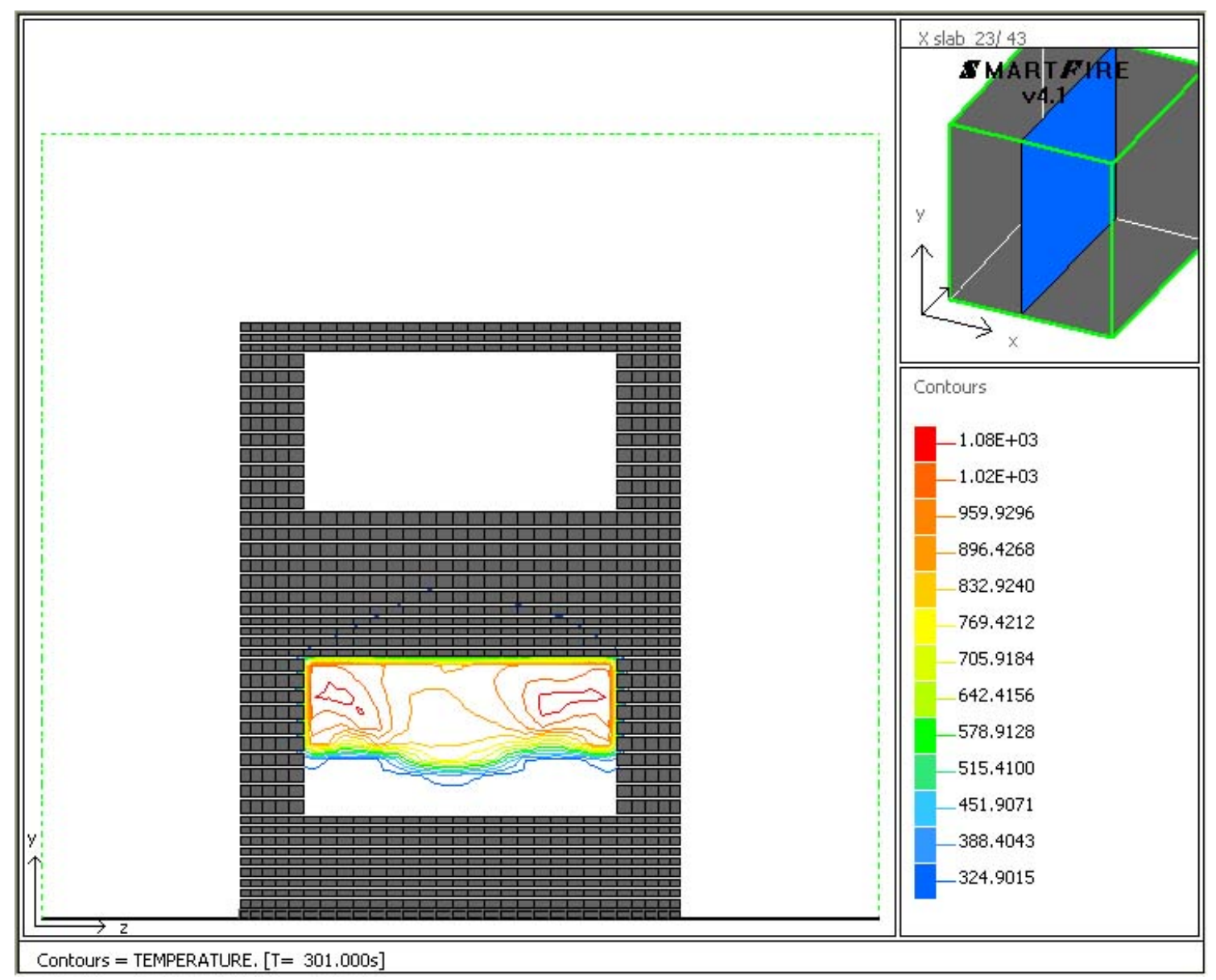

Figura 9.7 - Isotermas em Kelvin. Corte vertical (plano yz) localizado na janela do compartimento. 


\subsection{ALTURA DA CHAMA EXTERNA}

O comportamento da chama que emerge do compartimento foi analisado via Smartfire. A figura 9.8 mostra uma iso-superfície de temperatura $538{ }^{\circ} \mathrm{C}$, conforme consideração feita por Law (1978), para caracterizar a altura da chama externa.

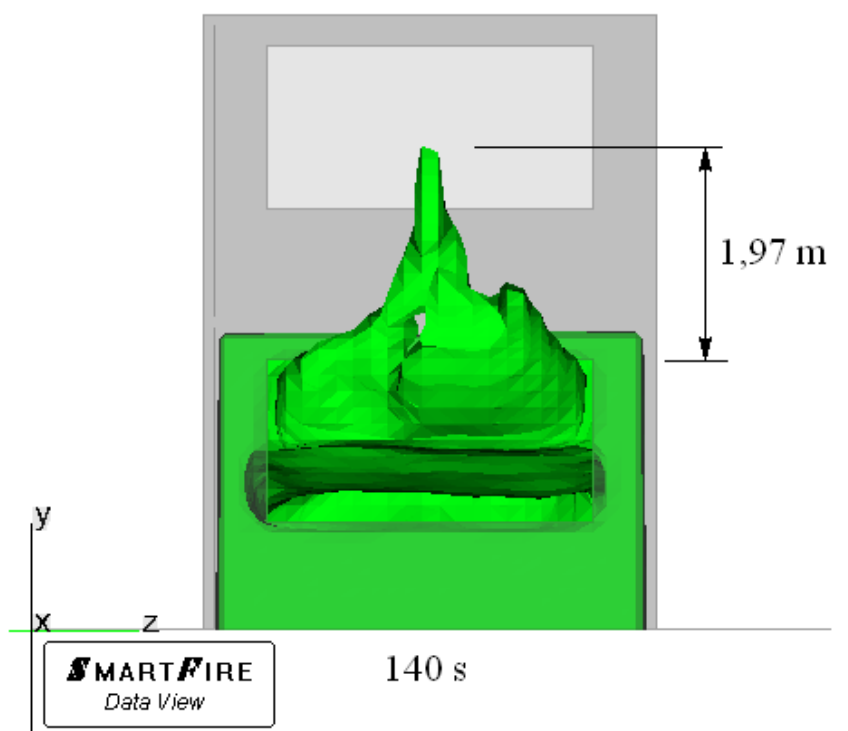

(a) Vista frontal. Tempo de simulação $140 \mathrm{~s}$

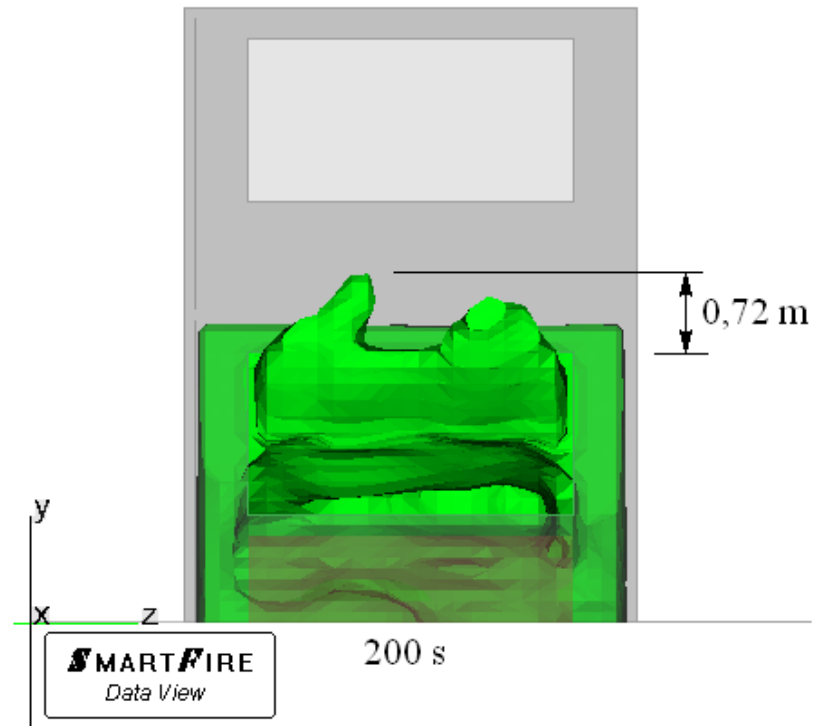

(c) Vista frontal. Tempo de simulação $200 \mathrm{~s}$

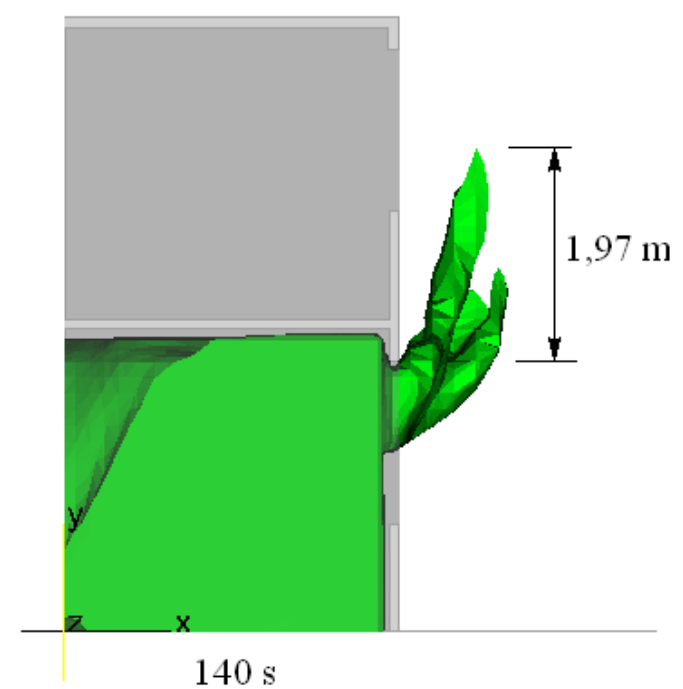

(b) Vista Lateral. Tempo de simulação $140 \mathrm{~s}$.

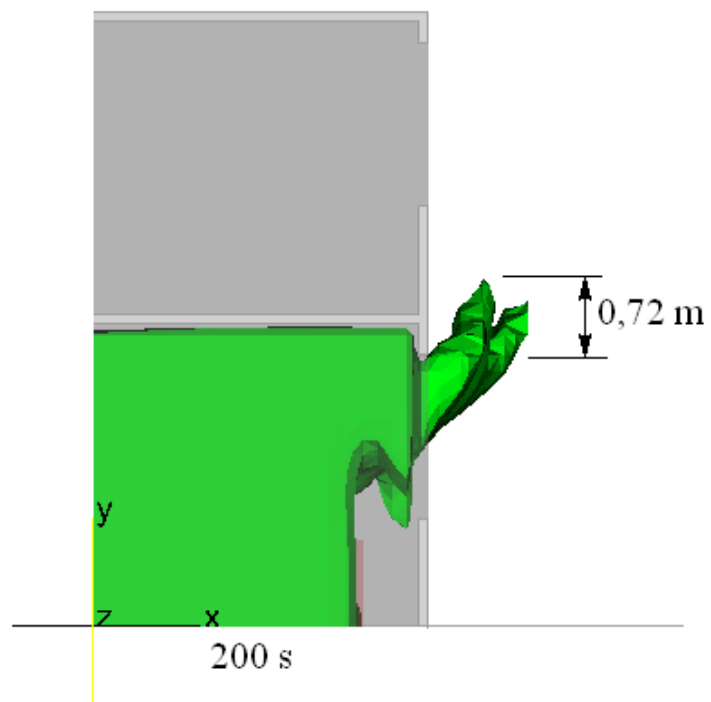

(d) Vista Lateral. Tempo de simulação $200 \mathrm{~s}$. Figura 9.8 - Chama externa considerando uma iso-superfície de $538^{\circ} \mathrm{C}$.

Após o incêndio atingir o valor de combustão máxima, a taxa de combustão permaneceu constante, verificou-se que a forma e a altura das chamas variaram com o tempo. A título de 
exemplo, mostra-se na figura 9.8 o aspecto das chamas para $140 \mathrm{~s}$ e $200 \mathrm{~s}$ de simulação, ressaltando a variação da altura.

Essa variação de formatos e alturas ocorreu durante toda a simulação, mesmo com a taxa máxima de calor permanecendo constante. Isso caracteriza o que acontece em um incêndio real, em que a chama que emerge do compartimento incendiado não apresenta geometria definida. 
Capítulo 10

COMPARAÇÃO ENTRE OS RESULTADOS DO EXTEELFIRE E DO SMARTFIRE/SUPER TEMPCALC

Para fins de comparação entre um método simplificado e outro via CFD, realizaram-se seis ensaios numéricos empregando-se os dois programas: ExteelFire 2.0, com base no Eurocode, e o SMARTFIRE V4.1, juntamente com o Super Tempcalc.

As geometrias do compartimento adotadas no estudo são apresentadas na figura 10.1.

As cargas de incêndio (para o ExteelFire) ou a taxa de combustão equivalente à determinada por meio do ExteelFire, para o Smartfire, adotadas estão indicadas na tabela 10.1.

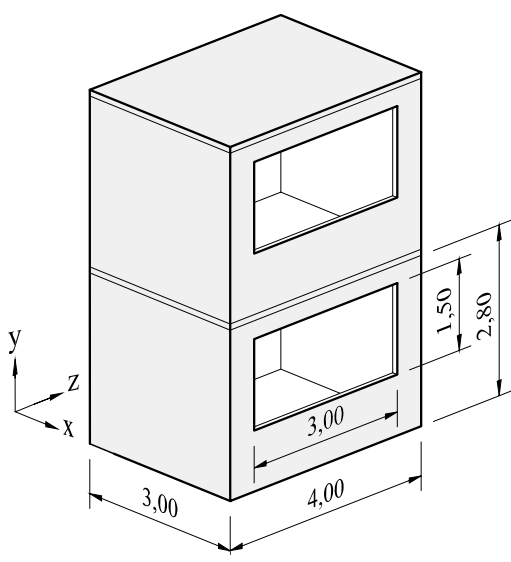

(a) Ensaio 1

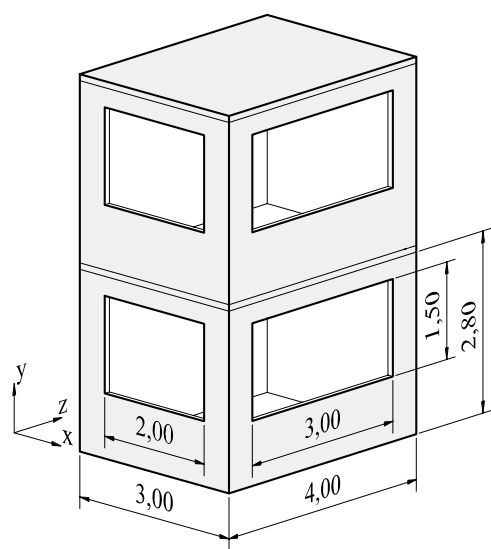

(d) Ensaio 4

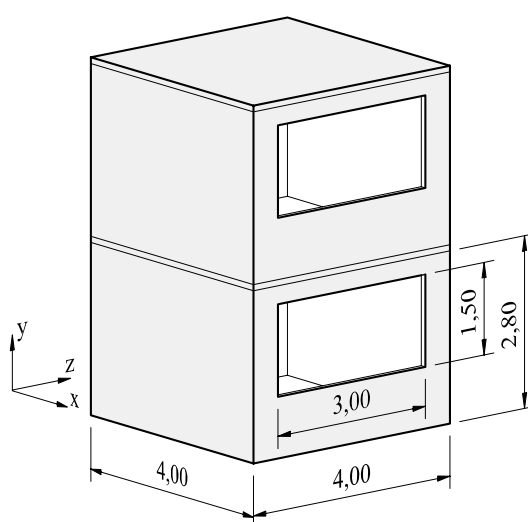

(b) Ensaio 2

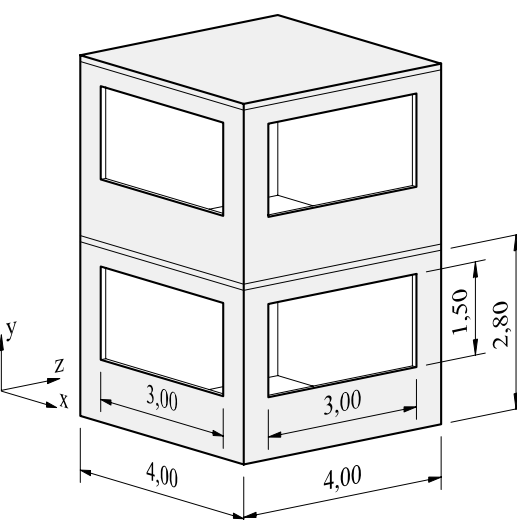

(e) Ensaio 5

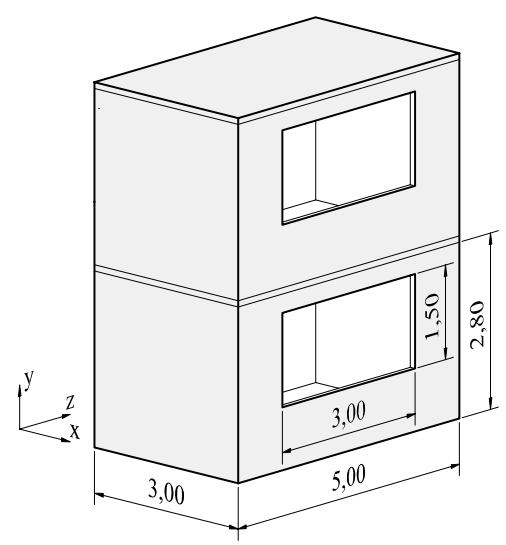

(c) Ensaio 3

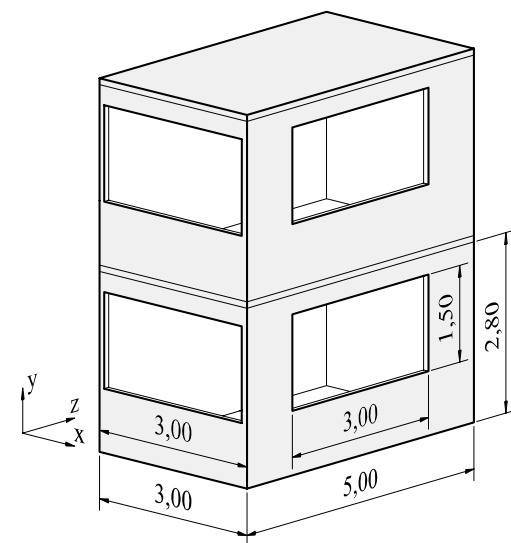

(f) Ensaio 6

Figura 10.1 - Geometria do compartimento. 
Nos compartimentos com uma abertura (ensaios 1, 2 e 3), o ExteelFire considerou o incêndio controlado pela ventilação, conforme tabela 10.1. Nos compartimentos com duas aberturas (ensaios 4, 5 e 6), foi considerado incêndio controlado pelo combustível. Essa alternativa é automaticamente adotada pelo ExteelFire em função de limites impostos (ver item 5.3.1 desta Tese).

Tabela 10.1 - Taxa de combustão determinada pelo ExteelFire

\begin{tabular}{c|c|c|c|c|c}
\hline Ensaio & $\begin{array}{c}\text { Carga de } \\
\text { incêndio } \\
\left(\mathrm{MJ} / \mathrm{m}^{2}\right)\end{array}$ & $\begin{array}{c}\text { Taxa de } \\
\text { combustão } \\
(\mathrm{MW})\end{array}$ & $\begin{array}{c}\text { Taxa de liberação } \\
\text { de massa } \\
(\mathrm{kg} / \mathrm{s})\end{array}$ & $\begin{array}{c}\text { Fator de } \\
\text { ventilação } \\
\left(\mathrm{m}^{1 / 2}\right)\end{array}$ & $\begin{array}{c}\text { Controle do } \\
\text { incêndio }\end{array}$ \\
\hline 1 & 700 & 6,384 & 0,5124 & 0,087 & Ventilação \\
2 & 700 & 6,535 & 0,5245 & 0,072 & Ventilação \\
3 & 700 & 8,253 & 0,6624 & 0,074 & Ventilação \\
4 & 700 & 7,000 & 0,5618 & 0,145 & Combustível \\
5 & 700 & 9,333 & 0,7490 & 0,144 & Combustível \\
\hline 6 & 700 & 8,750 & 0,7022 & 0,147 & Combustível \\
\hline
\end{tabular}

\subsection{TEMPERATURA NO INTERIOR DO COMPARTIMENTO}

Nas figuras 10.2 a 10.5, são apresentadas as isotermas, em Kelvin, em diferentes planos, e, a partir delas, indicada a posição em que ocorre a temperatura máxima dos gases dentro do compartimento, calculada por meio do ExteelFire, para o ensaio 1. 


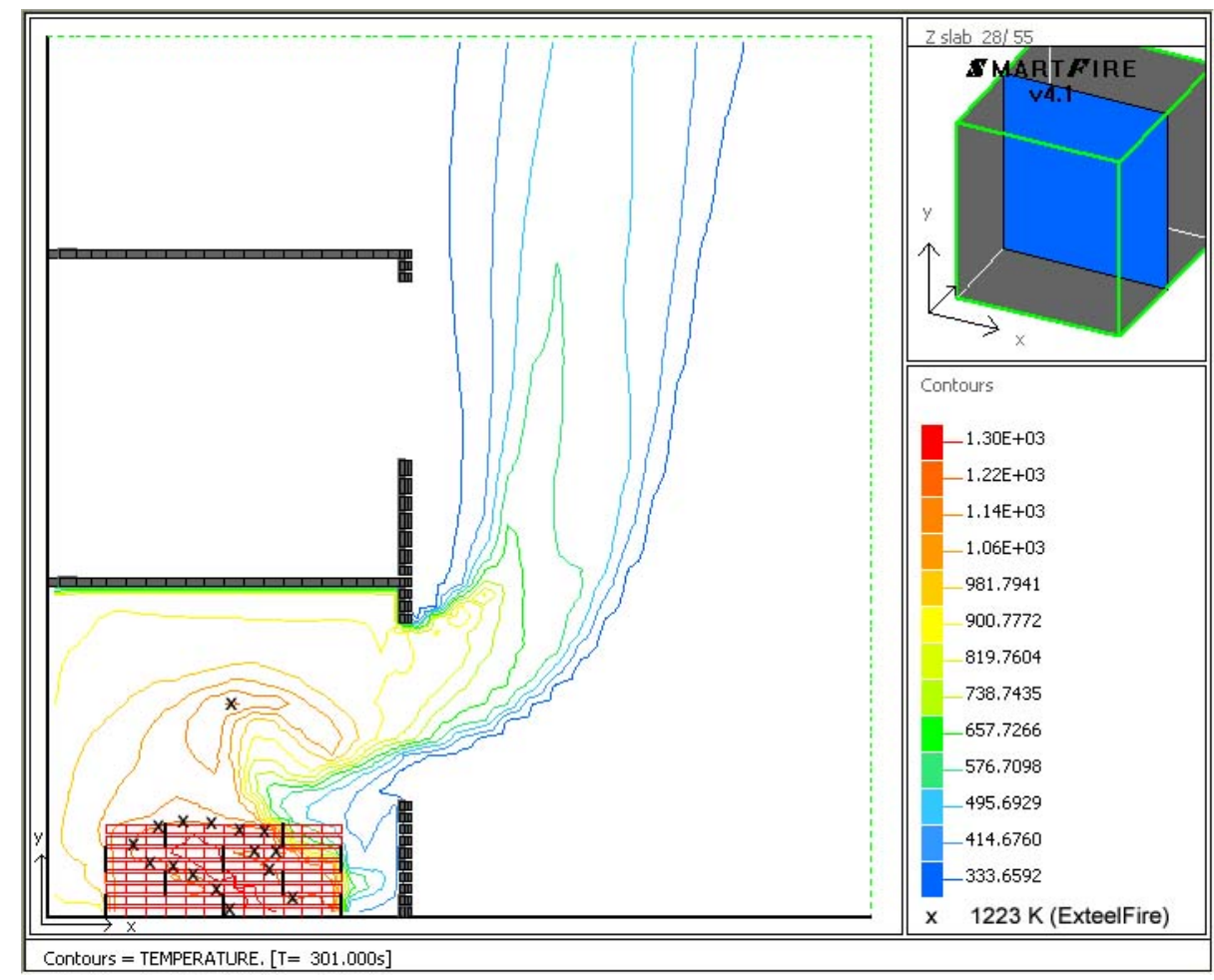

Figura 10.2 - Ensaio 1. Temperaturas (em Kelvin) no interior do compartimento. Corte no meio do vão (plano $\mathrm{xy})$.

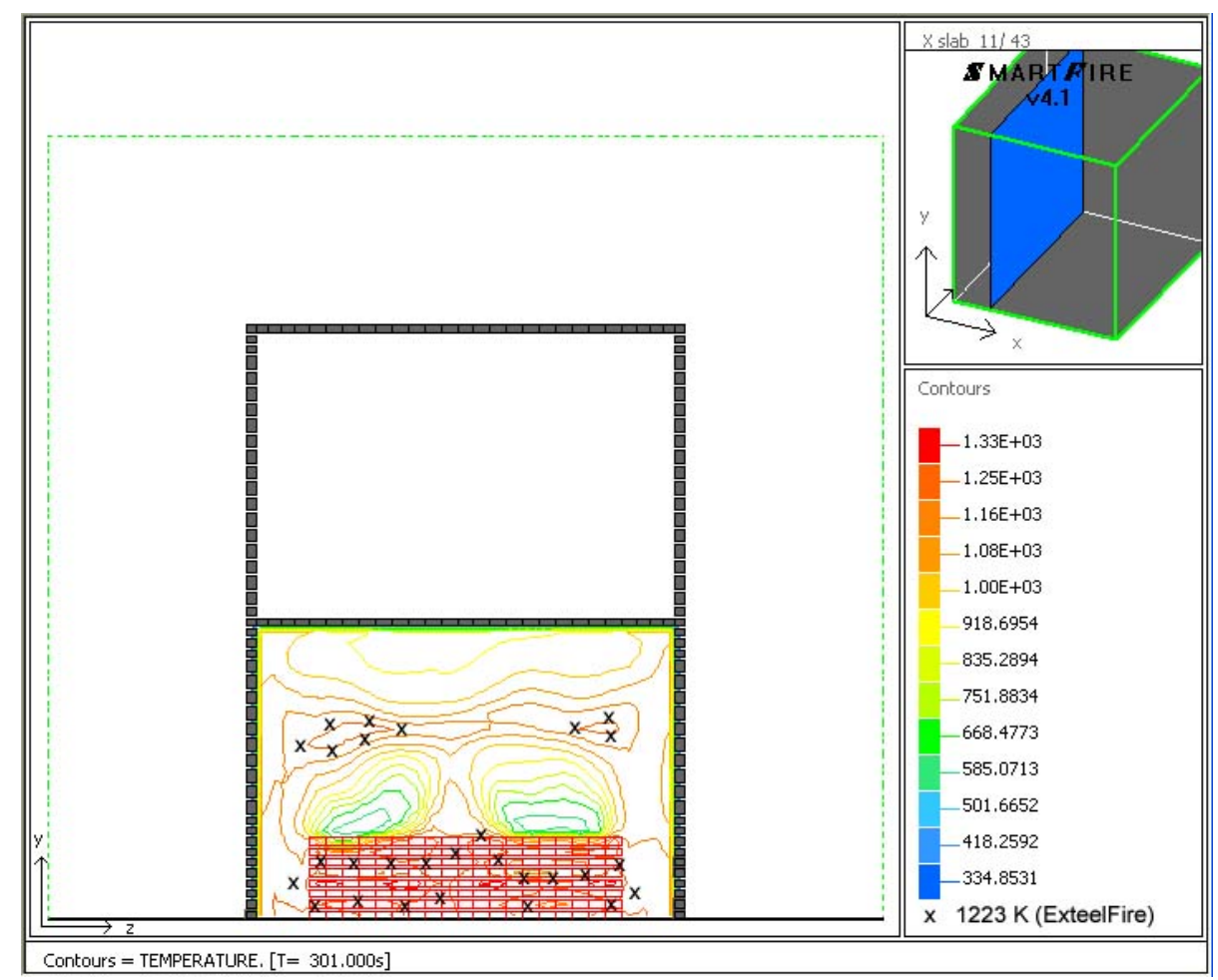

Figura 10.3 - Ensaio 1. Temperaturas (em Kelvin) no interior do compartimento. Corte no meio do vão (plano yz). 


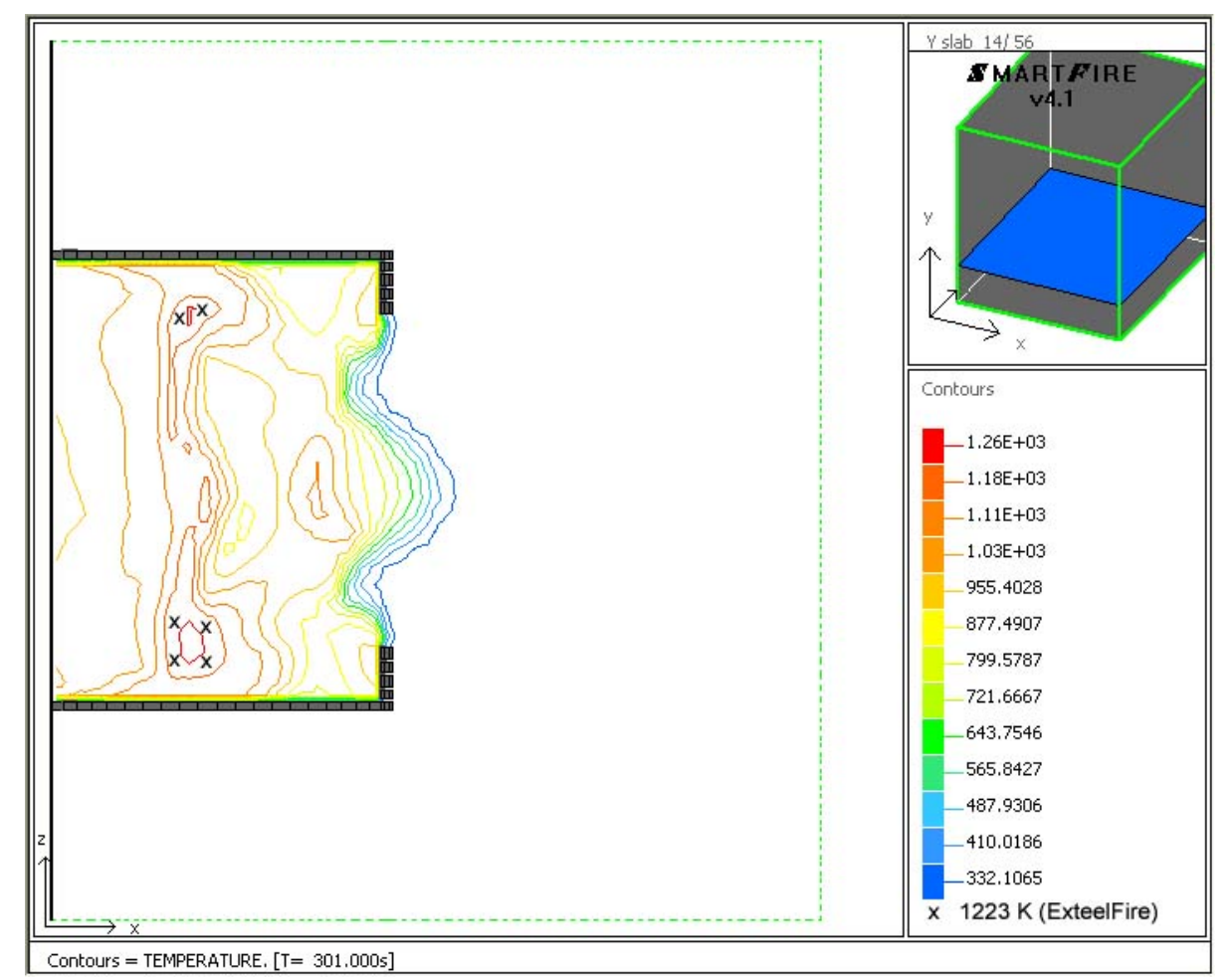

Figura 10.4 - Ensaio 1. Temperaturas (em Kelvin) no interior do compartimento. Corte na altura de 1,40 m do piso (plano xz).

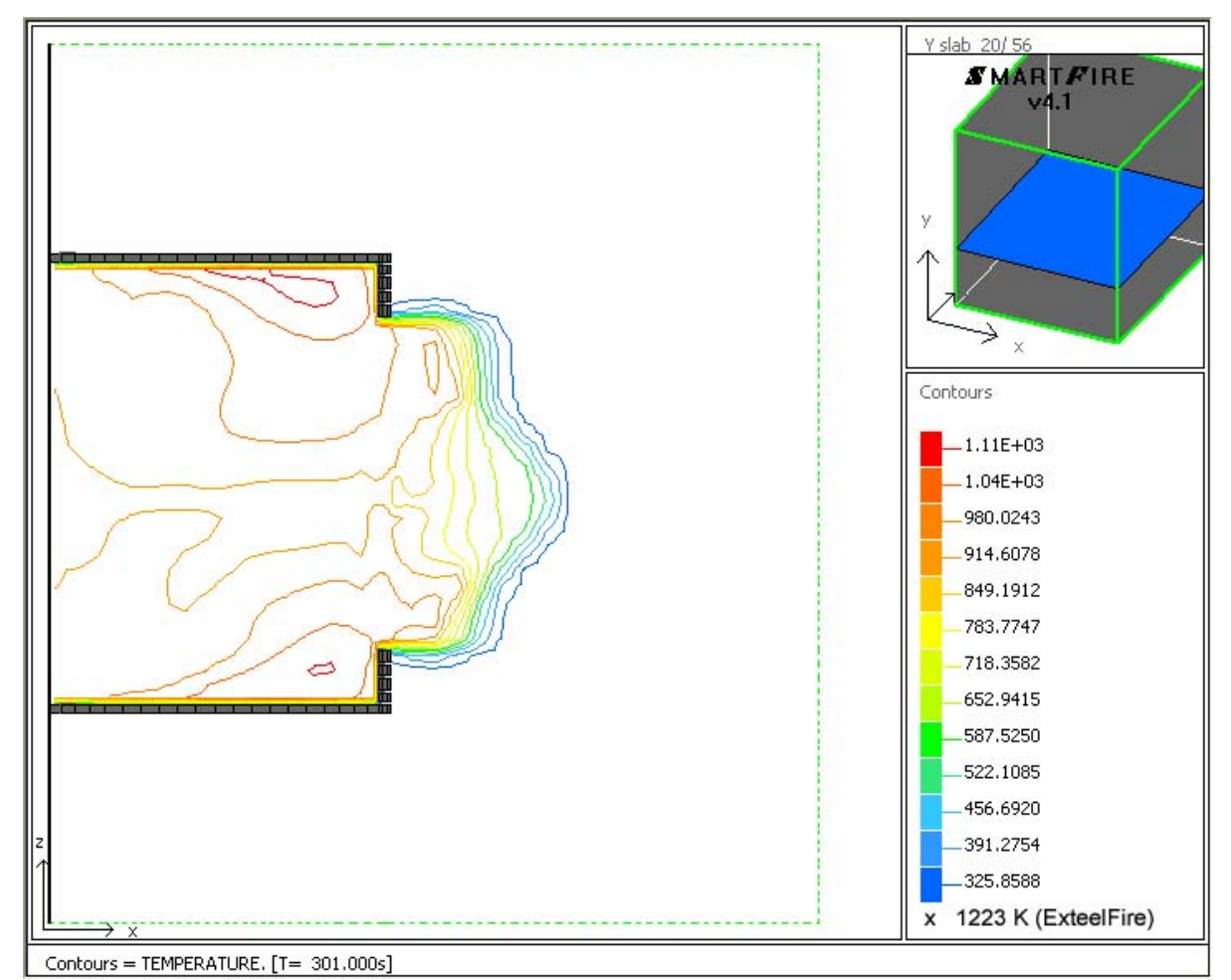

Figura 10.5 - Ensaio 1. Temperaturas (em Kelvin) no interior do compartimento. Corte na altura de 2,50 m do piso (plano xz). 
A partir das figuras 10.2 a 10.5 conclui-se que, nos dois cortes verticais, a temperatura máxima calculada pelo ExteelFire, $1223 \mathrm{~K}\left(950^{\circ} \mathrm{C}\right)$, ocorre a $1,75 \mathrm{~m}$ de altura. Nos cortes horizontais a 1,40 $\mathrm{m}$ de altura do piso, nota-se também uma região pequena com essa temperatura, que deixa de ser atingida a $2,50 \mathrm{~m}$ de altura.

De uma forma geral, no ensaio 1 , as temperaturas foram menores que a temperatura máxima dos gases dentro do compartimento calculadas pelo ExteelFire. Somente em determinados pontos, principalmente em torno da fonte de calor, ocorrem temperaturas iguais ou pouco maiores do que aquela calculada pelo ExteelFire.

Nas figuras 10.6 a 10.9, são apresentadas as isotermas em diferentes planos, em Kelvin, para o ensaio 2. Como se pode notar, em nenhuma das regiões analisadas encontrou-se a temperatura máxima calculada por meio do ExteelFire.

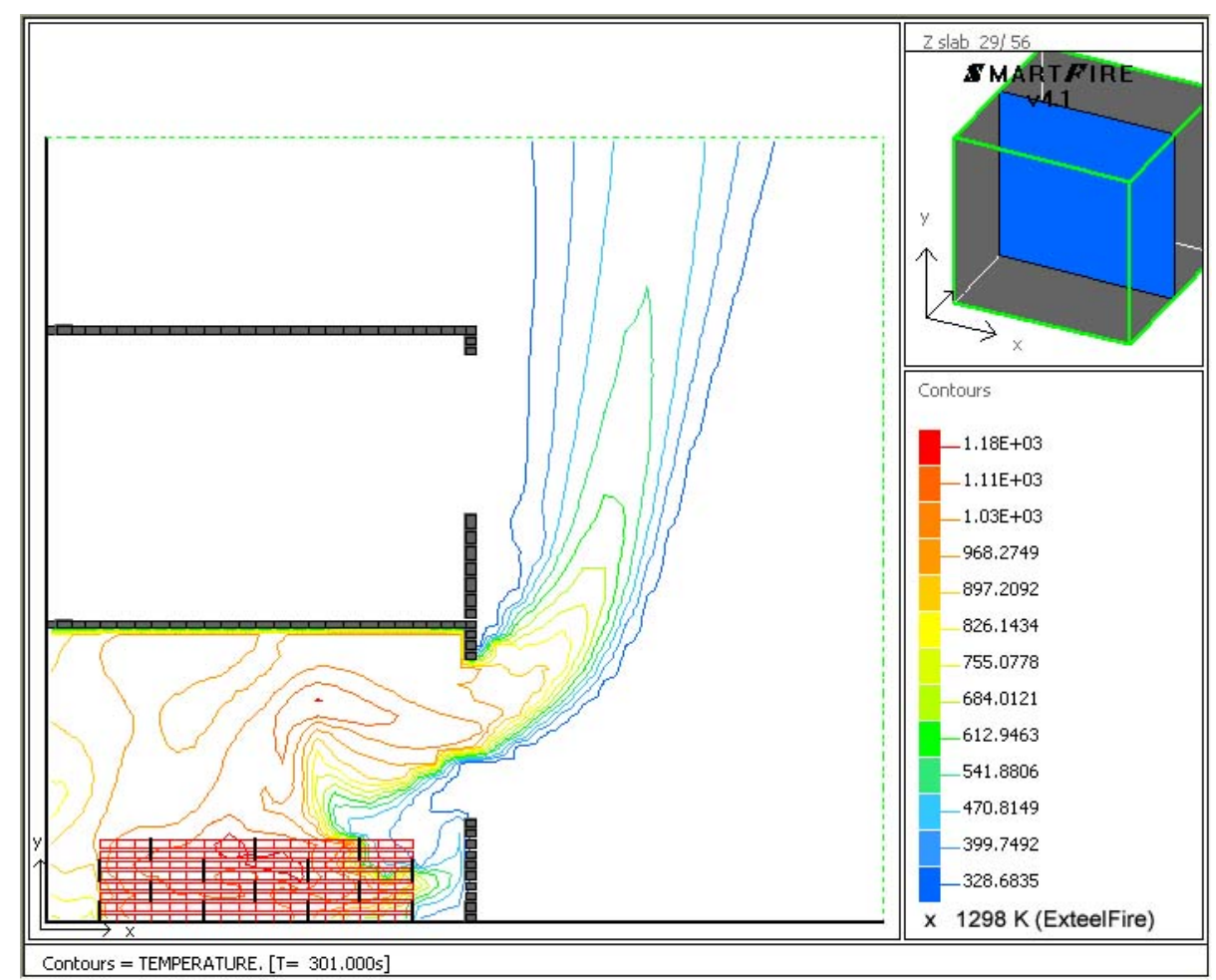

Figura 10.6 - Ensaio 2. Temperaturas (em Kelvin) no interior do compartimento. Corte no meio do vão (plano $x y)$. 


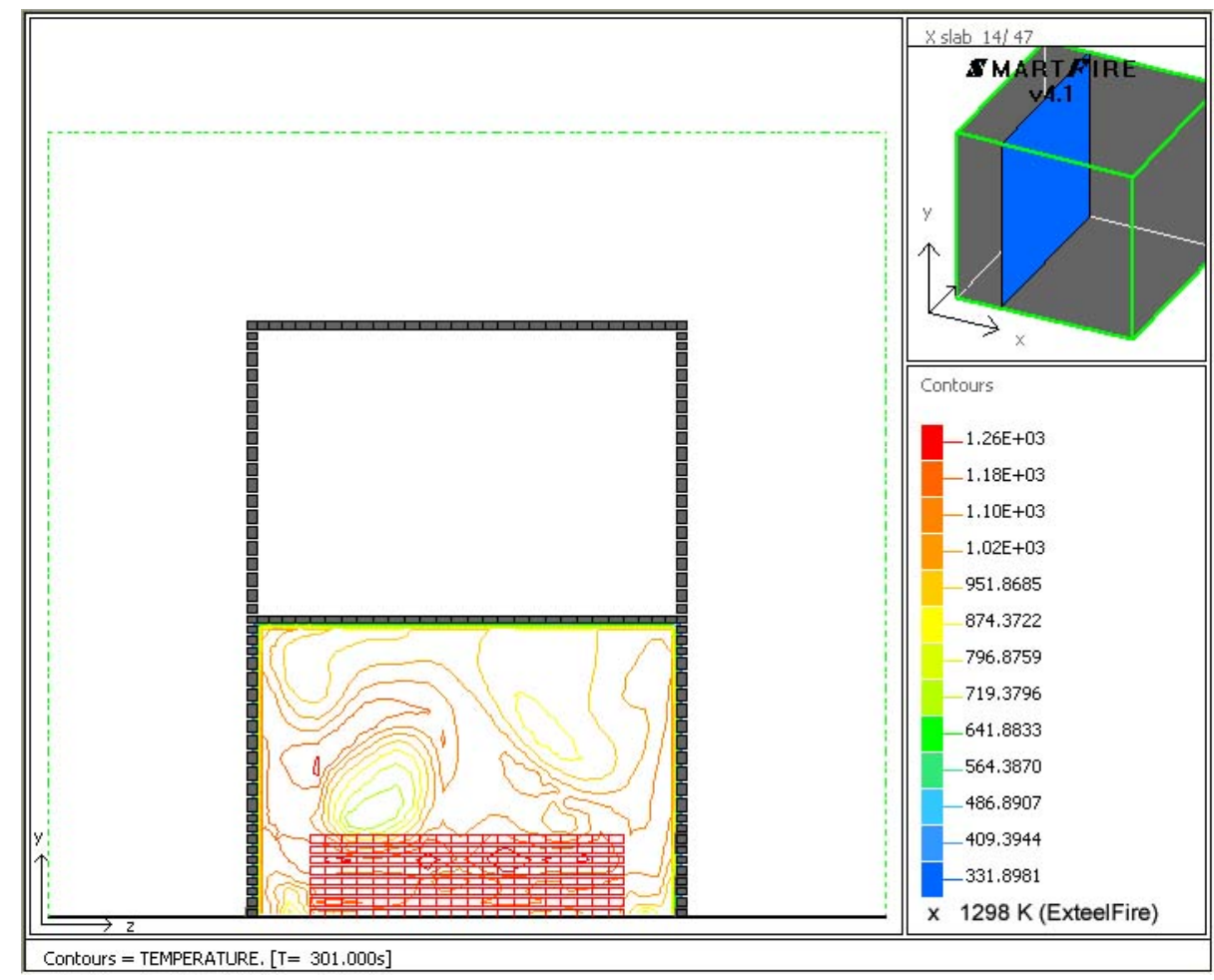

Figura 10.7 - Ensaio 2. Temperaturas (em Kelvin) no interior do compartimento. Corte no meio do vão (plano $y z)$.

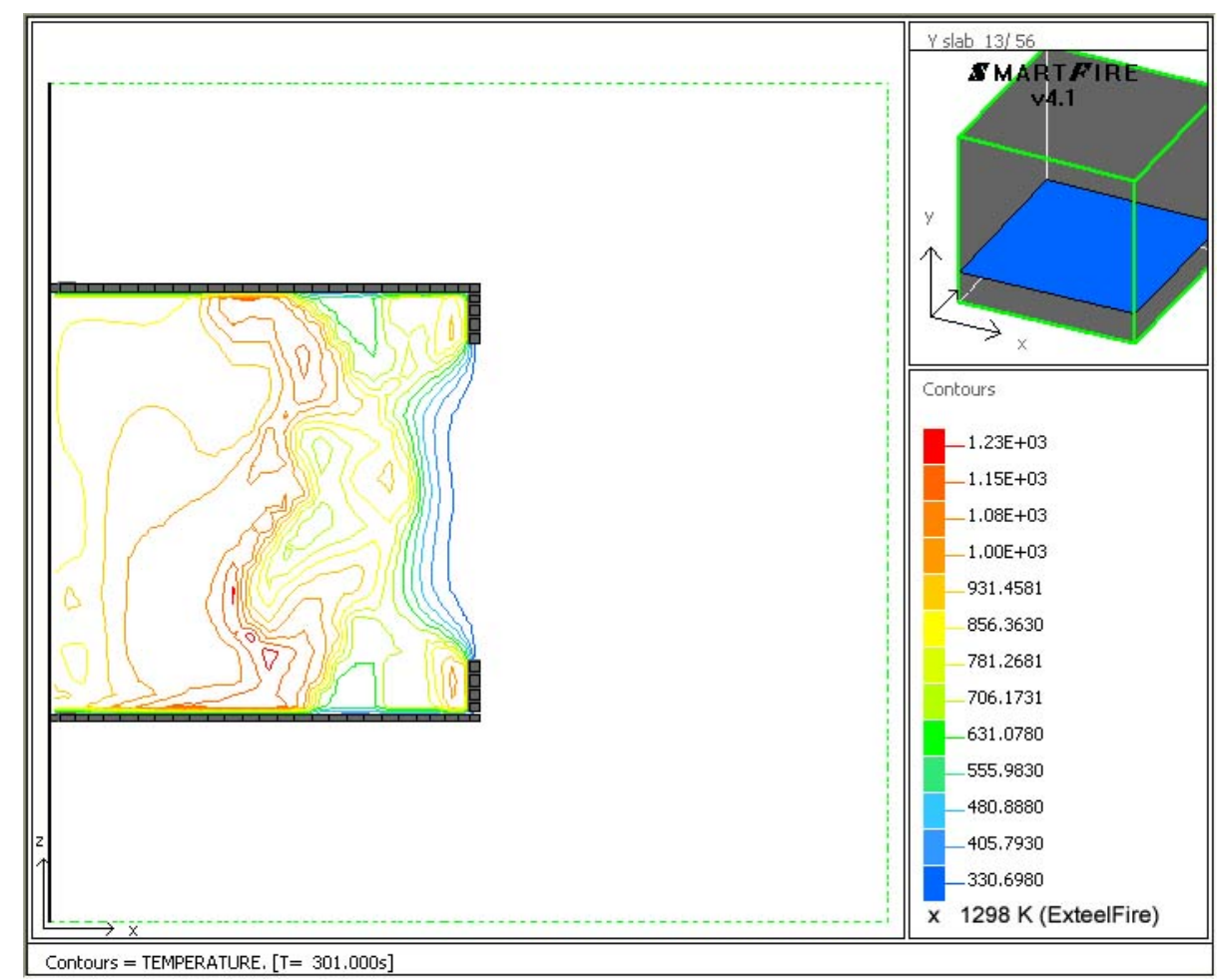

Figura 10.8 - Ensaio 2. Temperaturas (em Kelvin) no interior do compartimento. Corte na altura de 1,40 m do piso (plano xz). 


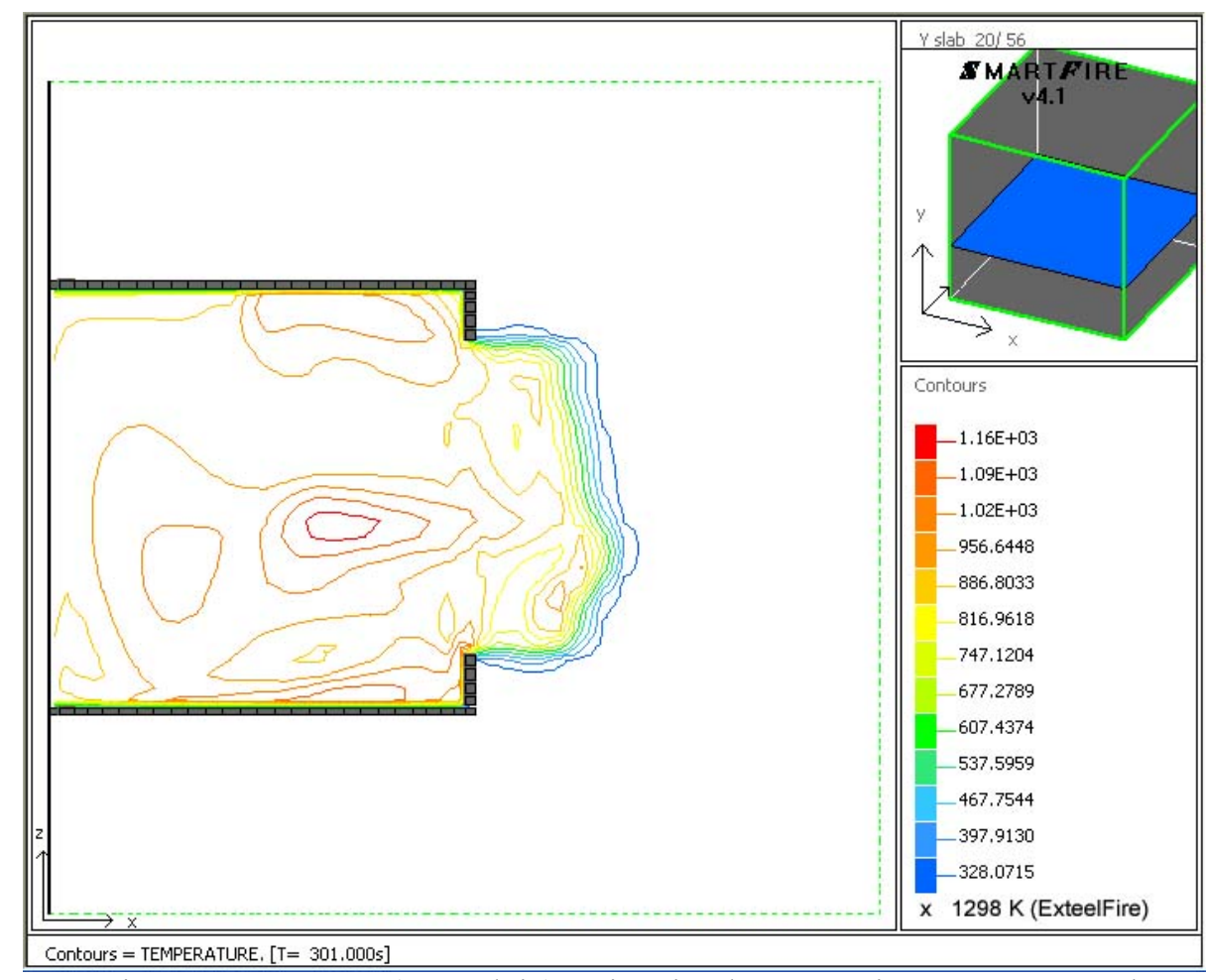

Figura 10.9 - Ensaio 2. Temperaturas (em Kelvin) no interior do compartimento. Corte na altura de 2,50 $\mathrm{m}$ do piso (plano $\mathrm{xz}$ ).

Nas figura 10.10 a 10.13, são apresentadas as isotermas em diferentes planos, em Kelvin, e, a partir delas, é indicada a posição em que ocorre a temperatura máxima dos gases dentro do compartimento, calculada por meio do ExteelFire, para o ensaio 3. 


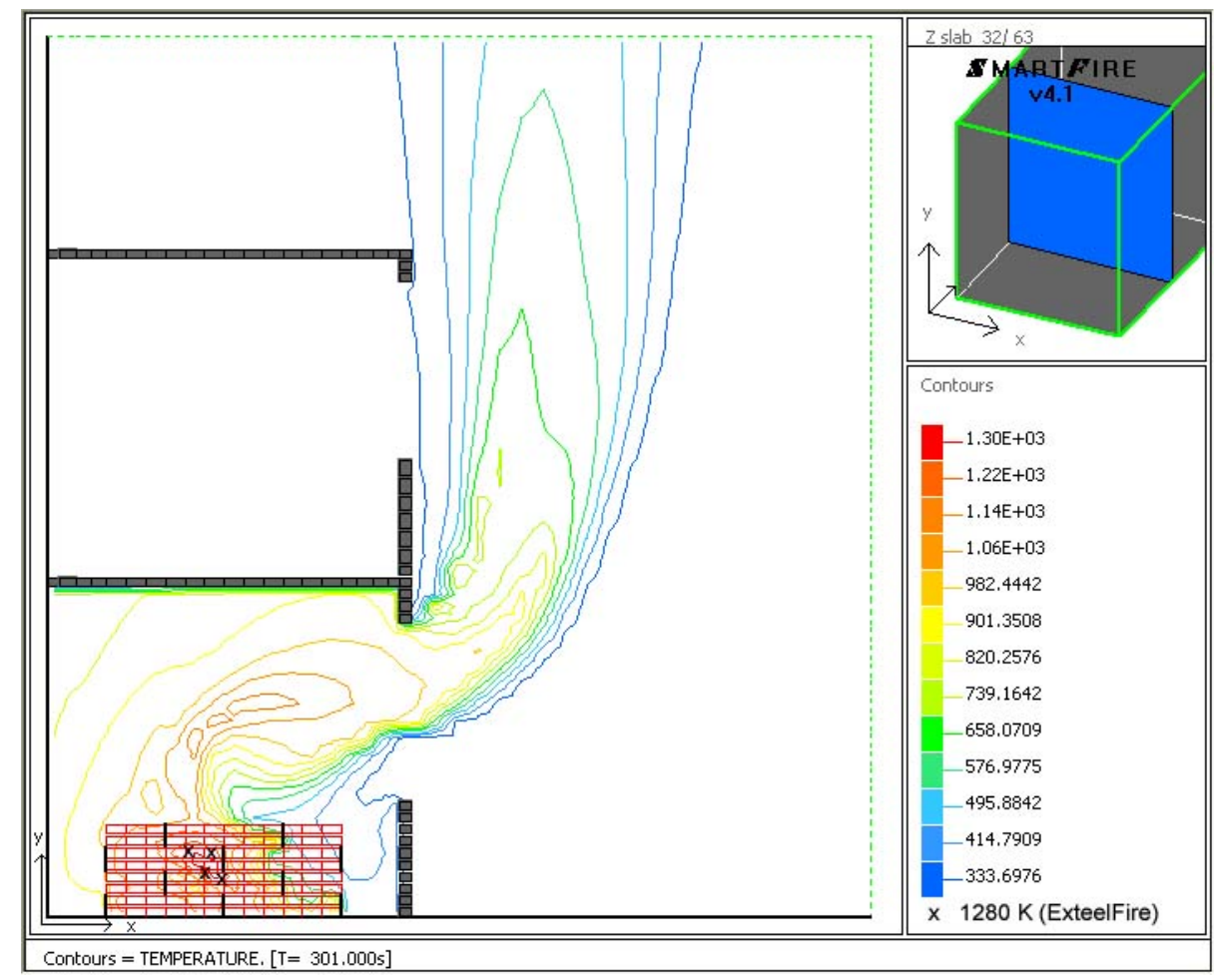

Figura 10.10 - Ensaio 3. Temperaturas (em Kelvin) no interior do compartimento. Corte no meio do vão (plano $x y)$.

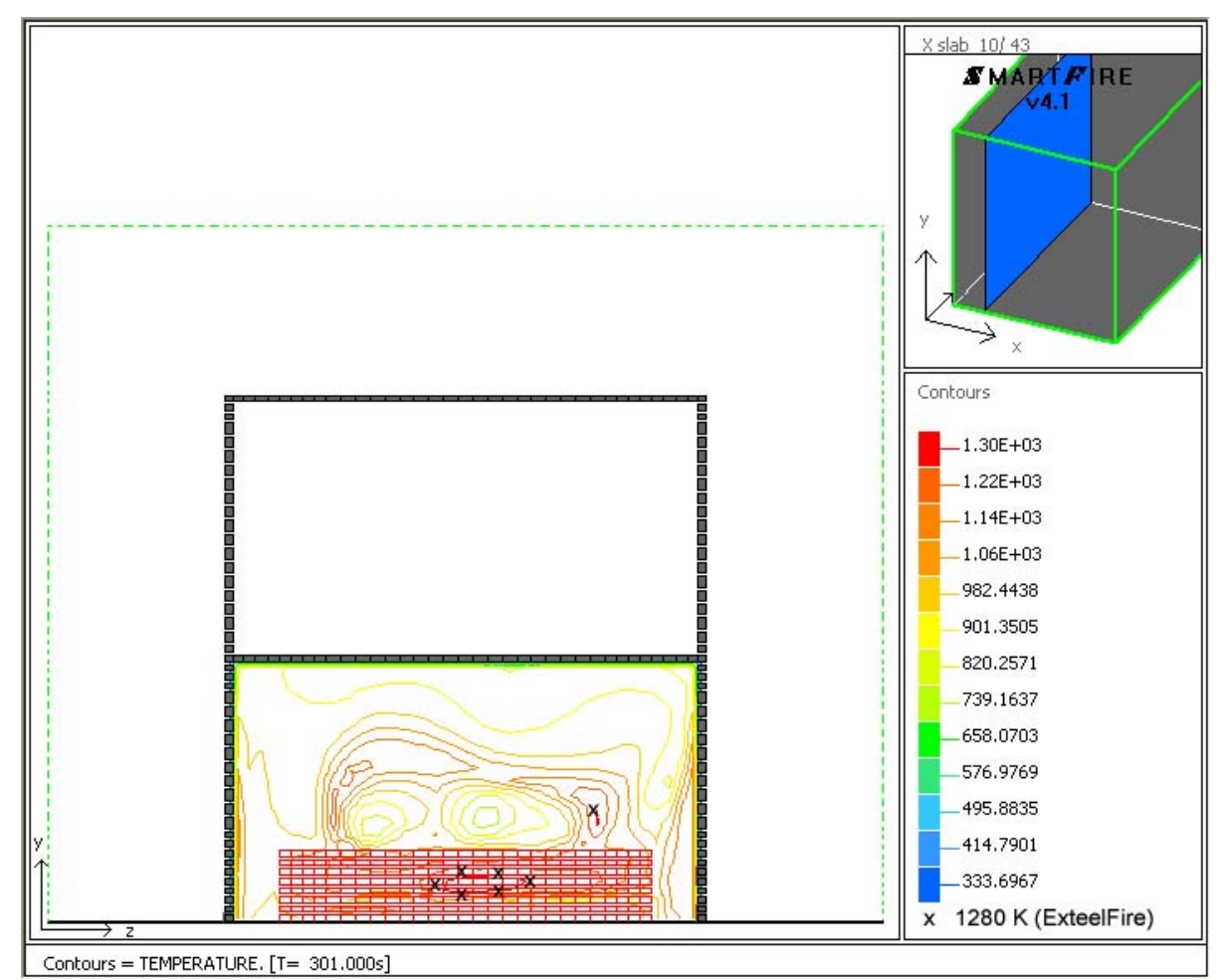

Figura 10.11 - Ensaio 3. Temperaturas (em Kelvin) no interior do compartimento. Corte no meio do vão (plano yz). 


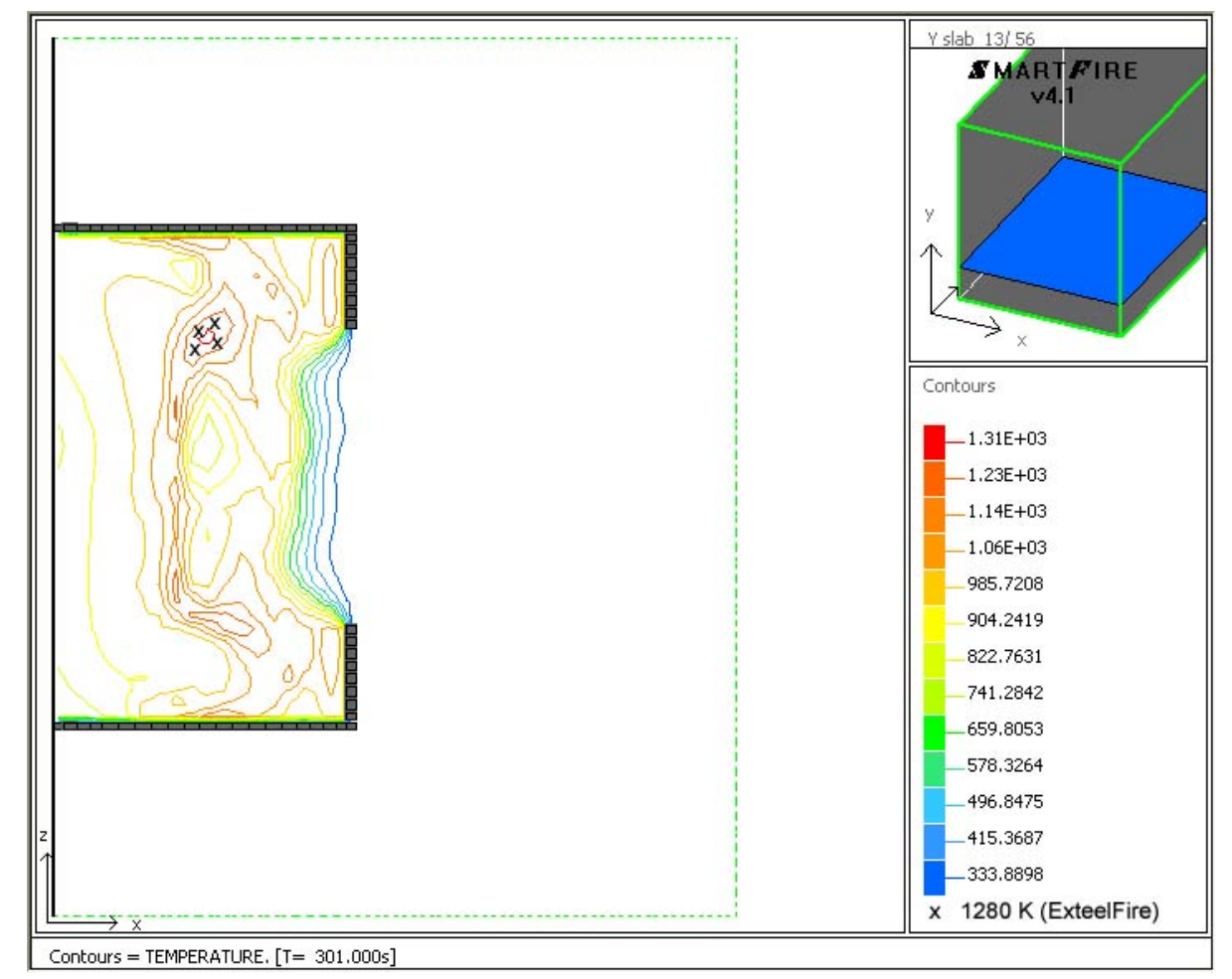

Figura 10.12 - Ensaio 3. Temperaturas (em Kelvin) no interior do compartimento. Corte na altura de $1,40 \mathrm{~m}$ do piso (plano xz).

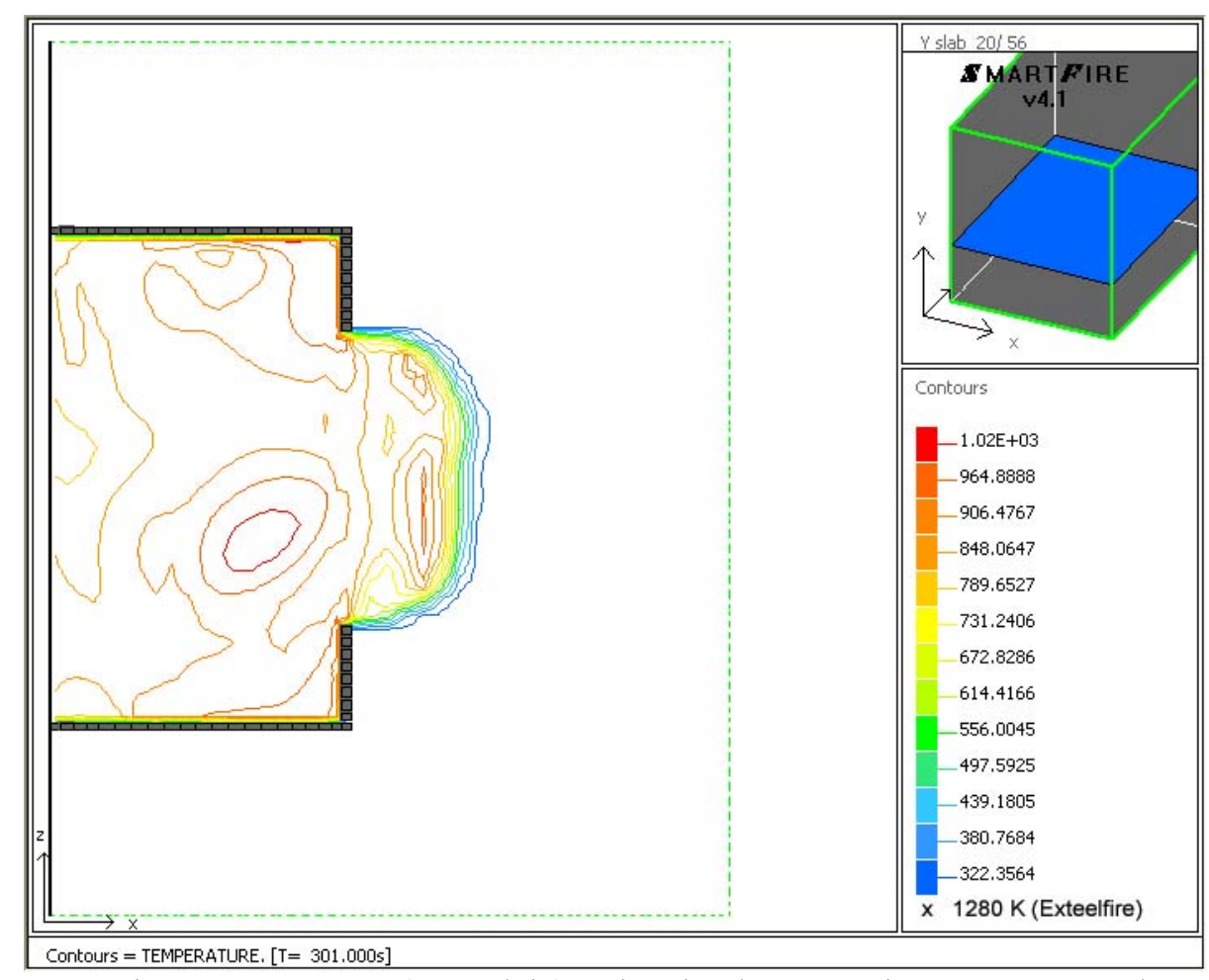

Figura 10.13 - Ensaio 3. Temperaturas (em Kelvin) no interior do compartimento. Corte na altura de 2,50 m do piso (plano xz). 
A partir das figuras 10.10 a 10.13 , verifica-se que nos dois cortes verticais a temperatura máxima calculada pelo ExteelFire, $1280 \mathrm{~K}\left(1007{ }^{\circ} \mathrm{C}\right)$, ocorre próxima à fonte de calor; no corte horizontal, a 1,40 m de altura, nota-se que há também regiões com essa temperatura, que não mais é atingida a $2,50 \mathrm{~m}$ de altura.

Nos ensaios de 1 a 3, onde o compartimento possui apenas uma janela, com fator de ventilação, $F$, próximo de $0,07 \mathrm{~m}^{1 / 2}$, verifica-se que as temperaturas dentro do compartimento estão abaixo da temperatura máxima dos gases calculada pelo ExteelFire. Salvo alguns pontos próximos à fonte de calor.

Nas figuras 10.14 a 10.17, são apresentadas as isotermas em diferentes planos, em Kelvin, e, a partir delas, é indicada a posição em que ocorre a temperatura máxima dos gases dentro do compartimento, calculada por meio do ExteelFire, para o ensaio 4.

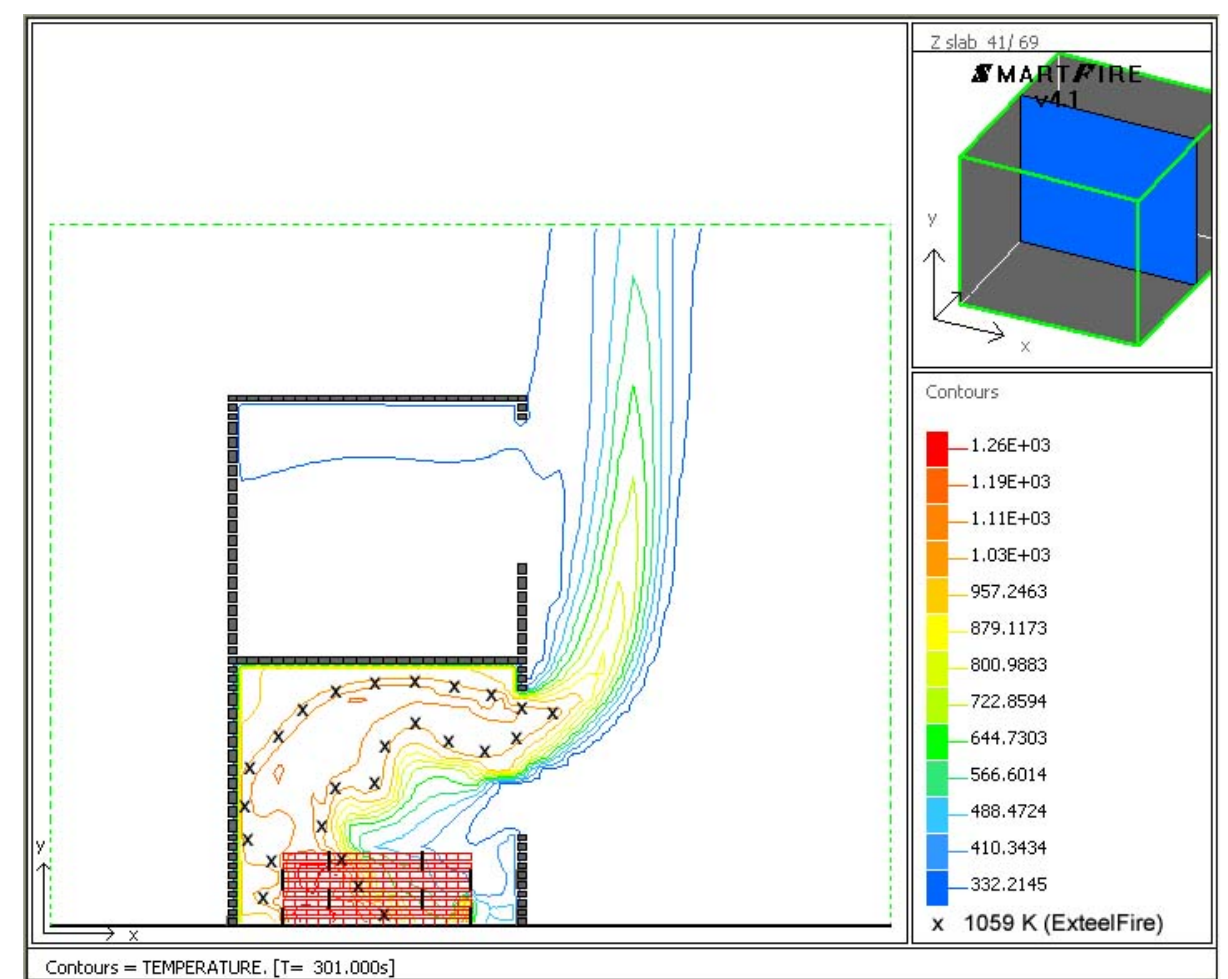

Figura 10.14 - Ensaio 4. Temperaturas (em Kelvin) no interior do compartimento. Corte no meio do vão (plano xy). 


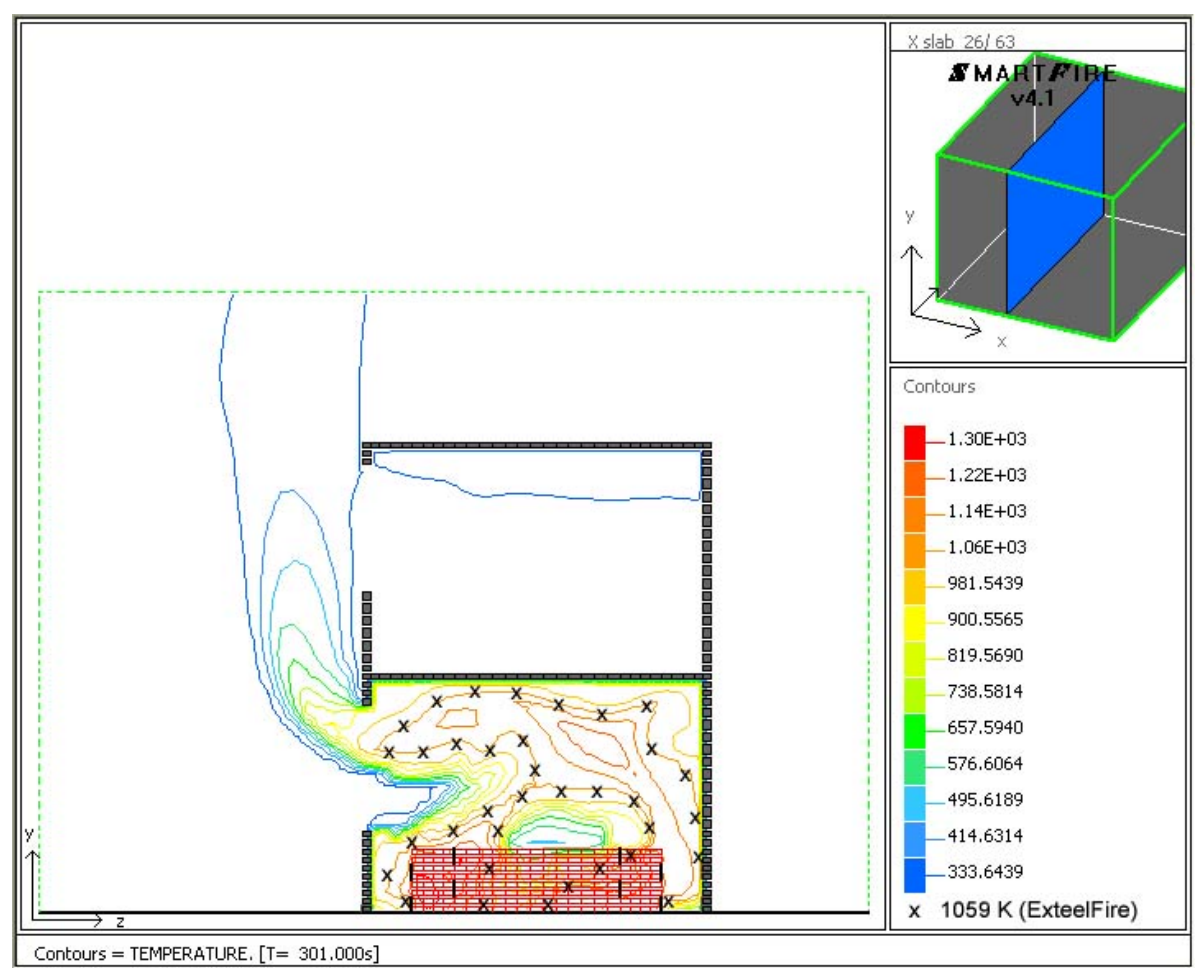

Figura 10.15 - Ensaio 4. Temperaturas (em Kelvin) no interior do compartimento. Corte no meio do vão (plano yz).

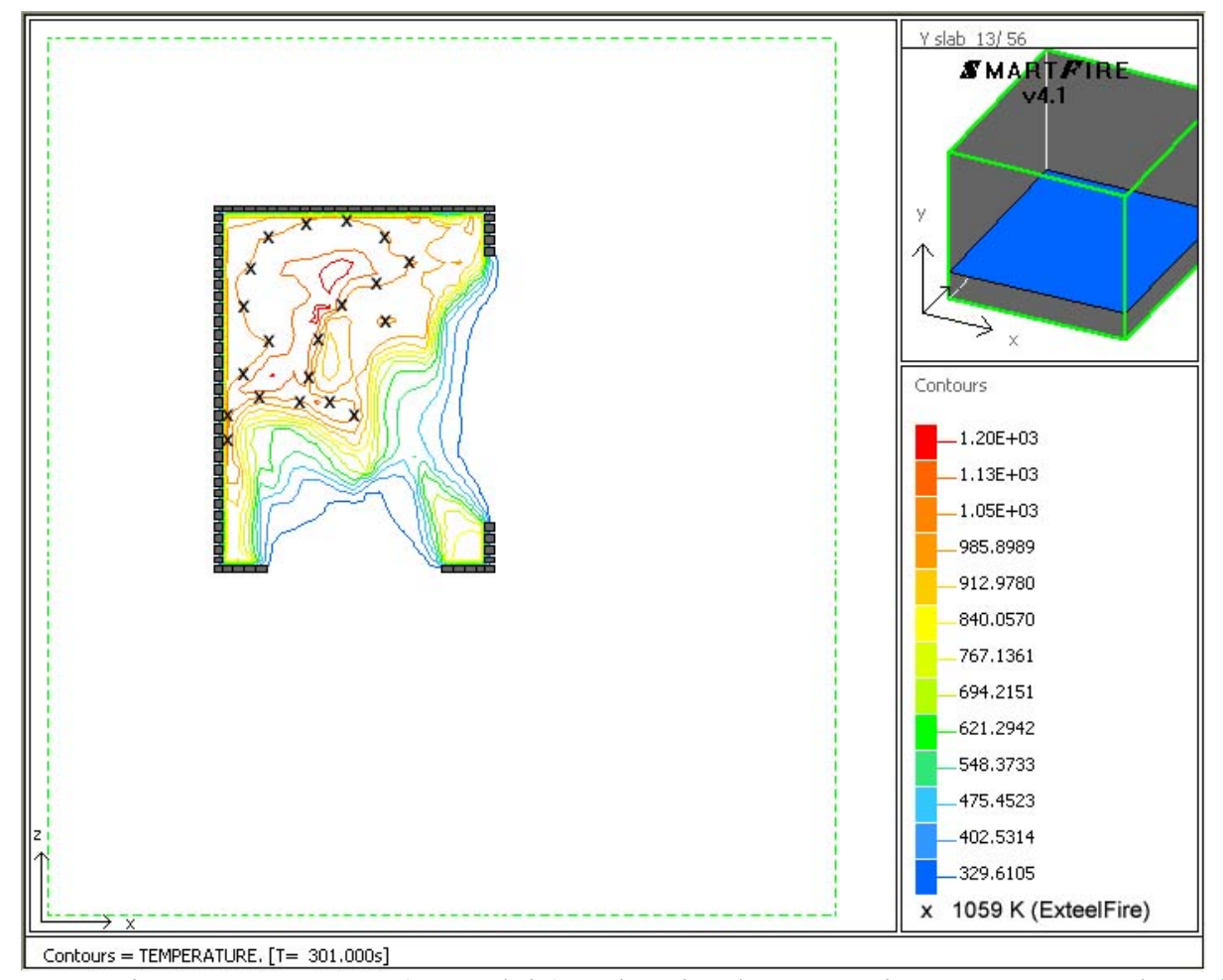

Figura 10.16 - Ensaio 4. Temperaturas (em Kelvin) no interior do compartimento. Corte na altura de 1,40 $\mathrm{m}$ do piso (plano Xz). 


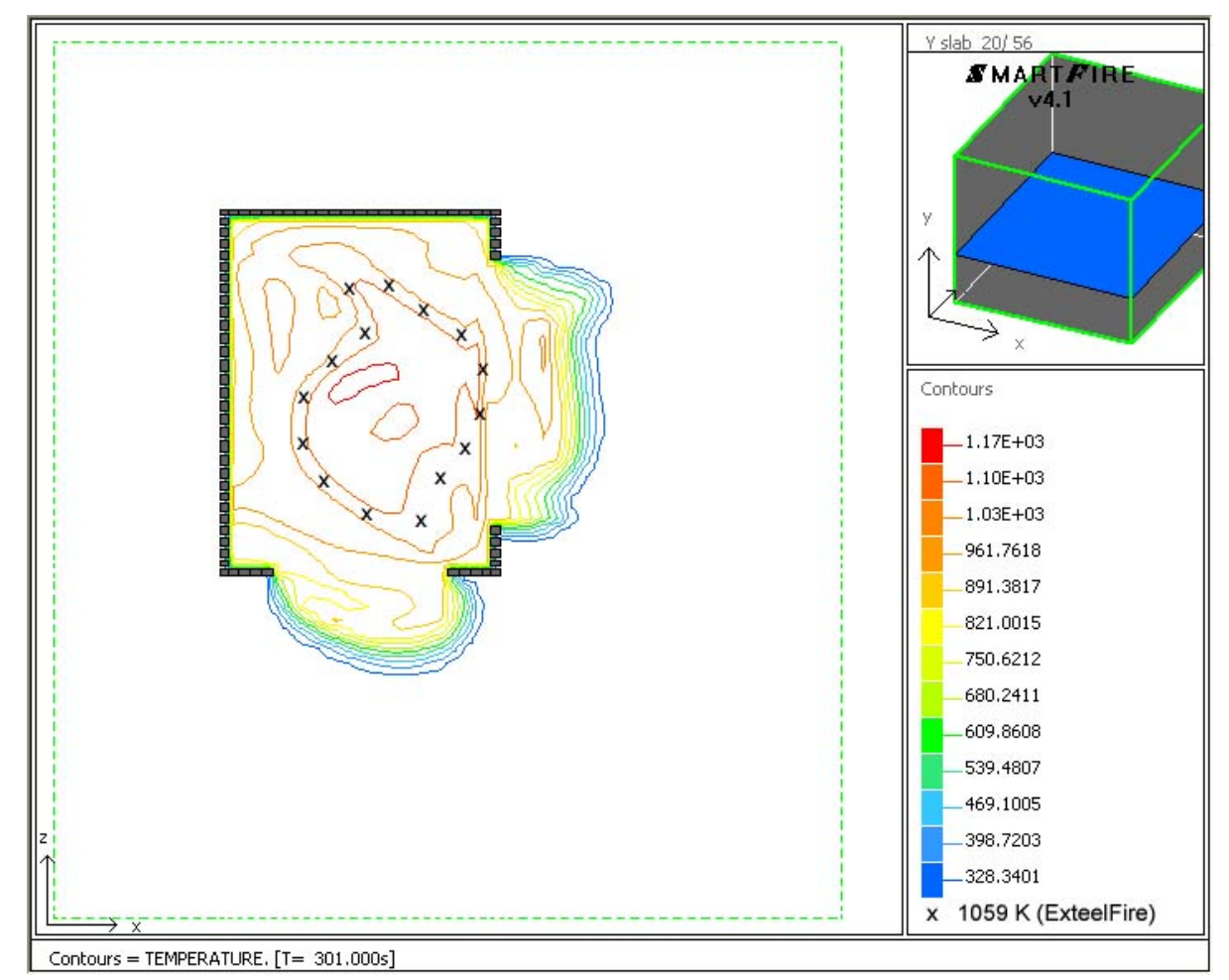

Figura 10.17 - Ensaio 4. Temperaturas (em Kelvin) no interior do compartimento. Corte na altura de 2,50 m do piso (plano xz).

Das figuras 10.14 a 10.17 , percebe-se que a temperatura máxima dos gases dentro do compartimento, calculada pelo ExteelFire, $1059 \mathrm{~K}\left(786{ }^{\circ} \mathrm{C}\right)$, distribui-se por todo o compartimento e é superada em algumas regiões de valores até $180^{\circ} \mathrm{C}$. Ressalta-se que essas regiões com valores inesperadamente altos são muito pequenas em relação ao volume do compartimento.

Nas figuras 10.18 a 10.21, são apresentadas as isotermas em diferentes planos, em Kelvin, e, a partir delas, indicada a posição em que ocorre a temperatura máxima dos gases dentro do compartimento, calculada por meio do ExteelFire, para o ensaio 5. 


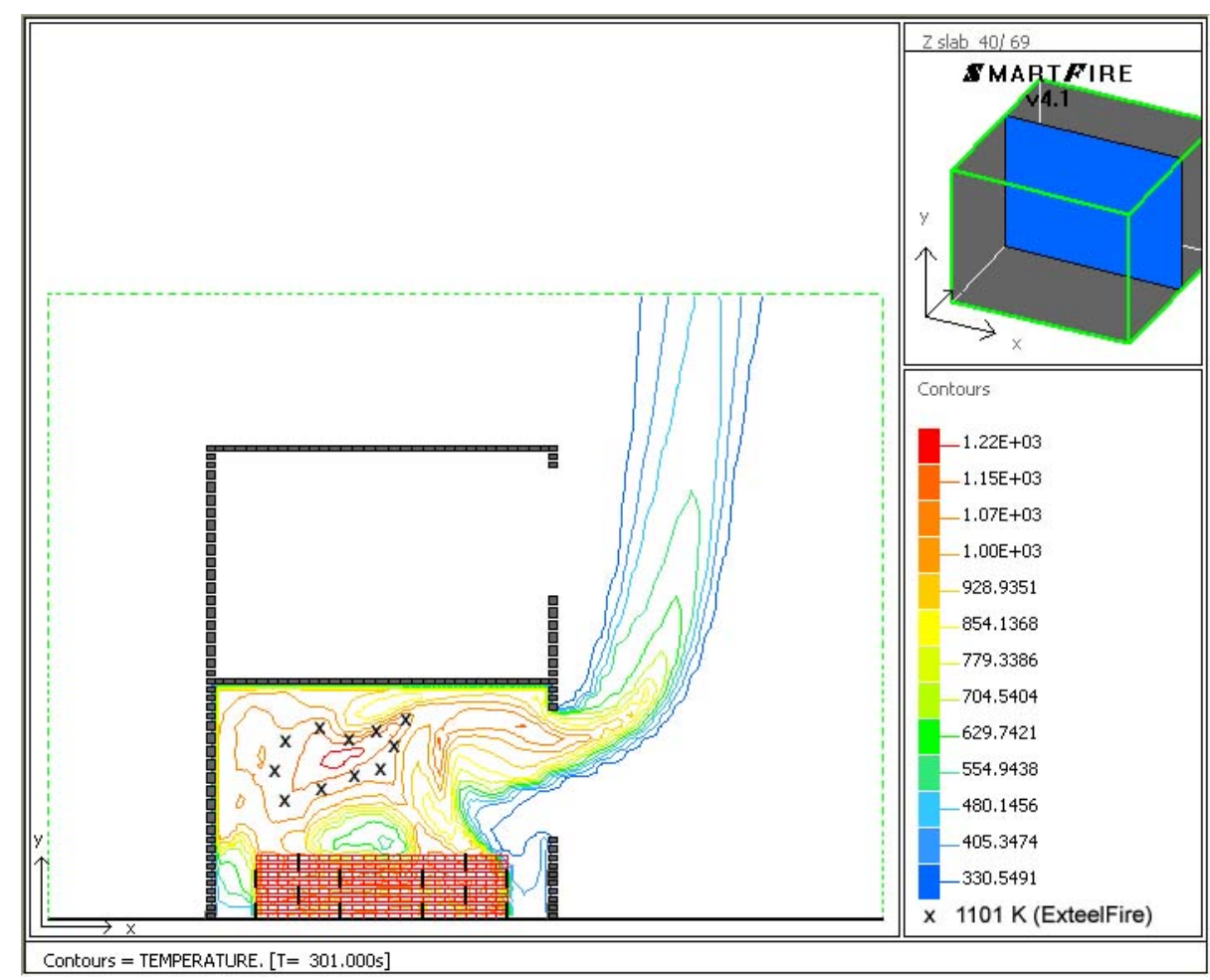

Figura 10.18 - Ensaio 5. Temperaturas (em Kelvin) no interior do compartimento. Corte no meio do vão (plano $\mathrm{xy})$.

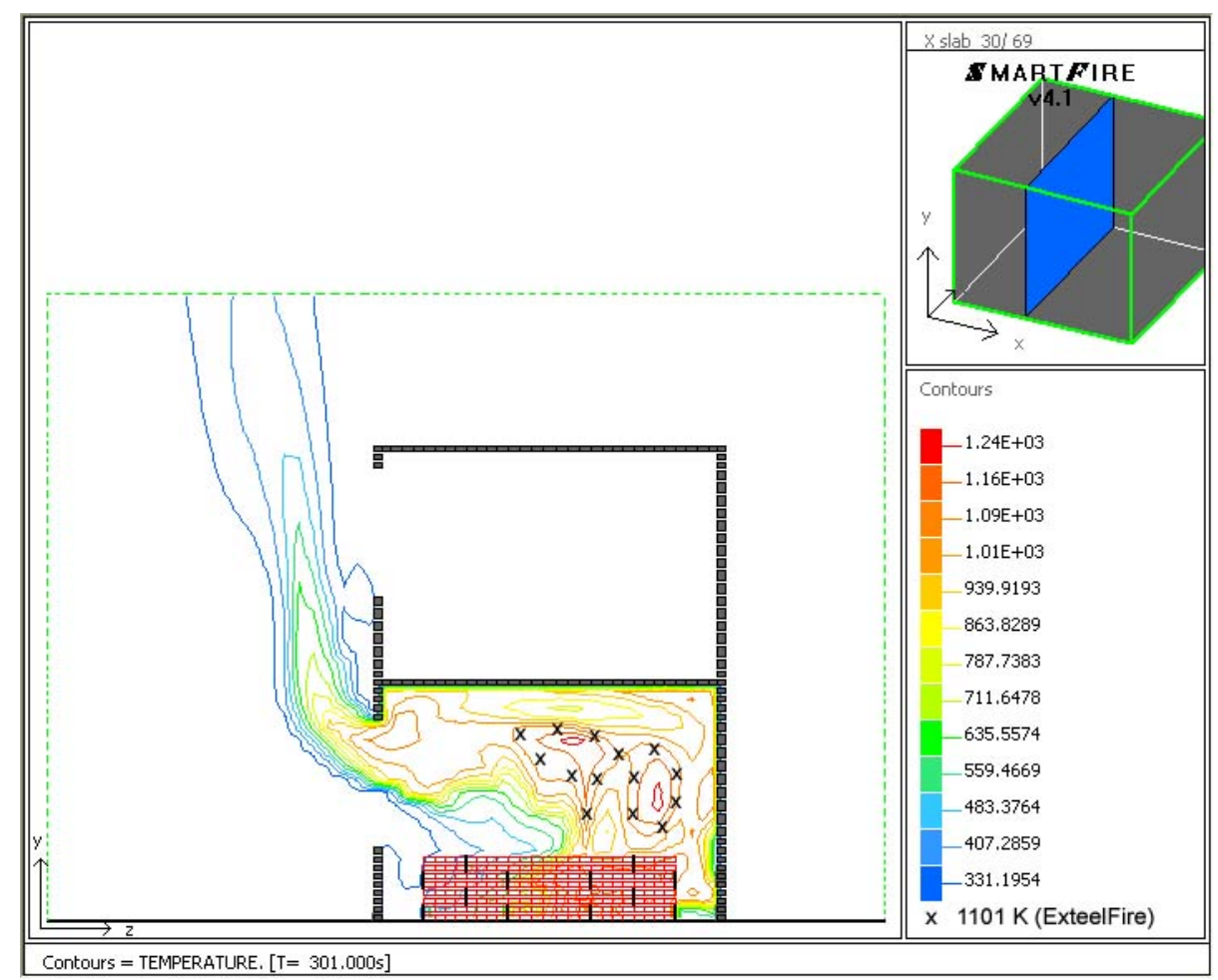

Figura 10.19 - Ensaio 5. Temperaturas (em Kelvin) no interior do compartimento. Corte no meio do vão (plano yz). 


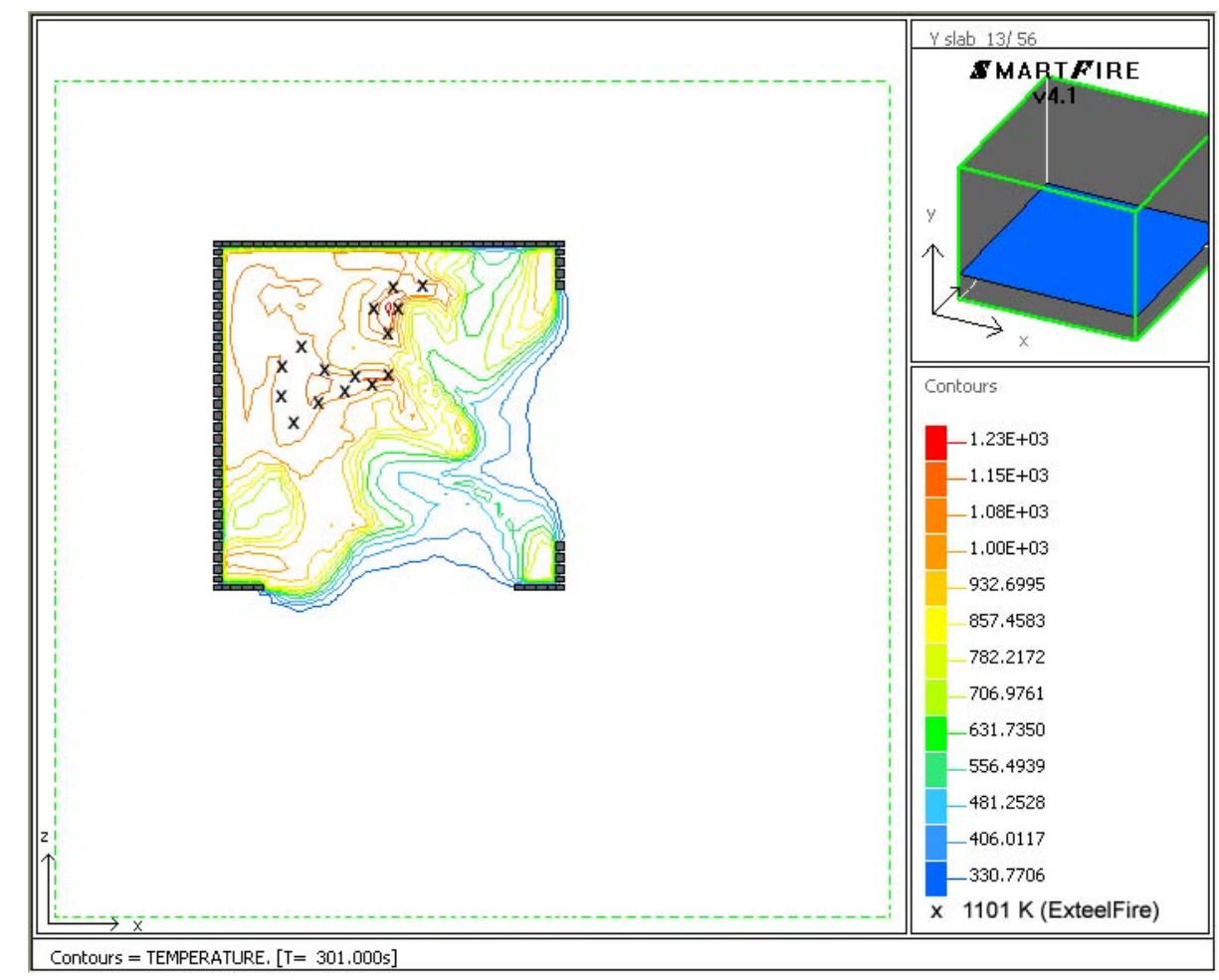

Figura 10.20 - Ensaio 5. Temperaturas (em Kelvin) no interior do compartimento. Corte na altura de 1,40 m do piso (plano xz).

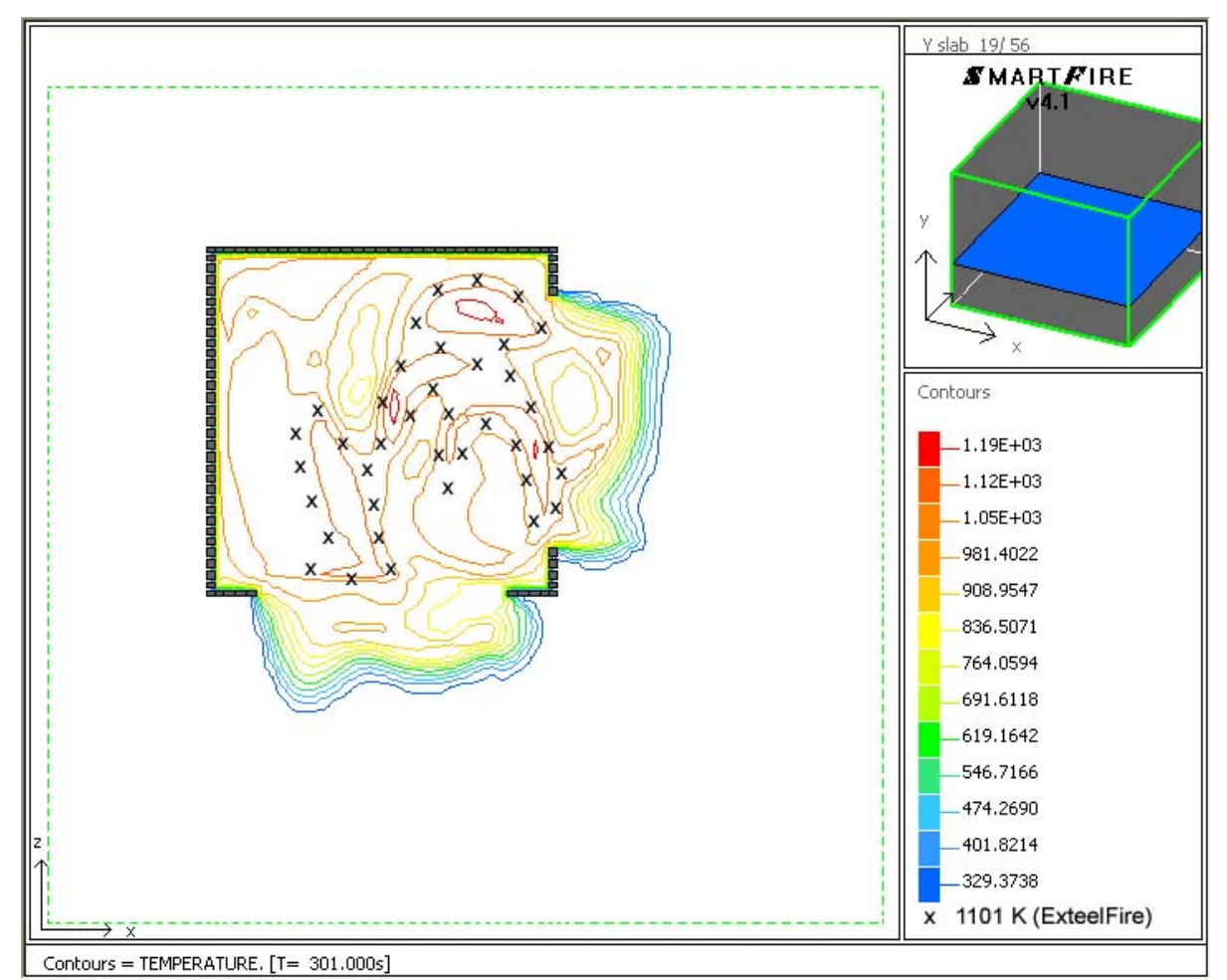

Figura 10.21 - Ensaio 5. Temperaturas (em Kelvin) no interior do compartimento. Corte na altura de 2,50 $\mathrm{m}$ do piso (plano $\mathrm{xz}$ ). 
Observando-se as figuras 10.18 a 10.21 , nota-se que a temperatura máxima dos gases dentro do compartimento, calculada pelo ExteelFire, $1101 \mathrm{~K}\left(828{ }^{\circ} \mathrm{C}\right)$, distribui-se por todo o compartimento e é superada em algumas pequenas regiões de valores até $140^{\circ} \mathrm{C}$.

Nas figuras 10.22 a 10.25, são apresentadas isotermas, em Kelvin, em diferentes planos, e, a partir delas, é indicada a posição em que ocorre a temperatura máxima dos gases dentro do compartimento calculada por meio do ExteelFire, para o ensaio 6.

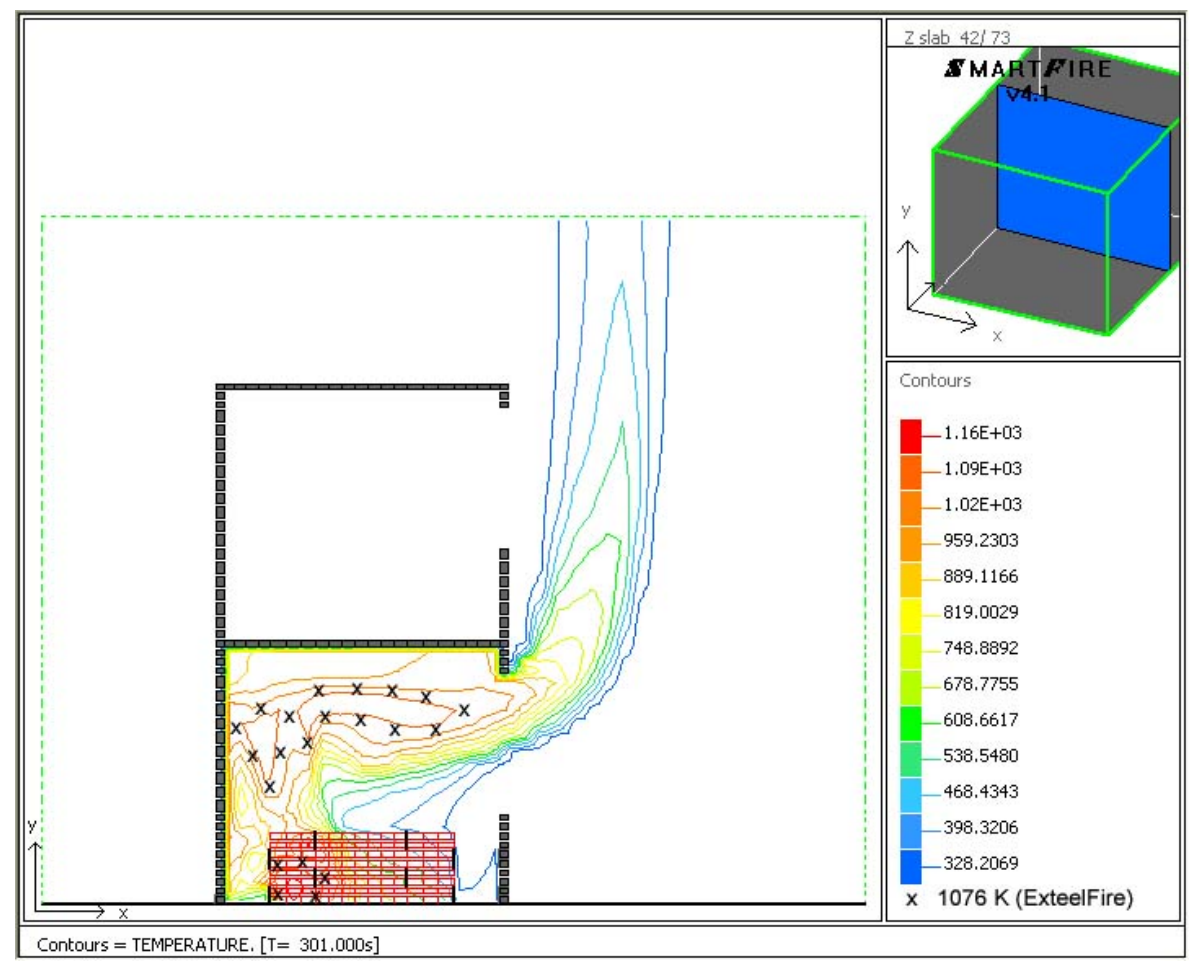

Figura 10.22 - Ensaio 6. Temperaturas (em Kelvin) no interior do compartimento. Corte no meio do vão (plano xy). 


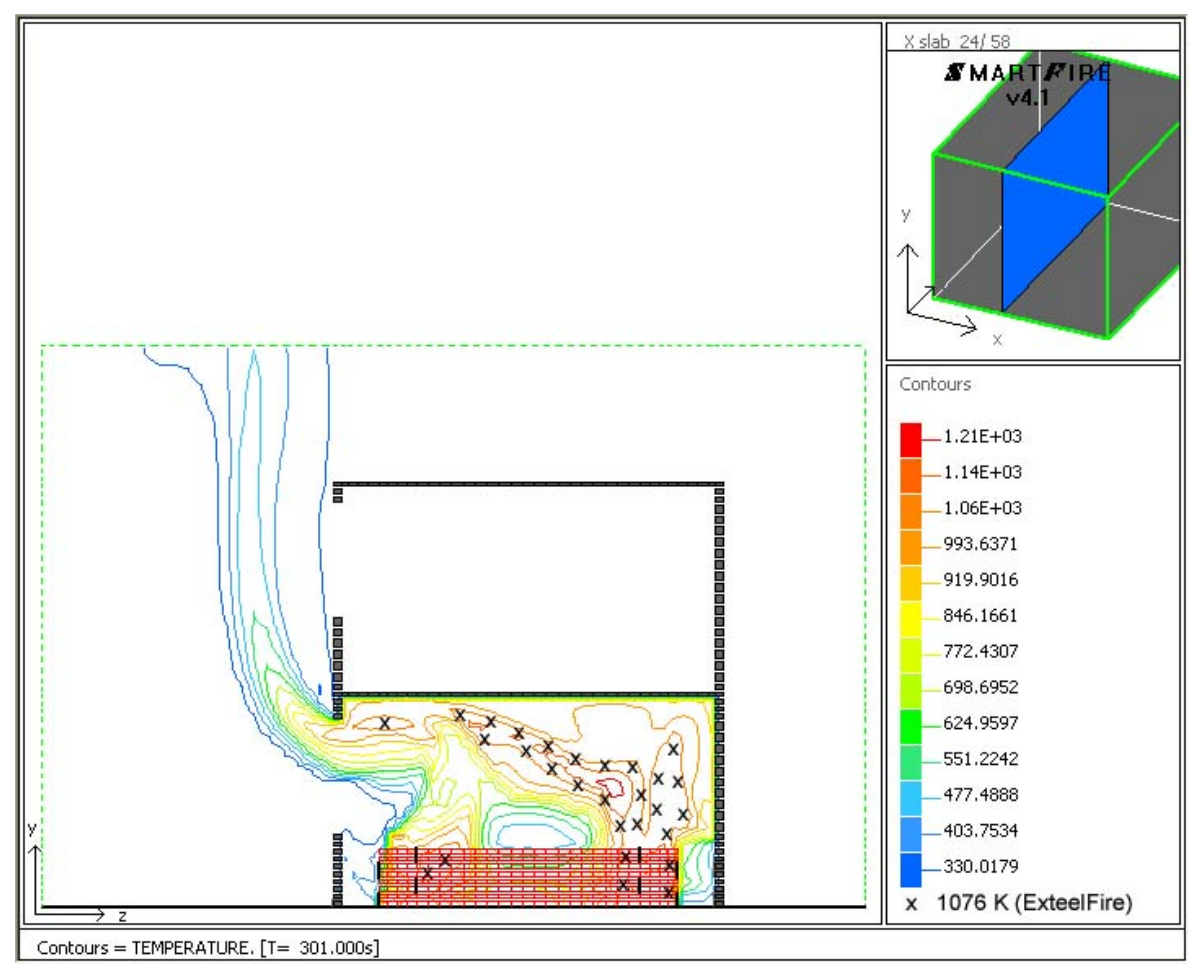

Figura 10.23 - Ensaio 6. Temperaturas (em Kelvin) no interior do compartimento. Corte no meio do vão (plano $y z)$.

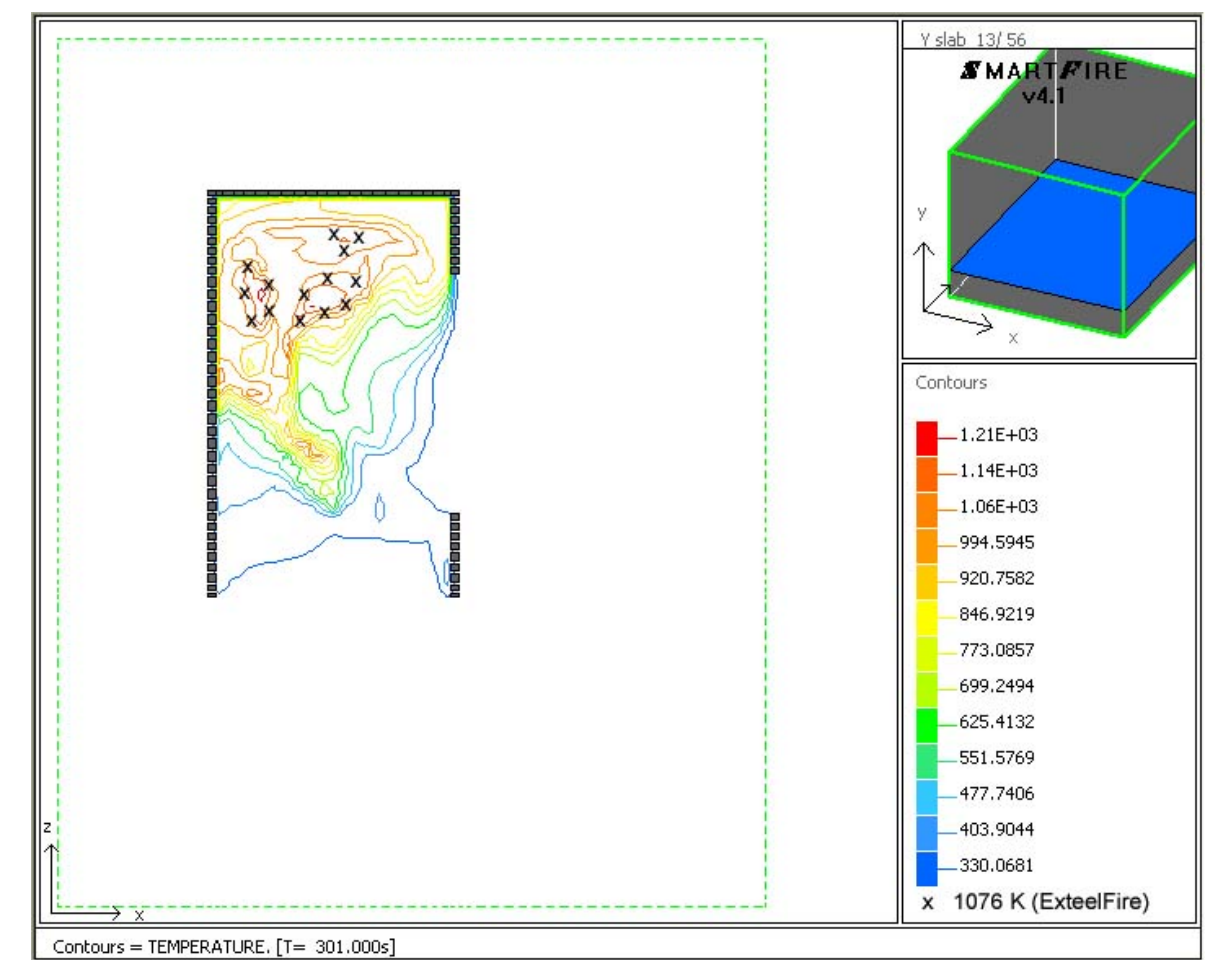

Figura 10.24 - Ensaio 6. Temperaturas (em Kelvin) no interior do compartimento. Corte na altura de 1,40 m do piso (plano xz). 


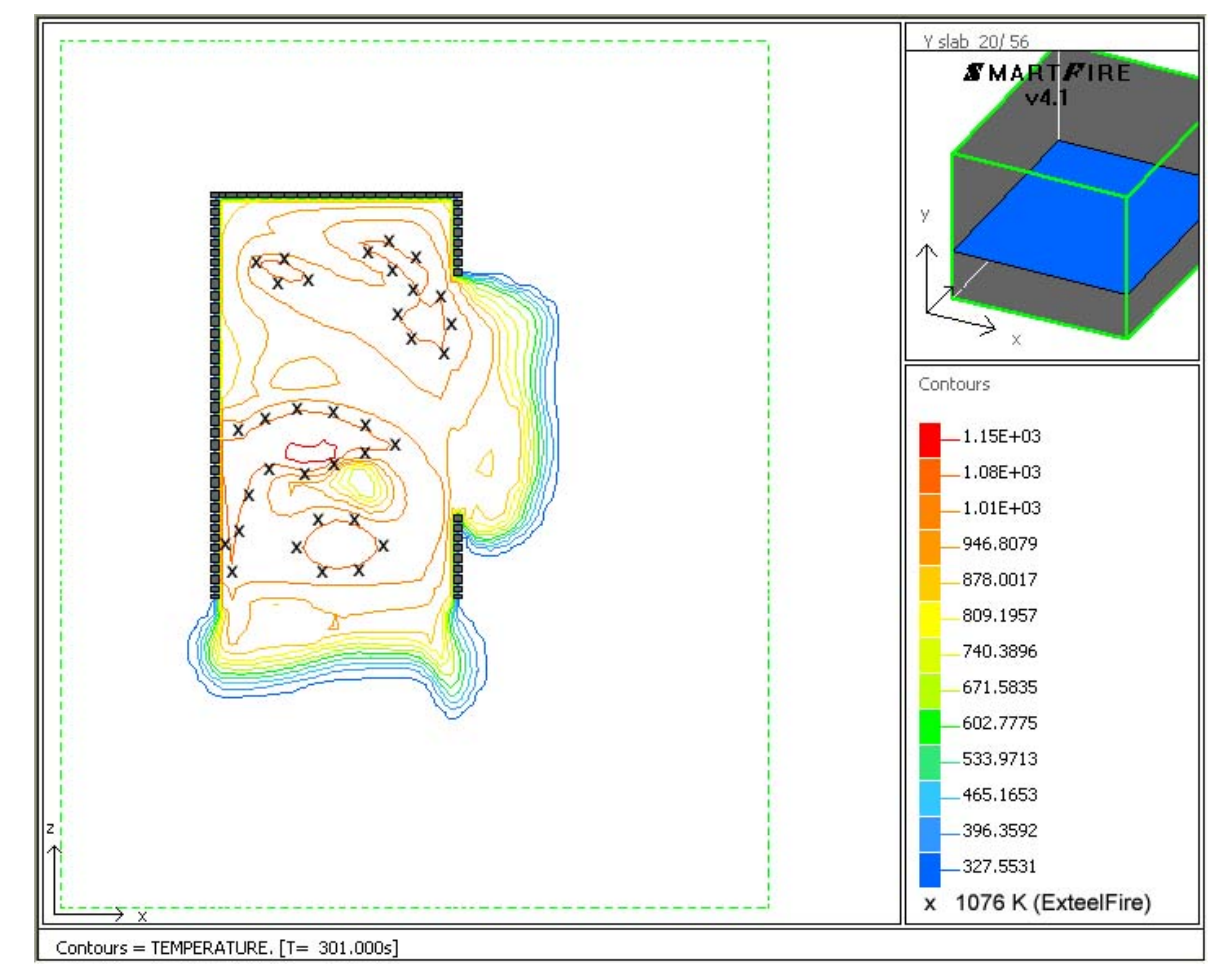

Figura 10.25 - Ensaio 6. Temperaturas (em Kelvin) no interior do compartimento. Corte na altura de 2,50 m do piso (plano Xz).

Nos ensaios 4 a 6 , onde o compartimento possui duas janelas, com fator de ventilação, $F$, próximo de $0,14 \mathrm{~m}^{1 / 2}$, o dobro dos ensaios 1 a 3 , verifica-se que a temperatura dos gases calculada pelo ExteelFire está distribuída pelo interior do compartimento.

Nota-se que os dados entre o ExteelFire e o Smartfire estão mais calibrados para compartimentos que possuem maior ventilação, em compartimento com pouca ventilação a tendência é que os resultados do ExteelFire sejam maiores.

A taxa de liberação de massa do combustível foi a mesma para os dois programas, sendo que pelo ExteelFire a limitação do incêndio para o compartimento com 1 janela foi pela ventilação, e, para os compartimento com 2 janelas pelo combustível, conforme a tabela 10.1. No Smartfire, utilizou-se uma limitação do oxigênio para sustentar a combustão dos gases. Os limites adotados foram: $23 \%$ para temperaturas abaixo de $400{ }^{\circ} \mathrm{C}, 14 \%$ para temperaturas acima de $600{ }^{\circ} \mathrm{C}$, conforme item 10.1.4 desta Tese.

\subsection{TEMPERATURA DA CHAMA NA JANELA}


Nas figuras 10.26 a 10.28, são apresentadas as isotermas, em Kelvin, em planos (xy) que passam pela janela do compartimento, para os ensaios 1,2 e 3 .

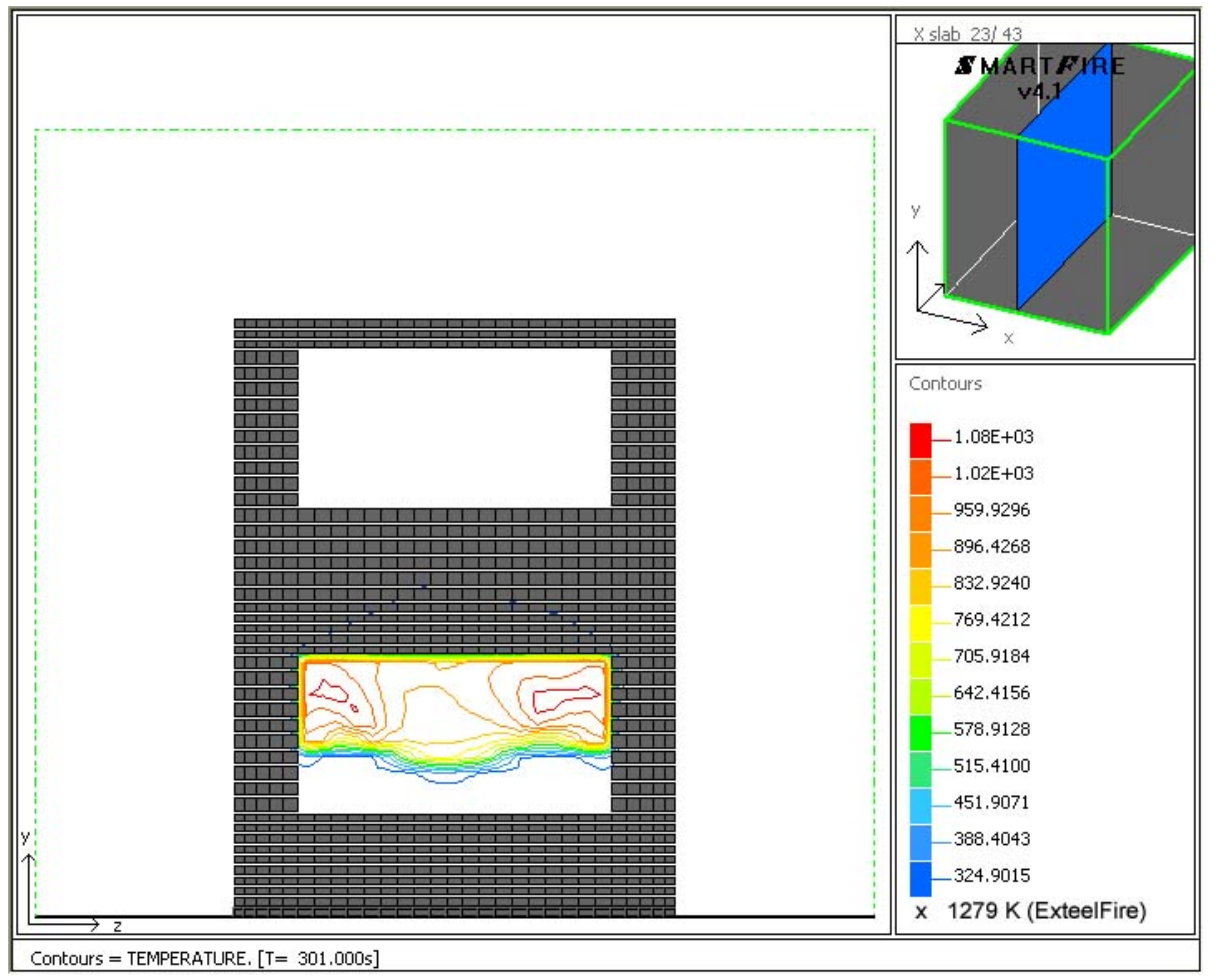

Figura 10.26 - Ensaio 1. Temperaturas (em Kelvin) no plano da janela. Corte no plano yz.

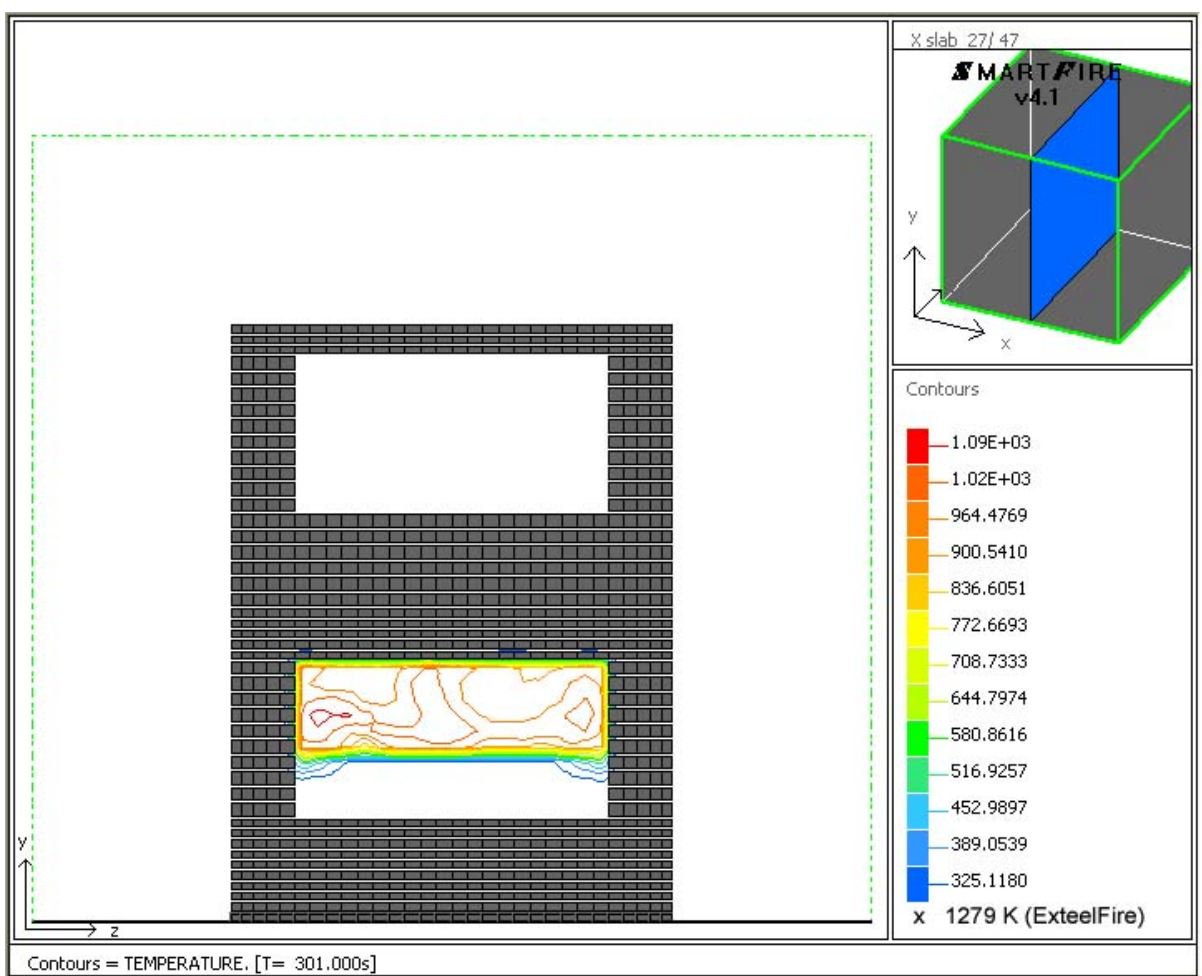

Figura 10.27 - Ensaio 2. Temperaturas (em Kelvin) no plano da janela. Corte no plano yz. 


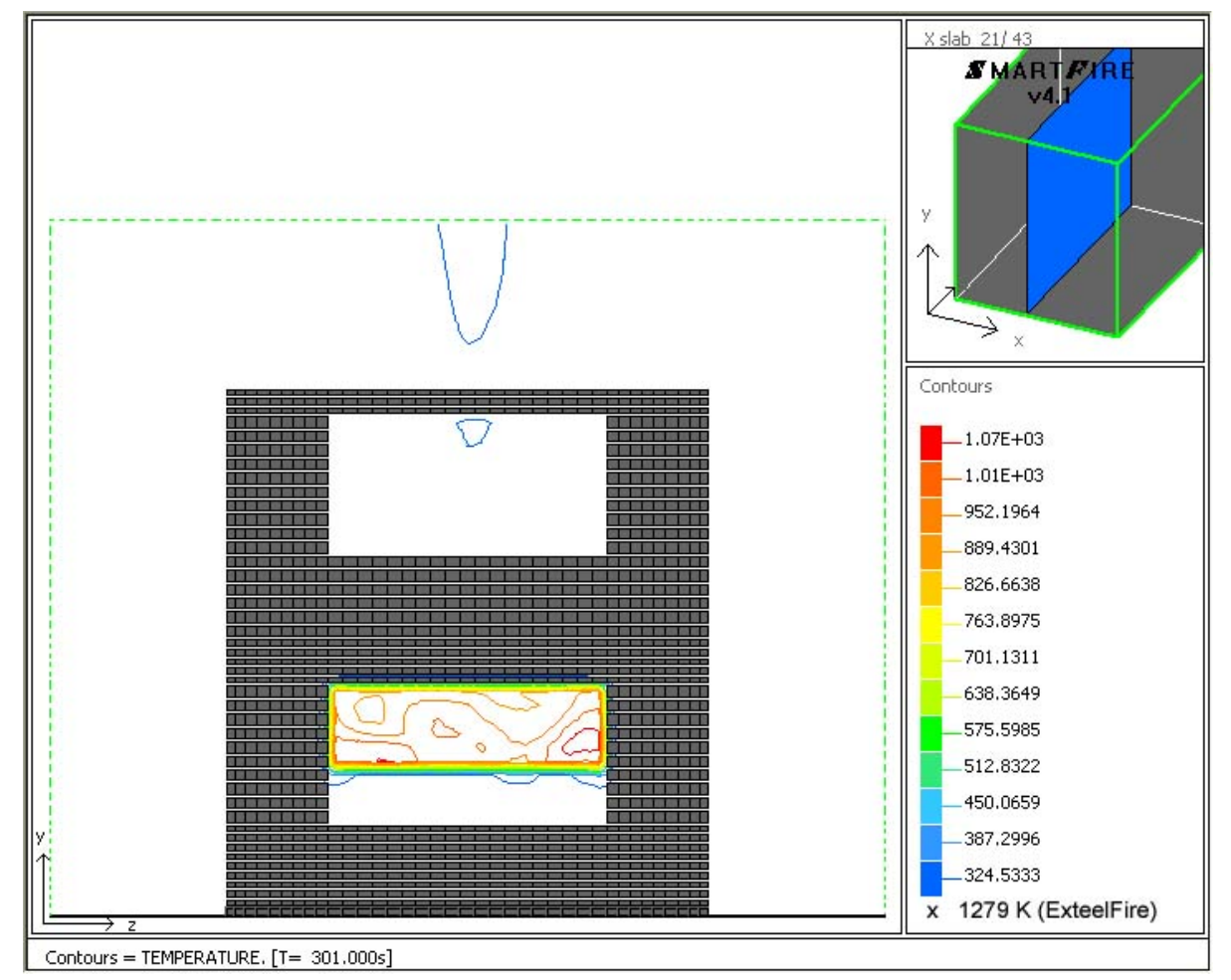

Figura 10.28 - Ensaio 3. Temperaturas (em Kelvin) no plano da janela. Corte no plano yz.

O Eurocode 1, Part 1-2 (2002) estabelece um limite superior para o valor da temperatura na janela, quando calculada por meio do método simplificado (ver Anexo A desta Tese). Por essa razão, para os três ensaios, a temperatura máxima na janela, determinada pelo ExteelFire, é coincidente e igual a $1279 \mathrm{~K}\left(1006{ }^{\circ} \mathrm{C}\right)$. Esse valor não é superado em nenhum caso, conforme as figuras 11.26 a 11.28 .

Nas figuras 10.29 a 10.31, são apresentadas as isotermas, em Kelvin, em planos (yz) que passam pela janela do compartimento, para os ensaios 4,5 e 6 . 


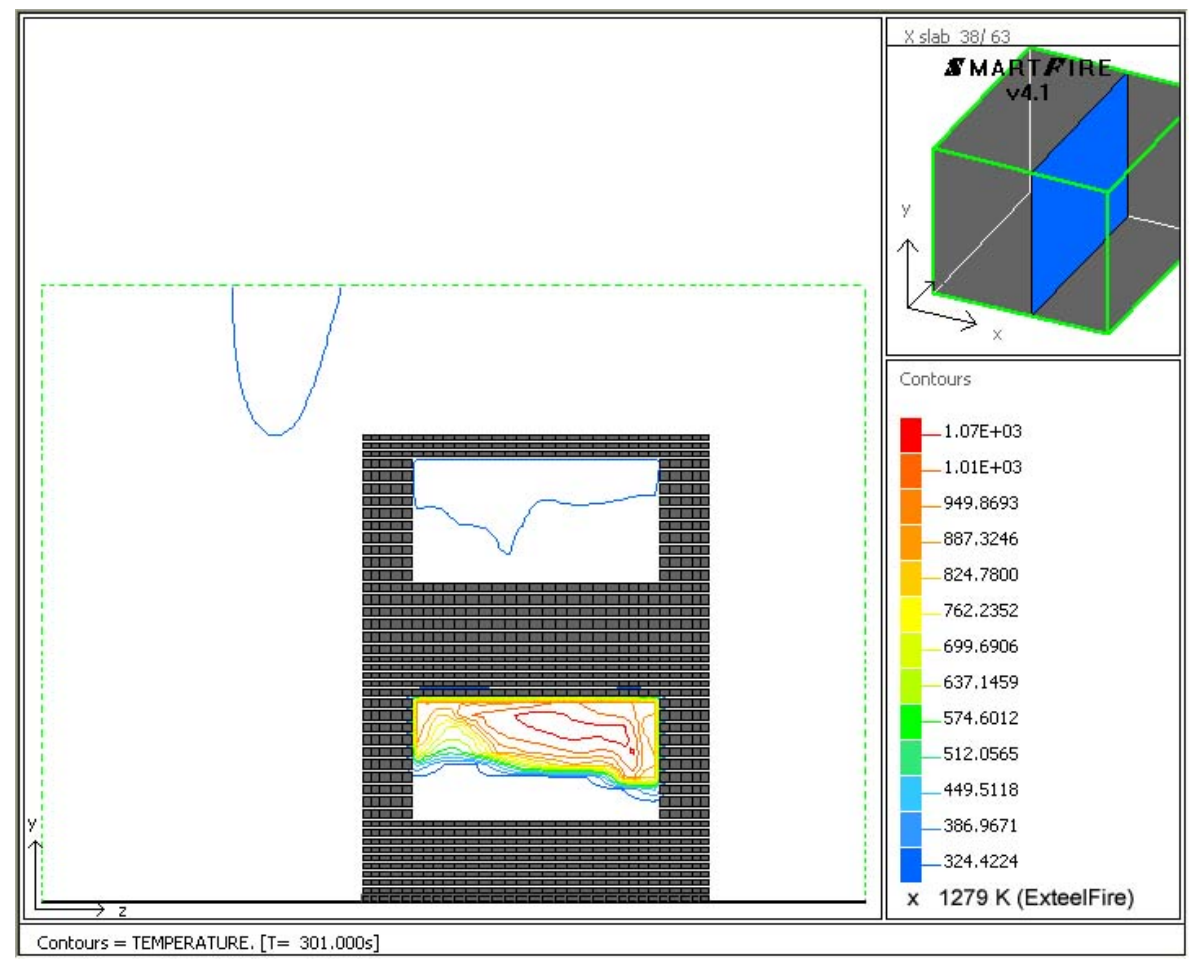

Figura 10.29 - Ensaio 4. Temperaturas (em Kelvin) no plano da janela. Corte no plano yz.

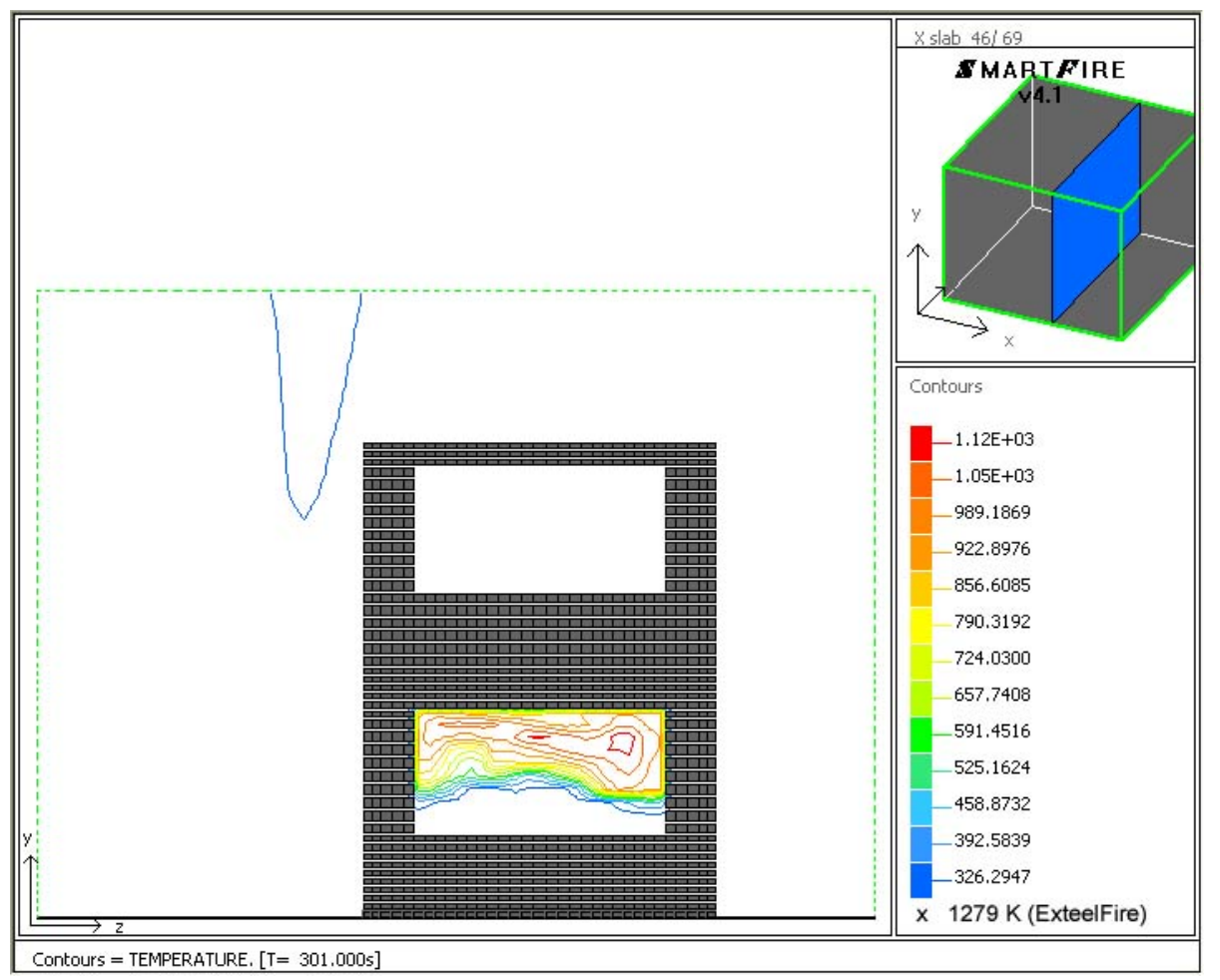

Figura 10.30 - Ensaio 5. Temperaturas (em Kelvin) no plano da janela. Corte no plano yz. 


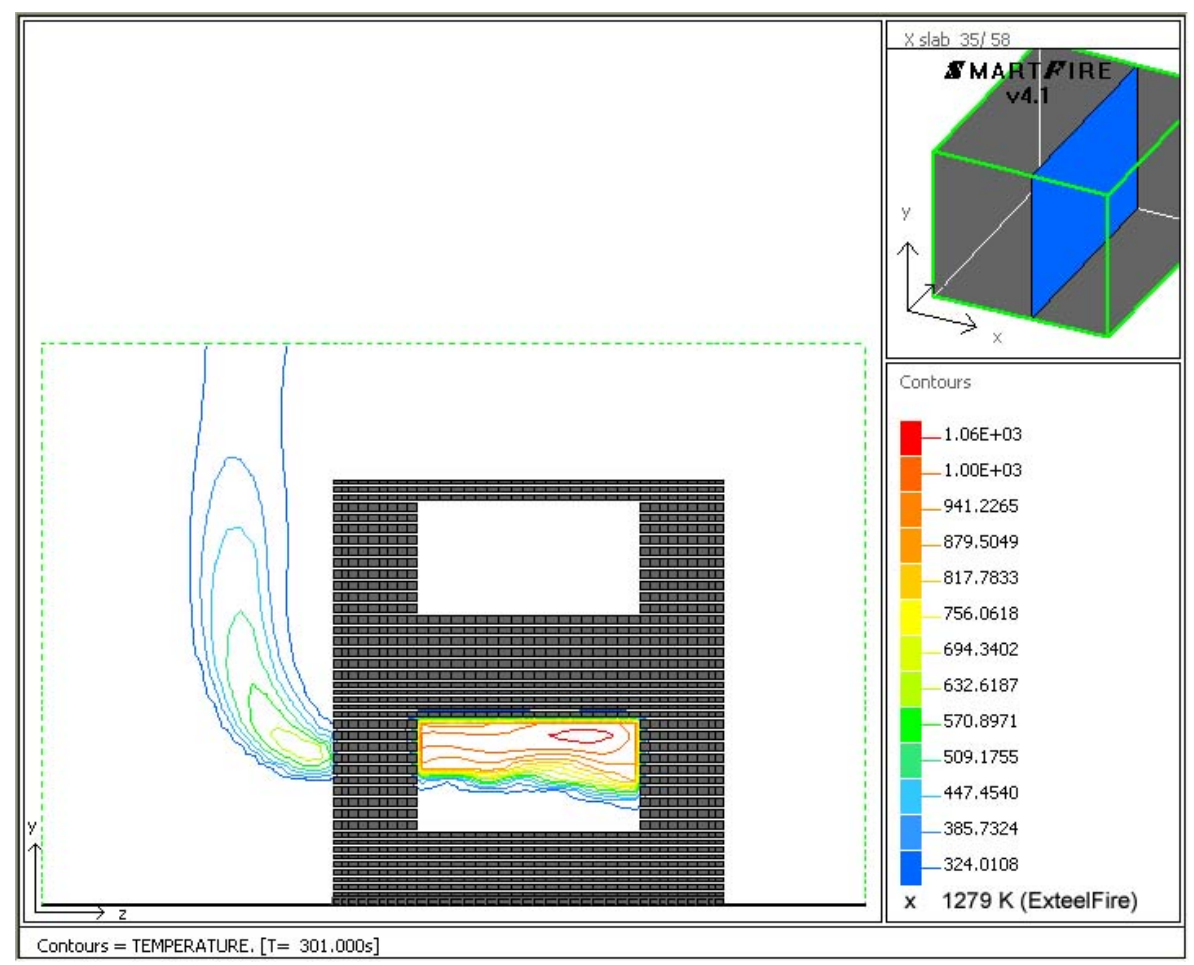

Figura 10.31 - Ensaio 6. Temperaturas (em Kelvin) no plano da janela. Corte no plano yz.

Conforme as figuras 10.29, 10.30 e 10.31, da mesma forma como os ensaios realizados em compartimentos com uma janela, os que possuem janelas em mais de uma parede também tiveram os valores de temperatura na janela menores do que a temperatura calculada pelo ExteelFire.

Law estabeleceu um valor de temperatura para o topo da chama como sendo $538^{\circ} \mathrm{C}$ e derivou uma equação até a temperatura na janela, conforme eq. 5.76.

A equação proposta por Law, em determinadas situações, resultava em valores muito altos em relação à temperatura dentro do compartimento, o Eurocode 1, Part 1-2 (2002), estabeleceu um limite superior para a temperatura da chama na janela (ver anexo A desta Tese), conforme a inequação 10.1 .

$$
X \frac{w_{t}}{\dot{m}}<1
$$

Onde:

$X \quad$ é o comprimento do eixo da chama (m);

$w_{t} \quad$ é a largura total das aberturas (m); 
$\dot{m} \quad$ é a taxa de liberação de massa do combustível $(\mathrm{kg} / \mathrm{s})$.

Nos ensaios de 1 a 6 , a eq. 10.1 deu valores superiores a 1 , então se adotou 1 e a temperatura da chama na janela obteve o mesmo valor nos 6 ensaios, $1279 \mathrm{~K}\left(1006^{\circ} \mathrm{C}\right)$. Se a limitação não tivesse sido considerada, o valor seria maior, aumentando ainda mais a diferença entre o valor da temperatura na janela e a temperatura no interior.

Conclui-se, então, que a temperatura calculada pelo ExteelFire superestima o valor da temperatura da chama na janela, se comparado aos resultados do Smartfire.

\subsection{ALTURA DA CHAMA EXTERNA}

No Smartfire, a taxa de liberação de massa do combustível, $\dot{m}$, foi determinada pela curva " $t$ ", conforme item 3.4 desta Tese. A taxa de liberação de massa atingiu o valor máximo em 100 s e, a partir daí, permaneceu constante até consumir o material combustível, conforme figura 10.32 .

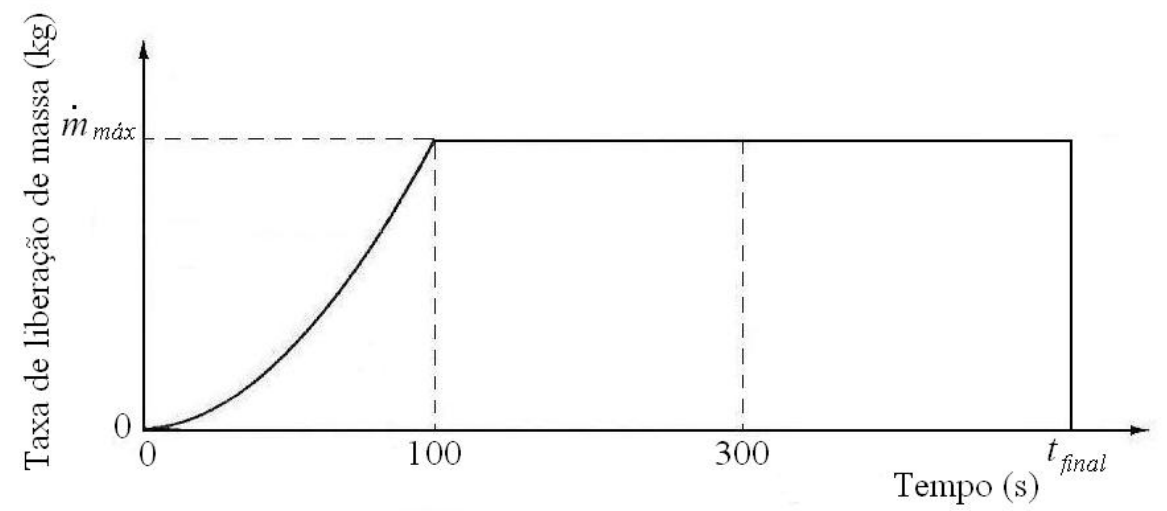

Figura 10.32 - Variação da taxa de liberação de massa do combustível com o tempo.

Nas figuras 10.33 a 10.38, mostra-se a variação da altura máxima da chama que emerge para fora do compartimento incendiado durante um período de simulação do SMARTFIRE e comparada à altura calculada pelo ExteelFire. Considerou-se como altura máxima da chama o 
maior valor alcançado, acima do topo da abertura, para a temperatura de $538{ }^{\circ} \mathrm{C}$, que é o valor adotado pelo método simplificado.

Nos ensaios realizados com o Smartfire, verificou-se que o perfil de temperaturas se estabilizava quando a taxa de liberação de massa permanecia em seu valor máximo e constante. Por esse motivo, foi utilizado apenas o trecho compreendido entre 100 e 300 s do ensaio, como representativo do ensaio.

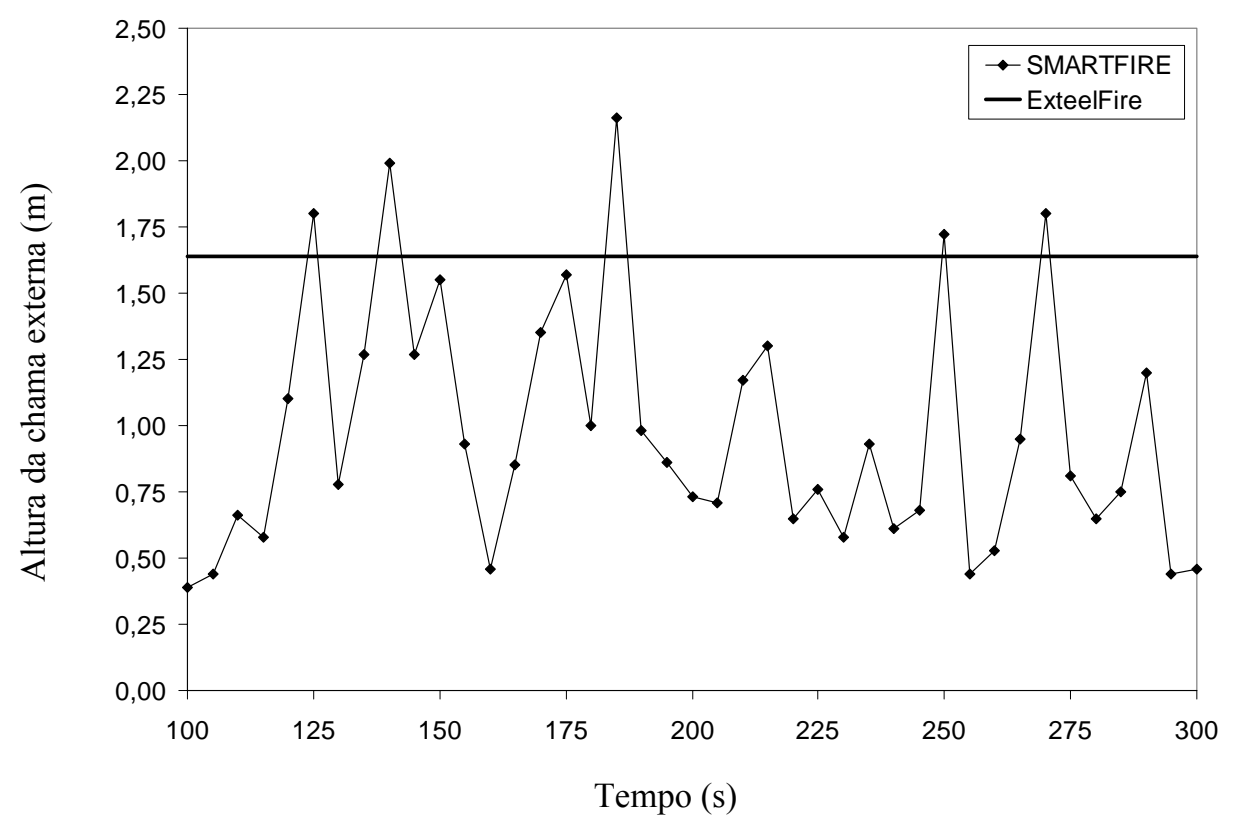

Figura 10.33 - Ensaio 1. Altura máxima da chama durante um intervalo de $200 \mathrm{~s}$ de simulação.

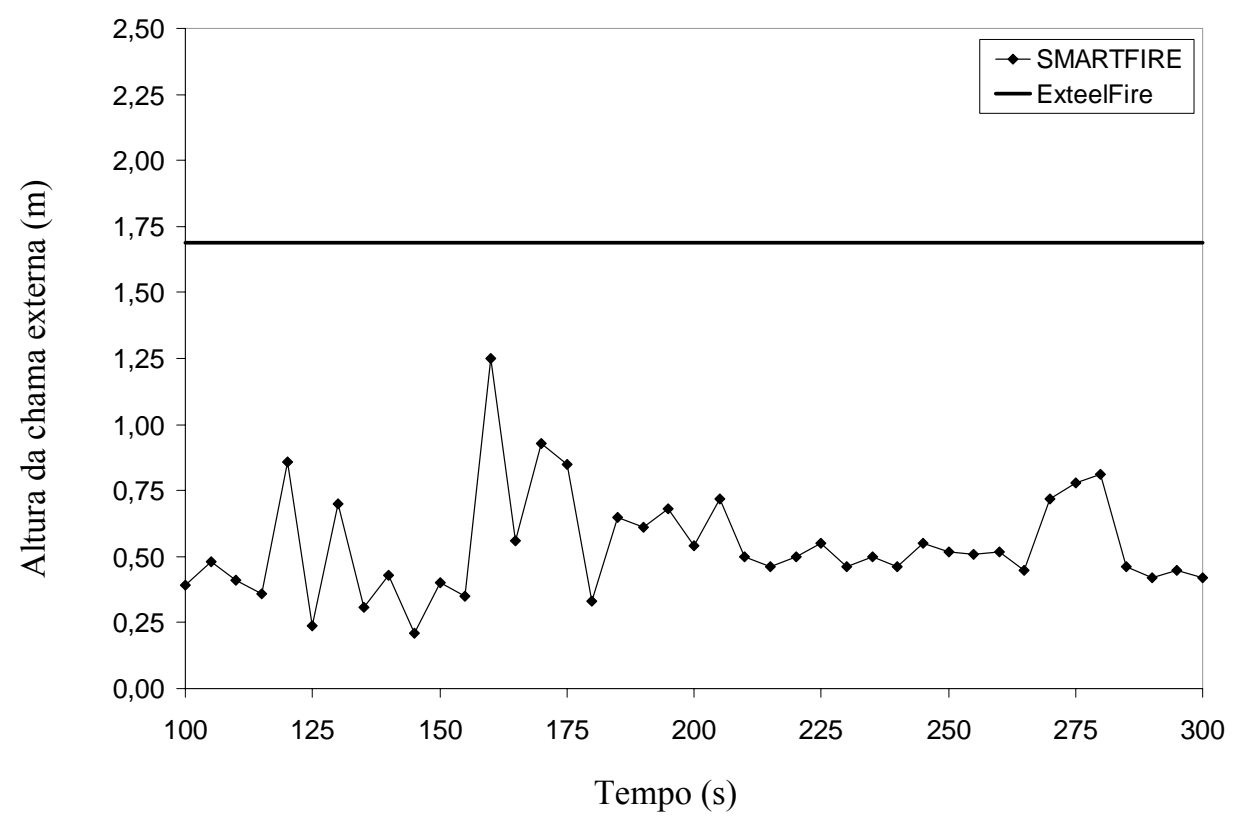

Figura 10.34 - Ensaio 2. Altura máxima da chama durante um intervalo de $200 \mathrm{~s}$ de simulação. 


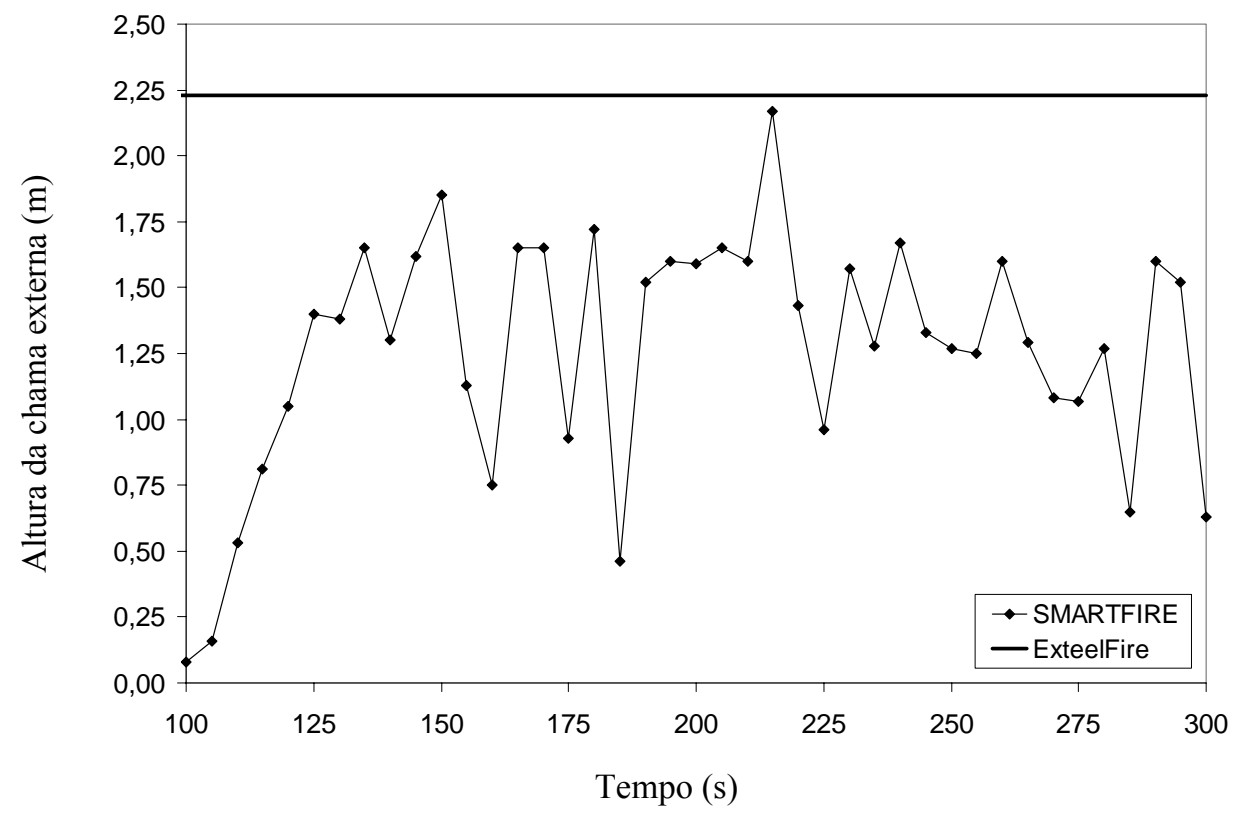

Figura 10.35 - Ensaio 3. Altura máxima da chama durante um intervalo de $200 \mathrm{~s}$ de simulação.

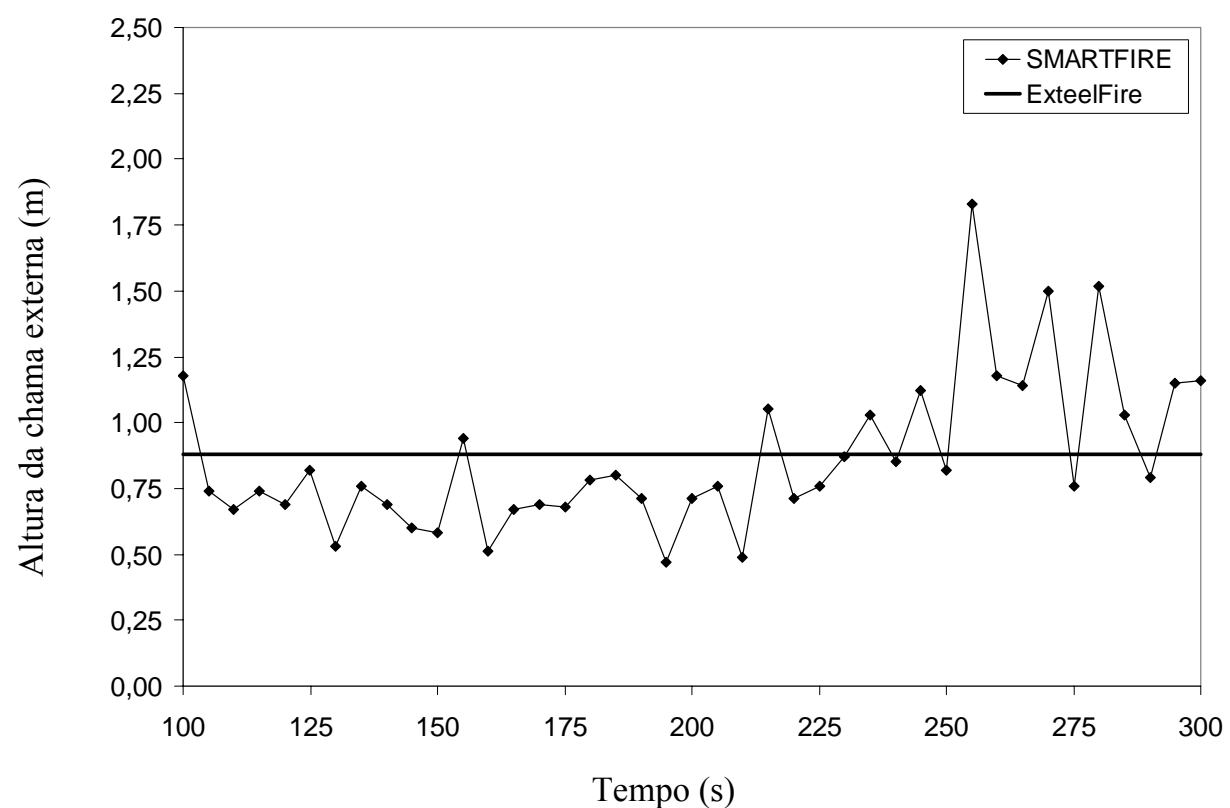

Figura 10.36 - Ensaio 4. Altura máxima da chama durante um intervalo de $200 \mathrm{~s}$ de simulação. 


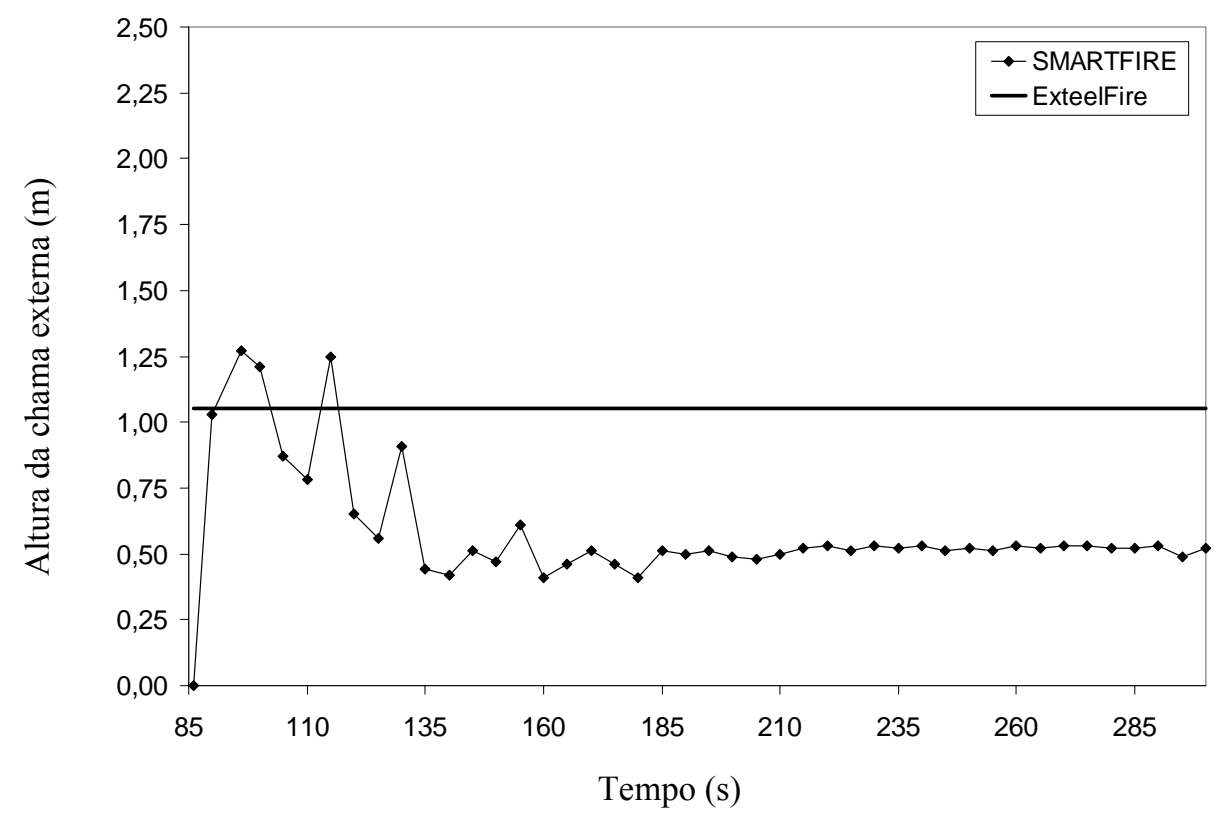

Figura 10.37 - Ensaio 5. Altura máxima da chama durante um intervalo de $200 \mathrm{~s}$ de simulação.

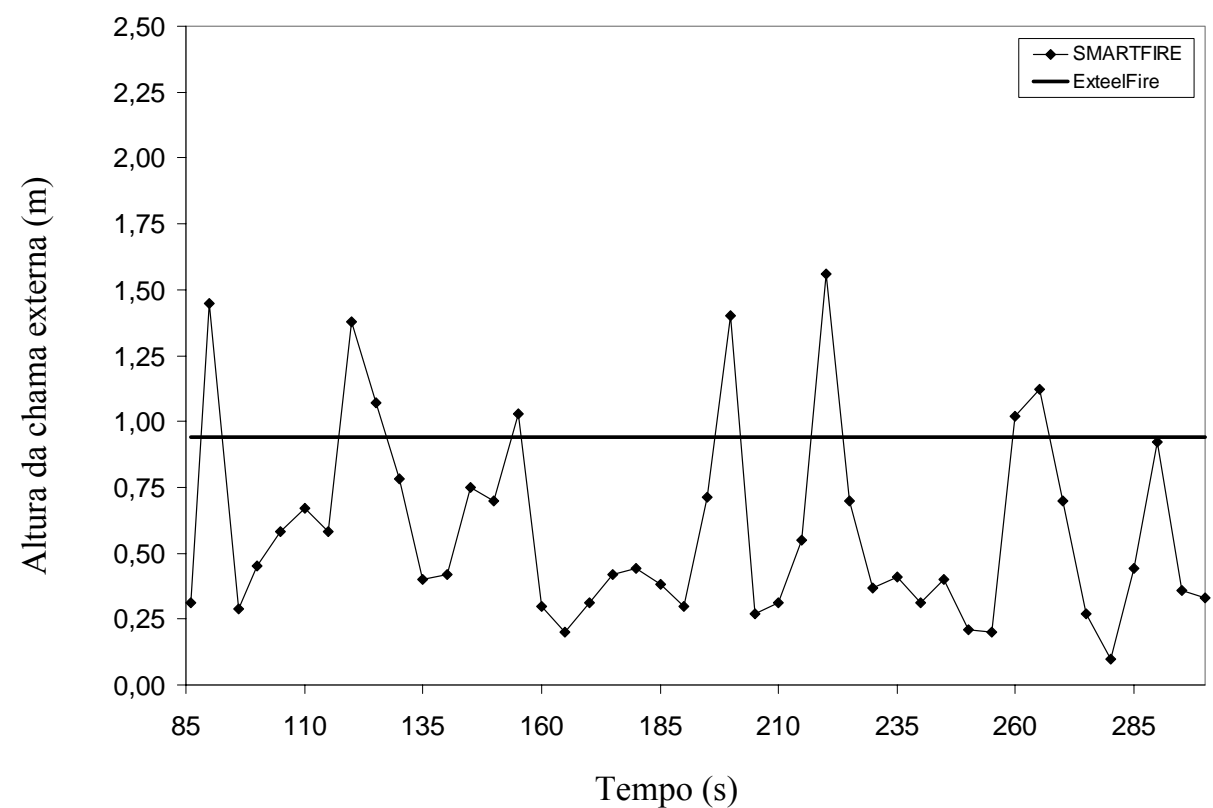

Figura 10.38 - Ensaio 6. Altura máxima da chama durante um intervalo de $200 \mathrm{~s}$ de simulação.

A tabela 10.2 mostra a altura da chama calculada pelo ExteelFire e a média das alturas da chama pelo Smartfire. Nessa tabela, nota-se que a altura da chama, conforme apresenta o ExteelFire, está sempre acima da média entre os valores encontrados pelo Smartfire. 
Tabela 10.2 - Altura da chama pelo ExteelFire e Smartfire

\begin{tabular}{c|c|c|c}
\hline Ensaio & $\begin{array}{c}\text { ExteelFire } \\
\text { Altura da chama } \\
(\mathbf{m})\end{array}$ & $\begin{array}{c}\text { Smartfire } \\
\text { Altura média da chama } \\
\mathbf{( m )}\end{array}$ & $\begin{array}{c}\text { Relação entre } \\
\text { Smartfire e ExteelFire } \\
(\mathbf{\%})\end{array}$ \\
\hline 1 & 1,64 & 0,97 & 59 \\
2 & 1,69 & 0,54 & 32 \\
3 & 2,23 & 1,26 & 57 \\
4 & 0,88 & 0,87 & 99 \\
5 & 1,05 & 0,57 & 54 \\
\hline 6 & 0,94 & 0,58 & 62 \\
\hline
\end{tabular}

Nos ensaios 1 e 3, a altura média da chama externa calculada pelo Smartfire em relação ao ExteelFire foi de $59 \%$ e $57 \%$, respectivamente. No ensaio 2, a profundidade do compartimento foi aumentada em $1 \mathrm{~m}$, e essa relação reduziu-se para $32 \%$. A altura da chama do ExteelFire depende da relação $\dot{m} / w_{t}$ conforme eq. 5.45; onde $\dot{m}$ é a taxa de liberação de massa $(\mathrm{kg} / \mathrm{s})$ e $w_{t}$ é a largura total das aberturas $(\mathrm{m})$. Como a largura das aberturas é a mesma nos três ensaios, a altura da chama vai depender de $\dot{m}$.

Para o ensaio 1: $\dot{m}=6,384 \mathrm{~kg} / \mathrm{s}$, resultando na altura da chama de 1,64 m.

Para o ensaio 2: $\dot{m}=6,535 \mathrm{~kg} / \mathrm{s}$, resultando na altura da chama de $1,69 \mathrm{~m}$.

Para o ensaio 3: $\dot{m}=8,253 \mathrm{~kg} / \mathrm{s}$, resultando na altura da chama de $2,23 \mathrm{~m}$.

Para o Smartfire a altura da chama dependerá, principalmente, do limite de oxigenação para sustentar a combustão da madeira, conforme item 9.4.4 desta Tese. Ao aumentar a profundidade do compartimento em $1 \mathrm{~m}$, houve o acréscimo do volume do compartimento para uma mesma abertura (área de ventilação). Sendo a quantidade de oxigênio a mesma e o volume a ser aquecido maior, o Smartfire conduziu a uma altura menor da chama externa. 
Para os ensaios 5 e 6, onde há duas aberturas idênticas e área de piso próximas, 16 e $15 \mathrm{~m}^{2}$ respectivamente, obteve-se a relação entre a altura média da chama, calculada pelo Smartfire, e a altura da chama calculada pelo ExteelFire, valores próximos, 57 e $58 \%$.

Para o ensaio 4, que também possui duas aberturas no compartimento, a relação entre a altura média da chama pelo Smartfire e a altura da chama pelo ExteelFire foi maior, 99\%. Isso ocorreu porque, para o ExteelFire, como já mencionado, a altura da chama é dependente da relação $\dot{m} / w_{t}$ (eq. 5.45), tornando a altura da chama menor, se comparada aos ensaios 5 e 6 .

Para o ensaio $4: \frac{\dot{m}}{w_{t}}=1,4$, consequentemente a altura da chama foi $0,88 \mathrm{~m}$.

Para o ensaio 6: $\frac{\dot{m}}{w_{t}}=1,5$, consequentemente a altura da chama foi $0,94 \mathrm{~m}$.

Para o ensaio 5: $\frac{\dot{m}}{w_{t}}=1,6$, consequentemente a altura da chama foi $1,05 \mathrm{~m}$.

A relação $\dot{m} / w_{t}$ estabelecida pelo método da Law e calculada pelo ExteelFire não se verificou nos resultados do Smartfire, obtendo-se um valor mais alto na razão entre a altura média da chama calculada pelo Smartfire e a altura da chama pelo ExteelFire.

O que se verificou pelo Smartfire foi que, no ensaio 4, o compartimento possui um volume de $33,6 \mathrm{~m}^{3}$ menor em relação ao ensaio 5 e 6 , que possuem $44,8 \mathrm{~m}^{3}$ e $42 \mathrm{~m}^{3}$, respectivamente. E a altura média da chama no ensaio 4 foi maior do que nos ensaios 5 e 6 .

\subsection{O SUPER TEMPCALC}

Para fins de comparação entre os resultados extraídos do ExteelFire e Smartfire, necessitou-se aplicar o campo de temperaturas obtido no Smartfire em elementos estruturais de aço e determinar a temperatura do aço. Para esse fim, foi utilizado o programa de computador Super Tempcalc.

A análise bidimensional dos elementos de aço foi executada com auxílio do Super Tempcalc - Temperature Calculation and Design v.5, desenvolvido pela FSD (Fire Safety Design - 
Suécia), para seções de elementos estruturais expostas ao calor, por meio do método dos elementos finitos (FSD, 2002). O Super Tempcalc ${ }^{\circledR}$ v.5 foi desenvolvido em ambiente Matlab, com geração automática de elementos finitos e interface gráfica compatível com a plataforma Windows. A confiabilidade do programa é internacionalmente reconhecida, sendo usado pelo CEB Task Group No. 4 na elaboração dos FIP-CEB Bulletins Nº 145 (FIP-CEB, 1982), No 174 (FIP-CEB, 1987) e No 208 (CEB-FIP, 1991), e na norma EN 1992-1-2:2004.

No Super Tempcalc, o fluxo de calor é bidimensional e é derivado da conservação de energia de um sistema. Isso significa que o fluxo de calor que entra no sistema é igual ao fluxo total de calor que sai. O domínio da seção dos perfis foi discretizada de forma retangular com 4 nós.

\subsection{CENÁRIO DO INCÊNDIO}

\subsubsection{O compartimento incendiado}

Para a determinação da temperatura do elemento de aço externo ao compartimento incendiado, foi utilizado o modelo de compartimento, conforme o item 9.4.3 desta Tese. A figura 10.39 mostra as dimensões do compartimento. 


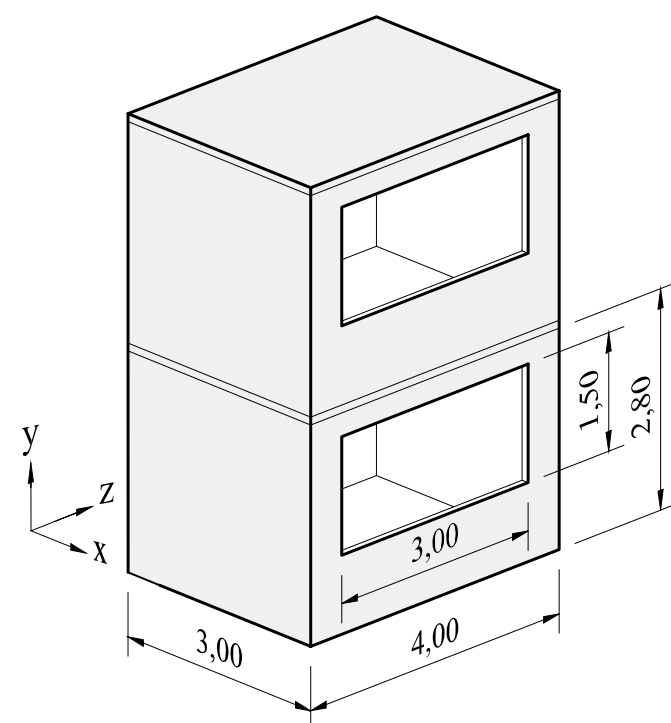

Figura 10.39 - Geometria do compartimento experimental.

\subsubsection{Os pilares de aço externos}

O posicionamento do pilar em relação à abertura é descrito na figura 10.40 . Na situação 1 , a distância do perfil à abertura é $0,50 \mathrm{~m}$ e na situação 2 a distância é $1,00 \mathrm{~m}$.

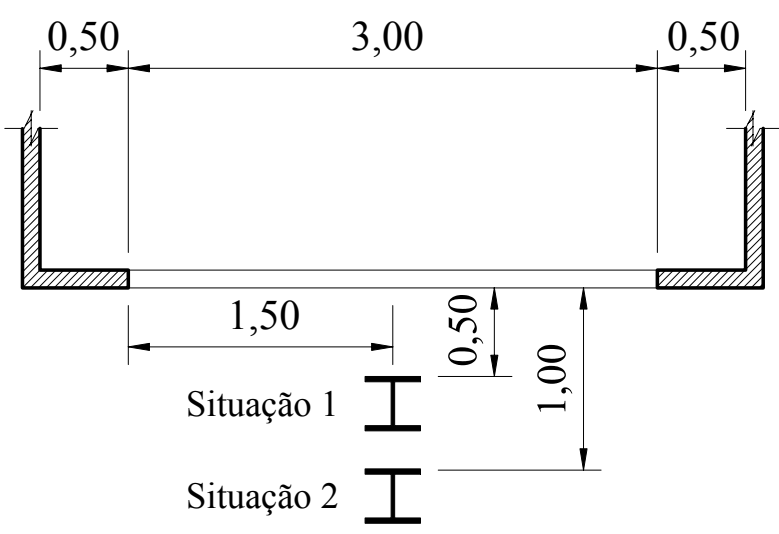

Figura 10.40 - Planta baixa das posições do elemento estrutural em relação à abertura.

A figura 10.41 mostra as dimensões e os respectivos fatores de massividade $(F)$ dos perfís de aço utilizados nos ensaios. 


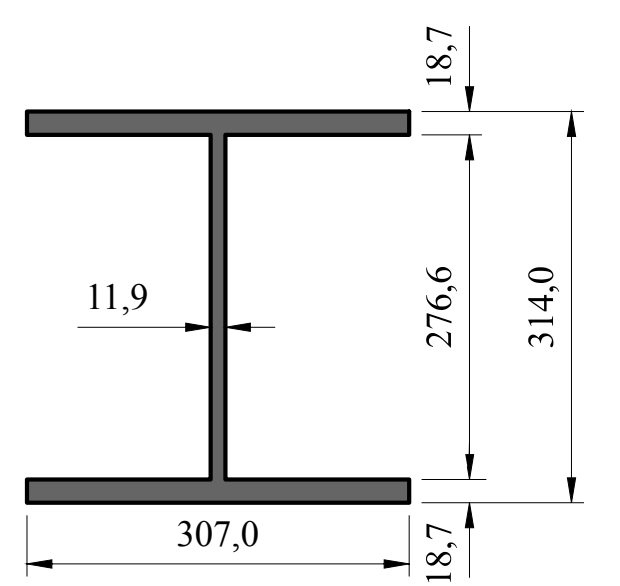

( a ) $\mathrm{F}=124 \mathrm{~m}^{-1}$

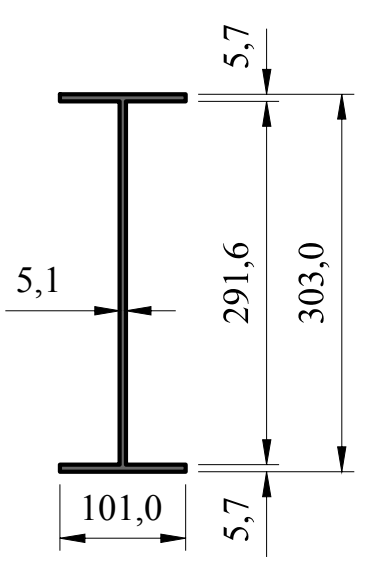

(c ) $\mathrm{F}=379 \mathrm{~m}^{-1}$

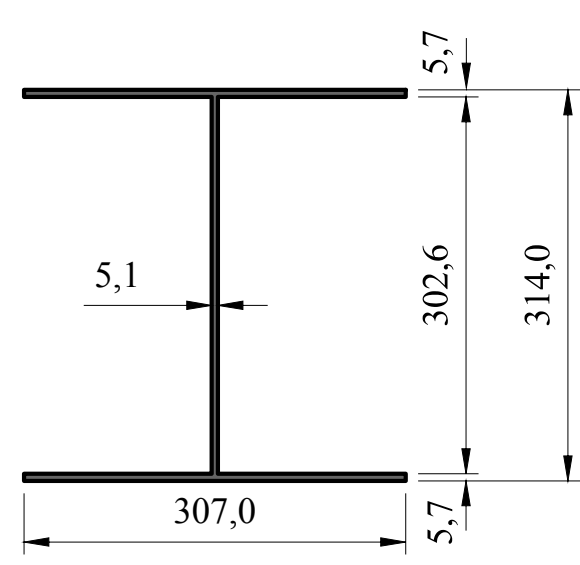

(b ) $\mathrm{F}=366 \mathrm{~m}^{-1}$

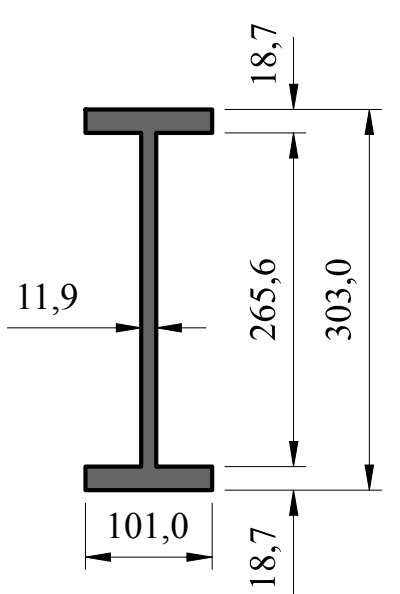

(d) $\quad F=142 \mathrm{~m}^{-1}$

Figura 10.41 - Dimensões e fatores de massividade dos perfis de aço.

Para o uso do Super Tempcalc, foram utilizadas, na discretização da seção transversal dos pilares, malhas compostas por elementos retangulares de 4 nós com dimensões máximas de 5 $\mathrm{mm}$, conforme figura 10.42. A discretização adotada teve por base a experiência do grupo de pesquisa da EPUSP (Escola Politécnica da Universidade de São Paulo). 


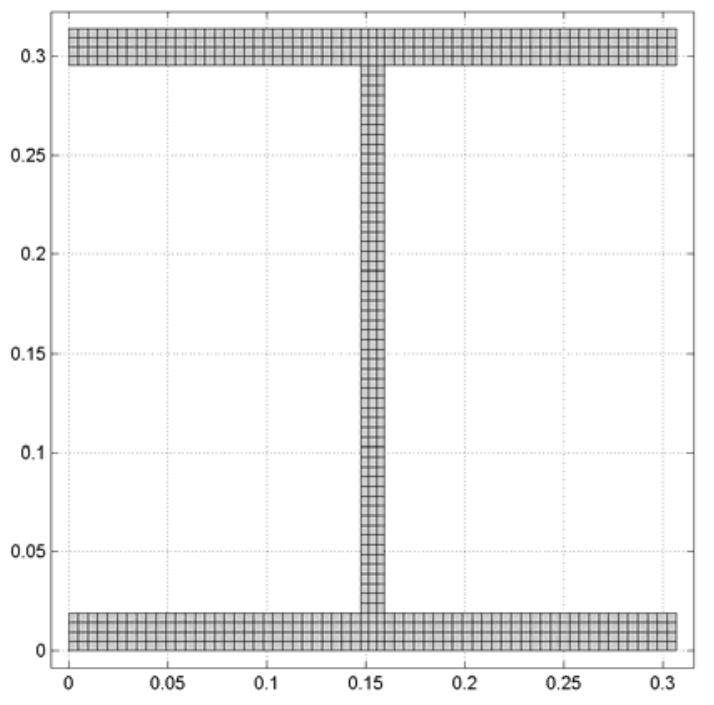

(a) Perfil (a)

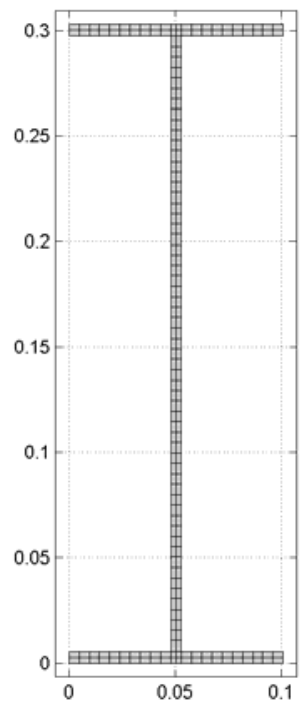

(c) Perfil (c)

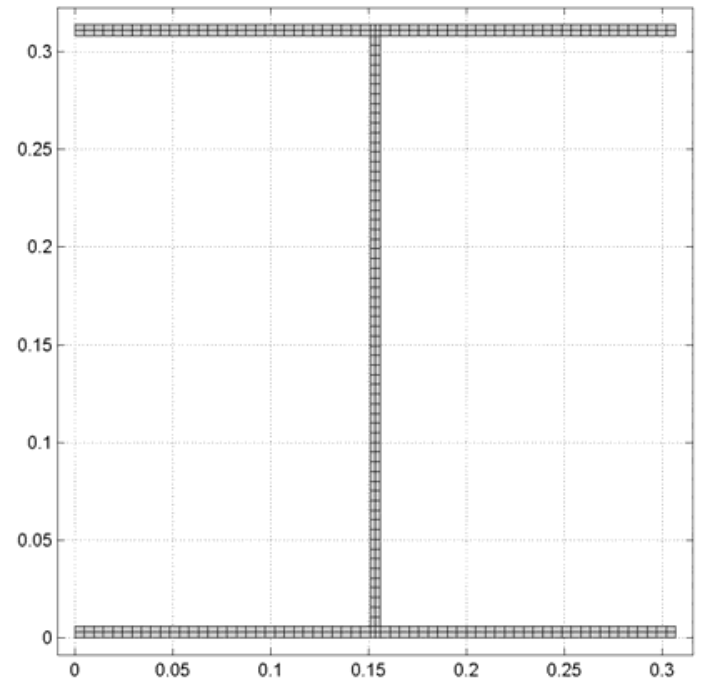

(b) Perfil (b)

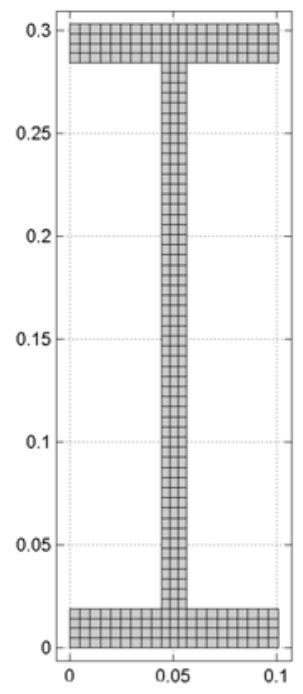

(d) Perfil (d)

Figura 10.42 - Discretização das malhas dos pilares da figura 10.41.

\subsubsection{Curva temperatura-tempo do gás}

Por meio do Smartfire, foram obtidas curvas temperatura-tempo do gás para os três pontos na figura 10.43, referentes aos perfis da figura 10.41, posicionados a $0,50 \mathrm{~m}$ e a $1,00 \mathrm{~m}$ da abertura. 


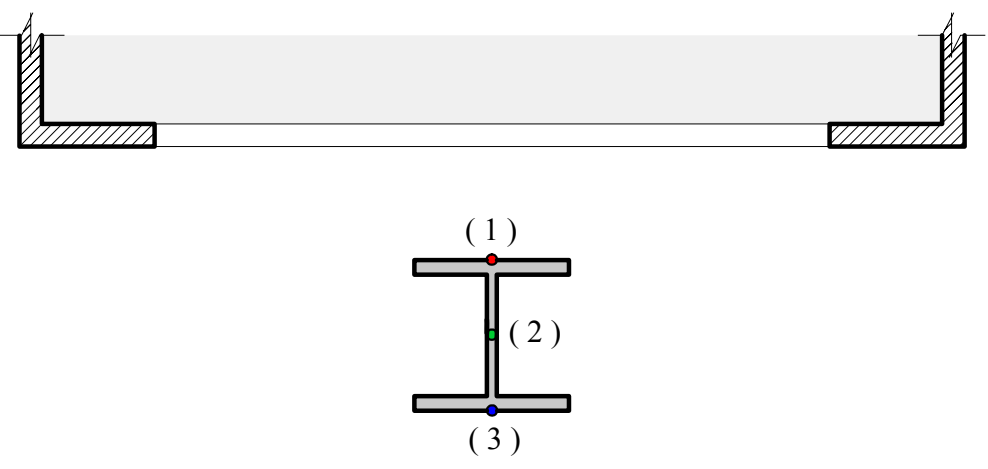

Figura 10.43 - Localização das curvas temperatura-tempo calculadas pelo Smartfire.

Para compatibilizar a curva temperatura-tempo do gás calculada pelo Smartfire aos dados de entrada do Super TempCalc, foi necessário ampliar o tempo total da curva temperatura-tempo de $300 \mathrm{~s}$ para de $1404 \mathrm{~s}(0,39 \mathrm{~h})$. Para isso, repetiu-se o último trecho da curva temperaturatempo do Smartfire, conforme mostram as figuras 10.44 e 10.45 .

O período de exposição ao fogo de $0,39 \mathrm{~h}$ foi determinado em função do limite operacional do Super Tempcalc. Como se notará mais adiante (figuras 10.46 a 10.49), para os perfis com seção transversal mais esbelta, (b) e (c), esse valor é suficiente, pois os valores de temperaturas se estabilizam. Para os perfis com seção transversal mais robusta, (a) e (d), as temperaturas serão um pouco maiores do que as encontradas via Super Tempcalc para a duração pré-estabelecida de incêndio.

$\mathrm{Na}$ figura 10.44, são apresentadas três curvas temperatura-tempo do gás para os pilares da figura 10.41, quando situados a 0,50 m da abertura. As curvas 1, 2 e 3 foram encontradas por meio do Smartfire, respectivamente nos pontos 1, 2 e 3 do pilar da figura 10.43 e foram aplicadas, respectivamente, em todo o contorno da mesa mais aquecida, alma e mesa menos aquecida. 


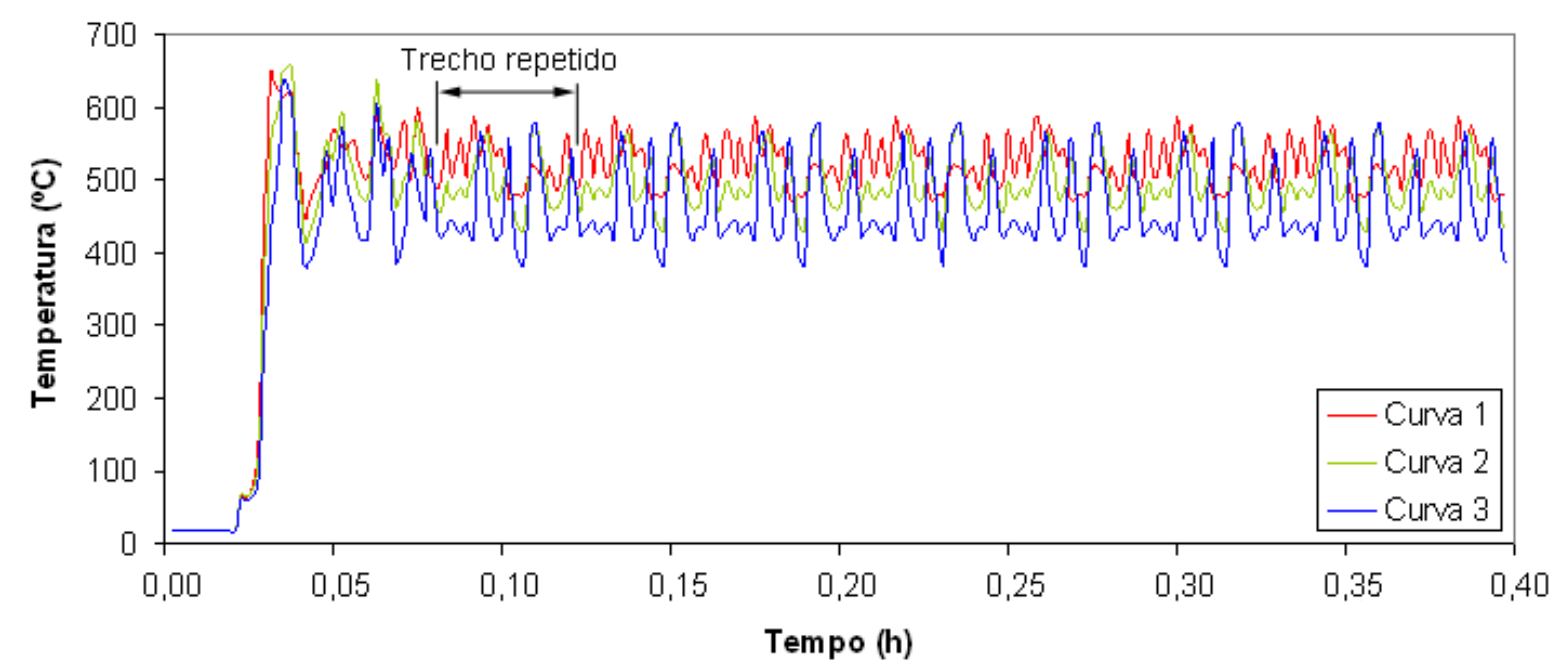

Figura 10.44 - Curvas temperatura-tempo calculadas pelo Smartfire. Perfis a 0,50m da abertura.

$\mathrm{Na}$ figura 10.45, são apresentadas as curvas temperatura-tempo para os pilares, quando situados a 1,00 m de distância da abertura.

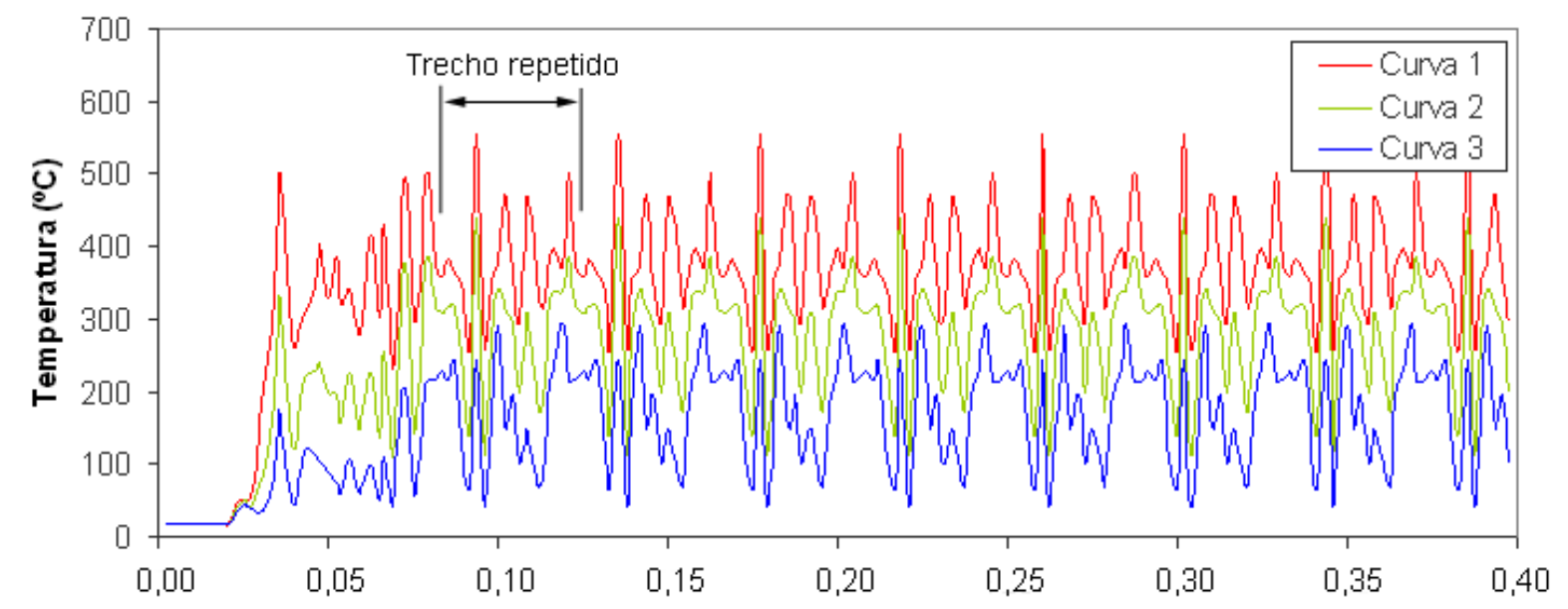

Figura 10.45 Curvas temperatura-tempo calculadas pelo Smartfire. Perfis a 1,00 m da abertura.

Verifica-se na figuras 10.44 e 10.45 que, em pontos mais afastados da janela, as temperaturas são menores e sua amplitude é maior, ou seja, oscilam mais entre o maior e o menor valor ao longo do tempo. 


\subsection{TEMPERATURA NOS PILARES}

As figuras 10.46 a 10.49 mostram a variação da temperatura do aço em função do tempo para os perfis (a) e (b) da figura 10.41. Os perfis possuem o mesmo contorno externo e diferenciam-se pela espessura das chapas, o que altera significativamente o seu fator de massividade.

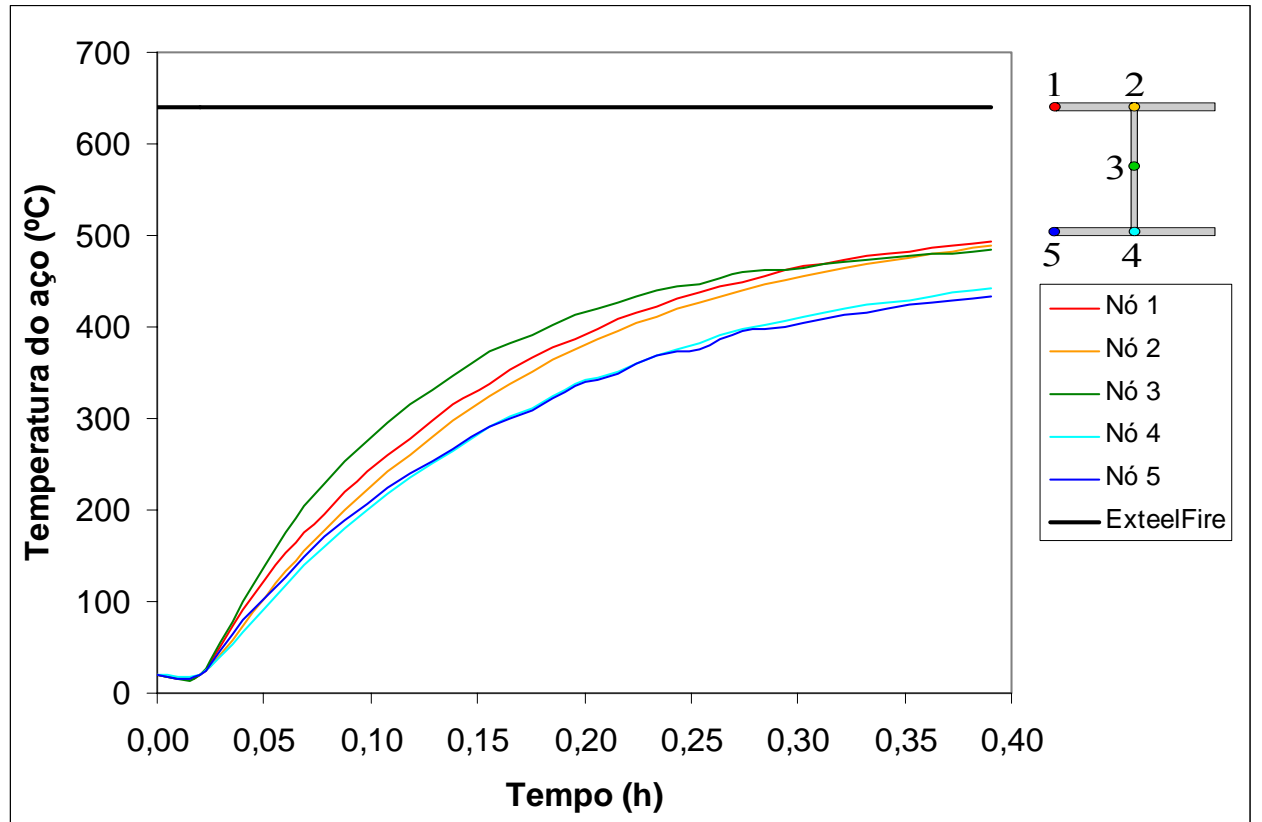

Figura 10.46 - Variação da temperatura do aço em função do tempo do pilar (a) da figura 12.3 a $0,50 \mathrm{~m}$ da abertura.

Para o pilar (a), mais robusto, distante $0,50 \mathrm{~m}$ da abertura, verifica-se na figura 10.46 que, inicialmente, a temperatura da alma (nó 3) é a de valor mais elevado, devido à sua maior esbeltez em relação às mesas. Em seguida, procurando o equilíbrio com a ação térmica, se converge para valores pouco menores daqueles determinados para a mesa mais aquecida (nós 1 e 2). Nota-se, também, que, de início, há um pequeno gradiente térmico na mesa mais aquecida, devido à maior exposição do nó 1 , no entanto, a tendência é a temperatura uniformizar-se com o tempo. O mesmo se observa na mesa menos aquecida (nós 4 e 5), porém com menor intensidade, devido às menores temperaturas atuantes. Ocorre uma inversão no sentido do gradiente nessa mesa, em função da condução de calor advinda da alma do perfil. 


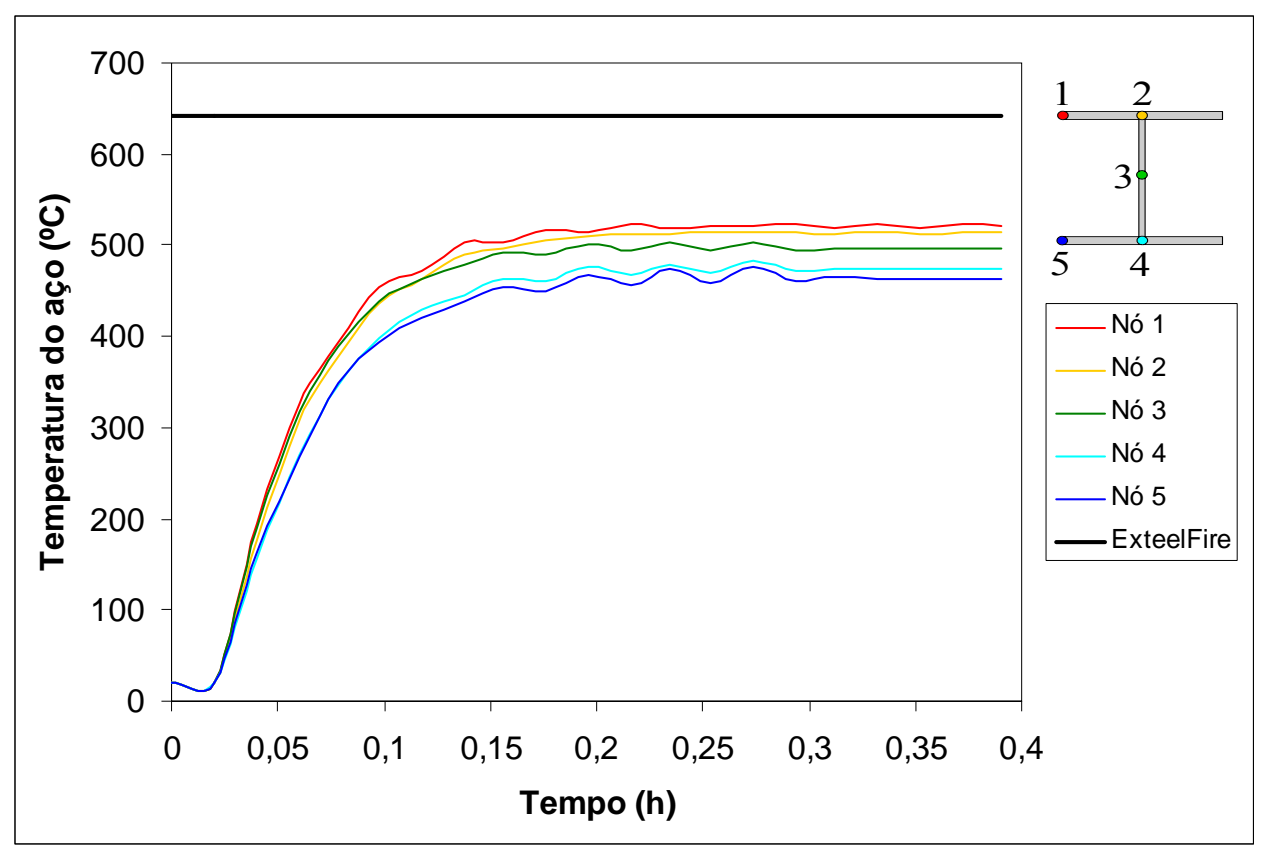

Figura 10.47 - Variação da temperatura do aço em função do tempo utilizando o pilar (b) da figura 10.41 a 0,50 $m$ da abertura.

Para o pilar (b), mais esbelto, distante $0,50 \mathrm{~m}$ da abertura, verifica-se na figura 10.47 que os valores relativos entre as temperaturas dos 3 elementos do perfil rapidamente convergem para a mesma relação das temperaturas atuantes.

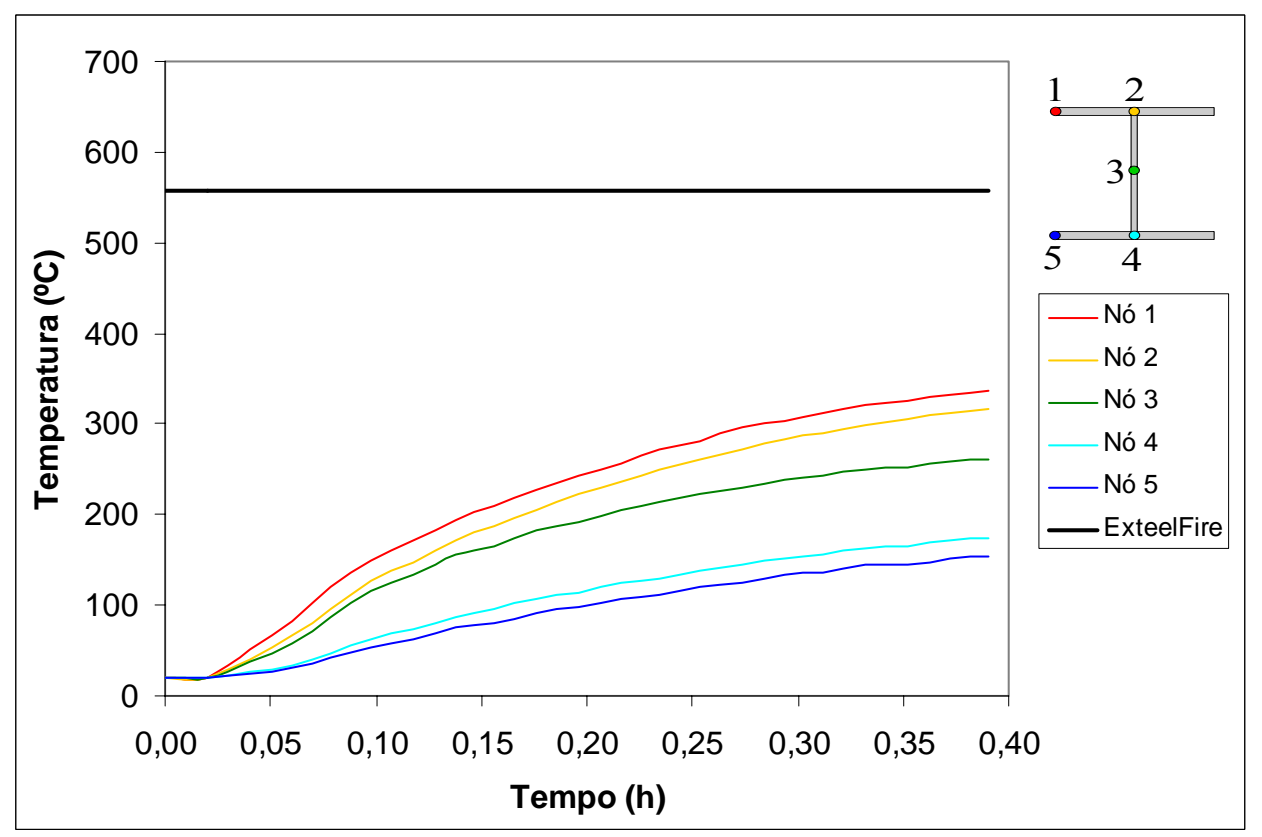

Figura 10.48 - Variação da temperatura do aço em função do tempo do pilar (a) da figura 10.41 a $1,00 \mathrm{~m}$ da abertura. 


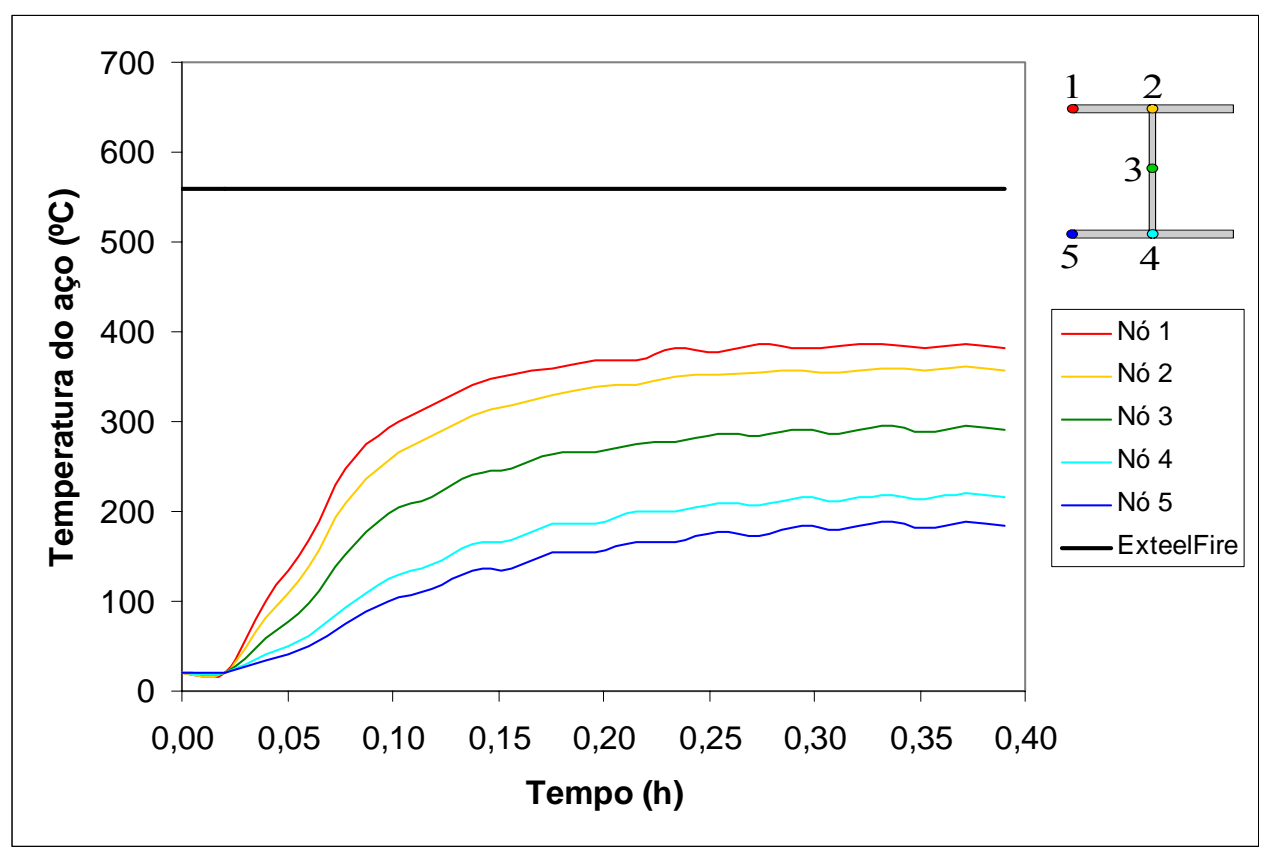

Figura 10.49 - Variação da temperatura do aço em função do tempo do pilar (b) da figura 10.41 a $1,00 \mathrm{~m}$ da abertura.

Nas figuras 10.48 e 10.49, para os pilares distantes 1,00 $\mathrm{m}$ da abertura, verifica-se que, devido à menor ação térmica, os valores relativos entre as temperaturas dos 3 elementos do perfil rapidamente convergem para a mesma relação das temperaturas atuantes. Um detalhe notável é que o gradiente térmico na mesa mais aquecida tem a direção da extremidade para o centro, devido à maior exposição do nó 1 . Na mesa menos aquecida, ocorre o contrário, devido à maior influência da condução de calor proveniente da alma.

A figura 10.50 mostra o campo de temperaturas na seção transversal do perfil para o tempo $0,15 \mathrm{~h}$ e $0,39 \mathrm{~h}$. 


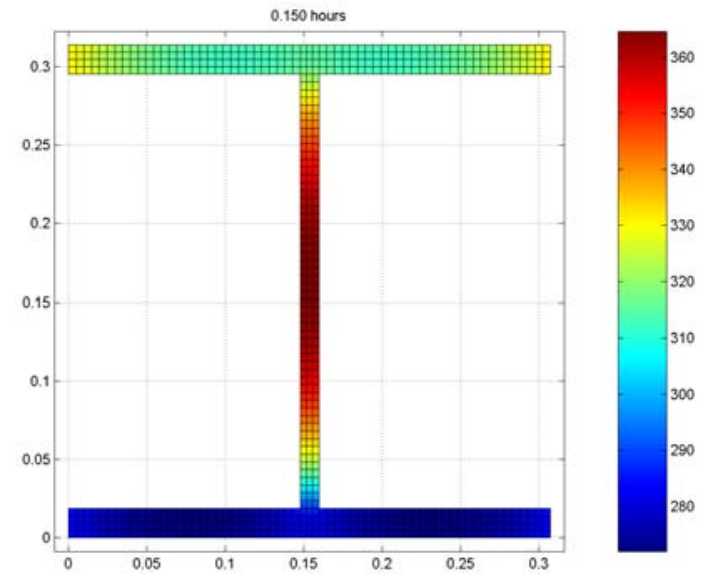

(a) Pilar (a) com tempo de simulação de $0,15 \mathrm{~h}$

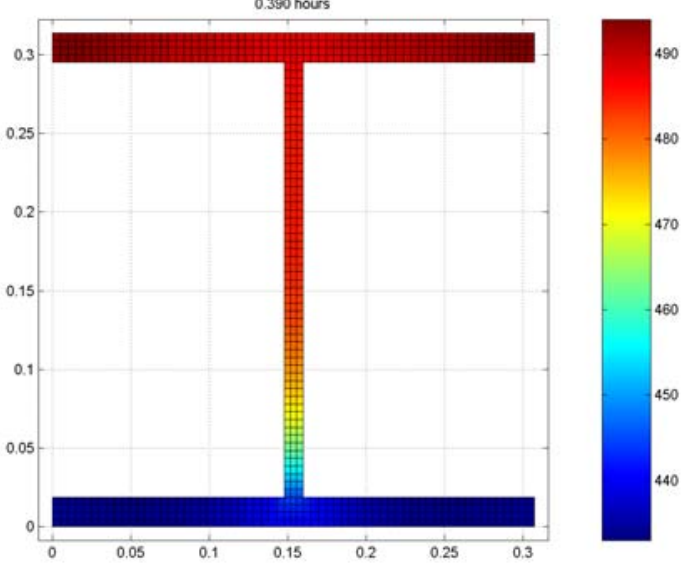

(c) Pilar (a) com tempo de simulação de $0,39 \mathrm{~h}$

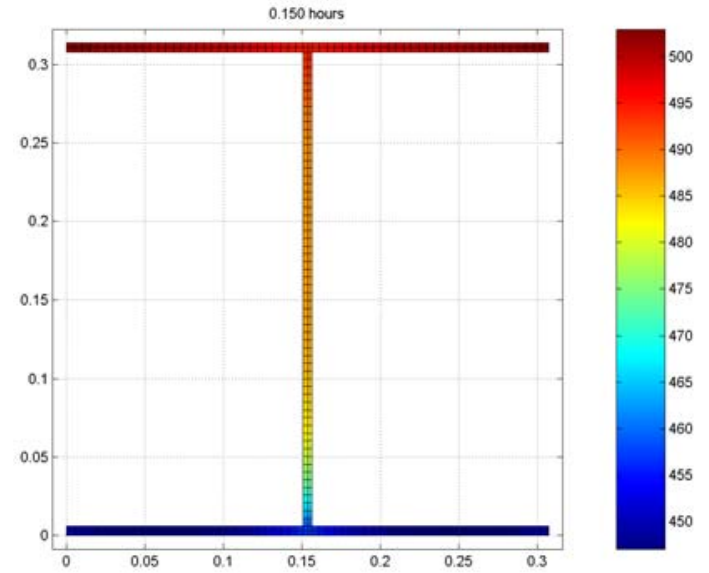

(b) Pilar (b) com tempo de simulação de $0,15 \mathrm{~h}$

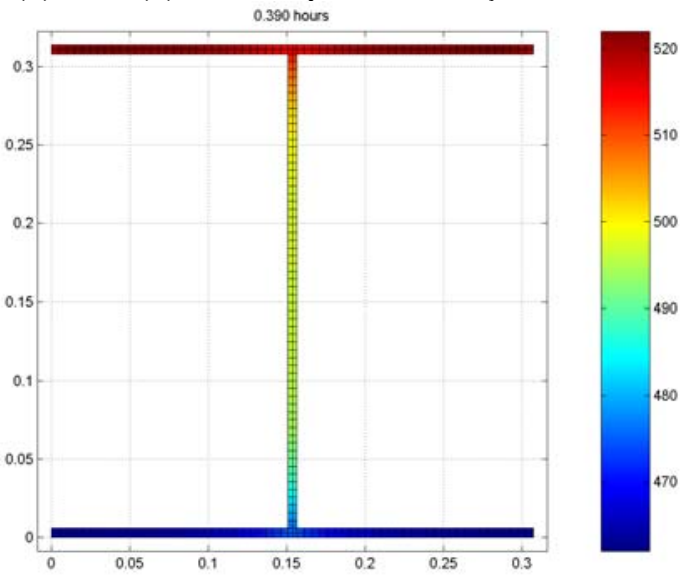

(d) Pilar (b) com tempo de simulação de $0,39 \mathrm{~h}$ pilares (a) e (b) da figura 10.41.

Outros perfis (c) e (d) com geometria diferente dos perfis (a) e (b) também foram ensaiados. O perfil (d) é mais robusto do que o perfil (c), conforme figura 10.41 .

As figuras 10.51 a 10.54 mostram a variação da temperatura do aço em função do tempo para os perfis (c) e (d). 


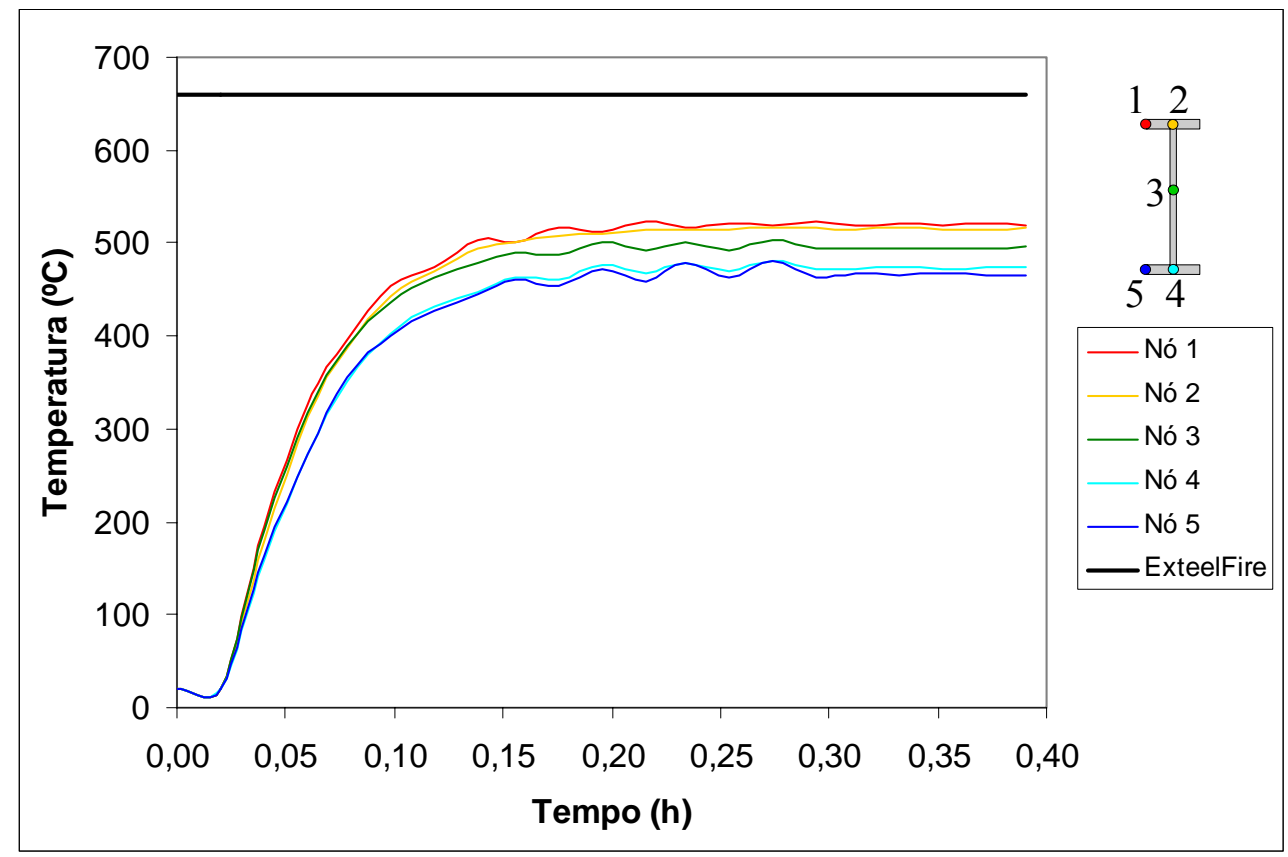

Figura 10.51 - Variação da temperatura do aço em função do tempo do pilar (c) da figura 10.41 a $0,50 \mathrm{~m}$ da abertura.

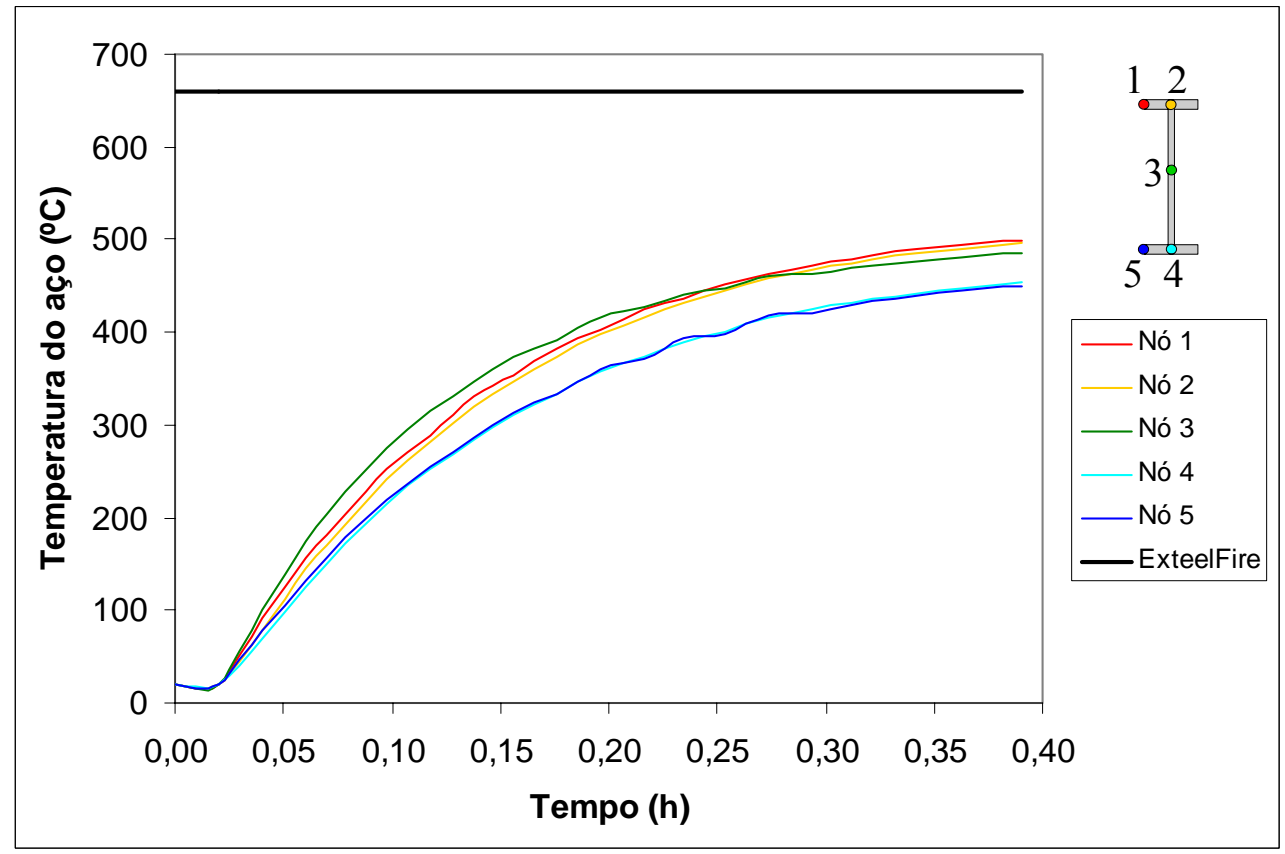

Figura 10.52 - Variação da temperatura do aço em função do tempo do pilar (d) da figura 10.41 a $0,50 \mathrm{~m}$ da abertura. 


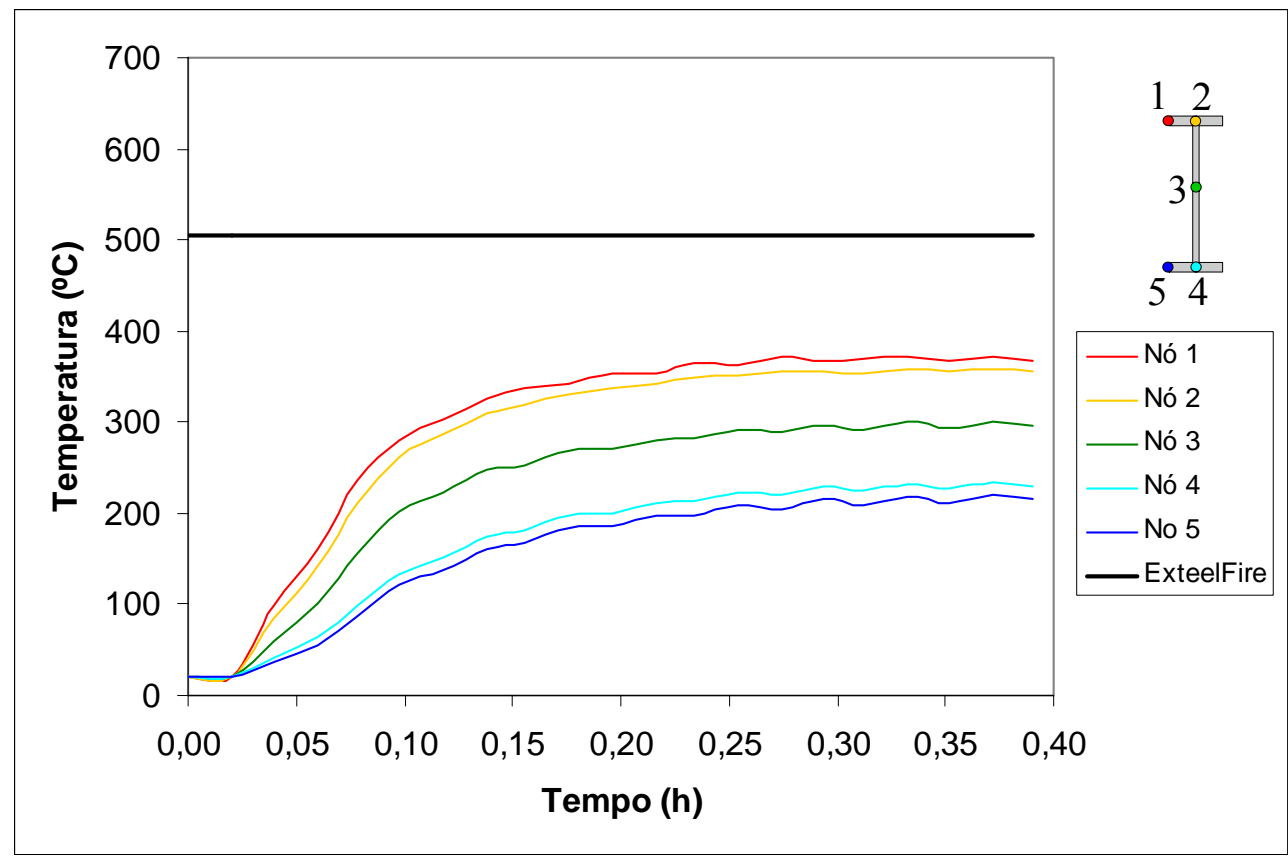

Figura 10.53 - Variação da temperatura do aço em função do tempo do pilar (c) da figura 10.41 a 1,00 m da abertura.

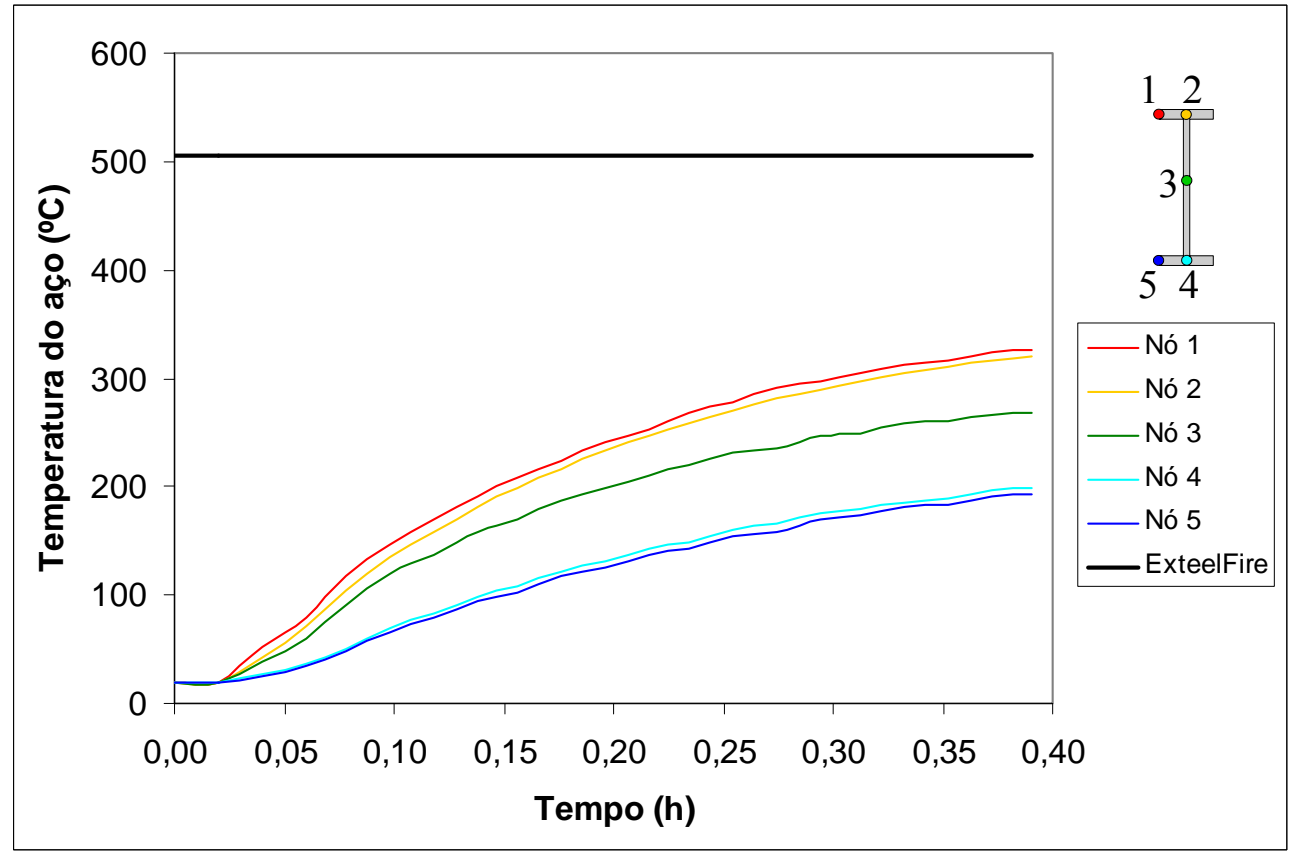

Figura 10.54 - Variação da temperatura do aço em função do tempo do pilar (d) da figura 10.41 a 1,00 m da abertura.

A figura 10.55 mostra o campo de temperaturas na seção transversal dos perfis (c) e (d) da figura 10.41 . 


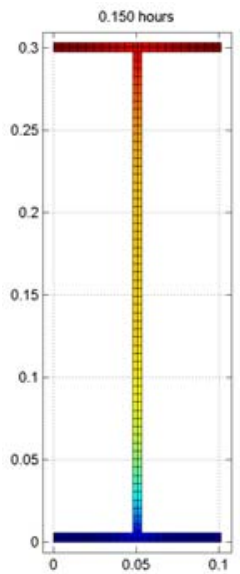

(a) Pilar (c) com tempo de simulação de $0,15 \mathrm{~h}$

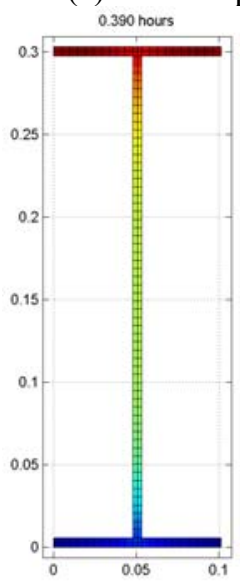

(c) Pilar (c) com tempo de simulação de $0,39 \mathrm{~h}$
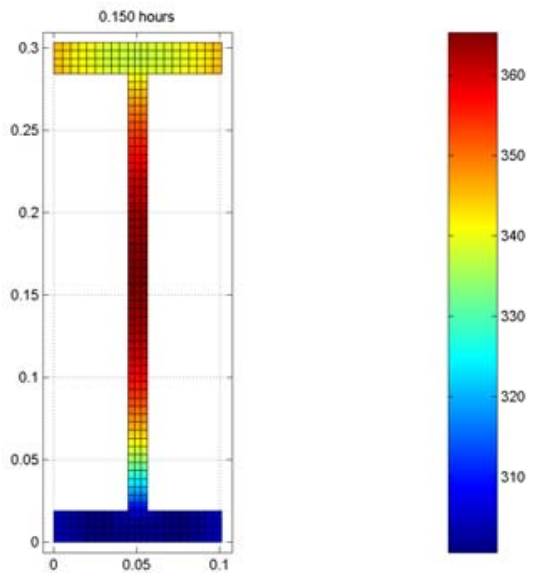

(b) Pilar (d) com tempo de simulação de $0,15 \mathrm{~h}$
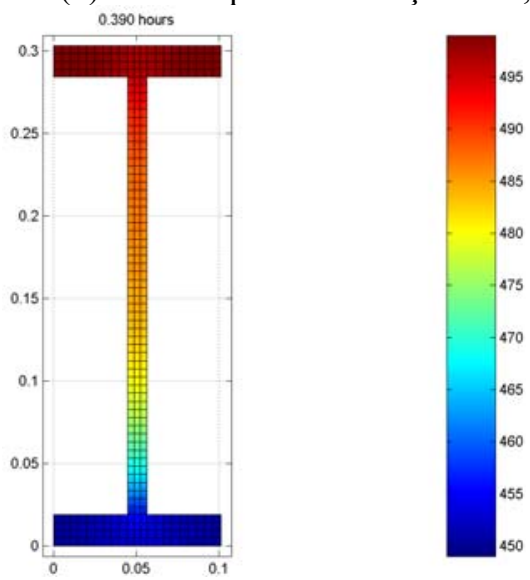

(d) Pilar (d) com tempo de simulação de $0,39 \mathrm{~h}$ Figura 10.55 - Temperatura na seção dos pilares (c) e (d) da figura 10.41.

Verifica-se nas figuras 10.51 e 10.55 que o comportamento dos perfis (c) e (d) foi similar ao dos perfis (a) e (b).

A tabela 10.3 mostra a temperatura máxima para os perfis da figura 10.41 calculada pelo Super Tempcalc e pelo ExteelFire. 
Tabela 10.3 - Temperatura máxima do pilar utilizando o Smartfire/Super Tempcalc e o ExteelFire

\begin{tabular}{|c|c|c|c|c|c|}
\hline \multirow{2}{*}{$\begin{array}{l}\text { Dimensões } \\
\text { externas }\end{array}$} & \multirow{2}{*}{$\begin{array}{c}\text { Distância à } \\
\text { janela }\end{array}$} & \multirow{2}{*}{$\begin{array}{c}\text { Fator de } \\
\text { massividade }\end{array}$} & \multirow{2}{*}{$\begin{array}{c}\text { Temperatura } \\
\text { média } \\
\text { Smartfire Super } \\
\text { Tempcal }\end{array}$} & \multicolumn{2}{|c|}{ Temperatura máxima } \\
\hline & & & & $\begin{array}{c}\text { Smartfire } \\
\text { Super } \\
\text { Tempcalc } \\
\left({ }^{\circ} \mathrm{C}\right)\end{array}$ & ExteelFire \\
\hline \multirow[t]{4}{*}{$314 \times 307$} & 50 & 124 & $466^{*}$ & $493^{*}$ & 641 \\
\hline & & 366 & 497 & 520 & \\
\hline & 100 & 124 & $252 *$ & $336^{*}$ & 558 \\
\hline & & 366 & 293 & 382 & \\
\hline \multirow[t]{4}{*}{$303 \times 101$} & 50 & 142 & $478^{*}$ & $499 *$ & 660 \\
\hline & & 379 & 496 & 519 & \\
\hline & 100 & 142 & $263^{*}$ & $326^{*}$ & 505 \\
\hline & & 379 & 300 & 368 & \\
\hline
\end{tabular}

* Como observado no ítem 10.6, para um período de incêndio mais longo, esses valores seriam ligeiramente maiores. 


\section{Capítulo 11}

SEGURANÇA ESTRUTURAL EM SITUAÇÃO DE

INCÊNDIO

\subsection{INTRODUÇÃO}

As condições de segurança de uma estrutura em situação de incêndio podem ser expressas pela eq. 11.1.

$$
\Phi\left(S_{f i, d}, R_{f i, d}\right) \geq 0
$$

Quando a segurança é verificada isolamente em relação aos esforços solicitantes, as condições de segurança podem ser expressas pela eq. 11.2, em que $S_{f i, d}$ é o valor de cálculo dos esforços atuantes em situação de incêndio, determinado a partir da combinação última excepcional das ações, conforme eq. 11.3, 11.4 e 11.5 (ABNT NBR 8681:2003) e $R_{f i, d}$ é o valor de cálculo correspondente ao esforço resistente do elemento estrutural para o estado limite último em situação de incêndio.

$$
S_{f i, d} \leq R_{f i, d}
$$

A eq. 11.3 é utilizada para locais em que não há predominância de pesos de equipamentos que permaneçam fixos por longos períodos de tempo, nem de elevadas concentrações de pessoas.

$$
1,2 \mathrm{~F}_{\mathrm{G}}+\mathrm{F}_{\mathrm{Q}, \mathrm{exc}}+0,21 \mathrm{~F}_{\mathrm{Q}}
$$

A eq. 11.4 é utilizada para locais em que há predominância de pesos de equipamentos que permaneçam fixos por longos períodos de tempo, ou de elevadas concentrações de pessoas.

$$
1,2 \mathrm{~F}_{\mathrm{G}}+\mathrm{F}_{\mathrm{Q}, \mathrm{exc}}+0,28 \mathrm{~F}_{\mathrm{Q}}
$$

A eq. 11.5 é utilizada para bibliotecas, arquivos, depósitos, oficinas e garagens.

$$
1,2 \mathrm{~F}_{\mathrm{G}}+\mathrm{F}_{\mathrm{Q}, \mathrm{exc}}+0,42 \mathrm{~F}_{\mathrm{Q}}
$$


Nas eq. 11.3 a $11.5, F_{G}$ é o valor característico das ações permanentes diretas; $F_{Q \text {,exc }}$ é o valor característico das ações térmicas decorrentes do incêndio; $F_{Q}$ é o valor característico das ações variáveis decorrentes do uso e ocupação da edificação.

Para o cálculo do esforço resistente, inclui-se o efeito da ação térmica por meio dos coeficientes de redução da resistência $k_{y, \theta}$ ou do módulo de elasticidade $k_{E, \theta}$, fornecidos pela ABNT NBR 14323:1999.

Para o caso de distribuição uniforme de temperaturas no elemento de aço, a eq. 11.2 pode ser transformada na eq. 11.6.

$$
\theta_{a} \leq \theta_{c r}
$$

Onde:

$\theta_{a} \quad$ é a temperatura atuante no elemento de aço em situação de incêndio $\left({ }^{\circ} \mathrm{C}\right)$;

$\theta_{c r} \quad$ é a temperatura crítica do elemento estrutural, qual seja a temperatura que conduz o elemento estrutural ao colapso $\left({ }^{\circ} \mathrm{C}\right)$.

\subsection{DETERMINAÇÃO DA TEMPERATURA ATUANTE NO ELEMENTO ESTRUTURAL}

A temperatura do aço, $\theta_{a}$, pode ser determinada, como mostrado na figura 11.1 , da seguinte maneira:

- a curva temperatura-tempo do incêndio terá uma elevação padronizada de temperatura, denominada incêndio-padrão (eq. 11.7);

- a curva temperatura-tempo do elemento de aço é construída empregando a formulação relacionada à transferência de calor entre chamas e elementos de aço apresentada na ABNT NBR 14323:1999;

- determina-se a temperatura do aço para um tempo pré-estabelecido na norma ABNT NBR 14432:2000, denominado tempo requerido de resistência ao fogo (TRRF), o qual é tabelado em função da edificação e seu tipo de uso. 


$$
\theta_{g}=345 \log (8 t+1)+20
$$

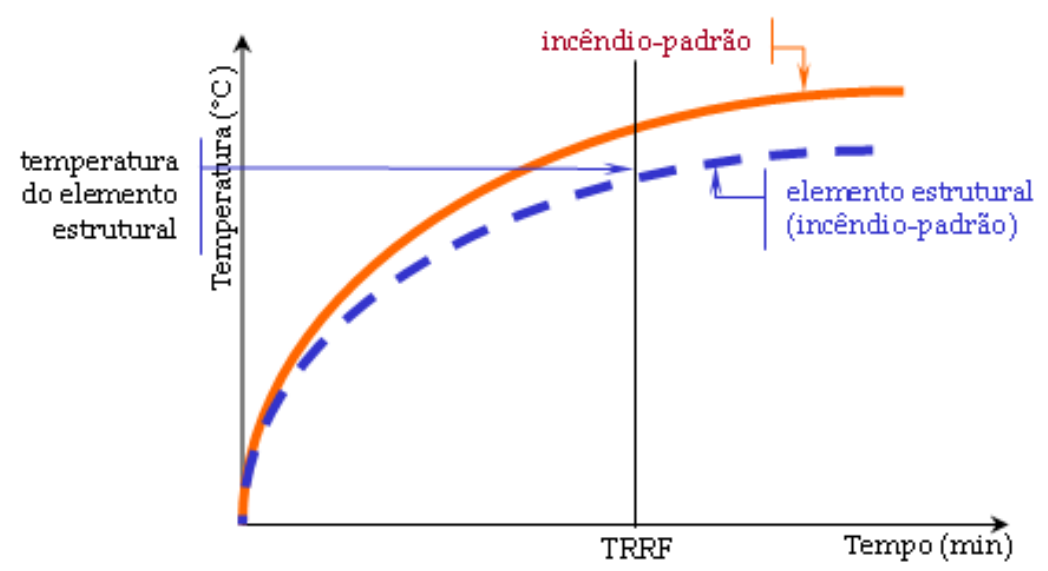

Figura 11.1 - Curva temperatura-tempo de um incêndio-padrão.

Essa estratégia é válida para elementos de aço sob temperatura uniforme e localizados no interior das edificações. A favor da segurança, também pode ser empregado para as estruturas localizadas no exterior dos edifícios. Visando uma abordagem mais realística e econômica, $\theta_{a}$ pode ser determinada pelo método proposto pelos EUROCODES 1 e 3 que tem por base o método de LAW (1978), conforme descrito no capítulo 5 desta Tese.

\subsection{DETERMINAÇÃO DA TEMPERATURA CRÍTICA DO ELEMENTO ESTRUTURAL}

O valor da temperatura crítica, $\theta_{c r}$, pode ser determinado por meio de métodos avançados de cálculo termoestrutural ou por meio dos métodos simplificados aceitos pela ABNT NBR 14323:1999 (SILVA, 2004). Em vista dessa Norma estar em revisão, apresentam-se na tabela 1 algumas das prescrições do Eurocode 3, parte 1-3 (2003), que deverá ser base da futura revisão da ABNT NBR 14323. A partir desse método simplificado é possível determinar o fator de redução da resistência $k_{y, \theta}$ ou $k_{E, \theta}$, igualando-se o esforço resistente ao solicitante. A seguir, determina-se a temperatura associada ao $k_{\theta}$, por meio da correlação existente entre eles, conforme apresentado na ABNT NBR 14323:1999. Essa temperatura é a $\theta_{c r}$. 


\begin{tabular}{|c|c|}
\hline Tração & $N_{f i, R d}=\frac{A_{g} k_{y, \theta} f_{y}}{\gamma_{a, f i}}$ \\
\hline $\begin{array}{l}\text { Compressão } \\
\text { (instabilidade } \\
\text { por flexão) }\end{array}$ & $\begin{array}{l}N_{f i, R d}=\frac{\chi_{f i} A_{g} k_{y, \theta} f_{y}}{\gamma_{a, f i}} \\
\chi_{f i}=\frac{1}{0,5\left[1+\alpha \lambda_{0, \theta}+\lambda_{0, \theta}^{2}\right]+\sqrt{\left[0,5\left(1+\alpha \lambda_{0, \theta}+\lambda_{0, \theta}^{2}\right)\right]^{2}-\lambda_{0, \theta}^{2}}} \\
\lambda_{0, \theta}=\frac{\lambda}{\sqrt{\pi^{2} \frac{k_{E, \theta} E}{k_{y, \theta} f_{y}}}} \\
\alpha=0,65 \sqrt{\frac{235}{\mathrm{f}_{\mathrm{y}}}, \mathrm{f}_{\mathrm{y}} \mathrm{em} \mathrm{MPa}}\end{array}$ \\
\hline $\begin{array}{l}\text { Momento } \\
\text { fletor } \\
\text { (instabilidade } \\
\text { lateral com } \\
\text { torção) }\end{array}$ & $\begin{array}{l}M_{f i, \mathrm{R} d}=\kappa_{1} \kappa_{2} \frac{k_{y, \theta} M_{p \ell}}{\gamma_{a, f i}} \leq \frac{M_{p \ell}}{\gamma_{a, f i}} \text { para vigas que permitam a plastificação total da } \\
\text { seção } \\
M_{f i, R d}=\frac{\chi k_{y, \theta} M_{p l}}{\gamma_{a, f i}} \text { para vigas sujeitas à instabilidade lateral com torção } \\
\chi \text { é determinado como na compressão, mas com } \lambda_{0, \theta} \text { determinado do seguinte } \\
\text { modo: } \lambda_{0, \theta}=\sqrt{\frac{k_{y, \theta} M_{p l}}{k_{E, \theta}} M_{c r}} \\
\text { - para uma viga com todos os quatro lados expostos: } \kappa_{1}=1,00 \text {; para uma viga } \\
\text { com três lados expostos, com uma laje de concreto no quarto lado: } \kappa_{1}=1,40 \\
\text { (aço não-revestido) ou } \kappa_{1}=1,15 \text { (aço revestido); nos apoios de uma viga } \\
\text { estaticamente indeterminada: } \kappa_{2}=1,15 \text { (outros casos: } \kappa_{2}=1,00 \text { ) }\end{array}$ \\
\hline
\end{tabular}

Na tabela 11.1: $A_{g}$, é a área bruta da seção transversal da barra; $E$ é o módulo de elasticidade tangente inicial do aço à temperatura ambiente; $M_{c r}$ é o momento fletor de flambagem elástica 
à temperatura ambiente; $M_{f i, R d}$ é o momento fletor resistente de cálculo em situação de incêndio; $M_{p l}$ é o momento de plastificação à temperatura ambiente; $N_{f i, R d}$ é a força normal resistente de cálculo de uma barra axialmente tracionada ou comprimida em situação de incêndio; $f_{y}$ é a resistência ao escoamento à temperatura ambiente dos aços laminados; $k_{E, \theta}$ é o fator de redução para o módulo de elasticidade dos aços em temperatura elevada relativo ao valor à temperatura ambiente; $k_{y, \theta}$ é o fator de redução para a resistência ao escoamento dos aços laminados em temperatura elevada relativo ao valor à temperatura ambiente; $\chi_{f i}$ é o fator de redução para barras axialmente comprimidas em situação de incêndio; $\lambda$ é o parâmetro de esbeltez à temperatura ambiente; $\lambda_{0, \theta}$ é o parâmetro de esbeltez reduzido para barras submetidas à compressão em temperatura elevada; $\kappa_{1}$ é o fator de correção para a temperatura não-uniforme na seção transversal; $\kappa_{2}$ é o fator de correção para temperatura não-uniforme ao longo do comprimento de um elemento estrutural; $\gamma_{a, f i}$ é o coeficiente de ponderação aplicado à resistência do aço, em situação excepcional e igual a 1.

A partir das expressões da tabela 11.1, é possível traçar gráficos que facilitem a determinação da temperatura crítica de pilares, conforme pode ser visto na figura 11.2 e 11.3 (VELARDE, 2008), ou de vigas sob lajes, como na figura 11.4. Nessas figuras, $\eta$ representa a razão entre a força normal solicitante de cálculo em situação de incêndio e a força normal resistente de cálculo à temperatura ambiente, conforme eq. 11.8.

$$
\eta=\frac{N_{f i, S d}}{N_{R d}}
$$




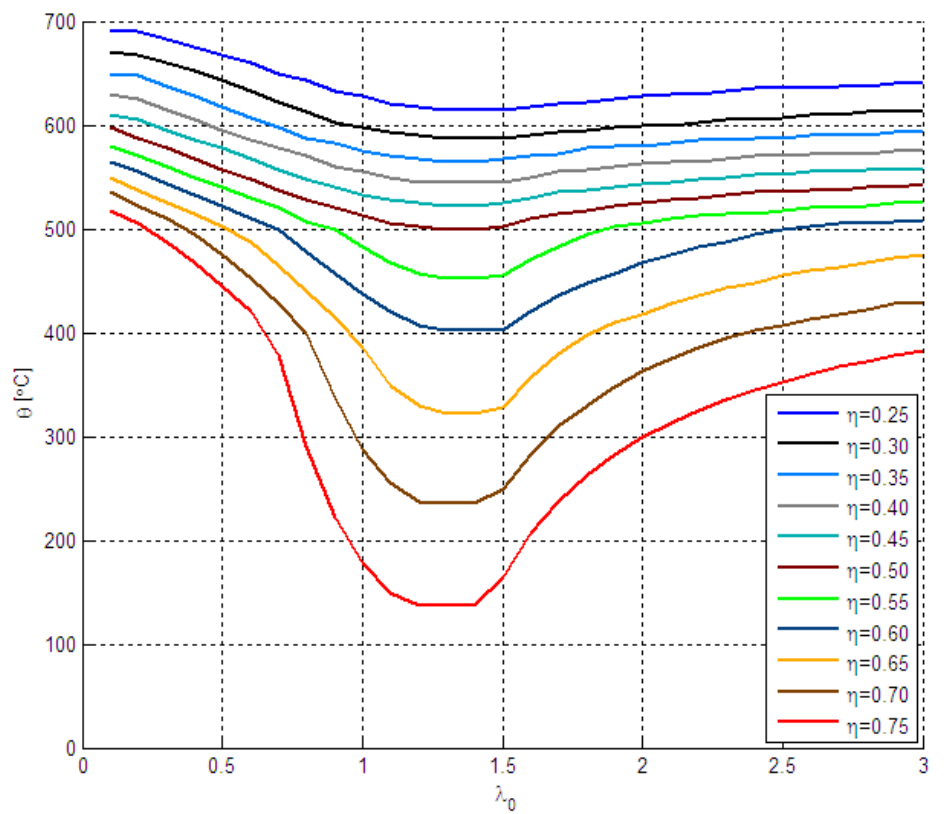

Figura 11.2 - Temperatura crítica de pilares de aço com fy $=250 \mathrm{MPa}$ (VELARDE, 2008).

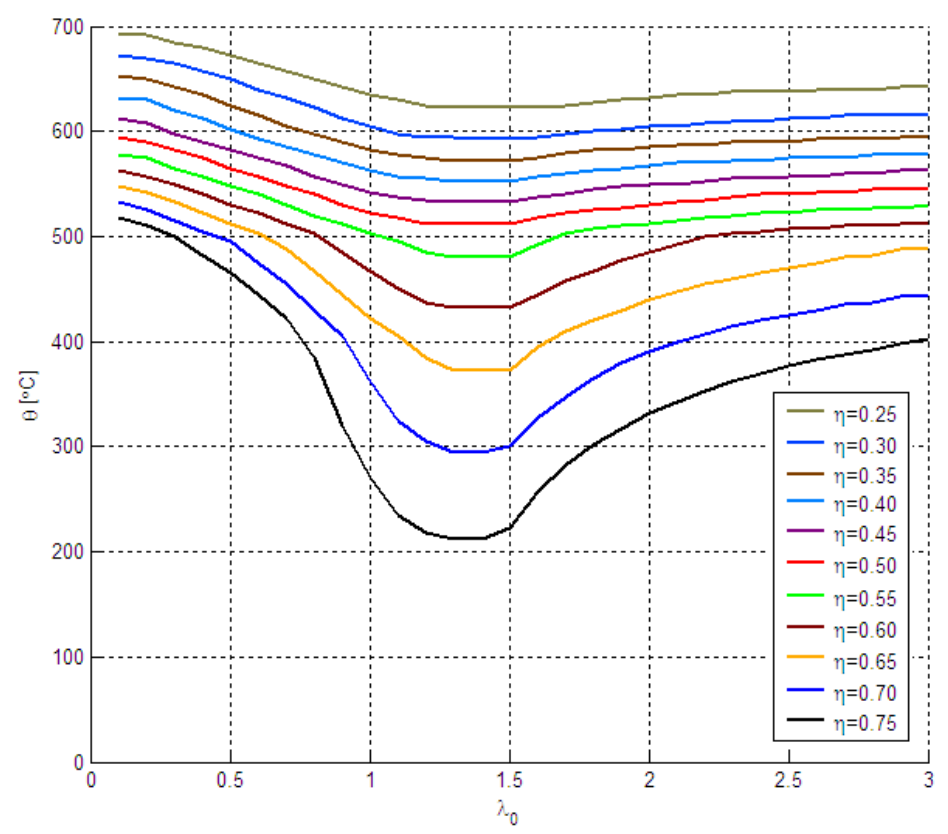

Figura $11.3-$ Temperatura crítica de pilares de aço com fy $=345 \mathrm{MPa}$ (VELARDE, 2008). 


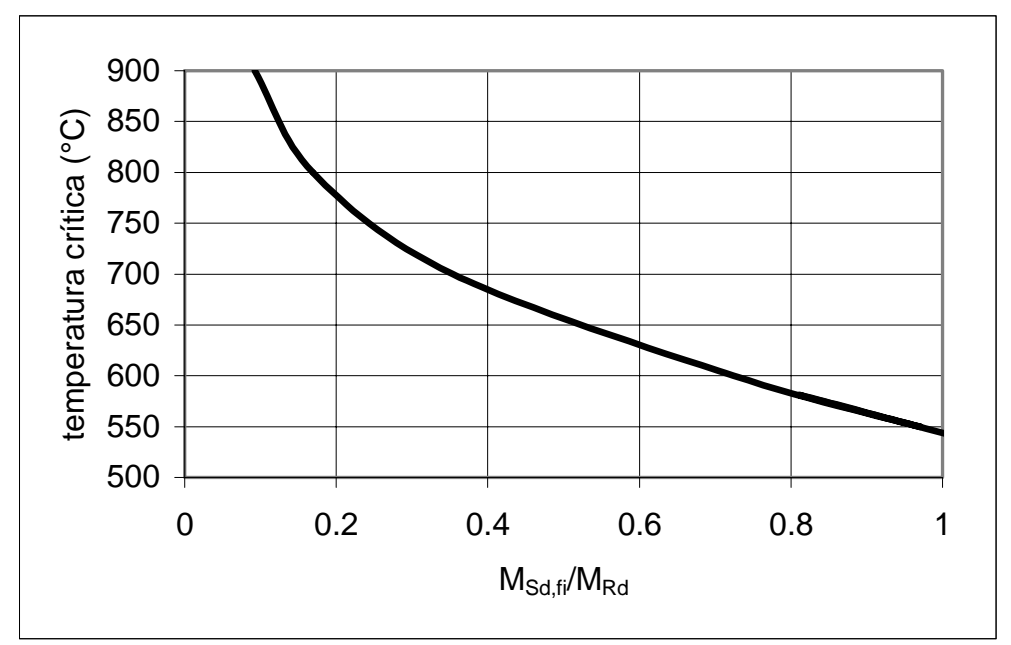

Figura 11.4 - Temperatura crítica de vigas de aço admitindo-se plastificação total da seção transversal, sob laje de concreto.

\subsection{EXEMPLO}

Neste item, será verificada a segurança estrutural em incêndio de um pilar simplesmente apoiado (figura 11.6), CS 300 x 115, de aço ASTM A36, com comprimento de $3 \mathrm{~m}$, com um nível de carregamento relativo $\eta=0,5$, situado na frente de uma abertura, a uma distância de $1,20 \mathrm{~m}$ da janela de um compartimento, conforme figura 11.5. O compartimento é um escritório com um valor de cálculo de carga de incêndio específica $q_{f i, d}$, igual a $700 \mathrm{MJ} / \mathrm{m}^{2}$.

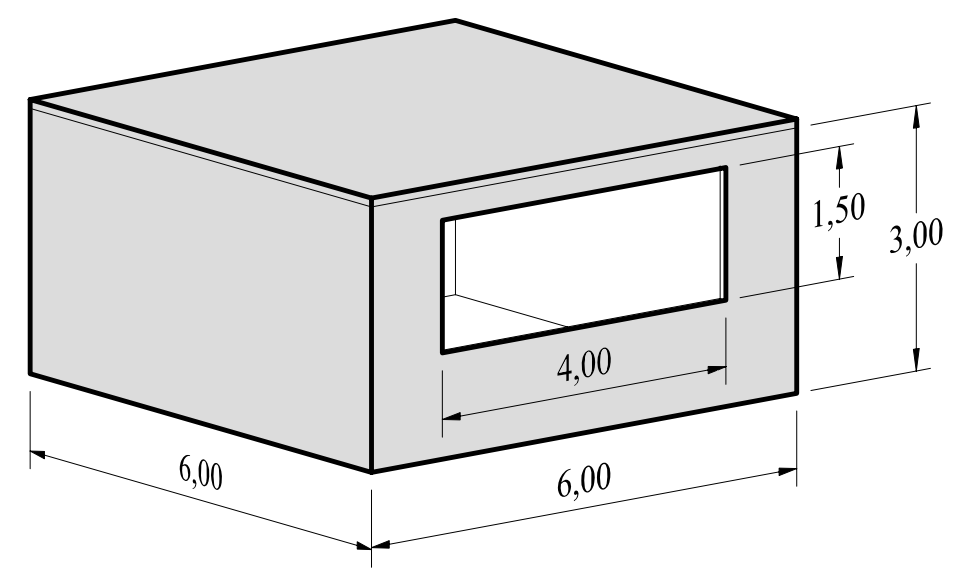

Figura 11.5 - Geometria do compartimento. 

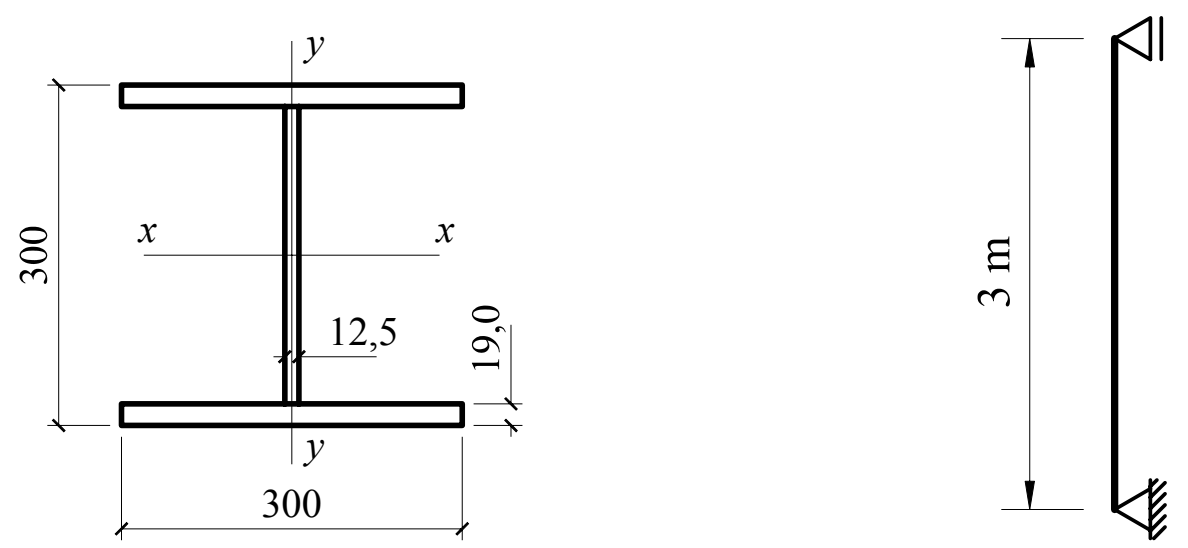

Figura 11.6 - Geometria e sistema estrutural do pilar.

Pelo ExteelFire, tem-se que a temperatura do aço vale $\theta_{a}=536^{\circ} \mathrm{C}$.

A esbeltez relativa do pilar à temperatura ambiente é determinada da seguinte forma:

$$
\begin{aligned}
& \lambda=\frac{k \cdot \ell}{r_{y}}=\frac{1 \times 300}{7,63}=39 \\
& \lambda_{0}=\frac{\lambda}{\sqrt{\pi^{2} \frac{E}{f_{y}}}}=\frac{39}{\sqrt{\pi^{2} \frac{20000}{25,0}}}=0,44
\end{aligned}
$$

A partir da figura 11.2 , com $\lambda_{0}=0,44$ e $\eta=0,5$, tem-se $\theta_{c r}=560{ }^{\circ} \mathrm{C}$, portanto, a segurança em incêndio do pilar está verificada, podendo-se dispensar o revestimento contra fogo. 
Capítulo 12

\section{OS EXPERIMENTOS DE DALMARNOCK E DA SIDERÚRGICA MITTAL STEEL OSTRAVA}

O presente capítulo apresenta uma comparação entre os resultados obtidos por meio do ExteelFire, que tem como base as normas Eurocode, e os medidos no experimento de Dalmarnock (ítem 2.2.5 desta Tese) e da Siderúrgica Mittal Steel Ostrava (item 2.2.4 desta Tese).

\subsection{O EXPERIMENTO DE DALMARNOCK}

O Centro Britânico para Engenharia de Segurança contra Incêndio da Universidade de Edimburgo conduziu uma série de ensaios de incêndio em escala natural, em um edifício a ser demolido na cidade de Dalmarnock, em Glasgow, Escócia. O compartimento experimental tinha as dimensões constantes na figura 12.1 .

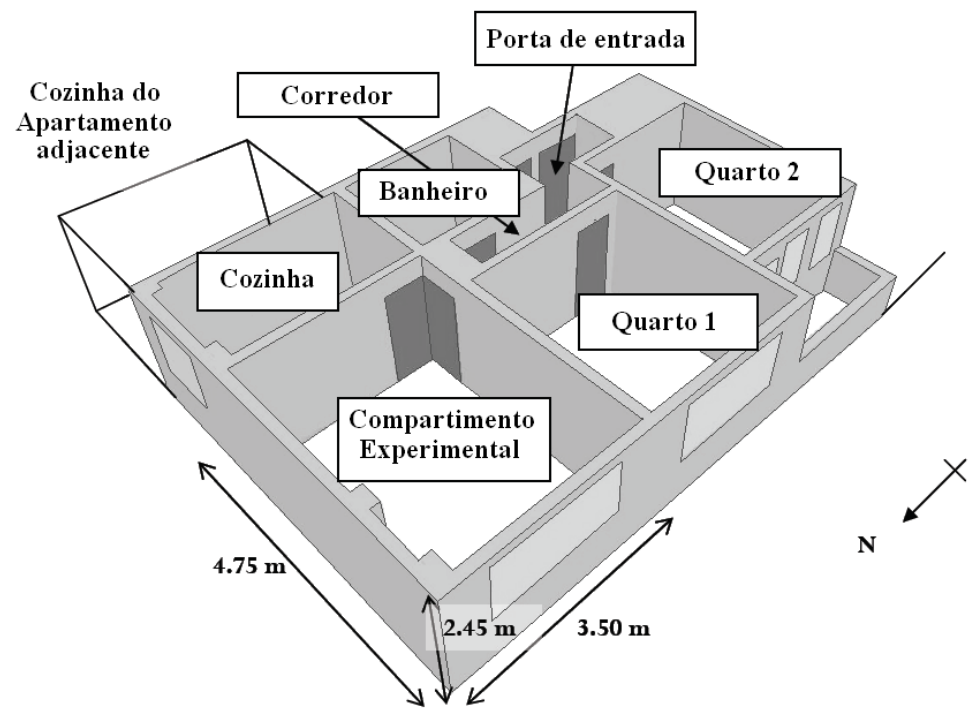

Figura 12.1 - Layout do compartimento experimental (REIN et al., 2007). 
A disposição da mobília foi feita de forma que o combustível fosse concentrado na parte de trás do compartimento, longe da janela. A figura 12.2 mostra a planta baixa do compartimento experimental, bem como a mobília e a instrumentação utilizada. A carga de incêndio específica estimada (REIN et al. 2007) foi de $32 \mathrm{~kg} / \mathrm{m}^{2}$ de madeira equivalente. Usando um potencial calorífico da madeira igual a 17,5 MJ/kg (EUROCODE 1, PART 1-2, 2002), resulta-se em $560 \mathrm{MJ} / \mathrm{m}^{2}$.

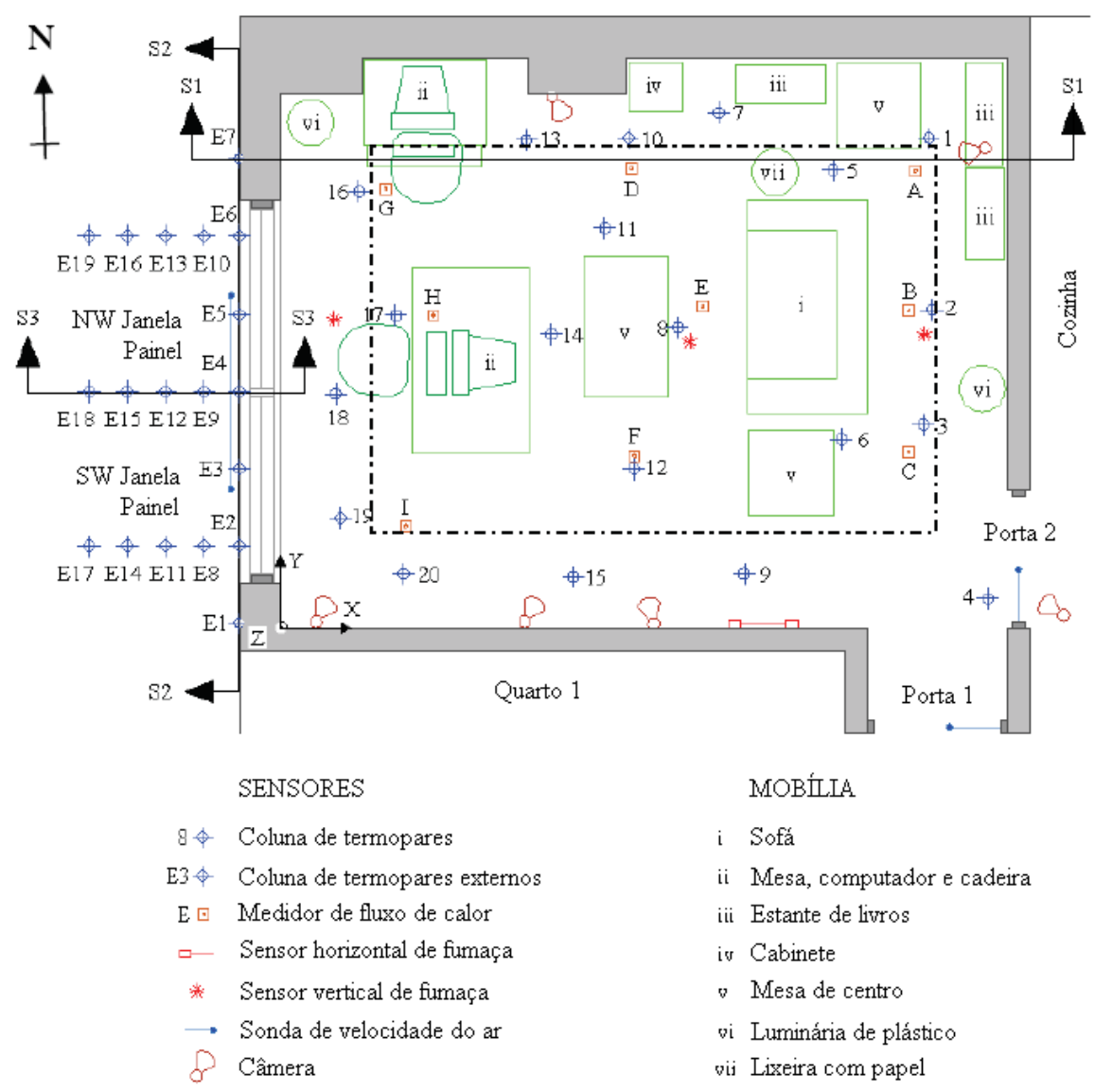

Figura 12.2 - Planta do compartimento ensaiado (REIN et al., 2007).

No compartimento ensaiado, foi considerado, inicialmente, que as duas portas, da cozinha e do corredor, estavam abertas e, as janelas, fechadas. Após 801 segundos da ignição (tabela 2.3 do ítem 2.2.5 desta Tese), as janelas se quebraram tornando o incêndio mais severo, conforme a figura 12.3 . 


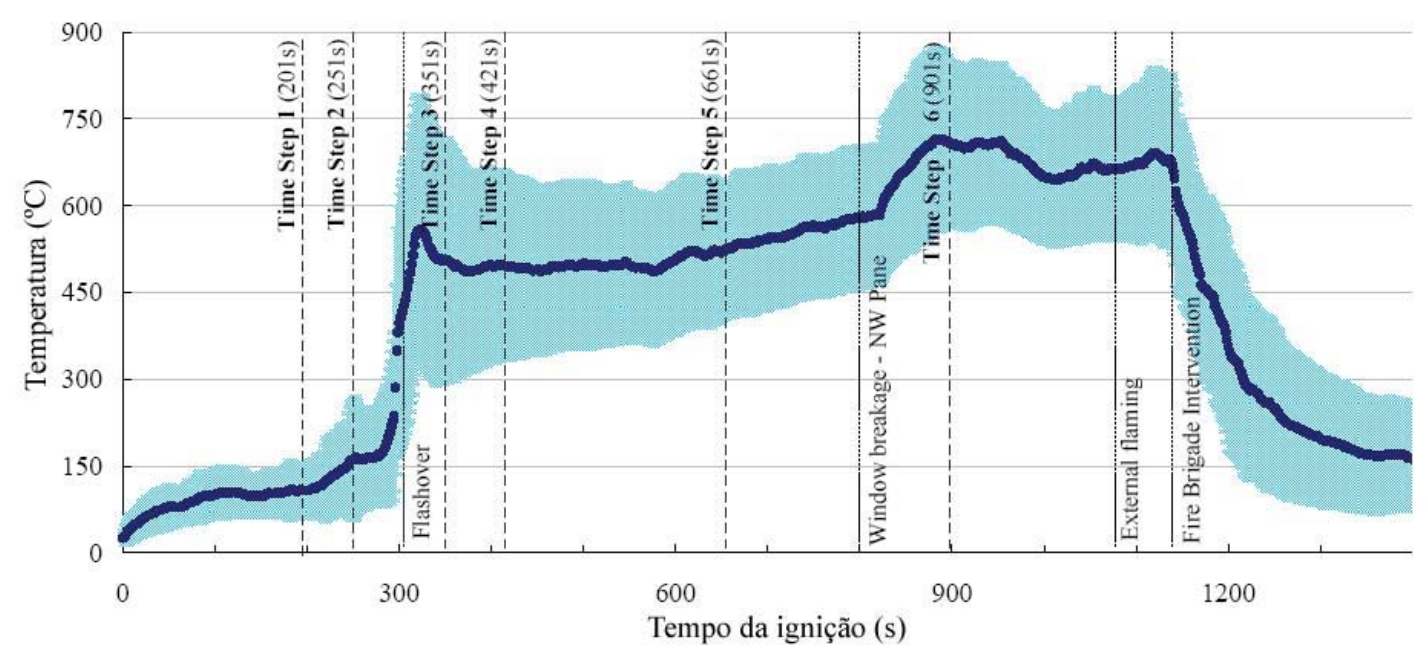

Figura 12.3 - Curva temperatura média-tempo dos gases dentro do compartimento (REIN et al., 2007).

A temperatura média mais alta dentro do compartimento foi de $740{ }^{\circ} \mathrm{C}$ a $901 \mathrm{~s}$ da ignição (figura 12.3). Essa não é a temperatura máxima dentro do compartimento, conforme figura 12.4. A tendência é que a taxa de liberação de calor corresponda à temperatura média do compartimento.

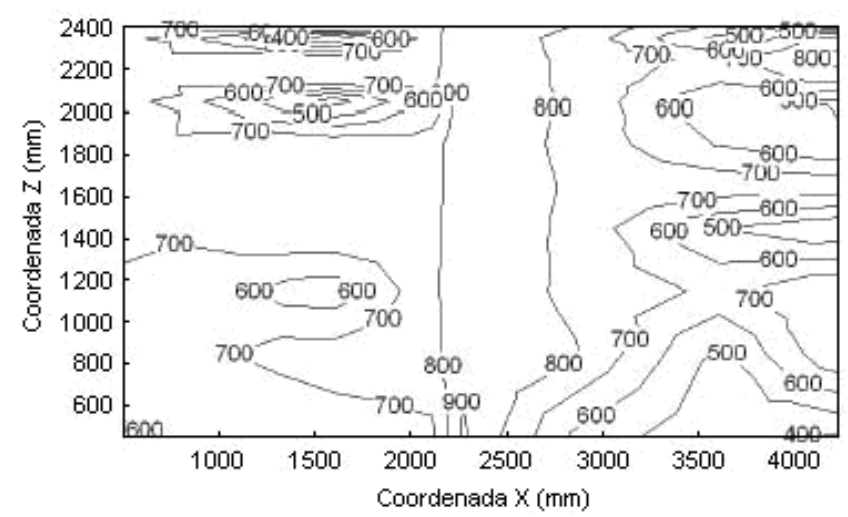

Figura 12.4 - Contornos da temperatura do gás $\left(\mathrm{em}^{\circ} \mathrm{C}\right)$ da seção S1-S1, de acordo com figura 12.2. Tempo após a ignição de $901 \mathrm{~s}$.

A taxa de liberação de calor cresce de um incêndio de estado quase estacionário a $3 \mathrm{MW}$, para um incêndio em torno de $5 \mathrm{MW}$, no instante em que a primeira janela do compartimento quebra, responsável por um aumento nas temperaturas do compartimento. 


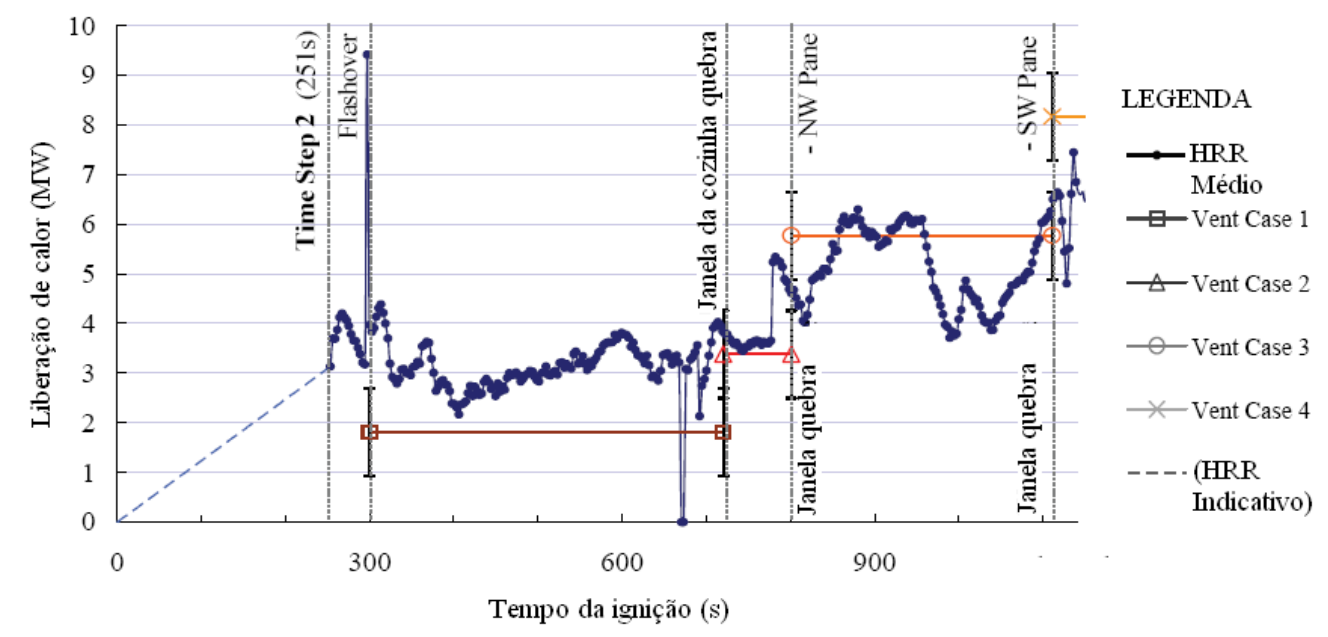

Figura 12.5 - Taxa de liberação de calor do incêndio do incêndio de Dalmarnock (REIN et al., 2007).

A temperatura máxima registrada pelo termopar da chama externa foi de $860^{\circ} \mathrm{C}$, com média de $400^{\circ} \mathrm{C}$, incluindo todos os termopares que medem até meia-altura da janela do $5^{\circ}$ piso.

As isotermas da figura 12.6(a) são mostradas segundo a seção S2-S2 da figura 12.2 e abrange os termopares E1 a E7, paralelos à janela do compartimento. As isotermas da figura 12.6(b) são mostradas segundo a seção S3-S3 da figura 12.2 e abrange os termopares 4, 9, 12, 15 e 18 , perpendiculares à janela e localizados na sua linha central.

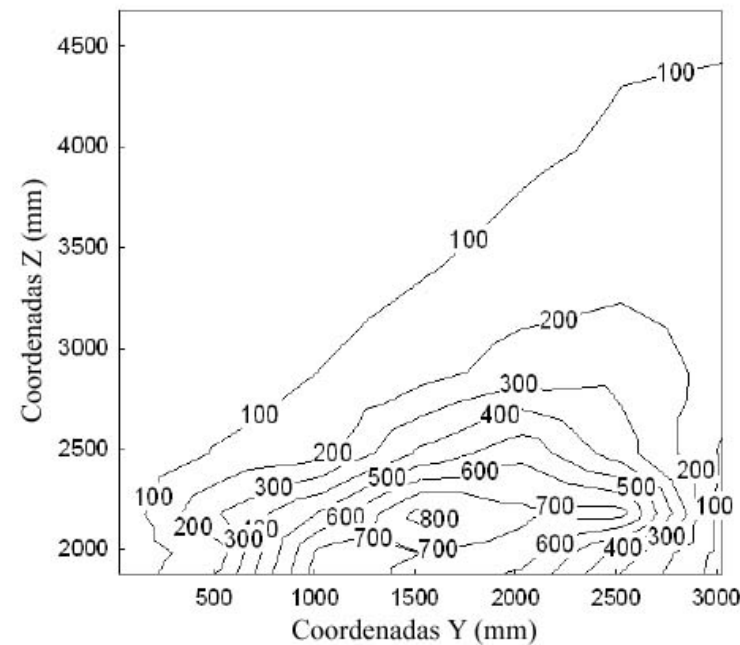

(a)

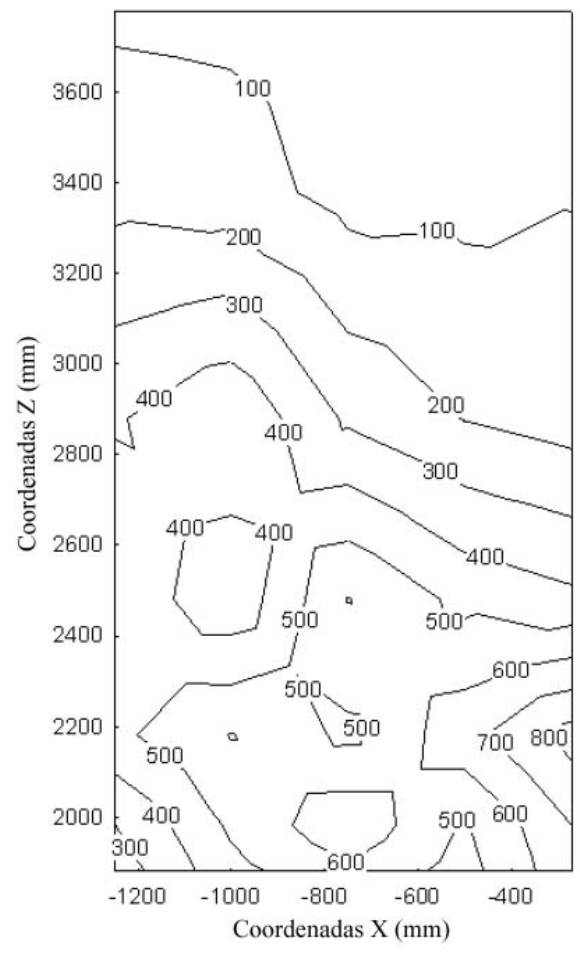

(b)

Figura 12.6 - Isotermas externas ao compartimento (em $\left.{ }^{\circ} \mathrm{C}\right)$. (a) seção S2-S2 às 12:41:36 e (b) S3-S3 às 12:41:36, com valores de eixo conforme figura 2.12 (REIN et al., 2007). 
De acordo com a figura 12.6 , a temperatura máxima da chama na janela tem o valor de $800^{\circ} \mathrm{C}$. Verifica-se também que o topo da chama para $538^{\circ}$ está na cota de $2500 \mathrm{~mm}$, descontando a altura da janela $(2290 \mathrm{~mm})$ resultando em uma altura da chama de $210 \mathrm{~mm}$.

Na figura 12.7, é apresentada a geometria do compartimento utilizado no ExteelFire. Para fins de avaliação, adotou-se na construção da tabela 14.1, para o ExteelFire, uma carga de incêndio específica de cálculo igual a $560 \mathrm{MJ} / \mathrm{m}^{2}$.

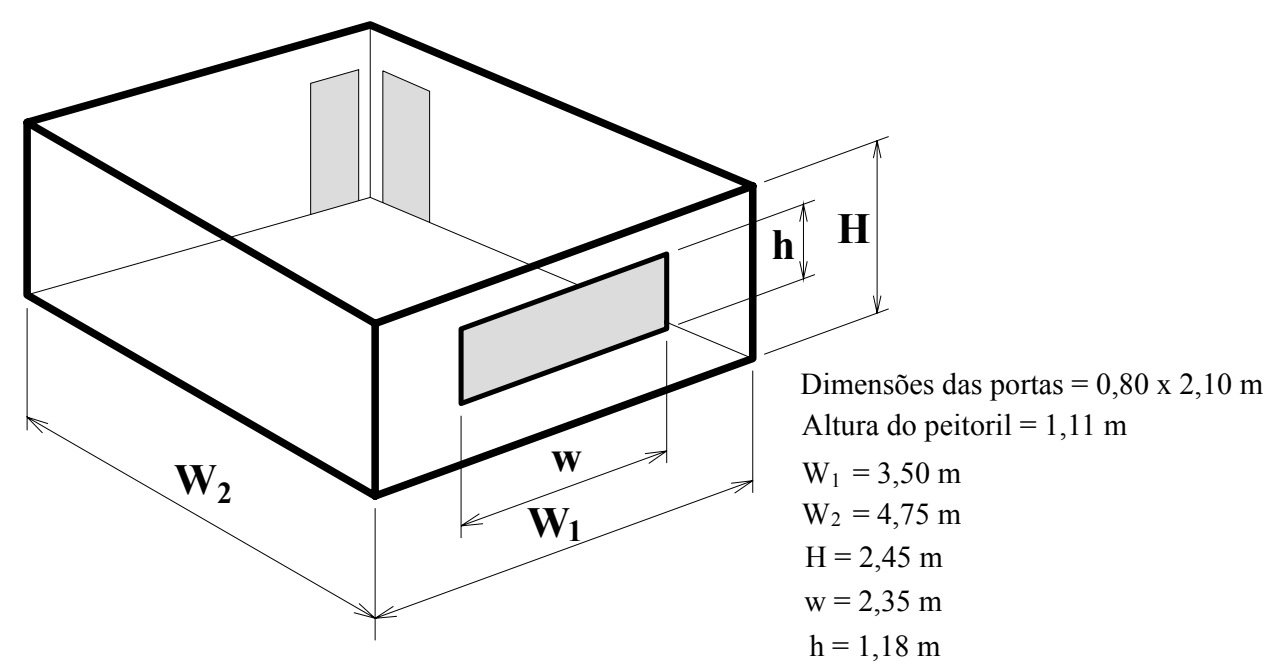

Figura 12.7 - Modelo do compartimento para o ExteelFire (Dalmanorck).

Na tabela 12.1, foi considerada a janela e as duas portas internas do compartimento como área de ventilação externa, na tabela 12.2, somente a janela foi considerada.

Tabela 12.1 - Comparação entre o Eurocode $\left(q_{f i, d}=560 \mathrm{MJ} / \mathrm{m}^{2}\right)$ e o experimento de Dalmarnock (considerando a janela e as portas como ventilação externa)

\begin{tabular}{l|l|l}
\hline & ExteelFire & Dalmarnock \\
\hline Taxa de liberação de calor & $7,8 \mathrm{MW}$ & 3 a $6 \mathrm{MW}$ \\
Temperatura dentro do compartimento & $896^{\circ} \mathrm{C}$ & $740^{\circ} \mathrm{C}$ \\
Altura da chama para $538^{\circ} \mathrm{C}$ & $1,30 \mathrm{~m}$ & $0,21 \mathrm{~m}$ \\
Temperatura máxima da chama na janela & $997^{\circ} \mathrm{C}$ & $800^{\circ} \mathrm{C}$ \\
\hline
\end{tabular}


Tabela 12.2 - Comparação entre o Eurocode $\left(q_{f i, d}=560 \mathrm{MJ} / \mathrm{m}^{2}\right)$ e o experimento de Dalmarnock (considerando apenas a janela como ventilação externa)

\begin{tabular}{l|l|l}
\hline & ExteelFire & Dalmarnock \\
\hline Taxa de liberação de calor & $4,7 \mathrm{MW}$ & 3 a $6 \mathrm{MW}$ \\
Temperatura dentro do compartimento & $972{ }^{\circ} \mathrm{C}$ & $740{ }^{\circ} \mathrm{C}$ \\
Altura da chama para $538^{\circ} \mathrm{C}$ & $1,82 \mathrm{~m}$ & $0,21 \mathrm{~m}$ \\
Temperatura máxima da chama na janela & $1006^{\circ} \mathrm{C}$ & $800{ }^{\circ} \mathrm{C}$ \\
\hline
\end{tabular}

Como se nota nas tabelas 12.1 e 12.2, os resultados obtidos por meio do ExteelFire 2.0 são sempre a favor da segurança.

\subsection{O EXPERIMENTO DA SIDERÚRGICA MITTAL STEEL OSTRAVA}

O ensaio do incêndio foi realizado em um edifício da Siderúrgica Mittal Steel Ostrava, conforme ítem 2.2.4 desta Tese. O tamanho interno do compartimento era de 3,80m x 5,95m, com altura de 2,78 m. No compartimento havia uma abertura de 2,40 m x 1,40 m.

A carga de incêndio foi composta por caibros de madeira macia seca. No compartimento os caibros de madeira foram colocados em oito pilhas, conforme a figura 12.8, criando uma carga específica de incêndio de $1039 \mathrm{MJ} / \mathrm{m}^{2}$. A ignição das oito pilhas foi simultânea. 

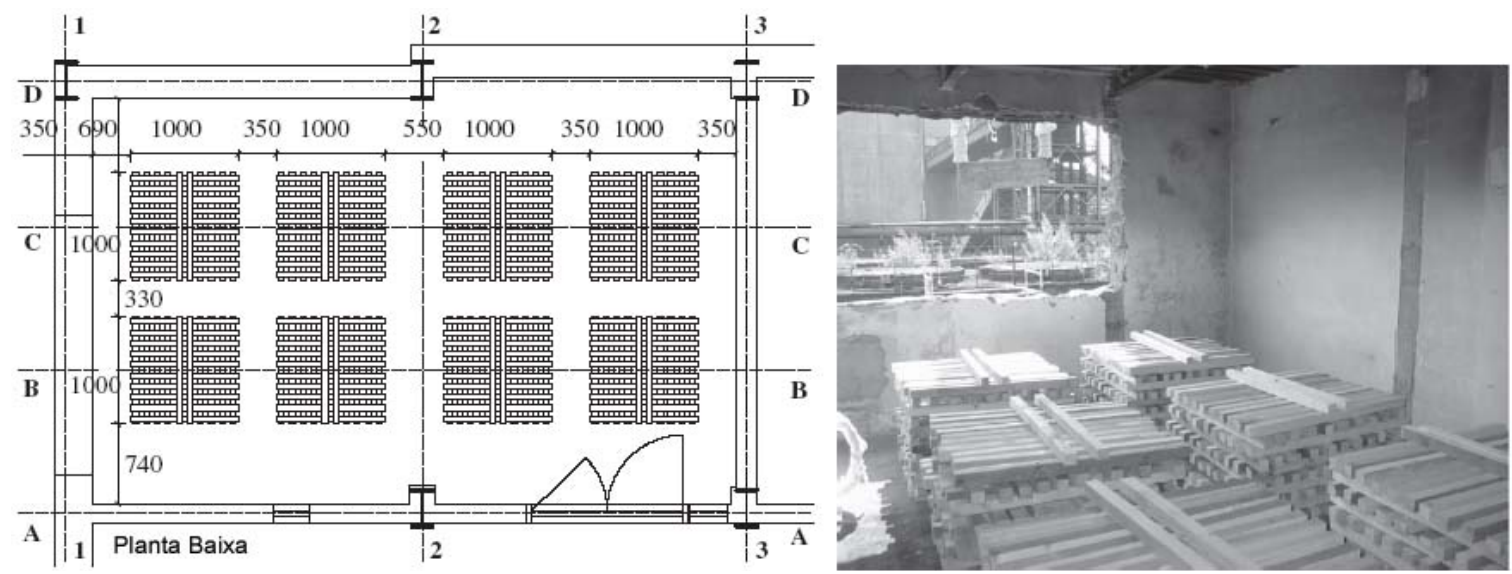

Figura 12.8 - Distribuição da carga de incêndio em madeira no compartimento (WALD, 2009).

A temperatura do gás dentro do compartimento incendiado foi medida por 4 termopares localizados $30 \mathrm{~cm}$ abaixo do teto, marcados por TGi na figura 12.9. Dois termopares foram colocados na frente do compartimento a $0,50 \mathrm{~m}$ e $1,00 \mathrm{~m}$ da parede. $\mathrm{Na}$ estrutura foram colocados 6 termopares e, nas conexões, mais 7, marcados por TCi.

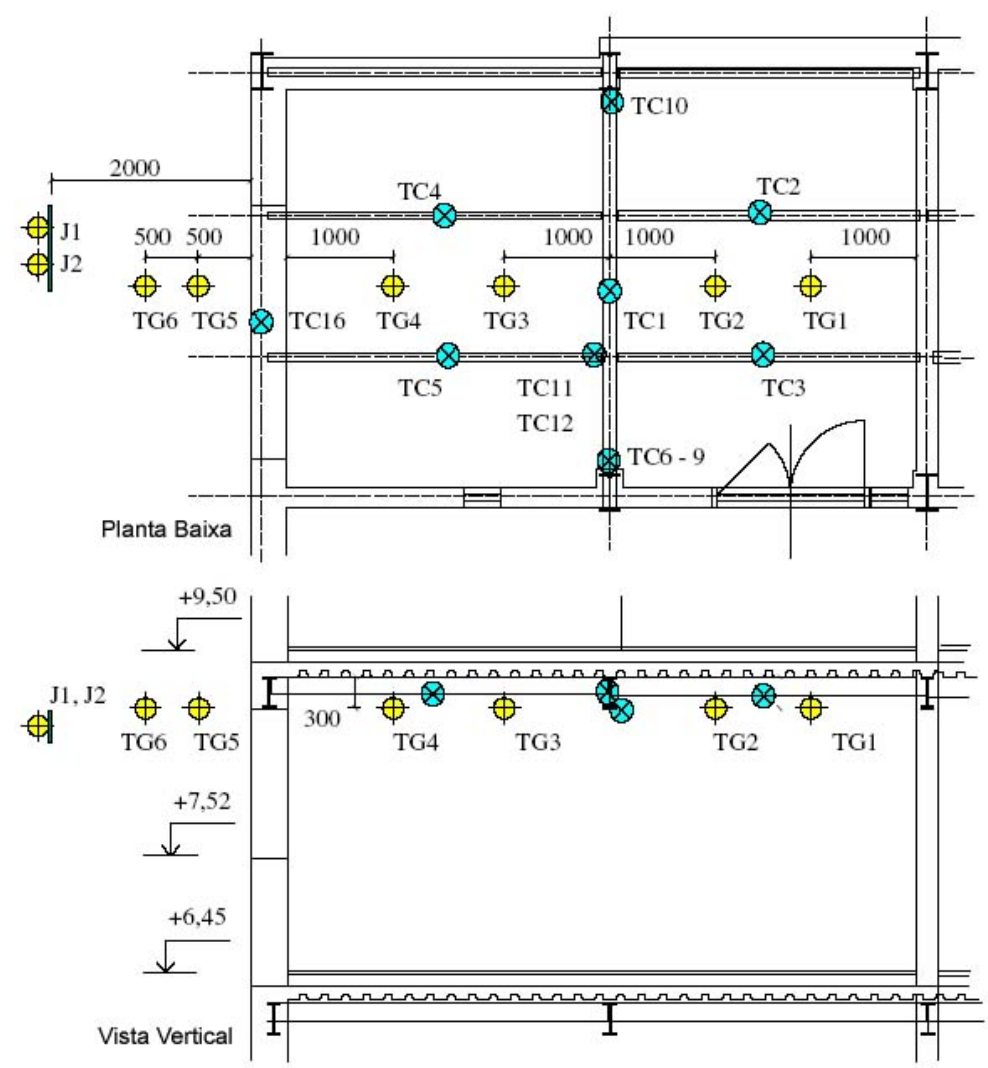

Figura 12.9 - Localização dos termopares para registrar temperaturas dos gases e do aço (WALD, 2009).

O desenvolvimento das temperaturas dos gases é mostrado na tabela 2.1 do item 2.2.4 desta Tese. As temperaturas máximas foram lidas nos termopares $\mathrm{TG} 1$ e $\mathrm{TG} 2,1050^{\circ} \mathrm{C}$ e $1032^{\circ} \mathrm{C}$, 
respectivamente. $\mathrm{Na}$ parte dianteira, foram registradas temperaturas máximas de $957^{\circ} \mathrm{C}$ e $920^{\circ} \mathrm{C}$ nos termopares TG3 e TG4, respectivamente.

Os termopares externos TG5 e TG6 situados a 0,50 e 1,00 $\mathrm{m}$ da abertura, registraram valores máximos de temperatura de $573{ }^{\circ} \mathrm{C}$ e $260{ }^{\circ} \mathrm{C}$, respectivamente.

Uma placa de aço de $0,95 \mathrm{~m}$ x 0,30 $\mathrm{m}$ e espessura de $10 \mathrm{~mm}$ foi colocada na frente da abertura do compartimento, a uma distância de 2,00 $\mathrm{m}$ da parede da fachada, conforme a figura 12.10. Dois termopares J1 e J2 foram colocados horizontalmente no centro dessa placa, a $250 \mathrm{~mm}$ das bordas.

As temperaturas máximas registradas pelos termopares $\mathrm{J} 1$ e $\mathrm{J} 2$ foram, respectivamente, $279^{\circ} \mathrm{C}$ e $306^{\circ} \mathrm{C}$.

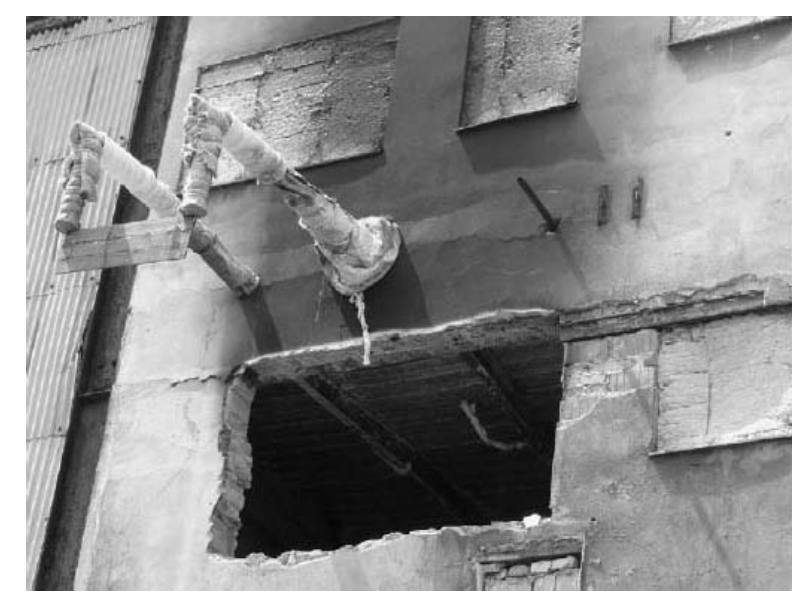

Figura 12.10 - Localização da placa externa de aço exposta ao calor durante o ensaio (WALD, 2009)

A figura 12.11 mostra o modelo do compartimento para o cálculo das temperaturas pelo ExteelFire. Foi utilizado como dado de entrada a carga de incêndio específica de cálculo de $1039 \mathrm{MJ} / \mathrm{m}^{2}$, a mesma do experimento. A figura 12.12 mostra a localização da chapa de aço em relação à abertura do compartimento. 


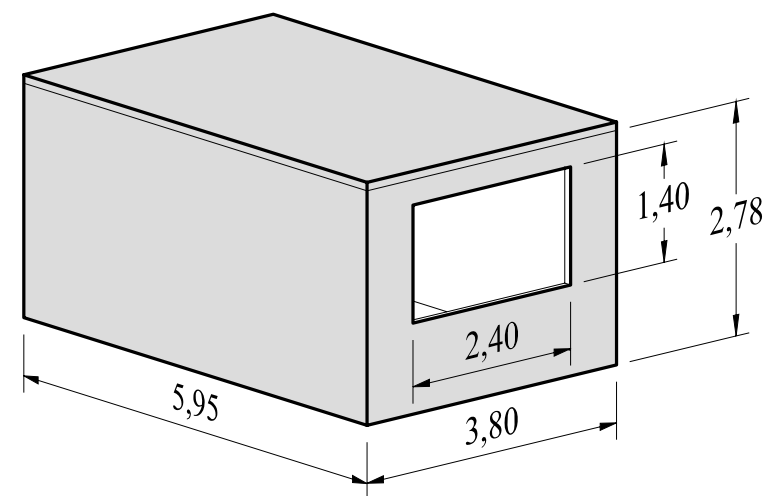

Figura 12.11 - Modelo do compartimento para o ExteelFire (Ostrava).

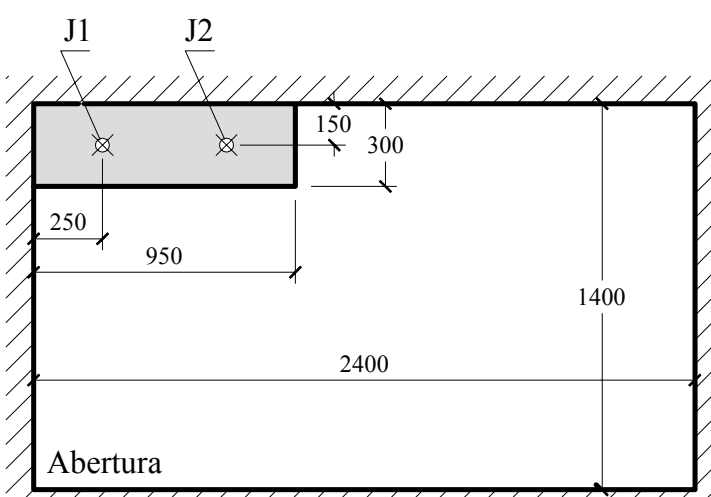

Vista externa

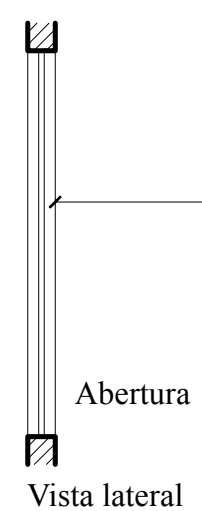

Vista lateral

Figura 12.12 - Dimensões e posição da chapa de aço em relação à abertura do compartimento.

A tabela 12.3 mostra a comparação dos resultados referentes às temperaturas do ExteelFire e do experimento da Siderúrgica Mittal Steel Ostrava, tendo como parâmetro de entrada a carga de incêndio específica e a geometria do compartimento. 
Tabela 12.3 - Comparação entre o ExteelFire e o experimento da Siderúrgica Mittal Steel Ostrava

\begin{tabular}{|c|c|c|}
\hline & Ostrava & ExteelFire \\
\hline Cargade incêndio específica & $1039 \mathrm{MJ} / \mathrm{m}^{2}$ & $1039 \mathrm{MJ} / \mathrm{m}^{2}$ \\
\hline $\begin{array}{l}\text { Temperatura no compartimento. } \\
\text { Maior temperatura no termopar (TG1) }\end{array}$ & $1050^{\circ} \mathrm{C}$ & \multirow{3}{*}{$1105^{\circ} \mathrm{C}$} \\
\hline Temperatura no compartimento. & \multirow[b]{2}{*}{$990^{\circ} \mathrm{C}$} & \\
\hline $\begin{array}{l}\text { Média entre as maiores temperaturas nos } \\
\text { termopares: }\left(\frac{T G 1+T G 2+T G 3+T G 4}{4}\right)\end{array}$ & & \\
\hline $\begin{array}{l}\text { Temperatura da chama externa na altura do topo da } \\
\text { abertura. } \\
\text { Maior temperatura no termopar (TG5) }\end{array}$ & $573^{\circ} \mathrm{C}$ & $871^{\circ} \mathrm{C}$ \\
\hline $\begin{array}{l}\text { Temperatura do aço. } \\
\text { Maior valor no termopar }(\mathrm{J} 2)\end{array}$ & $306^{\circ} \mathrm{C}$ & \multirow{3}{*}{$441^{\circ} \mathrm{C}$} \\
\hline Temperatura do aço. & & \\
\hline $\begin{array}{l}\text { Média entre as maiores temperaturas no } \\
\text { termopar: }\left(\frac{J 1+J 2}{2}\right)\end{array}$ & $293^{\circ} \mathrm{C}$ & \\
\hline
\end{tabular}

$\mathrm{Na}$ tabela 12.3, verifica-se que, para uma mesma geometria e carga específica de incêndio, os resultados do experimento da Siderúrgica Mittal Steel Ostrava ficaram abaixo dos resultados obtidos pelo ExteelFire. Isso era esperado, uma vez que o método analítico possui uma série de simplificações, conforme item 5 desta Tese. 


\section{Capítulo 13}

\section{CONCLUSÕES E RECOMENDAÇÕES PARA}

TRABALHOS FUTUROS

\subsection{CONCLUSÕES}

Para fins de determinação da temperatura de elementos de aço externos a edifícios em situação de incêndio, a ABNT NBR 14323:1999 recomenda, sem detalhar, o modelo proposto por Margaret Law, que consta nas normas europeias Eurocode 1 e 3.

Nesta Tese, esse modelo simplificado é amplamente analisado, comparando resultados a valores obtidos de forma numérica e experimental.

Foi elaborado um programa de computador, o ExteelFire 2.0, com base no modelo de Margaret Law, com o qual se pode determinar a máxima temperatura atingida por pilares e vigas externos à edificação em situação de incêndio. É aplicável a pilares localizados em frente às aberturas ou entre elas, e a vigas acima do topo da abertura posicionadas a qualquer distância vertical ou horizontal. O ExteelFire 2.0 é mais completo do que os programas com base no método de M. Law atualmente conhecidos: ExteelFire 1.0 e o Fires.

Foram realizadas análises numéricas via Smartfire de seis cenários de incêndio, para fins de comparação entre resultados obtidos pelo ExteelFire aos encontrados por meio de programas de computador CFD (Smartfire) para modelagem do incêndio e análise térmica (Super Tempcalc) dos elementos de aço; três dos compartimentos com uma abertura e outros três com duas aberturas em duas paredes perpendiculares. Dessa forma, concluiu-se que:

- as temperaturas dentro do compartimento estudado, determinadas por meio do Smartfire, foram inferiores às calculadas pelo ExteelFire em compartimentos com uma abertura. Em compartimentos com duas aberturas, a temperatura máxima dos gases dentro do 
compartimento, calculada pelo ExteelFire, é superada $\left(130{ }^{\circ} \mathrm{C}\right.$ a $\left.180{ }^{\circ} \mathrm{C}\right)$ apenas em regiões muito pequenas em relação ao volume do compartimento;

- as temperaturas das chamas na janela calculadas pelo ExteelFire foram sempre superiores (cerca de $15 \%$ ) às máximas determinadas pelo Smartfire;

- a altura máxima da chama fora do compartimento, determinada pelo ExteelFire, foi sempre superior à altura média determinada pelo Smartfire (entre $32 \%$ e 59\% para compartimento com uma abertura e $54 \%$ e $99 \%$ para compartimento com duas aberturas).

Empregou-se o ExteelFire para realizar análises de sensibilidade paramétrica, em que se concluiu o seguinte:

- à medida que um pilar se afasta de uma abertura, sua temperatura diminui, ocorrendo uma redução brusca ao sair das chamas;

- a temperatura de um pilar diminui à medida que aumentam as dimensões do contorno da sua seção transversal, quando ele se localiza dentro das chamas, e pouco varia, quando ele está fora das chamas;

- a temperatura de pilares entre aberturas eleva-se, conforme aumenta a dimensão da seção transversal perpendicular à fachada;

- a temperatura de pilares e vigas aumenta, ao se aumentar a carga de incêndio específica até um determinado valor, a partir do qual ela se estabiliza, pois o incêndio passa a ser controlado pela ventilação;

- o aumento da altura do compartimento reduz a temperatura de pilares e vigas;

- a temperatura de pilares e vigas varia com o aumento da profundidade do compartimento. De início, a temperatura aumenta acompanhando o aumento da carga de incêndio total, em seguida, diminui, pois a relação entre a profundidade e a largura do compartimento aumenta;

- a temperatura do pilar em frente a uma abertura é máxima quando o pilar está centrado na janela e diminui à medida em que o pilar se aproxima das bordas;

- a temperatura de uma viga diminui à medida em que aumenta a sua distância vertical da borda superior da abertura. 
Foram analisadas diversas situações de pilares e vigas externas a edificações, de uso corrente na construção civil, e indicadas as posições em que os elementos estruturais devem ser projetados para poderem dispensar o revestimento contra fogo.

Foram realizadas análises térmicas, via Smartfire e Super Tempcalc, para 8 situações de perfis de aço, concluindo-se que:

- os perfis mais esbeltos atingem temperaturas maiores do que os perfis mais robustos. Essa verificação não foi possível realizar com o ExteelFire, pois o fator de massividade dos perfis não é levado em conta no modelo simplificado, em vista da transferência de calor por convecção e radiação ser considerada em regime estacionário na máxima temperatura dos gases;

- a temperatura do perfil de aço depende mais da distância à abertura (cerca de $200{ }^{\circ} \mathrm{C}$ ) do que das dimensões do perfil $\left(18{ }^{\circ} \mathrm{C}\right.$ a $\left.41{ }^{\circ} \mathrm{C}\right)$. As dimensões influenciam um pouco mais para distâncias maiores $\left(37^{\circ} \mathrm{C}\right.$ a $\left.41^{\circ} \mathrm{C}\right)$, ou seja, quando a influência da fonte de calor é menor. Conclusão similar é conseguida a partir dos resultados determinados pelo ExteelFire;

- os valores de temperatura determinados por meio do ExteelFire estão a favor da segurança em relação aos calculados pelos métodos numéricos, inclusive tornando irrisório o pequeno aumento de temperatura que sofrem as seções com maior fator de massividade;

- os valores dos gradientes térmicos encontrados via numérica são relevantes apenas nos perfis mais afastados, nos quais a temperatura encontrada é relativamente baixa.

Compararam-se resultados obtidos experimentalmente em dois ensaios (Dalmarnock e Mittal) a valores calculados por meio do ExteelFire, obtendo-se as seguintes conclusões:

- os valores relativos entre o ensaio de Dalmarnock e ExteelFire foram: $83 \%$ para a temperatura no interior do compartimento, $80 \%$ para a temperatura máxima na janela e $16 \%$ para a altura da chama;

- os valores relativos entre o ensaio de Mittal e ExteelFire foram: 95\% para a temperatura máxima no interior do compartimento e $66 \%$ para a temperatura no perfil de aço. 


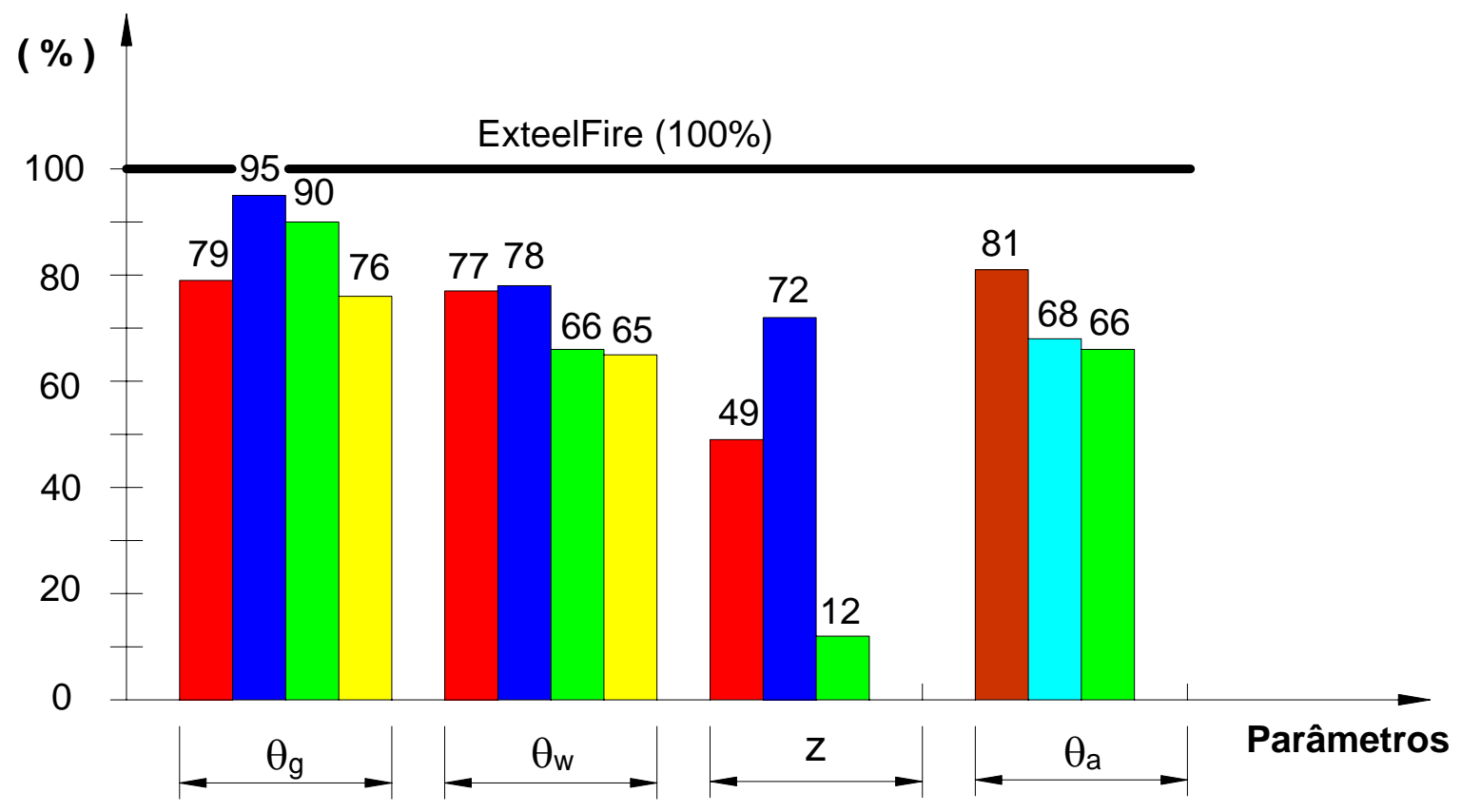

\section{Legenda:}

Smartfire 1 janela

Smartfire 2 janelas

Mittal

Dalmarnock

Figura 13.1 - Comparação entre os resultados do ExteelFire aos resultados do Smartfire, Super Tempcalc, de Mittal e de Dalmarnock.

Em todas as comparações realizadas (figura 13.1), tanto para resultados experimentais quanto numéricos, os valores obtidos por meio do ExteelFire estiveram sempre a favor da segurança. Pode-se até afirmar que o método é antieconômico para algumas situações. Nos casos das temperaturas mais baixas do aço, a busca pela precisão é ainda mais importante, uma vez que é nessa situação que o revestimento pode ser dispensado.

Apesar de a pesquisa realizada nesta Tese ter sido exaustiva e pioneira em vários aspectos, considerando-se que a base do método empregado data de mais de 30 anos, faz-se necessário prosseguir nas investigações, com novos experimentos e mais simulações numéricas, para melhor calibrar o método, visando reduzir sua margem de segurança, tornando-o mais realístico. 


\subsection{SUGESTÕES PARA TRABALHOS FUTUROS}

Como sugestões para futuros trabalhos a serem desenvolvidos sobre a elevação da temperatura para elementos estruturais de aço externos a edificações, acrescentam-se:

- verificação da segurança estrutural dos pilares externos, considerando-se o efeito do gradiente térmico encontrado via numérica, em comparação aos resultados obtidos por meio do ExteelFire 2.0, em que se considera a distribuição uniforme de temperaturas;

- desenvolver a equação diferencial de equilíbrio térmico para elemento envolvido ou não pela chama, considerando a transferência de calor em regime transiente;

- considerar a influência do fator de massividade na elevação da temperatura do elemento estrutural de aço em incêndio;

- analisar o comportamento térmico e mecânico de estruturas de aço externa a edificações protegidas contra a ação do fogo;

- realizar novas análises experimentais e numéricas visando um método mais realístico. 


\section{REFERÊNCIAS BIBLIOGRÁFICAS}

AMERICAN IRON AND STEEL INSTITUTE. Fire-safe structural steel - A design guide. Washington.1979.

AMERICAN SOCIETY TESTING AND MATERIALS (ASTM E-119-07) - Standard test methods for fire tests of building constructions and material. West Conshohocken (USA), 2007.

ARUP GROUP. Arup Fire Safety. Disponível em <http://www.arup.com/fire/index.cfm>. Acesso em: 21 set. 2006.

ASSOCIAÇÃO BRASILEIRA DE NORMAS TÉCNICAS. NBR 14323: Dimensionamento de estruturas de aço de edifícios em situação de incêndio - procedimento. Rio de Janeiro, 2003.

ASSOCIAÇÃO BRASILEIRA DE NORMAS TÉCNICAS. NBR 14432: Exigência de resistência ao fogo de elementos construtivos de edificações. Procedimento. Rio de Janeiro, 2000.

ASSOCIAÇÃO BRASILEIRA DE NORMAS TÉCNICAS. NBR 8681: Ações e segurança nas estruturas - procedimento. Rio de Janeiro, 2003.

ASSOCIAÇÃO BRASILEIRA DE NORMAS TÉCNICAS. NBR 8800: Projeto e execução de estruturas de aço de edifícios (método dos estados limites) - Procedimento. Rio de Janeiro, 1986. 
ASTM Designation: E119-07 "Standard Test Methods for Fire Testes of Building Construction and Materials". United States. 2007.

ATREYA, A. Convection heat transfer. The SFPE handbook of Fire Protection Engineering. $3^{\text {rd }}$ ed. Massachussets: Society of fire protection engineers: National fire protection association, 2002. section 1, p. 44-72.

AZEVEDO, M. S.; FERREIRA, W. G.; CORREIA, E. V. S. Estrutura de aço em situação de incêndio com e sem proteção. Revista Engenharia, Ciência \& Tecnologia, Vitória, v. 07, n.4, p.35-44, 2004.

AZEVEDO, M. S. Determinação da temperatura em elementos estruturais de aço externos a edificações. 230 p. Dissertação (Mestrado em Engenharia Civil) - Centro Tecnológico, Universidade Federal do Espírito Santo, Vitória, 2005.

AZEVEDO, M. S.; FERREIRA, W. G.; SILVA, V. P. Determinação da temperatura em pilares de aço externos a edificações em situação de incêndio. In: JORNADAS SULAMERICANAS DE ENGENHARIA ESTRUTURAL, 32. Anais... Hotel Nacional Inn., Campinas, 2006.

AZEVEDO, M. S.; MURAKI, A.; SILVA, V. P. Segurança das estruturas de aço externas a edificçaões em situação de incêndio. Revista Escola de Minas, Ouro Preto, v. 60 (4), 2007.

BUCHANAN, A. H. Fire engineering design guide. New Zealand: Centre for Advanced Engineering, 1994. 203 p.

BUCHANAN, A. H. Structural Design for Fire Safety. 1. ed. England: Wiley \& Sons, $2001.421 \mathrm{p}$. 
BUCHANAN, A. H. International developments in design for structural fire safety. Revista Sul-Americana de Engenharia Estrutural, Passo Fundo, v. 1, n.1, p. 53-80, 2004.

CARLSSON, J. External Fire Spread to Adnoining Buildings. 1999. 125 f. Final requirement for a degree (Bachelor of Science in Fire Protection Engineering). Department of Fire Safety Engineering, Lund University, Sweden. 1999.

CARLSSON, J. Fire modelling using CFD. An introduction for fire safety engineers. 1999. 120 f. Report 5025. Department of fire safety engineering. Lund University, Sweden. 1999.

COMITÉ EURO-INTERNATIONAL DU BÉTON. Fire design of concrete structures. Bulletin D‘Information N 145. Lausanne: CEB-FIP, 1982.

COMITÉ EURO-INTERNATIONAL DU BÉTON. Fire design of concrete structures. Bulletin D‘Information N²08. Lausanne: CEB-FIP, 1991.

COMITÉ EURO-INTERNATIONAL DU BÉTON. Fire design of concrete structures. Bulletin D‘Information N 174. Lausanne: CEB-FIP, 1987.

COSTA, C. N. Dimensionamento de elementos de concreto armado em situação de incêndio. 379 p. Tese (Doutorado em Engenharia Civil) - Escola Politécnica da Universidade de São Paulo, São Paulo. 2007.

COSTA C. N., SILVA V. P. O método do tempo equivalente para o projeto de estruturas de concreto em situação de incêndio. In: CONGRESSO BRASILEIRO DO CONCRETO IBRACON, 47. Anais ... 2005. p. III 154-167. 
DHIMA, D.; FOUQUET, G.; JOYEUX, D.; KRUPPA, J.; ZHAO, B. Experimental and numerical assessment of the behaviour of external heavy steel columns under natural fire. Journal of Constructional Steel Research, v. 46, n. 1-3, paper n. 173, France, 1998.

DRYSDALE, D. An introdution to fire dynamics. 2. ed. Wiley, Chichester, UK, 2002.

EUROPEAN COMMITTEE FOR STANDARDIZATION. Actions on structures, Part 1-2: General Actions - Actions on structures exposed to fire. Eurocode 1. Brussels, 2002.

EUROPEAN COMMITTEE FOR STANDARDIZATION. Design of concrete structures Part 1.2: General Rules - Structural Fire Design. Eurocode 2. Brussels: 2004.

EUROPEAN COMMITTEE FOR STANDARDIZATION. Design of steel structures, Part 12: General rules - Structural fire design. Eurocode 3. Brussels, 2003.

EWER, J. Fire Safety Engineering Group, University of Greenwich, London. Correpondência pessoal, 2008.

EWER, J.; JIA, F.; GRANDISON, A.; GALEA, E.; PATEL, M. SMARTFIRE 4.0 user guide and technical manual. Inglaterra: Fire Safety Engineering Group, 2004.

FIRE SAFETY DESIGN (FSD). TCD with SUPER-TEMPCALC. Lund: Fire Safety Design Ltd., 2000. Disponível em: < http://www.fsd.seleng/index.html>. Acesso em: 09 out. 2002.

FIRE SAFETY ENGINEERING GROUP. School of computing e mathematical sciences the University of Greenwich. London. Disponível em: < http://fseg.gre.ac.uk/smartfire>. Acesso em: 14 fev. 2008. 
HOLMAN, J. P. Transferência de Calor. 1. ed. São Paulo: McGraw-Hill do Brasil, 1983. $640 \mathrm{p}$.

HUMES, A. F. P. C.; MELO, I. S.H.; YOSHIDA, L. K.; MARTINS, W. T. Noções de cálculo numérico. São Paulo: McGRAW-HILL, 1984. 201 p.

INCROPERA, F. P.; DE WITT, D. P. Fundamentos de transferência de calor e de massa. 6. ed. Rio de Janeiro: LTC, 2008. 644 p.

KARLSSON, B.; QUINTIERE J. G. Enclosure fire dynamics. United States: CRC Press, $2000.315 \mathrm{p}$.

KERN, D. Q. Processos de Transmissão de Calor. Rio de Janeiro: Editora Guanabara Dois, 1982.

LAW, M. Fire safety of external building elements. The design approach. Engineering Journal. American Institute of Steel Construction, $2^{\mathrm{n}}$ Quarter, p. 59-74, 1978.

OLIVEIRA, K.; VARGAS, E. Guia Prático - Microsoft Visual Basic 6.0. 1. ed. São Paulo: Editora Viena, 2003.

ÖZISIK, M. N. Transferência de calor - um texto básico. Rio de Janeiro: Editora Guanabara Koogan S. A., 1990.

REAL, P. V. Incêndio em Estruturas Metálicas - Cálculo Estrutural.1. ed. Aveiro: Edições Orion. 2003. 
REIN, G.; EMPIS, C. A.; CARVEL R. The Dalmarnock fires tests: experiments and modelling. School of Engineering and Electronics. University of Edinburgh. United Kingdom, 2007. Disponível em: < http://www.era.lib.ed.ac.uk>. Acesso em: 1 abr. 2009.

RugGiero, M. A. G.; LOPES, V. L. R. Cálculo Numérico - Aspéctos Teóricos e Computacionais. 2. ed. São Paulo: Makron Books, 1997.

SILER, B.; SPOTTS J. Usando Visual Basic 6 - O Guia de Referência Mais Completo. 1. ed. São Paulo: Editora Campus, 2003.

SILVA, V. P. Estruturas de aço em situação de incêndio. 1. ed. São Paulo: Zigurate, 2001. $249 \mathrm{p}$.

SILVA, V. P.; PIMENTA, P. M. Diagrama Tensão-Deformação dos Aços Estruturais Submetidos a Altas Temperaturas. Boletim Técnico da Escola Politécnica da USP, São Paulo, v. 9519, p. 1-21, 1995.

SILVA, V. P.; PIMENTA, P. M. Determinação da Curva Temperatura-Tempo de Um Incêndio Natural Compartimentado. Boletim Técnico da Escola Politécnica da USP, São Paulo, v. 9624, p. 1-23, 1996.

SILVA, V. P.; FAKURY, R. H.; PIMENTA, R. J. et al. Estruturas de Aço de Edifícios em situação de Incêndio. Método Simplificado para Dimensionamento. Revista da Escola de Minas de Ouro Preto, Ouro Preto, v. 3, p. 31-36, 1997.

SILVA, V. P. A Segurança contra Incêndio nas Edificações. Associação Brasileira da Construção Metálica, São Paulo, v. 29, p. 28-30, 1997. 
SILVA, V. P. Ação Térmica nas Estruturas - Determinação da Temperatura nos Elementos Estruturais de Aço sem Proteção Térmica em Situação de Incêndio. Boletim Técnico da Escola Politécnica da USP, São Paulo, v. 1, p. 01-15, 1999.

SILVA, V. P. Exigências de Resistência ao Fogo de Elementos Construtivos de Edificações. Associação Brasileira da Construção Metálica, São Paulo, n. 43, p. 27-34, 2000.

SILVA, V. P. Segurança das Estruturas em Situação de Incêndio. Infra, São Paulo, v. ano5, n. 42, p. 22, 2003.

SILVA, V. P.; COSTA, C. N. Exigências de Resistência ao fogo para Estruturas - O Método do Tempo Equivalente. Revista Engenharia, Ciência e Tecnologia, Vitória, 2005.

UNIVERSITÉ DE LIÈGE, DÉPARTEMENT M\&S. Ozone V2.0, The design fire tool OZone V2.0 - Theoretical description and validation on experimental fire tests. Liège, Belgium, 2001.

VARGAS, M.R.; SILVA, V.P. Resistência ao Fogo das Estruturas de Aço. 1. ed. Rio de Janeiro: Instituto Brasileiro de Siderurgia - IBS / Centro Brasileiro da Construção em aço CBCA, 2003.

Velarde, J. S. S. Sobre o comportamento de pilares de aço em situação de incêndio. Dissertação de Mestrado apresentada à Escola Politécnica da Universidade de São Paulo. 2008. São Paulo.

WAld, F.; CHLOUBA, J.; UHLIR, A.; KALlEROVA, P.; STUJBEROVA, M. Temperatures during fire tests on structure and its prediction according to Eurocodes. Fire safety journal, v. 44, p. 135-146, 2009. Disponível em: $<$ http://www.elsevier.com/locate/firesaf>. Acesso em: 1 abr. 2009. 
WANG, Z.; JIA, F.; GALEA, E. R., PATEL, M. K.; EWER, J. Simulating one of the CIB W14 round robin test cases using the SMARTFIRE fire field model. Fire safety journal, v. 36, p. 661-677, 2001. 
ANEXO A 


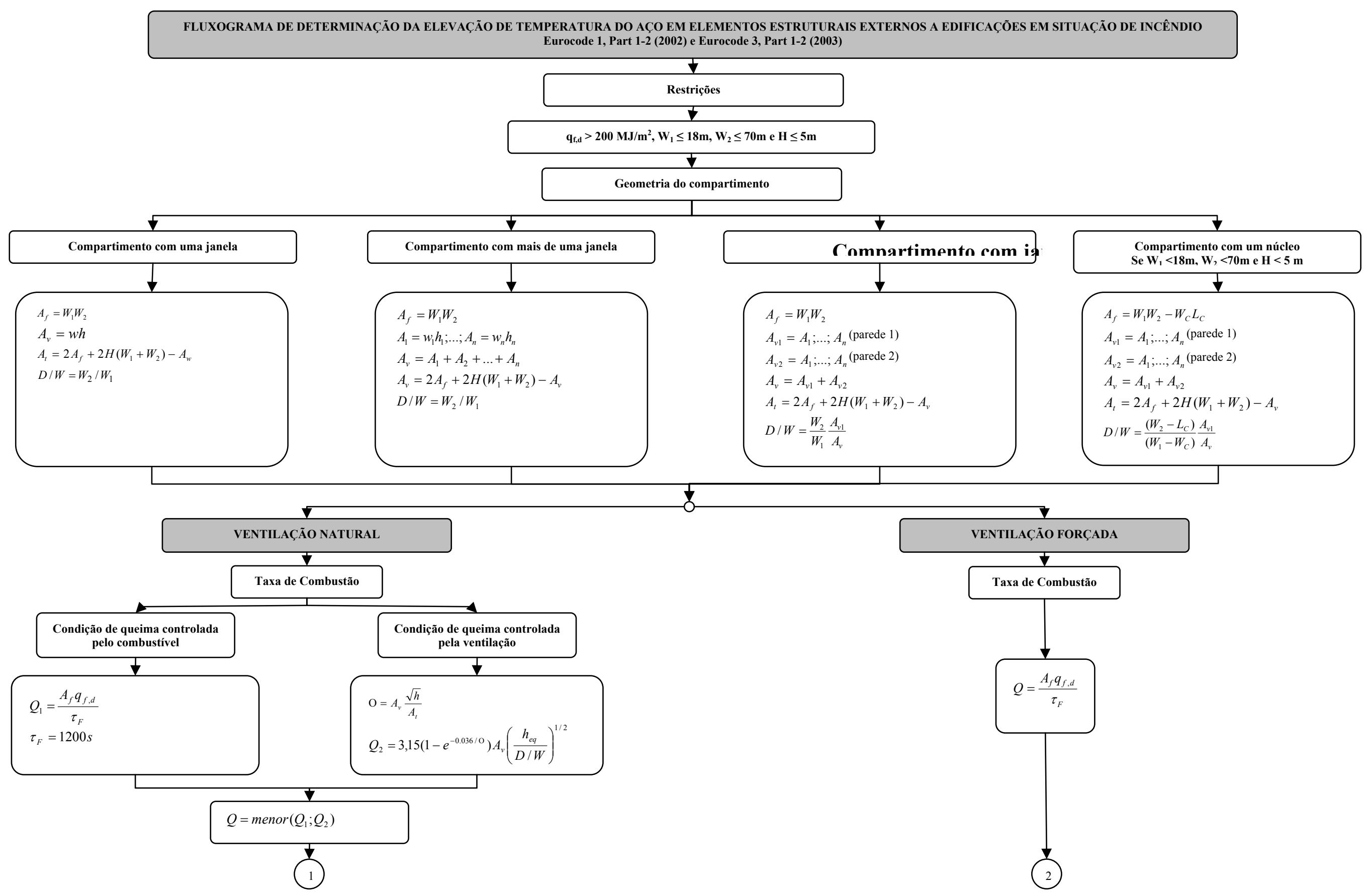



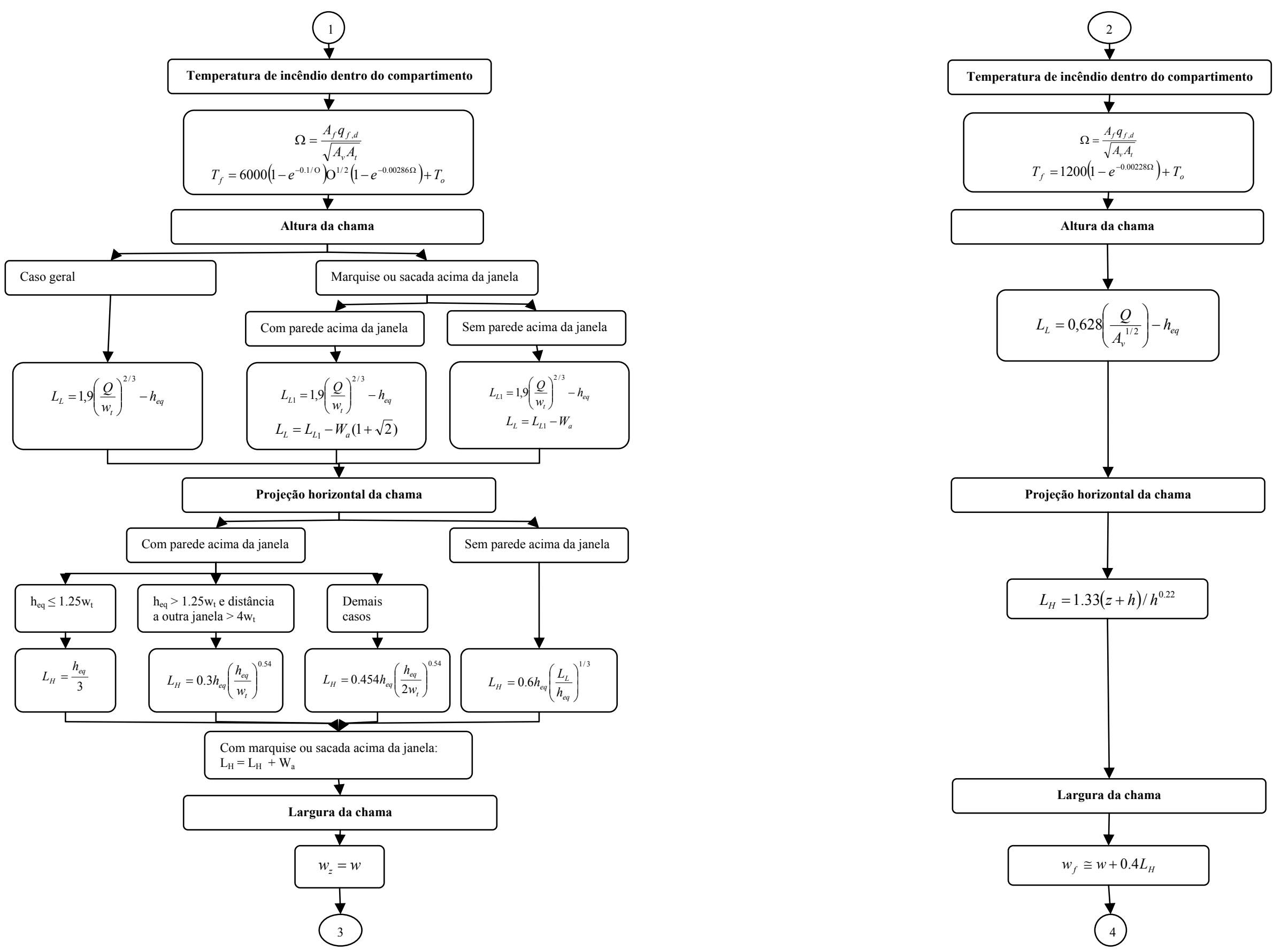


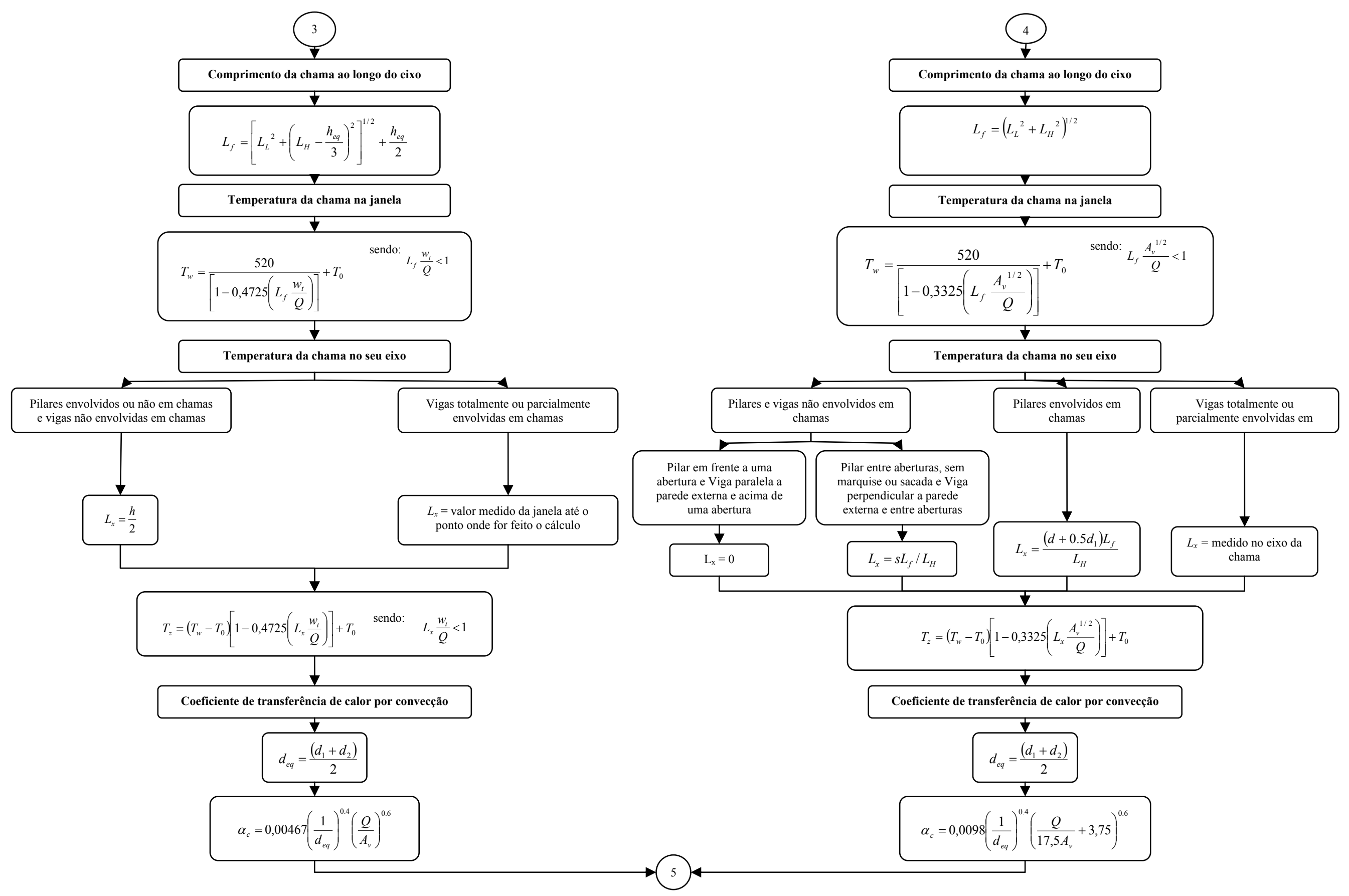




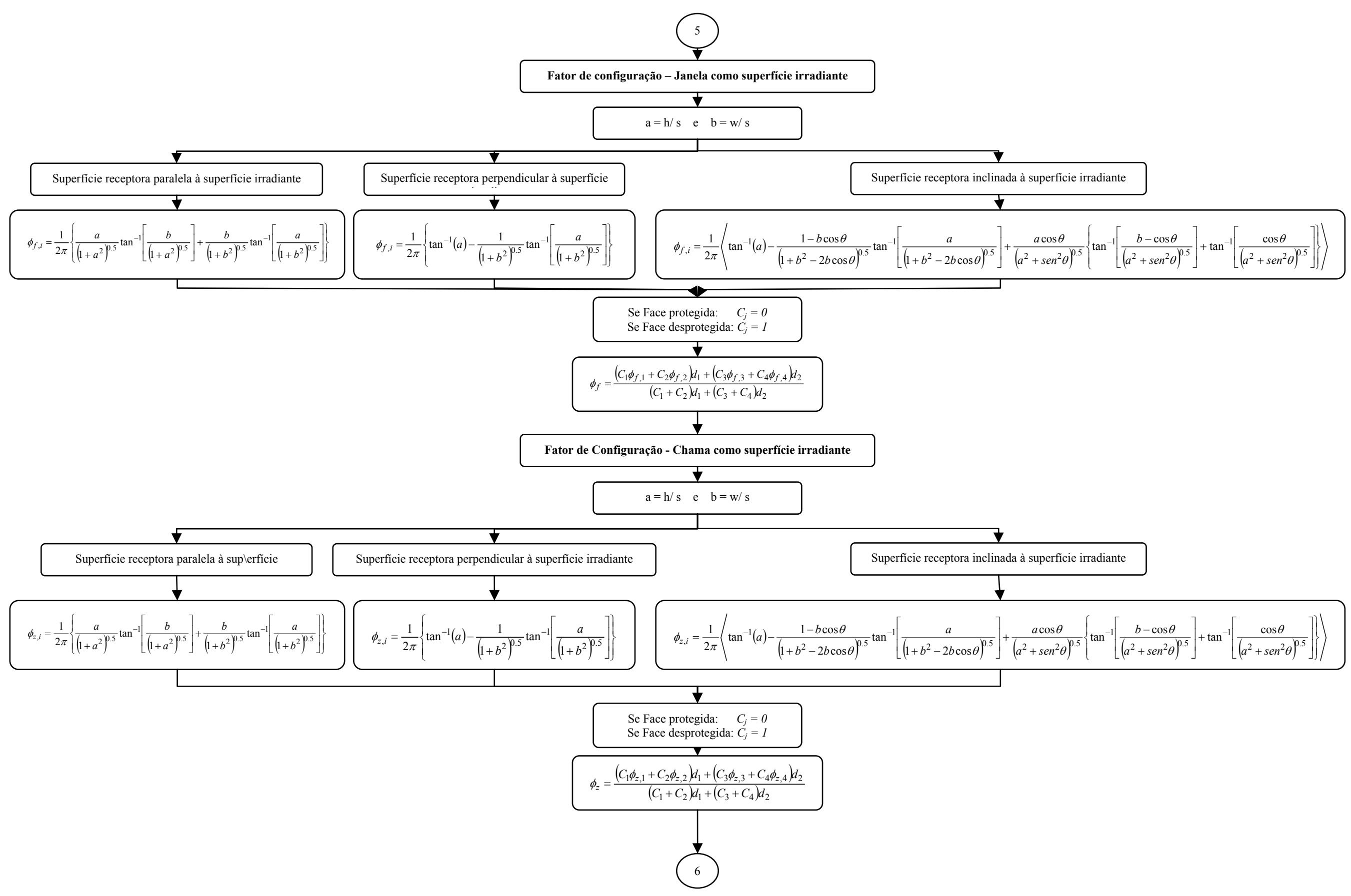




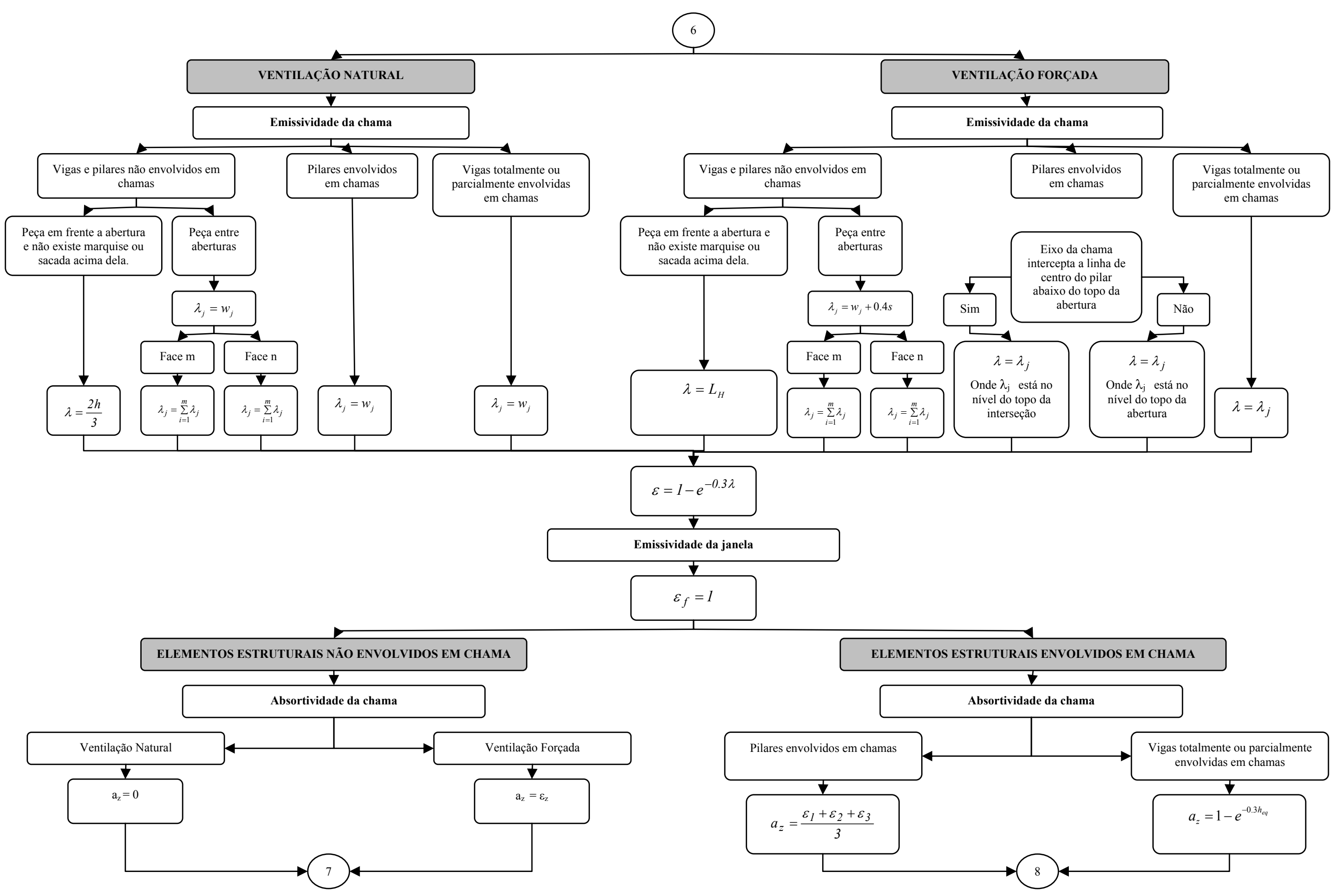




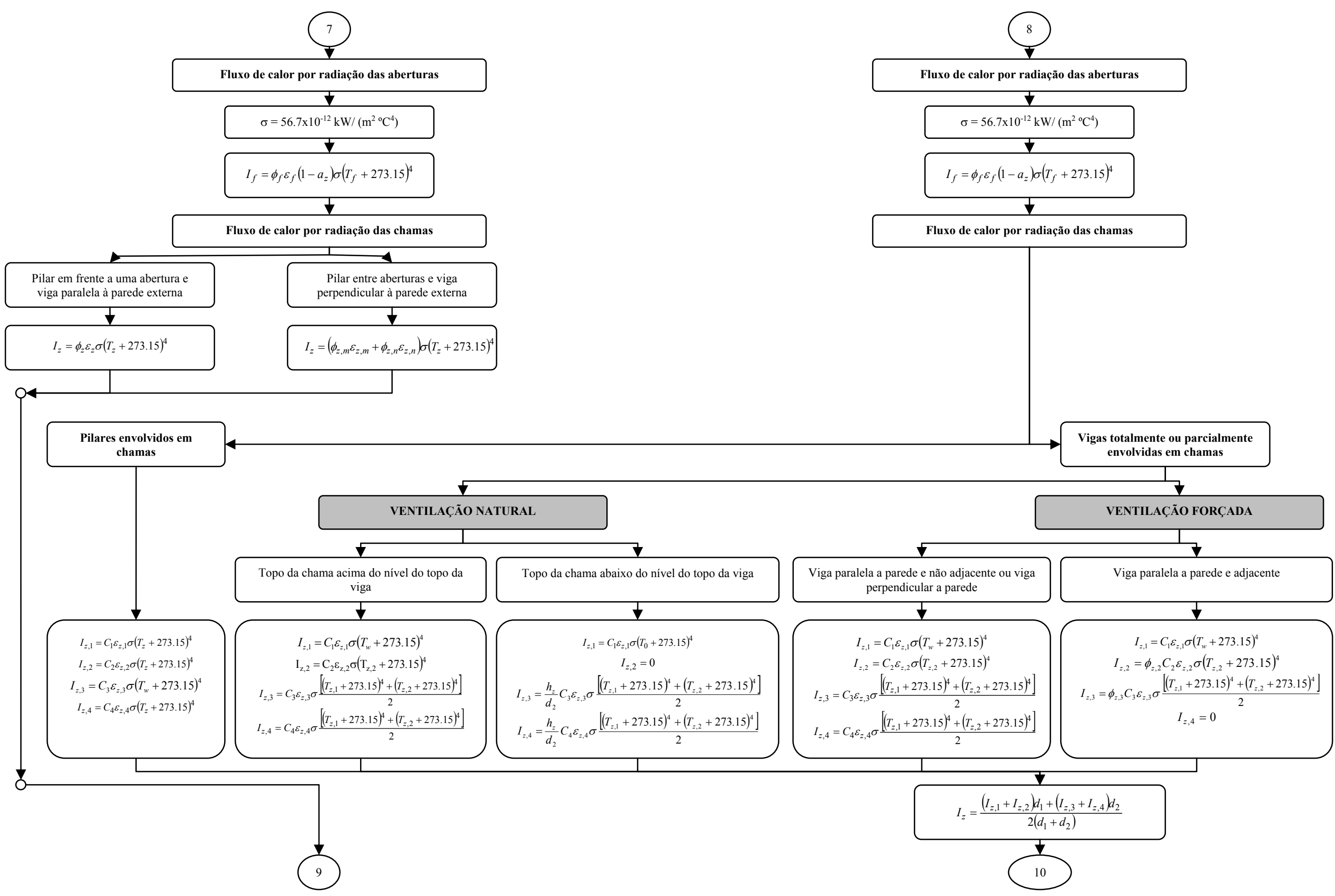



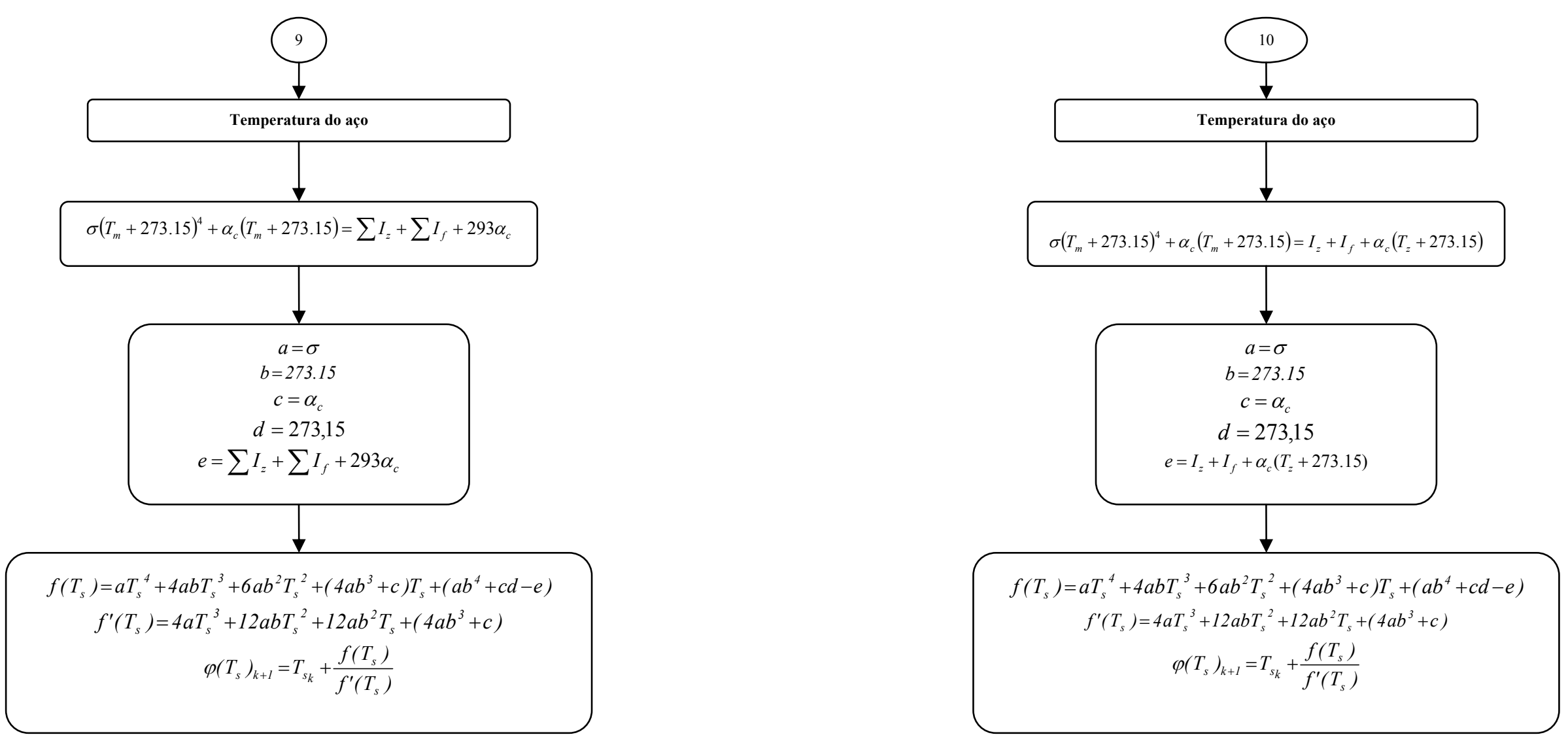